\title{
Gegen falsche Götter und falsche Bildung
}

Tatian, Rede an die Griechen

Scripta Antiquitatis Posterioris

ad Ethicam REligionemque pertinentia

XXVIII

Mohr Siebeck 


$$
\begin{gathered}
\text { SAPERE } \\
\text { Scripta Antiquitatis Posterioris } \\
\text { ad Ethicam REligionemque pertinentia } \\
\text { Schriften der späteren Antike } \\
\text { zu ethischen und religiösen Fragen }
\end{gathered}
$$

\section{Herausgegeben von}

Reinhard Feldmeier, Rainer Hirsch-Luipold und Heinz-Günther Nesselrath

$$
\text { unter der Mitarbeit von }
$$

Natalia Pedrique und Andrea Villani

\section{Band XXVIII}





\title{
Gegen falsche Götter und falsche Bildung
}

\author{
Tatian, Rede an die Griechen
}

\author{
eingeleitet, übersetzt und \\ mit interpretierenden Essays versehen von \\ Peter Gemeinhardt, Marie-Luise Lakmann, \\ Heinz-Günther Nesselrath, \\ Ferdinand R. Prostmeier, Adolf Martin Ritter, \\ Holger Strutwolf und Andrei Timotin
}

herausgegeben von

Heinz-Günther Nesselrath

Mohr Siebeck 
SAPERE ist ein Forschungsvorhaben der Akademie der Wissenschaften zu Göttingen im Rahmen des Akademienprogramms der Union der Deutschen Akademien der Wissenschaften.

ISBN 978-3-16-152821-7 / eISBN 978-3-16-156427-7

ISSN 1611-5945 (SAPERE. Scripta antiquitatis posterioris ad ethicam religionemque pertinentia)

Die Deutsche Nationalbibliothek verzeichnet diese Publikation in der Deutschen Nationalbibliographie; detaillierte bibliographische Daten sind im Internet über http://dnb.dnb.de abrufbar.

\section{(C) 2016 Mohr Siebeck Tübingen. www.mohr.de}

Das Werk einschließlich aller seiner Teile ist urheberrechtlich geschützt. Jede Verwertung außerhalb der engen Grenzen des Urheberrechtsgesetzes ist ohne Zustimmung des Verlags unzulässig und strafbar. Das gilt insbesondere für Vervielfältigungen, Übersetzungen, Mikroverfilmungen und die Einspeicherung und Verarbeitung in elektronischen Systemen.

Der Band wurde vonseiten des Herausgebergremiums von Heinz-Günther Nesselrath betreut und von Magdalena Albrecht, Marius Pfeifer, Janjenka Szillat und Andrea Villani in der SAPERE-Arbeitsstelle in Göttingen gesetzt. Druck von Gulde Druck in Tübingen auf alterungsbeständiges Werkdruckpapier, gebunden von der Buchbinderei Spinner in Ottersweier. 


\section{SAPERE}

Griechische und lateinische Texte der späteren Antike (1.-4. Jh. n. Chr.) haben lange Zeit gegenüber den sogenannten ,klassischen' Epochen im Schatten gestanden. Dabei haben die ersten vier nachchristlichen Jahrhunderte im griechischen wie im lateinischen Bereich eine Fülle von Werken zu philosophischen, ethischen und religiösen Fragen hervorgebracht, die sich ihre Aktualität bis heute bewahrt haben. Die - seit Beginn des Jahres 2009 von der Union der deutschen Akademien der Wissenschaften geförderte - Reihe SAPERE ( $\underline{\text { Scripta }}$ Antiquitatis Posterioris ad Ethicam REligionemque pertinentia, ,Schriften der späteren Antike zu ethischen und religiösen Fragen') hat sich zur Aufgabe gemacht, gerade solche Texte über eine neuartige Verbindung von Edition, Übersetzung und interdisziplinärer Kommentierung in Essayform zu erschließen.

Der Name SAPERE knüpft bewusst an die unterschiedlichen Konnotationen des lateinischen Verbs an. Neben der intellektuellen Dimension (die Kant in der Übersetzung von sapere aude, „Habe Mut, dich deines eigenen Verstandes zu bedienen“, zum Wahlspruch der Aufklärung gemacht hat), soll auch die sinnliche des "Schmeckens" zu ihrem Recht kommen: Einerseits sollen wichtige Quellentexte für den Diskurs in verschiedenen Disziplinen (Theologie und Religionswissenschaft, Philologie, Philosophie, Geschichte, Archäologie ...) aufbereitet, andererseits aber Leserinnen und Leser auch "auf den Geschmack" der behandelten Texte gebracht werden. Deshalb wird die sorgfältige wissenschaftliche Untersuchung der Texte, die in den Essays aus unterschiedlichen Fachperspektiven beleuchtet werden, verbunden mit einer sprachlichen Präsentation, welche die geistesgeschichtliche Relevanz im Blick behält und die antiken Autoren zugleich als Gesprächspartner in gegenwärtigen Fragestellungen zur Geltung bringt. 



\section{Vorwort zu diesem Band}

Tatians nach der Mitte des 2. Jh.s n. Chr. entstandene Rede an die Griechen ist eine ebenso wortgewaltige wie vehemente Attacke, in der sich ein gebildeter Christ gegen die gesamte hellenische Kultur- und Götterwelt wendet; sie stellt damit gewissermaßen bereits einen Vorläufer der umwälzenden geistigen Auseinandersetzungen zwischen religiös-paganen Traditionen und Christentum im 4. Jh. n. Chr. dar.

Meine erste Begegnung mit dieser Schrift liegt über zwanzig Jahre zurück: Im Sommer 1993 wurde ich von der Patristischen Kommission der Union der deutschen Akademien der Wissenschaften darum gebeten, die damals im Manuskript vorliegende Textedition von Miroslav Marcovich zu begutachten. Was mir damals rasch auffiel, war die große Fülle eigener Konjekturen, die Marcovich auf jeder Seite in diesem Text für nötig hielt und die den Stil des Autors in erheblichem Maße veränderten, indem sie ihn in Stilnormen einzwängten, wie sie vielleicht im 4. Jh. v. Chr. die Regel waren, ganz gewiss aber nicht mehr in der frühchristlichen Literatur des 2. Jh.s n. Chr. Ich kam deshalb in meinem Gutachten zu dem Ergebnis, dass Marcovich mindestens $90 \%$ seiner Konjekturen zurücknehmen müsse, bevor das Manuskript gedruckt werden könne. Leider zeitigte das Gutachten zu seiner Zeit überhaupt keine Folgen - als die Edition zwei Jahre später (1995) im Druck erschien, enthielt sie keineswegs weniger, sondern sogar noch mehr in den Text aufgenommene Konjekturen -, aber es hatte jedenfalls mein Interesse an diesem Text geweckt und mir zugleich gezeigt, dass die vorhandenen Editionen diesen Text in unbefriedigender Weise präsentierten: Die Edition von Molly Whittaker (1982, nachgedruckt 2003), die durch einen zu engen Anschluss an die Überlieferung gekennzeichnet ist - oft ist er so eng, dass der daraus resultierende Text an vielen Stellen kein befriedigendes Bild bietet -, hat nur ein gemischtes Echo gefunden. Die vor wenigen Jahren (2012) erschienene zweisprachige Ausgabe von Jörg Trelenberg steht ähnlich wie Whittaker Konjekturen äußerst zurückhaltend gegenüber. Angesichts dieser großen Diskrepanz zwischen Marcovich einerseits und Whittaker / Trelenberg andererseits musste die hier vorgelegte Textkonstitution viel häufiger, als dies in anderen SAPERE-Bänden der Fall ist, ihren eigenen Weg finden. Trelenberg hat seine Ausgabe auch mit umfangreichen kommentierenden Anmerkungen, einer langen Einleitung und Appendices versehen; doch machten die nicht geringen Defizite in den Anmerkungen es notwendig, dem vorliegenden Band eine ausführliche Textkommentierung beizugeben. Trelenbergs Einleitung und Appendices 
behandeln vor allem theologische Fragen, aber Tatians Schrift ist nicht nur für die Theologie, sondern für die gesamte griechisch-römische Kultur des 2. Jh.s n. Chr. interessant; deswegen hat der vorliegende Band es sich zur Aufgabe gemacht, diesen Text - in bereits bekannter SAPERE-Manier in insgesamt fünf Essays aus einer Reihe von verschiedenen Perspektiven (theologischen wie nicht-theologischen) zu beleuchten.

Im ersten dieser Essays stellt Ferdinand R. Prostmeier, ausgewiesener Kenner der christlichen Apologeten, Tatians Schrift in den Rahmen des Diskurses über ,Religion' in der frühen Kaiserzeit und charakterisiert die möglichen Stoßrichtungen des Textes innerhalb dieses Diskurses. Geht es dabei noch um ein vornehmlich (aber nicht ausschließlich) christliches Umfeld der Schrift, so stellen der Patristiker Holger Strutwolf und die Klassische Philologin Marie-Luise Lakmann die von Tatian entwickelte Seelenlehre in den Kontext der zeitgenössischen, vor allem mittelplatonisch geprägten Philosophie und zeigen, dass sich Tatians Seelenvorstellung nicht ohne ihre Bezüge zur zeitgenössischen nichtchristlichen Philosophie verstehen lässt. Ausdrücklich als „Wanderer zwischen zwei (Bildungs-)Welten" stellt der Kirchengeschichtler Peter Gemeinhardt Tatian in seinem Werdegang vor und würdigt ausführlich seine Auseinandersetzung mit dem damaligen pagan-griechischen Bildungsideal; in dieser Auseinandersetzung entwickelt er eine eigene („barbarische“) Bildungsvorstellung, die freilich sehr viel von dem enthält, was auf der nichtchristlichen Seite philosophisch gedacht wurde. Als Spezialist für platonische Religionsphilosophie beschäftigt sich Andrei Timotin mit Tatians Vorstellungen über den christlichen Gott und den ihm entgegenstehenden Dämonen, in denen die griechisch-römischen Götter weiterleben, und zeigt, dass diese Dämonologie eine originelle Synthese jüdischer und mittelplatonischer Traditionen ist. Schließlich geht Adolf Martin Ritter, ausgewiesener Kenner des antiken und mittelalterlichen Christentums, den Spuren Tatians und seiner Rede an die Griechen in der christlichen Literatur der Spätantike nach und macht (u.a.) deutlich, dass vor allem sein Beweis des Alters (und damit des Vorrangs) der christlichen („,barbarischen“) Philosophie gegenüber der paganen sowie der von ihm vielleicht als erstem formulierte Gedanke der creatio ex nihilo stark weitergewirkt haben. Insgesamt entsteht in diesen Essays ein Bild der hier präsentierten Schrift, das - so steht zu hoffen - ihrem Facettenreichtum, aber auch der Einbettung ihres Autors in die vielstimmige geistige Welt seiner Zeit, einigermaßen gerecht wird.

Für die vorzügliche Vorbereitung dieses Bandes zum Druck sei der SAPERE-Arbeitsstelle und namentlich Andrea Villani (der auch die Indices erstellt hat) herzlich gedankt. 


\section{Inhaltsverzeichnis}

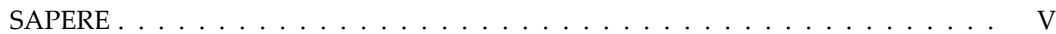

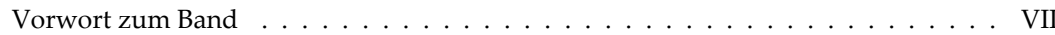

\section{A. Einführung}

Einführung in die Schrift (Heinz-Günther Nesselrath) . . . . . . . . . . . . . . . . . . . 3

1. Tatian - Leben und Werk . . . . . . . . . . . . . . . . . . . . . . . 4

1.1. Leben . . . . . . . . . . . . . . . . . . . . 4 4

1.2. Werk ...................... 7

2. Die Oratio ad Graecos . . . . . . . . . . . . . . . . . . . . . . . . . 9

2.1. Aufbau der Schrift . . . . . . . . . . . . . . . . . . . . . 9

2.2. Situierung und Datierung $\ldots \ldots \ldots \ldots \ldots$

2.3. Die Gattungsfrage . . . . . . . . . . . . . . . . . . . . . . . 17

2.4. Zu Überlieferung und Text der Oratio ad Graecos . . . . . . . . . . . . . . 19

2.4.1. Frühe indirekte Überlieferung . . . . . . . . . . . . . . . . . 19

2.4.2. Handschriften . . . . . . . . . . . . . . . . . . . 24

2.4.3. Zu den modernen Editionen . . . . . . . . . . . . . . . . 25

2.5. Textabweichungen dieser Ausgabe von früheren $\ldots \ldots \ldots . \ldots 26$

\section{B. Text, Übersetzung und Anmerkungen}

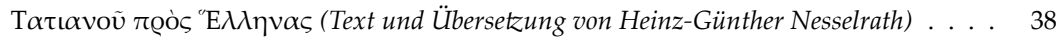

Anmerkungen zur Übersetzung (Heinz-Günther Nesselrath) . . . . . . . . . . . . . . . 114

\section{Essays}

Tatians Oratio ad Graecos und der Diskurs über ,Religion' in der frühen

Kaiserzeit (Ferdinand R. Prostmeier) . . . . . . . . . . . . . . . . . . . 193

1. Antiochia am Orontes und sein religiöser Kosmos . . . . . . . . . . . . . 193

2. Bildungsmilieu . . . . . . . . . . . . . . . . . . 202

3. Vorgänge - Konfliktdisposition - Wissbegier . . . . . . . . . . . . 207

3.1. Gott ist Schöpfer und Retter . . . . . . . . . . . . . . . . . . . . . . 210

3.2. Konfliktdispositionen . . . . . . . . . . . . . . . . . . . . . . . 212

3.3. Tradition, religiöse Wissbegier und Prestige . . . . . . . . . . . . 215

4. Achsenthemen und Protagonisten in der frühchristlichen Apologetik . . . . 220

5. Diskurs und Konstruktion . . . . . . . . . . . . . . . . . . 222

Tatians Seelenlehre im Kontext der zeitgenössischen Philosophie

(Holger Strutwolf/Marie-Luise Lakmann) . . . . . . . . . . . . . . . . . . . . 225

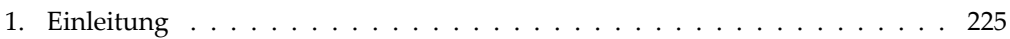

2. Wesen und Ursprung der Seele . . . . . . . . . . . . . . . . . . 227

3. Die Unsterblichkeit der Seele . . . . . . . . . . . . . . . . . . . . 236 
4. Fazit . . . . . . . . . . . . . . . . . . . . . . . . 244

Tatian und die antike Paideia. Ein Wanderer zwischen zwei

(Bildungs-)Welten (Peter Gemeinhardt) . . . . . . . . . . . . . . . . . 247

1. Zum Einstieg: Uneindeutigkeit als Programm? . . . . . . . . . . . . . . . 247

2. Ein weit gereister Autor: Bildungsbiographische Streiflichter . . . . . . . . 248

3. Tatians Auseinandersetzung mit dem hellenischen Bildungsideal . . . . . . . 253

4. Fazit: Ein Wanderer zwischen den (Bildungs-)Welten . . . . . . . . . . . . . 264

Gott und die Dämonen bei Tatian (Andrei Timotin) . . . . . . . . . . . . . . 267

1. Tatians Theologie . . . . . . . . . . . . . . . . . . . . . . . . . . 267

1.1. Die Gotteslehre ．. . . . . . . . . . . . . . . . . . . . . . . . . . . . . . 268

1.2. Die Logoslehre . . . . . . . . . . . . . . . . . . . . . . . . . . . . . . . . 269

1.3. Die Pneumatologie . . . . . . . . . . . . . . . . . . . . . . . . . . 272

2. Tatians Dämonologie . . . . . . . . . . . . . . . . . . . . . . . 274

2.1. Der Ursprung der Dämonen . . . . . . . . . . . . . . . . . . . 274

2.2. Die Konstitution der Dämonen . . . . . . . . . . . . . . . . . . 275

2.3. Die Tätigkeiten der Dämonen . . . . . . . . . . . . . . . . . . 278

2.3.1. Die Astrologie . . . . . . . . . . . . . . . . . . . . . . . . 278

2.3.2. Die Mantik . . . . . . . . . . . . . . . . . . . . . . . . 281

2.3.3. Die Magie . . . . . . . . . . . . . . . . . . . . . . . 283

2.3.4. Die Heilkunde . . . . . . . . . . . . . . . . . . . . . . . . 285

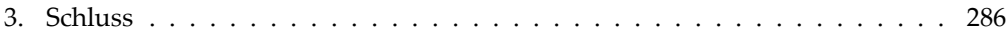

Spuren Tatians und seiner Oratio ad Graecos in der christlichen

Literatur der Spätantike (Adolf Martin Ritter) . . . . . . . . . . . . . . . . . . . 287

1. Vorbemerkungen . . . . . . . . . . . . . . . . . . . . . . 287

2. Spuren Tatians in antiken Geschichtsquellen - ein Überblick . . . . . . . . . . 288

3. Zum Problem der Nachwirkung Tatians am Leitfaden von Hauptthemen seiner Oratio ad Graecos . . . . . . . . . . . . . . . . . . . . . . . . . . . . . . . 294

3.1. Der göttliche Ursprung und Charakter des Christentums . . . . . . . . . 294

3.2. Altersbeweis für das Christentum . . . . . . . . . . . . . . . . . . 296

3.3. Die Einheit des Christentums als Problem . . . . . . . . . . . . . . . . 298

3.4. Christentum als „Barbarenphilosophie“ . . . . . . . . . . . . . . 299

3.5. Gegen die philosophische These von der Ewigkeit der Materie:

Creatio ex nihilo . . . . . . . . . . . . . . . . . . . . . . . . . . 301

3.6. Fazit. . . . . . . . . . . . . . . . . . . 302

\section{Anhang}

I. Literaturverzeichnis . . . . . . . . . . . . . . . . . . . . . . . . . . . . . . . . . . . . . 307

1. Abkürzungen . . . . . . . . . . . . . . . . . . . . 307

2. Ausgaben, Kommentare und Übersetzungen . . . . . . . . . . . . . . . . . . . . . . 308

3. Sekundärliteratur (und Ausgaben anderer Autoren) . . . . . . . . . . . . . 309

II. Indices (Andrea Villani) $\ldots \ldots \ldots$. . . . . . . . . . . . . . . 315

1. Stellenregister (in Auswahl) . . . . . . . . . . . . . . . . . . . . 315

2. Namens- und Sachregister . . . . . . . . . . . . . . . . . . . . . . . 321

III. Die Autoren dieses Bandes . . . . . . . . . . . . . . . . . . . . 333 
A. Einführung 



\title{
Einführung in die Schrift
}

\author{
Heinz-Günther Nesselrath
}

\begin{abstract}
„Es hat in der ganzen Antike weder vorher noch nachher eine so niedrig-gemeine Schmähschrift gegen die Bildung, Kultur und Philosophie gegeben ...; sie ist eine einzige wüste Schimpferei ... Es ist eine Ehre für die Kirche, daß sie diesen Mann rechtzeitig ausgeschieden hat ..." (Carl Schneider, Geistesgeschichte der christlichen Antike, $180^{1}$ )

„... diesem zweifellos logisch denkenden und scharfsinnigen Verfechter des ältesten Christentums ..." (Kukula $1900,4)$
\end{abstract}

Auf der einen Seite ein geradezu vernichtendes Urteil über Tatians Oratio ad Graecos (das keineswegs alleinsteht), auf der anderen aber auch Hochachtung für die gedankliche Leistung des Autors: Tatian hat bei seinen Lesern und Kritikern (offenbar auch schon denen der Antike) immer wieder starke Emotionen freigesetzt. ${ }^{2}$ Dass es sich also auf jeden Fall lohnt, diesen Autor und seine Schrift näher kennenzulernen, versuchen die folgenden Seiten zu zeigen.

\footnotetext{
${ }^{1}$ C. SCHNEIDER, Geistesgeschichte der christlichen Antike (München 1970).

${ }^{2}$ Zwei (weitere) Beispiele mögen genügen. Vgl. zum einen (den noch vergleichsweise gemäßigt formulierenden) Harnack 1884, 3: „Die masslosen Angriffe, welche Tatian gegen die Religion und die Philosophie, gegen die Wissenschaft und die Kunst der Griechen richtet, ... die gemeinen Verleumdungen der grössten griechischen Denker, die er ungeprüft nachspricht - diese ganze Methode des Kampfes erinnert aufs lebhafteste an die rohen Standreden der Kyniker, nicht selten auch an die frivolen Witze der Freigeister"; 6: „Die Härte, Ungerechtigkeit und Masslosigkeit in den Ausführungen muss heutzutage jeden Leser abstossen ....". Wesentlich ungnädiger äußert sich GeFFCKEN 1907, 105-113: Er attestiert Tatian „Abneigung gegen alles Wissen, verbunden mit prahlender Aftergelehrsamkeit“ (107); er sei „ein höchst unfertiger Kopf, ein ganz seichter Denker“ (ebd.), zwar „ein Original, aber ein ziemlich trauriges, ein Mensch von äußerst geringer Ehrlichkeit gegen andere und gegen sich selbst“ (112), schließlich ein "halbgebildete[r] Besserwisser" (113).
} 


\section{Tatian - Leben und Werk}

\subsection{Leben}

Über Tatians Leben ist nur wenig bekannt und dieses Wenige auch nicht sicher. Die wichtigste Quelle zu seinem Leben sind die ,autobiographischen Abschnitte ${ }^{3}$ der Oratio ad Graecos selbst; hinzu kommen Texte von drei christlichen Autoren des späteren 2., des 3. und des 4. Jh.s: das Werk Adversus haereses des Irenaeus von Lyon, ${ }^{4}$ die Kirchengeschichte des Eusebios von Kaisareia ${ }^{5}$ und das Panarion des Bischofs Epiphanios von Salamis auf Zypern. ${ }^{6}$

Schon Tatians Herkunft ist nicht völlig klar. In Or. 42,1 weist er auf seine Geburt „im Land der Assyrer" hin; doch ist diese Angabe mit einigen Unsicherheiten belastet, denn schon seit den Zeiten Herodots ist der Begriff „Assyrien“ in der griechischen Vorstellungswelt ein ziemlich vager. ${ }^{7}$

\footnotetext{
${ }^{3}$ Or. 29,1-3; 35,1f.; 42,1.
}

${ }^{4}$ Adv. haer. I 26,1 ist ein Fragment aus der griechischen Originalfassung des Werks, das als Auszug in der Kirchengeschichte des Eusebios (HE IV 29,2f.) erhalten ist: Hier wird Tatian ausdrücklich als „Hörer“ (= Schüler) Justins bezeichnet, der erst nach Justins Tod vom wahren Glauben abgewichen sei und sich Gedanken von Gnostikern zu eigen gemacht habe.

${ }^{5}$ HE IV 16,7 hebt Tatians griechische Bildung hervor („Tatian, ein Mann, der den ersten Teil seines Lebens sich als Sophist mit den Bildungsgütern $[\mu \alpha \theta \eta \dot{\mu} \mu \alpha \tau \alpha]$ der Griechen beschäftigte und sich in ihnen keine geringe Reputation erworben hatte"); HE IV 29,2f. ist der in der vorangehenden Anmerkung vorgestellte Auszug aus Irenaeus.

${ }^{6}$ Epiphanios gibt eine kurze biographische Skizze zu Tatian, als er dessen Häresie be-

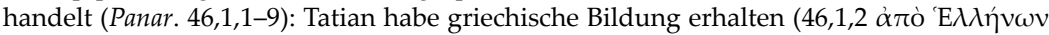

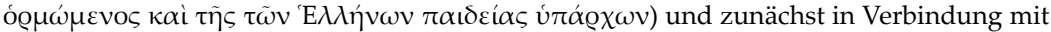
dem späteren Märtyrer Justin die wahre Lehre befolgt, sei dann aber nach dessen Tod in

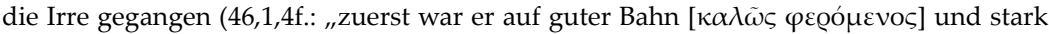
im Glauben, solange er mit dem heiligen Märtyrer Justin zusammen war. Als aber der heilige Justin starb, da erging es ihm wie einem Blinden, der sich an der Hand führen lässt: wie dieser, wenn er von dem, der ihn führte, verlassen ist, sich einem Abgrund preisgibt und dann wegen der ihm anhaftenden Blindheit unaufhaltsam hinabfällt, bis er in den Tod stürzt - so erging es auch diesem“). Nach Justins Tod sei Tatian von Rom wieder in den Osten gegangen und habe hier ähnliche gnostische Gedanken wie Valentinos entwickelt (46,1,7: „von Rom nämlich zog er nach der Vollendung des heiligen Justin in die Gegenden des Ostens, hielt sich dort auf, und da er schlechtem Denken anheimfiel, führte er entsprechend den Fabeleien des Valentinos auch seinerseits irgendwelche Aiones und Prinzipien und Emanationen in seine Lehre ein“); er habe „um das zwölfte Jahr des Kaisers Anto-

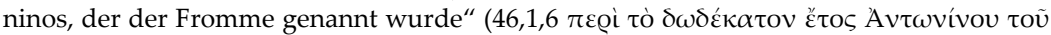

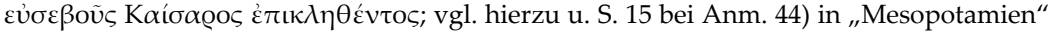

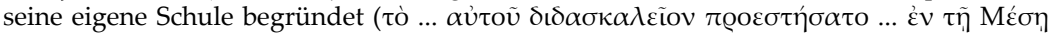
$\tau \tilde{\omega} \nu \pi 0 \tau \alpha \mu \tilde{\omega} \nu)$ und damit vom syrischen Antiochia bis nach Kilikien und Pisidien große Wirkung entfaltet $(46,1,8)$.

${ }^{7}$ Bei Herodot bildet „,Babylonien“, also das Kernland Mesopotamiens mit Babylon (am Euphrat) als Hauptstadt, nur einen Teil „Assyriens“ (vgl. Hdt. I 106,2; 178,1); in Hdt. IV 39,1 wird "Assyrien“ zwischen Persien und Arabien lokalisiert und umfasst damit offenbar auch Syrien. Ferner zeigt auch Hdt. VII 63, dass es eine recht große Nähe zwischen den 
Im Fall Tatians glaubt nun sogar noch der bisher letzte (2012 erschienene) Kommentar zur Oratio ad Graecos, dass ,, assyrisch“ hier auf die Region um den mittleren Lauf des Flusses Tigris verweist, ${ }^{8}$ was deutlich jenseits der damaligen Ostgrenze des Römischen Reiches wäre, und man könnte sich fragen, was Tatian dann überhaupt ins Römische Reich hineingezogen hätte. Nun nennt aber auch Tatians Zeitgenosse Lukian sich selbst gelegentlich einen "Assyrer", ${ }^{9}$ und von ihm wissen wir mit Bestimmtheit, dass er aus Samosata, ${ }^{10}$ d.h. einer auf dem Westufer des Euphrat und damit innerhalb der damaligen römischen Reichsgrenzen gelegenen Stadt, kam; und deshalb spricht nichts gegen die Annahme, dass auch die Ursprünge des "Assyrers" Tatian in etwa dem gleichen Gebiet, also den östlichen Teilen der römischen Provinz Syrien, gewesen sein könnten und Tatian mithin von Anfang kein Untertan der parthischen Könige, sondern der römischen Kaiser war.

Vor allem aus Tatians späterer Verbindung zu Justin (der etwa zwischen 100 und 165 lebte; vgl. u.) lässt sich schließen, dass Tatian wahrscheinlich um 120 geboren wurde. Er erhielt eine pagane, vor allem rhetorische (vielleicht auch philosophische) Schulausbildung ${ }^{11}$ und behauptet, es in ihr zu einiger Bedeutung gebracht zu haben. ${ }^{12}$ Wiederum nach eigenem Zeugnis unternahm er weite Reisen ${ }^{13}$ und will auf ihnen viele pagane Kulte kennengelernt haben und selbst in Mysterien eingeweiht worden sein. ${ }^{14}$ Als

Begriffen „syrisch“ und „, assyrisch“ gibt, da die hier genannten Assyrer „,von den Griechen Syrer, von den Barbaren Assyrer genannt wurden“. Vgl. auch Xen. Anab. VII 8,25; Cyr. I

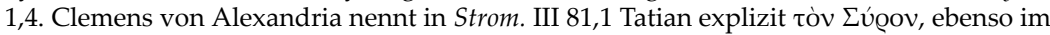

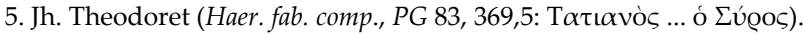

8 Trelenberg 2012, 1. Auch Whittaker 1982, ix lokalisiert Tatians Geburtsstätte „east of the Euphrates“. Dagegen hält Pouderon 2005, 175 Anm. 1 neben „Haute Mésopotamie ... entre l'Euphrate et le Tigre“ zumindest für möglich, dass mit „Assyrien“ auch „la Syrie romaine dans son ensemble“ gemeint sein könnte, „, car il semble bien y avoir eu une certaine confusion entre Syrie et Assyrie, Syrien et Assyrien“; vgl. die vorangehende Anmerkung.

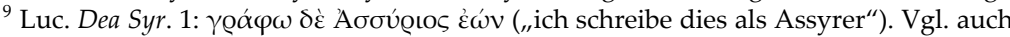
Luc. Bis Acc. 27, wo die personifizierte Rhetorik erzählt, sie habe den jungen Lukian zu-

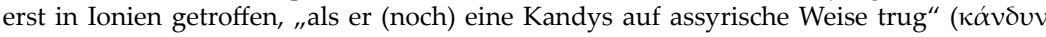

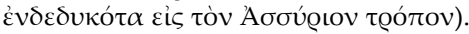

${ }^{10}$ Cf. Luc. Pisc. 19; Hist. Conscr. 24.

${ }^{11} \mathrm{Vgl}$. Or. 35,1 („nachdem ich mir eure sophistischen Künste erworben habe“) und 42,1 (,ich lernte zuerst eure Bildung kennen“).

${ }^{12} \mathrm{Vgl}$. Or. 1,5 (,ich habe eurer ,Weisheit’ eine Absage erteilt, auch wenn ich in ihr eine recht respektable Figur machte“).

${ }^{13}$ Or. 35,1 (,nachdem ich ein großes Stück Erde bereist habe“).

${ }^{14}$ Or. 29,1 („da ich auch an Mysterien teilgenommen und die bei allen vorkommenden Riten geprüft hatte ${ }^{\prime}$ ). Wiederholt beruft er sich darauf, Dinge nicht aus zweiter oder dritter Hand, sondern selbst und in Autopsie kennengelernt zu haben (29,1: „Da ich dies nun gesehen hatte ..."; 35,1: „Dies nun habe ich nicht, weil ich es von einem anderen lernte, (hier) ausgebreitet, sondern nachdem ich ... auch vielen (anderen) Künsten und Vorstellungen begegnet bin ... und die von euch [scil. den Griechen] zu ihnen [scil. den Römern] gebrachten vielfältigen Statuen kennengelernt habe"). 
letzte Station vor der Abfassung der Oratio gibt er einen Aufenthalt in Rom an, ${ }^{15}$ wo er sich offenbar dem späteren Märtyrer Justin angeschlossen hat, den er zweimal in der Oratio erwähnt. ${ }^{16}$ In welchem Umfang die Begegnung mit Justin für die Konversion Tatians zum Christentum von Bedeutung oder gar ausschlaggebend war, lässt sich nicht mehr genau sagen; in Tatians eigener Darstellung dieser Konversion (Or. 29,1-3) fällt Justins Name nicht.

Justin erlitt um 165 den Märtyrertod, wobei der damals ebenfalls in Rom weilende Kyniker Crescens unheilvolle ,Hilfestellung' geboten zu haben

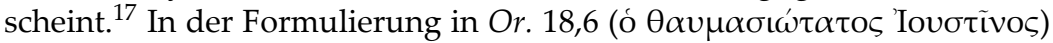
scheint Tatian bereits auf den toten Justin zurückzublicken, was für die Datierung der Oratio von Bedeutung ist (vgl. u.). Nach Justins Tod scheint es zu einer Entfremdung zwischen Tatian und der römischen Christengemeinde gekommen zu sein: Nach der Darstellung des Irenaeus (Adv. haer. I 26,1; vgl. o.) habe Tatian sich nunmehr selber als Lehrer aufspielen wollen, sei dabei aber auf gnostische Abwege geraten. Dass Tatian noch in Rom als Lehrer gewirkt hat, bezeugt Eusebios, der als einen seiner dortigen Schüler Rhodon nennt. ${ }^{18}$ Whittaker ${ }^{19}$ hat als Schüler Tatians auch keinen Geringeren als Clemens von Alexandria erwogen, der im ersten Buch seiner Stromateis Tatian zweimal explizit nennt; ${ }^{20}$ doch reichen die dortigen Formulierungen nicht aus, um eine Schülerschaft zu erweisen.

Die letzte aus Tatians Leben bekannte Station ist seine Rückkehr in den Osten, wo er „in Mesopotamien“ eine eigene Schule begründete, wie uns freilich explizit erst Epiphanios berichtet (vgl. o. Anm. 6). Das Erbe dieser Schule war - wiederum nach Epiphanios - in den betreffenden Regionen noch einige Zeit wirksam und einflussreich, vor allem was die Rolle von Tatians Diatessaron (vgl. u.) in der syrischen Kirche betraf.

Tatians eigene Auskünfte in der Oratio über sein Leben sind mehrfach mit großer Skepsis aufgenommen worden; der letzte Kommentator glaubt sogar, Tatian habe „im Sinne seiner apologetischen Technik und Taktik zu-

\footnotetext{
${ }^{15}$ Or. 35,1: „,nachdem ich mich zuletzt auch in der Stadt der Römer aufgehalten habe.“

${ }^{16}$ Or. 18,6; 19,2. TreLEnBerg 2012, 195-203 hat sehr wahrscheinlich gemacht, dass „Tatian die Schriften Justins kannte und damit mit Recht als sein Schüler bezeichnet werden kann" (203).

${ }^{17}$ In Or. 19,2 führt Tatian Crescens als geldgierigen Päderasten ein, der Justin ans Messer zu liefern versucht habe, weil dieser die Philosophen seines Schlages offen als "Schlemmer und Betrüger" darstellte. Vgl. Eus. HE IV 16,1.3.7.

${ }^{18}$ Eus. HE V 13,1: „Rhodon, der aus Kleinasien stammte, wurde in Rom, wie er selbst berichtet, Schüler Tatians, den wir in früheren Abschnitten kennengelernt haben, und verfasste diverse Schriften ..."

${ }^{19}$ Whittaker 1982, ix.

${ }^{20}$ Strom. I 101,2: „Über diese Dinge ist genau berichtet von Tatian in seiner ,Rede an die Griechen“"; 102,2: „,von Kekrops, dem aus zwei Gestalten bestehenden (Kéк@отоऽ той

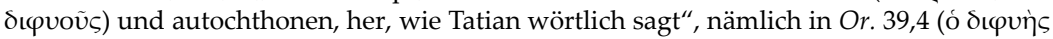

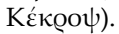


mindest teilweise bewusst die Unwahrheit" gesagt. ${ }^{21}$ Diese negative Bewertung knüpft sich vor allem an Tatians Äußerungen über angebliche Menschenopfer in nächster Nähe zur Weltstadt Rom (Or. 29,1) und an seinen Anspruch, er habe die in Or. 33f. behandelten Kunstwerke alle selbst gesehen. ${ }^{22}$ Da es inzwischen aber Hinweise gibt, dass Tatian zumindest Einiges davon doch gesehen haben könnte, ${ }^{23}$ sollen diese Partien in den Anmerkungen zur Übersetzung einer genaueren Betrachtung unterzogen werden.

\subsection{Werk}

Die Oratio ad Graecos ist nicht das einzige schriftstellerische Produkt des rhetorisch gebildeten (s.o.) Tatian gewesen. Hier sollen andere noch bezeugte Werke aus seiner Hand kurz vorgestellt werden.

Das bedeutendste und wirkmächtigste von Tatians Werken war die vermutlich nach seiner Rückkehr in den Osten entstandene Evangelienharmonie (Diatessaron), eine an der Chronologie des Johannes-Evangeliums orientierte ,Summe' aller vier später kanonisch gewordenen Evangelien, die in der syrischen Kirche bis ins 5. Jh. anstelle der vier Evangelien der autoritative Text zum Leben Jesu war $^{24}$ und selbst, nachdem er im 5. Jh. durch die Bischöfe Rabbula von Edessa und Theodoret von Kyros durch die vier Einzel-Evangelien ersetzt worden war, durch (zum Teil noch erhaltene) Übersetzungen ins Armenische, Arabische, Persische, Alt-Georgische, Althochdeutsche, Niederdeutsche und Mittelenglische noch bis ins spätere Mittelalter wirkte. ${ }^{25}$

In Or. 15,4 spricht Tatian im Zusammenhang des Verhältnisses des Men-

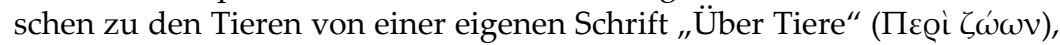
in der er sich über dieses Verhältnis genauer geäußert habe.

In Or. 40,3 kündigt er eine Schrift „An diejenigen, die die Dinge über

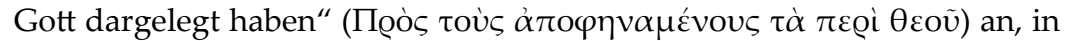
der er sich mit paganen Autoren auseinandersetzen wolle, die sich über Gesetze, Sitten und Lebensweise der Christen geäußert hätten. Ob diese

${ }^{21}$ Trelenberg 2012, 5.

${ }^{22}$ Vgl. hierzu vor allem A. KalkmanN, ,"Tatians Nachrichten über Kunstwerke“, RhM 42 (1887) 489-524; dagegen ist Kukula 1900 der Meinung, dass „der ,Künstlerkatalog', wie man dem Redner ohneweiters glauben kann, auf persönliche Erinnerungen und Notizen aus seiner langjährigen Wanderzeit zurückgeht" (20). Zuletzt äußert sich Trelenberg 2012, 5 Anm. 22 wieder äußerst skeptisch: „Ponschab (Rede, S. 6) und Whittaker (Background, S. 59) ziehen eine Autopsie Tatians zwar in Erwägung, liefern aber weder Argumente noch Belege."

${ }^{23}$ Vgl. dazu unten S. 173, Anm. 517 zu Or. 33,3.

${ }^{24}$ Vgl. Eus. HE IV 29,6: „Er [scil. Tatian] verfasste eine zusammenhängende Sammeldarstellung der Evangelien und nannte sie Diatessaron, welches bei manchen noch bis jetzt im Gebrauch ist."

${ }^{25}$ Vgl. Petersen 1994. 
Schrift freilich je niedergeschrieben wurde, ist mangels anderer Zeugnisse unbekannt.

In Or. 16,2 lässt Tatian nebenbei verlauten, dass er sich bereits „in anderen Darlegungen" ( $\dot{\varepsilon} \vee \alpha ٌ \lambda \lambda$ oı $)$ über Fragen der Seelenlehre geäußert habe (insbesondere offenbar zur Frage, ob menschliche Seelen „Dämonen“ seien, die über Menschen Macht ausübten).

Darüber hinaus gibt es externe Zeugnisse für zwei weitere Schriften: Im dritten Buch seiner Stromateis zitiert Clemens einen Auszug aus Tati-

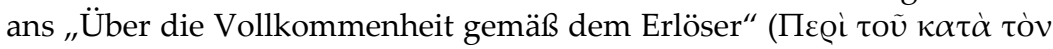
$\sigma \omega \tau \tilde{\eta} \mathrm{\rho} \alpha \kappa \tau \alpha \varrho \tau \iota \sigma \mu о \tilde{v})$, in dem Tatian die geschlechtliche Vereinigung in der Ehe als Verführung des Teufels zum Laster brandmarkt. ${ }^{26}$ Und in Eusebios' Kirchengeschichte wird Tatians Schüler Rhodon (vgl. o.) mit einem Hinweis auf Tatians Werk Problemata zitiert, in dem Tatian auf Unklares und Kryptisches in den Heiligen Schriften hingewiesen und Rhodon selber Lösungen für solche Fragen in einem daran anschließenden Werk in Aussicht gestellt habe. ${ }^{27}$

Tatian scheint also zu Lebzeiten ein recht beachtliches Oeuvre hervorgebracht zu haben; ${ }^{28}$ vollständig erhalten geblieben ist davon nur die Oratio ad Graecos, weil sie über den Verdacht der Häresie, der sich offenbar schon bald an die übrigen Werke Tatians hängte, erhaben war. ${ }^{29}$

\footnotetext{
${ }^{26}$ Clem. Alex. Strom. III 81,1f.

${ }^{27}$ Eus. HE V 13,8: „Er [scil. Rhodon] sagt, von Tatian sei auch ein ,Buch schwieriger

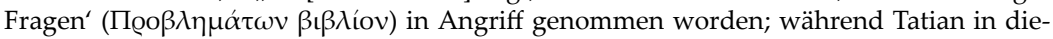
sem das Unklare und Verborgene der Heiligen Schriften zu erläutern versprach, kündigt Rhodon selbst an, er werde in einer eigenen Schrift die Lösungen der von jenem dargebotenen Fragen darlegen."

${ }^{28}$ Vgl. auch Eus. HE IV 16,7: „Tatian hinterließ ... sehr viele Erinnerungsstücke an sich in seinen Schriften ..."

${ }^{29}$ Bezeichnend ist die Charakteristik des Eusebios in HE IV 29,7 zu Tatians Gesamtwerk: „Dieser Mann hat eine große Menge an Schriften hinterlassen, von denen bei vielen am

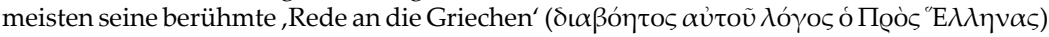
in Erinnerung ist; in ihr kommt er auf die alten Zeiten zu sprechen und hat im Vergleich $\mathrm{zu}$ allen bei den Griechen in Ansehen Stehenden Moses und die Propheten der Juden als älter erwiesen. So scheint diese Rede denn auch von allen seinen Werken das schönste und nützlichste zu sein." Zu der Frage, ob Tatian wirklich ein häretischer Gnostiker war oder dazu wurde, vgl. jetzt die sorgfältigen Erwägungen bei Trelenberg 2012, 203-217, der zu folgendem Urteil zur Oratio ad Graecos gelangt: „Tatian präsentiert sich in der oratio als ein christlich-philosophischer Schriftsteller, dessen Kosmologie, Soteriologie, Pneumatologie, Psychologie, Anthropologie und Ethik von vielfältigen gnostizistischen Tendenzen durchzogen sind, welche sich im Regelfall und bei wohlwollender Beurteilung noch innerhalb des Rahmens großkirchlicher Rechtgläubigkeit verorten lassen, diesen im Einzelfall jedoch eindeutig verlassen" (219).
} 


\section{Die Oratio ad Graecos}

\subsection{Aufbau der Schrift}

„The incoherence of the work as a whole is on a par with his often confused and incoherent arguments and the obscurity of his style." (Whittaker 1982, xx)

„1... turbat lectorem ordo rerum saepe neglectus et confusa descriptionis ratio ... accedunt transitiones plane singulares et audaces, quibus ad alia non tam transire quam transilire videtur, ita ut oratio oriatur amputata et abscissa." (von Otto 1851, XXXII)

Wie diese beiden Zitate zeigen, ist den Interpreten von Tatians Schrift eine Aufschlüsselung ihrer Gedankenabfolge und Struktur nicht immer leichtgefallen. ${ }^{30}$ Nachstehend sollen einige neuere Versuche besprochen und anschließend ein eigener Vorschlag gemacht werden (der freilich viel der inzwischen über 150 Jahre alten Ausgabe von Ottos verdankt).

In Mary Whittakers Gliederungsversuch (1982, xviiif.) präsentiert sich die Oratio ad Graecos vor allem als eine Abfolge von ",attacks", „doctrines" und „digressions". Auf eine „,introductory attack on Greek claims to culture“ (Kap. 1) folgt sogleich eine ",attack on philosophers in particular and in general“ (Kap. 2-3); dann werde in Kap. 4-7 Tatians ",doctrine on creation" dargelegt, der eine erste "digression to attack astrology and mythology" (Kap. 8-11) folge. In Kap. 12-15 schließe sich eine „return to doctrine“ an, danach (Kap. 16-18) eine "digression to attack sorcery and medicine“. In Kap. 19 gibt es eine neuerliche "attack on philosophers, Crescens in particular, and divination"; es folgt in Kap. 20 eine mehr doktrinäre Partie zu „The Fall and the end of the world“, wonach die Attacken fortgesetzt werden: „attack on mythology“ (Kap. 21), „attack on pagan practices“ (Kap. 22-28). Einen eigenen Teil bilden dann die Darlegungen zu „Tatian's own conversion“ in Kap. 29-30. In Kap. 31 beginnt das ,"chronological argument to show by the various Greek datings of the Trojan War $^{31}$ that Homer was later than Moses", woran sich aber sofort eine "digression on Christian attitude towards age and sex“ (Kap. 32-34) und eine "brief description of Tatian's travels and education, which had qualified him to write of such things as an eye-witness“ anhängen. In Kap. 36-41 findet dann die „return to the chronological argument and evidence for the antiquity of Moses" statt, wonach die Schrift mit einem kurzen Epilog in Kap. 42 endet. Die Inhaltsübersicht in der Einleitung von Marcovichs Edition ${ }^{32}$ präsentiert zum Teil eine etwas andere Nomenklatur, bietet aber im Übrigen nahezu die gleiche Abschnittseinteilung wie Whittaker. Demgegenüber bemüht sich der jüngste Glie-

\footnotetext{
${ }^{30}$ Ein sehr negatives Urteil über die sprunghafte Gedankenführung der Schrift findet sich auch bei GEFFCKEN 1907, 107-110.

31 „Datings of the Trojan War" ist nicht korrekt, denn es geht hier um die vielen unterschiedlichen Datierungen Homers, nicht aber des Trojanischen Krieges, für den Tatian das inzwischen traditionell gewordene Datum des Eratosthenes (1184/3 v. Chr.) zu akzeptieren scheint.

${ }^{32}$ Marcovich 1995, $5 f$.
} 
derungsversuch (der von Trelenberg ${ }^{33}$ ) im Gefolge Harnacks ${ }^{34}$ um den Erweis eines sehr durchdachten, gelegentlich geradezu symmetrisch anmutenden Aufbaus der Schrift. Zwischen einem Einleitungsteil (Kap. 1-4 $4^{35}$ ) und dem kurzen Schluss in Kap. 42 setzt Trelenberg den Hauptteil (Kap. 5-41) an, den er in zwei etwa gleich lange Großabschnitte gliedert: Kap. 5-20 bietet „die grundlegenden Lehren des Christentums“, Kap. 21-41 sieht er als „dem Vergleich dieser Lehren mit der heidnischen Anschauung und Praxis gewidmet" (26). Die beiden Großabschnitte gliedert er wiederum in jeweils vier Unterabschnitte: Der dogmatische Teil biete zunächst Aussagen zum Schöpfergott selbst (Kap. 5-7), dann zu den Dämonen (Kap. 8-11), zur Seelenlehre (Kap. 12-15a) und zur Anthropologie (Kap. 15b-20); der vergleichende Teil beginne mit Ausführungen zum „Erweis der Minderwertigkeit der heidnisch-griechischen Kultur (Kap. 21-24), sodann zur „Eitelkeit und Geschwätzigkeit im Schulbetrieb der Philosophen und Rhetoren (Kap. 25-30a), darauf - dazu in scharfem Kontrast - zur "hohe(n) christliche(n) Ethik und Sittlichkeit“ (Kap. 30b-35); schließlich folge "der gut strukturierte Abschnitt über den Altersbeweis, dem bereits in Kap. 31 vorgearbeitet wurde" (27). ${ }^{36}$ Mit dieser zuletzt zitierten Bemerkung holt Trelenberg etwas nach, was er zunächst unterschlagen hat, weil es die schöne Systematik seiner Darbietung doch merklich gestört hätte: Kapitel 31 ist nicht einfach eine „Vorarbeit" zum Altersbeweis, sondern dessen eigentlicher und unverzichtbarer Beginn. Dass dieser Beginn dann noch einmal abgebrochen und vier Kapitel lang etwas völlig anderes traktiert wird, ${ }^{37}$ stellt Tatians Strukturierungsfähigkeit nicht das allerbeste Zeugnis aus, sondern zeigt sehr plastisch, dass er sich gern von momentanen Assoziationen auf völlig andere Gleise lenken lässt. Trelenbergs Bemühen, die Struktur der Oratio ad Graecos in einem besseren Licht erscheinen zu lassen, als sie es verdient, lässt ihrerseits den letzten großen Teil der Schrift - eben den Altersbeweis der jüdisch-christlichen Überlieferung gegenüber der griechisch-paganen - zu

\footnotetext{
${ }^{33}$ Trelenderg 2012, 25-29.

${ }^{34}$ Harnack 1884, 8 billigt der Oratio eine „planmässige Anordnung im Grossen und Ganzen" zu.

${ }^{35}$ In gleicher Weise hatte bereits von Отто 1851, XXXVf., in den ersten vier Kapiteln das "exordium“ der Schrift gesehen.

${ }^{36}$ Manches von Trelenbergs Gliederung hat Kukula 1913, 7-10 vorweggenommen: KuKULA lässt die Einleitungspartie bis in die Mitte von Kap. 4 reichen, wonach der Haupt-

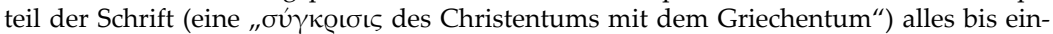
schließlich Kap. 41 umfasse, wonach 42 nur noch eine kurze Schlussbemerkung darstelle. Den Hauptteil gliedert KuкUlA in folgende Abschnitte: „A. Kap. IV 3 - VII 6: christliche Kosmologie“, „B. Kap. VIII - XX: christliche Dämonologie“ (mit mehreren Unterabschnitten, die dem Obertitel des Abschnitts durchaus nicht immer entsprechen), „C. Kap. XXI - XXX: Götterlehre, Theaterwesen, Philosophie, Ethik und Gesetzgebung des Griechentums im Lichte christlicher Weltanschauung" (die Vielzahl dieser Titelstichworte zeigt die Schwierigkeit, das alles unter einen Hut zu bringen), „D. Kap. XXXI - XLI: Höheres Alter und höhere Sittlichkeit des Christentums mit besonderer Zurückweisung des Vorwurfs der Unzucht, Blutschande und Anthropophagie" (auch hier zeigt die Länge des Titels die Vielgestaltigkeit der Thematik).

${ }^{37}$ Trelenberg 2012, 25 spielt sogar mit dem Gedanken, dass Kapitel 31 „ursprünglich nach Kapitel 35 stand" und durch eine "äußere Kontamination“ vor Kapitel 32 versetzt worden ist (bezeichnenderweise springen die Eusebios-Auszüge von Tatians Oratio in PE X 11,1-35 denn auch zwischen $\S 5$ und 6 von Tatians Kapitel 31 zu 36). Aber weshalb hätte das jemand tun sollen, wenn dies wirklich die ursprüngliche Abfolge war? Dafür, dass „der Altersbeweis in Kap. 31 begonnen, danach jäh abgebrochen und erst in Kapitel 36 mit stilistisch hartem Einsatz fortgeführt wird“" (so völlig zutreffend TRELENBERG 2012, 25), kann kaum jemand anders als Tatian selbst verantwortlich sein.
} 
sehr in den Hintergrund treten; doch wurde gerade dieser Teil der Schrift in der Folgezeit besonders gern und aufmerksam zur Kenntnis genommen. ${ }^{38}$

Es scheint daher besser, eine Gliederung der Schrift vorzuschlagen, die keine so schöne Struktur wie Trelenbergs Vorschlag zum Vorschein bringen wird, stattdessen aber wichtige Teile ihres Inhalts besser hervortreten lässt:

\section{Kap. 1-4: Einleitungsteil}

Kap. 1: Einleitender polemischer Appell an „die Griechen“: sie sollen ihre Verachtung der „Barbaren“ aufgeben, denn die gesamte griechische Kultur beruhe auf deren Erfindungen, während die eigenen griechischen Kulturleistungen zutiefst defizitär seien.

Kap. 2-3: Attacke gegen griechische Philosophen und griechische Philosophie.

Kap. 4: Rückkehr zur Eingangsapostrophe „ihr Griechen“ (Ringkomposition). Der Sprecher bekundet seine Loyalität gegenüber dem römischen Staat, mit der einen Ausnahme des Gottesglaubens. Dieses Stichwort führt zu einer ersten Darlegung von Gottes Natur, deren Transzendenz betont wird - ein wichtiges Argument dafür, dass man einen solchen (eben transzendenten) Gott nicht zum Gegenstand einer irdisch-staatlichen Loyalität machen kann. ${ }^{39}$ Die Ankündigung "Noch deutlicher aber werde ich unsere Lehren darlegen" im letzten Satz leitet zum ersten Hauptteil über.

\section{Kap. 5-30: Erster Hauptteil}

Kap. 5-11: Erster Abschnitt - die göttliche Konstituierung der Welt und ihre Denaturierung durch die abgefallenen Dämonen

Kap. 5: Gott und sein Logos; die Weltschöpfung.

\footnotetext{
${ }^{38}$ Vgl. hierzu Clem. Alex. Strom. I 101,1f.: ,Jetzt ist über die Zeiten des Mose zu sprechen, durch die unbestreitbar erwiesen werden wird, dass im Vergleich zu aller (anderen) Weisheit die älteste die Philosophie der Juden ist. Über diese Dinge hat (bereits) sorgfältig Tatian in seiner ,Rede an die Griechen' gehandelt ..."; Orig. C. Cels. I 16: „Von dem jüngeren [scil.: im Vergleich zu Flavius Josephus] Tatian ist seine ,Rede an die Griechen' im Umlauf, (eines Autors) der in hochgelehrter Weise diejenigen Autoren vorstellt, die über das Alter der Juden und des Mose berichtet haben. " In HE IV 29,7 beruht Eusebios' sehr positive Charakteristik von Tatians Oratio (zitiert o. in Anm. 29) gerade auf den Kapiteln zum Altersbeweis. Vgl. noch in byzantinischer Zeit Georg. Mon. Chron. 40,17-20 DE Boor: "Clemens (Alexandrinus) und (Julius) Africanus und Tatian, von den Juden aber Josephus und Justus haben berichtet, dass der göttliche Mose seine Lebensblüte zur Zeit des Inachos hatte, wobei jeder auf eigene Weise aus alter Überlieferung den Beweis führte“; vgl. auch Georg. Sync. Ecl. chron. 71,2-4 Mosshammer.

${ }^{39}$ Whittaker (und andere, z.B. auch Мarcovich) ziehen dieses Kapitel also zu Unrecht zum Folgenden; es gehört vielmehr noch zur Einleitung, in der ein deutlicher Gegensatz zwischen Griechen und „Barbaren“ (= Christen) entwickelt wird.
} 
Kap. 6: Ausblick auf Welt-Ende und Auferstehung (beides wird als einmaliges Ereignis aus der ebenfalls einmaligen Weltschöpfung begrün$\left.\operatorname{det}^{40}\right)$.

Kap. 7: Rückkehr zur Schöpfungsgeschichte: Der Logos erschafft Menschen und (noch zuvor) Engel, beide mit freiem Willen; die Revolte einiger Engel, der die Menschen sich anschließen, führt zu deren Sterblichkeit, während die revoltierenden Engel zu Dämonen (= den heidnischen Göttern) werden.

Kap. 8: Genauere Vorstellung der Dämonen.

Kap. 9: Die Dämonen konstruieren die Heimarmene; Aufzeigung der sich daraus ergebenden Ungereimtheiten und Folgen für die Menschen.

Kap. 10: Weitere Folgen des Dämonen-Wirkens: entwürdigende Metamorphosen und absurde Katasterismen.

Kap. 11: Ablehnung einer von der Heimarmene regierten Welt; die Hinwendung zum wahren Gott macht den Menschen frei.

Kap. 12-21: Zweiter Abschnitt: Die Situation und das Verhältnis der Dämonen und Menschen zueinander in der diesseitigen Welt

Kap. 12: Die zwei Arten von „Geistern“ ( $\pi v \varepsilon v ́ \mu \alpha \tau \alpha)$ : „Seele“ ( $\psi v \chi \eta ́)$ und

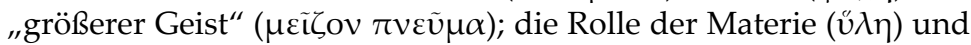
des v́גıкòv $\pi v \varepsilon \tilde{u} \mu \alpha$ im Kosmos und bei den Dämonen.

Kap. 13: Die Natur der $\psi v \chi \eta$; ihre Möglichkeit, in Verbindung mit dem $\theta \varepsilon \tilde{\text { ioov }}(=\mu \varepsilon \tilde{\zeta} \zeta \mathrm{ov}) \pi v \varepsilon \tilde{v} \mu \alpha$ die verlorene Unsterblichkeit (vgl.Kap. 7) zurückzuerlangen.

Kap. 14: Das Schicksal der der v̛ $\lambda \eta$ verhafteten Dämonen.

Kap. 15: Das den Menschen (aufgrund ihrer Fähigkeit zur Umkehr) mögliche andere Schicksal.

Kap. 16-18: Die Arten des Einwirkens der Dämonen auf die Menschen: Sinnestäuschungen, Krankheiten (mit Digression in 17,1-3: die Absurdität der Antipathienlehre Demokrits), diverse Zauber, Gespenstererscheinungen, Medizin.

Kap. 19: Weitere Folgen des Dämonenregiments: Selbst die paganen Philosophen fürchten den Tod (Beispiel des Crescens); Absurditäten der Divination.

Kap. 20: Der gegenwärtige Zustand der Menschen auf dieser Erde ist ein Exil; doch ist eine Rückkehr „zur alten Verwandtschaft" mit Gott möglich.

Kap. 21: Die griechische Mythologie enthält viel absurdere Geschichten als die christliche Offenbarung, und bei diesen Geschichten helfen auch allegorische Deutungen nichts.

\footnotetext{
${ }^{40}$ Whittaker 1982, xviii bezeichnet auch dieses Kapitel als eine „digression“; es wäre vielleicht besser, es als zweiten Teil eines großen inhaltlichen Bogens zu verstehen, der in Kap. 5f. gespannt wird.
} 
Kap. 22-28: Dritter Abschnitt: Frag- und kritikwürdige Erscheinungen in der paganen Umwelt der Christen

Kap. 22: Pantomimen und sophistische Vorträge.

Kap. 23: athletische Wettkämpfe und Gladiatorenspiele.

Kap. 24: Theater- und sonstige musische Darbietungen.

Kap. 25: Philosophenauftritte.

Kap. 26: Sinn- und fruchtlose naturwissenschaftliche und linguistischgrammatikalische Studien.

Kap. 27: Intoleranz gegenüber Christen bei gleichzeitiger Duldung oder sogar Ehrung anderer „devianter" religiöser Meinungen; nochmalige Betonung der Nutzlosigkeit griechischer wissenschaftlicher Studien.

Kap. 28: Widersprüche in den Gesetzen und Sitten der Menschen.

Kap. 29-30: Abschluss des ersten Hauptteils

Tatians persönliche Konsequenz aus der vorangegangenen Bestandsaufnahme: die Konversion zum Christentum.

\section{Kap. 31-41: Zweiter Hauptteil}

Nachweis, dass die christlichen Lehren viel älter, ursprünglicher und damit wahrer sind als die griechisch-paganen („Altersbeweis“).

\section{Kap. 31: Erster Beweisschritt}

Die großen Meinungsverschiedenheiten über das Alter Homers; erste Schlussfolgerungen aus diesem Dissens.

Kap. 32-35: Exkurs:

Christliche Harmonie gegenüber paganer disharmonischer Polyphonie

Kap. 32: Gegenüber der Zerstrittenheit paganer Lehrmeinungen gibt es keinen Lehr-Dissens bei den Christen, an deren Bildung alle ohne Ausnahme partizipieren können: jung und alt, Mann und Frau.

Kap. 33: Gegenüber den sittsamen christlichen Frauen haben die Griechen viele verworfene Frauenzimmer geehrt und sogar durch Standbilder prominent gemacht (Statuenkatalog, 1. Teil).

Kap. 34: Ausweitung des Gedankens: Nicht nur zweifelhafte Frauen, sondern auch fragwürdige Männer sind bei den Griechen durch Kunstwerke geehrt worden (Statuenkatalog, 2. Teil).

Kap. 35: Bekräftigung des gerade Vorgeführten durch Hinweis auf eigene Erfahrung und Autopsie; beides hat Tatian zu seiner Konversion geführt (vgl.Kap. 29). 


\section{Kap. 36-41: Fortsetzung des Altersbeweises}

Nachweis, dass die Überlieferungen des Moses älter und wahrer sind als die Inhalte nicht nur Homers, sondern auch aller anderen griechischen Dichter und Intellektuellen älterer Zeit:

Kap. 36: Hinweis zur Methode des Nachweises; das Zeugnis der Chaldäer (= Babylonier).

Kap. 37: Das Zeugnis der Phönizier.

Kap. 38: Das Zeugnis der Ägypter.

Kap. 39: Erläuterungen des Abstandes zwischen Inachos-Zeit (= MosesZeit) und Trojanischem Krieg (als frühest-möglicher Zeit Homers) mit Hilfe der argivischen und der attischen Königschronologie.

Kap. 40: Resultat: Da Moses so viel älter ist als Homer, können die Griechen ihre Kenntnisse nur durch Kopierung und Verzerrung der Moses-Lehren gewonnen haben.

Kap. 41: Ausweitung des Resultats: Moses ist älter nicht nur als Homer, sondern auch als alle anderen griechischen Intellektuellen, auf denen die griechische Kultur und Paideia beruht.

\section{Kap. 42: Epilog}

Kurze Selbstvorstellung des Autors Tatian; er ist bereit, für das Vorgetragene weiter Rede und Antwort zu stehen.

\subsection{Situierung und Datierung}

Weder hinsichtlich der Zeit, in der die Oratio entstanden sein soll, noch hinsichtlich des Ortes ihrer Entstehung herrscht in der Forschung Einigkeit: Bei der Datierung schwanken die Ansätze zwischen 150 und 178 n. Chr., und für den Ort wurden neben Rom und Syrien auch noch dazwischenliegende Gegenden ins Spiel gebracht, beispielsweise Griechenland. ${ }^{41}$ Die Geschichte der einzelnen Hypothesen und ihrer Argumente ist in Trelenbergs Kommentar detailliert aufgearbeitet ${ }^{42}$ und braucht hier nicht wiederholt zu werden; besprochen werden sollen dagegen einzelne Indizien, die vielleicht doch eine Eingrenzung zumindest der Entstehungszeit (und des Ortes, soweit sich die Entstehungszeit mit Lebensstationen Tatians vgl. o. - in Verbindung bringen lässt) ermöglichen.

\footnotetext{
${ }^{41}$ Vgl. Harnack 1897, 287, der sich dafür auf Or. 35,1 beruft, wo Tatian recht distanziert von der "Stadt der Römer" spricht, in der er sich „zuletzt" aufgehalten habe, dagegen die "Griechen" direkt apostrophiert, von denen die zuvor evozierten Statuen zu den Römern gelangt seien. Nun apostrophiert Tatian die Griechen jedoch von Beginn der Schrift an immer wieder, so dass es offen bleiben muss, ob sich daraus wirklich eine distinkte Lokalität ableiten lässt; schließlich waren „Griechen“ im ganzen Römischen Reich verbreitet.

${ }^{42}$ TRelenberg 2012, 8-15.
} 
Das sicherste Indiz ${ }^{43}$ für eine Frühdatierung der Schrift könnte die Notiz in Epiphanios' Panarion sein, die die Eröffnung von Tatians Schule in "Mesopotamien“",um das zwölfte Jahr des Kaisers Antoninos, der der Fromme genannt wurde" datiert. ${ }^{44}$ Wäre damit der Kaiser Antoninus Pius gemeint, wie es zunächst den Anschein hat, dann hätte Tatian seine Schule bereits im Jahr 152 eröffnet, über ein Jahrzehnt vor Justins Märtyrertod, auf den er jedoch in Or. 18,6 als einen bereits Toten zurückzublicken scheint. Es spricht daher Vieles dafür, dass mit dem bei Epiphanios genannten Kaiser Marc Aurel gemeint ist, der die Bestandteile Antoninus und Pius ebenfalls in seiner offiziellen Nomenklatur führte. Das sich dann ergebende Jahr 172 für die Eröffnung von Tatians Schule lässt sich erheblich besser mit anderen mutmaßlichen Daten aus Tatians Biographie in Einklang bringen. ${ }^{45}$

Es wurde bereits in der Skizze von Tatians Leben darauf hingewiesen, dass uns vor allem seine Verbindung mit Justin eine halbwegs verlässliche chronologische Einordnung ermöglicht, und dies hat auch für eine Datierung der Entstehung der Oratio ad Graecos zu gelten. Vor allem dank Trelenbergs detaillierten Studien ${ }^{46}$ darf inzwischen als gesichert gelten, dass Tatian nicht nur ein Schüler Justins in Rom war, sondern auch seine Schriften kannte und sich mehrfach auf sie bezieht. Wenn er also in Or. 18,6 auf den nunmehr toten Justin zurückblickt, bedeutet dies, dass die Oratio erst nach 165 (dem mutmaßlichen Todesjahr Justins) geschrieben worden sein kann. Es bleibt dann die Frage, wie bald die Niederschrift nach Justins Tod erfolgte, und insbesondere, ob dies noch vor Tatians Schulgründung im Osten geschah oder danach oder vielleicht gar zu ihrem Anlass, wie ebenfalls prominent vertreten worden ist. ${ }^{47}$

Wieder gilt es, an dieser Stelle ein mögliches chronologisches Indiz, diesmal für eine Spätdatierung der Schrift, zu besprechen: In Or. 19,1 bemerkt Tatian mit deutlich sarkastischem Unterton, die „bei euch agierenden Philosophen“ seien ",so weit von der Askese entfernt, dass einige vom römischen Kaiser jährlich 600 Goldstücke für keinen nützlichen Zweck beziehen". Hier ist die Versuchung groß, diese Notiz mit dem bekannten Faktum in Verbindung zu bringen, dass Kaiser Marc Aurel im Jahr 176 in Athen regelrechte „Lehrstühle“ je paarweise für die Stoiker, die Platoniker, die Epikureer und die Peripatetiker eingerichtet und mit einem Jah-

\footnotetext{
${ }^{43}$ Andere, die bereits im 19. Jh. von Zahn 1881 und Harnack 1882 oder im 20. von Elze 1960 und G. W. Clarke, „The Date of the Oration of Tatian“, Harvard Theological Revue 60 (1967) 122-126 angeführt wurden, erweisen sich bei näherem Hinsehen als wenig stichhaltig; vgl. die Zusammenfassung der entsprechenden Diskussionen bei Trelenberg 2012, $8-10$ und $12-14$.

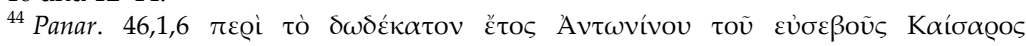

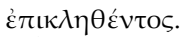

${ }^{45}$ Vgl. Trelenberg 2012, 2 Anm. 8.

${ }^{46}$ Trelenderg 2012, 195-203.

${ }^{47}$ Vor allem von Kukula 1900, 52 und 1913, 18; dazu Trelenberg 2012, 10 und 231-233.
} 
resgehalt von je 10.000 Drachmen dotiert hatte. ${ }^{48}$ Mary Whittaker ${ }^{49}$ hat jedoch darauf hingewiesen, dass die von Tatian genannte Summe weder mit der von Cassius Dio überlieferten Dotation der athenischen PhilosophenLehrstühle übereinstimmt noch mit der in Suetons Vespasian-Vita genannten Besoldung, die dieser Kaiser lateinischen und griechischen Rhetoren sowie ausgezeichneten Dichtern und bildenden Künstlern zukommen ließ ${ }^{50}$ Damit wird es fraglich, ob man die Cassius-Dio-Stelle wirklich mit Tatians Bemerkung in Verbindung bringen und gar ein chronologisches Indiz daraus gewinnen darf. Es ist durchaus denkbar, dass Marc Aurel auch an anderen Orten als Athen für eine Besoldung von Philosophen sorgte und Tatian bei seiner Bemerkung eine solche Dotation vorschwebte; doch fehlen uns dazu die Zeugnisse.

Ist auf diese Weise eine Spät-Datierung der Oratio nach 176 also nicht zu erweisen, so bleibt es nach wie vor möglich, dass ihre Abfassung gleichwohl mit der Schule Tatians im Osten in Verbindung steht. Es gibt kein verlässliches Indiz (innerhalb der Oratio oder außerhalb von ihr) dafür, dass sie sehr bald nach Justins Tod geschrieben wurde, und gegen eine Abfassung noch in Rom spricht vielleicht, dass keine Formulierung der Schrift auf Einbettung in ein aktuelles stadtrömisches Umfeld hindeutet; im Gegenteil, die Insinuationen in Or. 29,1, dass in größerer Nähe zur Stadt Rom immer noch Menschenopfer für Jupiter und Diana stattfinden, waren ohne Gefahr sofortiger Widerlegung wohl nur zu machen, wenn der Insinuierende sich weit entfernt von Rom aufhielt. Die vollmundige Erklärung Tatians in Or. 35,2, er habe „sowohl der Prahlerei der Römer als auch der kalten Klügelei der Athener ... Lebewohl gesagt“", lässt ebenfalls vermuten, dass diese Worte weder in Rom noch in Athen gesprochen oder geschrieben worden sind, sondern zu einer Zeit, da der Autor seine weiten Reisen (deren letzte bedeutende Station Rom gewesen war, vgl. Or. 35,1) beendet und sich am Ort seiner künftigen Lehrtätigkeit niedergelassen hatte.

Wurde die Oratio also vielleicht tatsächlich aus Anlass der Schulgründung Tatians verfasst, wie vor allem Kukula zu erweisen gesucht hat? Zuletzt hat Trelenberg ${ }^{51}$ dagegen starke Bedenken geäußert, vor allem ge-

\footnotetext{
${ }^{48}$ Vgl. Cass. Dio LXXII 31,3, ferner Philostr. V. Soph. II 2, S. 566; in seinem Dialog Eunuchus (Kap. 3 und 8) scheint Lukian sich dieses Faktum ebenfalls zunutze gemacht zu haben, um sich über die Geldgier der Philosophen zu mokieren. Die Nachricht wurde von R. McQ. Grant, „The date of Tatian's Oration“, Harvard Theological Review 46 (1953) [99-101] 99f. und dems., „The heresy of Tatian“, JTS, N.S. 5 (1954) [62-68] 63 als Argument für eine Spätdatierung von Tatians Rede in die Jahre 177 oder 178 geltend gemacht; vgl. TRELENBERG 2012, 12. Einen ausführlichen Kommentar zu den Philostrat- und Lukian-Stellen (= Baustein 73,3, 4a, 4b) bieten Dörrie / Baltes 1993, 135-139.

${ }^{49}$ WhitTaKer 1982, 39 Anm. a.

${ }^{50}$ Suet. Vesp. 18. Gerade Philosophen werden an dieser Stelle freilich nicht genannt; insofern verwundert es etwas, dass Trelenberg 2012, 135 in seiner Anmerkung zu Tat. Or. 19,1 nur auf die Sueton-Stelle hinweist.

${ }^{51}$ Trelenberg 2012, $232 \mathrm{f}$.
} 
gen Kukulas These, die Oratio sei eine tatsächlich ursprünglich von Tatian vor Publikum mündlich vorgetragene Rede gewesen. In der vorliegenden Form ist sie das in der Tat wohl nicht; es gilt jedoch zu beachten, dass bereits die großen attischen Redner des 4. Jh.s v. Chr. (und Ähnliches gilt z.B. im römischen Bereich auch für Cicero) ihre tatsächlich gehaltenen Reden nach dem Vortrag in schriftlicher, überarbeiteter Form publizierten; ähnlich haben es die prominenten Redner der Zweiten Sophistik gehalten, und etwas Vergleichbares ist auch für Tatian (der ja nach eigenem Bekunden aus solchem rhetorisch-sophistischen Milieu kommt) zumindest denkbar, d.h. in etwas anderer Form könnte die Oratio durchaus vorgetragen worden sein.

\subsection{Die Gattungsfrage}

Weitere Parallelen zum Bereich paganer Rhetorik nicht nur in klassischer, sondern auch noch in der Kaiserzeit lassen sich vielleicht fruchtbar machen, um Situierung und Eigenart der Oratio weiter zu erhellen. Die Frage nach der Gattung dieser Schrift ist seit langem umstritten; zuletzt hat Trelenberg die betreffende Diskussion detailliert nachgezeichnet ${ }^{52}$ und ist zu dem Ergebnis gelangt, dass Bestimmungsversuche wie "tatsächlich gehaltene Rede“, „Spott- oder Schmähschrift", „Lehrschrift“ und „Protreptikos“ immer nur Teilaspekte erfassen und die Klassifizierung als „Apologie“ dem Ganzen immer noch am besten gerecht werde. Dass man jedoch den Aspekt des Werbens für die eigene Sache bzw. die eigene Schule als einen Hauptaspekt dieser Schrift ansehen kann, dafür spricht eine bemerkenswerte Parallele bereits aus klassischer Zeit: Als der athenische Publizist Isokrates um 390 v. Chr. seine eigene Schule in Athen aufmachte, publizierte er einen programmatischen Text, dessen Titel Kata tōn sophistōn („Gegen die Sophisten“, Or. 13) eine deutlich polemische Stoßrichtung (gegen konkurrierende Bildungslehrer) verrät, in dieser aber auch gewissermaßen ein Programm für die eigene Schule verpackt, ${ }^{53}$ die Kurzbeschreibung dieses Textes dürfte die Parallelen zu Tatians Oratio bereits deutlich machen.

In Tatians eigener Zeit gab es bekanntlich eine zum Teil durchaus polemische Frontstellung in den Bereichen der Kultur der führenden Schichten des Römischen Reiches zwischen Rhetorik und Philosophie als Bildungsmächten, die jede für sich eine Art geistiger Führerschaft beanspruchten und den Gegner zurückzudrängen versuchten: Bekannt ist die Kontroverse zwischen Marc Aurel und seinem Rhetoriklehrer Fronto um die Bedeutung der beiden Bereiche; bekannt sind ferner die Attacken, die Ae-

\footnotetext{
52 Trelenberg 2012, 230-240.

${ }^{53} \mathrm{Vgl}$. Ch. EuCKEN, ,IIsokrates, Bildungsreden“, in: Kindlers Literaturlexikon. Band 8 (Stuttgart / Weimar ${ }^{3}$ 2009) 154.
} 
lius Aristides in umfangreichen Texten gegen Platons Verdammung der Rhetorik und seine Verurteilung der klassischen athenischen Staatsmänner vortrug; bekannt sind schließlich die satirischen Schlaglichter, die Lukian sowohl der Rhetorik als auch der Philosophie zukommen lässt. ${ }^{54}$ Als ehemaliger Sophist (vgl. o. S. 5 mit Anm. 11) hat Tatian diese Kontroverse sicher gekannt und sich von den polemischen Schachzügen beider Seiten inspirieren lassen. ${ }^{55}$

Noch ein weiterer Aspekt verdient Beachtung, den man sich ebenfalls am besten durch eine Parallele aus dem traditionellen griechischen Rhetorikbetrieb klarmachen kann. Schon in dessen frühesten uns noch erkennbaren Zeiten (dem späteren 5. Jh. v. Chr.) haben Rhetoriklehrer („Sophisten“), um für ihren Unterricht zu werben, Reden über fiktive Themen und an fiktive Adressaten verfasst, um auf diese Weise ihre argumentative Gewandtheit zu demonstrieren und vorzuführen, welche Fähigkeiten sie Schülern in ihren Schulen beizubringen versprachen. So hat bereits ein Gorgias eine fiktive Rede (später heißt so etwas in der antiken Schulrhetorik „Deklamation") verfasst, in der der griechische Held Palamedes sich gegen den Vorwurf verteidigt, er habe mit den feindlichen Trojanern gemeinsame Sache gemacht; ebenso hat der schon erwähnte Isokrates Reden zum Lob oder zur Verteidigung zweifelhafter mythischer Gestalten wie der schönen Helena und des grausamen ägyptischen Königs Busiris geschrieben, um seine Gewandtheit in der Darstellung dieser Sujets zu zeigen. Noch zweihundert Jahre nach Tatian hat der bedeutende heidnische Redelehrer Libanios Reden an den christlichen Kaiser Theodosius verfasst, die in dieser Form wohl nie direkt dem Kaiser vorgetragen wurden (ihm gleichwohl aber auf indirekte Weise bekannt werden und so für Anliegen des Libanios werben konnten ${ }^{56}$ ). Vielleicht kann man einen solchen Kunstgriff auch in Tatians scheinbarer Adressierung seiner Oratio "An die Griechen“ an-

\footnotetext{
${ }^{54}$ Die ,klassische' Darstellung der bis ins 4. Jh. v. Chr. zurückreichenden Kontroverse zwischen Rhetorik und Philosophie ist H. von Arnim, Leben und Werke des Dio von Prusa. Mit einer Einleitung: Sophistik, Rhetorik, Philosophie in ihrem Kampf um die Jugendbildung (Berlin 1898) 4-114 (,,Sophistik, Rhetorik, Philosophie in ihrem Kampf um die Jugendbildung“); vgl. ferner Nesselrath 1985, 126f. 153-155; eine jüngere Zusammenschau der Positionen von Fronto und Marc Aurel, Aelius Aristides und Lukian bietet D. Karadimas, Sextus Empiricus against Aelius Aristides: The Conflict between Philosophy and Rhetoric in the Second Century A.D. Studia Graeca et Latina Lundensia (Lund 1996), vor allem 1-33.

${ }^{55}$ Einer dieser Schachzüge ist es, die Gegner als „Sophisten“ darzustellen, die die Unzulänglichkeit ihrer Position durch Spitzfindigkeiten auszugleichen versuchen (vgl. hierzu B. Wyss, „Philon und die Sophisten - Philons Sophistendiskurs vor dem Hintergrund des alexandrinischen Bildungsumfelds", in: M. Hirschberger [Hg.], Jüdisch-hellenistische Literatur in ihrem interkulturellen Kontext [Frankfurt/M. 2012] [89-105] 96-101. 103). Auch Tatian bringt die "Griechen", gegen die er polemisiert, wiederholt mit diesem Etikett in Verbindung (vgl. 12,9.10; 35,1.4; 40,2).

${ }^{56}$ Vgl. H.-G. Nesselrath, Libanios - Zeuge einer schwindenden Welt. Standorte in Antike und Christentum 4 (Stuttgart 2012) 27 und 35.
} 
gewendet finden: Die immer wieder direkt angeredeten „Griechen“ sind mehr oder weniger fiktive Adressaten - es ist zu Recht bemerkt worden, dass die ihnen gegenüber wiederholt ausgesprochene Werbung, sich doch dem christlichen Glauben anzuschließen, durch Tatians ständig wiederkehrende bitterscharfe Polemik mehr als konterkariert wird ${ }^{57}$-, während die ,wahren' Adressaten für den christlichen Glauben bereits gewonnen sind und durch die Inhalte dieser Rede in ihren Überzeugungen bestärkt werden sollen ${ }^{58}$ oder dem Christentum zumindest bereits nahestehen und nun endgültig ihm zugeführt werden sollen. Man könnte also diese Rede durchaus auch als "Deklamation" verstehen, die vorführt, wie ein überzeugter christlicher Prediger den auf die scheinbar minderwertigen „Barbaren" herunterblickenden „Griechen" wortgewaltig Paroli bietet.

\subsection{Zu Überlieferung und Text der Oratio ad Graecos}

\subsubsection{Frühe indirekte Überlieferung}

Wie bereits angedeutet, wurden einige Teile der Oratio schon recht früh zur Kenntnis genommen und in anderen christlichen Texten zitiert oder reproduziert. Eusebios von Kaisareia zitiert zum einen Tatians Bemerkungen über Justin in seiner Kirchengeschichte, ${ }^{59}$ zum anderen den Altersbeweis und Epilog der Oratio (Or. 31 und 36-42) zur Gänze in der Praeparatio evangelica. ${ }^{60}$ Vor allem das umfangreiche Exzerpt des Altersbeweises ermöglicht einen aufschlussreichen Vergleich zwischen der Textfassung, die Eusebios etwa anderthalb Jahrhunderte nach der Entstehung von Tatians Schrift vorlag, und der Textfassung, die die maßgeblichen Handschriften bieten (vgl. u.).

\footnotetext{
${ }^{57}$ Vgl. Trelenberg 2012, 233 mit Anm. 192.

${ }^{58} \mathrm{Vgl}$. Trelenberg 2012, 239. Aus Or. 30,3 geht deutlich hervor, dass die Schrift „unsere Vertrauten" als Adressaten hat.

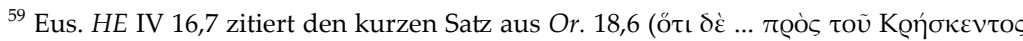

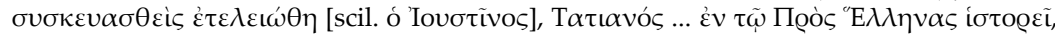

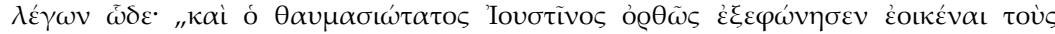

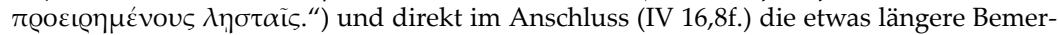

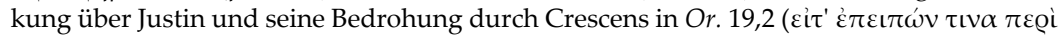

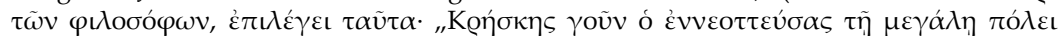

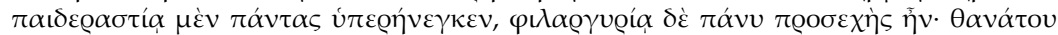

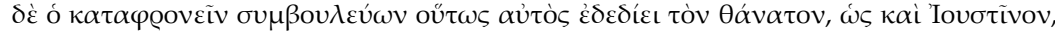

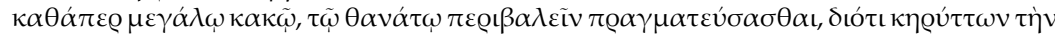

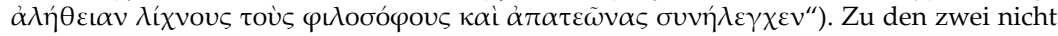
unerheblichen Abweichungen in diesem Zitat vom handschriftlich überlieferten TatianText vgl. jeweils ad loc.

${ }^{60} P E X 11,1-5=$ Or. 31,1-6, sodann PE X 11,6-35 = Or. 36,1-42,2. Die Auslassung von Or. 32-35 ist bei Eusebios zu Beginn von X 11,6 durch die eingeschobenen Worte Kai $\mu \varepsilon \tau \dot{\alpha}$ $\beta \varrho \alpha \chi \varepsilon ́ \alpha$ angezeigt.
} 
Etwas schwieriger ist die Frage, ob auch bestimmte Teile der Stromateis des Clemens von Alexandria als indirekte Textzeugen der Oratio gelten können. In Stromateis I $74^{61}$ beginnt ein längerer Katalog (er reicht bis einschließlich Kap. 76), der die vorangestellte These „Erfinder nicht nur der Philosophie, sondern mehr oder weniger jeder Kunst sind Nichtgriechen ${ }^{\prime 62}$ illustrieren und untermauern soll, und hier zeigen sich deutliche Parallelen zu dem Katalog der Erfindungen von Nichtgriechen, mit dem Tatian im ersten Kapitel seiner Oratio dem griechischen Anspruch entgegentritt, den „Barbaren“ überlegen zu sein. Wegen dieser Parallelen hat Schwartz von einer „Benutzung“ von Tatians Katalog durch Clemens gesprochen; Clemens selber freilich nennt unter den von ihm in I 77,1 angeführten Quellenautoren Tatian nicht, und sein Katalog erweist sich nicht nur als viel umfangreicher, sondern zum Teil auch anders angeordnet als der Tatians, ${ }^{63}$ so dass die Gemeinsamkeiten auf keine lineare Abhängigkeit, sondern auf gemeinsame Vorlagen hindeuten, die die beiden Autoren jeweils verschieden ausgewertet haben.

Dagegen erkennt Clemens etwas später (in Stromateis I 101, ${ }^{64}$ ) Tatians Schrift - genauer: dessen Kapitel zum Altersbeweis - als eine Quelle explizit an, und zwar dort, wo er zum Nachweis ansetzt, dass die auf Moses zurückgehende Philosophie der Juden die älteste Form menschlicher Weisheit und damit auf jeden Fall älter ist als die griechische. Auch hier jedoch ist Tatian nicht seine einzige Quelle, sondern neben ihm verweist

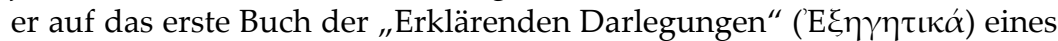
Kassianos. ${ }^{65}$

\footnotetext{
${ }^{61}$ Nach älterer Einteilung fällt der Beginn von Kap. 74 mit dem Beginn des Großkapitels 16 zusammen.

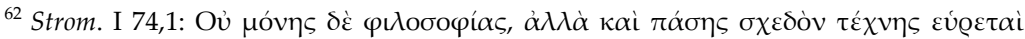

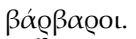

${ }^{63}$ Bei Tatian (Or. 1,1f.) ist die Reihenfolge der Barbarenvölker (und Individuen), die bestimmte Erfindungen gemacht haben sollen, folgende: Telmessier, Karer, Phryger, Isaurer, Kyprier, Babylonier, Perser, Ägypter, Phönizier, Orpheus, „Tuskanoi“, Ägypter, die Phryger Marsyas und Olympos, ,"ländliche Menschen“ (vgl. dazu ad loc.), Tyrrhener, Kyklopen, die Perserkönigin Atossa. Bei Clemens (Strom. I 74-76) sieht die Liste folgendermaßen aus (diejenigen, die auch bei Tatian vorkommen, erscheinen kursiv): Ägypter, Karer, Phryger, „Tuskoi", Isaurer und Araber, Telmessier, Tyrrhener, die Phryger Olympos und Marsyas, der Phönizier Kadmos, Phönizier und Syrer, Ägypter, der Libyer Atlas, idäische Daktylen, Thraker, Illyrer, „Tuskanoi“, der Samnite Itanos, der Phönizier Kadmos, Kappadokier, Assyrer, Karthager, Medea, „Noroper“ (entsprechen den Kyklopen bei Tatian?), der Bebrykenkönig Amykos, die Perserkönigin Atossa.

${ }^{64}$ Der Anfang des Kapitels 101 fällt mit dem älteren Großkapitel 21 zusammen.

${ }^{65}$ Strom. I 101,2: „Über diese Dinge ist zum einen sorgfältig von Tatian in seiner ,Rede an die Griechen' gehandelt, zum anderen von Kassianos im ersten Buch seiner ,Erklärungs-

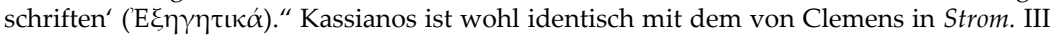

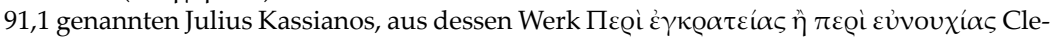
mens dort zitiert.
} 
Im einzelnen zeigen sich folgende Korrespondenzen zwischen Strom. I 101-107 und Tatian Or. 31.36-41:

Strom. I 101,3-5 zitiert den Grammatiker Apion, der als Gewährsmann für den Synchronismus zwischen dem ägyptischen König Amosis und dem argivischen König Inachos den Priester-Autor Ptolemaios von Mendes anführt und diesen wiederum als Gewährsmann dafür, dass zur Zeit des Amosis die Juden unter Moses aus Ägypten aufbrachen. ${ }^{66}$ Die gleichen Angaben (mit dem gleichen wörtlichen Zitat aus Apion, jedoch in etwas anderer Reihenfolge) finden sich in Tatian Or. 38,1f., doch liefert Clemens einige zusätzliche Details zu den Quellenautoren Apion und Ptolemaios.

In Strom. I 102,1 kommt Clemens auf die argivische Königs-Chronologie zu sprechen, die Tatian in Or. 39 behandelt. ${ }^{67}$ In Strom. I 102,2 stellt Clemens die argivische KönigsChronologie in Korrelation zur attischen und verweist für ein Detail sogar explizit auf Tatian $\left(\right.$ Or. 39, $\left.4^{68}\right)$. Die von Clemens ferner (Strom. I 102,3f.) angeführten Korrelationen zu weiteren Königshäusern haben bei Tatian keine Entsprechung; dagegen ist der Hinweis in Strom. I 102,5, dass zur Zeit des Inachos-Nachfolgers Phoroneus die erste große, auf die Regierungszeit des athenischen Königs Ogygos datierte Flut stattfand, auch bei Tatian $(O r .39,4)$ zu finden, weitere von Clemens an dieser Stelle erwähnte Synchronismen aber wiederum nicht. Der in Tatian 39,4 folgende Satz (über Phorbas und Aktaios) und alles weitere bis zum Ende von 39,5 findet sich mit geringen Abweichungen wörtlich auch in Strom. I 103,2-104,1. ${ }^{69}$

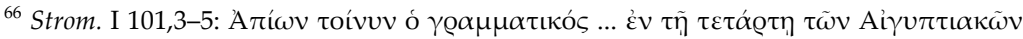

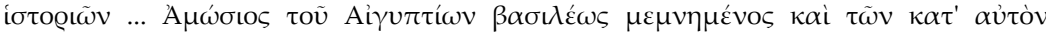

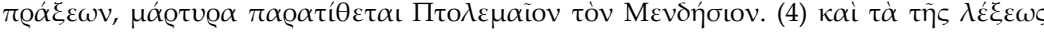

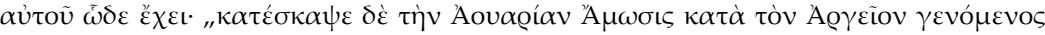

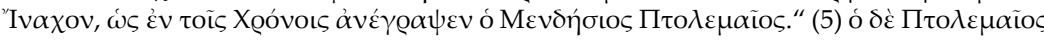

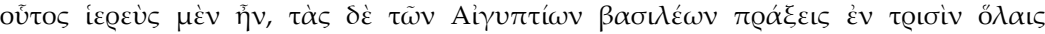

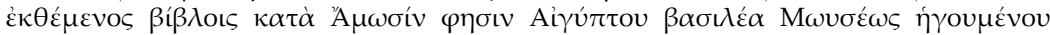

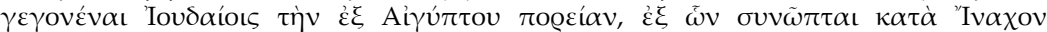

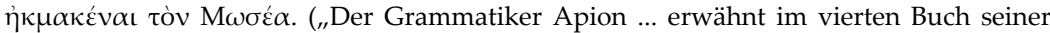
, ̈̈gyptischen Geschichte ‘... den Ägypterkönig Amosis und seine Taten und führt dazu als Zeugen Ptolemaios von Mendes an. Und das wörtliche Zitat lautet folgendermaßen: ,Amosis, der zu den Zeiten des Argivers Inachos lebte, zerstörte Avaris, wie in seinen ,Zeiten' Ptolemaios von Mendes aufgeschrieben hat.' Dieser Ptolemaios aber war ein Priester; er stellt die Taten der ägyptischen Könige in drei ganzen Büchern dar und sagt, zur Zeit des Königs von Ägypten Amosis sei unter der Führung des Mose der Auszug der Juden aus Ägypten geschehen, woraus sich ergibt, dass Mose seine Lebensblüte zur Zeit des Inachos hatte.")

${ }^{67}$ Clemens gibt als Quellentext die Xoóvoı des Dionys von Halikarnass an; diese Angabe fehlt bei Tatian. Dieser zählt in Or. 39,1 zwanzig Generationen argivische Könige namentlich auf; in Clem. Alex. Strom. I 102,3 wird nur die Zahl von zwanzig Generationen genannt, die bei Tatian in Or. 38,3 steht.

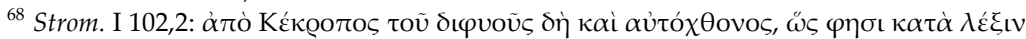

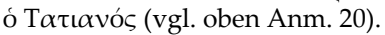

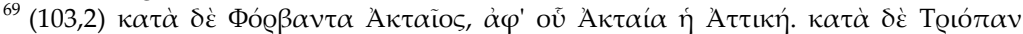

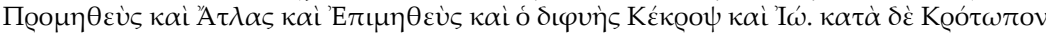

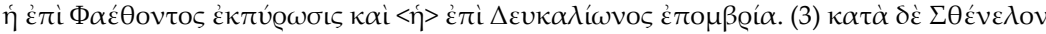

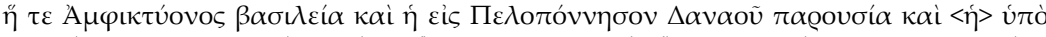

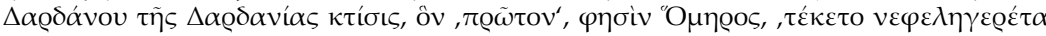

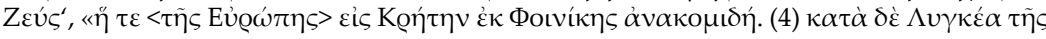

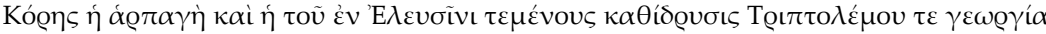

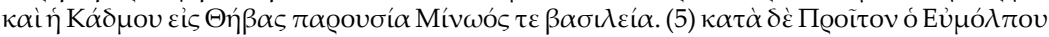


Die weiteren in Strom. I 104,1f. gegebenen Informationen fehlen bei Tatian; der Hinweis in 104,3, der Herakles-Nacheiferer Theseus sei eine Generation älter als der trojanische Krieg, ist bei Tatian $(O r .41,2)$ direkt auf Herakles übertragen. ${ }^{70}$

In Strom. I 105,1-5 zählt Clemens weitere mythische griechische Heroen auf, die alle jünger als Moses sind, in Strom. I 106,1-6 eine Reihe von ägyptischen Gottheiten, für die das Gleiche gilt; in Strom. I 107,1f. kommen die griechischen Gottheiten Leto und Apollon hinzu. Diese Befunde scheint Tatian in dem kurzen Satz in Or. 40,1 zusammengefasst zu haben: „So also ist ... klar, dass Moses älter als die (genannten) Helden, Städte und Dämonen ist. ${ }^{\text {.71 }}$

Gegenüber der Nennung von Amphion und Zethos sowie Orpheus, Linos und Musaios in Strom. I 107,3-4 bietet Tatian in Or. 41,1 freilich eine viel längere Liste früher griechischer Sänger, die jünger als Moses sind. Zu den in Strom. I 107,5f. genannten griechischen Intellektuellen, die jünger als Moses sind, ${ }^{72}$ lässt sich Tatian Or. 41,6-10 vergleichen, wo aber noch weitere Namen über die von Clemens genannten hinaus erscheinen, dagegen nicht Pherekydes.

In Strom. I117 geht es um die chronologische Bestimmung Homers, und hier sind viele Parallelen zu Tatian Or. 31,4f. erkennbar, jedoch auch Abweichungen: Entsprechungen haben Philochoros, Aristarch, Apollodor, Krates und Eratosthenes; dagegen tauchen Euthymenes, Archemachos und Sosibios Lakon bei Tatian nicht auf, und die Thesen Theopomps

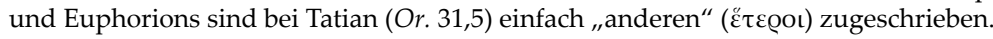

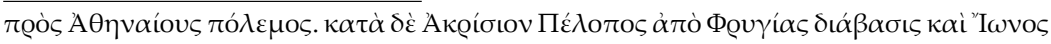

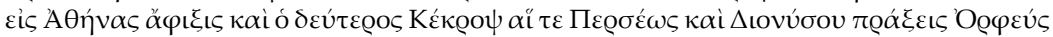

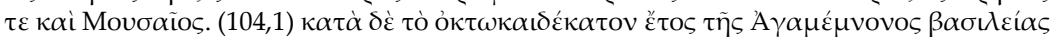

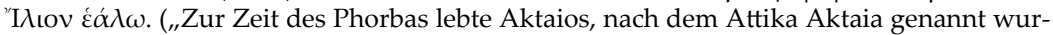
de. Zur Zeit des Triopas lebten Prometheus, Atlas, Epimetheus, der aus zwei Gestalten bestehende Kekrops und Io. Zur Zeit des Krotopos gab es den Weltenbrand des Phaethon und die Flut des Deukalion. Zur Zeit des Sthenelos war die Königsherrschaft des Amphiktyon, das Erscheinen des Danaos in der Peloponnes, die Gründung von Dardania durch Dardanos, den, wie Homer sagt, ,als ersten zeugte der Wolkensammler Zeus', und der Transport der Europa von Phönizien aus Kreta. Zur Zeit des Lynkeus fand der Raub der Persephone statt, die Errichtung des Heiligtums in Eleusis, der Ackerbau des Triptolemos, das Erscheinen des Kadmos in Theben und die Königsherrschaft des Minos. Zur Zeit des Proitos war der Krieg des Eumolpos gegen die Athener. Zur Zeit des Akrisios ist anzusetzen der Übergang des Pelops aus Phrygien [scil. in die Peloponnes], die Ankunft des Ion in Athen, der zweite Kekrops, die Taten des Perseus und Dionysos sowie Orpheus und Musaios. Im achtzehnten Jahr der Herrschaft des Agamemnon wurde Ilion erobert.“) Lediglich das Homerzitat (Strom. I 103,3) fehlt bei Tatian, und der allerletzte Satz ist verkürzt, da die Information über das achtzehnte Regierungsjahr Agamemnons bereits in Or. 39,1 vermerkt ist.

${ }^{70}$ Bei beiden Autoren wird diese Angabe durch den Hinweis auf den vor Troja kämpfenden Herakles-Sohn Tlepolemos unterstützt (Strom. I 104,3 - Tat. Or. 41,2).

${ }^{71} \mathrm{Zu}$ diesem Satz vgl. aber immerhin auch Strom. I 107,6: „Folglich ist auch im Vergleich zu den meisten Göttern bei den Griechen, nicht nur den genannten Weisen und Dichtern,

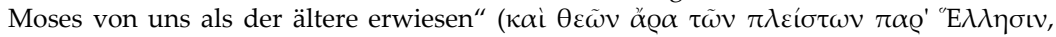

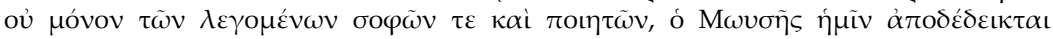
$\pi \varrho \varepsilon \sigma \beta u ́ \tau \varepsilon \varrho о \varsigma)$.

${ }^{72}$ Nach Homer und Hesiod werden Lykurg und Solon als Gesetzgeber erwähnt, dann die Sieben Weisen, dann Pherekydes von Syros und Pythagoras.
} 
In Strom. I 131 behandelt Clemens alte Dichter und Seher bei den Griechen, und hier finden sich zum Teil wörtliche Entsprechungen zu Bemerkungen bei Tatian in Or. 41,3-5, etwa zu Onomakritos, ${ }^{73}$ Amphion, ${ }^{74}$ Demodokos und Phemios. ${ }^{75}$

Bei Clemens' umfangreichen Ausführungen zur altjüdischen Geschichte gibt es nur in Strom. I 114, $2^{76}$ eine Entsprechung zu einem Tatian-Passus, betreffend die Beziehungen zwischen Salomon und dem phönizischen König Hiram. Angesichts dieses dürftigen Befundes scheint Trelenbergs Kommentar zu dieser Stelle stark übertrieben: „Clemens kompiliert die Ausführungen Tatians und verwendet sie ebenfalls für seinen ,Altersbeweis' . " ${ }^{77}$

Insgesamt sind also zwar sachliche und (jedoch viel seltener) auch sprachliche Übereinstimmungen zwischen den Ausführungen des Tatian und des Clemens zum Altersbeweis zu erkennen; doch weicht Clemens in der Ausführlichkeit und auch in der Anordnung seines Materials so stark von Tatian ab, dass man ihn nur in wenigen Fällen als sekundäre Überlieferung zu Tatians Text wird verwenden können. ${ }^{78}$

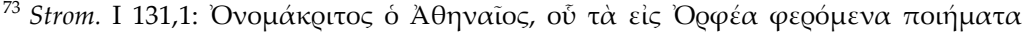

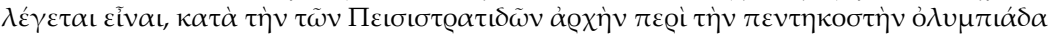

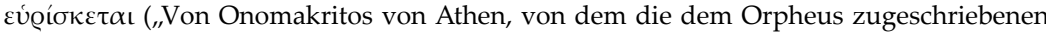
Gedichte stammen sollen, findet sich, dass er während der Herrschaft der Peisistratiden um die fünfzigste Olympiade lebte") - vgl. Tat. Or. 41,3.

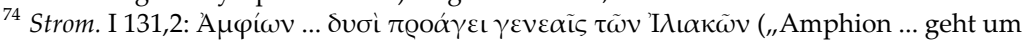
zwei Generationen den Ereignissen um Ilion voran“) - vgl. Tat. Or. 41,4.

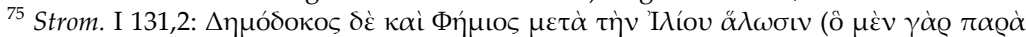

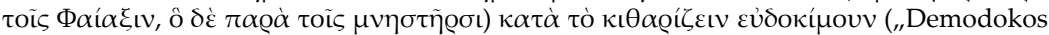
und Phemios waren nach der Eroberung von Ilion, der eine nämlich bei den Phäaken, der andere bei den Freiern [scil. am Hof des Odysseus], für ihr Kitharaspiel berühmt") - vgl. Tat. Or. 41,5 .

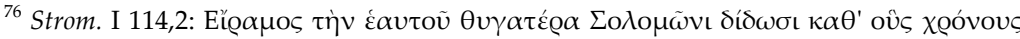

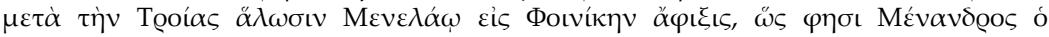

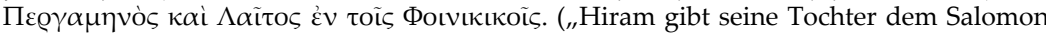
zu den Zeiten, als nach der Eroberung Trojas die Ankunft des Menelaos in Phönizien stattfand, wie Menandros von Pergamon sagt und Laitos in seiner ,Phönizischen Geschichte'.")

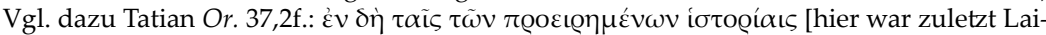

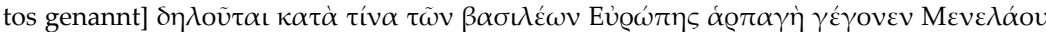

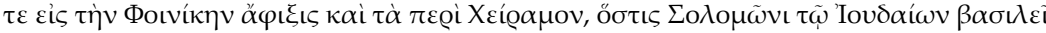

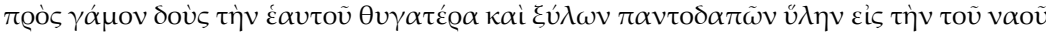

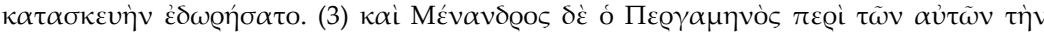

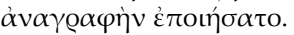

77 Trelenberg 2012, 183 Anm. 396. Auch an anderen Stellen spricht Trelenberg etwas undifferenziert von „Übernahmen“ des Clemens aus Tatian.

${ }^{78}$ Die Zusammenhänge zwischen Tatian und Clemens hat bereits W. CHRIst, Philologische Studien zu Clemens Alexandrinus. Abhandlungen der Königlich-Bayerischen Akademie der Wissenschaften 21.3 (München 1901) 455-526 detailliert behandelt (speziell Tatian sind die Seiten 497-504 gewidmet) und ist dabei zu dem Ergebnis gekommen, dass Tatian eine „Hauptvorlage“ sei, Clemens daneben aber auch Tatians Quelle benutzt habe. Nach den obigen Ausführungen darf selbst die „Hauptvorlage“ in Zweifel gezogen werden; denkbar wäre aber, dass Tatian durch seine eigenen Quellenangaben Clemens dazu veranlasst hat, sich auch diese älteren Quellen genauer anzusehen.
} 


\subsubsection{Handschriften}

Die direkte Überlieferungslage ist eine vergleichsweise einfache. ${ }^{79}$ Es darf inzwischen als sicher gelten, dass der 914 für Arethas, den damaligen Erzbischof von Caesarea in Kappadokien, geschriebene Codex Parisinus Graecus 451 (A) einmal die älteste uns noch erfassbare Handschrift mit Tatians Oratio war, aus der jedoch - wie Harnack 1882 erwiesen hat ${ }^{80}$ - gerade der Teil (insgesamt 32 Blätter), der die Oratio enthielt, entfernt wurde und heute verloren ist. ${ }^{81}$ Bevor dies geschah, wurden jedoch mindestens drei $\mathrm{Ab}$ schriften genommen, die die Oratio bis heute enthalten: Der aus dem 11. Jh. stammende Codex Mutinensis Misc. gr. 126 (gekennzeichnet mit der Sigle M), ${ }^{82}$ der ebenfalls aus dem 11. Jh. stammende Codex Marcianus Graecus 343 (V), und der aus dem 12. Jh. stammende Codex Parisinus Graecus 174 (P). Die relativ hohe Zuverlässigkeit dieser Abschriften in Hinsicht auf ihre Vorlage lässt sich aus ihrer Behandlung derjenigen Schriften erschließen, für die ihre Vorlage noch vorhanden ist. ${ }^{83}$ Alle weiteren bekannten Handschriften sind mit Sicherheit oder hoher Wahrscheinlichkeit Abschriften des zuletzt genannten Parisinus und brauchen deshalb für die Textkonstitution nicht weiter berücksichtigt $\mathrm{zu}$ werden.

Für vier Fünftel der Schrift bilden die drei genannten Apographa des Arethas-Codex also die alleinige Textgrundlage; für das fünfte Fünftel (namentlich die bei Eusebios überlieferten Kap. 31 und 36-42) tritt die sekundäre Überlieferung hinzu, wobei die Meinungen, ob diese sekundäre oder aber die Handschriftenüberlieferung den besseren Text bewahrt haben, zum Teil weit auseinandergehen und dementsprechend auch das Bild der Editionen stark bestimmt haben.

\footnotetext{
${ }^{79}$ Vgl. dazu zuletzt TreLenberg 2012, 17-24.

${ }^{80}$ Harnack 1882, $25 \mathrm{f}$.

${ }^{81}$ Wurde dieser Teil vielleicht deswegen beseitigt, weil Tatian als Häretiker galt?

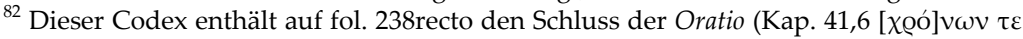
- 42,2 Ende) sogar noch ein weiteres Mal, was auf eine ursprünglich vorhandene noch weitere Abschrift schließen lässt.

${ }^{83}$ Trelenberg 2012, 21f. Anm. 109 hat hierzu die Ergebnisse zusammengefasst, die bereits HARNACK 1882 erarbeitet hatte: Der Parisinus P „,weicht von A nur sehr selten ab ... Wenn P ... manchmal in den Text eingreift, dann handelt es sich um leichte orthographische Korrekturen oder um glättende, den Text leise verbessernde Änderungen“. Auch der Mutinensis $M$,ist eine treue Reproduktion von A ... Die Abweichungen teilen sich auf wenige Abschreibefehler und absichtliche, allerdings nicht immer sachgerechte Konjekturen auf". Der Marcianus V schließlich "geht ein wenig freier mit der Vorlage um als P und M, doch ohne sie zu verunstalten“; immerhin konstatiert Trelenberg, dass diese Handschrift "Worte umstellt, kleinere Änderungen bei Artikeln und Partikeln vornimmt, Verbal- und Nominalformen mitunter leicht korrigiert ... , bisweilen andere Worte als die Vorlage einsetzt ... und insbesondere geläufigere Ausdrücke anstelle von ungewöhnlicheren setzt" .
} 


\subsubsection{Zu den modernen Editionen}

$\mathrm{Zu}$ den älteren Editionen (vom 16. bis zum 18. Jh.) bietet Trelenberg eine gut einführende Übersicht, die hier nicht wiederholt zu werden braucht. ${ }^{84}$ Die älteste heute immer noch mit Gewinn zu benutzende (auch wenn sie der Klärung der Überlieferung durch Harnack vorausgeht) Ausgabe ist die von Ottos aus dem Jahr 1851, mit lateinischer Übersetzung und nützlichem lateinischen Kommentar. Die erste wirklich kritische (da auf Harnacks Ergebnissen beruhende) Edition ist die von Eduard Schwartz aus dem Jahr 1888, zu der sein Lehrer Ulrich von Wilamowitz-Moellendorff zahlreiche (und in vielen Fällen bis heute überzeugende) textkritische Verbesserungsvorschläge beigesteuert hat. Die 1914 erschienene Ausgabe von E. J. Goodspeed (die im elektronischen TLG, freilich ohne Apparat, reproduziert ist) bietet gegenüber der Ausgabe von Schwartz kaum Änderungen (gelegentlich bevorzugt sie überlieferte Textlesarten gegenüber von Schwartz oder Wilamowitz in den Text eingebrachten Konjekturen).

Das spätere 20. Jh. hat das Erscheinen von zwei Textausgaben sehr unterschiedlicher Gestalt erlebt: Während Molly Whittaker 1982 einen sehr konservativen Text herausgibt, der sehr viele von Schwartz oder Wilamowitz gemachte Textvorschläge zurückweist, hat Miroslav Marcovich aufgrund der Überzeugung, dass die handschriftliche Überlieferung der Schrift extrem verderbt sei, was ein Vergleich, wo möglich, mit der sekundären Überlieferung etwa bei Eusebios zeige ${ }^{85}$ - in seiner Ausgabe von 1995 exzessiv zum Mittel der Konjektur gegriffen, wo immer ihm dies geboten schien; herausgekommen ist dabei ein Text, der möglicherweise mehr von Marcovich als von Tatian enthält. ${ }^{86}$

Demgegenüber ist die jüngste Textgestaltung durch Trelenberg wieder auf die Spuren von Whittaker zurückgekehrt; ${ }^{87}$ ja sie hat sogar noch eine Reihe von Konjekturen von Schwartz und Wilamowitz wieder aus dem Text beseitigt, die Whittaker noch stehen gelassen hatte. Obwohl Trelenberg wohl grundsätzlich darin Recht zu geben ist, dass die handschriftliche Überlieferung besser ist, als Marcovich sie eingeschätzt hat, lässt sich doch an vielen Stellen dieses Textes durchaus darüber streiten, was noch „mög-

\footnotetext{
${ }^{84}$ Trelenberg 2012, 15-17.

${ }^{85}$ Vgl. Marcovich 1995, 4: „All these old apographs (MVP) display the same scribal errors and lacunae, thus attesting to the assumption that already in A [= dem Arethas-Codex] the text of Tatian was heavily corrupt (which is confirmed by a comparison with Eusebius)."

${ }^{86}$ Vgl. auch die Charakteristik der Marcovich-Ausgabe bei Nesselrath 2005, $243 f$.

${ }^{87}$ Vgl. Trelenserg 2012, 21: „Der Tatiantext, der in der hiesigen Ausgabe geboten wird, fühlt sich einer textkritischen Tradition und Auffassung verpflichtet, wie sie im 19. Jahrhundert - ... - namentlich von Otto und Harnack, im 20. Jahrhundert insbesondere Whittaker vertreten haben: Den Lesarten der Handschriften wird, wo immer es möglich und erträglich ist, der Vorzug vor der Spekulation gegeben. Die moderate Konjektur findet nur bei eindeutig [kursive Hervorhebung durch den Autor] verderbten Stellen Anwendung."
} 
lich und erträglich“ oder vielleicht doch „eindeutig verderbt“ ist. Der hier gebotene Text, der auf meinen 2005 zur Schrift publizierten Studien aufbaut und sie weiterführt, wird daher in einer Reihe von Stellen (sie sind nachstehend als Liste präsentiert) von Trelenbergs Text abweichen.

\subsection{Textabweichungen dieser Ausgabe von früheren}

In der folgenden Übersicht sind textliche Abweichungen der hier vorgelegten Ausgabe von Schwartz 1888, aber auch von Whittaker 1982 / Trelenberg 2012 einerseits und Marcovich 1995 andererseits zusammengestellt. Textänderungen, die lediglich von Marcovich vorgenommen wurden, werden hier nicht aufgeführt, da sie jeden Rahmen sprengen würden.

\begin{tabular}{|c|c|c|c|c|}
\hline Stelle & Schwartz & $\begin{array}{l}\text { Whittaker / } \\
\text { Trelenberg }\end{array}$ & Marcovich & Nesselrath \\
\hline 1,1 & $\mathrm{~T} \varepsilon \lambda \mu \eta \sigma \sigma \varepsilon \dot{\varepsilon} \omega \nu$ & 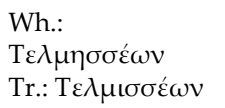 & 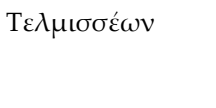 & 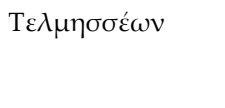 \\
\hline 1,2 & 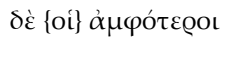 & 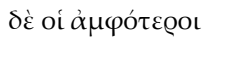 & 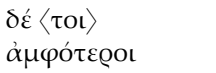 & 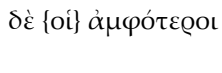 \\
\hline 1,2 & 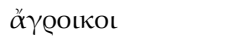 & 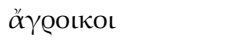 & 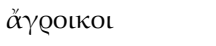 & 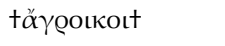 \\
\hline 1,3 & 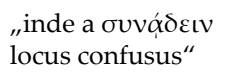 & $\begin{array}{l}\sigma U \nu \alpha \dot{\alpha} \delta \varepsilon เ \nu \tau \varepsilon \kappa \alpha i \\
\varepsilon \mathcal{\varepsilon} \tau \tilde{\eta}\end{array}$ & $\begin{array}{l}\sigma u v \alpha \dot{\alpha} \delta \varepsilon \iota v \delta \dot{\varepsilon} \kappa \alpha \grave{~} \\
\langle\pi \tilde{\alpha} \sigma \iota v\rangle \dot{\varepsilon} \nu \tau \tilde{\eta}\end{array}$ & $\begin{array}{l}\sigma u v \alpha \dot{\alpha} \delta \varepsilon \iota \tau \tau \varepsilon \kappa \alpha \grave{\imath} \\
\langle * * *\rangle \varepsilon \nu \tau \tilde{\eta}\end{array}$ \\
\hline 1,4 & $\begin{array}{l}\tau \dot{\alpha} v\langle\tau \omega v\rangle \\
\dot{\alpha} \tau 0 \tau \omega \epsilon \alpha \tau o v\end{array}$ & 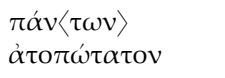 & $\begin{array}{l}\tau \dot{\alpha} v\langle\tau \omega v\rangle \\
\dot{\alpha} \tau 0 \pi \omega \tau \alpha \tau o v\end{array}$ & $\pi \alpha \nu \alpha \tau о \pi \omega ́ \tau \alpha \tau о \nu$ \\
\hline 1,4 & $\Sigma v \mu \varphi v ́ \varrho \delta \eta v$ & $\begin{array}{l}\text { Wh.: } \sigma v \mu \varphi v ́ \varrho \delta \eta v \\
\text { Tr.: } \sigma u ́ \mu \varphi v \varrho \tau o v\end{array}$ & $\Sigma \dot{\mu} \mu \varphi v \varrho \tau о \nu$ & $\sigma v \mu \varphi v ́ \rho \delta \eta v$ \\
\hline 2,2 & $\langle\dot{\varepsilon} v\rangle \sigma v \mu \pi$ oбíoıs & 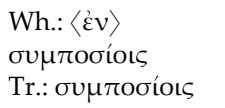 & $\langle\dot{\varepsilon} v\rangle \sigma u \mu \pi$ oбíoıs & 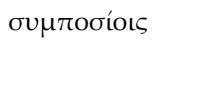 \\
\hline 3,1 & 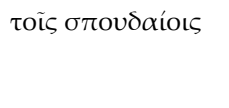 & 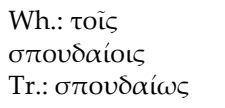 & 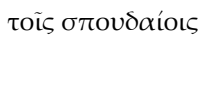 & 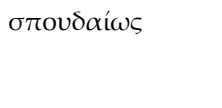 \\
\hline 3,5 & $\pi \varepsilon \varrho i ̀ ~ \tau o u ́ \tau o u\langle\varsigma\rangle$ & 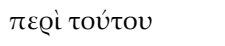 & $\pi \varepsilon \varrho i ̀ ~ \tau o u ́ \tau o u\langle\varsigma\rangle$ & 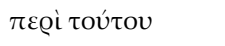 \\
\hline 3,6 & 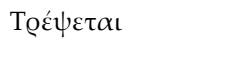 & 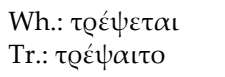 & 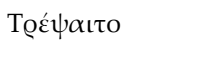 & $\tau \varrho \varepsilon ́ \psi \varepsilon \tau \alpha \iota$ \\
\hline 3,7 & 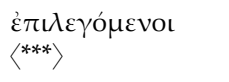 & $\varepsilon \dot{\pi} \pi \iota \varepsilon \gamma \gamma$ ó $\mu \varepsilon v o \iota$ & $\begin{array}{l}\dot{\varepsilon} \pi \mathrm{L} \lambda \varepsilon \gamma \text { ó } \mu \varepsilon v \mathrm{ol} \\
\langle\pi \alpha \varrho \dot{\alpha}\rangle\end{array}$ & $\varepsilon \dot{\pi} \pi \Lambda \varepsilon \gamma \gamma$ ó $\mu \varepsilon v o \mathrm{~L}$ \\
\hline 3,7 & 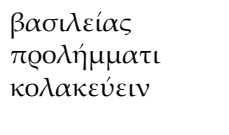 & 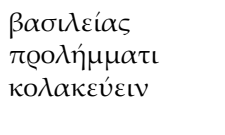 & 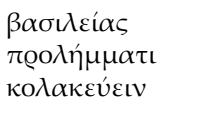 & 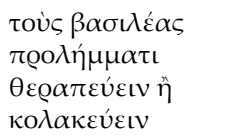 \\
\hline
\end{tabular}




\begin{tabular}{|c|c|c|c|c|}
\hline Stelle & Schwartz & $\begin{array}{l}\text { Whittaker / } \\
\text { Trelenberg }\end{array}$ & Marcovich & Nesselrath \\
\hline 4,4 & $\begin{array}{l}\tau \tilde{\eta} \ddot{v} \lambda \eta(\text { sed p. } \\
\text { VII: } \psi v \chi \eta \dot{\eta})\end{array}$ & $\begin{array}{l}\text { Wh.: } \tau \tilde{\eta} \tilde{u} \lambda \eta \\
\text { Tr.: } \psi v \chi \tilde{\eta}\end{array}$ & $\psi v \chi \dot{\eta}\langle\tau \tilde{\eta} \tilde{u} \lambda \eta\rangle$ & $\psi v \times \tilde{\eta}$ \\
\hline 4,5 & 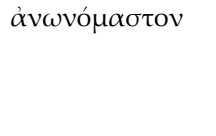 & $\begin{array}{l}\text { Wh.: } \\
\dot{\alpha} v \omega v o ́ \mu \alpha \sigma \tau o v \\
\text { Tr.: } \\
\dot{\alpha} \text { vovó } \mu \alpha \sigma \tau o v\end{array}$ & ג̇vovó $\mu \alpha \sigma \tau o v$ & 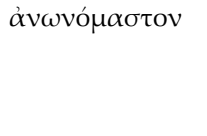 \\
\hline 5,1 & 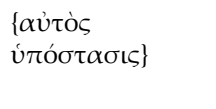 & 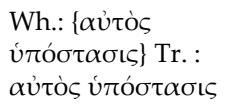 & 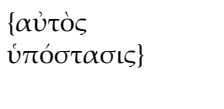 & $\begin{array}{l}\{\alpha u ̉ \tau o ̀ \varsigma \\
\hat{u} \pi o ́ \sigma \tau \alpha \sigma ı \varsigma\}\end{array}$ \\
\hline 5,1 & 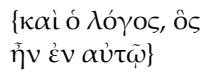 & 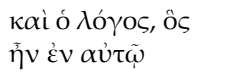 & 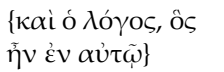 & 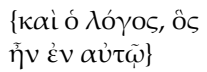 \\
\hline 5,3 & 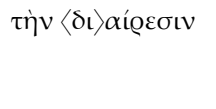 & 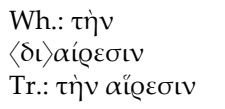 & 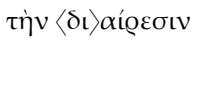 & 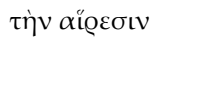 \\
\hline 5,7 & 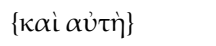 & 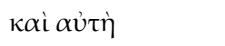 & 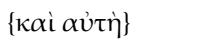 & $\{\kappa \alpha \grave{\iota} \alpha \hat{v} \tau \grave{\eta}\}$ \\
\hline 6,1 & 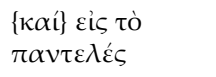 & 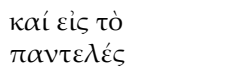 & 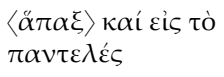 & 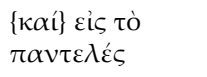 \\
\hline 6,1 & $\begin{array}{l}\left\{\varepsilon \varepsilon^{\prime} \sigma \varepsilon \sigma \alpha \iota\right\} \chi \alpha ́ \varrho \iota v \\
\kappa \varrho i ́ \sigma \varepsilon \omega \varsigma\end{array}$ & 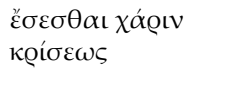 & 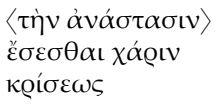 & 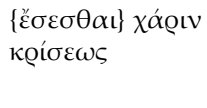 \\
\hline 7,1 & $\begin{array}{l}\dot{\alpha} \pi \mathrm{ò} \tau \mathrm{ov} \\
\pi v \varepsilon \dot{u} \mu \alpha \tau \sigma \varsigma\end{array}$ & 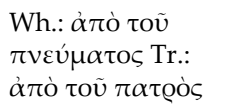 & 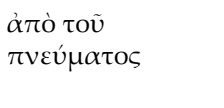 & 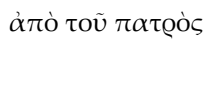 \\
\hline 7,2 & $\hat{o}\langle * * *\rangle \pi \lambda \eta \dot{ } v$ & ö $\pi \varepsilon \varrho$ & 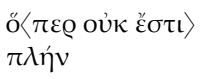 & о̆ $\pi \varepsilon \varrho$ \\
\hline 7,3 & 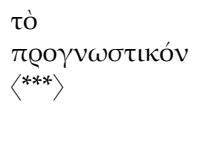 & 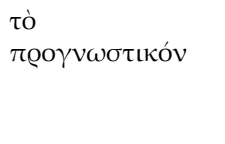 & 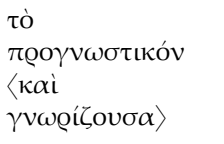 & $\pi \varrho о \gamma \nu \omega \sigma \tau o ́ v$ \\
\hline 7,4 & 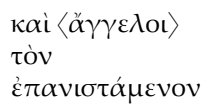 & 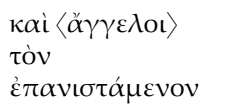 & 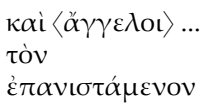 & 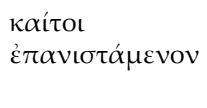 \\
\hline 7,5 & 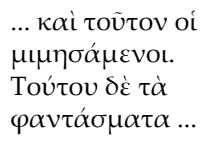 & 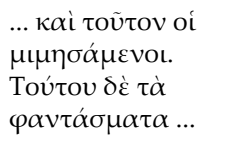 & 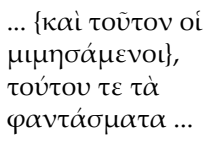 & 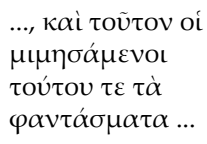 \\
\hline 8,2 & 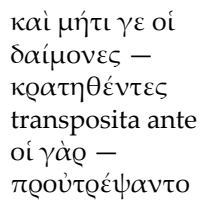 & $\begin{array}{l}\text { traditus } \\
\text { sententiarum } \\
\text { ordo servatus }\end{array}$ & 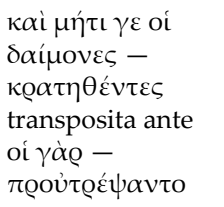 & 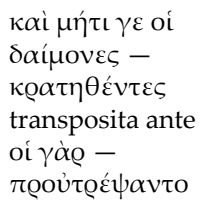 \\
\hline
\end{tabular}




\begin{tabular}{|c|c|c|c|c|}
\hline Stelle & Schwartz & $\begin{array}{l}\text { Whittaker / } \\
\text { Trelenberg }\end{array}$ & Marcovich & Nesselrath \\
\hline 8,2 & $\sigma \pi 0 v \delta \alpha ́ \alpha \omega \nu\langle * * * *$ & 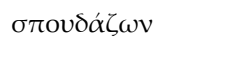 & 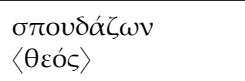 & 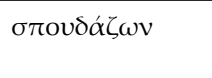 \\
\hline 8,4 & 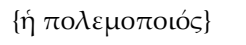 & 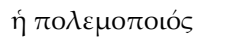 & $\{\dot{\eta} \pi 0 \lambda \varepsilon \mu о \pi о \circ о \varsigma\}$ & $\{\dot{\eta} \pi \mathrm{o} \lambda \varepsilon \mu \mathrm{o} \pi \mathrm{o} \mathrm{ó} \varsigma\}$ \\
\hline 8,5 & 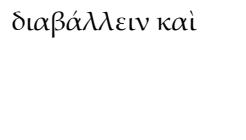 & $\begin{array}{l}\text { Wh.: } \delta\llcorner\alpha \beta \alpha ́ \alpha \lambda \varepsilon ı v \\
\kappa \alpha i \\
\text { Tr.: } \delta\llcorner\alpha \beta \alpha \alpha \lambda \lambda \varepsilon เ v \\
\{\kappa \alpha i\}\end{array}$ & 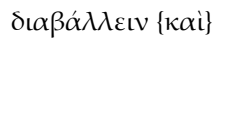 & 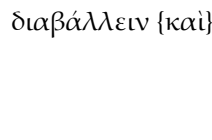 \\
\hline 8,5 & 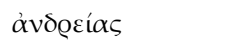 & 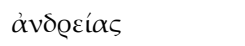 & $\dot{\alpha} \gamma \nu \varepsilon i ́ \alpha \varsigma$ & $\alpha \gamma \nu \varepsilon i ́ \alpha \varsigma$ \\
\hline 9,1 & 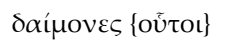 & 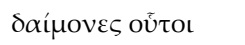 & 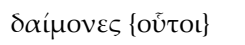 & 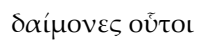 \\
\hline 9,2 & 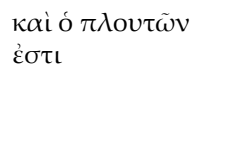 & 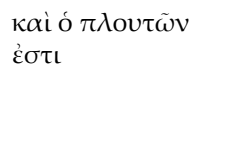 & 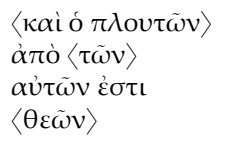 & $\begin{array}{l}\langle\kappa \alpha \grave{i} \text { ó } \pi \lambda \mathrm{ov} \tau \tilde{\omega} v\rangle \\
\dot{\alpha} \pi^{\prime} \alpha \dot{v} \tau \tilde{\omega} \nu \dot{\varepsilon} \sigma \tau \mathrm{L}\end{array}$ \\
\hline 9,2 & $\pi \lambda \alpha v \tilde{\eta} \tau \alpha \mathrm{L}\left\langle\left\langle^{* * *}\right\rangle\right.$ & $\pi \lambda \alpha v \tilde{\eta} \tau \alpha \iota$ & $\pi \lambda \alpha v \tilde{\eta} \tau \alpha \iota$ & $\pi \lambda \alpha v \tilde{\eta} \tau \alpha \iota$ \\
\hline 9,6 & $\begin{array}{l}\langle\alpha \hat{i} \\
\pi \varrho 0 \sigma \omega v v \mu i ́ \alpha \mathrm{l}\rangle \\
\gamma \varrho \alpha \mu \mu \alpha ́ \tau \omega \nu \\
\sigma \chi \eta \mu \alpha \tau o v \varrho \gamma \dot{\alpha} \alpha\end{array}$ & 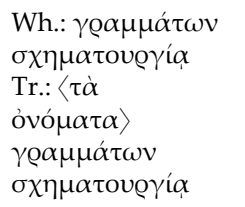 & 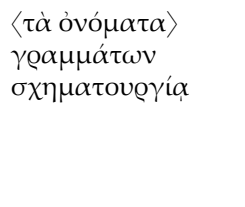 & $\begin{array}{l}\gamma \varrho \alpha \mu \mu \alpha ́ \tau \omega \nu \\
\sigma \chi \eta \mu \alpha \tau o v \varrho \gamma^{\prime} \alpha \iota\end{array}$ \\
\hline 9,6 & $\kappa \alpha \tau \eta \sigma \tau \varepsilon @ i ́ \sigma \theta \eta \sigma \alpha \nu$ & $\kappa \alpha \tau \eta \sigma \tau \varepsilon \varrho i ́ \sigma \theta \eta \sigma \alpha \nu$ & 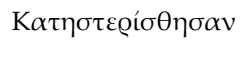 & $\begin{array}{l}\text { к } \alpha \tau \varepsilon \sigma \tau \eta ́^{-} \\
\chi \theta \eta \sigma \alpha \nu\end{array}$ \\
\hline 10,1 & $\alpha i ́ \gamma \varepsilon\llcorner\varrho o i ́\langle\tau \varepsilon\rangle$ & $\alpha$ & $\alpha i ́ \gamma \varepsilon\llcorner\varrho o i ́\langle\tau \varepsilon\rangle$ & 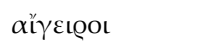 \\
\hline 10,3 & $\tau o \tilde{v} \theta \varepsilon \circ \tilde{v}$ & 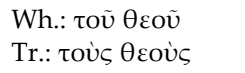 & $\tau o \tilde{v} \theta \varepsilon o \tilde{v}$ & toùs $\theta$ coùs \\
\hline 10,4 & $\begin{array}{l}\langle\dot{\mathrm{o}}\rangle \tau \dot{\mathrm{o} v} \\
\dot{\alpha} v \theta \varrho \omega \pi \mathrm{O} \pi \mathrm{otòv} \\
\ldots \kappa \alpha \tau \alpha \varphi \alpha \gamma \omega \dot{ }\end{array}$ & 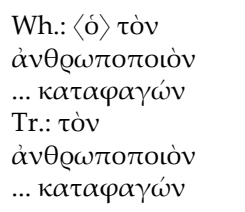 & 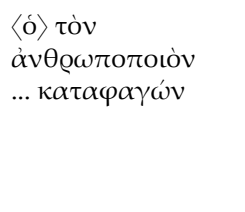 & 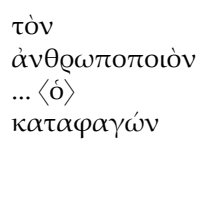 \\
\hline 11,3 & 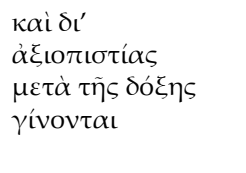 & 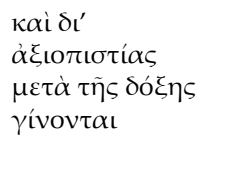 & 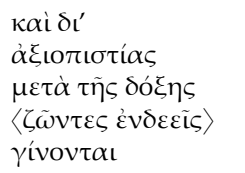 & 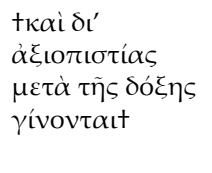 \\
\hline 12,2 & 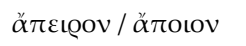 & áro@ov & ărtotov & áro@ov \\
\hline 12,2 & $\{\dot{\varepsilon} \vee \alpha \dot{u} \tau \tilde{\eta}\}$ & $\dot{\varepsilon} v \alpha \hat{v} \tau \tilde{\eta}$ & $\tau \alpha u ́ \tau \eta$ & $\dot{\varepsilon} v \alpha \hat{v} \tau \tilde{\eta}$ \\
\hline 12,2 & 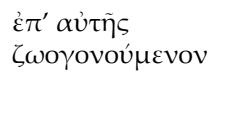 & 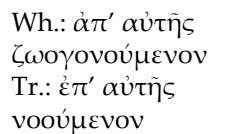 & 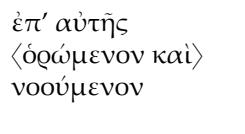 & 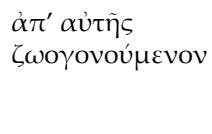 \\
\hline
\end{tabular}




\begin{tabular}{|c|c|c|c|c|}
\hline Stelle & Schwartz & $\begin{array}{l}\text { Whittaker / } \\
\text { Trelenberg }\end{array}$ & Marcovich & Nesselrath \\
\hline 12,3 & 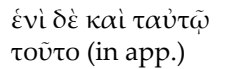 & $\pi \varepsilon \varrho i ̀ ~ \delta \varepsilon ่ ~ \alpha u ̉ \tau \tilde{\omega}$ & 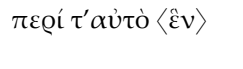 & 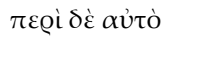 \\
\hline 12,3 & $\tau \grave{\alpha} \delta \dot{\varepsilon}\{\tau \iota v \alpha\}$ & $\tau \grave{\alpha} \delta \grave{\varepsilon} \tau ı \nu \alpha$ & $\tau \dot{\alpha} \delta \dot{\varepsilon}\{\tau \iota v \alpha\}$ & $\tau \grave{\alpha} \delta \grave{\varepsilon}\{\tau ı v \alpha\}$ \\
\hline 12,5 & ö $\mu \omega \varsigma$ & $\begin{array}{l}\text { Wh.: ő } \mu \omega \varsigma \\
\text { Tr.: ó } \mu \tilde{\omega} \varsigma\end{array}$ & $o ́ \mu\langle o i ́\rangle \omega \varsigma$ & óm $\tilde{\omega}$ \\
\hline 12,7 & 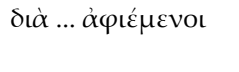 & 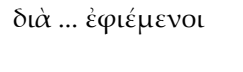 & 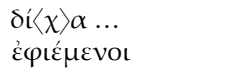 & $\delta \iota \grave{\alpha} \ldots \dot{\alpha} \varphi \iota \varepsilon ́ \mu \varepsilon v o \iota$ \\
\hline 12,9 & 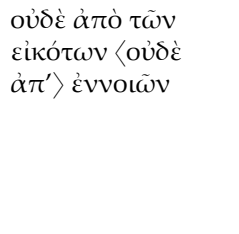 & 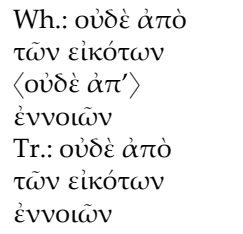 & 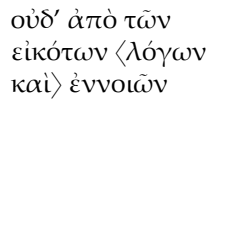 & 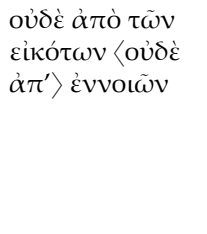 \\
\hline 12,9 & $\{$ oûs\} & $\begin{array}{l}\text { Wh.: }\{\text { oús\} } \\
\text { Tr.: oûs }\end{array}$ & $\langle\dot{v} \mu \tilde{\omega} v\rangle\{0 \hat{v} \varsigma\}$ & $\{$ oûs\} \\
\hline 13,5 & 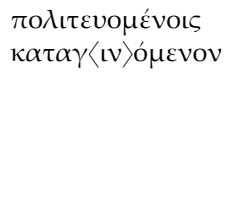 & 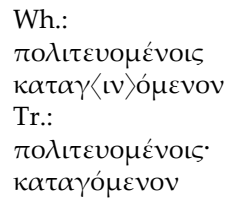 & 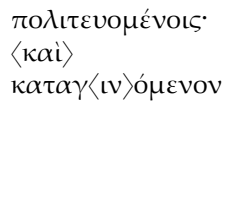 & 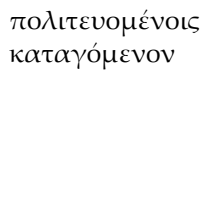 \\
\hline 14,1 & 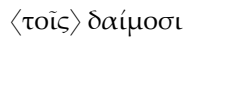 & 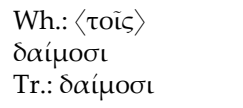 & $\begin{array}{l}\langle\dot{\alpha} \sigma \varphi \alpha \lambda \dot{\varepsilon} \varsigma \tau о \tilde{\varsigma}\rangle \\
\delta \alpha \dot{\mu} \mu \sigma \mathrm{\iota}\end{array}$ & $\langle\tau o \tilde{\varsigma}\rangle\rangle \alpha \dot{\prime} \mu о \sigma \iota$ \\
\hline 14,4 & 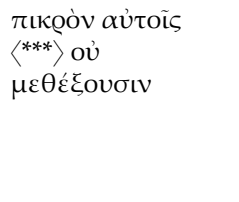 & 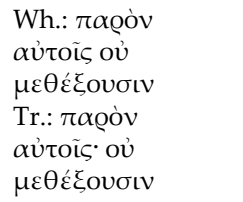 & 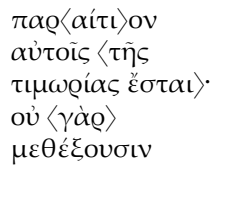 & 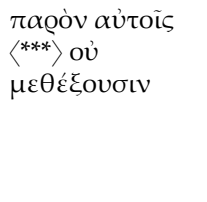 \\
\hline 14,4 & 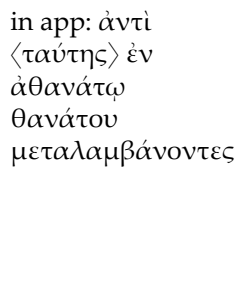 & 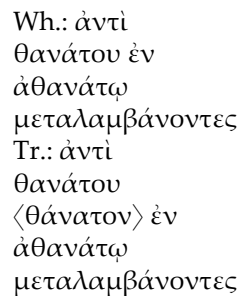 & 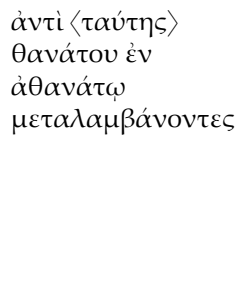 & 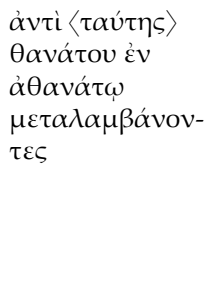 \\
\hline
\end{tabular}




\begin{tabular}{|c|c|c|c|c|}
\hline Stelle & Schwartz & $\begin{array}{l}\text { Whittaker / } \\
\text { Trelenberg }\end{array}$ & Marcovich & Nesselrath \\
\hline 14,5 & $\begin{array}{l}\delta ı \grave{\alpha} \pi \alpha v \tau \dot{\varsigma} \varsigma \kappa \alpha \grave{\imath} \\
\delta ı \dot{\alpha} \tau o \tilde{u} \zeta \tilde{\eta} v\end{array}$ & 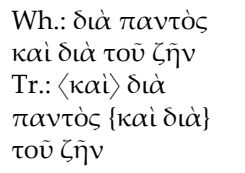 & 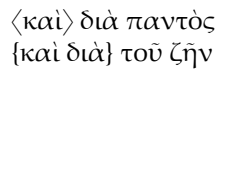 & 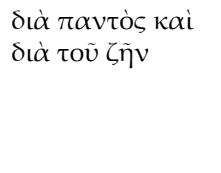 \\
\hline 14,5 & 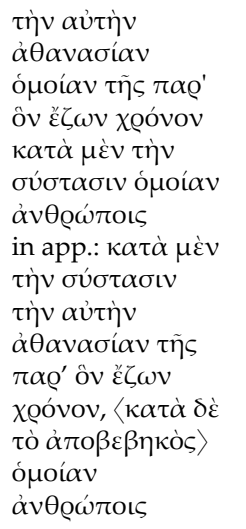 & 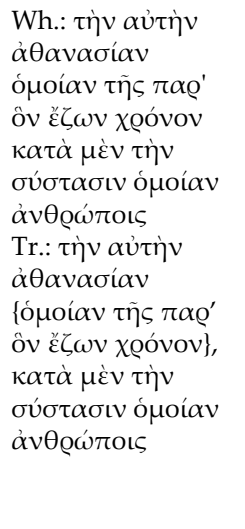 & 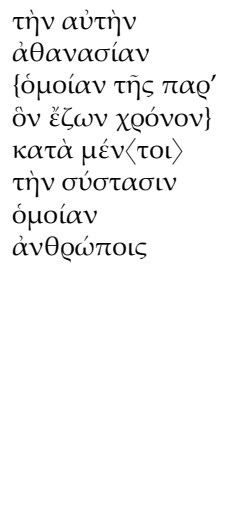 & 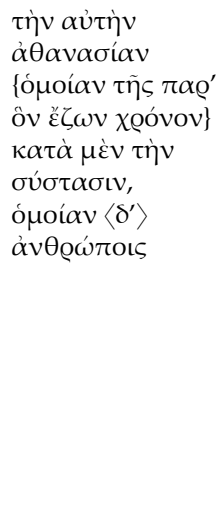 \\
\hline 14,6 & 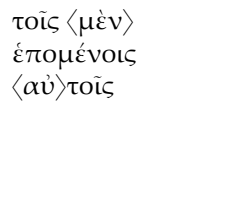 & 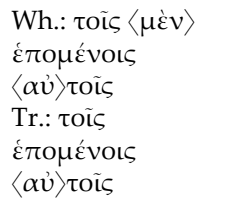 & 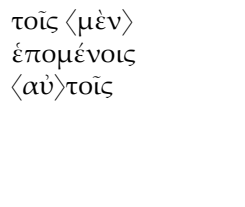 & 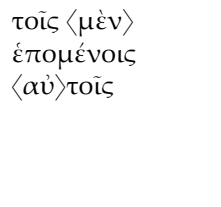 \\
\hline 15,1 & 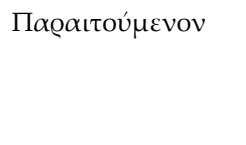 & 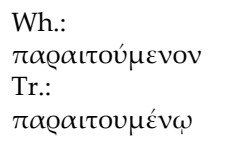 & $\pi \alpha \varrho \alpha ı \tau о v \mu \varepsilon ́ v \omega$ & 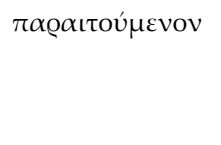 \\
\hline 16,4 & 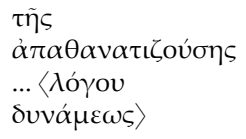 & $\begin{array}{l}\tau \tilde{\eta} \varsigma \\
\dot{\alpha} \pi \alpha \theta \alpha v \alpha \tau ı \zeta o v ́ \sigma \eta \varsigma \\
\ldots\langle\delta v v \alpha \dot{\mu} \mu \varepsilon \omega \varsigma\rangle\end{array}$ & $\begin{array}{l}\tau \tilde{\eta} \varsigma \\
\dot{\alpha} \pi \alpha \theta \alpha v \alpha \tau \iota \zeta o u ́ \sigma \eta \varsigma \\
\ldots\langle\theta \varepsilon \sigma \tilde{v} \\
\delta v v \alpha \dot{\mu} \mu \omega \varsigma\rangle\end{array}$ & $\begin{array}{l}\tau \tilde{\eta} \varsigma \\
\dot{\alpha} \pi \alpha \theta \alpha v \alpha \tau \iota \zeta o u ́- \\
\sigma \eta \varsigma \ldots \\
\langle * * *\rangle\end{array}$ \\
\hline $17,4-5$ & 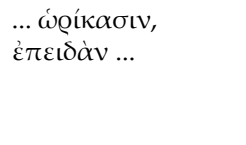 & 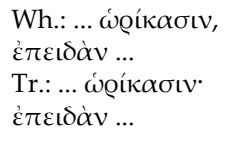 & 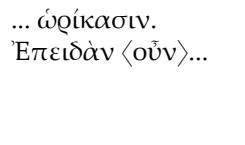 & 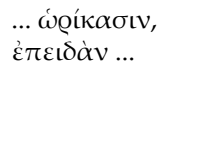 \\
\hline 17,7 & 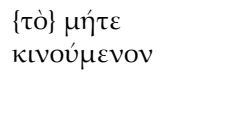 & 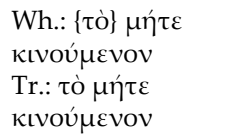 & 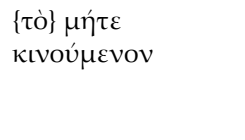 & $\begin{array}{l}\{\tau \dot{\jmath}\} \mu \eta ́ \tau \varepsilon \\
\kappa เ v o u ́ \mu \varepsilon v o v\end{array}$ \\
\hline 19,1 & 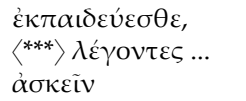 & $\begin{array}{l}\dot{\varepsilon} \kappa \pi \alpha \mathrm{t} \delta \varepsilon v ́ \varepsilon \sigma \theta \varepsilon \\
\lambda \varepsilon ́ \gamma \gamma \nu \tau \varepsilon \varsigma\end{array}$ & 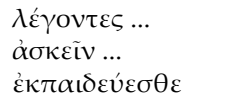 & 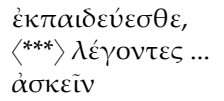 \\
\hline
\end{tabular}




\begin{tabular}{|c|c|c|c|c|}
\hline Stelle & Schwartz & $\begin{array}{l}\text { Whittaker / } \\
\text { Trelenberg }\end{array}$ & Marcovich & Nesselrath \\
\hline 19,1 & $\langle\hat{\eta}\rangle$ ö $\pi \omega \varsigma$ & 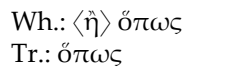 & 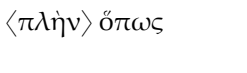 & о̆ $\pi \omega \varsigma$ \\
\hline 19,2 & 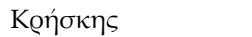 & 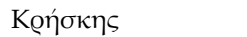 & 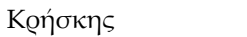 & 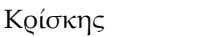 \\
\hline 19,2 & 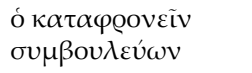 & 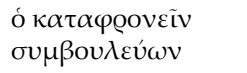 & 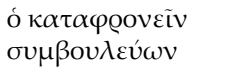 & 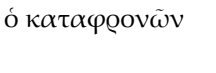 \\
\hline 19,2 & 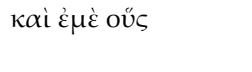 & 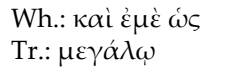 & $\mu \varepsilon \gamma \alpha \dot{\alpha} \lambda \omega$ & $\kappa \alpha \grave{i} \varepsilon \dot{\varepsilon} \mu \grave{\varepsilon} \omega \varsigma$ \\
\hline 19,2 & 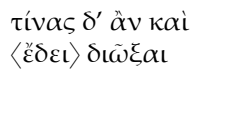 & 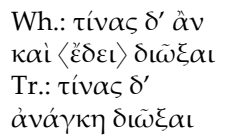 & $\begin{array}{l}\tau i ́ v \alpha \varsigma \delta^{\prime} \hat{\alpha} \nu \kappa \alpha \grave{\imath} \\
\left\langle\varepsilon^{\prime} \delta \varepsilon \iota\right\rangle \delta \iota \tilde{\omega} \xi \alpha \iota\end{array}$ & $\begin{array}{l}\tau i ́ v \alpha \varsigma \delta^{\prime} \alpha \ddot{\alpha} \nu \kappa \alpha \grave{\imath} \\
\left\langle\varepsilon^{\prime} \delta \varepsilon \iota\right\rangle \delta \iota \tilde{\omega} \xi \alpha \iota\end{array}$ \\
\hline 20,2 & $\varepsilon \varepsilon^{\prime} \pi \tau \eta \xi \varepsilon \nu$ & $\varepsilon ้ \pi \tau \eta$ & $\varepsilon \varepsilon^{\prime} \pi \tau \eta \xi \varepsilon \nu$ & $\varepsilon ้ \pi \tau \eta \xi \varepsilon \nu$ \\
\hline 20,3 & $\begin{array}{l}\mu \varepsilon \tau \omega \kappa i ́ \sigma \theta \eta \sigma \alpha \nu \\
\langle\gamma \dot{\alpha} \varrho\rangle . . . \\
\dot{\varepsilon} \xi \omega \varrho i ́ \sigma \theta \eta \sigma \alpha \nu \delta \dot{\varepsilon}\end{array}$ & $\begin{array}{l}\text { Wh.: } \\
\mu \varepsilon \tau \omega \kappa i ́ \sigma \theta \eta \sigma \alpha v \\
\langle\gamma \dot{\alpha} \varrho \ldots \\
\dot{\varepsilon} \xi \omega \varrho i ́ \sigma \theta \eta \sigma \alpha \nu \delta \dot{\varepsilon} \\
\text { Tr.: } \\
\mu \varepsilon \tau \omega \kappa i ́ \sigma \theta \eta \sigma \alpha \nu \\
\ldots . \dot{\varepsilon} \xi \omega \varrho i ́ \sigma \theta \eta \sigma \alpha v \\
\delta \dot{\varepsilon}\end{array}$ & $\begin{array}{l}\mu \varepsilon \tau \omega \kappa i ́ \sigma \theta \eta \sigma \alpha v \\
\langle\gamma \sigma \tilde{v}\rangle \ldots \\
\dot{\varepsilon} \xi \omega \varrho i ́ \sigma \theta \eta \sigma \alpha v \delta \dot{\varepsilon}\end{array}$ & 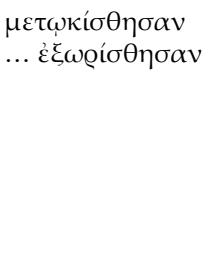 \\
\hline 20,5 & $\{\delta \iota \alpha\} \pi \varepsilon \pi \eta \gamma$ ó & 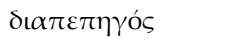 & $\delta\llcorner\alpha \pi \varepsilon \pi \eta \gamma o ́ \varsigma$ & 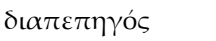 \\
\hline 20,6 & 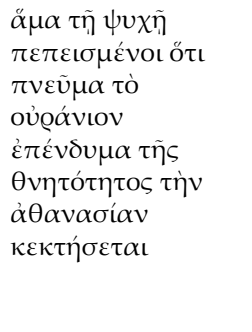 & 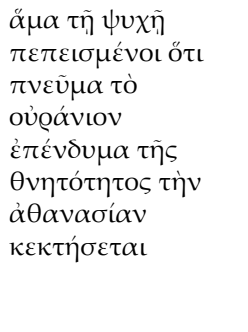 & 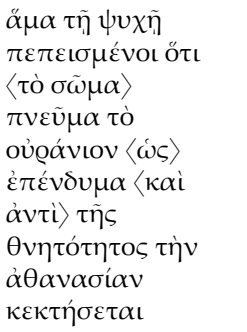 & 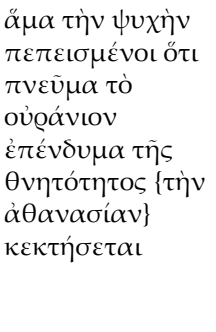 \\
\hline 21,3 & 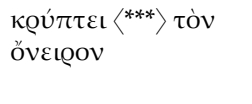 & 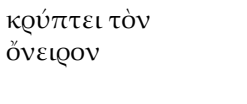 & 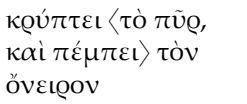 & 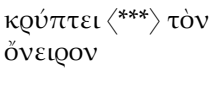 \\
\hline 21,3 & 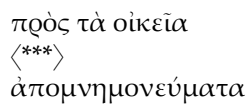 & 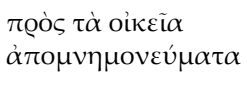 & 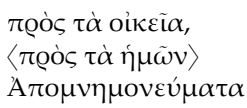 & 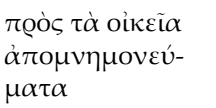 \\
\hline 22,2 & $\begin{array}{l}\langle\tau \text { tòv }\rangle \\
\alpha \beta \text { ¿ }\end{array}$ & $\alpha \beta \varrho v$ vóucvov & 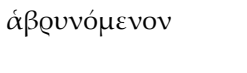 & $\alpha \beta \varrho v$ vóucvov \\
\hline 23,5 & 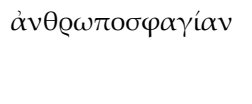 & 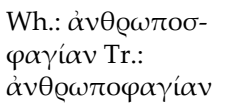 & $\alpha \dot{\alpha} \theta \varrho \omega \pi о \varphi \alpha \gamma^{\prime} \alpha v$ & $\begin{array}{l}\dot{\alpha} v \theta \varrho \omega \pi о \sigma \varphi \alpha- \\
\gamma \dot{\alpha} \alpha v\end{array}$ \\
\hline
\end{tabular}




\begin{tabular}{|c|c|c|c|c|}
\hline Stelle & Schwartz & $\begin{array}{l}\text { Whittaker / } \\
\text { Trelenberg }\end{array}$ & Marcovich & Nesselrath \\
\hline 24,2 & $\begin{array}{l}\text { ПuӨıкòv } \\
\alpha \dot{u} \lambda \eta \tau \eta ́ v ~\end{array}$ & 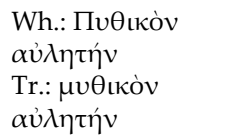 & $\begin{array}{l}\text { ПuӨıкòv } \\
\alpha \dot{u} \lambda \eta \tau \eta ́ v\end{array}$ & $\begin{array}{l}\mu v \theta \text { เкòv } \\
\alpha \dot{u} \lambda \eta \tau \eta ́ v\end{array}$ \\
\hline 24,3 & 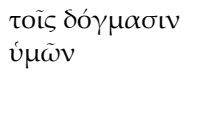 & 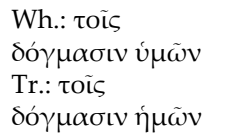 & 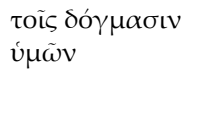 & 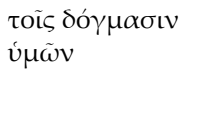 \\
\hline 25,1 & 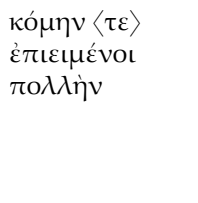 & 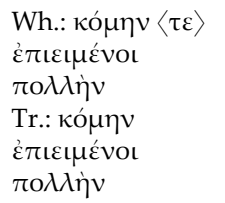 & 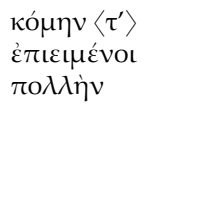 & 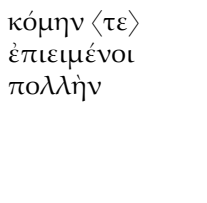 \\
\hline 26,2 & ¿’v $\alpha \theta \dot{\varepsilon} \sigma \varepsilon \iota \varsigma$ & 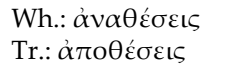 & 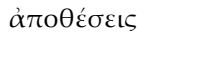 & $\dot{\alpha} v \alpha \theta \dot{\varepsilon} \sigma \varepsilon \iota \varsigma$ \\
\hline 26,6 & $\dot{\varepsilon} \sigma \tau \varepsilon$ & $\begin{array}{l}\text { Wh.: 'ं } \bar{\tau} \varepsilon \\
\text { Tr.: í } \sigma \tau \varepsilon\end{array}$ & $\dot{\varepsilon} \sigma \tau \varepsilon$ & $\dot{\varepsilon} \sigma \tau \varepsilon$ \\
\hline 27,1 & $\delta ı \delta \alpha \gamma \mu \alpha ́ \tau \omega \nu$ & $\delta о \gamma \mu \alpha ́ \tau \omega \nu$ & $\delta о \gamma \mu \alpha \tau\langle\iota \sigma \tau\rangle \tilde{\omega} \nu$ & $\delta о \gamma \mu \alpha ́ \tau \tau \omega \nu$ \\
\hline 27,1 & 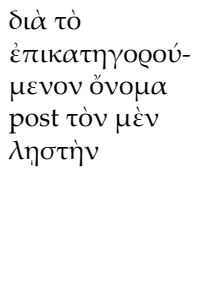 & 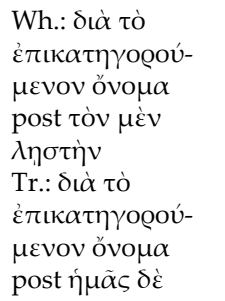 & 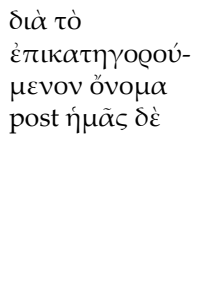 & 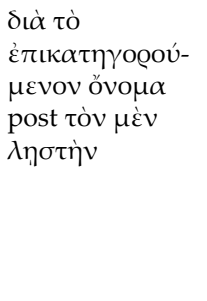 \\
\hline 27,2 & 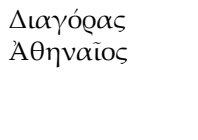 & 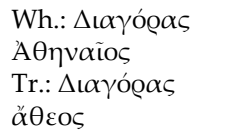 & 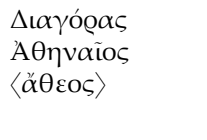 & 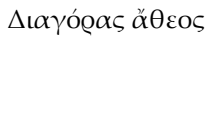 \\
\hline 27,2 & 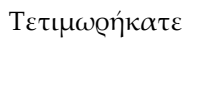 & $\begin{array}{l}\text { Wh.: } \\
\tau \varepsilon \tau \iota \mu \omega \varrho \eta ́ \kappa \alpha \tau \varepsilon \\
\text { Tr.: } \tau \varepsilon \tau \iota \mu \eta ́ \kappa \alpha \tau \varepsilon\end{array}$ & $\tau \varepsilon \tau \iota \mu \omega \emptyset \eta ́ \kappa \alpha \tau \varepsilon$ & $\tau \varepsilon \tau \iota \mu \eta ́ \kappa \alpha \tau \varepsilon$ \\
\hline 27,5 & $\langle\sigma \varepsilon \dot{\beta} \omega\rangle$ & $\begin{array}{l}\text { Wh.: }\langle\sigma \varepsilon \hat{\varepsilon} \omega\rangle \\
\text { Tr.: }\langle\tau \tau \mu \tilde{\omega}\rangle\end{array}$ & $\langle\tau \iota \mu \tilde{\omega}\rangle$ & $\langle\sigma \varepsilon \hat{\varepsilon} \beta \omega\rangle$ \\
\hline 28,3 & dútoĩs & $\alpha \hat{\tau} \tau \tilde{\omega} v$ & dútoĩs & $\alpha \hat{\tau} \tau \tilde{\omega} v$ \\
\hline 29,3 & $\begin{array}{l}\kappa \alpha \tau \alpha \delta i ́ \kappa \eta \varsigma \ldots \\
\tau \varrho o ́ \pi о \nu\end{array}$ & 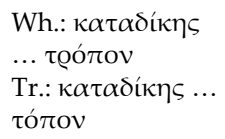 & $\begin{array}{l}\kappa \alpha \tau \alpha \delta i ́ \kappa \eta \varsigma . . \\
\tau o ́ \pi о \nu\end{array}$ & 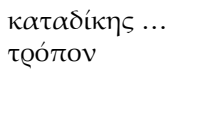 \\
\hline
\end{tabular}




\begin{tabular}{|c|c|c|c|c|}
\hline Stelle & Schwartz & $\begin{array}{l}\text { Whittaker / } \\
\text { Trelenberg }\end{array}$ & Marcovich & Nesselrath \\
\hline 30,1 & $\begin{array}{l}\tau \tilde{\omega} v \beta \varrho \varepsilon \varphi \tilde{\omega} v\langle * * *\rangle \\
\dot{\alpha} \tau \sigma \delta \tilde{v} \sigma \alpha \sigma \theta \alpha \mathrm{\iota}\end{array}$ & $\begin{array}{l}\tau \tilde{\omega} v \beta \varrho \varepsilon \varphi \tilde{\omega} v \\
\dot{\alpha} \pi \circ \delta \tilde{v} \sigma \alpha \sigma \theta \alpha \iota\end{array}$ & 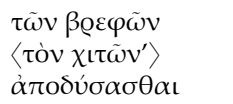 & $\begin{array}{l}\tau \tilde{\omega} \nu \beta \varrho \varepsilon \varphi \tilde{\omega} \nu\langle * * *\rangle \\
\dot{\alpha} \pi \mathrm{o \delta} \tilde{\sigma} \sigma \alpha \sigma \theta \alpha \mathrm{\iota}\end{array}$ \\
\hline 30,2 & П $\alpha \varrho \varepsilon ́ \sigma \chi о \mu \varepsilon \nu$ & $\pi \alpha \varrho \varepsilon ́ \chi о \mu \varepsilon \nu$ & $\pi \alpha \varrho \varepsilon ́ \sigma \chi \mathrm{O} \mu \varepsilon \nu$ & $\pi \alpha \varrho \varepsilon ́ \chi о \mu \varepsilon \nu$ \\
\hline 30,2 & $\begin{array}{l}\alpha \dot{v} \tau o \tilde{v} \pi \tilde{\alpha} \varsigma \ldots \\
\kappa \tau \tilde{\eta} \mu \alpha\end{array}$ & $\begin{array}{l}\text { Wh.: } \alpha \hat{v} \tau o \tilde{v} \pi \tilde{\alpha} \varsigma \\
\ldots \kappa \tau \tilde{\eta} \mu \alpha \\
\text { Tr.: } \alpha \dot{v} \tau o \tilde{v} \pi \tilde{\alpha} v . . \\
\kappa \tau \tilde{\eta} \mu \alpha\end{array}$ & $\begin{array}{l}\alpha \dot{v} \tau o \tilde{v} \pi \tilde{\alpha} \varsigma \ldots \\
\kappa \tau \tilde{\eta} \mu \alpha\end{array}$ & $\begin{array}{l}\alpha \hat{v} \tau o \tilde{v} \pi \tilde{\alpha} \nu \ldots \\
\kappa \tau \tilde{\eta} \mu \alpha\end{array}$ \\
\hline 30,4 & 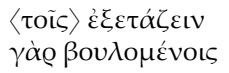 & 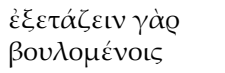 & 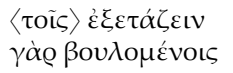 & $\begin{array}{l}\dot{\varepsilon} \xi \varepsilon \tau \alpha \dot{\alpha} \zeta \varepsilon \mathrm{tv} \gamma \dot{\alpha} \varrho \\
\beta о u \lambda o ́ \mu \varepsilon v o \varsigma\end{array}$ \\
\hline 31,1 & $\begin{array}{l}\pi \alpha \lambda \alpha i ́ \tau \alpha \tau о \nu . . . \\
\pi \varrho \varepsilon \sigma \beta u ́ \tau \alpha \tau o v\end{array}$ & 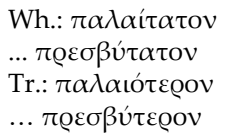 & $\begin{array}{l}\tau \alpha \lambda \alpha i ́ \tau \alpha \tau о \nu . . . \\
\pi \varrho \varepsilon \sigma \beta u ́ \tau \alpha \tau о \nu\end{array}$ & $\begin{array}{l}\pi \alpha \lambda \alpha i ́ \tau \alpha \tau о \nu . . . \\
\pi \varrho \varepsilon \sigma \beta u ́ \tau \alpha \tau о \nu\end{array}$ \\
\hline 31,1 & $\varepsilon ̌ \tau \iota ~ \delta \grave{~}$ & $\begin{array}{l}\text { Wh.: } \varepsilon^{\prime} \tau \iota ~ \delta \dot{\varepsilon} \\
\text { Tr.: } \dot{\alpha} \lambda \lambda^{\prime} \varepsilon^{\prime} \tau \iota \delta \dot{\varepsilon}\end{array}$ & 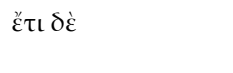 & $\varepsilon \varepsilon^{\prime} \tau \iota \delta \dot{~}$ \\
\hline 31,2 & $\begin{array}{l}\dot{v} \varphi^{\prime} \eta \dot{\eta} \mu \tilde{\omega} v \\
\pi \alpha \varrho \alpha \delta \varepsilon \kappa \tau o ́ v\end{array}$ & 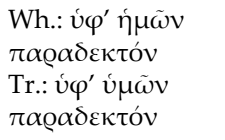 & $\begin{array}{l}\dot{v} \varphi^{\prime} \dot{v} \mu \tilde{\omega} v \\
\pi \alpha \varrho \alpha \delta \varepsilon \kappa \tau o ́ v\end{array}$ & 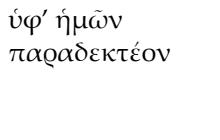 \\
\hline 31,2 & óтót $\alpha v$ & óтót $\alpha v$ & ótót $\alpha v$ & ö $\tau \alpha v$ \\
\hline 31,2 & $\Lambda \alpha \mu \beta \alpha ́ \alpha \omega$ & $\begin{array}{l}\text { Wh.: } \lambda \alpha \mu \beta \alpha ́ v \omega \\
\text { Tr.: } \\
\pi \alpha \varrho \alpha \lambda \alpha \mu \beta \alpha \dot{\nu} \omega\end{array}$ & $\pi \alpha \varrho \alpha \lambda \alpha \mu \beta \alpha ́ v \omega$ & $\lambda \alpha \mu \beta \alpha \dot{\alpha} \omega$ \\
\hline 31,3 & 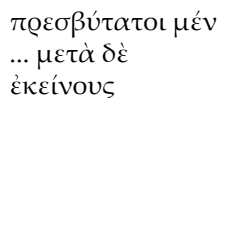 & 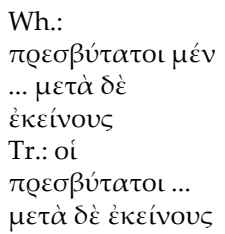 & 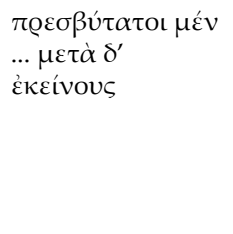 & 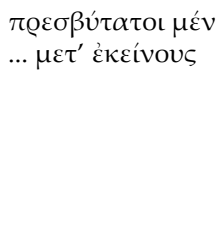 \\
\hline 31,3 & $\begin{array}{l}\kappa \alpha i ̀ \\
\Sigma \tau \eta \sigma \dot{\mu} \mu \beta \varrho о \tau o s\end{array}$ & 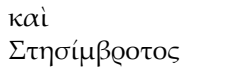 & $\begin{array}{l}\kappa \alpha \grave{i} \\
\Sigma \tau \eta \sigma i ́ \mu \beta \varrho о \tau о \varsigma\end{array}$ & 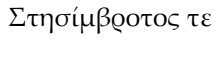 \\
\hline 31,3 & 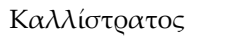 & К $\alpha \lambda \lambda i ́ \sigma \tau \varrho \alpha \tau о \varsigma$ & К $\alpha \lambda \lambda i ́ \sigma \tau \varrho \alpha \tau о \varsigma$ & К $\alpha \lambda \lambda i ́ \mu \alpha \chi о \varsigma$ \\
\hline 31,4 & $\tau o u ́ \tau \omega \nu ~ \delta \dot{~ o i ~} \mu \varepsilon v^{\prime}$ & $\tau o u ́ \tau \omega \nu ~ \delta \dot{\varepsilon}$ oi $\mu \varepsilon v^{\prime}$ & 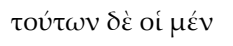 & 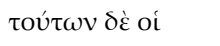 \\
\hline 31,4 & 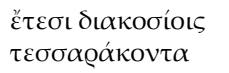 & 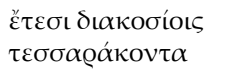 & 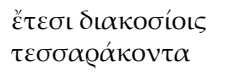 & 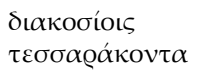 \\
\hline 31,5 & $\begin{array}{l}\pi \varrho o ̀ ~ \tau \tilde{\omega} v \\
\text { 'О } \lambda v \mu \pi \iota \alpha \dot{\alpha} \delta \omega v\end{array}$ & 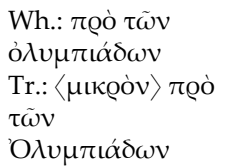 & 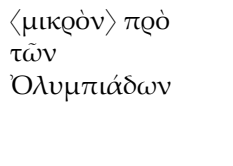 & $\begin{array}{l}\pi \varrho o ̀ ~ \tau \tilde{\omega} v \\
\text { O } \lambda v \mu \pi \iota \alpha \dot{\alpha} \delta v\end{array}$ \\
\hline
\end{tabular}




\begin{tabular}{|c|c|c|c|c|}
\hline Stelle & Schwartz & $\begin{array}{l}\text { Whittaker / } \\
\text { Trelenberg }\end{array}$ & Marcovich & Nesselrath \\
\hline 31,5 & 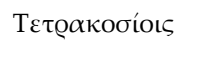 & 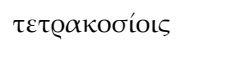 & 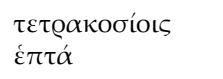 & 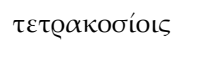 \\
\hline 32,3 & 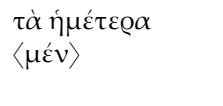 & 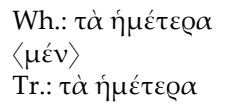 & 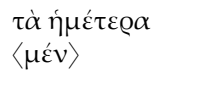 & $\tau \grave{\alpha} \dot{\eta} \mu \varepsilon ́ \tau \varepsilon \varrho \alpha$ \\
\hline 32,7 & 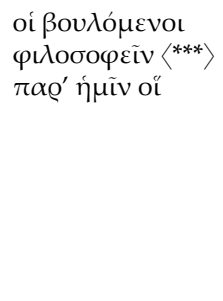 & 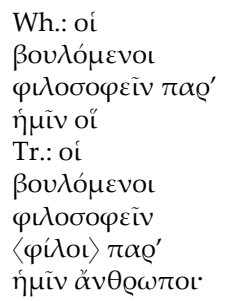 & 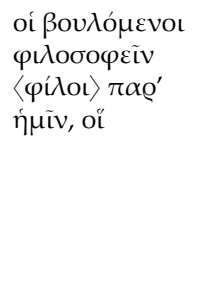 & 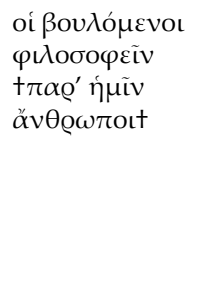 \\
\hline 33,1 & 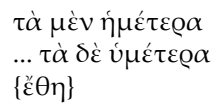 & 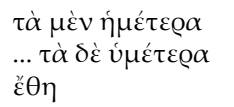 & $\begin{array}{l}\tau \dot{\alpha} \mu \dot{\varepsilon} v \eta \dot{\eta} \mu \dot{\varepsilon} \tau \varepsilon \varrho \alpha \\
\langle\check{\varepsilon} \theta \eta\rangle \ldots \tau \dot{\alpha} \delta \dot{\varepsilon} \\
\dot{v} \mu \varepsilon \dot{\varepsilon} \tau \varrho \alpha\{\tilde{\varepsilon} \theta \eta\}\end{array}$ & 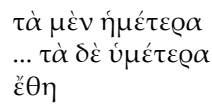 \\
\hline 33,1 & $\lambda \tilde{\eta} \varrho o v$ & 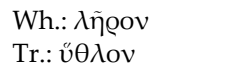 & $\lambda \tilde{\eta} \varrho o v$ & v̈$\theta \lambda o v$ \\
\hline 33,3 & 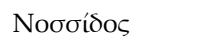 & 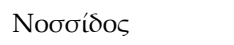 & 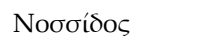 & 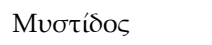 \\
\hline 34,1 & 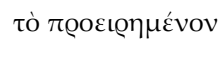 & 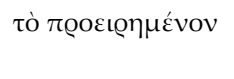 & $\begin{array}{l}\{\tau o ̀ \\
\pi \varrho 0 \varepsilon เ \eta \mu \varepsilon ́ v o v\}\end{array}$ & 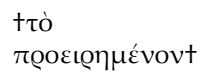 \\
\hline 34,2 & $\begin{array}{l}\tau \dot{\alpha} \sigma \chi \eta \dot{\eta} \mu \alpha \tau \alpha \\
\{\kappa \alpha \dot{i}\}\end{array}$ & $\begin{array}{l}\text { Wh.: } \tau \dot{\alpha} \sigma \chi \eta \dot{\mu} \mu \alpha \tau \alpha \\
\{\kappa \alpha \grave{i}\} \operatorname{Tr} .: \tau \dot{\alpha} \\
\sigma \chi \eta \dot{\eta} \mu \alpha \alpha \kappa \alpha \grave{i}\end{array}$ & $\begin{array}{l}\tau \dot{\alpha} \sigma \chi \eta \dot{\eta} \mu \alpha \tau \alpha \\
\{\kappa \alpha \dot{i}\}\end{array}$ & $\begin{array}{l}\tau \dot{\alpha} \sigma \chi \eta \dot{\eta} \mu \alpha \tau \alpha \\
\{\kappa \alpha i\}\end{array}$ \\
\hline 34,3 & 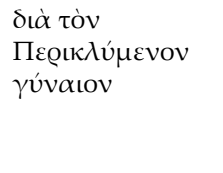 & 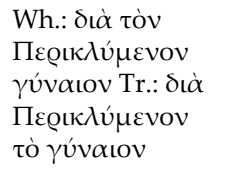 & 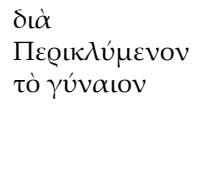 & 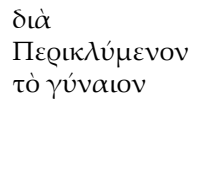 \\
\hline 34,3 & $\begin{array}{l}\eta \gamma \varepsilon \varepsilon \tilde{\iota} \sigma \theta \varepsilon \kappa \alpha \grave{~} \\
\kappa \alpha \tau \alpha \nu 0 \varepsilon \tilde{\iota} \nu\end{array}$ & 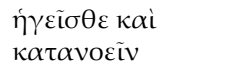 & 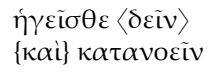 & 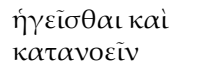 \\
\hline 34,5 & $\begin{array}{l}\tau \tilde{\eta} \varsigma \chi \alpha \lambda \kappa \varepsilon v \tau \iota \kappa \tilde{\eta} \varsigma \\
\{\tilde{\eta}\}\end{array}$ & $\begin{array}{l}\tau \tilde{\eta} \varsigma \\
\hat{\eta}\end{array}$ & $\begin{array}{l}\tau \tilde{\eta} \varsigma\langle * * *\rangle \\
\chi \alpha \lambda \kappa \varepsilon v \tau \leftarrow \kappa \tilde{\eta} \varsigma\{\hat{\eta}\}\end{array}$ & $\begin{array}{l}\tau \tilde{\eta} \varsigma\langle * * *\rangle \\
\chi \alpha \lambda \kappa \varepsilon v \tau \iota \kappa \tilde{\eta} \varsigma \tilde{\eta}\end{array}$ \\
\hline 34,5 & 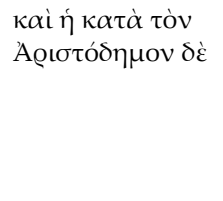 & 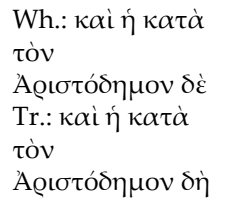 & 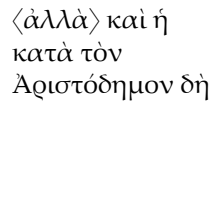 & 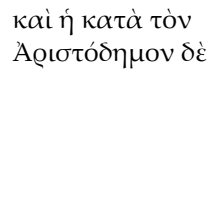 \\
\hline
\end{tabular}




\begin{tabular}{|c|c|c|c|c|}
\hline Stelle & Schwartz & $\begin{array}{l}\text { Whittaker / } \\
\text { Trelenberg }\end{array}$ & Marcovich & Nesselrath \\
\hline 34,5 & $\pi \varepsilon \varrho ı \sigma \tau о u ́ \delta \alpha \sigma \tau о \varsigma$ & $\begin{array}{l}\text { Wh.: } \\
\pi \varepsilon \varrho ı \sigma \pi o u ́ \delta \alpha \sigma \tau o v \\
\text { Tr.: } \\
\pi \varepsilon \varrho ı \sigma \text { ó́ } \alpha \sigma \tau о \varsigma\end{array}$ & $\pi \varepsilon \varrho ı \sigma \pi о u ́ \delta \alpha \sigma \tau о \varsigma$ & $\pi \varepsilon \varrho ı \sigma o u ́ \delta \alpha \sigma \tau o v$ \\
\hline 34,7 & 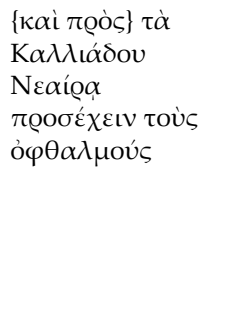 & 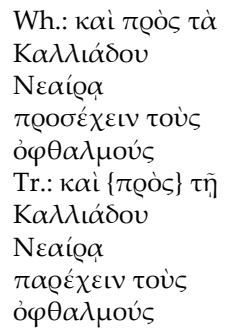 & 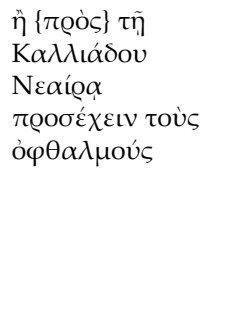 & 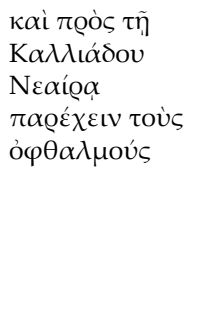 \\
\hline 34,7 & ó Tógvos & ó Tógvos & ó Tó@vos $\langle * * *\rangle$ & ó troũ Qvost \\
\hline 35,2 & 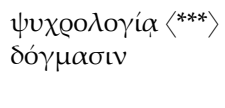 & $\begin{array}{l}\psi v \chi \varrho о \lambda о \gamma \dot{\alpha} \alpha \\
\delta o ́ \gamma \mu \alpha \sigma \iota v\end{array}$ & 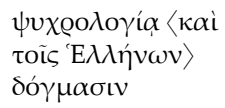 & $\begin{array}{l}\psi v \chi \varrho о \lambda о \gamma \dot{\alpha} \alpha, \\
\delta o ́ \gamma \mu \alpha \sigma \iota v\end{array}$ \\
\hline 35,2 & $\kappa \alpha \theta^{\prime} \dot{\eta} \mu \tilde{\alpha} \varsigma$ & $\kappa \alpha \theta^{\prime} \dot{v} \mu \tilde{\alpha} \varsigma$ & $\kappa \alpha \theta^{\prime} \eta \mu \tilde{\alpha} \varsigma$ & $\kappa \alpha \theta^{\prime} \dot{v} \mu \tilde{\alpha} \varsigma$ \\
\hline 35,2 & $\langle * * *\rangle \pi \varepsilon\llcorner\varrho \alpha ́ \sigma o \mu \alpha \iota$ & $\pi \varepsilon \iota \varrho \alpha ́ \sigma o \mu \alpha \iota$ & $\pi \varepsilon \iota \varrho \alpha ́ \sigma o \mu \alpha \iota$ & $\langle * * *\rangle) \pi \varepsilon\llcorner\varrho \alpha ́ \alpha \sigma \mu \alpha \iota$ \\
\hline 36,1 & 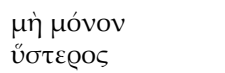 & 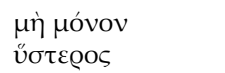 & 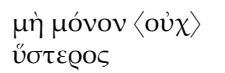 & 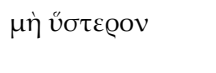 \\
\hline 36,1 & 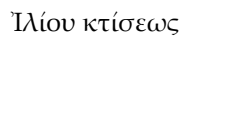 & 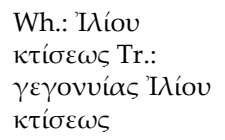 & 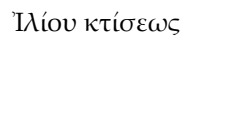 & 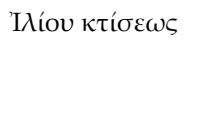 \\
\hline $36,2-3$ & 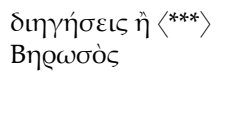 & 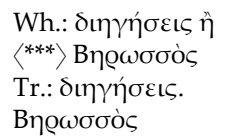 & 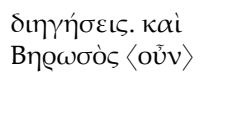 & 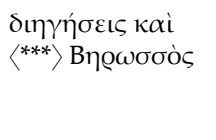 \\
\hline 40,1 & Пó $\lambda \varepsilon \omega v$ & 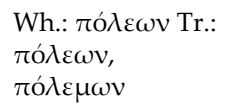 & 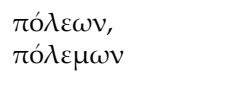 & $\pi o ́ \lambda \varepsilon \omega \nu$ \\
\hline 40,2 & 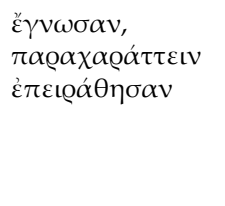 & 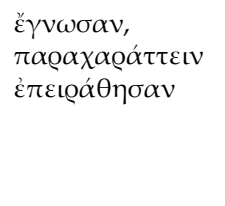 & 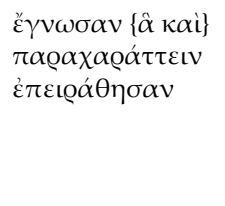 & 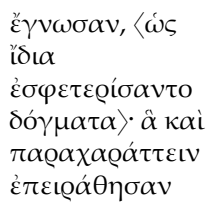 \\
\hline 41,2 & $\begin{array}{l}\tau o \tilde{v} \\
\sigma \tau \varrho \alpha \tau \varepsilon v ́ \sigma \alpha \nu \tau o \zeta\end{array}$ & 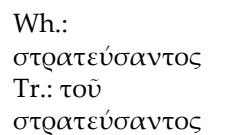 & $\begin{array}{l}\tau o \tilde{v} \\
\sigma \tau \varrho \alpha \tau \varepsilon v ́ \sigma \alpha \nu \tau o \varsigma\end{array}$ & $\sigma \tau \varrho \alpha \tau \varepsilon v ́ \sigma \alpha \nu \tau о \varsigma$ \\
\hline
\end{tabular}




\begin{tabular}{|c|c|c|c|c|}
\hline Stelle & Schwartz & $\begin{array}{l}\text { Whittaker / } \\
\text { Trelenberg }\end{array}$ & Marcovich & Nesselrath \\
\hline 41,6 & 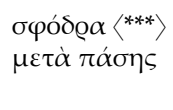 & $\begin{array}{l}\sigma \varphi o ́ \delta \varrho \alpha \mu \varepsilon \tau \dot{\alpha} \\
\pi \alpha ́ \sigma \eta \varsigma\end{array}$ & 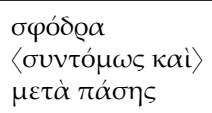 & $\begin{array}{l}\sigma \varphi o ́ \delta \varrho \alpha\left\langle\left\langle^{* * *}\right\rangle\right. \\
\mu \varepsilon \tau \dot{\alpha} \pi \alpha \dot{\alpha} \sigma \zeta \varsigma\end{array}$ \\
\hline
\end{tabular}

Jede dieser Textvarianten ist im griechischen Text durch einen Asteriskos $\left(^{*}\right)$ markiert. 
B. Text, Übersetzung und Anmerkungen 


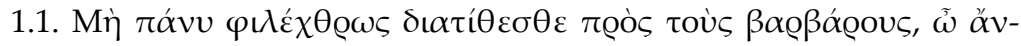

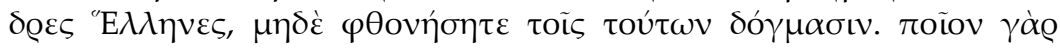

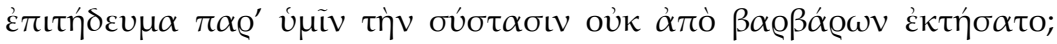

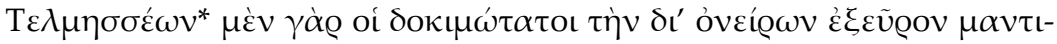

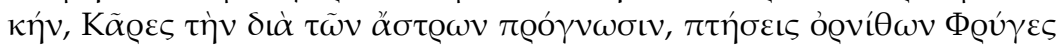

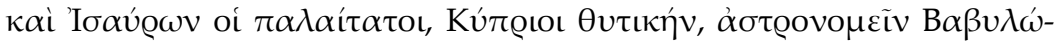

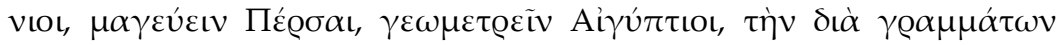

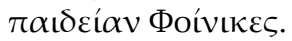

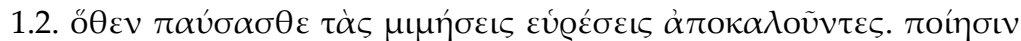

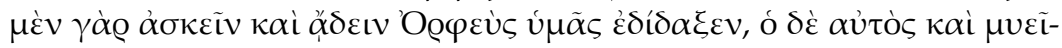

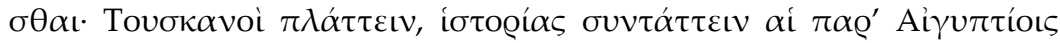

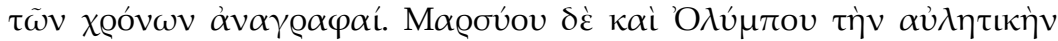

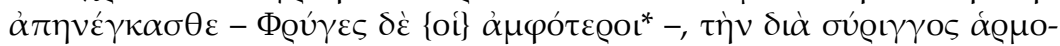

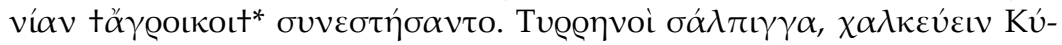

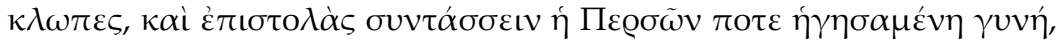

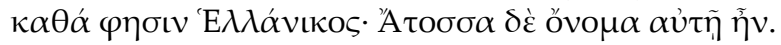

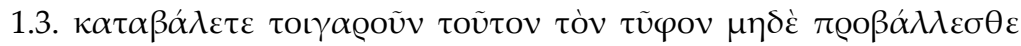

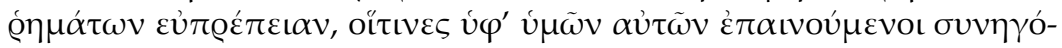

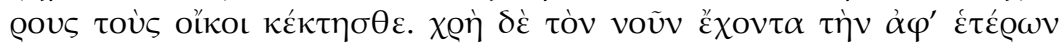

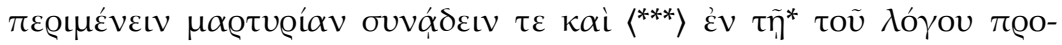
$\varphi \circ \varrho \tilde{\alpha}$.

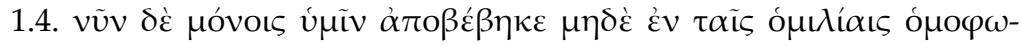

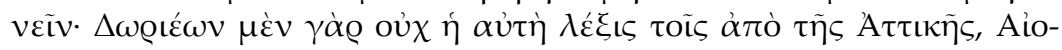

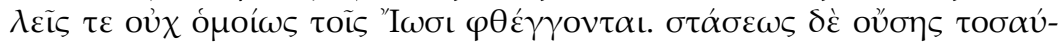

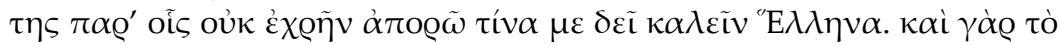

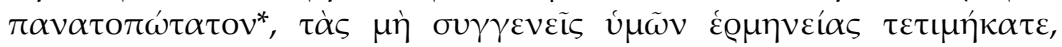

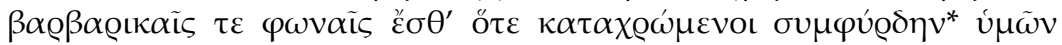

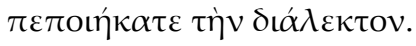

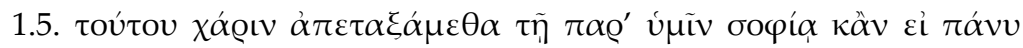

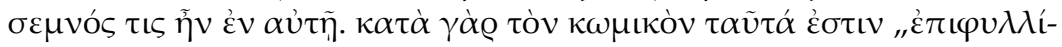

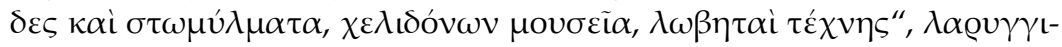

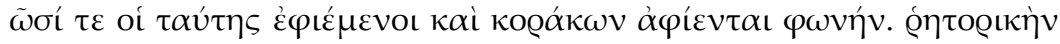

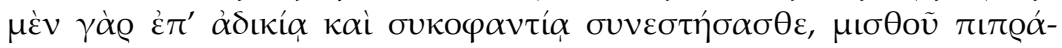




\section{Tatian, An die Griechen}

1.1. Seid nicht so absolut feindlich eingestellt gegenüber den Barbaren, ihr Griechen, und neidet ihnen nicht ihre Überzeugungen! Welches Tätigkeitsfeld bei euch hat nämlich nicht seinen Bestand von Barbaren gewonnen? ${ }^{1}$ Die bedeutendsten der Telmessier ${ }^{2}$ ja haben die durch Träume arbeitende Mantik herausgefunden, die Karer ${ }^{3}$ das Weissagen mit Hilfe der Sterne, die Flugbewegungen von Vögeln die Phryger ${ }^{4}$ und die ältesten von den Isaurern, ${ }^{5}$ die Bewohner von Zypern die Eingeweideschau nach dem Opfer, ${ }^{6}$ die Sternkunde die Babylonier, die Magie die Perser, die Geometrie die Ägypter, die Erziehung durch Schrift die Phönizier.

1.2. Deshalb hört auf damit, eure Nachahmungen als Erfindungen zu bezeichnen! Die Poesie nämlich zu betreiben und die Sangeskunst lehrte euch Orpheus, ${ }^{7}$ der gleiche auch, sich (in Mysterien) einweihen zu lassen; die Tuskaner ${ }^{8}$ die Plastik, Geschichtswerke zu verfassen die bei den Ägyptern gepflegten chronologischen Aufzeichnungen. Von Marsyas und Olympos habt ihr das Aulos-Spiel bezogen - Phryger waren beide -; den aus der Syrinx zu holenden Wohlklang entwickelten tLandleutet. ${ }^{9}$ Die Tyrrhener $^{10}$ vermittelten die Trompete, die Erzbearbeitung die Kyklopen, ${ }^{11}$ und das Briefe-Verfassen die Frau, die einmal über die Perser herrschte, wie Hellanikos sagt; Atossa war ihr Name. ${ }^{12}$

1.3. Lasst also diesen Dünkel fallen und schiebt nicht zierliche Worte vor, die ihr euch von euch selbst loben lasst und als Fürsprecher die eigenen Leute besitzt. Wer jedoch Verstand hat, muss das Zeugnis von anderen abwarten, und er muss übereinstimmen $<* * * 13$ auch im Vortrag der Argumentation.

1.4. Jetzt aber hat es sich so ergeben, dass allein ihr nicht einmal im sprachlichen Umgang (miteinander) harmoniert. Die Dorer haben nämlich nicht die gleiche Sprechweise wie die Leute aus Attika, und die Aioler sprechen nicht in ähnlicher Weise wie Ionier, ${ }^{14}$ da es aber eine solche Differenz bei denen gibt, bei denen das nicht sein sollte, weiß ich nicht, wen ich (überhaupt) "Griechen“ nennen soll. Und was ja das Allerabsurdeste $^{15}$ ist: Redeweisen, die euch nicht naheliegen, haltet ihr in Ehren, und manchmal wendet ihr barbarische Wörter missbräuchlich an und macht eure Sprache zu einem Mischmasch.

1.5. Aus diesem Grund habe ich eurer "Weisheit" eine Absage erteilt, auch wenn ich in ihr eine recht respektable Figur machte. ${ }^{16}$ Wie nämlich der Komödiendichter sagt, sind das „Nachlesetrauben und Geschwätz und Schwalbenzwitscherschulen und Verderber der Kunst" ${ }_{17}{ }_{17}$ und es strapazieren ihre Stimmröhre, die nach dieser (Weisheit) trachten, und 


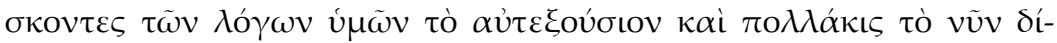

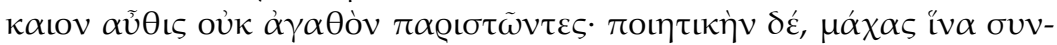

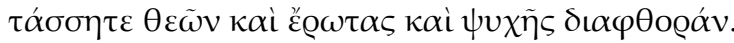

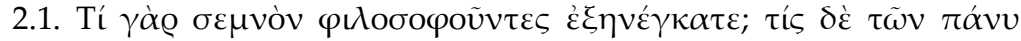

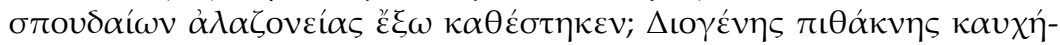

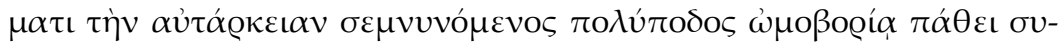

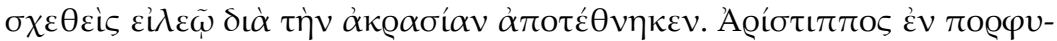

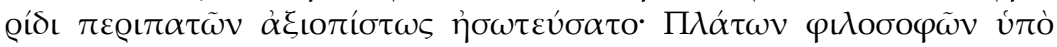

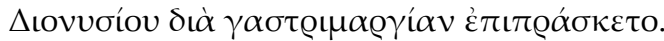

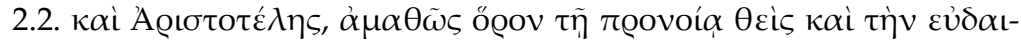

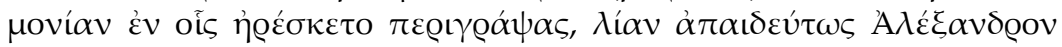

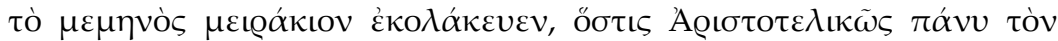

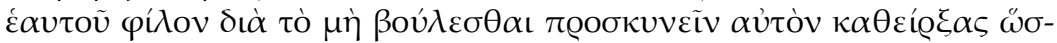

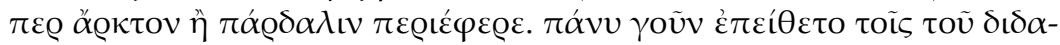

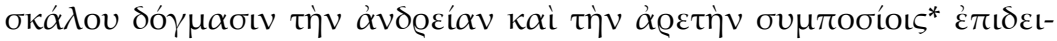

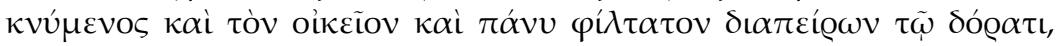

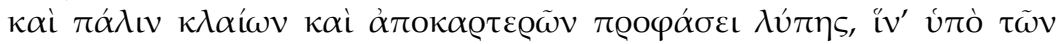

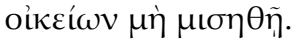

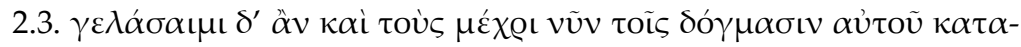

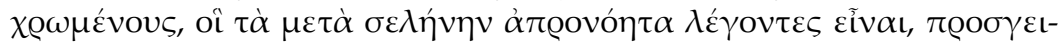

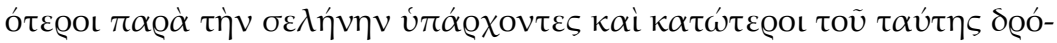

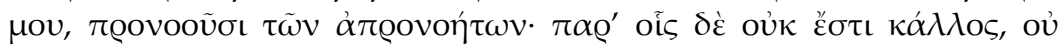

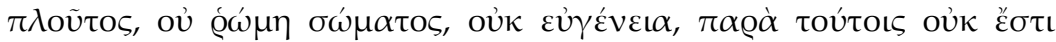

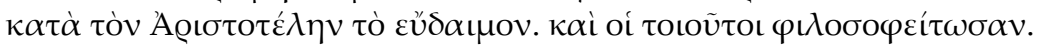

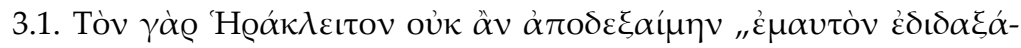

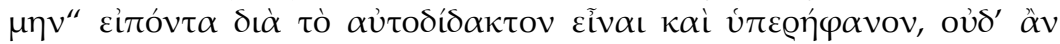

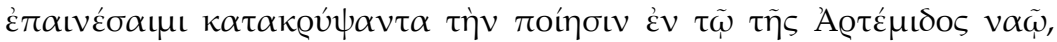

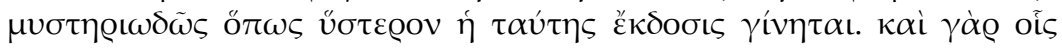

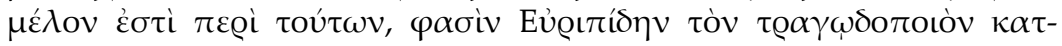


geben nur Rabengekrächze ${ }^{18}$ von sich. Denn die Redekunst habt ihr entwickelt, um Unrecht zu tun und andere anzuschwärzen; gegen Geld verkauft ihr die Freiheit eurer Worte und stellt oft das, was jetzt gerecht ist, ein anderes Mal als nicht gut hin; ${ }^{19}$ die Dichtkunst aber (habt ihr entwickelt), um Kämpfe und Liebschaften von Göttern und Verderbnis der Seele darzustellen. ${ }^{20}$

2.1. Was nämlich habt ihr Großartiges in der Philosophie hervorgebracht? Wer von den ach so ernsten Herren hat Prahlerei vermieden? Diogenes erhob großmächtig Anspruch auf Genügsamkeit, indem er sich mit seinem Fass brüstete, und aufgrund des rohen Verzehrs eines Tintenfischs von einem Leiden befallen, einer Darmverschlingung, starb er wegen seiner Unmäßigkeit. ${ }^{21}$ Aristipp stolzierte im Purpurgewand umher und schwelgte auf glaubwürdige Weise; Platon philosophierte und wurde von Dionysios wegen seiner Gefräßigkeit verkauft. ${ }^{22}$

2.2. Und Aristoteles, ${ }^{23}$ der dumm der Vorsehung eine Grenze setzte ${ }^{24}$ und die Glückseligkeit mit den Dingen umschrieb, an denen er Gefallen hatte, ${ }^{25}$ schmeichelte in außerordentlich törichter Weise Alexander, dem verrückten Jüngelein, ${ }^{26}$ der gar sehr aristotelisch seinen eigenen Freund, weil der ihm nicht die Proskynese erweisen wollte, wie einen Bären oder einen Panther einsperrte und mit sich führte. ${ }^{27}$ Gar sehr also folgte er ${ }^{28}$ den Lehrsätzen seines Lehrers, da er seine Tapferkeit und Vortrefflichkeit durch Gelage zur Schau stellte, ${ }^{29}$ den vertrauten und herzallerliebsten Gefährten mit dem Speer durchbohrte ${ }^{30}$ und dann wieder weinte und sich durch Hunger umzubringen versuchte, ${ }^{31}$ um Trauer vorzuspielen, damit er nicht von seinen Leuten gehasst werde.

2.3. Lachen möchte ich auch über die, die sich bis jetzt seinen Lehrsätzen verschreiben: Während sie behaupten, dass die Dinge unterhalb des Mondes der Vorsehung nicht unterliegen ${ }^{32}$ - wobei sie (selber) im Vergleich zum Mond näher an der Erde sind und unterhalb seines Laufes -, kümmern sie sich um die Zukunft von Dingen, für die man keine Zukunftsmaßnahmen treffen kann. ${ }^{33}$ Bei den Menschen aber, die nicht über Schönheit, Reichtum oder einen kräftigen Körper verfügen, bei denen gibt es laut Aristoteles keine Glückseligkeit. ${ }^{34}$ Solche Leute sollen Philosophie betreiben!

3.1. Was nämlich Heraklit betrifft, der behauptet: „Ich war mein eigener Lehrer!“35 - den kann ich nicht billigen, weil er "selbstgelehrt“ und arrogant ist, und ich kann auch nicht loben, dass er sein Werk im Artemis-Tempel versteckt hat, ${ }^{36}$ damit später deren Veröffentlichung Mysteriengeruch an sich hat. Diejenigen nämlich, denen diese Dinge am Her- 


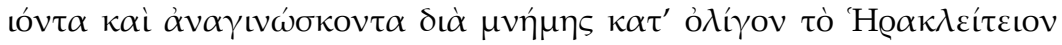

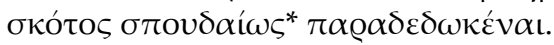

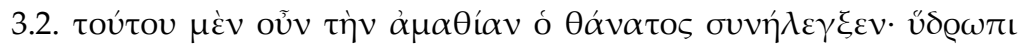

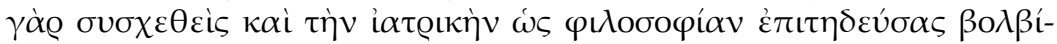

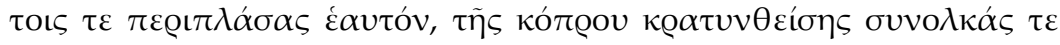

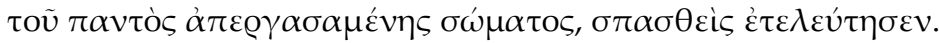

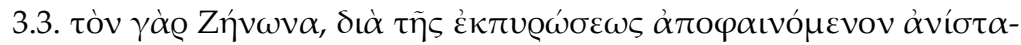

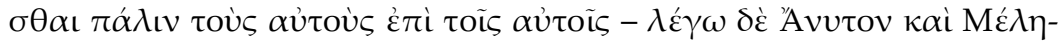

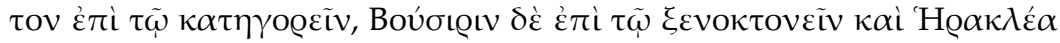

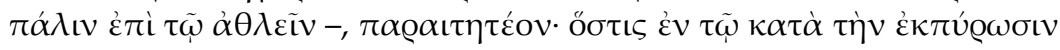

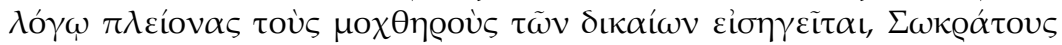

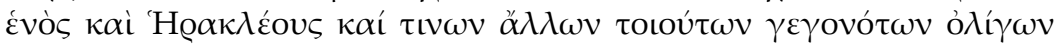

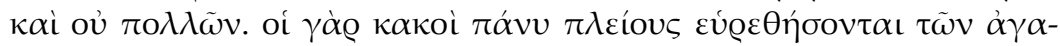

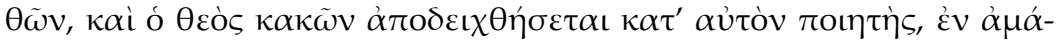

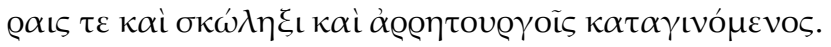

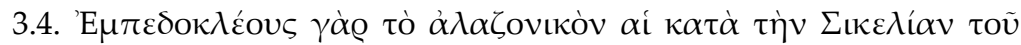

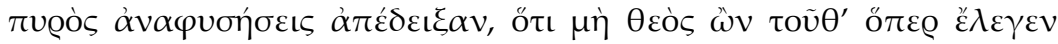

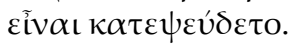

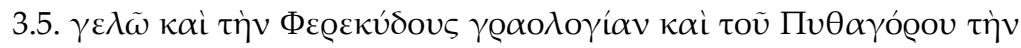

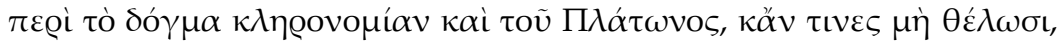

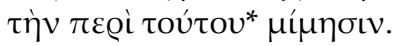

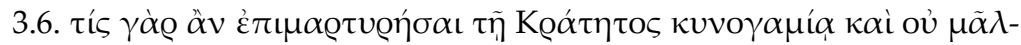

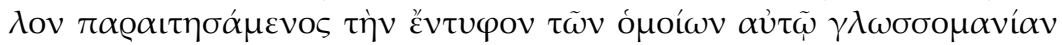

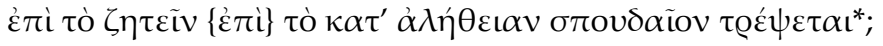

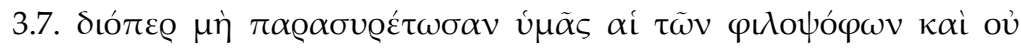

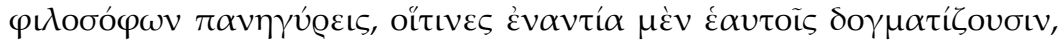

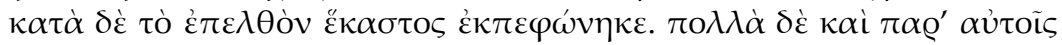

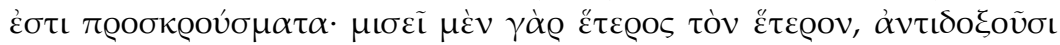

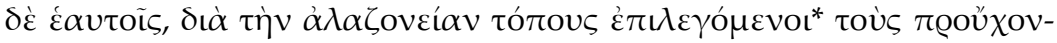

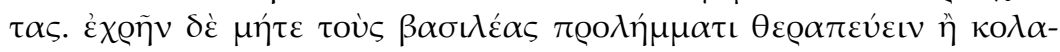

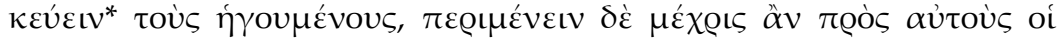

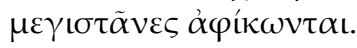


zen liegen, sagen, der Tragödiendichter Euripides sei hingegangen, habe das Buch gelesen und aus dem Gedächtnis peu à peu das heraklitische Dunkel allen Ernstes ${ }^{37}$ weiterverbreitet. ${ }^{38}$

3.2. Dessen Dummheit nun hat der Tod mit entlarvt: Da er nämlich von der Wassersucht befallen wurde ${ }^{39}$ und die Heilkunst wie die Philosophie betrieb ${ }^{40}$ und sich ringsum mit Kuhfladen zupflasterte, ${ }^{41}$ starb er unter Krämpfen, als der Kot sich verhärtete und Zusammenziehungen des ganzen Körpers bewirkte.

3.3. Was nämlich den Zenon angeht, der darlegt, dass aufgrund der Ekpyrosis die gleichen Leute zu den gleichen Tätigkeiten wieder auferstehen würden, ${ }^{42}$ d.h. Anytos und Meletos zum Anklagen, Busiris, um Fremde umzubringen, und Herakles, um seine Taten zu vollbringen ${ }^{43}$ das ist abzulehnen. Zenon führt in seiner Darlegung der Ekpyrosis viel mehr Übeltäter als gerechte Menschen ein, da der eine Sokrates und Herakles und noch ein paar andere von dieser Art nur wenige und nicht viele sind. Die Schlechten werden sich gegenüber den Guten als gewaltig in der Überzahl herausstellen, und Gott wird nach Zenon als ein Schöpfer des Schlechten befunden werden, da er in Kloaken und Würmern und Unholden ${ }^{44}$ seine Wohnstatt nimmt. ${ }^{45}$

3.4. Das Prahlwesen des Empedokles nämlich haben die Feuerausbrüche auf Sizilien erwiesen, da er, ohne ein Gott zu sein, dies, was er zu sein behauptete, nur erlog. ${ }^{46}$

3.5. Ich lache auch über die Ammenmärchen des Pherekydes, ${ }^{47}$ über sein Erbe, das Pythagoras mit seiner Lehre angetreten hat, ${ }^{48}$ und über Platons Nachahmung in dieser, ${ }^{49}$ auch wenn einige diese bestreiten. ${ }^{50}$

3.6. Wer möchte sich nämlich für die "Hundehochzeit" des Krates ${ }^{51}$ als Zeuge zur Verfügung stellen und wird nicht lieber den eingebildeten Zungenwahnsinn ${ }^{52}$ von seinesgleichen abweisen und sich der Suche nach dem wirklich echten Wahren zuwenden ${ }^{53}$

3.7. Deshalb sollen euch die Festversammlungen der Lärm- und nicht Weisheitsliebhaber ${ }^{54}$ nicht vom Weg abbringen; sie verbreiten inhärente Widersprüche, ${ }^{55}$ und ein jeder gibt zum Besten, was ihm gerade in den Sinn kommt. Viele Konflikte auch gibt es bei ihnen: Der eine nämlich hasst den anderen, ${ }^{56}$ und sie verkünden widersprechende Lehren, während sie sich Plätze auswählen, ${ }^{57}$ die besonders herausragen. Sie sollten ferner nicht in vorauseilendem Gehorsam den Königen aufwarten ${ }^{58}$ oder den führenden Persönlichkeiten schmeicheln, sondern warten, bis die Großkopfeten ${ }^{59} \mathrm{zu}$ ihnen kommen. 


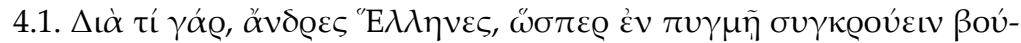

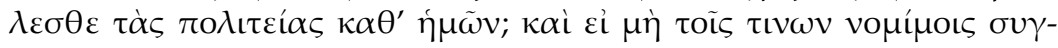

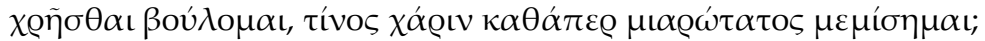

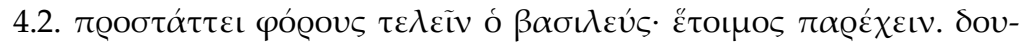

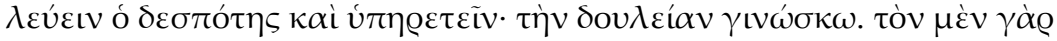

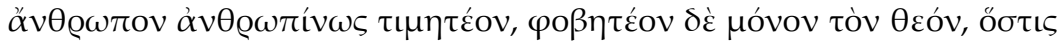

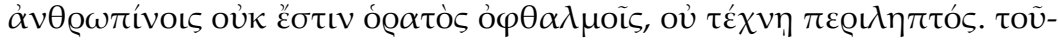

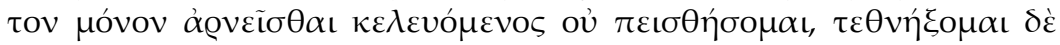

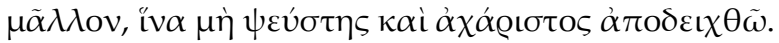

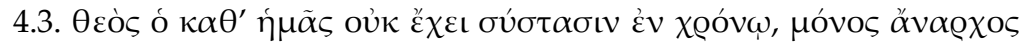

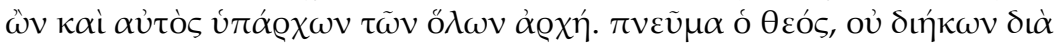

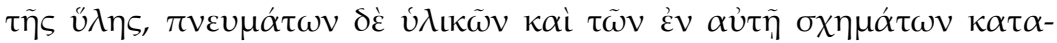

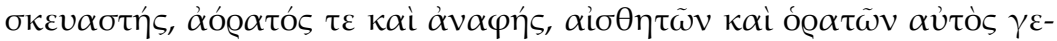

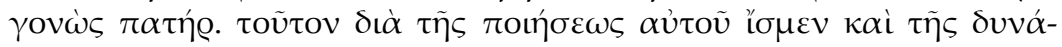

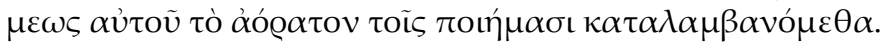

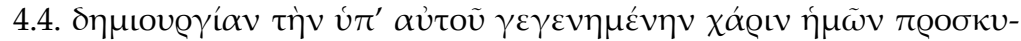

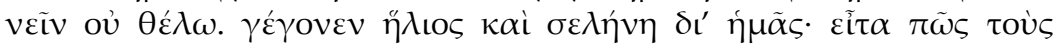

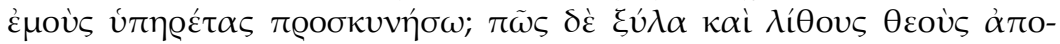

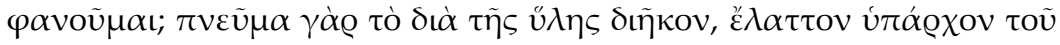

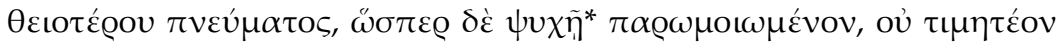

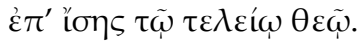

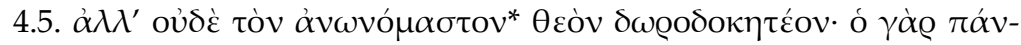

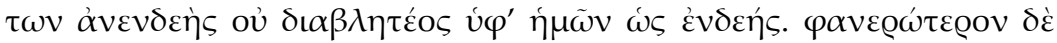

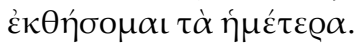

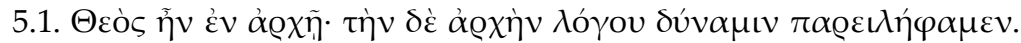

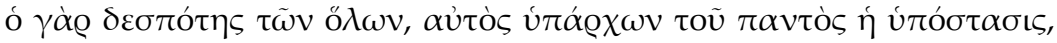

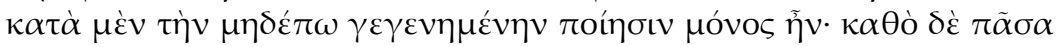

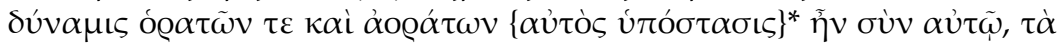

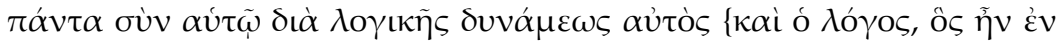
$\alpha \dot{v} \tau \tilde{\omega},\}^{*} \dot{v} \pi \varepsilon \dot{\varepsilon} \sigma \tau \eta \sigma \varepsilon v$.

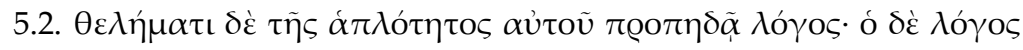

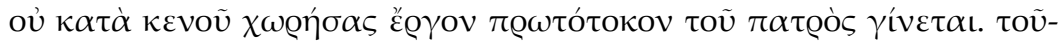

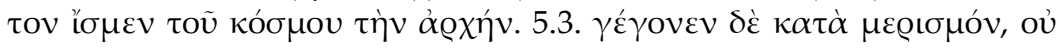


4.1. Weshalb denn, ihr Griechen, wollt ihr wie bei einem Faustkampf die staatlichen Institutionen ${ }^{60}$ gegen uns aufhetzen? Und wenn ich die Bräuche gewisser Leute nicht mitmachen will, weshalb werde ich dann wie das verworfenste Subjekt gehasst?

4.2. Steuern zu zahlen befiehlt der Kaiser - ich bin bereit, das zu tun. Untertan zu sein und zu dienen befiehlt der Herr - ich erkenne den Untertanenstatus an. ${ }^{61}$ Denn den Menschen muss man auf menschliche Weise ehren; fürchten aber muss man allein den Gott, ${ }^{62}$ der menschlichen Augen nicht sichtbar und durch (menschliche) Kunst nicht erfassbar ist. ${ }^{63}$ Bei ihm allein werde ich nicht gehorchen, wenn man mir befiehlt, ihn zu verleugnen, sondern ich werde eher sterben, um nicht als Lügner und Undankbarer erwiesen zu werden.

4.3. Gott, wie wir ihn verstehen, hat keinen Bestand innerhalb der Zeit; er allein ist ohne Anfang und zugleich der Anfang von Allem. Ein Geist ist Gott, ${ }^{64}$ aber nicht einer, der durch die Materie dringt, ${ }^{65}$ sondern der Schöpfer der materiellen Geister und der in der Materie zu findenden Formen; er ist unsichtbar und unberührbar, ${ }^{66}$ da er selbst der Vater der wahrnehmbaren und sichtbaren Dinge ist. Ihn erkennen wir durch seine Schöpfung, und das Unsichtbare seiner Macht erfassen wir in seinen Werken. ${ }^{67}$

4.4. Die Schöpfung, die von ihm um unseretwillen Existenz bekommen hat, will ich nicht anbeten. Entstanden sind Sonne und Mond wegen uns; wieso soll ich dann diese meine Diener anbeten? ${ }^{68}$ Wieso soll ich Hölzer und Steine zu Göttern erklären ${ }^{69}$ Der Geist nämlich, der die Materie durchdringt, ist geringer als der göttlichere Geist, und wie er der (stofflichen) Seele angeglichen ist, ${ }^{70}$ darf er nicht auf der gleichen Stufe wie der vollkommene Gott verehrt werden.

4.5. Aber ebensowenig darf man den unnennbaren Gott ${ }^{71}$ bestechen; derjenige nämlich, der aller Dinge unbedürftig ist, ${ }^{72}$ darf von uns nicht verleumdet werden, als wäre er bedürftig. Noch deutlicher aber werde ich unsere Lehren darlegen:

5.1. Gott war im Anfang, ${ }^{73}$ den Anfang aber haben wir als des Logos $\mathrm{Kraft}^{74}$ überliefert erhalten. Denn der Herr aller Dinge, der selbst die Grundlage des Alls darstellt, war zur Zeit, als es die Schöpfung noch nicht gab, allein; insoweit aber das ganze Potenzial der sichtbaren und unsichtbaren Dinge bei ihm war, ${ }^{75}$ verlieh er selbst diesem allen, was bei ihm war ${ }^{76}$, durch die Kraft des Logos ${ }^{77}$ Existenz.

5.2. Durch den Willen seines einfach-ungeteilten Wesens springt (nun) der Logos hervor; ${ }^{78}$ der Logos aber geht nicht ins Leere und wird das erstgeborene Werk ${ }^{79}$ des Vaters; ihn kennen wir als den Anfang der 


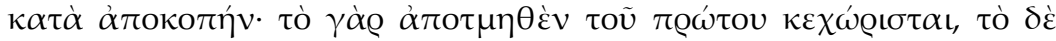

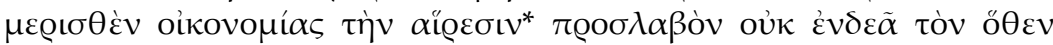

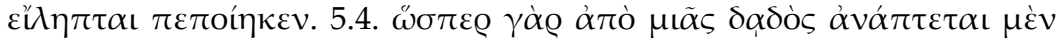

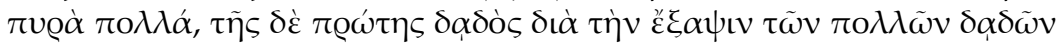

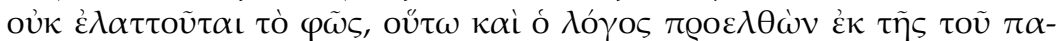

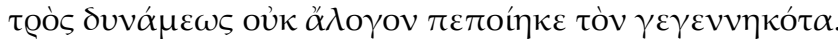

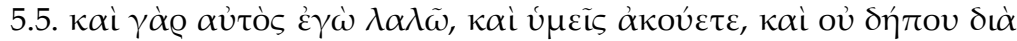

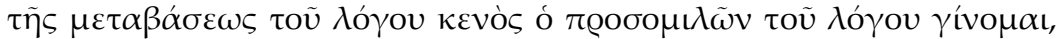

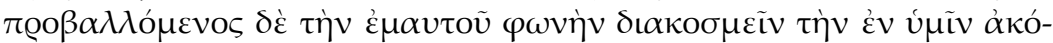

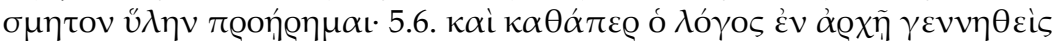

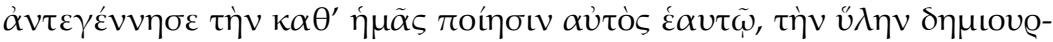

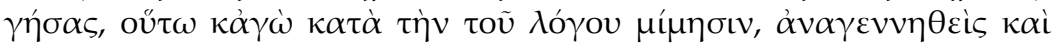

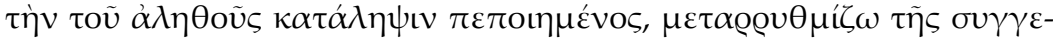
voũ $\varsigma \tilde{u} \lambda \eta \varsigma \tau \eta \dot{v} \sigma u ́ \gamma \chi v \sigma \iota v$.

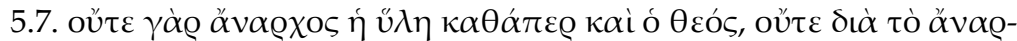

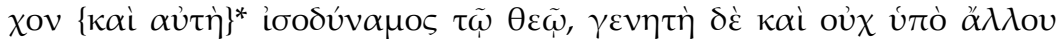

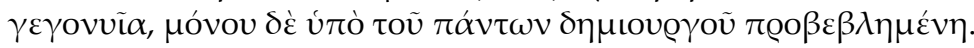

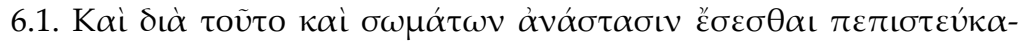

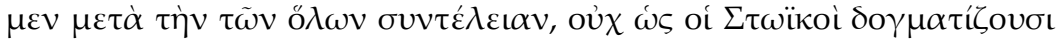

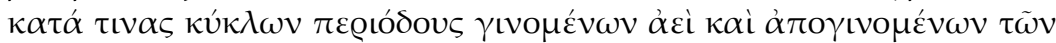

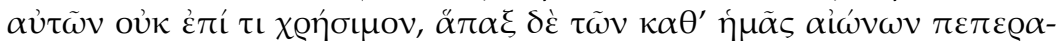

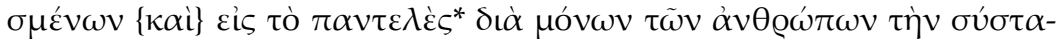

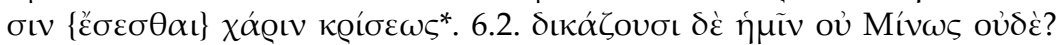

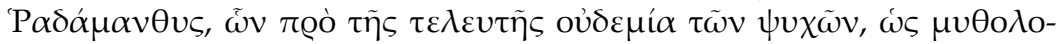

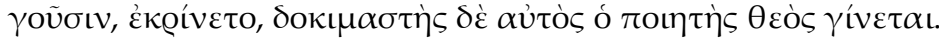

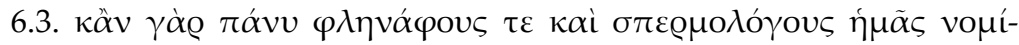

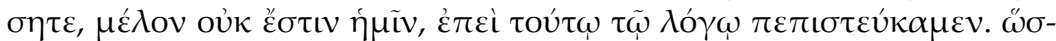

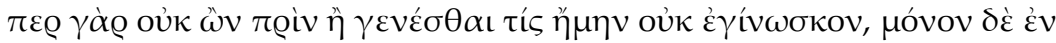

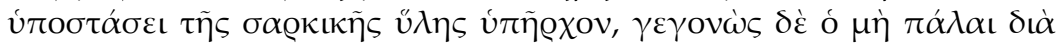

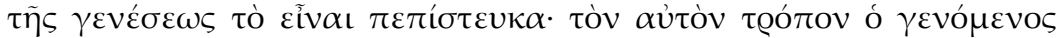

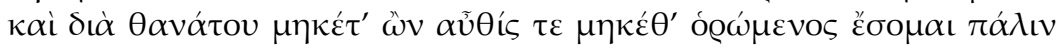

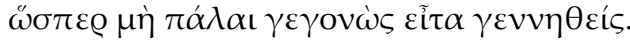


Welt. 5.3. Er ist aber durch Teilung, nicht durch Abtrennung entstanden; denn das Abgetrennte ist vom Ersten geschieden, das Geteilte aber erfährt (nur) eine „hauswirtschaftliche“ Funktionsteilung und verursacht bei dem, von dem es genommen ist, keinen Mangel. 5.4. Wie sich nämlich von einer einzigen Fackel viele Feuer entzünden lassen, ${ }^{80}$ bei der ersten Fackel aber wegen des Anzündens der vielen (weiteren) Fackeln das Licht nicht vermindert wird, so hat auch der Logos, da er aus der Macht des Vaters hervorging, nicht „logos-los“ den gemacht, der ihn hervorgebracht hat.

5.5. Denn auch ich spreche (jetzt), und ihr hört zu, und durch den Übergang meines Vortrags stellt sich doch wohl kein Mangel an Vortrag bei mir, der ich zu euch spreche, ein, sondern indem ich meine Stimme aussende, habe ich das Bestreben, die ungeordnete Materie in euch zu ordnen; 5.6. und wie der Logos, nachdem er im Anfang hervorgebracht worden war, selbst wiederum unsere Schöpfung durch sich selbst hervorbrachte, indem er die Materie formte, so gestalte auch ich, da ich wieder geboren wurde ${ }^{81}$ und da ich die Wahrnehmung des Wahren erlangt habe, in der Nachahmung des Logos die Verwirrung der (mir) verwandten Materie zum Besseren um.

5.7. Denn weder ohne Anfang ${ }^{82}$ ist die Materie wie Gott, noch hat sie, weil sie ohne Anfang wäre, gleiche Macht ${ }^{83}$ wie Gott; sondern sie ist geworden, und zwar nicht durch das Wirken eines anderen, sondern sie ist allein durch den Schöpfer von Allem hervorgebracht. ${ }^{84}$

6.1. Und deswegen glauben wir auch, dass es die Auferstehung der Leiber geben wird nach der Vollendung aller Dinge; wobei nicht, wie die Stoiker lehren, in gewissen periodischen Umläufen stets die gleichen Dinge entstehen und vergehen zu keinem Nutzen, ${ }^{85}$ sondern nachdem ein einziges Mal die uns betreffenden Zeitläufte ${ }^{86}$ vollständig vollendet sind, wegen der Zusammenbringung allein der Menschen um des Gerichts willen. ${ }^{87}$ 6.2. Es richten aber über uns nicht Minos oder Rhadamanthys, ${ }^{88}$ vor deren Ableben keine von den Seelen, wie man im Mythos erzählt, vor Gericht gestellt wurde, ${ }^{89}$ sondern zum Richter wird der Schöpfer selbst, Gott.

6.3. Denn auch wenn ihr uns für völlige Schwätzer und Windbeutel ${ }^{90}$ haltet, kümmert uns das nicht, denn wir schenken dieser Lehre Glauben. Wie ich nämlich nicht war, bevor ich wurde, und daher (auch) nicht erkannte, wer ich war, sondern nur im Bestand der fleischlichen Materie vorhanden war, nachdem ich aber - der ich nicht von altersher bin geworden bin, erst durch mein Werden den Glauben an meine Existenz habe, auf die gleiche Weise werde ich, nachdem ich geworden und 


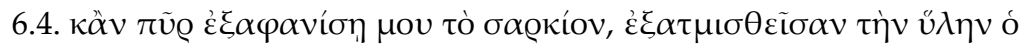

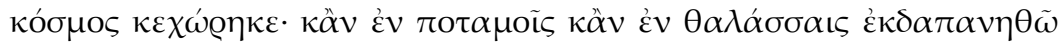

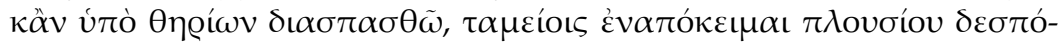

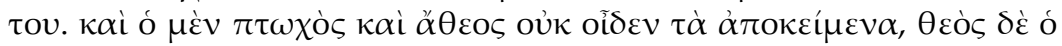

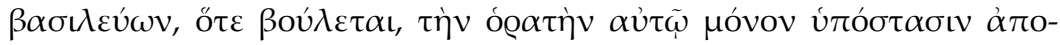

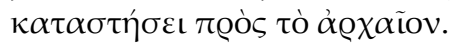

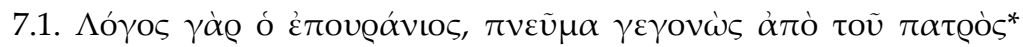

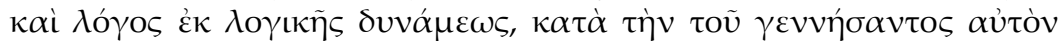

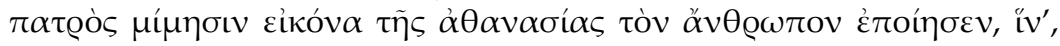

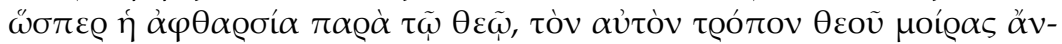

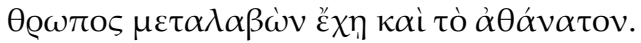

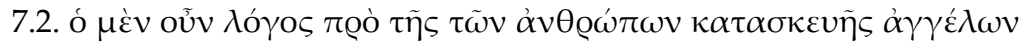

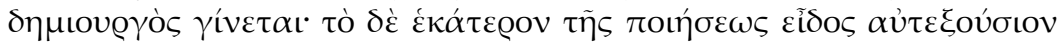

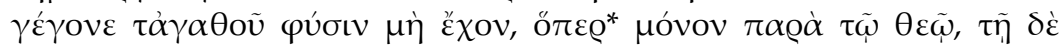

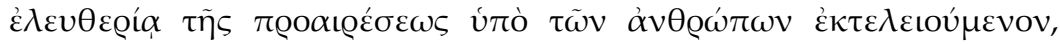

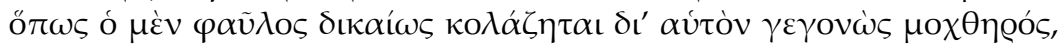

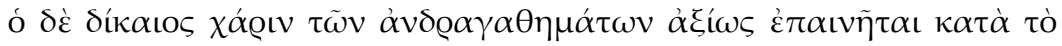

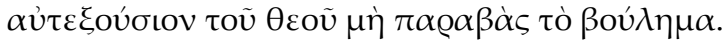

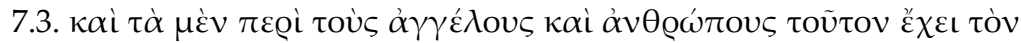

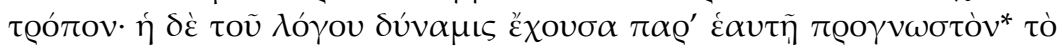

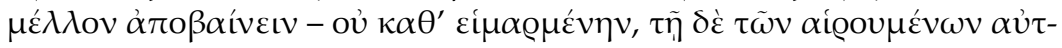

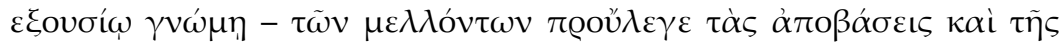

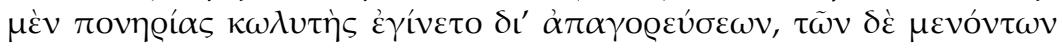

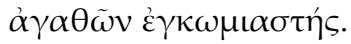

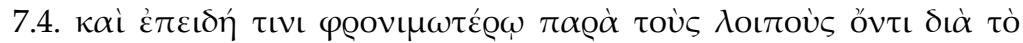

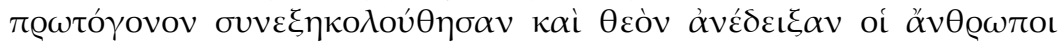

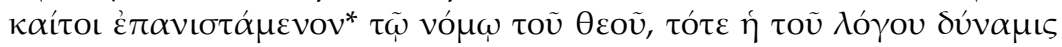

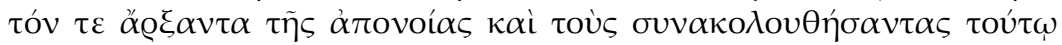

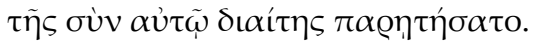

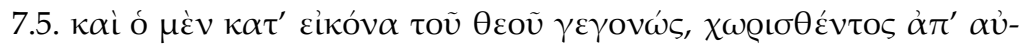

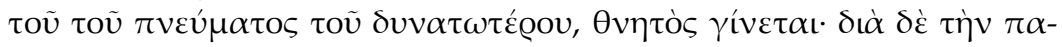

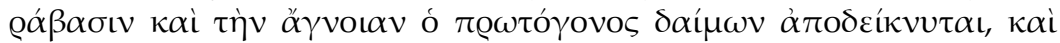

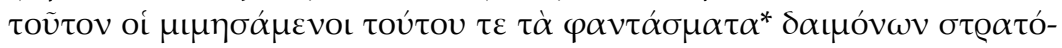


durch den Tod nicht mehr bin und man mich dann auch erneut nicht mehr sieht, wiederum sein, wie ich, nicht von altersher entstanden, dann erst hervorgebracht wurde.

6.4. Auch wenn Feuer mein bisschen Fleisch vernichtet, nimmt der Kosmos die in Rauch verwandelte Materie auf; auch wenn ich in Flüssen oder in Meeren dahingerafft oder von Tieren zerrissen werde, bin ich in den Vorratskammern eines reichen Herren aufbewahrt. Und der Bettler und Gottlose weiß nicht, was aufbewahrt ist; Gott der König aber wird, wann er will, den ihm allein sichtbaren Bestand in den alten Zustand zurückversetzen.

7.1. Der himmlische Logos nämlich, der Geist vom Vater her ${ }^{991}$ geworden ist und Logos aus der Kraft des Logos, machte in Nachahmung des Vaters, der ihn hervorgebracht hatte, zum Abbild der Unsterblichkeit den Menschen, damit, wie die Unvergänglichkeit bei Gott ist, auf die gleiche Weise der Mensch am göttlichen Wesen Anteil erhalte und so auch die Unsterblichkeit habe. ${ }^{92}$

7.2. Der Logos nun wird noch vor der Erschaffung der Menschen zum Schöpfer der Engel; jede von beiden Gattungen der Schöpfung ist in ihrem Wesen frei, ohne die Natur des Guten zu haben, welche ja allein bei Gott ist; ${ }^{93}$ durch die Freiheit der Entscheidung aber wird es von den Menschen erfüllt, damit der Schlechte zu Recht bestraft wird, da er aus sich selbst heraus schlecht geworden ist, der Gerechte aber um seiner wackeren Taten willen in angemessener Weise gelobt wird, da er in freier Entscheidung den Willen Gottes nicht übertreten hat.

7.3. Und die Dinge hinsichtlich Engeln und Menschen verhalten sich auf diese Weise; die Macht des Logos aber, da sie bei sich die Zukunft voraussehen konnte ${ }^{94}$ - nicht in Hinsicht auf ein (unabänderliches) Schicksal, sondern aufgrund des freien Willens der eine Entscheidung treffenden Menschen -, sagte voraus, was sich in Zukunft ergeben werde, und wurde durch Verbote zum Verhinderer von Schlechtigkeit, zum Lobredner aber derjenigen, die gut blieben.

7.4. Und als die Menschen einem folgten, der die übrigen an Verstand überragte ${ }^{95}$ aufgrund seines Erstgeborenenstatus, und ihn zum Gott erklärten, obwohl ${ }^{96}$ er sich gegen das Gesetz Gottes auflehnte, da verbannte die Macht des Logos den, der diesen Wahnsinn begonnen hatte, und seine Gefolgsleute aus seiner Gegenwart.

7.5. Und der, der nach dem Abbild Gottes entstanden war, ${ }^{97}$ wurde, nachdem sich von ihm der mächtigere Geist getrennt hatte, ${ }^{98}$ sterblich; wegen seiner Übertretung und Torheit aber wurde der Erstgeborene zum Dämon, und diejenigen, die ihn und seine Wahnvorstellungen 


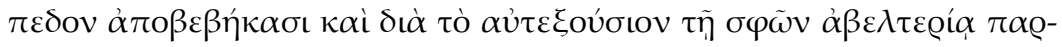
$\varepsilon \delta o ́ \theta \eta \sigma \alpha v$.

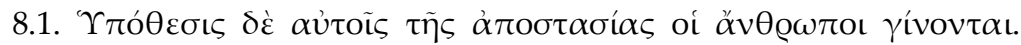

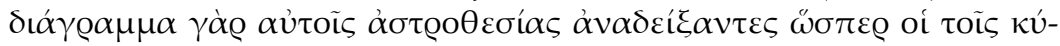

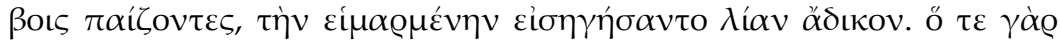

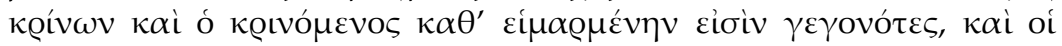

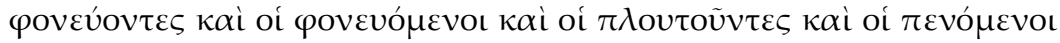

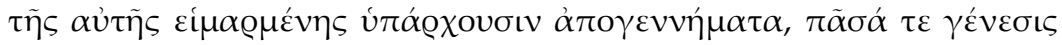

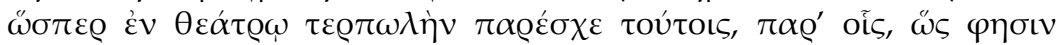

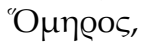

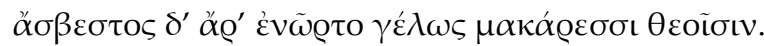

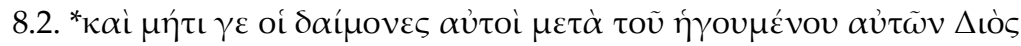

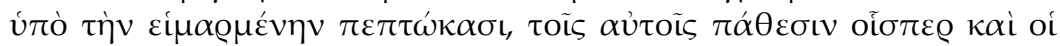

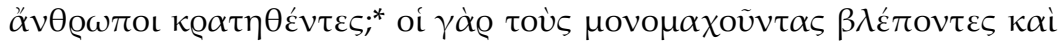

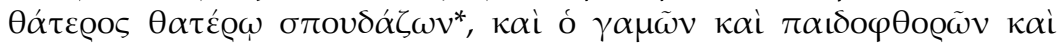

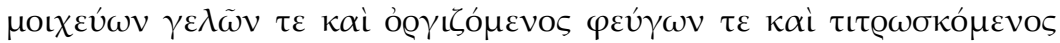

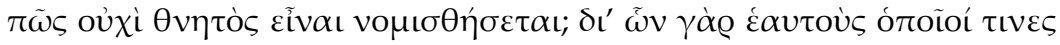

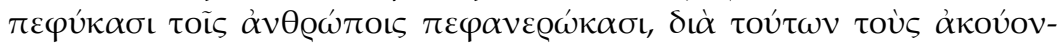

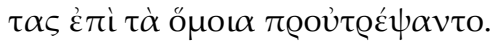

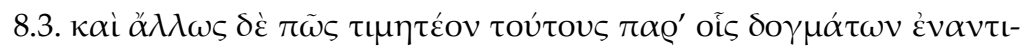

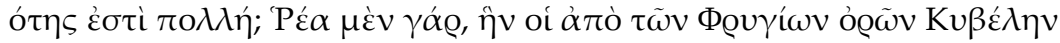

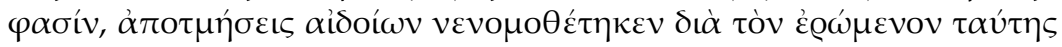

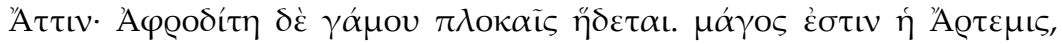
$\theta \varepsilon \varrho \alpha \pi \varepsilon v ́ \varepsilon ı$ ó Āó $\lambda \lambda \omega v$.

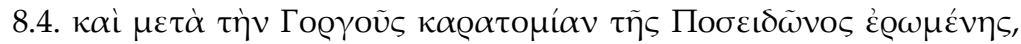

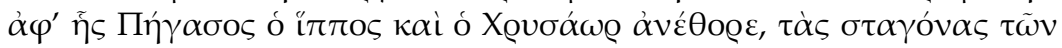

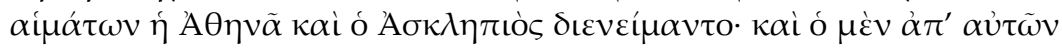

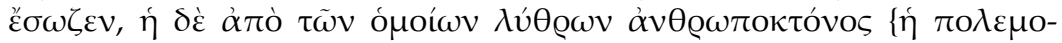

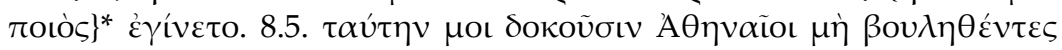

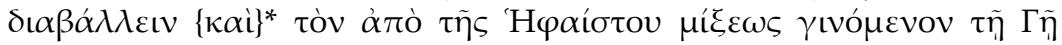

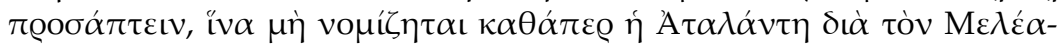

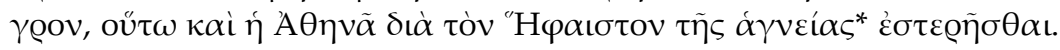

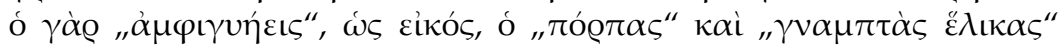

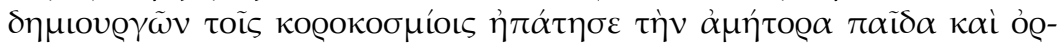

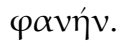


nachahmten, ${ }^{99}$ wurden $\mathrm{zu}$ einem Heerlager von Dämonen ${ }^{100}$ und aufgrund ihrer freien Wahl ihrer eigenen Dummheit überantwortet.

8.1. Gegenstand ihres Abfalls aber wurden die Menschen. Da sie ihnen nämlich einen Plan mit der Stellung der Sterne zeigten - wie die, die mit Würfeln spielen ${ }^{101}$-, führten sie die Heimarmene ${ }^{102}$ ein, eine außerordentlich ungerechte Macht. Denn sowohl, wer richtet, als auch, wer gerichtet wird, sind so geworden gemäß der Heimarmene, ${ }^{103}$ und die, die morden, wie auch die, die gemordet werden, die Reichen und die Armen sind Kinder der gleichen Heimarmene, und die ganze Schöpfung bietet wie in einem Theater Unterhaltung diesen Wesen, bei denen, wie Homer sagt, „,unauslöschliches Gelächter sich da bei den seligen Göttern erhob". 104

8.2. Und sind nicht die Dämonen selbst, mitsamt dem sie anführenden Zeus, ${ }^{105}$ unter die Macht der Heimarmene gefallen, da sie von den gleichen Leidenschaften beherrscht werden wie auch die Menschen? ${ }^{106}$ Denn die, die sich einen Zweikampf Ausführende anschauen und der eine für den, der andere für jenen fiebert, ${ }^{107}$ und der, der heiratet, der einen Knaben schändet, der Ehebruch treibt, ${ }^{108}$ der lacht und in Zorn gerät, der flieht und sich verwunden lässt ${ }^{109}$ - wie wird man nicht glauben, dass solche Wesen sterblich ${ }^{110}$ sind? Durch die Dinge nämlich, durch welche sie ihre eigene Natur den Menschen offenbart haben, durch diese Dinge forderten sie die, die ihnen Gehör schenkten, zu gleichem Tun auf.

8.3. Und im Übrigen: Wie soll man diese Wesen ehren, bei denen es einen großen Gegensatz der Dinge gibt, die sie gutheißen? ${ }^{111}$ Was nämlich Rhea betrifft, die die aus den phrygischen Bergen Kybele nennen: Sie hat das Abschneiden von Schamteilen zum Gesetz erhoben wegen ihres Geliebten Attis. ${ }^{112}$ Aphrodite dagegen freut sich an hochzeitlichen Umarmungen. ${ }^{113}$ Eine Zauberin ist Artemis, Heilkunst treibt Apollon. ${ }^{114}$

8.4. Und nach dem bei der Gorgo praktizierten Kopfabschneiden - sie war die Geliebte Poseidons, und aus ihr sprangen das Pferd Pegasos und Chrysaor hervor - teilten sich ihre Blutstropfen Athena und Asklepios auf: ${ }^{115}$ Er pflegte durch sie Leben zu retten, sie wurde mit Hilfe des gleichen Blutes zur Menschentöterin. ${ }^{116}$ 8.5. Weil die Athener diese Göt$\operatorname{tin}^{117}$ nicht verleumden wollten, ${ }^{118}$ haben sie, wie ich glaube, den Sohn, der aus ihrer Verbindung mit Hephaistos entstand, der Erde zugeschrieben, ${ }^{119}$ damit man nicht glaube, dass, wie Atalante durch Meleager ${ }^{120}$ so auch Athena durch Hephaistos ihrer Reinheit ${ }^{121}$ beraubt worden sei. Denn der „mit zwei krummen Füßen“, der Fabrizierer von „Spangen" und "gekrümmten Ohrringen"122 hat natürlich mit seinen Mädchen- 


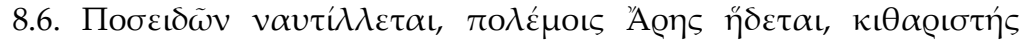

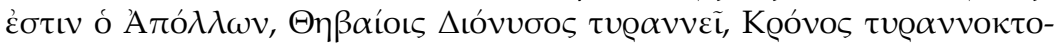

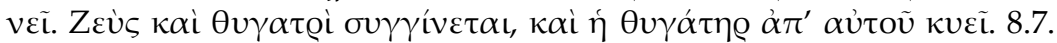

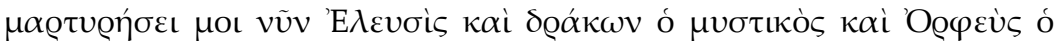

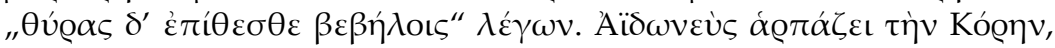

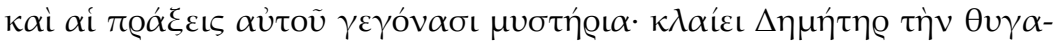

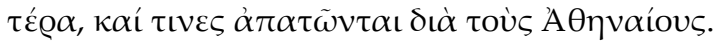

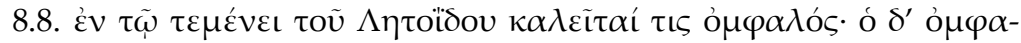

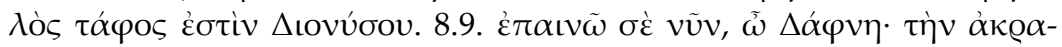

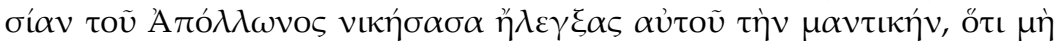

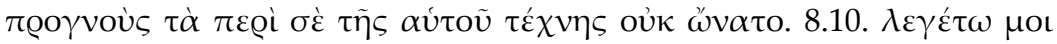

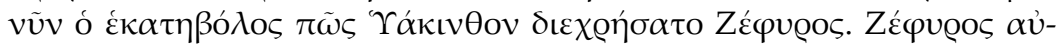

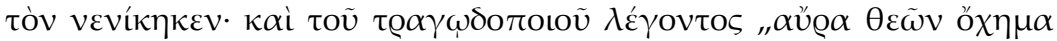

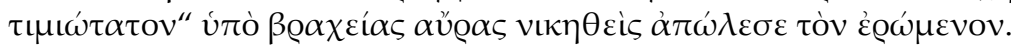

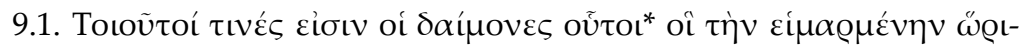

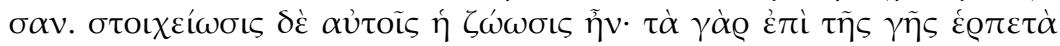

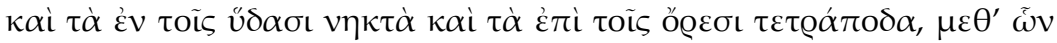

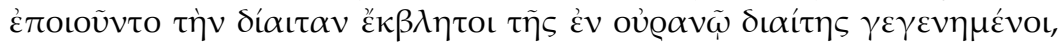

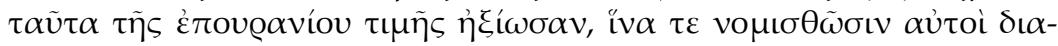

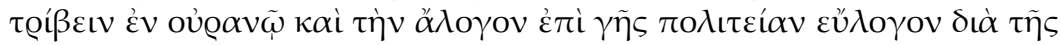

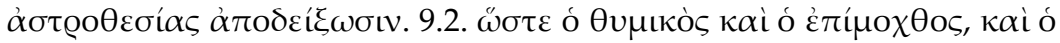

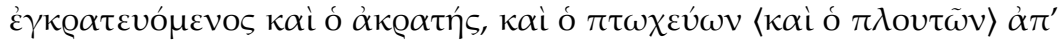

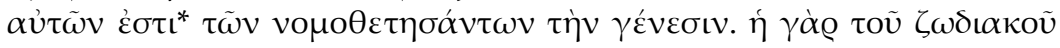

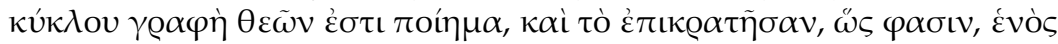

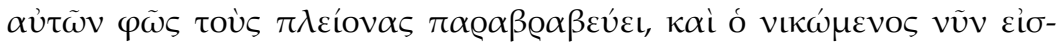

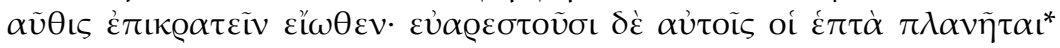
$\omega$

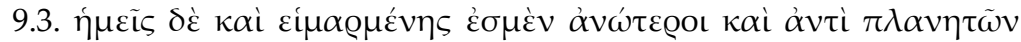

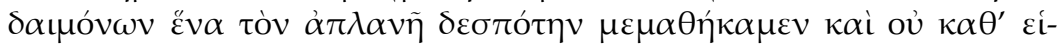

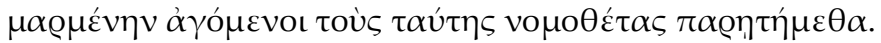


schmucksachen das mutterlose und verwaiste Mädchen ${ }^{123}$ hinters Licht geführt.

8.6. Poseidon fährt zur See, an Kriegen hat Ares seinen Spaß, Kitharaspieler ist Apollon, über die Thebaner ist Dionysos Tyrann,, ${ }^{124}$ Kronos ermordet den Tyrannen. ${ }^{125}$ Zeus schläft sogar mit seiner Tochter, und die Tochter wird von ihm schwanger! ${ }^{126}$ 8.7. Zeugen (dafür) werden mir jetzt Eleusis sein und die mystische Schlange und Orpheus, der sagt: „Macht die Türen vor den Unreinen zu!" ${ }^{227}$ Hades $^{128}$ raubt Kore, ${ }^{129}$ und seine Taten werden zu Mysterien; es weint Demeter um ihre Tochter, und so manche lassen sich durch die Athener hinters Licht führen. ${ }^{130}$

8.8. Im heiligen Bezirk des Leto-Sohns ${ }^{131}$ wird etwas "Nabel“ genannt; dieser Nabel aber ist das Grab des Dionysos. ${ }^{132}$ 8.9. Ich spreche dir jetzt mein Lob aus, Daphne; du hast die Promiskuität Apollons besiegt und dadurch seine Seherkunst entlarvt, da er das, was mit dir geschehen würde, nicht voraussah ${ }^{133}$ und so von seiner eigenen Kunst keinen Nutzen hatte. 8.10. Sagen soll mir jetzt der "Fernhintreffer", 134 wie den Hyakinthos der Zephyr zur Strecke gebracht hat. ${ }^{135}$ Zephyros hat ihn besiegt; und obwohl der Tragödiendichter sagt: „Der Lufthauch ist das höchstgeehrte Fahrzeug der Götter", ${ }^{136}$ wurde er von einem kurzen Lufthauch besiegt und verlor den Geliebten.

9.1. Derartige Wesen sind diese ${ }^{137}$ Dämonen, die die Heimarmene festlegten. Die Elemente dafür ${ }^{138}$ lieferte ihnen die irdische Fauna:139 Denn die auf der Erde kriechenden Tiere und die in den Gewässern schwimmenden und die Vierfüßler auf den Bergen, mit denen zusammen sie ihr Leben verbrachten, nachdem sie vom himmlischen Leben ausgeschlossen worden waren, diese Tiere erachteten sie himmlischer Ehre für würdig, damit man glaube, sie selbst lebten (noch) im Himmel, und um die logos-lose Ordnung auf Erden als vernünftig durch die Sternkonstellation zu erweisen. ${ }^{140}$ 9.2. So haben der leicht Erregbare und der Schwerfällige, der sich beherrscht und der sich nicht beherrschen kann, der Bettler und der Reiche ihren Ursprung gerade von denen, ${ }^{141}$ die ihre "Nativität" gesetzlich festlegten. ${ }^{142}$ Denn die Aufzeichnung des Tierkreises ist ein Werk von Göttern, und das (jeweils) dominierende Licht, wie sie sagen, eines von ihnen übertrumpft die Mehrheit, und der, der jetzt unterliegt, scheint ein andermal wieder dominant zu sein; es haben aber ihr Gefallen an ihnen die sieben Planeten(götter) ${ }^{143}$ wie die, die sich mit den Brettspielen vergnügen. ${ }^{144}$

9.3. Wir aber stehen höher als die Heimarmene, und anstelle der herumirrenden Planeten-Dämonen haben wir den einen Herrn, der nicht 


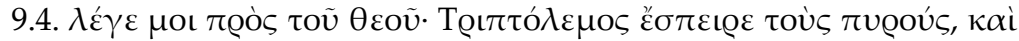

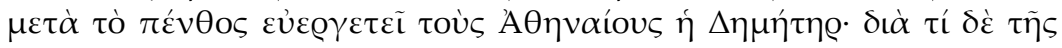

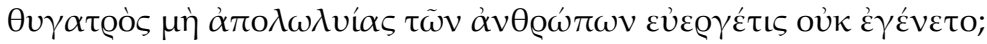

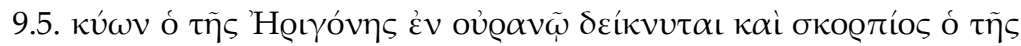

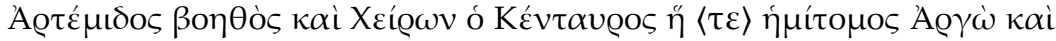

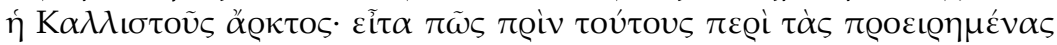

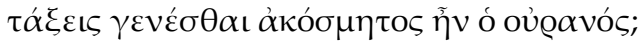

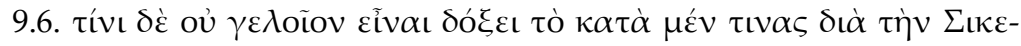

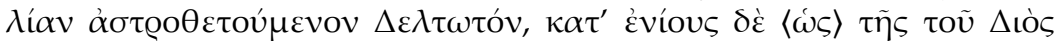

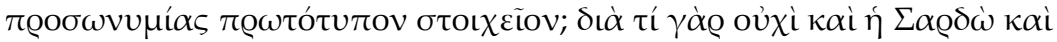

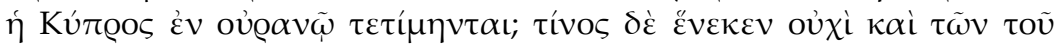

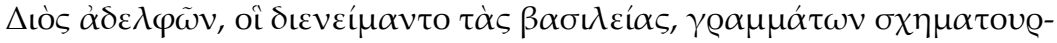

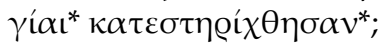

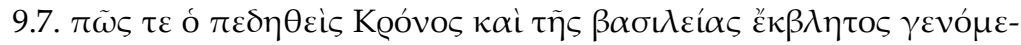

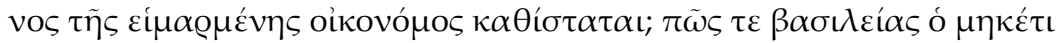

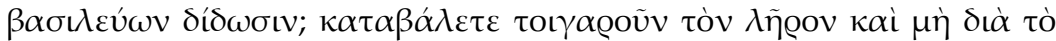

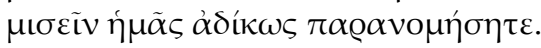

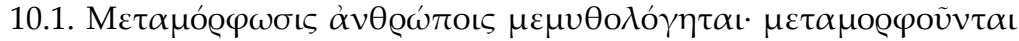

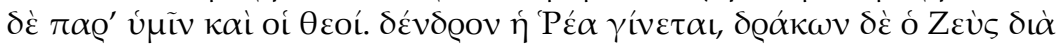

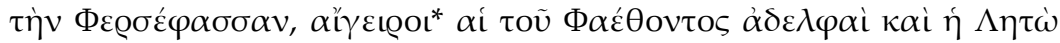

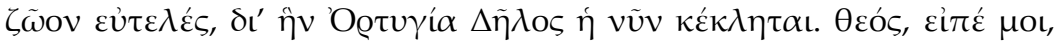

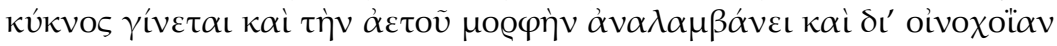

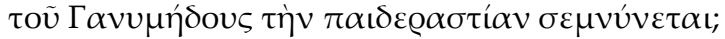

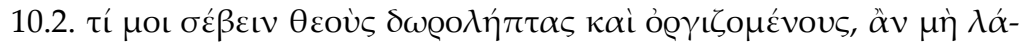

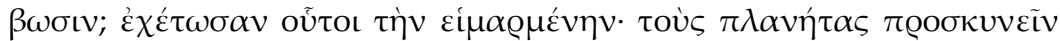
oú $\beta$ oú $\lambda$ он $\alpha$ t.

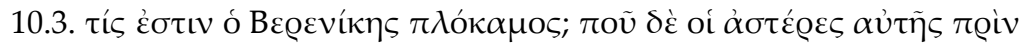

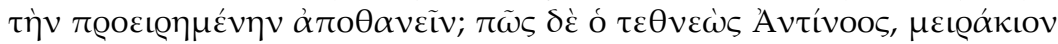

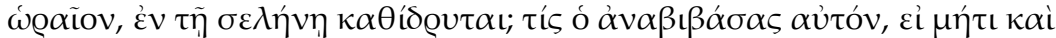

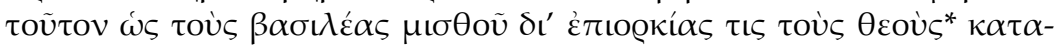

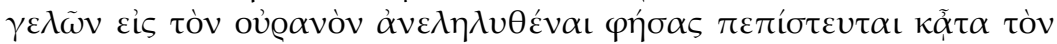
ő 
irrt, kennengelernt; und da wir uns nicht von der Heimarmene dirigieren lassen, haben wir ihren Gesetzgebern abgeschworen.

9.4. Sag mir, bei Gott: ${ }^{145}$ Triptolemos säte den Weizen, ${ }^{146}$ und nach ihrer Trauer erweist den Athenern Demeter Gutes; ${ }^{147}$ warum aber wurde sie nicht zur Wohltäterin der Menschen, als ihre Tochter (noch) nicht verloren war?

9.5. Der Hund der Erigone ${ }^{148}$ wird im Himmel gezeigt und der Skorpion, der Artemis beistand, ${ }^{149}$ und der Kentaure Cheiron ${ }^{150}$ und die halbzerschnittene Argo ${ }^{151}$ und die Bärin der Kallisto ${ }^{152}$ - wie war dann aber, bevor diese Wesen an die genannten Stellen gelangten, der Himmel noch unausgestattet?

9.6. Wem aber wird es nicht lächerlich erscheinen, dass gewissen Leuten zufolge wegen Sizilien das Deltazeichen zum Sternzeichen gemacht wurde, einigen (anderen) zufolge als der erste Buchstabe des Namens des Zeus? ${ }^{153}$ Weshalb sind denn nicht auch Sardinien und Zypern im Himmel geehrt worden? Und weswegen wurden nicht auch von den Brüdern des Zeus, ${ }^{154}$ die sich (mit ihm) die Herrschaftsbereiche aufteilten, die Zeichenbildungen ihrer Buchstaben ${ }^{155}$ im Himmel fixiert? ${ }^{156}$

9.7. Und wieso wird Kronos, der doch gefesselt und aus seiner Herrschaft vertrieben wurde, 157 zum Sachwalter der Heimarmene eingesetzt? ${ }^{158}$ Und wieso kann Königsherrschaften der vergeben, der (selbst) nicht mehr König ist? Lasst deshalb endlich einmal dieses Geschwätz fallen und begeht keinen Gesetzesbruch, nur weil ihr uns in ungerechter Weise hasst!

10.1. Verwandlung ist Menschen angedichtet worden; verwandelt werden bei euch auch die Götter. Zum Baum wird Rhea, ${ }^{159}$ zur Schlange Zeus wegen Phersephassa, ${ }^{160}$ zu Pappeln ${ }^{161}$ die Schwestern Phaëthons ${ }^{162}$ und Leto $\mathrm{zu}$ einem banalen kleinen Tier, um deretwillen Ortygia die jetzige Insel Delos genannt worden ist. ${ }^{163}$ Ein Gott - sag' mir - wird zum Schwan und nimmt eines Adlers Gestalt an, und wegen der Mundschenkdienste des Ganymedes ist er auf seine Päderastie noch stolz? ${ }^{164}$

10.2. Was soll es mir, Götter zu ehren, die sich durch Geschenke bestechen lassen und zornig sind, wenn sie keine bekommen ${ }^{165}$ Mögen diese ihre Heimarmene behalten; vor Planeten in den Staub fallen will ich nicht. ${ }^{166}$

10.3. Was ist die „Locke der Berenike“? Wo waren ihre Sterne, bevor die genannte Dame starb? ${ }^{167}$ Und wie wurde der tote Antinoos - ein süßes Knäblein! - auf dem Mond etabliert? ${ }^{168}$ Wer war es, der ihn da oben hinbrachte, wenn nicht auch von diesem - wie von den Kaisern jemand für Lohn meineidig behauptete (und damit die Götter ${ }^{169}$ ver- 


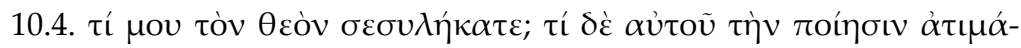

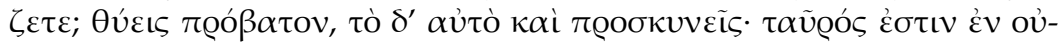

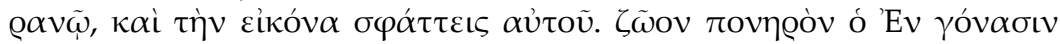

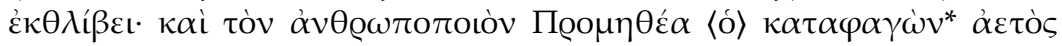

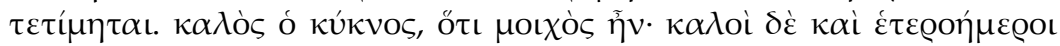

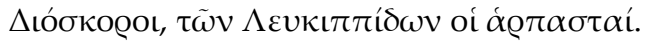

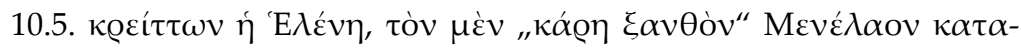

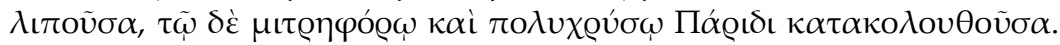

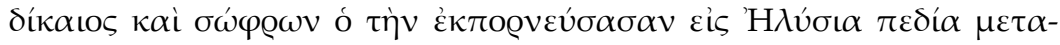

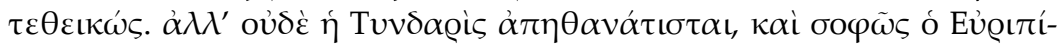

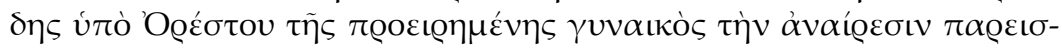

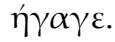

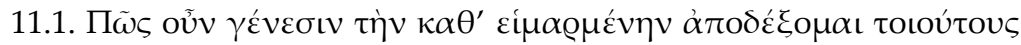

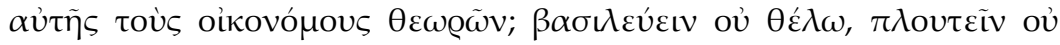

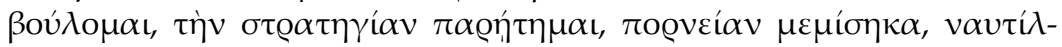

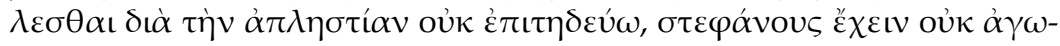

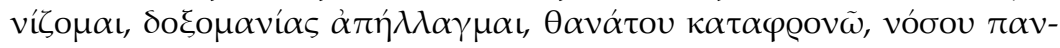

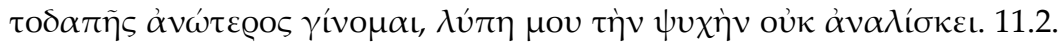

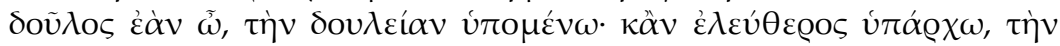

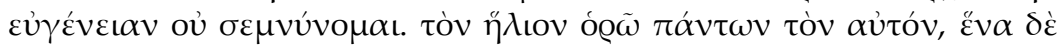

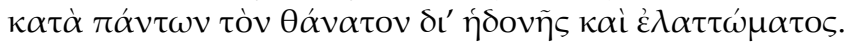

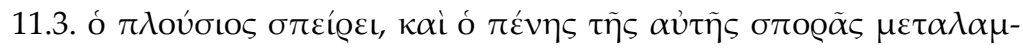

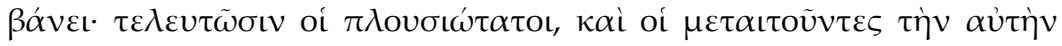

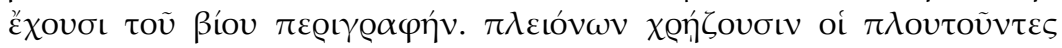

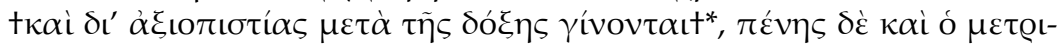

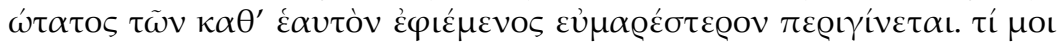

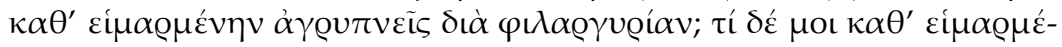

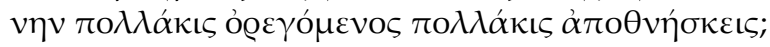

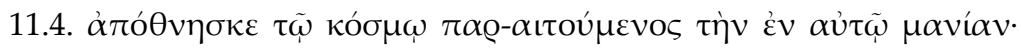

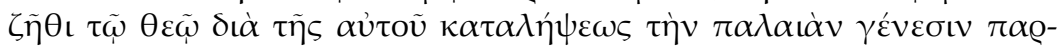


lachte), er sei in den Himmel aufgestiegen, ${ }^{170}$ damit Glauben gefunden hat und dann dafür, dass er seinesgleichen zum Gott erklärte, einer Ehrung und materieller Belohnung für würdig befunden worden ist?

10.4. Was habt ihr meinen Gott beraubt? Und warum entehrt ihr seine Schöpfung? Du opferst ein Schaf, das gleiche Wesen betest du aber auch an; ein Stier ist im Himmel, und sein Ebenbild schlachtest du. ${ }^{177}$ Ein böses Tier ${ }^{172}$ drückt der im Sternbild Engonasin nieder; ${ }^{173}$ und der Adler, der $^{174}$ den Menschenschöpfer Prometheus auffrisst, ${ }^{175}$ steht in Ehren. ${ }^{176}$ Schön ist der Schwan, weil er ein Ehebrecher war; 177 und schön sind auch die "tagewechselnden" Dioskuren, ${ }^{178}$ die Räuber der LeukipposTöchter. ${ }^{179}$ 10.5. Besser noch ist Helena: ${ }^{180}$ Sie verließ Menelaos „mit den blonden Haaren"181 und folgte dem Mitra-Träger und goldreichen Paris. ${ }^{182}$ Gerecht und maßvoll ist der, der die Herumhurende in die Elysischen Felder versetzt hat. ${ }^{183}$ Andererseits ist aber die Tyndareos-Tochter $^{184}$ nicht unsterblich geworden, und weise brachte Euripides die Ermordung der gerade genannten Frau durch Orestes auf die Bühne.

11.1. Wie soll ich ein Geboren-Werden, das von der Heimarmene beherrscht wird, akzeptieren, wenn ich betrachte, dass ihre Sachwalter von solcher Art sind? König sein will ich nicht, ${ }^{185}$ reich zu sein begehre ich nicht, das Feldherrnamt lehne ich ab, Hurerei verabscheue ich, Seefahrt aus unersättlicher Gier betreibe ich nicht, wegen des Gewinns von Siegeskränzen trete ich in keinen Wettkampf ein, von wahnwitziger Ruhmsucht ${ }^{186}$ bin ich befreit, den Tod verachte ich, über jegliche Krankheit bin ich erhaben, Trauer kann meine Seele nicht verzehren. 11.2. Wenn ich ein Sklave bin, ertrage ich meine Knechtschaft; und wenn ich frei bin, brüste ich mich nicht mit meiner Wohlgeborenheit. Die Sonne ist, wie ich sehe, für alle die gleiche, ${ }^{187}$ und einer ist für alle der Tod, ${ }^{188}$ in Freude wie in Mangel.

11.3. Der Reiche sät, und der Arme hat Anteil an derselben Aussaat; es sterben die Reichsten, und die Bettler haben die gleiche Grenze ihres Lebens. Nach (immer) mehr verlangen die, die (bereits) reich sind, ${ }^{189}$ tund dadurch, dass man ihnen vertraut, kommen sie in den Genuss von Reputationt; 190 ein Armer aber und derjenige, der am maßvollsten nach den Dingen gemäß seiner Situation strebt, kommt unbeschwerlicher durchs Leben. Was bleibst du mir nach den Gesetzen der Heimarmene ohne Schlaf wegen deiner Habgier? ${ }^{191}$ Was hast du mir nach den Gesetzen der Heimarmene vielfache Begierden und stirbst deshalb vielfache Tode?

11.4. Stirb der Welt ${ }^{192}$ und lehne den in ihr herrschenden Wahnsinn ab! Lebe für Gott und sage dadurch, dass du ihn ergreifst, dich von dem 


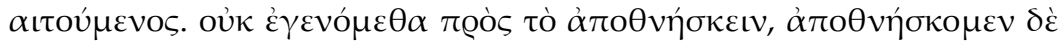

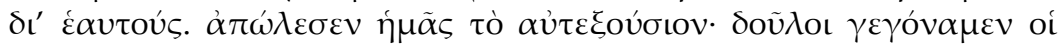

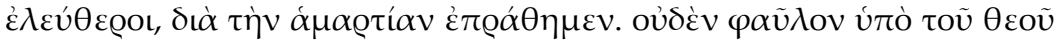

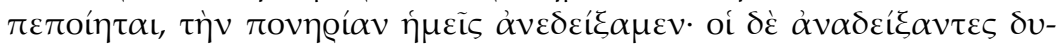

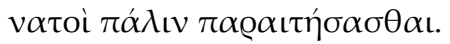

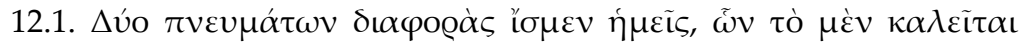

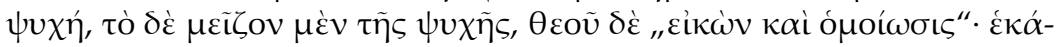

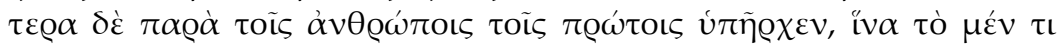

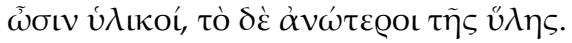

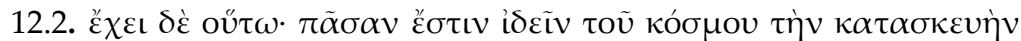

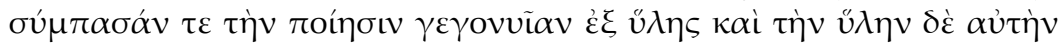

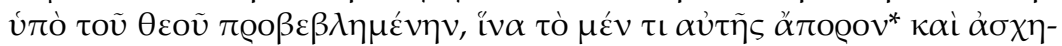

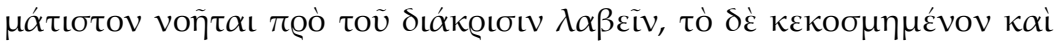

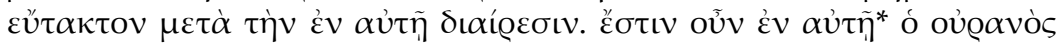

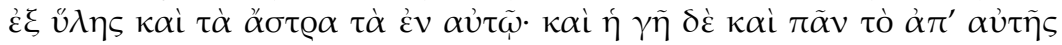

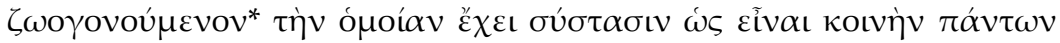

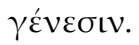

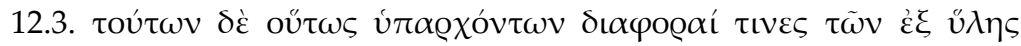

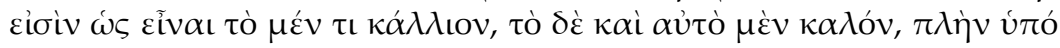

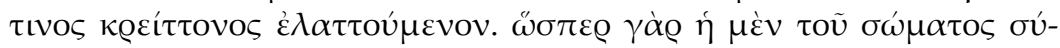

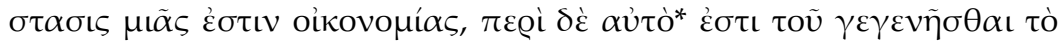

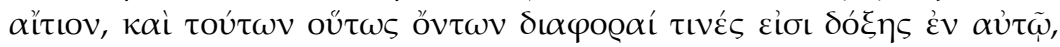

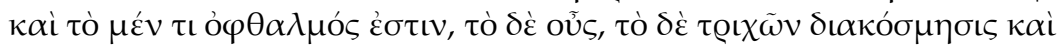

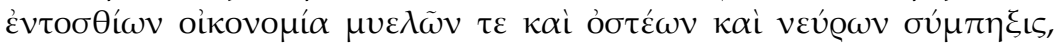

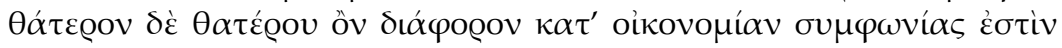

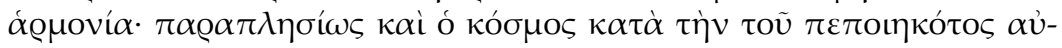

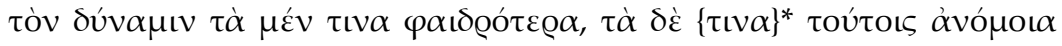

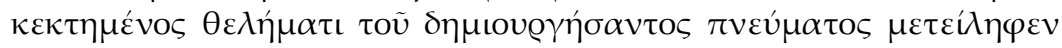

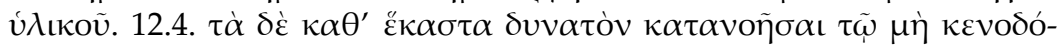

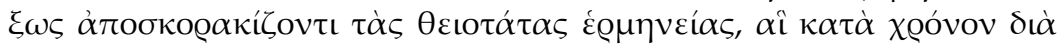

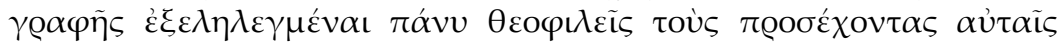

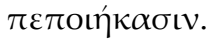


alten Werden ${ }^{193}$ los. Nicht sind wir entstanden zum Sterben, ${ }^{194}$ sondern wir sterben wegen uns selbst. Zugrunde gerichtet hat uns die Freiheit; ${ }^{195}$ Sklaven sind wir, die Freien, geworden, wegen der Sünde wurden wir verkauft. ${ }^{196}$ Nichts Schlechtes ist von Gott geschaffen, die Schlechtigkeit haben gerade wir ans Licht gebracht; die aber, die sie ans Licht gebracht haben, sind (auch) in der Lage, sich wieder von ihr abzuwenden.

12.1. Zwei unterschiedliche Arten von Geistern ${ }^{197}$ kennen wir, von denen die eine "Seele" genannt wird, die andere aber größer als die Seele ist und Gottes "Bild und Gleichnis"; 198 beide Arten aber waren bei den ersten Menschen vorhanden, damit sie einerseits zur Materie gehörten, andererseits aber höher als sie stünden.

12.2. Es verhält sich aber folgendermaßen: Man kann sehen, dass der ganze Aufbau des Kosmos und die gesamte Schöpfung aus Materie entstanden und die Materie ihrerseits von Gott hervorgebracht ist, ${ }^{199}$ so dass man zum einen etwas von ihr als hilflos ${ }^{200}$ und ungeformt zu denken hat, bevor sie eine Differenzierung erhielt, zum anderen aber als geordnet und wohlgestaltet nach der Aufteilung, die in ihr geschah. ${ }^{201}$ Es besteht also in ihr ${ }^{202}$ der Himmel aus Materie und auch die Sterne in ihm; und die Erde und alles, was aus ihr an Lebewesen hervorgegangen ist, ${ }^{203}$ hat die gleiche Beschaffenheit, so dass allen ein gemeinsamer Ursprung zukommt.

12.3. Obwohl dies aber so ist, gibt es Unterschiede bei den Dingen aus Materie, so dass das eine schöner ist, das andere aber für sich zwar auch schön ist, aber von einem Besseren übertroffen wird. Wie nämlich die Zusammensetzung des Körpers einem einzigen Plan unterliegt und sich um den Körper (als Ganzes) der Grund der Existenz dreht; ${ }^{204}$ und wie es, obwohl dies so ist, gewisse Unterschiede an Wertigkeit in ihm gibt und das eine das Auge ist, das andere das Ohr, ein weiteres die schmuckvolle Ordnung der Haare und die Anordnung der Eingeweide und der Zusammenhalt von Mark, Knochen und Sehnen; und wie das eine vom anderen verschieden ist und trotzdem gemäß dem (Gesamt-) Plan einen harmonischen Zusammenklang bildet - in ähnlicher Weise besitzt auch der Kosmos ${ }^{205}$ gemäß der Macht seines Schöpfers zum einen glänzendere, zum anderen diesen unähnliche Teile und hat nach dem Willen dessen, der ihn gebildet hat, Anteil am materiellen Geist erhalten. 12.4. Wie sich das im Einzelnen verhält, kann jeder erkennen, der nicht die göttlichsten Offenbarungen zum Geier wünscht, die mit der Zeit in Schriftform ausgedrückt wurden und diejenigen, die ihnen Aufmerksamkeit schenken, zu von Gott Geliebten ${ }^{206}$ gemacht haben. 


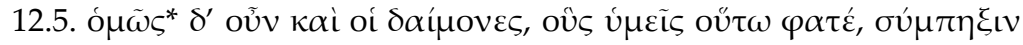

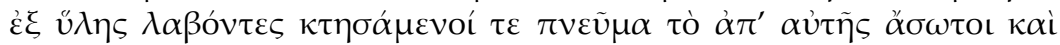

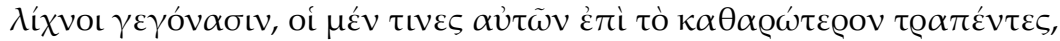

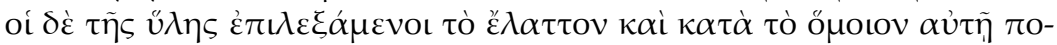

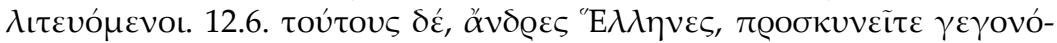

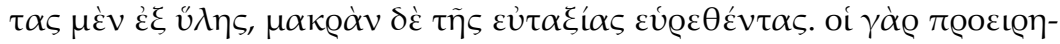

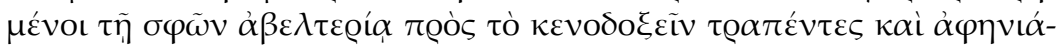

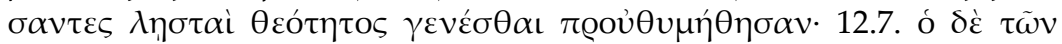

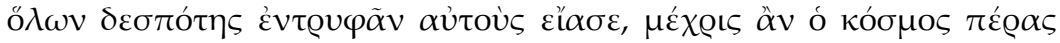

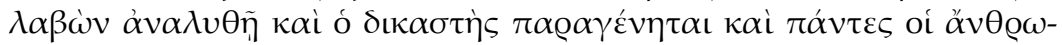

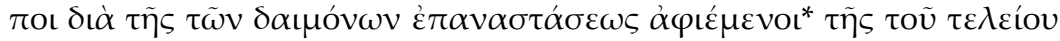

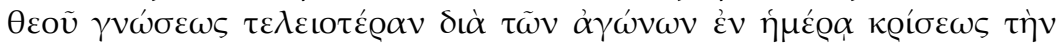
$\mu \alpha \varrho \tau v @ i ́ \alpha v \lambda \alpha ́ \beta \omega \sigma \iota v$.

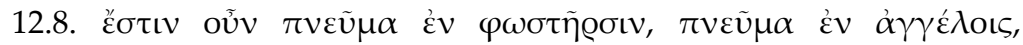

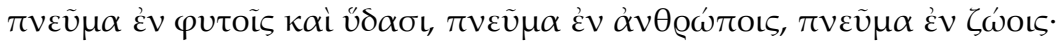

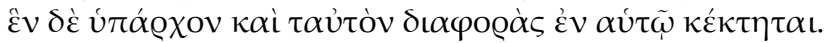

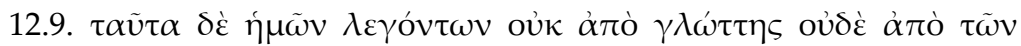

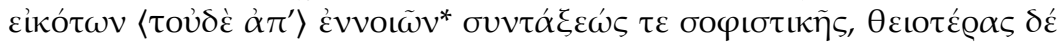

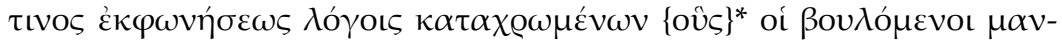

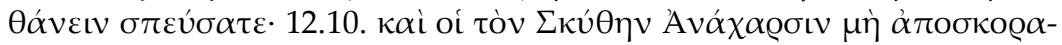

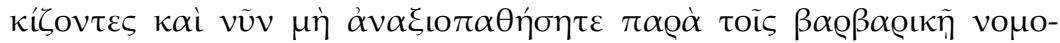

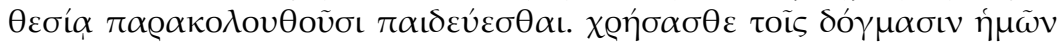

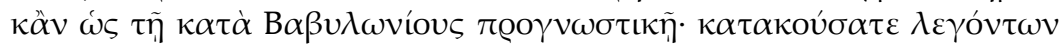

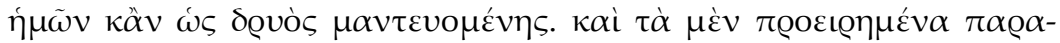

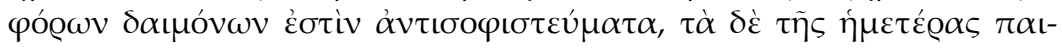

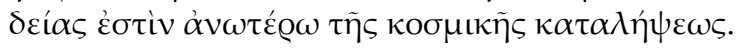

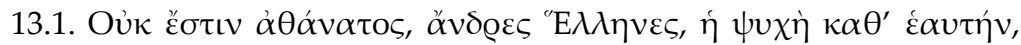

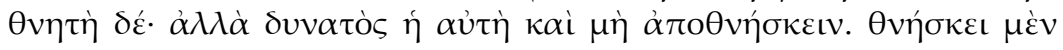

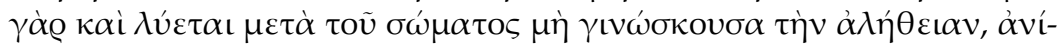

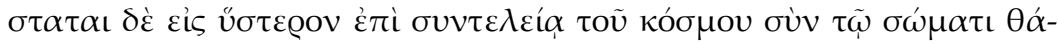

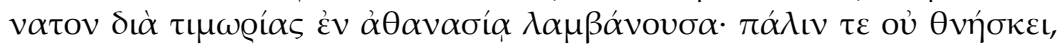

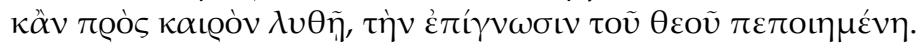


12.5. In gleicher Weise ${ }^{207}$ nun haben auch die Dämonen, die ihr selber so nennt, ${ }^{208}$ ihre Zusammenfügung aus Materie erhalten sowie als Geist den aus der Materie stammenden bekommen ${ }^{209}$ und sind zügellos und schwelgerisch geworden; einige von ihnen wandten sich zwar zum Reineren (der Materie) hin, die anderen aber suchten sich das Minderwertige der Materie aus und lebten in Übereinstimmung mit ihr. ${ }^{210} 12.6$. Und diese, ihr Griechen, betet ihr an, obwohl sie aus Materie sind und als weit entfernt von guter Ordnung erfunden wurden. Die gerade Genannten haben sich nämlich aufgrund ihrer eigenen Dummheit ${ }^{211}$ hin zu leeren Wahnvorstellungen gewandt, die Zügel abgestreift und die eifrige Begierde entwickelt, zu Räubern des Gottesstatus ${ }^{212} \mathrm{zu}$ werden; 12.7. der Herr des Alls aber lässt sie ihren Übermut ausleben, bis der Kosmos sein Ende nimmt, aufgelöst wird und der Richter sich einfindet, und bis alle Menschen, nachdem sie durch den Aufstand der Dämonen von einer Erkenntnis des vollkommenen Gottes abgekommen sind, ${ }^{213}$ durch ihre Kämpfe am Tag des Gerichts ein vollkommeneres Zeugnis erlangen.

12.8. Es gibt also Geist in den Sternen, Geist in den Engeln, Geist in den Pflanzen und Gewässern, Geist in den Menschen, Geist in den Tieren; ${ }^{214}$ obwohl er aber ein und derselbe ist, trägt er doch Unterschiede in sich.

12.9. Da wir dies aber nicht (einfach) mit der Zunge behaupten oder aufgrund von Wahrscheinlichkeiten oder gedanklichen Schlüssen ${ }^{215}$ und sophistischer Kombinatorik, sondern weil wir uns auf die Inhalte einer göttlicheren Offenbarung berufen, ${ }^{216}$ so $^{217}$ eilt her, alle, die ihr lernen wollt! 12.10. Und die ihr den Skythen Anacharsis ${ }^{218}$ nicht zum Geier geschickt habt, ereifert euch auch jetzt nicht, als sei es unwürdig, sich von denen, die einer barbarischen Satzung folgen, Bildung vermitteln zu lassen! Macht von unseren Lehren Gebrauch, und sei es auch nur wie von der babylonischen Weissagekunst!219 Hört unseren Worten zu, und sei es auch nur wie der sprechenden Eiche! ${ }^{220}$ Die gerade genannten Phänomene sind die sophistischen Widerlegungsspiele auf Abwege geratener Dämonen; die Gegenstände unserer Paideia dagegen stehen höher als die Erfassungskraft dieser Welt. ${ }^{221}$

13.1. Nicht ist unsterblich, ihr Griechen, die Seele an und für sich, ${ }^{222}$ sondern sterblich; doch ist die gleiche in der Lage, auch nicht zu sterben.223 Sie stirbt nämlich und löst sich zusammen mit dem Körper auf, wenn sie die Wahrheit nicht erkennt; sie aufersteht aber zu einer späteren Zeit, bei der Vollendung des Kosmos, ${ }^{224}$ zusammen mit dem Körper und erhält dann den Tod zur Bestrafung in der Unsterblichkeit; und 


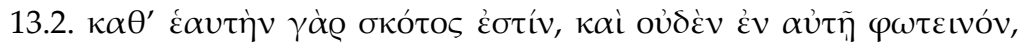

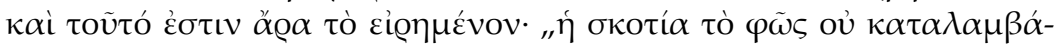

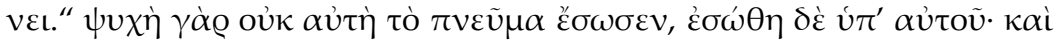

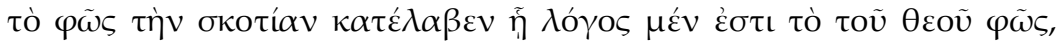

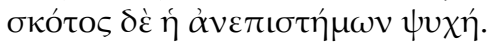

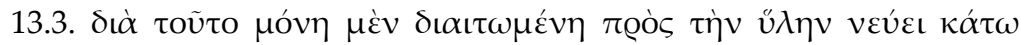

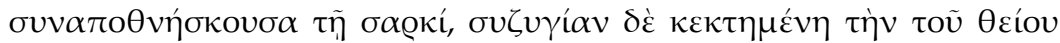

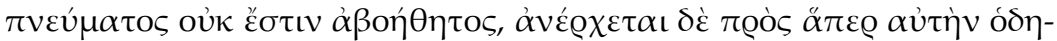

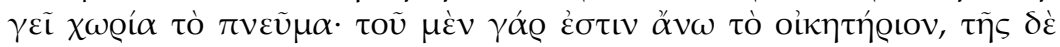

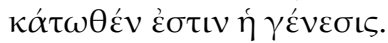

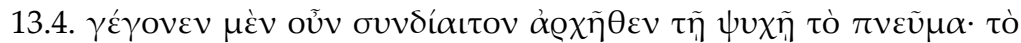

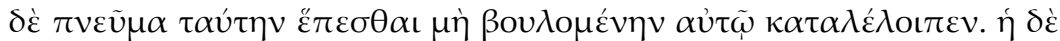

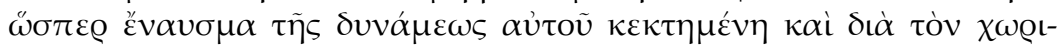

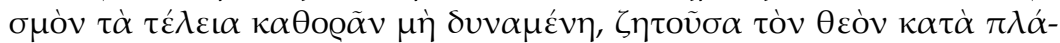

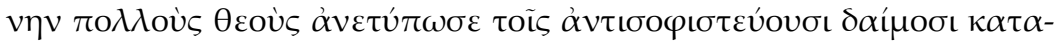

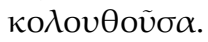

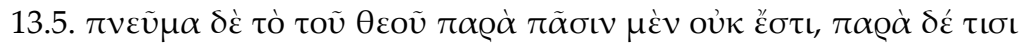

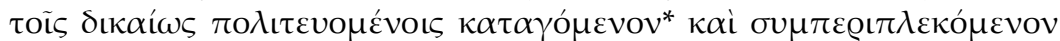

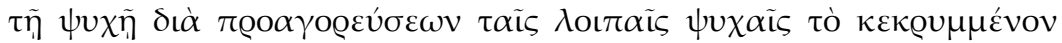

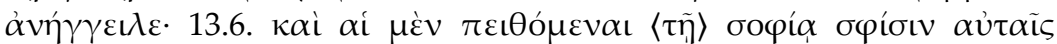

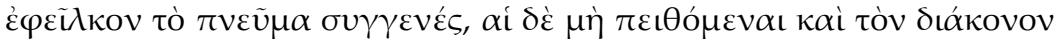

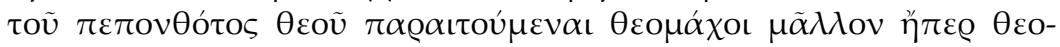

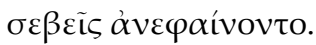

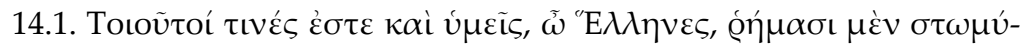

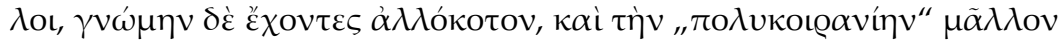

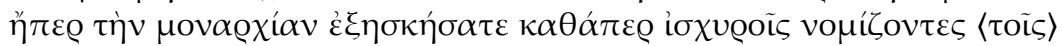

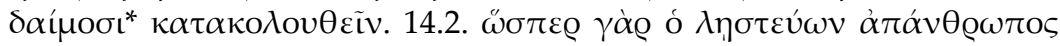

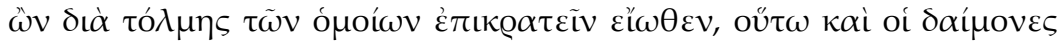

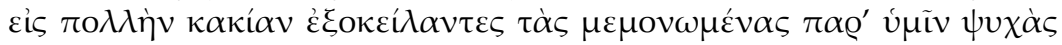

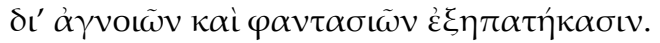

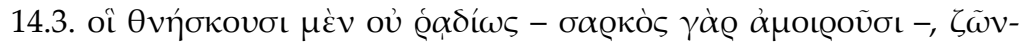

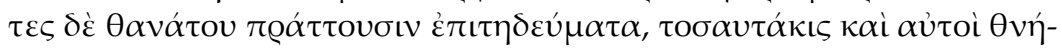

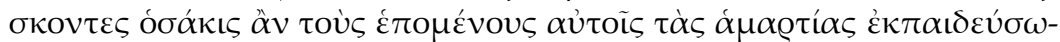

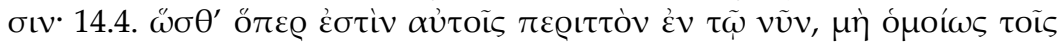

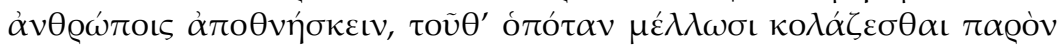


wiederum stirbt sie nicht, auch wenn sie für eine (gewisse) Zeit aufgelöst wird, wenn sie sich die Erkenntnis Gottes zueigen gemacht hat.

13.2. An und für sich nämlich ist sie Dunkelheit, und nichts in ihr ist leuchtend, und dies ist also, was gesagt worden ist: „Die Finsternis ergreift das Licht nicht. “225 Denn die Seele rettet nicht selbst den Geist, ${ }^{226}$ sondern wird von ihm gerettet; und das Licht ergreift die Finsternis in der Weise, dass der Logos das Licht Gottes ist, ${ }^{227}$ Finsternis aber die unverständige Seele.

13.3. Deshalb strebt sie, wenn sie allein ihr Leben verbringt, abwärts zur Materie und stirbt zusammen mit dem Fleisch; wenn sie aber eine Gemeinschaft mit dem göttlichen Geist besitzt, dann ist sie nicht ohne Hilfe, sondern steigt auf zu eben den Orten, zu denen sie der Geist führt; denn er hat oben seine Wohnstatt, sie aber unten ihre Entstehung.

13.4. So hat also am Anfang zusammen mit der Seele der Geist gelebt,;28 der Geist aber hat sie, da sie ihm nicht folgen wollte, verlassen. Sie aber - da sie gleichsam einen Funken seiner Macht besitzt und wegen der Trennung das Vollkommene nicht sehen kann - hat bei der Suche nach Gott in ihrem Umherirren sich Bilder vieler Götter geformt, wobei sie den gegen sie Tricks anwendenden Dämonen folgte. ${ }^{229}$

13.5. Der Geist Gottes aber ist nicht bei allen, sondern (nur) bei einigen - denen, die gerecht leben - kehrt er ein ${ }^{230}$ und verbindet sich mit der Seele und verkündet durch Vorhersagen den übrigen Seelen das Verborgene. ${ }^{231}$ 13.6. Und diejenigen Seelen, die der Weisheit folgten, ${ }^{232}$ zogen an sich den verwandten Geist; diejenigen aber, die ihr nicht folgten und den Diener des Gottes, der gelitten hat, ${ }^{233}$ abwiesen, erwiesen sich mehr als Gottesbekämpfer ${ }^{234}$ denn als Gottesfürchtige.

14.1. Leute solcher Art seid auch ihr, ihr Griechen: mit Worten sehr gewandt, aber von einer seltsamen Urteilsart; und ihr habt mehr die "Vielherrschaft" ${ }^{\prime 235}$ ausgebildet als die Alleinherrschaft, da ihr den Dämonen zu folgen pflegt, als seien sie mächtig. ${ }^{236}$ 14.2. Wie nämlich der, der sich als Räuber betätigt, als außerhalb der Menschheit Stehender durch seinen Wagemut seinesgleichen zu überwältigen pflegt, so haben auch die Dämonen in große Schlechtigkeit die bei euch vereinsamten ${ }^{237}$ Seelen getrieben und durch Unwissenheit und falsche Vorstellungen getäuscht.

14.3. Diese (Dämonen) sterben nicht leicht - sie haben nämlich keinen Anteil am Fleisch -, obwohl sie aber leben, gehen sie Tätigkeiten des Todes nach, wobei sie soviele Male auch selber sterben, wie sie diejenigen, die ihnen folgen, in den Sünden unterrichten; 14.4. daher wird ihnen, was ihnen im jetzigen Dasein im Überfluss zuteil ist - nicht in glei- 


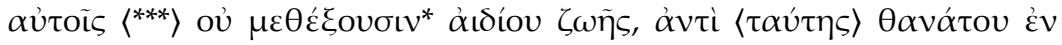

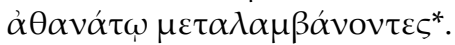

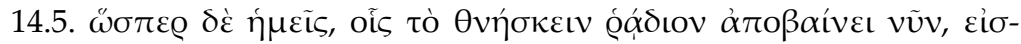

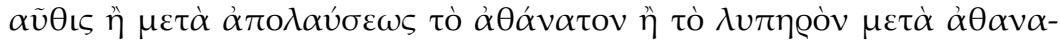

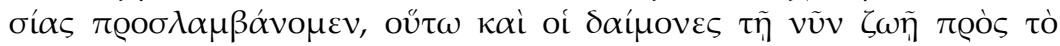

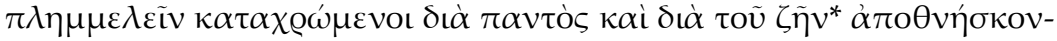

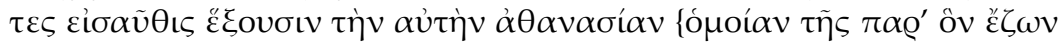

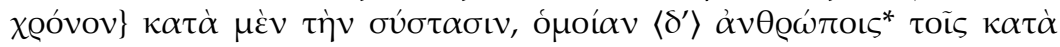

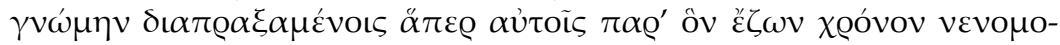

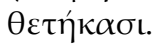

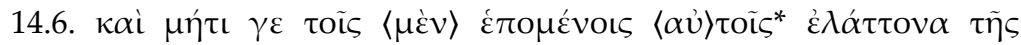

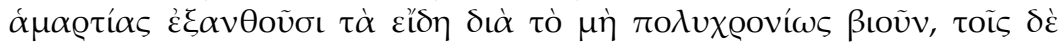

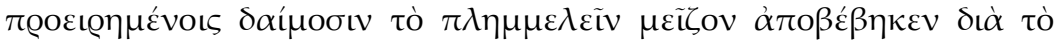

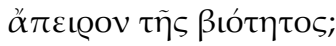

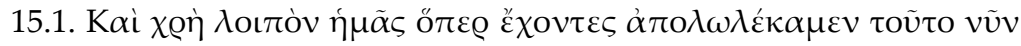

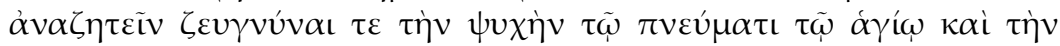

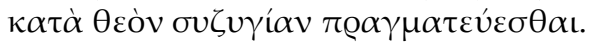

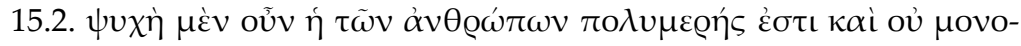

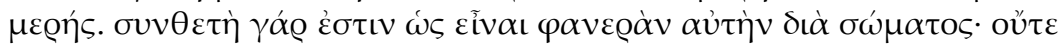

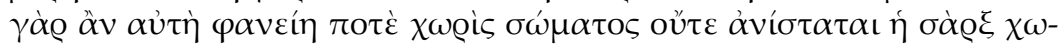
@is $\psi v \times \tilde{\eta} \varsigma$.

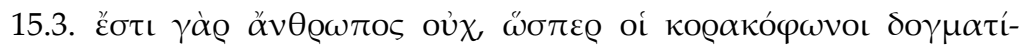

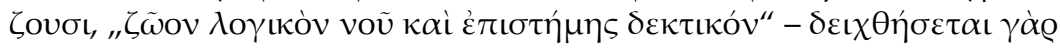

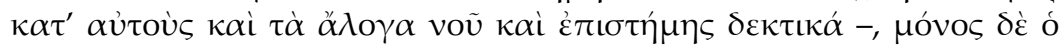

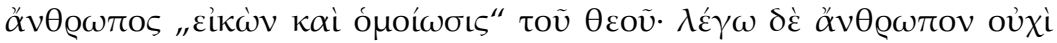

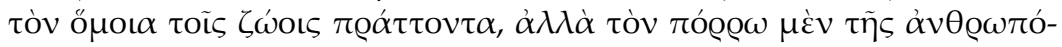

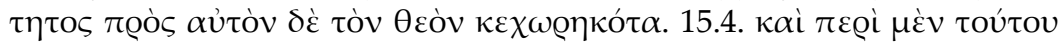

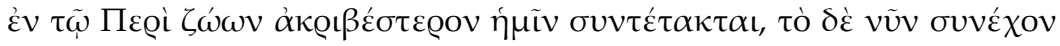

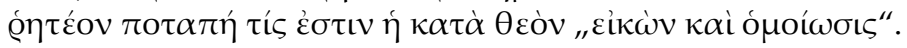

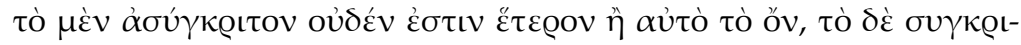

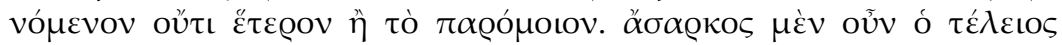

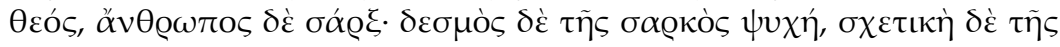

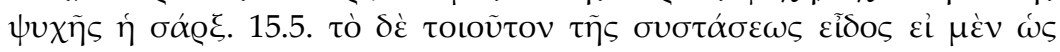

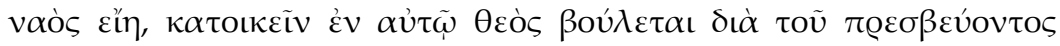

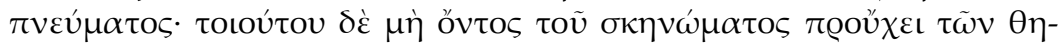


cher Weise wie die Menschen sterben zu müssen -, dies (wird) ihnen, wenn sie davor stehen, bestraft zu werden, da ihnen zugegen ist $\langle * * *$ nicht werden sie Anteil haben am ewigen Leben und an seiner statt Anteil am Tod in der Unsterblichkeit bekommen. ${ }^{238}$

14.5. Wie aber wir, denen das Sterben jetzt leicht widerfährt, zu einer anderen Zeit entweder zusammen mit Genuss die Unsterblichkeit oder (aber) das Leid in Ewigkeit erhalten, so werden auch die Dämonen, da sie das jetzige Leben in allem für Untaten missbrauchen und durch ihr Leben ${ }^{239}$ sterben, zu einer anderen Zeit die gleiche Unsterblichkeit haben, was ihre Substanz betrifft, und eine ähnliche wie die Menschen, ${ }^{240}$ die freiwillig das taten, was die Dämonen ihnen während ihrer Lebenszeit als Gesetz aufgestellt haben.

14.6. Und blühen nicht denen, die ihnen folgen, ${ }^{241}$ in geringerer Zahl und Schwere die Arten der Sünde, weil sie nicht lange leben, bei den genannten Dämonen aber ergibt sich ein viel größeres Unrechttun, weil ihre Lebenszeit keine Grenzen hat?

15.1. Und so müssen wir, was wir (einmal) hatten und verloren haben, dies nun wieder suchen und unsere Seele mit dem heiligen Geist verbinden und die Gemeinschaft (mit ihm) gemäß Gott betreiben.

15.2. Die Seele der Menschen nun ist vielteilig ${ }^{242}$ und nicht einheitlich. Zusammengesetzt nämlich ist sie, so dass sie durch den Körper sichtbar ist; denn weder könnte sie selbst jemals in Erscheinung treten getrennt vom Körper, noch kann das Fleisch getrennt von der Seele aufstehen.

15.3. Es ist nämlich der Mensch nicht, wie „die mit den Rabenstimmen“243 lehren, ein „Logos-Wesen, das Verstehen und Wissen aufnehmen kann" ${ }^{244}$ - es wird sich nämlich gemäß dieser Auffassung nachweisen lassen, dass auch die logos-losen Wesen Verstehen und Wissen aufnehmen können ${ }^{245}$-, sondern allein der Mensch ist ein „Bild und Gleichnis“246 Gottes; als Menschen bezeichne ich aber nicht den, der wie die Tiere handelt, sondern den, der (bereits) fern von seinem Menschsein ist und sich auf dem Weg zu Gott selbst befindet. 15.4. Und über dies ist in der Schrift „Über Tiere“247 genauer von mir gehandelt; jetzt ist die Hauptsache zu sagen, welcher Art und was das Gott entsprechende „Bild und Gleichnis" ist.

Das, was unvergleichbar ${ }^{248}$ ist, ist nichts anderes als das Seiende ${ }^{249}$ selbst, das aber, was sich vergleichen lässt, nichts anderes als das (sehr) Ähnliche. Ohne Fleisch ${ }^{250}$ nun ist der vollkommene Gott, der Mensch aber ist Fleisch; das (zusammenhaltende) Band des Fleisches ist die Seele, ${ }^{251}$ und das, was die Seele (fest-)hält, ist das Fleisch. ${ }^{252}$ 15.5. Wenn nun die derartige Gestalt dieser Verbindung etwa wie ein Tempel ist, ${ }^{253}$ 


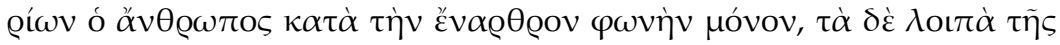

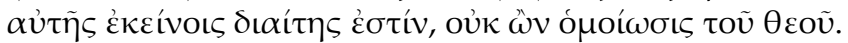

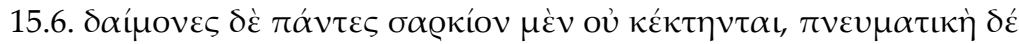

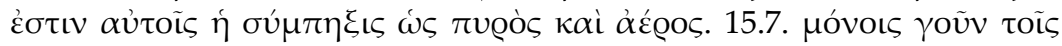

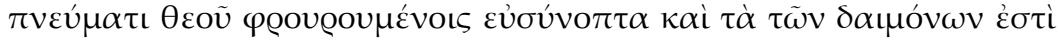

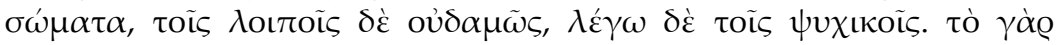

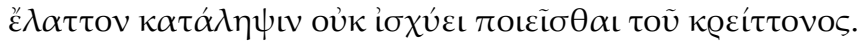

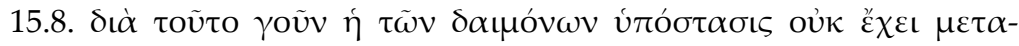

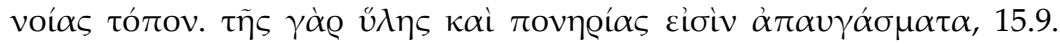

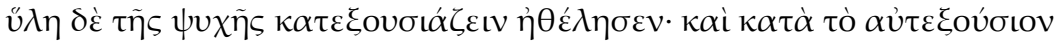

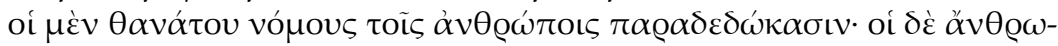

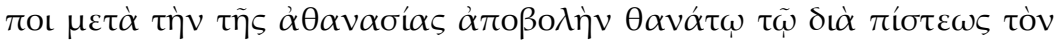

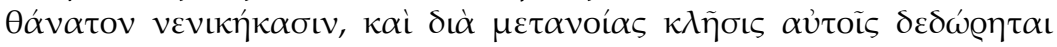

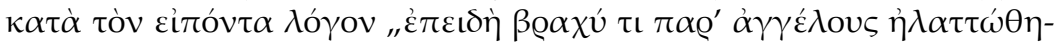
$\sigma \alpha v^{\prime \prime}$.

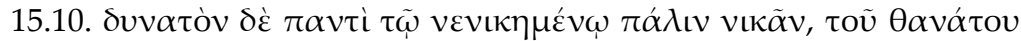

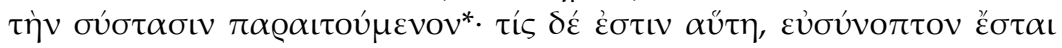

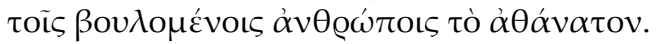

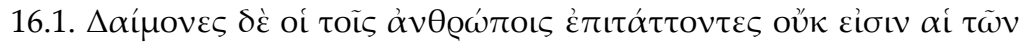

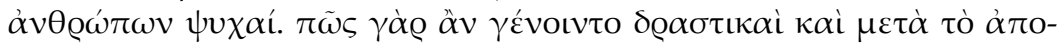

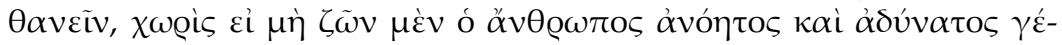

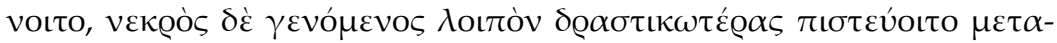

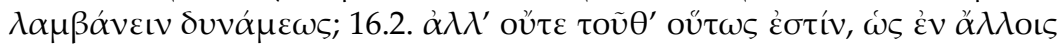

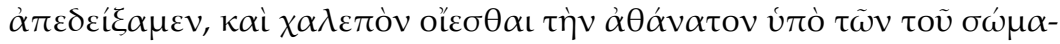

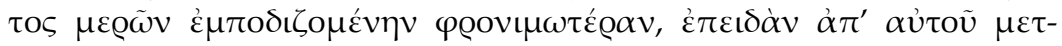

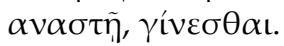

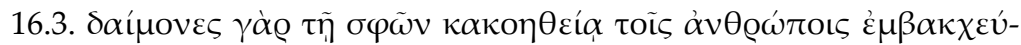

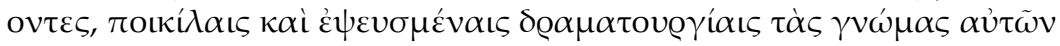

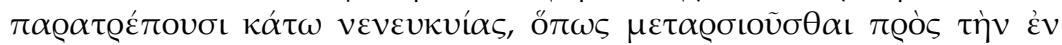

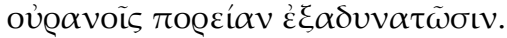


dann will Gott in ihm wohnen durch den Geist, der sein Abgesandter ist,; ${ }^{254}$ ist solcher Art aber nicht das Zelt (des Körpers), ${ }^{255}$ dann ist der Mensch den Tieren nur in Hinsicht auf seine artikulierte Stimme überlegen ${ }^{256}$ und hat im Übrigen die gleiche Lebensweise wie sie, ist also kein ,Gleichnis' Gottes. ${ }^{257}$

15.6. Die Dämonen besitzen alle kein Fleisch, ${ }^{258}$ sondern geisthaft ${ }^{259}$ ist ihr Zusammenhalt wie der von Feuer und Luft. 15.7. Allein für die nun, die vom Geist Gottes behütet werden, sind gut erkennbar auch die Leiber der Dämonen, den Übrigen aber keineswegs (ich meine die nur eine Seele Habenden ${ }^{260}$ ). Denn das Schwächere ist nicht stark genug, das Stärkere zu erfassen.

15.8. Deshalb also hat das Wesen der Dämonen keinen Ort für Buße und Umkehr. ${ }^{261}$ Denn sie sind (nur) Ausstrahlungen von Materie ${ }^{262}$ und Schlechtigkeit, 15.9. die Materie aber wollte über die Seele Macht ausüben. ${ }^{263}$ Und entsprechend ihrer Freiheit haben die einen den Menschen Gesetze des Todes gegeben; die Menschen aber haben nach dem Verlust der Unsterblichkeit mit Hilfe des Todes durch den Glauben den Tod besiegt, und aufgrund ihrer Umkehr ist ihnen Berufung geschenkt gemäß dem Wort, das sagt: „nachdem sie nur kurz im Vergleich zu den Engeln zurückgesetzt worden waren“. ${ }^{264}$

15.10. Möglich aber ist es jedem Besiegten, wiederum zu siegen, indem er die Verbindung mit dem Tod zurückweist; 265 was diese aber ist, wird gut erkennbar sein für die Menschen, die die Unsterblichkeit wollen.

16.1. Die Dämonen aber, die den Menschen Befehle erteilen wollen, das sind nicht die Seelen der (verstorbenen) Menschen. Denn wie könnten sie tätig werden auch nach dem Tod? Es sei denn, dass als Lebender der Mensch unverständig und kraftlos wäre, man dann aber annähme, dass er, wenn er zum Leichnam geworden ist, Anteil an größerer Tatkraft erhielte. 16.2. Aber zum einen ist dies nicht so - wie ich in anderen Darlegungen ${ }^{266}$ gezeigt habe -, und zum anderen fällt es schwer zu glauben, dass die unsterbliche Seele von den Gliedern des Körpers gehemmt sein und erst dann vernünftiger werden soll, ${ }^{267}$ wenn sie sich von ihm trennt.

16.3. Dämonen nämlich toben sich aufgrund ihrer Bösartigkeit an den Menschen aus und lenken mit bunten und verlogenen Spektakeln ihren Sinn - der ohnehin schon nach unten geneigt is $\mathrm{t}^{268}$ - in die Irre, damit sie nicht in der Lage sind, sich zur Reise in die Himmel zu erheben. 


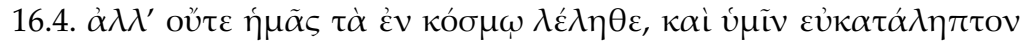

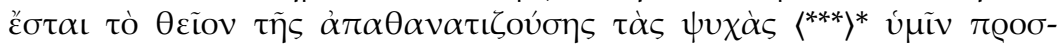
$\varepsilon \lambda \theta$ oúōs.

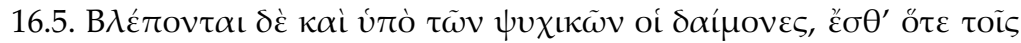

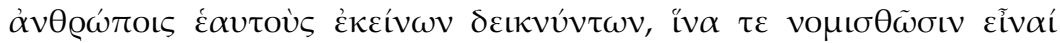

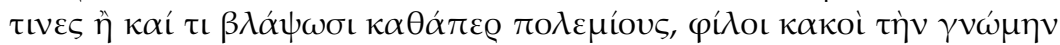

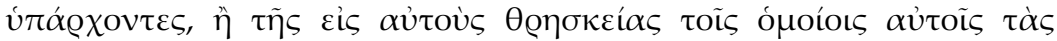

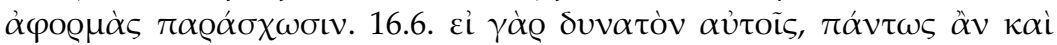

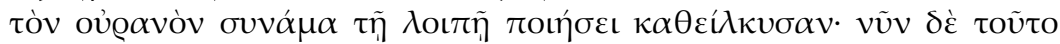

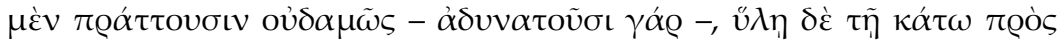

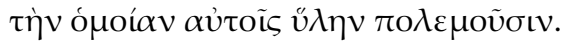

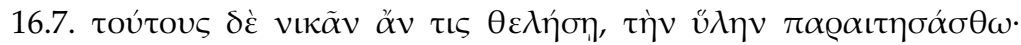

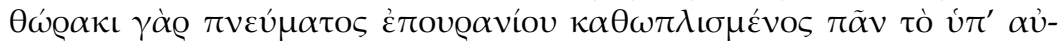

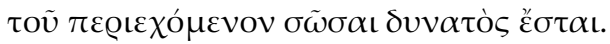

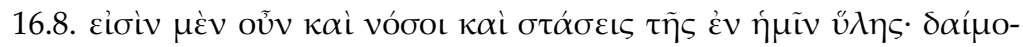

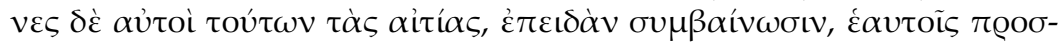

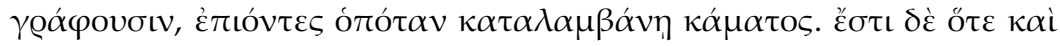

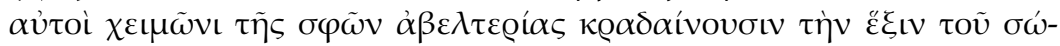

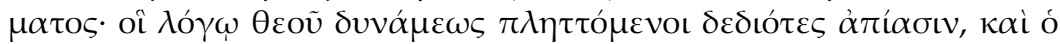
$\kappa \alpha \dot{\mu \nu \omega \nu} \theta \varepsilon \varrho \alpha \pi \varepsilon v ́ \varepsilon \tau \alpha \mathrm{s}$.

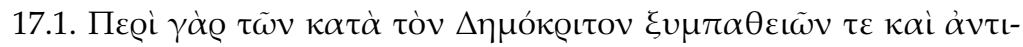

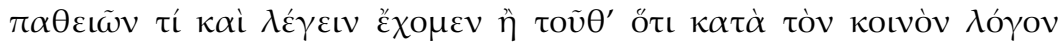

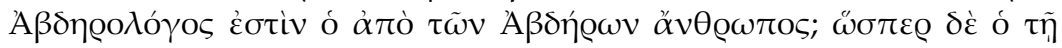

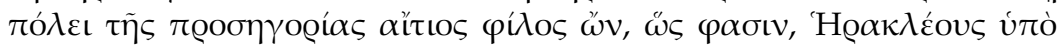

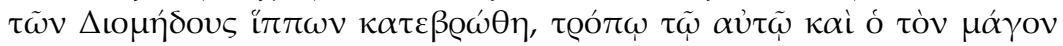

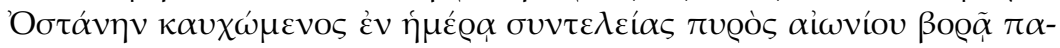

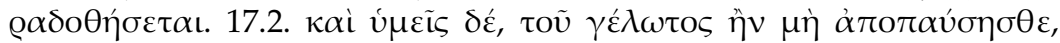

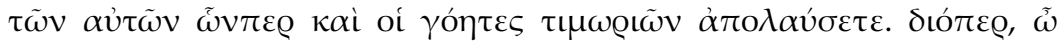

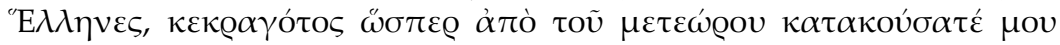

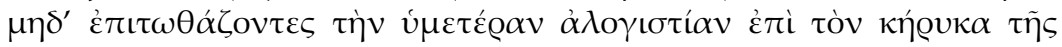
$\dot{\alpha} \lambda \eta \theta \varepsilon i ́ \alpha \varsigma \mu \varepsilon \tau \alpha ́ \gamma \varepsilon \tau \varepsilon$.

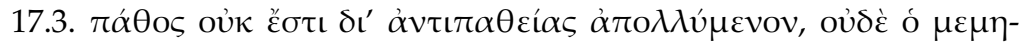

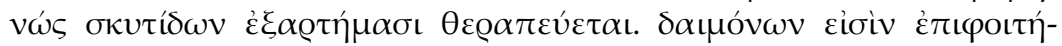

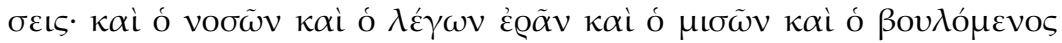

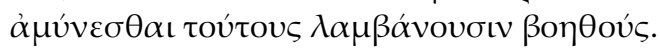


16.4. Aber einerseits sind uns die Dinge in der Welt nicht verborgen, und andererseits wird euch das Göttliche leicht begreifbar sein, wenn die $\langle * * *, 269$ die die Seelen unsterblich macht, zu euch kommt.

16.5. Erblickt werden aber auch von den (nur) mit einer Seele Ausgestatteten $^{270}$ die Dämonen, wenn jene manchmal sich den Menschen zeigen, damit man glauben soll, dass sie etwas darstellen, oder auch, um ihnen Schaden zuzufügen wie Feinden - da sie (in Wahrheit) schlecht gesinnte Freunde sind -, oder um denen, die ihnen ähnlich sind, Anreize zu ihrer religiösen Verehrung zu bieten. 16.6. Wenn es ihnen nämlich möglich wäre, würden sie auf jeden Fall auch den Himmel mitsamt der übrigen Schöpfung herabziehen; nun aber tun sie dies zwar keineswegs - sie können es nämlich nicht -, aber mit Hilfe der niederen Materie führen sie Krieg gegen die Materie, die ihnen ähnlich ist.

16.7. Wenn diese aber jemand besiegen will, so entsage er der Materie; mit dem Panzer nämlich des himmlischen Geistes gewappnet, ${ }^{271}$ wird er alles, was von diesem umfasst wird, zu retten in der Lage sein.

16.8. Es gibt zwar nun auch Krankheiten und Rebellionen der Materie in uns; die Dämonen aber schreiben sich selbst die Verursachung dieser Erscheinungen, wenn sie sich ereignen, zu und kommen heran, wann immer Ermattung (uns) ergreift. Manchmal aber schütteln sie auch selbst durch einen Sturm ihrer Torheit den Zustand des Körpers; sie ziehen jedoch, durch das Wort der Macht Gottes getroffen, ${ }^{272}$ in Furcht $\mathrm{ab}$, und der Kranke wird geheilt.

17.1. Was nämlich die "Sympathien und Antipathien“ à la Demokrit $^{273}$ betrifft: Was sollen wir darüber auch anderes sagen als dies, dass nach allgemeiner Kunde ein "Abderitenschwätzer" der aus Abdera stammende Mann ist? ${ }^{274}$ Wie aber der für den Namen der Stadt Verantwortliche $^{275}$ ein Freund des Herakles war, wie man sagt, und von den Rossen des Diomedes aufgefressen wurde, auf die gleiche Weise wird auch der, der sich mit dem Magier Ostanes brüstet, ${ }^{276}$ am Tag der Vollendung ${ }^{277}$ dem Fraß des ewigen Feuers übergeben werden. 17.2. Und ihr werdet, wenn ihr mit dem Gelächter ${ }^{278}$ nicht aufhört, die gleichen Strafen genießen wie auch die Scharlatane. Deshalb, ihr Griechen, hört auf mich, der ich gleichsam von der Höhe rufe, ${ }^{279}$ und übertragt nicht mit eurem Spott die eigene Gedankenlosigkeit auf den Herold der Wahrheit!

17.3. Ein Leiden, das durch „Antipathie“ zugrunde geht, gibt es nicht, und der, der verrückt ist, wird nicht durch Anhängsel an Lederriemen ${ }^{280}$ geheilt. Dämonen-Heimsuchungen gibt es, und der Kranke, der seine Liebe Beteuernde, der Hassende und der, der sich rächen will, nehmen diese Wesen als Beistand. 


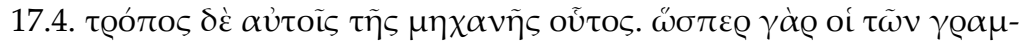

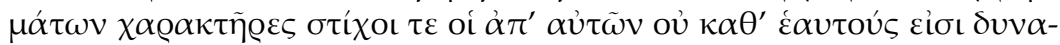

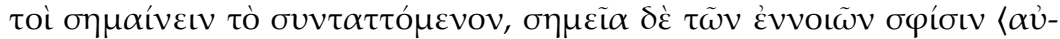

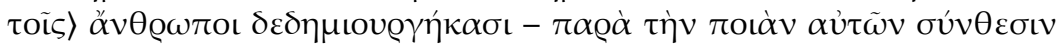

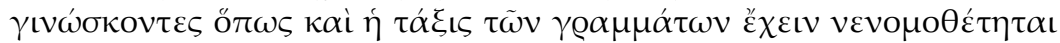

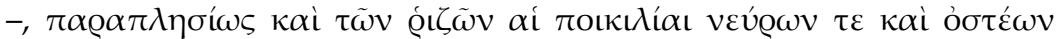

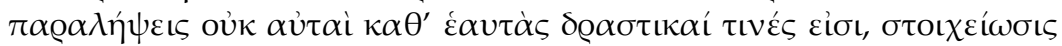

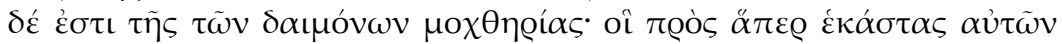

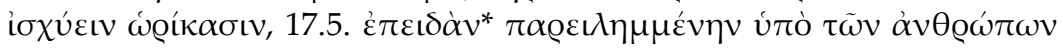

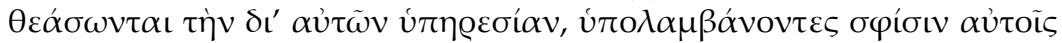

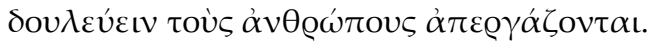

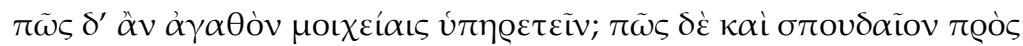

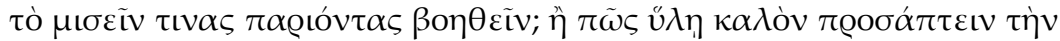

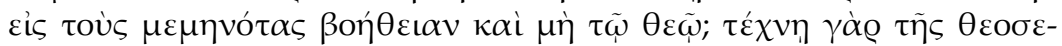

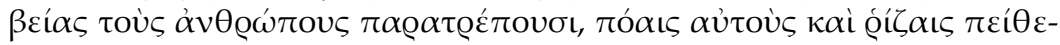

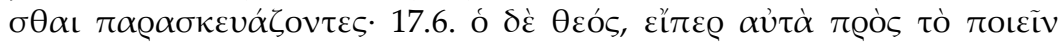

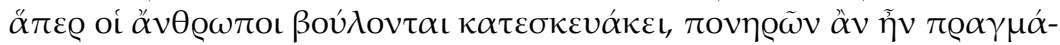

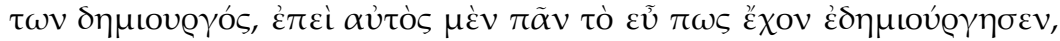

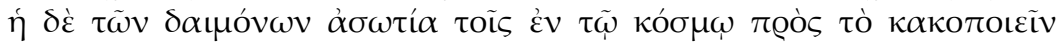

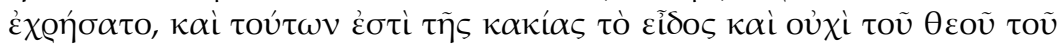
$\tau \varepsilon \lambda \varepsilon i ́ o v$.

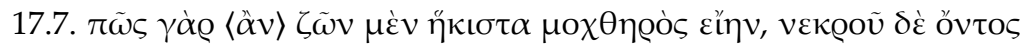

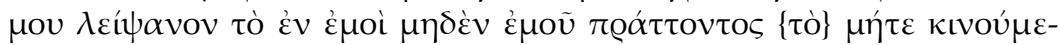

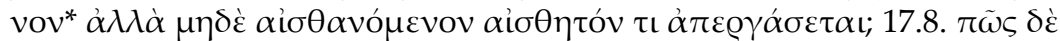

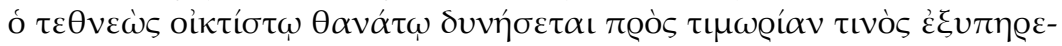

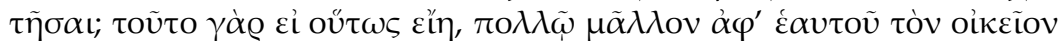

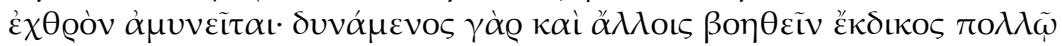

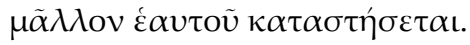

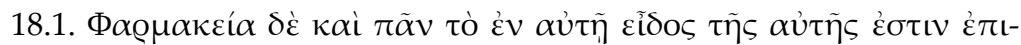

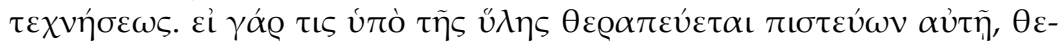

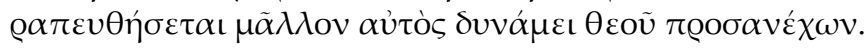


17.4. Die Art ihrer Trickserei aber ist folgende: Wie nämlich die Formen der Buchstaben und die aus ihnen gebildeten Zeilen nicht für sich selbst fähig sind, das Zusammengestellte mit Bedeutung zu füllen, sondern die Menschen sie als Anzeiger ihrer Gedanken für sich selbst geschaffen haben - wobei sie aus ihrer auf eine bestimmte Weise arrangierten Kombination erkennen, wie auch die Anordnung der Buchstaben sich nach der Regel verhält -, in ähnlicher Weise sind auch die vielfältigen Anwendungen von Wurzeln und Sehnen und Knochen nicht an und für sich irgendwie wirkmächtig, sondern sie sind die Instrumente ${ }^{281}$ der Schlechtigkeit der Dämonen. Diese haben festgelegt, zu welchen Wirkungen ein jedes von diesen Dingen tauglich sein soll, 17.5. und sobald sie beobachten, dass die durch sie festgelegte "Hilfe“ von den Menschen in Anspruch genommen worden ist, schalten sie sich ein und bringen die Menschen dazu, ihnen selbst zu dienen.

Wie aber könnte es gut sein, Ehebrüchen zur Hand zu gehen? ${ }^{282}$ Wie auch kann es ehrenhaft sein, hinzugehen und Menschen in ihrem Hass gegen andere zu unterstützen? ${ }^{283}$ Oder wie kann es schön sein, der Materie die Hilfe für Wahnsinnige zuzuschreiben und nicht Gott? Mit List nämlich wenden sie (= die Dämonen) die Menschen von der Gottesverehrung ab und bringen sie dazu, Gräsern und Wurzeln zu vertrauen; 17.6. Gott, wenn er diese Dinge dazu geschaffen hätte, dass sie tun, was die Menschen wollen, wäre ein Schöpfer schlechter Dinge gewesen, denn er selbst hat alles, was sich in irgendeiner Weise gut verhält, geschaffen; ${ }^{284}$ die Lasterhaftigkeit der Dämonen aber gebraucht die Dinge im Kosmos, um Übles zu tun; so stammt von ihnen die Kategorie der Schlechtigkeit und nicht von dem vollkommenen Gott.

17.7. Wie nämlich könnte ich als Lebender ganz und gar nicht schlecht sein, wenn ich aber tot bin, wird etwas, was an mir übrig ist, ohne dass ich etwas tue und ohne ${ }^{285}$ dass es sich bewegt oder gar etwas wahrnimmt, irgendetwas Wahrnehmbares zustandebringen? ${ }^{286} 17.8$. Und wie wird der, der durch einen ganz jämmerlichen Tod gestorben ist, ${ }^{287}$ in der Lage sein, zur Bestrafung irgendeines (anderen) einen Beitrag zu leisten? Wenn dies nämlich so sein könnte, wird er noch viel mehr den eigenen Feind von sich selbst abwehren; denn wenn er auch anderen helfen kann, wird er noch viel mehr zum Rächer seiner selbst werden.

18.1. Die Heilkunde ${ }^{288}$ und jegliche Erscheinung in ihr gehört der gleichen Trickserei an. Wenn nämlich jemand von der Materie geheilt wird, da er ihr vertraut, wird er noch viel sicherer geheilt werden, wenn er sich auf die Macht Gottes verlässt. 


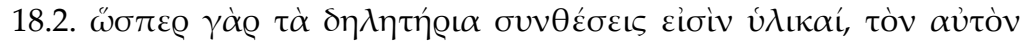

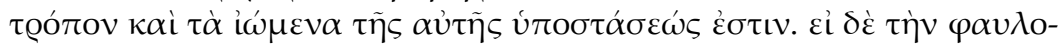

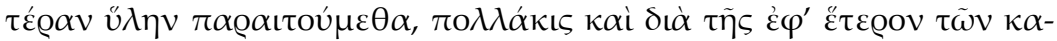

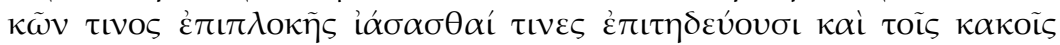

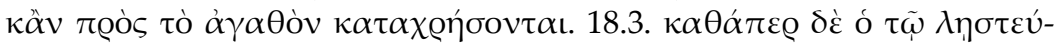

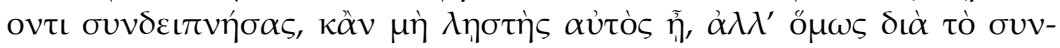

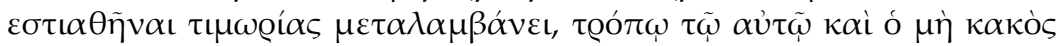

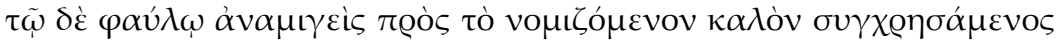

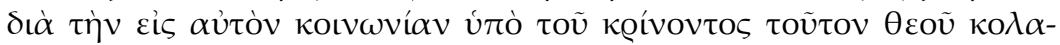
$\sigma \theta \eta \dot{\sigma \varepsilon \tau \alpha \iota . ~}$

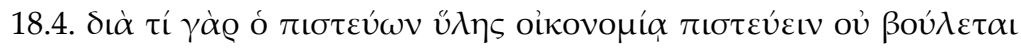

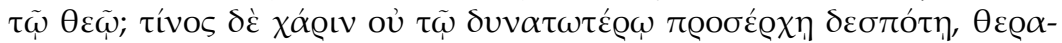

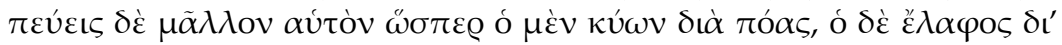

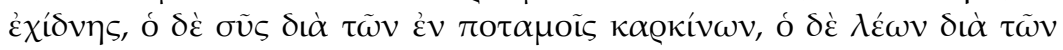

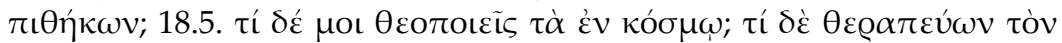

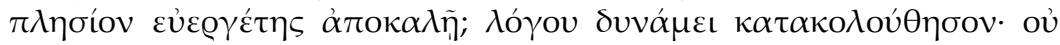

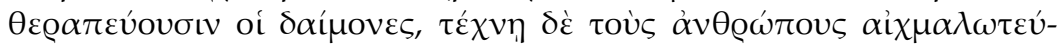

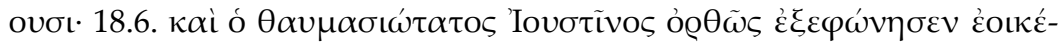

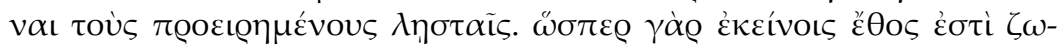

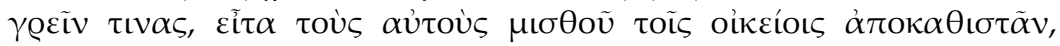

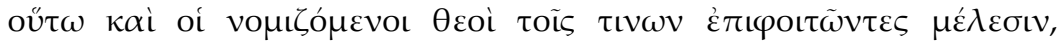

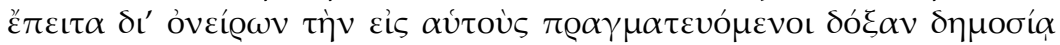

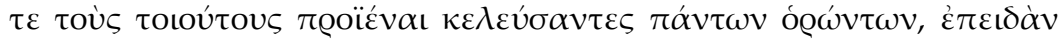

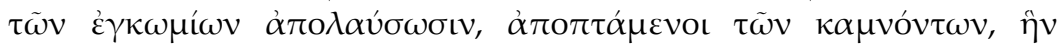

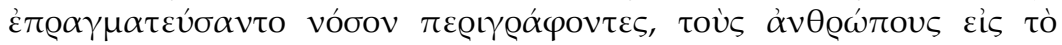

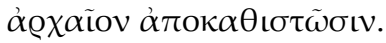

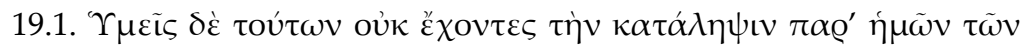

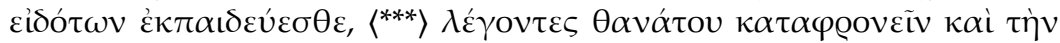

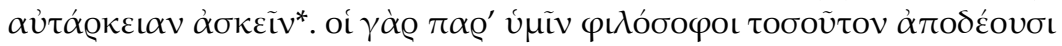

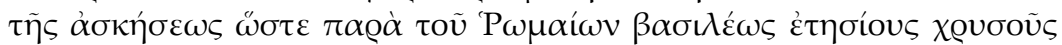

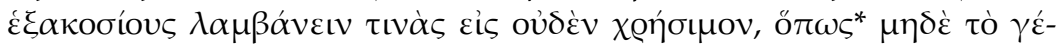

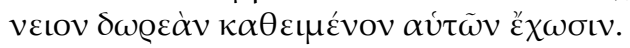


18.2. Wie nämlich die Gifte stoffliche Zusammensetzungen sind, so gehören auf die gleiche Weise auch die heilenden Mittel der gleichen Substanzart an. Wenn wir aber die schlechtere Materie ablehnen, so unternehmen es jedoch manche oft, auch durch die Verknüpfung eines der schlechten Mittel mit einem anderen ${ }^{289} \mathrm{zu}$ heilen, und sie werden die schlechten Mittel geradezu für das Gute "missbrauchen“. 18.3. Wie aber der, der sich zusammen mit einem Räuber an den gleichen Tisch setzt, auch wenn er selbst kein Räuber ist, und (daraufhin) gleichwohl in die Bestrafung einbezogen wird, weil er sich zusammen mit ihm hat bewirten lassen, auf die gleiche Weise wird auch der, der nicht übel ist, sich aber mit dem Üblen verbunden hat und ihn für das, was er für schön hält, mit einsetzt, ${ }^{290}$ wegen der Gemeinschaft mit ihm von Gott, der diesen richtet, bestraft werden.

18.4. Weshalb nämlich will derjenige, der der Wirkweise der Materie vertraut, nicht Gott vertrauen? Und aus welchem Grund gehst du nicht zu dem mächtigeren Herrn, sondern versuchst, dich selbst zu heilen wie der Hund durch Gras, der Hirsch durch die Schlange, das Schwein durch die Krebse in den Flüssen, der Löwe durch die Affen? ${ }^{291}$ 18.5. Weshalb machst du mir die Dinge in der Welt zu Göttern? Warum lässt du dich, wenn du deinen Nächsten heilst, Wohltäter nennen? Folge der Macht des Logos! Nicht wirklich heilen können die Dämonen, sondern sie machen durch Trickserei die Menschen zu ihren Gefangenen;'292 18.6. und der hochbewunderungswürdige Justin hat richtig den Ausspruch getan, dass die gerade Genannten Räubern gleichen. ${ }^{293}$ Wie es nämlich deren Gewohnheit ist, Leute gefangenzunehmen und die gleichen dann gegen Lösegeld ihren Angehörigen zurückzugeben, so suchen auch die angeblichen Götter die Glieder von Leuten heim; sodann betreiben sie durch Träume ${ }^{294}$ die Erzeugung einer Reputation für sich selbst, befehlen denen, die sich in solchem Zustand befinden, öffentlich aufzutreten $^{295}$ - wobei alle zuschauen -, und sobald sie die Lobeshymnen genossen haben, fliegen sie von den Kranken fort, beenden die Krankheit, die sie (selber) bewirkt hatten, und versetzen die Menschen wieder in ihren alten Zustand.

19.1. Ihr aber, die ihr diese Dinge nicht erfasst, lasst euch von uns, die um sie wissen, belehren, $<* * *>296$ behauptend, den Tod zu verachten und Selbstgenügsamkeit zu üben. Die bei euch agierenden Philosophen nämlich sind so weit von der Askese entfernt, dass einige vom römischen Kaiser jährlich 600 Goldstücke für keinen nützlichen Zweck beziehen, ${ }^{297}$ damit $^{298}$ sie nicht einmal ihren herabwallenden Bart ${ }^{299}$ umsonst haben. 


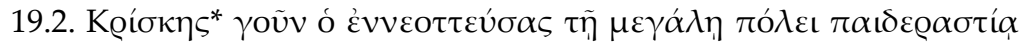

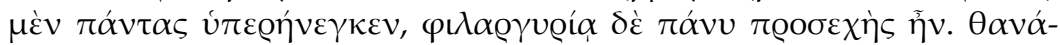

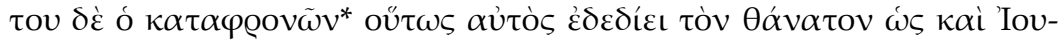

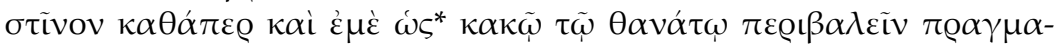

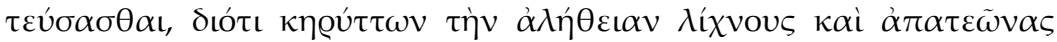

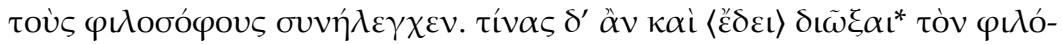

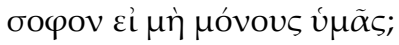

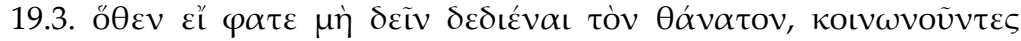

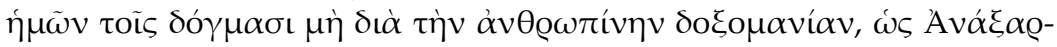

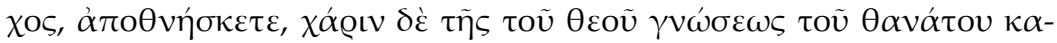

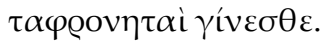

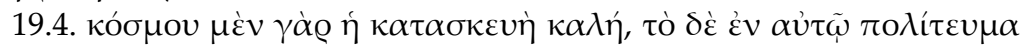

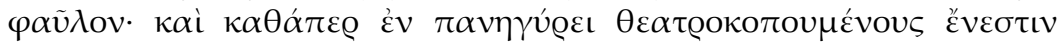

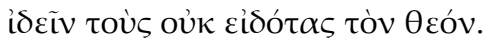

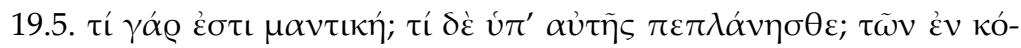

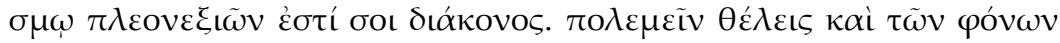

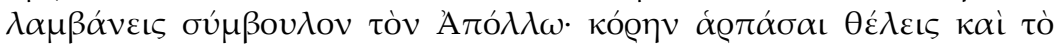

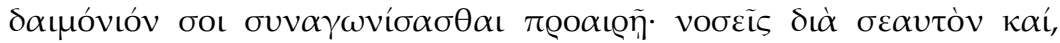

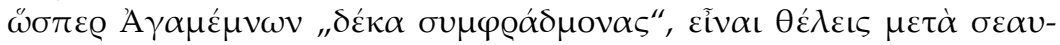

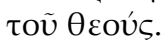

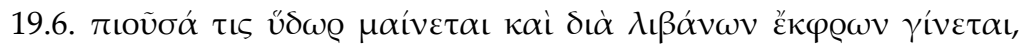

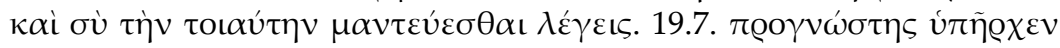

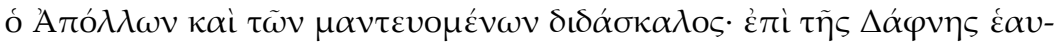

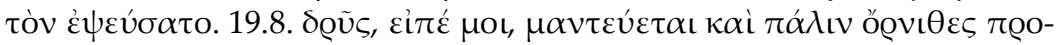

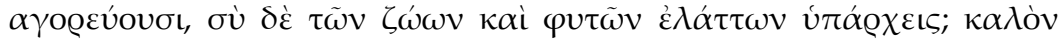

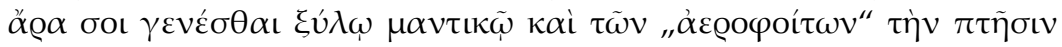
$\lambda \alpha \mu \beta \alpha ́ v \varepsilon เ v$.

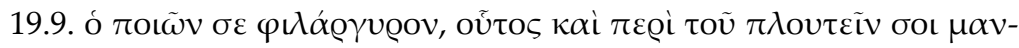

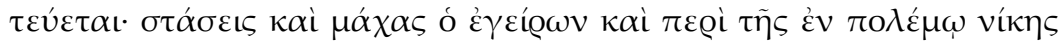

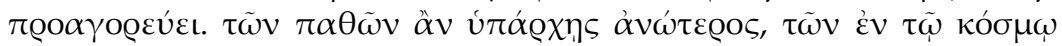

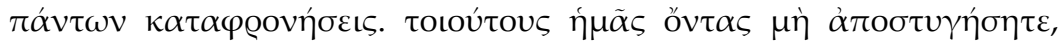

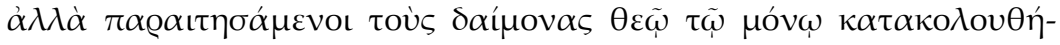

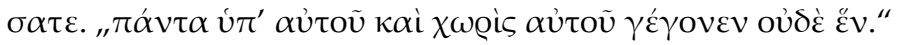

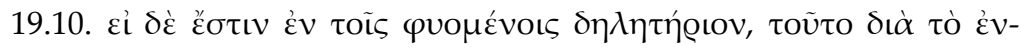

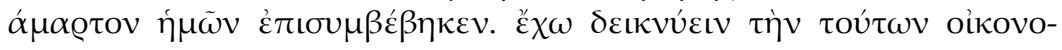

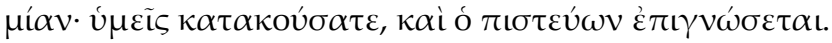


19.2. Crescens ${ }^{300}$ jedenfalls, der sein Nest in der großen Stadt gebaut hat, übertraf an Knabenliebe alle und war der Geldgier sehr zugetan. ${ }^{301}$ Er, der Todesverächter, ${ }^{302}$ fürchtete selbst ${ }^{303}$ den Tod so sehr, dass er sowohl Justin als auch mich ${ }^{304} \mathrm{zu}$ Tode $\mathrm{zu}$ bringen betrieb, als ob das ein Übel sei; er tat dies, weil Justin die Wahrheit verkündete und die Philosophen als Schlemmer und Betrüger entlarvte. Welche Leute aber hätte der „Philosoph“ eigentlich verfolgen sollen, wenn nicht euch allein?305

19.3. Wenn ihr deshalb sagt, man dürfe den Tod nicht fürchten - womit ihr mit unseren Lehren übereinstimmt -, dann sterbt nicht, wie Anaxarchos, ${ }^{306}$ wegen der menschlichen Verrücktheit nach Ruhm, sondern werdet um der Erkenntnis Gottes willen zu Verächtern des Todes!

19.4. Denn der Bau der Welt ist schön, ${ }^{307}$ aber der in ihm grassierende Lebenswandel schlecht, und wie bei einem Fest ${ }^{308}$ kann man hier Leute um Beifall heischen ${ }^{309}$ sehen, die Gott nicht kennen.

19.5. Was nämlich ist die Seherkunst? Warum lasst ihr euch von ihr in die Irre führen? Sie ist dir nur eine Dienerin der Begehrlichkeiten in der Welt. Krieg führen willst du, und als Ratgeber für die (geplanten) Morde ziehst du Apollon hinzu; 310 ein Mädchen rauben willst du, und du möchtest, dass die Gottheit ${ }^{311}$ dein Komplize ist; krank bist du aus eigenem Verschulden, und wie Agamemnon zehn Ratgeber ${ }^{312}$ wünschst du auf deiner Seite Götter zu haben. ${ }^{313}$

19.6. Eine Frau gebärdet sich verrückt, nachdem sie Wasser getrunken hat, und gerät durch Weihrauch von Sinnen, ${ }^{314}$ und du behauptest, dass die sich so gerierende Person weissage. 19.7. Ein Vorauswisser war Apollon und Lehrer der Weissager - bei Daphne hat er sich selbst getäuscht. 315 19.8. Sag mir: Eine Eiche prophezeit, 316 und wiederum Vögel $^{317}$ sagen Dinge voraus - du aber bist geringer als die Tiere und Pflanzen? Da wäre es dann gut für dich, ein weissagendes Holz zu werden und von den „Luftwandlern" 318 das Fliegen zu nehmen.

19.9. Der, der dich geldgierig macht, der gibt dir auch Weissagungen über das Reichsein; der, der Aufstände und Schlachten provoziert, macht auch Voraussagen über den Sieg im Krieg. ${ }^{319}$ Wenn du über die Leidenschaften erhaben bist, wirst du auf alle Dinge in der Welt herabsehen. Da wir von solcher Art sind, verabscheut uns nicht, sondern schwört den Dämonen ab und folgt dem einzigen Gott! "Alles ist von ihm und ohne ihn ist nichts gemacht." 320

19.10. Wenn es aber in den Dingen, die gewachsen sind, etwas Schädliches gibt, dann ist dies durch unsere Sündhaftigkeit in die Welt gekommen. Ich bin in der Lage, den diesen Dingen zugrundeliegenden Prozess aufzuzeigen; hört ihr zu, und der, der glaubt, wird zur Erkenntnis kommen. 


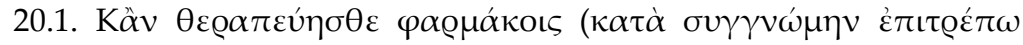

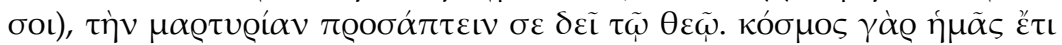

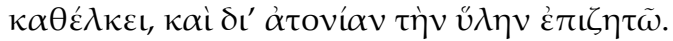

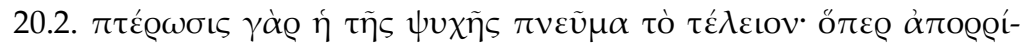

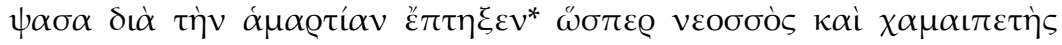

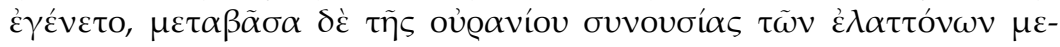

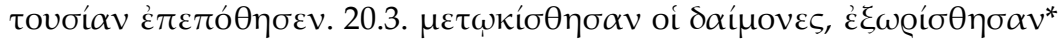

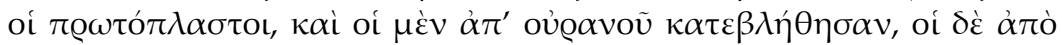

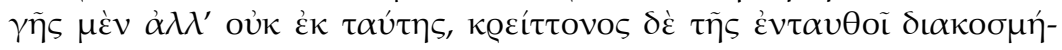
$\sigma \varepsilon \omega \varsigma$.

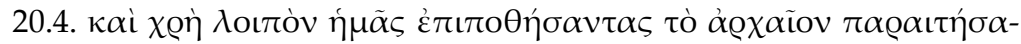

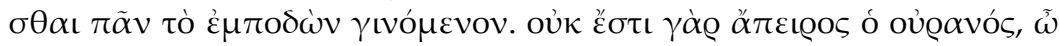

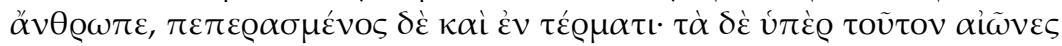

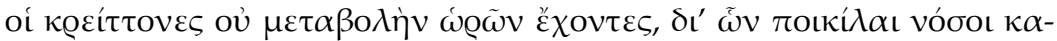

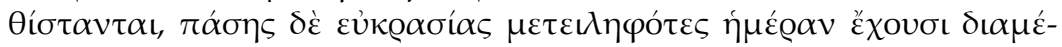

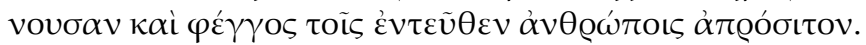

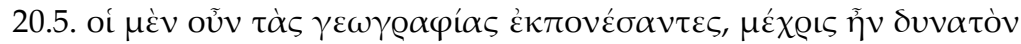

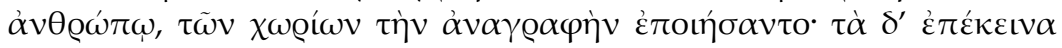

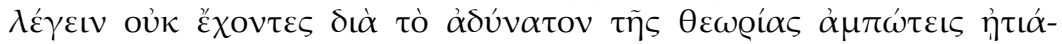

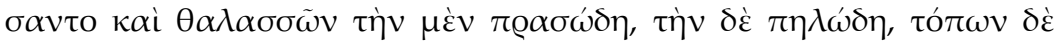

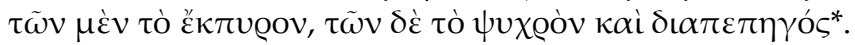

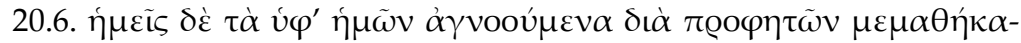

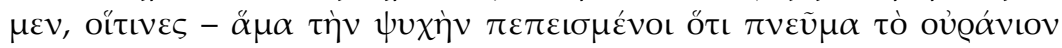

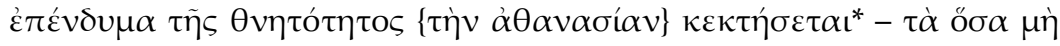

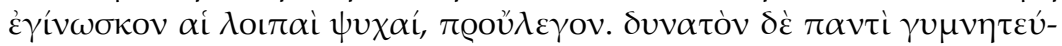

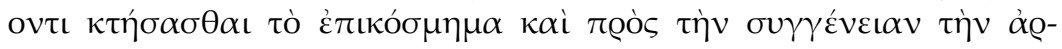

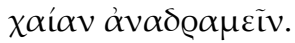

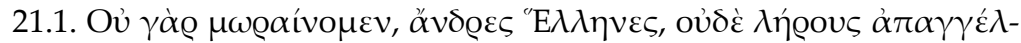

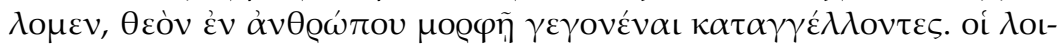

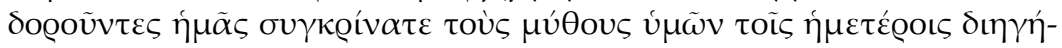
$\mu \alpha \sigma i v$.

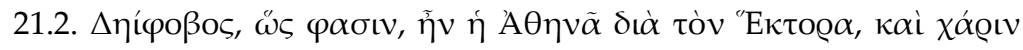

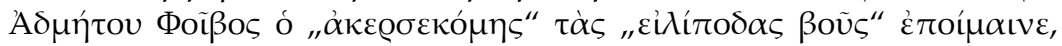


20.1. Und auch wenn ihr durch Arzneimittel geheilt werdet (ich will dir das großzügig zugestehen), so musst du doch das Zeugnis für die Heilung Gott beilegen. Die Welt nämlich zieht uns (immer) noch hinab, und wegen meiner Schwäche suche ich meine Zuflucht in der Materie.

20.2. Beflügelung der Seele nämlich ist der vollkommene Geist; als sie ihn wegen ihrer Sünde verloren hatte, duckte sie sich ${ }^{321}$ wie ein Küken und kroch nur noch auf der Erde umher, und da sie aus der himmlischen Gemeinschaft gewichen war, erstrebte sie Gemeinschaft mit den niedrigeren Erscheinungen. ${ }^{322}$ 20.3. Umgesiedelt ${ }^{323}$ wurden die Dämonen, verbannt die "zuerst Geformten",324 und die einen wurden vom Himmel herabgeworfen, die anderen von der Erde, jedoch nicht von dieser (unserer), sondern von einer besseren als die hier eingerichtete. ${ }^{325}$

20.4. Und so müssen wir künftig, wenn wir den früheren Zustand ersehnen, von allem uns lossagen, was im Weg steht. Denn nicht unendlich ist der Himmel, Mensch, sondern umgrenzt und endlich; und was jenseits von ihm liegt, sind bessere Welten ohne einen Wechsel der Jahreszeiten, durch die mannigfache Krankheiten entstehen; und da sie an einem in jeder Hinsicht guten Klima Anteil haben, verfügen sie über einen immerwährenden Tag und ein Licht, das den hier unten lebenden Menschen unzugänglich ist. ${ }^{326}$

20.5. Diejenigen nun, die die Erdbeschreibungen ausarbeiteten, fertigten Darstellungen der Regionen an, soweit es einem Menschen möglich war; da sie jedoch über das jenseits davon Befindliche nichts sagen konnten - aufgrund der Unmöglichkeit, diese Dinge zu schauen -, postulierten sie Gezeiten ${ }^{327}$, und dass von den Meeren das eine lauchgrün $^{328}$, das andere schlammig sei, ${ }^{329}$ und von den einen Gebieten nahmen sie eine feurige Natur an, von den anderen eine kalte und völlig gefrorene. ${ }^{330}$

20.6. Wir aber haben das, was wir nicht wissen, durch Propheten erfahren, ${ }^{331}$ die - wobei sie zugleich überzeugt waren, dass die Seele den himmlischen Geist als Umhüllung ihrer Sterblichkeit besitzen wird ${ }^{332}$ all das voraussagten, was die übrigen Seelen nicht erkannten. Es ist aber für jeden, der nackt ist, ${ }^{333}$ möglich, diesen Schmuck zu erwerben und zurückzukehren zur alten Verwandtschaft.

21.1. Wir sind nämlich keine Dummköpfe, ihr Griechen, und wir verkünden auch keinen Unsinn, wenn wir verkünden, dass Gott in Menschengestalt erschienen ist. Ihr, die ihr uns beschimpft: Vergleicht einmal eure Mythen mit unseren Erzählungen! ${ }^{334}$

21.2. Athena, wie man sagt, war einmal Deïphobos wegen Hektor, ${ }^{335}$ und um Admets willen weidete Phoibos, ${ }^{336}$ der „mit den ungeschorenen 


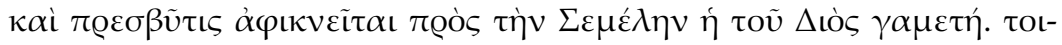
$\alpha \tilde{v} \tau \alpha \delta \dot{\varepsilon} \mu \varepsilon \lambda \varepsilon \tau \tilde{\omega} \nu \tau \varepsilon \varsigma \pi \tilde{\omega} \varsigma \dot{\eta} \mu \tilde{\alpha} \varsigma \delta\llcorner\alpha \gamma \varepsilon \lambda \tilde{\alpha} \tau \varepsilon$

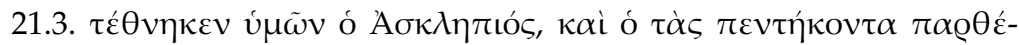

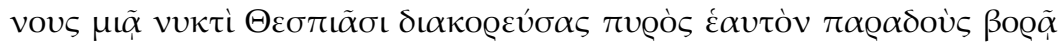

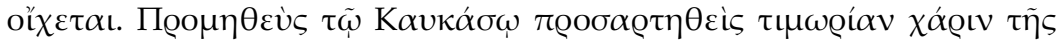

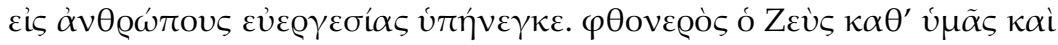

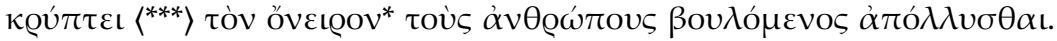

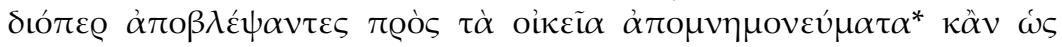

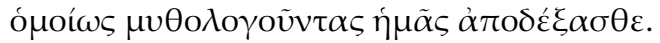

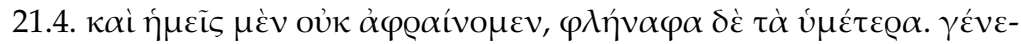

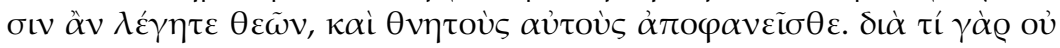

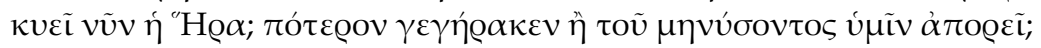

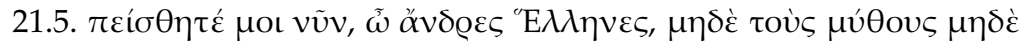

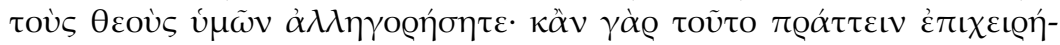

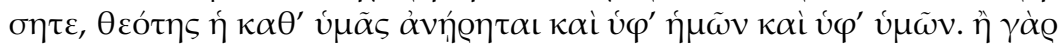

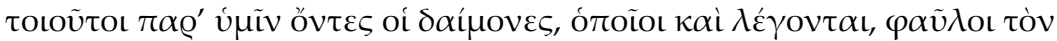

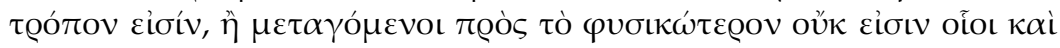

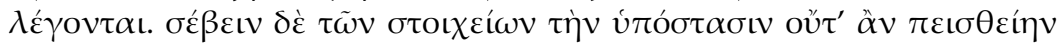

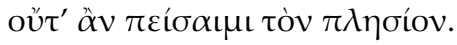

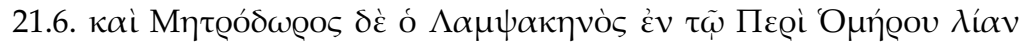

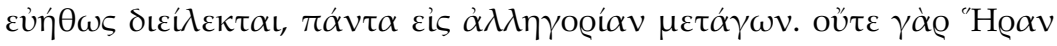

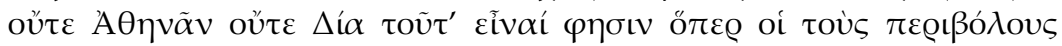

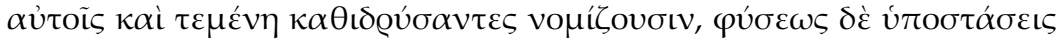

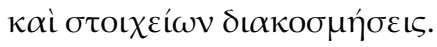

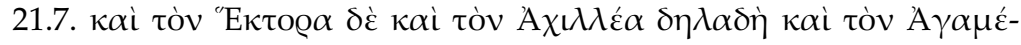

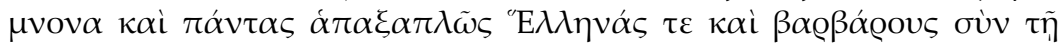

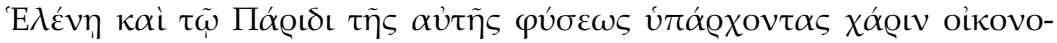

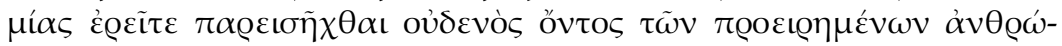
$\pi \omega v$. 
Haaren", 337 die "schleppfüßigen Rinder", 338 und als alte Frau kommt zu Semele die Gattin des Zeus. ${ }^{339}$ Wenn ihr solchen Geschichten eure Aufmerksamkeit schenkt, wie könnt ihr euch da über uns lustig machen?

21.3. Tot ist euer Asklepios, ${ }^{340}$ und der, der die fünfzig Jungfrauen in einer einzigen Nacht in Thespiai entjungferte, ${ }^{341}$ überantwortete sich selbst dem Fraß des Feuers und ist dahin. ${ }^{342}$ Prometheus wurde an den Kaukasos angekettet und erlitt dies als Strafe für seine Wohltat gegenüber den Menschen. ${ }^{343}$ Neidisch ist Zeus nach eurer Darstellung und verbirgt $<^{* * *}>$ den Traum, ${ }^{344}$ weil er will, dass die Menschen zugrunde gehen. Schaut deshalb einmal in die eigenen ,Unterlagen ${ }^{345}$ und akzeptiert uns, und sei es auch nur als Leute, die in gleicher Weise Mythen erzählen!

21.4. Und wir jedenfalls sind nicht von Sinnen, Unsinn dagegen sind eure Geschichten. Wenn ihr eine Entstehung von Göttern erzählt, werdet ihr sie auch als sterblich erweisen. ${ }^{346}$ Weshalb denn ist Hera jetzt nicht (mehr) schwanger? ${ }^{347}$ Ist sie alt geworden oder hat sie keinen, der es euch verkünden kann?

21.5. Glaubt mir nun, ihr Griechen, und allegorisiert nicht eure Mythen und auch nicht eure Götter;,;48 wenn ihr nämlich dies zu tun unternehmt, dann ist "Göttlichkeit", wie ihr sie versteht, aufgehoben, und zwar sowohl von uns als auch von euch selbst. Entweder nämlich sind eure Dämonen, wenn sie von der Art sind, wie man es ja auch behauptet, in ihrem Wesen schlecht, oder aber sie sind, wenn man sie ins mehr Physikalische hin deutet, nicht von der Art, wie man es eben behauptet. Die Substanz von Elementen aber zu verehren, dazu lasse ich mich weder selber überreden, noch würde ich meinen Nächsten dazu bringen wollen.

21.6. Und Metrodor von Lampsakos ${ }^{349}$ hat in seiner Schrift „Über Homer" doch allzu törichte Ausführungen gemacht, da er alles in Allegorie zu überführen versucht. Weder nämlich Hera noch Athena noch Zeus seien das - behauptet er -, was die glauben, die ihnen Umfriedungen und Tempelbezirke errichtet haben, sondern Wesenheiten der Natur und Anordnungen von Elementen.

21.7. Und was natürlich Hektor und Achill und Agamemnon und überhaupt alle Griechen und Barbaren zusammen mit Helena und Paris betrifft, da werdet ihr sagen, dass sie von der gleichen Natur sind und nur wegen der literarischen Komposition neben den Göttern eingeführt wurden, da keiner von den gerade genannten Menschen (jemals) existierte. 


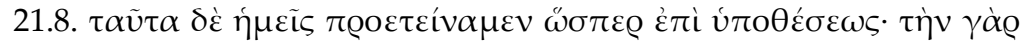

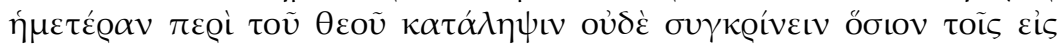

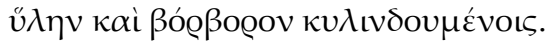

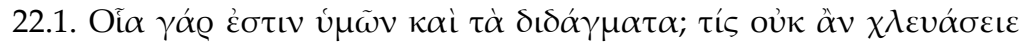

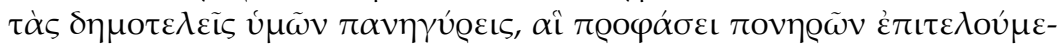

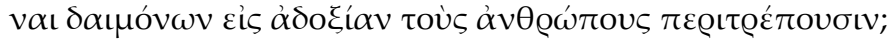

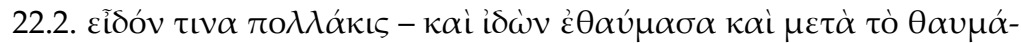

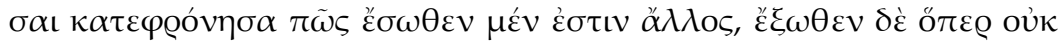

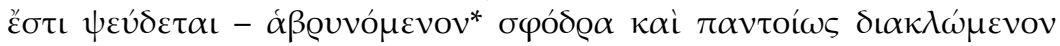

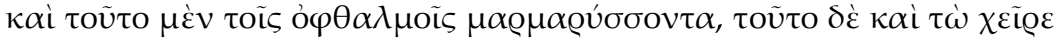

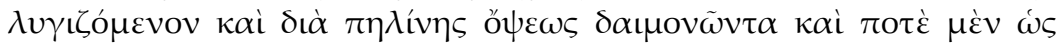

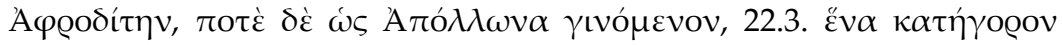

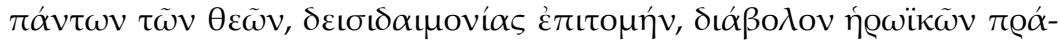

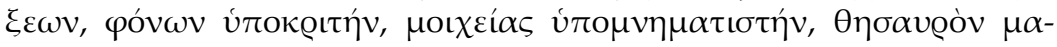

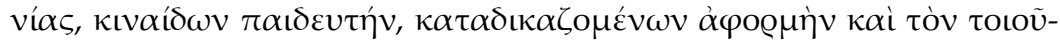

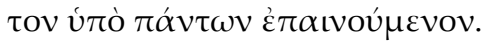

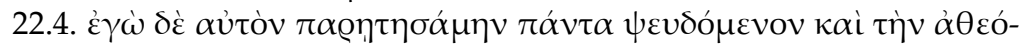

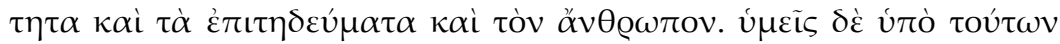

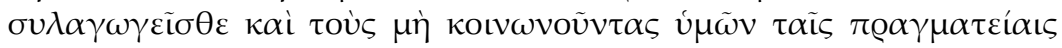

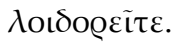

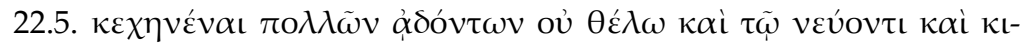

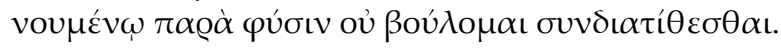

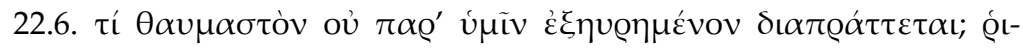

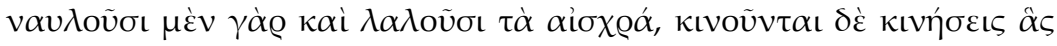

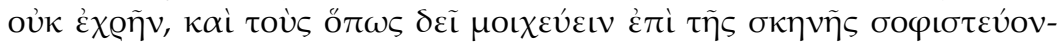

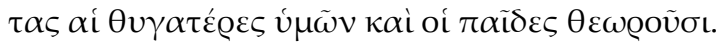

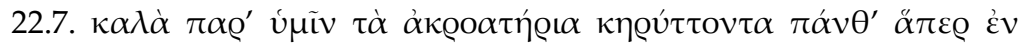

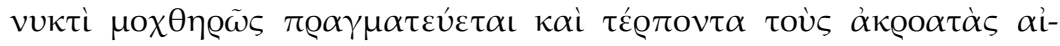

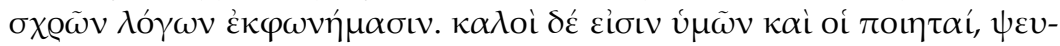

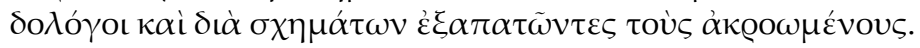


21.8. Dies jedoch habe ich hier nur gleichsam hypothetisch entwickelt; denn was unseren Begriff von Gott betrifft, so wäre es blasphemisch, ihn mit den "Göttern"auch nur zu vergleichen, die sich in Materie und Schlamm wälzen. ${ }^{350}$

22.1. Denn welcher Art sind auch eure „Unterweisungen“?351 Wer dürfte nicht über eure öffentlichen Festversammlungen spotten, die um schlechter Dämonen willen zelebriert werden ${ }^{352}$ und die Menschen nur in schlechten Ruf bringen?

22.2. Ich habe da einen oft gesehen - und nachdem ich ihn sah, war ich verwundert, und nach der Verwunderung kam bei mir die Verachtung darüber, wie er innen drin ein anderer ist, äußerlich aber etwas zu sein fingiert, was er nicht ist -, wie er ${ }^{353}$ sehr affektiert auftrat und sich auf allerlei Art verrenkte und zum einen mit seinen Augen funkelte, zum anderen auch seine beiden Hände verdrehte und durch eine Tonmaske den Verrückten spielte und bald wie Aphrodite, bald wie Apollon wurde, ${ }^{354}$ 22.3. ein Ankläger aller Götter in einer Person, eine Zusammenfassung des Aberglaubens, ein Verleumder heldischer Taten, ein Darsteller von Morden, ein Chronist von Ehebruch, ${ }^{355}$ eine Schatzkammer des Wahnsinns, ein Erzieher von Strichjungen, eine Inspiration für Leute, die einmal verurteilt werden ${ }^{356}$ - und einer, der, obwohl er von dieser Art ist, von allen Applaus bekommt! 22.4. Ich aber wies ihn zurück, da er alles fälscht: (Ich lehne ab) seine Gottlosigkeit, seine Tätigkeiten, den (ganzen) Menschen. ${ }^{357}$ Ihr aber lasst euch von diesen Leuten faszinieren und beschimpft diejenigen, die sich nicht an eurem Treiben beteiligen.

22.5. Mit offenem Mund dabei sein, wenn viele singen, ${ }^{358}$ das will ich nicht, und ich will auch nicht zusammen mit dem, der widernatürlich gestikuliert und sich bewegt. ${ }^{359}$

22.6. Welches sonderbare Zeug ist nicht von euch erfunden worden und wird vorgeführt? Man schnaubt durch die Nase, ${ }^{360}$ erzählt Zoten, bewegt sich, wie man nicht sollte, und diejenigen, die auf der Bühne kunstvoll vorführen, wie man Ehebruch praktizieren soll, die sind ein Schauspiel für eure Töchter und Söhne. ${ }^{361}$

22.7. Ihr habt wunderbare Hör-Säle, die alles verkünden, was nachts auf schändliche Weise praktiziert wird, und die Zuhörer mit der lauten Darbietung schändlicher Reden erfreuen. ${ }^{362}$ Wunderbar sind auch eure Dichter, Lügenerzähler und Leute, die mit Hilfe stilistischen Putzes die Zuhörenden hinters Licht führen. 


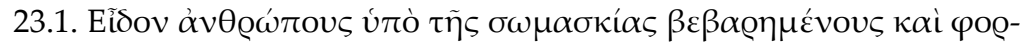

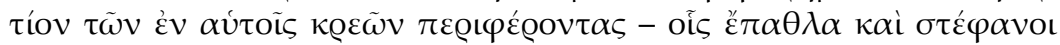

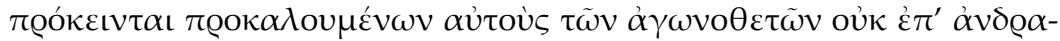

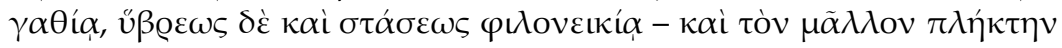

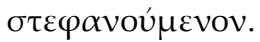

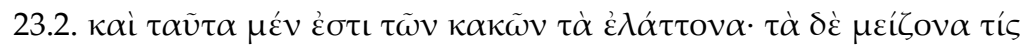

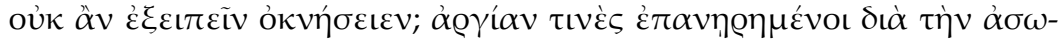

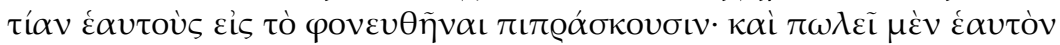

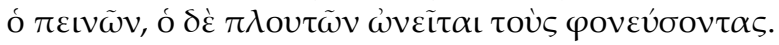

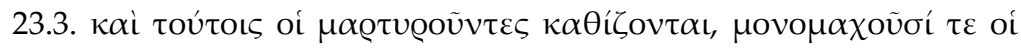

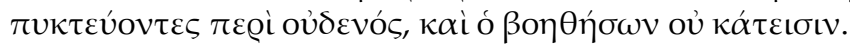

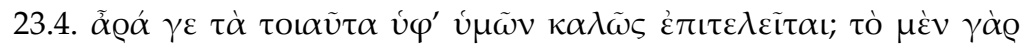

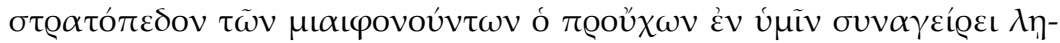

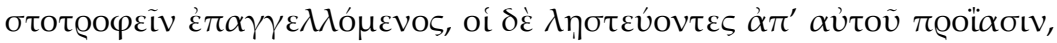

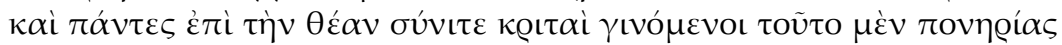

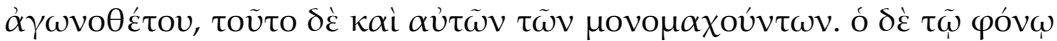

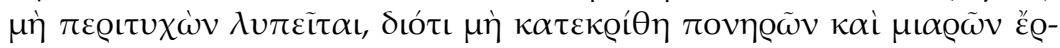

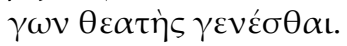

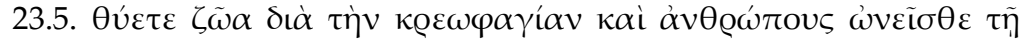

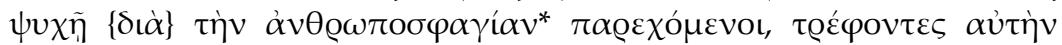

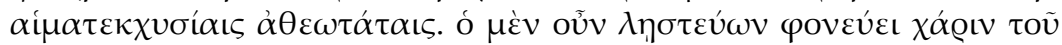

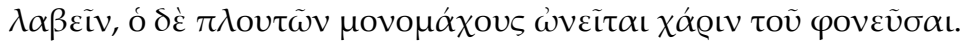

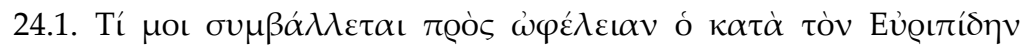

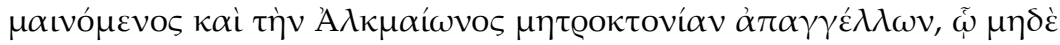

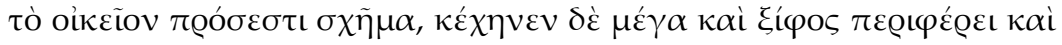

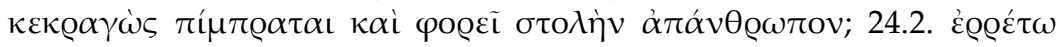

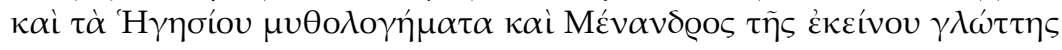

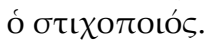

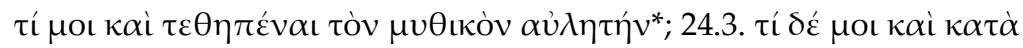

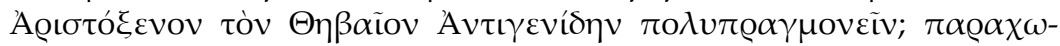


23.1. Ich sah, wie Menschen infolge ihrer ,körperlichen Ertüchtigung schwer geworden sind und die Last der in ihnen befindlichen Fleischmengen herumtragen ${ }^{363}$; ihnen sind Belohnungen und Siegerkränze ausgesetzt, wobei die Kampfrichter sie nicht zu männlicher Tapferkeit aufrufen, sondern zu einem Wettstreit in Frevel und Aufruhr, und (ich sah) wie der bekränzt wird, der in höherem Maße zuschlägt.

23.2. Und das sind noch die geringeren von den Übeln; was die größeren $^{364}$ betrifft - wer würde wohl nicht zögern, sie auszusprechen? Manche Leute haben das Nichtstun auf ihre Fahnen geschrieben und verkaufen sich um ihres zügellosen Lebenswandels willen selbst, um sich abschlachten zu lassen; und es verkauft sich auch selbst der, der hungert, während der Reiche die kauft, die zu Schlächtern werden sollen. 365

23.3. Und bei ihnen sitzen diejenigen, die Zeugen (dieses Geschehens) sein könnten, es kämpfen die, die da ringen, ${ }^{366}$ um ein Nichts, und einer, der helfen sollte, steigt nicht (in die Arena) hinab.

23.4. Werden also solche Dinge schön von euch ausgeführt? Das Heerlager brutaler Mörder sammelt der, der bei euch das Sagen hat, und macht sich anheischig, sie wie Räuber zu ernähren, sie aber gehen als Räuber aus seiner Obhut hervor, und alle strömt ihr zum Spektakel zusammen und werdet dabei Richter zum einen über die Schlechtigkeit des Spieleveranstalters, zum anderen über die der Gladiatoren selbst. Wer aber bei dem Morden nicht dabei sein konnte, ist betrübt, dass er nicht dazu verurteilt wurde, zum Betrachter von schlechten und scheußlichen Taten zu werden.

23.5. Ihr opfert Tiere um des Fleischverzehrs willen, ${ }^{367}$ und ihr kauft Menschen und präsentiert damit eurer Seele die Schlachtung von Menschen; 368 dadurch nährt ihr sie mit gottlosesten Blutvergießungsorgien. Der, der als Räuber lebt, tötet, um zu rauben; der Reiche aber kauft Gladiatoren, um zu morden.

24.1. Was trägt mir zu meinem Heile derjenige bei, der à la Euripides tobt und den Muttermord des Alkmaion verkündet, 369 der auch nicht seine normale Erscheinung wahrt, sondern den Mund weit aufsperrt, ein Schwert mit sich herumschleppt, vor lauter Schreien geradezu in Flammen steht und ein Gewand trägt, das $\mathrm{zu}$ keinem Menschen passt? ${ }^{370}$ 24.2. Fort auch mit den Mythengeschichten des Hegesias ${ }^{371}$ und mit Menander, ${ }^{372}$ der seine Verse für die Zunge jenes Menschen ${ }^{373}$ gedichtet hat!

Was soll es mir auch, den mythischen Flötenspieler ${ }^{374} \mathrm{zu}$ bestaunen? 24.3. Was soll es mir auch, nach Art des Aristoxenos ${ }^{375}$ ein Gewese um 


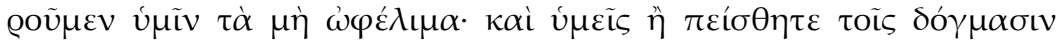

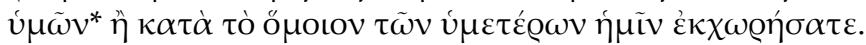

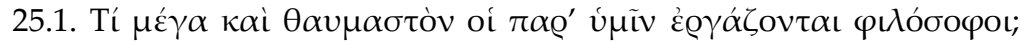

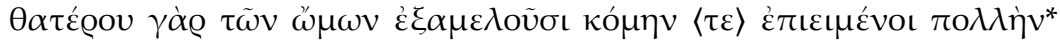

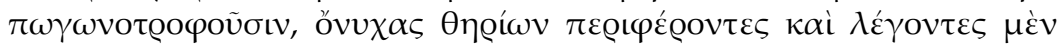

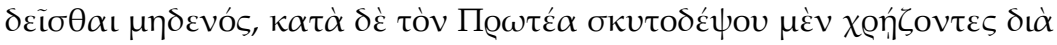

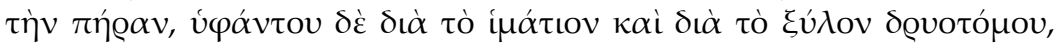

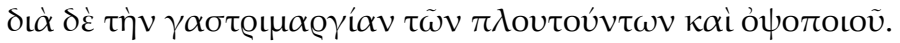

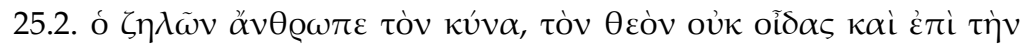

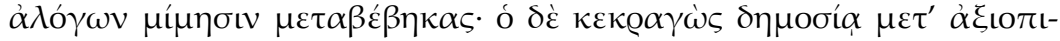

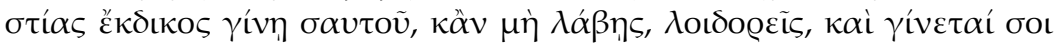

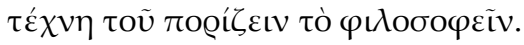

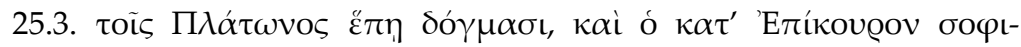

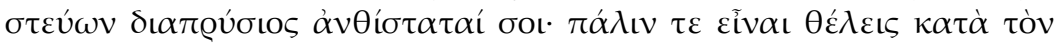

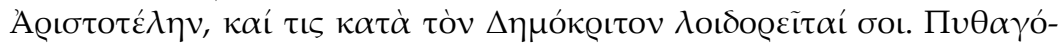

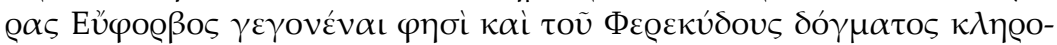

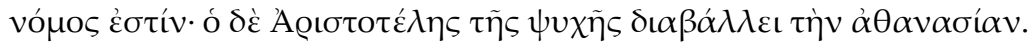

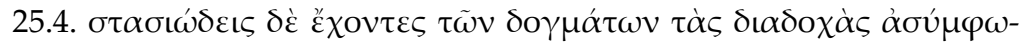

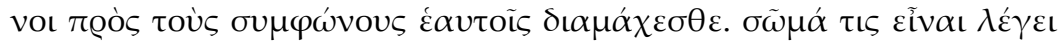

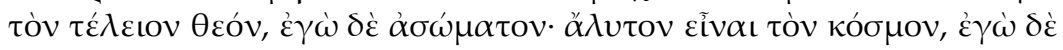

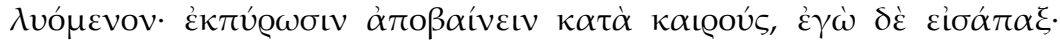

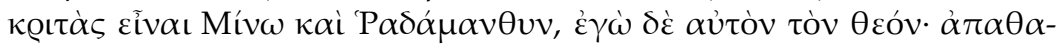

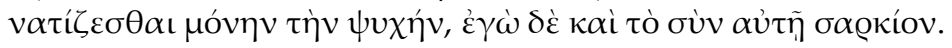

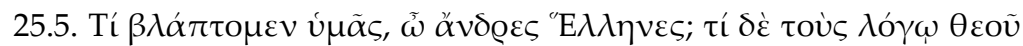

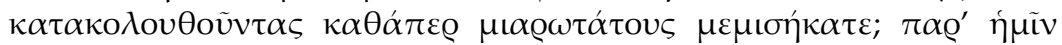

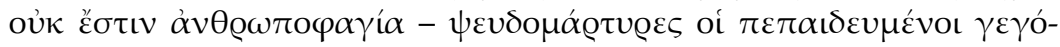

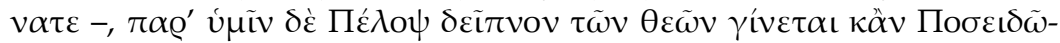

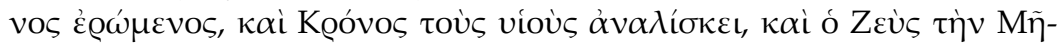

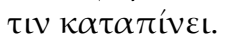


den Thebaner Antigenides zu machen? Wir überlassen euch das nutzlose Zeug. Und was euch betrifft: Glaubt entweder euren Lehren ${ }^{376}$ oder verlasst euer Zeug ähnlich wie wir!

25.1. Was bringen eure Philosophen Großes und Wunderbares zustande? Sie lassen die eine ihrer Schultern frei, ${ }^{377}$ lassen ihr Haar üppig wachsen ${ }^{378}$ und betreiben Bartwuchs; ${ }^{379}$ sie tragen die Krallen von Tieren mit sich herum und behaupten, völlig bedürfnislos zu sein, brauchen aber - wie man bei Proteus ${ }^{380}$ sieht - einen Gerber für den Ranzen, ${ }^{381}$ einen Weber für das Gewand und für den Stock ${ }^{382}$ einen Holzfäller, für ihre Gefräßigkeit ${ }^{383}$ aber die Reichen und einen Koch.

25.2. Mensch, der du dem Hund nacheiferst, ${ }^{384}$ Gott kennst du nicht und bist zur Nachahmung unvernünftiger Wesen übergegangen; du schreist mit vertrauenheischender Pose öffentlich herum ${ }^{385}$ und wirst zum Anwalt deiner selbst, und wenn du nichts bekommst, dann schimpfst du, und zur Erwerbskunst wird dir das Philosophieren. 386

25.3. Den Lehren Platons folgst du, und der, der à la Epikur seine Spitzfindigkeiten vertritt, stellt sich dir mit durchdringendem Schrei ${ }^{387}$ entgegen; dann wiederum willst du auf der Seite des Aristoteles sein, und einer à la Demokrit beschimpft dich. ${ }^{388}$ Pythagoras behauptet, er sei Euphorbos gewesen, ${ }^{389}$ und ist Erbe der Lehre des Pherekydes, ${ }^{390}$ Aristoteles aber verleumdet die Unsterblichkeit der Seele. ${ }^{391}$

25.4. Während ihr Lehrtraditionen habt, die voller Konflikte sind, und (selber) untereinander nicht übereinstimmt, streitet ihr gegen die, die untereinander in Übereinstimmung sind. Ein Körper, so behauptet einer, sei der vollkommene Gott, ${ }^{392}$ ich aber sage, dass er körperlos ist; unauflösbar (sagt einer) sei der Kosmos ${ }^{393}$, ich aber, dass er aufgelöst wird; eine Auflösung im Feuer (sagt einer) finde zu bestimmten Zeiten statt, ${ }^{394}$ ich aber (sage): nur einmal; Richter seien (sagt einer) Minos und Rhadamanthys, ${ }^{395}$ ich aber: Gott selbst; Unsterblichkeit (sagt einer) erlange nur die Seele, ich aber: auch der kleine fleischliche Leib, der mit ihr zusammen ist. 396

25.5. Was für einen Schaden fügen wir euch zu, ihr Griechen? Warum hasst ihr diejenigen, die dem Logos Gottes folgen, wie die Verworfensten (aller Menschen)? Bei uns gibt es keine Menschenfresserei ${ }^{397}$ - da seid ihr, die Gebildeten, zu falschen Zeugen geworden -, bei euch aber wird Pelops zum Mahl für die Götter, obwohl er ein Geliebter des Poseidon ist, ${ }^{398}$ und Kronos verspeist seine Söhne ${ }^{399}$, und Zeus verschlingt die Metis. ${ }^{400}$ 


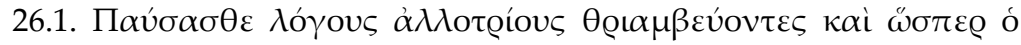

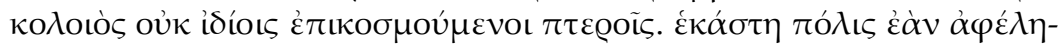

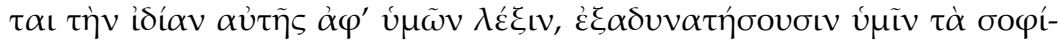
$\sigma \mu \alpha \tau \alpha$.

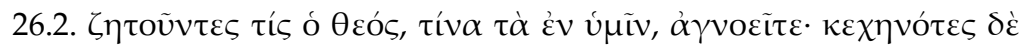

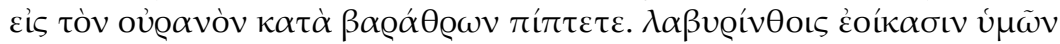

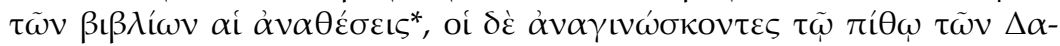
vait $\delta \omega v$.

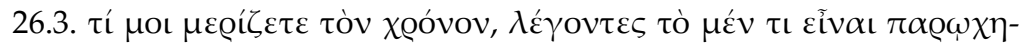

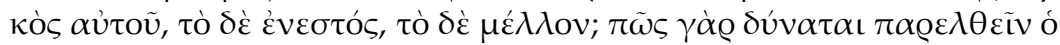

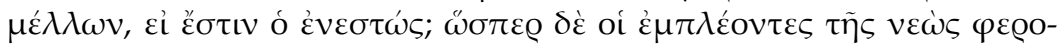

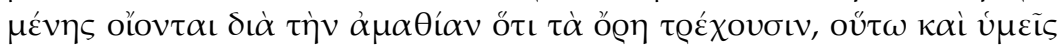

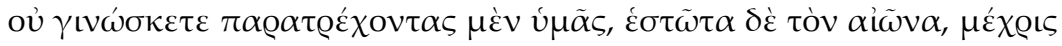

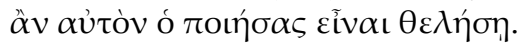

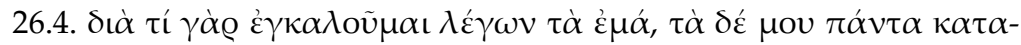

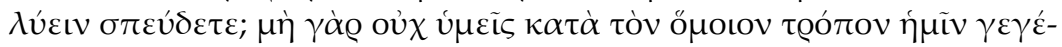

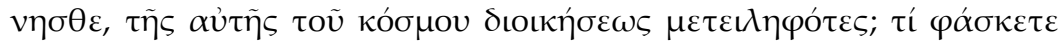

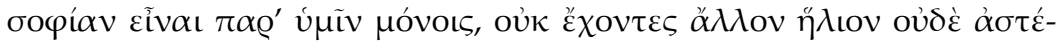

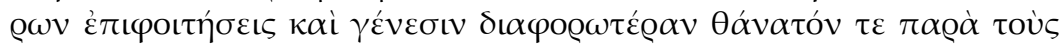

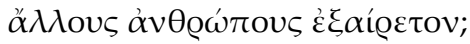

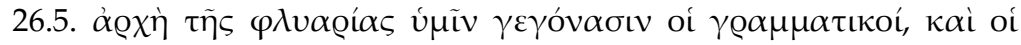

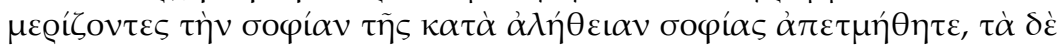

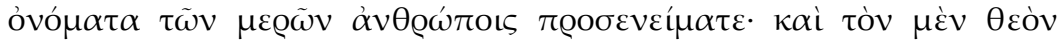

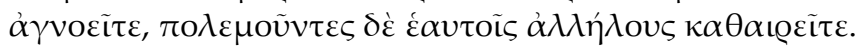

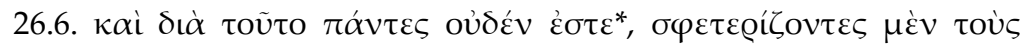
$\lambda$

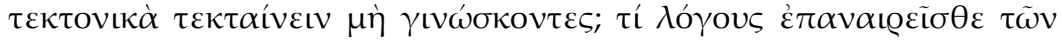

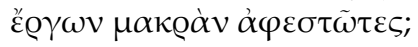

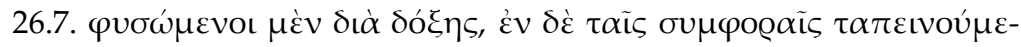

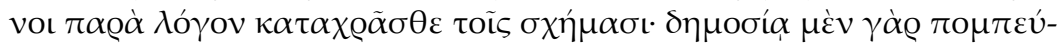

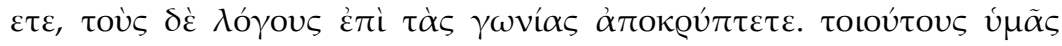

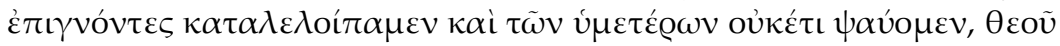

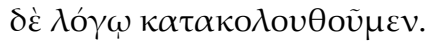

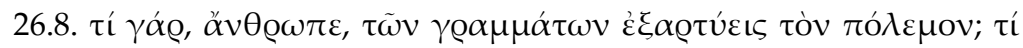

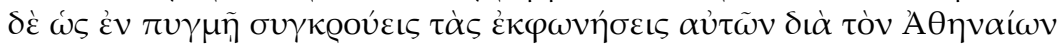


26.1. Hört auf damit, fremde Darlegungen zu paradieren und euch wie die Dohle mit fremden Federn zu schmücken. ${ }^{401}$ Wenn eine jede Stadt die ihr eigene Ausdrucksweise euch wieder wegnimmt, werden eure Spitzfindigkeiten unhaltbar sein.

26.2. Ihr sucht danach, was Gott ist, und wisst nicht, was in euch ist. ${ }^{402}$ Ihr schaut mit offenem Mund gen Himmel und fallt in Gruben. ${ }^{403}$ Labyrinthen $^{404}$ gleichen die Aufstellungen ${ }^{405}$ eurer Bücher und die, die sie lesen, dem Fass der Danaiden. ${ }^{406}$

26.3. Was zerteilt ihr mir die Zeit und behauptet, der eine Teil von ihr sei vergangen, der andere gegenwärtig, der dritte zukünftig? Wie kann denn die Zukunft vorbeigehen, wenn (dazwischen) die Gegenwart existiert? ${ }^{407}$ Und wie die, die auf einem Schiff fahren, bei dessen Bewegung wegen ihrer Dummheit glauben, dass die Berge (vorbei)laufen, ${ }^{408}$ so erkennt auch ihr nicht, dass ihr vorbeilauft, das Zeitalter aber feststeht, solange der, der es geschaffen hat, will, dass es existiert.

26.4. Warum macht man mir Vorwürfe, wenn ich sage, was mir am Herzen liegt, und warum trachtet ihr so eifrig, alles, was von mir kommt, zu vernichten? Seid ihr denn nicht in gleicher Weise wie wir entstanden und habt Anteil an derselben Weltordnung? Warum behauptet ihr, Weisheit sei bei euch allein, obwohl ihr keine andere Sonne habt, ${ }^{409}$ keine anderen Aufgänge von Sternen, keine ausgezeichnetere Geburt und keinen Tod, der gegenüber den anderen Menschen etwas Besonderes ist?

26.5. Am Anfang eures Geschwätzes stehen die Grammatiker, ${ }^{410}$ und da ihr die Weisheit aufteiltet, wurdet ihr von der wahren Weisheit abgeschnitten, und die Namen der Teile habt ihr Menschen zugewiesen. ${ }^{411}$ Und Gott kennt ihr nicht; vielmehr führt ihr mit euch selbst Krieg und bringt euch gegenseitig um. ${ }^{412}$

26.6. Und deswegen seid ${ }^{413}$ ihr alle nichts, da ihr euch zwar Argumentationen aneignet, aber miteinander redet wie ein Blinder mit einem Tauben. Warum verfügt ihr über Werkzeuge zum Bauen, versteht dies aber nicht zu tun? Warum kümmert ihr euch so sehr um Worte und seid von den Taten weit entfernt? ${ }^{414}$

26.7. Durch Ruhm lasst ihr euch aufblasen, im Unglück lasst ihr euch niederdrücken, und so missbraucht ihr gegen die Vernunft die kunstvollen Redeweisen; ihr prahlt in der Öffentlichkeit, ${ }^{415}$ versteckt aber eure klugen Worte in den Winkeln. ${ }^{416}$ Da wir euch als solche erkannt haben, haben wir euch zurückgelassen und rühren eure Dinge nicht mehr an, sondern folgen dem Logos Gottes.

26.8. Warum nämlich, Mensch, rüstest du zu einem Krieg der Buchstaben ${ }^{417}$ Warum lässt du wie bei einem Faustkampf ihre Aussprache 


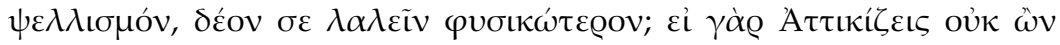

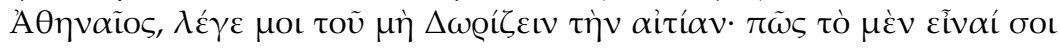

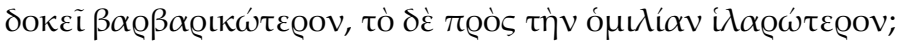

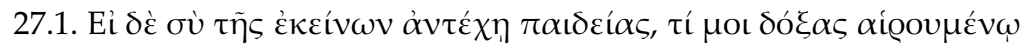

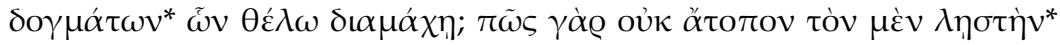

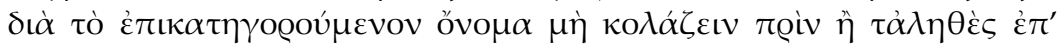

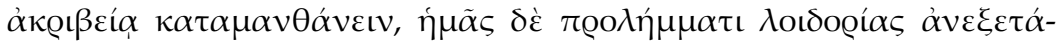
$\sigma \tau \omega \varsigma \mu \varepsilon \mu เ \sigma \eta \kappa \varepsilon ́ v \alpha \mathrm{l} ;$

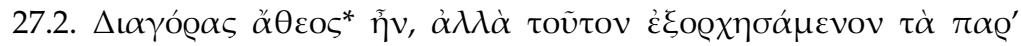

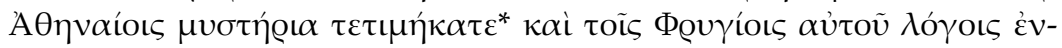

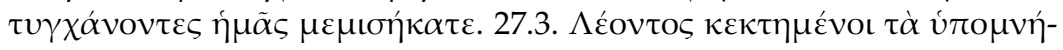

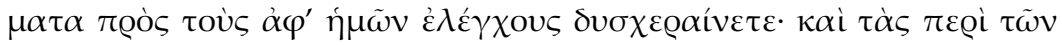

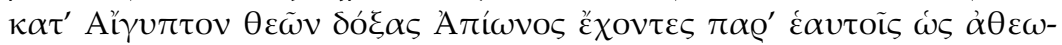

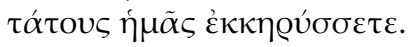

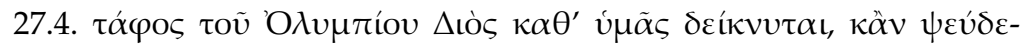

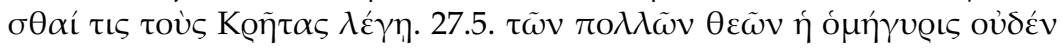

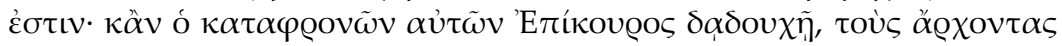

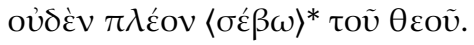

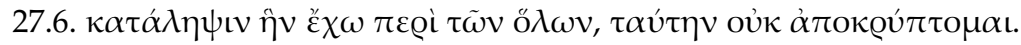

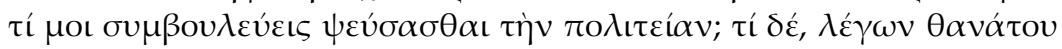

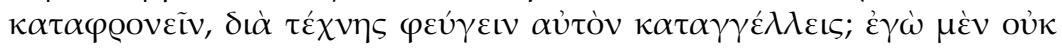

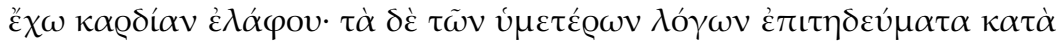

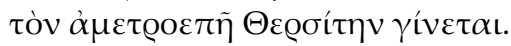

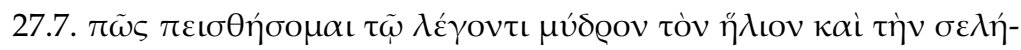

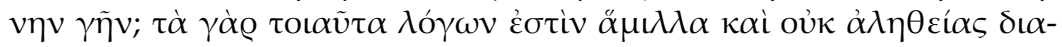

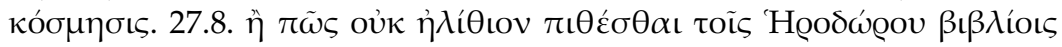

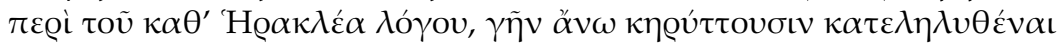

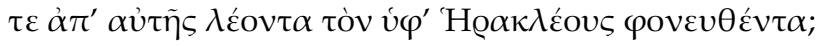

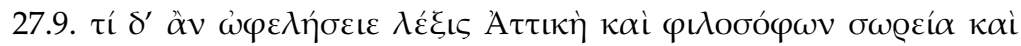

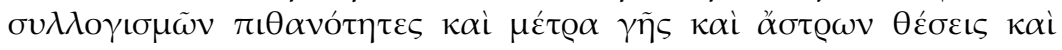


aufeinanderprallen wegen des Stammelns der Athener, obwohl du doch natürlicher reden müsstest? Wenn du nämlich Attisch sprichst, ohne Athener zu sein, dann sag mir den Grund dafür, dass du nicht Dorisch sprichst; wieso scheint dir das eine barbarischer, das andere aber für die Unterhaltung angenehmer zu sein ${ }^{418}$

27.1. Wenn aber du an der ,Bildung' jener Leute festhältst, warum legst du dich mit mir an, wenn ich die Meinungen von Lehren wähle, die ich will? ${ }^{419}$ Wie ist es denn nicht absurd, den Räuber aufgrund der Bezeichnung, die ihm als Anklage vorgehalten wird, ${ }^{420}$ nicht zu bestrafen, bevor man die Wahrheit genau festgestellt hat, uns aber hasserfüllt gegenüberzustehen aufgrund einer auf Vorurteil beruhenden Schmähung, ohne eine genaue Prüfung vollzogen zu haben?

27.2. Diagoras ${ }^{421}$ war ein Atheist; ${ }^{422}$ aber obwohl dieser Mann die Mysterien der Athener schamlos an die Öffentlichkeit gebracht hat, ${ }^{423}$ haltet ihr ihn in Ehren, ${ }^{424}$ und während ihr seine „Phrygischen Darlegungen"425 lest, steht ihr uns in Hass gegenüber. 27.3. Obwohl ihr Leons Abhandlungen ${ }^{426}$ besitzt, seid ihr empört über die von uns kommenden Widerlegungen; und obwohl ihr die Ansichten Apions ${ }^{427}$ über die Götter Ägyptens bei euch habt, denunziert ihr uns als die Gottlosesten.

27.4. Ein Grab des olympischen Zeus ${ }^{428}$ wird bei euch gezeigt, auch wenn jemand behauptet, dass die Kreter lügen. ${ }^{429} 27.5$. Der vielen Götter Versammlung ist nichts; (und) auch wenn der sie verachtende Epikur ${ }^{430}$ die Mysterienfackel schwingt, ${ }^{431}$ ehre ich ${ }^{432}$ die leitenden Amtsträger in keiner Weise mehr als Gott.

27.6. Die Auffassung, die ich vom All habe, die verberge ich nicht. Warum rätst du mir, meine Lebensweise $\mathrm{zu}$ verleugnen? Und warum behauptest du, den Tod zu verachten, forderst mich aber auf, ihn durch Trickserei $\mathrm{zu}$ vermeiden ${ }^{433}$ Ich jedenfalls habe nicht das „Herz eines Hirsches";434 die Anwendung eurer Rhetorik dagegen vollzieht sich gemäß dem „unmäßig Worte machenden“" Thersites. ${ }^{435}$

27.7. Wie soll ich dem glauben, der behauptet, dass die Sonne ein rotheißer Eisenklumpen ist und der Mond eine Erde? ${ }^{436}$ Solche Dinge stellen nämlich (nur) rhetorische Streitgefechte dar und nicht die wahre Weltordnung. ${ }^{437}$ 27.8. Oder wie ist es nicht töricht, den Büchern Herodors über die Herakles-Geschichte ${ }^{438}$ zu glauben, die eine „obere Erde“ verkünden und dass von ihr der Löwe herabgekommen sei, ${ }^{439}$ der von Herakles getötet wurde?

27.9. Und was dürften von Nutzen sein attische Redeweise, das Häufelschluss-Machen ${ }^{440}$ der Philosophen, Überzeugung heischende Syllogismen, Vermessungen der Erde, Positionierungen von Sternen und 


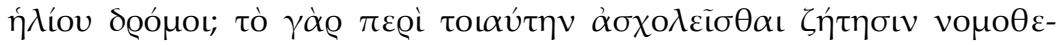

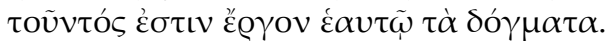

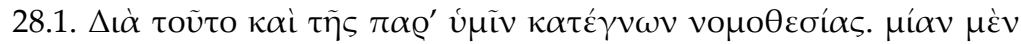

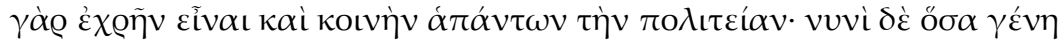

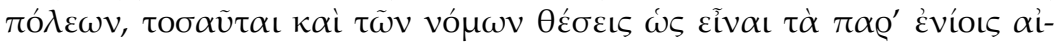

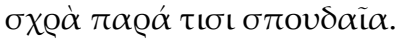

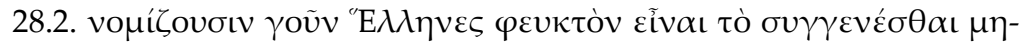

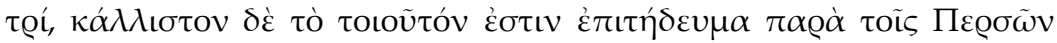

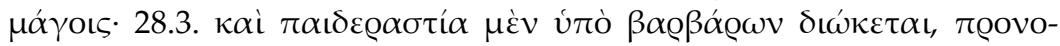

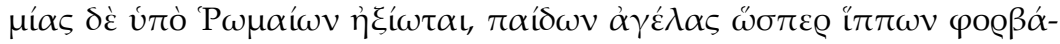

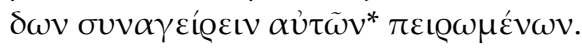

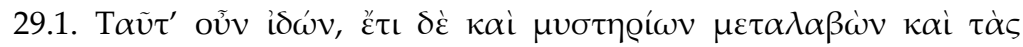

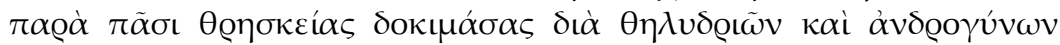

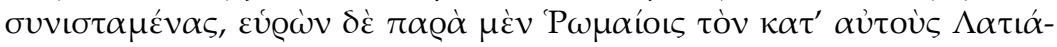

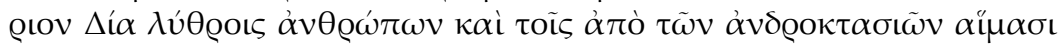

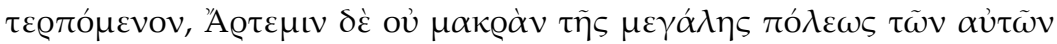

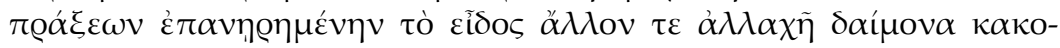

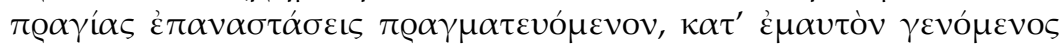

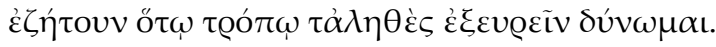

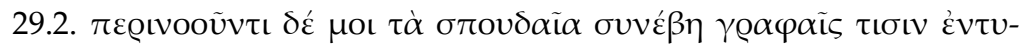

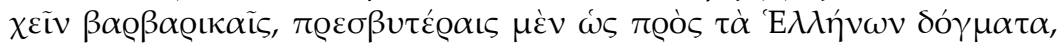

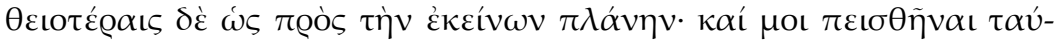

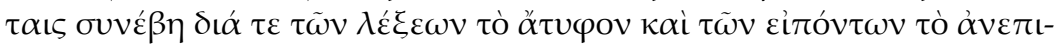

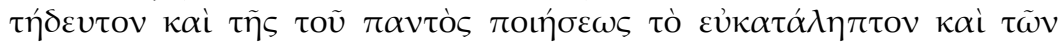

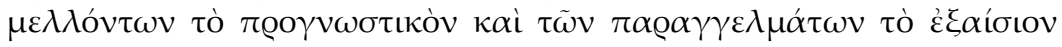

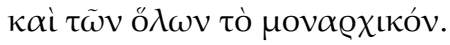

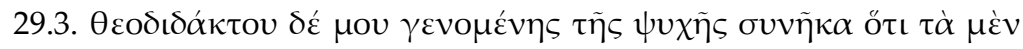

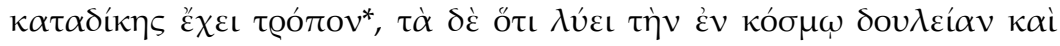

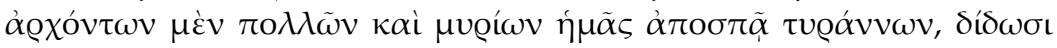

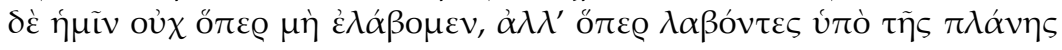

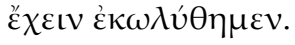


Laufbahnen der Sonne? Denn mit solcher Art von Untersuchung sich zu beschäftigen ist die Arbeit von jemand, der sich seine eigene Lehren zu Gesetzen erhebt.

28.1. Deshalb bin ich auch zur Verachtung eurer Gesetzgebung gelangt. Eine einzige nämlich und für alle gemeinsame sollte die Art des gemeinschaftlichen Lebens sein; jetzt aber (ist es so): So viele Arten von Staatsgebilden es gibt, so viele Gesetzgebungen gibt es auch, so dass das, was bei manchen schändlich ist, bei anderen als ehrenvoll gilt. ${ }^{441}$

28.2. So glauben jedenfalls die Griechen, etwas zu Meidendes sei der geschlechtliche Verkehr mit der Mutter; besonders schön aber ist eine solche 'Beschäftigung' bei den Magiern der Perser. ${ }^{442}$ 28.3. Und Päderastie wird von Barbaren geächtet, wird jedoch als ein besonderes Vorrecht von den Römern erachtet, da sie versuchen, Herden von Knaben wie Weidepferde zusamenzubringen. ${ }^{443}$

29.1. Da ich dies nun gesehen, ferner auch an Mysterien teilgenommen und die bei allen vorkommenden Riten geprüft hatte, die durch weibische und androgyne Priester durchgeführt werden, ${ }^{444}$ und da ich bei den Römern gefunden hatte, dass ihr Iuppiter Latiaris ${ }^{445}$ sich an geronnenem Blut von Menschen und dem aus Menschentötungen sich ergebenden Blutvergießen erfreut; dass Artemis nicht weit von der groBen Stadt die Art und Weise der gleichen Praktiken zu ihren Riten erhoben hat; ${ }^{446}$ und dass überall je ein anderer Dämon das Anstiften üblen Tuns zu seiner Sache macht - da ging ich in mich und suchte nach einer Antwort, auf welche Weise ich die Wahrheit finden könne.

29.2. Und als ich über diese ernsten Fragen nachdachte, geschah es, dass ich auf Schriften von Barbaren stieß, die gegenüber den Lehren der Griechen älter und gegenüber ihrem ziellosen Dahinirren göttlicher sind; und ich gelangte dazu, ihnen Glauben zu schenken wegen ihrer unaffektierten Ausdrucksweise, des Unverstellten ihrer Sprecher, der guten Erfassung der Schöpfung des Alls, der Vorausschau auf das Zukünftige, des Außerordentlichen ihrer Anordnungen und des Prinzips, dass es einen Herrscher über das All gibt.

29.3. Und da meine Seele (auf diese Weise) von Gott unterrichtet ${ }^{447}$ wurde, begriff ich, dass die einen Lehren einer Verurteilung gleichkommen, ${ }^{448}$ die anderen aber die Knechtschaft in der Welt lösen und von vielen Herschaftsträgern und unzähligen Tyrannen ${ }^{449}$ uns wegziehen und uns als Gabe nicht das geben, was wir nicht empfangen hatten, sondern was wir zwar empfangen hatten, aufgrund unseres Fehlgehens aber verhindert waren zu besitzen. ${ }^{450}$ 


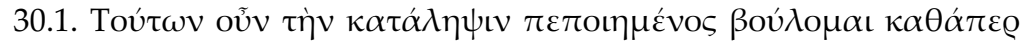

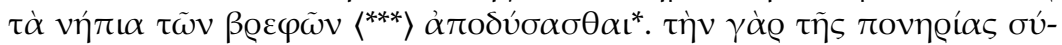

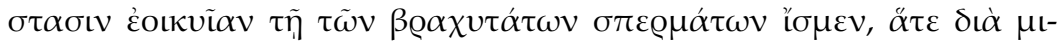

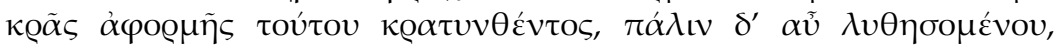

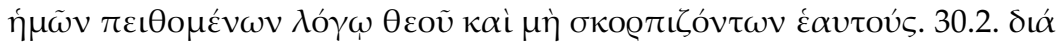

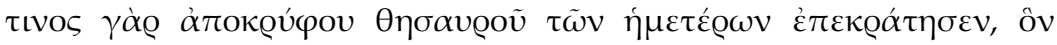

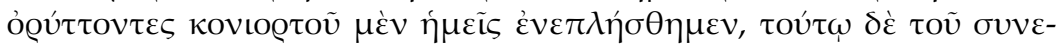

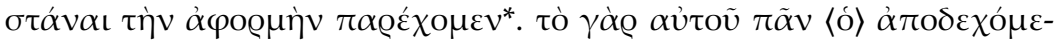

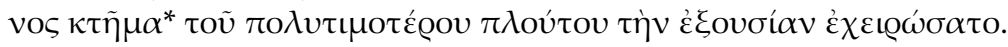

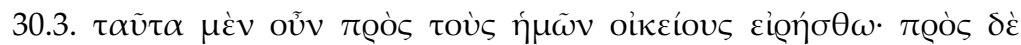

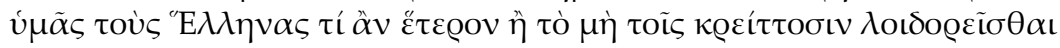

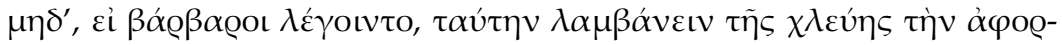

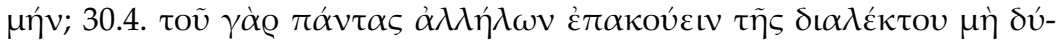

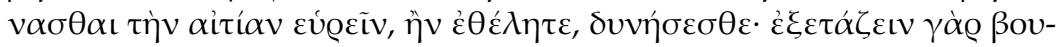

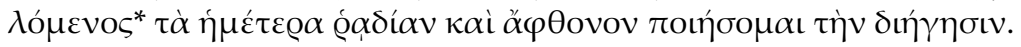

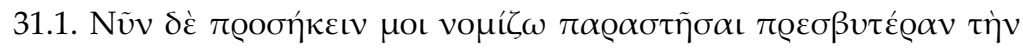

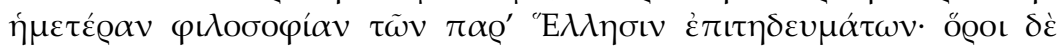

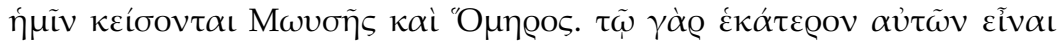

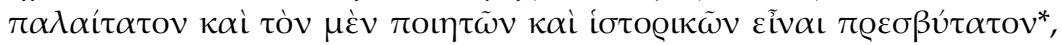

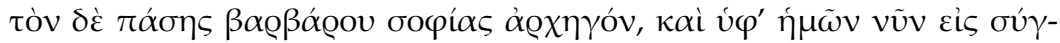

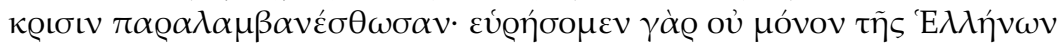

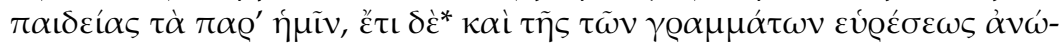
$\tau \varepsilon \varrho \alpha$.

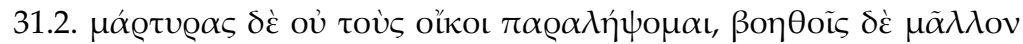

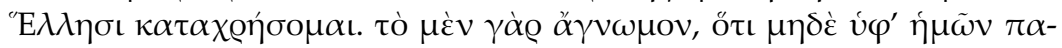

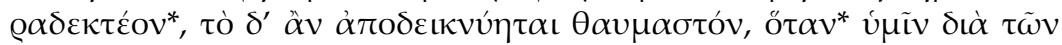

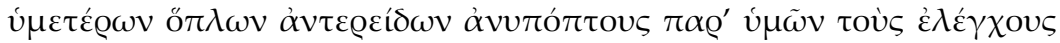
$\lambda \alpha \mu \beta \alpha ́ \alpha \omega^{*}$.

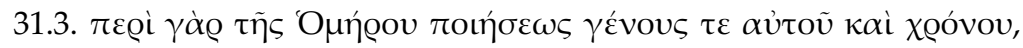

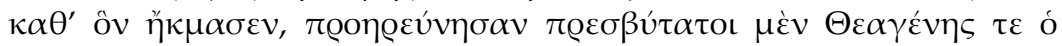

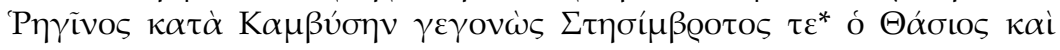

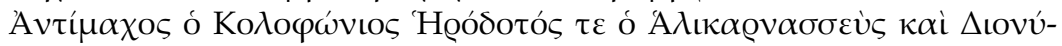


30.1. Nachdem ich also diese Dinge erfasst habe, will ich wie die unmündigen von den kleinen Kindern ${ }^{451}<* * *>452$ abstreifen. ${ }^{453}$ Was nämlich die Konstitution des Bösen betrifft, so wissen wir, dass sie derjenigen kleinster Samen ${ }^{454}$ gleicht; sie ${ }^{455}$ erstarkt nämlich von kleinem Anstoß her, ${ }^{456}$ wird sich aber andererseits wiederum auflösen, wenn wir dem Logos Gottes glauben und uns nicht selber zerstreuen. 30.2. Durch eine Art verborgenen Schatz ${ }^{457}$ nämlich ist er über unsere Angelegenheiten Herr geworden; als wir nach ihm gruben, wurden wir zwar mit Staub bedeckt, geben ${ }^{458}$ damit dem Logos ${ }^{459}$ aber den Ausgangspunkt dafür, Bestand (bei uns) zu haben. Denn wer seinen ${ }^{460}$ Besitz zur Gänze empfängt, hat damit die Möglichkeit kostbareren Reichtums in die Hand bekommen.

30.3. Dies also sei zu unseren Vertrauten gesagt; zu euch Griechen aber, was soll ich anderes sagen, als dass ihr nicht die Besseren schmähen sollt und auch nicht, wenn man sie ,Barbaren' nennt, dies zum Ausgangspunkt des Spotts nehmen? 30.4. Denn dafür, dass nicht alle die jeweilige Sprache des anderen verstehen können, werdet ihr, wenn ihr wollt, eine Ursache finden; ${ }^{461}$ da ich bereit bin, unsere Lehren auf den Prüfstand zu stellen, ${ }^{462}$ werde ich eine leicht fassliche und reichliche Darlegung geben.

31.1. Jetzt ${ }^{463}$ aber glaube ich, dass es sich für mich ziemt zu erweisen, dass unsere Philosophie älter ist als die Dinge, die bei den Griechen betrieben werden; Marksteine dafür werden uns sein Moses und Homer. Weil nämlich jeder von beiden der (jeweils) älteste ${ }^{464}$ und der eine der früheste ${ }^{465}$ der Dichter und Geschichtsschreiber ist, der andere aber der Archeget jeglicher Weisheit der Barbaren, sollen sie von uns nun zu einem Vergleich herangezogen werden; wir werden nämlich feststellen, dass unsere Lehren nicht nur über die Paideia der Griechen, sondern ${ }^{466}$ auch über die Erfindung der Schrift hinaufreichen.

31.2. Als Zeugen aber werde ich nicht die aus dem eigenen Haus beibringen, sondern werde vielmehr als Helfer Griechen verwenden. ${ }^{467}$ Das eine wäre ja töricht, weil man es auch von unserer Seite nicht akzeptieren dürfte, ${ }^{468}$ das andere aber wäre, wenn es sich beweisen lässt, staunenswert, wenn ${ }^{469}$ ich nämlich, indem ich mich euch durch eure eigenen Waffen entgegenstemme, von euch Argumente bekomme, ${ }^{470}$ die unverdächtig sind.

31.3. Was nämlich die Dichtung Homers, seine Abstammung und die Zeit betrifft, in der er blühte, haben als die ältesten ${ }^{471}$ Theagenes von Rhegion, ${ }^{472}$ der zur Zeit des Kambyses ${ }^{473}$ lebte, Stesimbrotos von Thasos, ${ }^{474}$ Antimachos von Kolophon, ${ }^{475}$ Herodot von Halikarnass ${ }^{476}$ und 


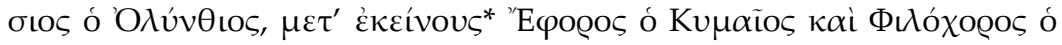

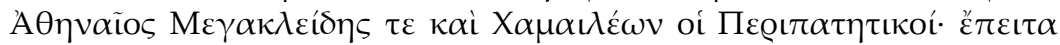

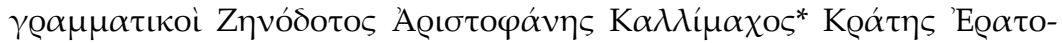

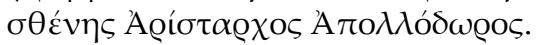

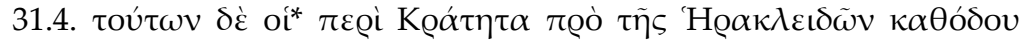

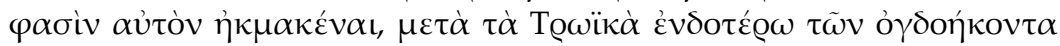

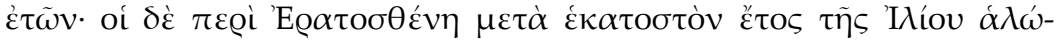

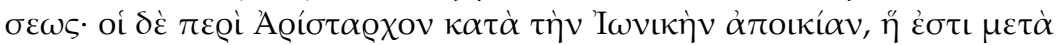

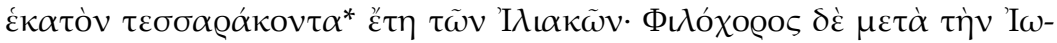

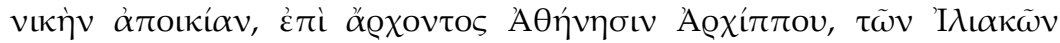

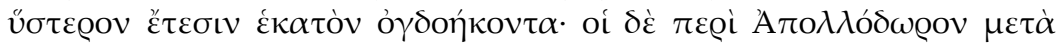

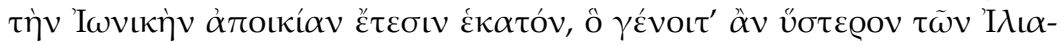

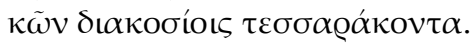

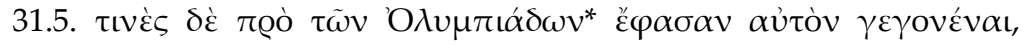

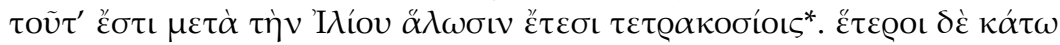

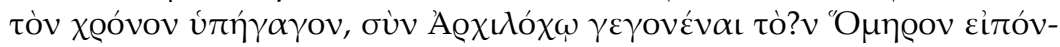

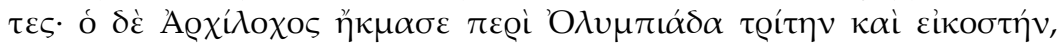

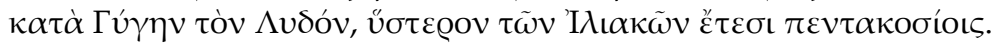

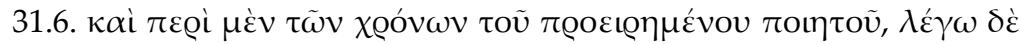

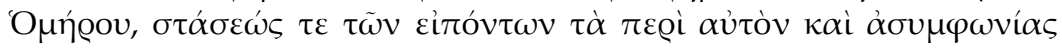

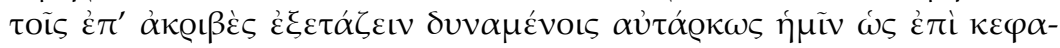

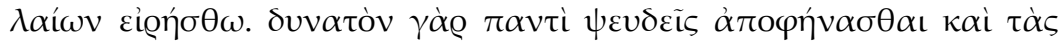

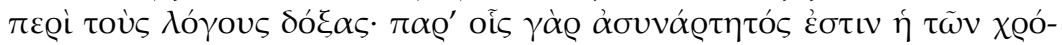

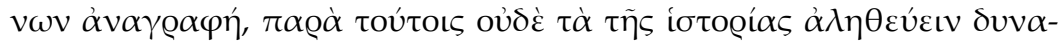

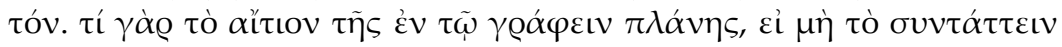
$\tau \dot{\alpha} \mu \grave{\eta} \dot{\alpha} \lambda \eta \theta \tilde{\eta}$

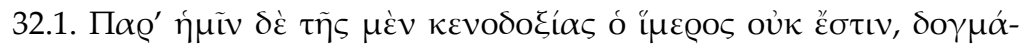

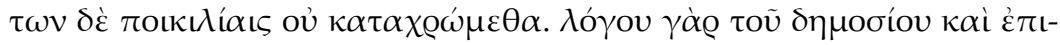

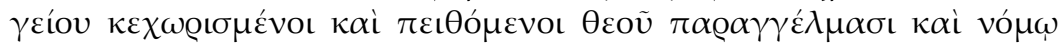

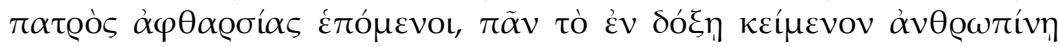

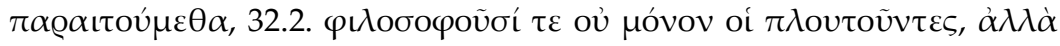

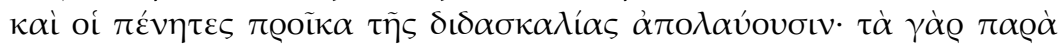

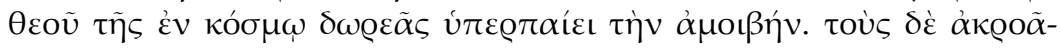

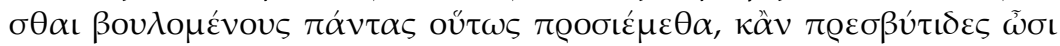

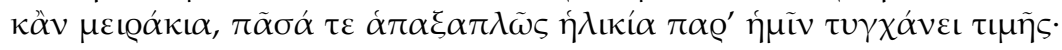

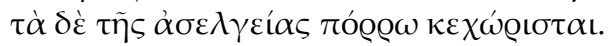


Dionysios von Olynth ${ }^{477}$ Nachforschungen angestellt, und nach ihnen Ephoros von Kyme, ${ }^{478}$ Philochoros von Athen ${ }^{479}$ und die Peripatetiker Megakleides ${ }^{480}$ und Chamaileon; ${ }^{481}$ danach die Grammatiker Zenodot, ${ }^{482}$ Aristophanes, ${ }^{483}$ Kallimachos, ${ }^{484}$ Krates, ${ }^{485}$ Eratosthenes, ${ }^{486}$ Aristarch $^{487}$ und Apollodor. ${ }^{488}$

31.4. Von diesen sagt Krates, ${ }^{489}$ er habe vor der Rückkehr der Herakliden $^{490}$ geblüht, innerhalb von achtzig Jahren nach dem Trojanischen Krieg;491 Eratosthenes, hundert Jahre nach der Einnahme von Ilion; Aristarch, zur Zeit der Ionischen Kolonisierung, ${ }^{492}$ die 140 Jahre nach dem Trojanischen Krieg datiert wird; Philochoros aber, nach der ionischen Kolonisierung, als Archippos in Athen Archon war, 180 Jahre nach dem Trojanischen Krieg; Apollodor, hundert Jahre nach der ionischen Kolonisierung, was 240 Jahre $^{493}$ nach dem Trojanischen Krieg wäre.

31.5. Einige aber behaupteten, er habe vor ${ }^{494}$ dem Beginn der Olympiadenrechnung gelebt, d.h. vierhundert ${ }^{495}$ Jahre nach der Einnahme von Ilion; andere aber gingen in der Zeit (noch weiter) hinunter und sagten, er habe gleichzeitig mit Archilochos gelebt; Archilochos aber blühte zur Zeit der 23. Olympiade, zur Zeit des Lyders Gyges, fünfhundert Jahre später als der Trojanische Krieg.

31.6. Und was die Zeiten des gerade genannten Dichters, also Homers, angeht und den Streit und die Diskrepanz derer, die über ihn sprachen, sei (damit) für die, die (diese Sache) genau untersuchen können, genügend, soweit es die Hauptpunkte betrifft, gesagt. Es ist nämlich jedem möglich, auch die Meinungen über seine (Homers) Darstellungen als falsch zu erweisen; bei wem nämlich die Dokumentation der Zeiten inkohärent ist, bei diesen Leuten können auch die Inhalte der Geschichte nicht der Wahrheit entsprechen. Was ist nämlich der Grund für das Fehlgehen in der schriftlichen Darstellung, wenn nicht der Umstand, dass man unwahre Dinge zusammenschreibt?

32.1. Bei uns aber ist das Verlangen nach leerem Ruhm nicht existent, und wir treiben kein Schindluder mit vielfältigen Lehrmeinungen. Denn von vulgärer und irdischer Lehre getrennt, gehorchen wir den Geboten Gottes und folgen dem Gesetz des Vaters der Unvergänglichkeit, und so lehnen wir alles, was nur auf menschlicher Meinung beruht, ab; 32.2. es philosophieren (bei uns) nicht nur die Reichen, sondern auch die Armen kommen kostenlos in den Genuss der Unterrichtung; denn die von Gott kommenden Gaben übertreffen die Vergeltung eines innerweltlichen Geschenks. Die aber zuhören wollen, die alle lassen wir in dieser Weise $\mathrm{zu}$, seien sie alte Frauen oder junge Burschen, und, mit einem Wort, je- 


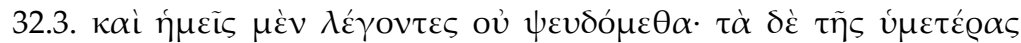

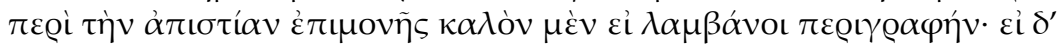

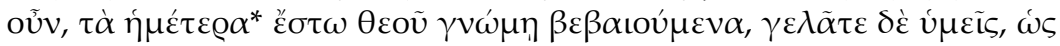

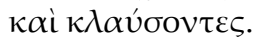

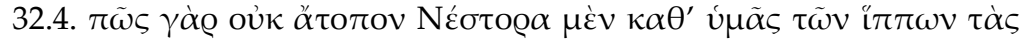

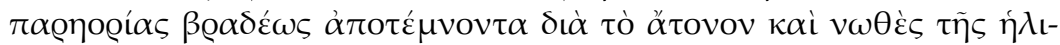

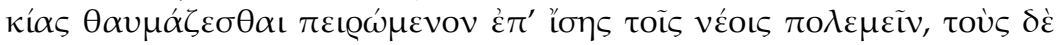

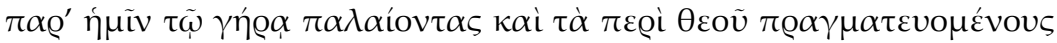
$\gamma \varepsilon \lambda \tilde{\alpha} \sigma \theta \alpha \mathrm{l} ;$

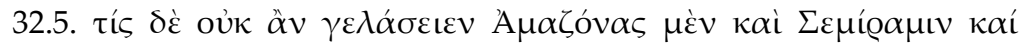

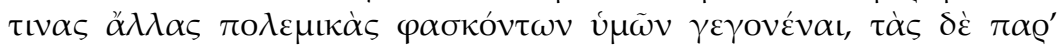

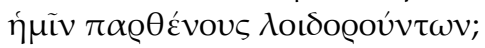

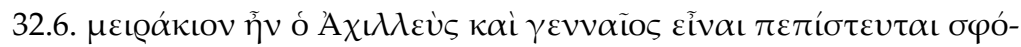

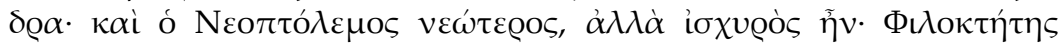

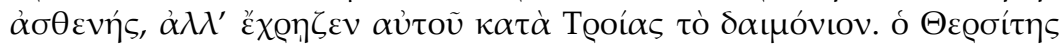

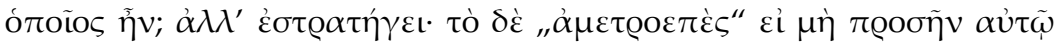

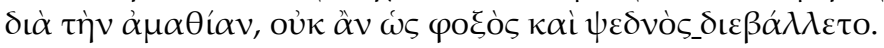

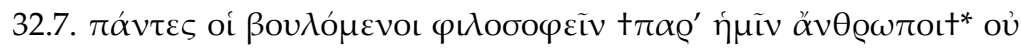

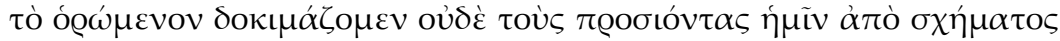

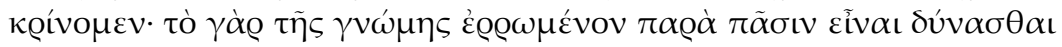

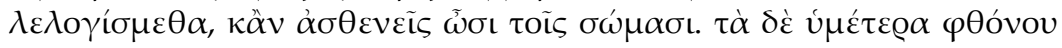

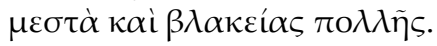

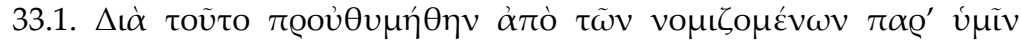

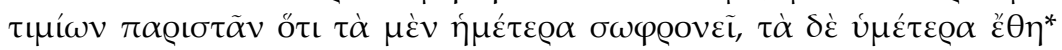

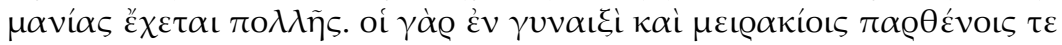

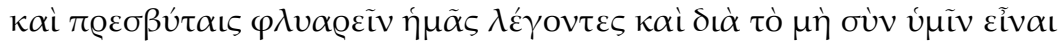

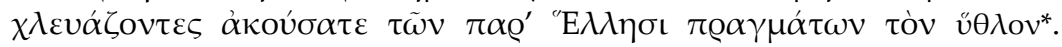

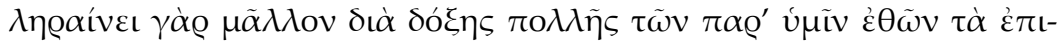

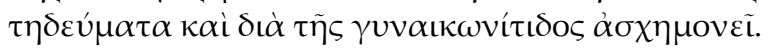


dem Lebensalter wird bei uns Ehre erwiesen; die Manifestationen der Zügellosigkeit aber sind verbannt.

32.3. Und wir lügen nicht mit unseren Worten; was aber euer hartnäckiges Verharren im Unglauben betrifft, so wäre es schön, wenn es einmal an eine Grenze käme. Wenn es nun aber einmal so ist (dass es dazu nicht kommt), so seien unsere ${ }^{496}$ Lehren durch das Urteil Gottes bekräftigt; ihr aber, lacht ihr nur - ihr werdet auch einmal weinen!

32.4. Denn wie ist es nicht absurd, dass bei euch Nestor, obwohl er die Seitenzügel der Pferde wegen der Schlaffheit und Langsamkeit seines Alters nur mühsam abschnitt, 497 bewundert wird, weil er versuchte, in gleicher Weise wie die Jungen in der Schlacht zu kämpfen, ${ }^{498}$ dass aber diejenigen, die bei uns mit dem Alter ringen und die Dinge Gottes betreiben, verlacht werden?

32.5. Wer aber dürfte nicht lachen, wenn ihr zwar behauptet, es habe Amazonen $^{499}$ und eine Semiramis ${ }^{500}$ und noch irgendwelche anderen kriegerischen Frauen gegeben, die jungen Frauen bei uns aber beschimpft?

32.6. Ein junger Bursche war Achill, und man glaubt, er sei besonders edel gewesen; und Neoptolemos war noch jünger, aber ein starker Held; Philoktet war schwach, aber die Gottheit bedurfte seiner gegen Troja. ${ }^{501}$ Was für ein Kerl war Thersites? ${ }^{502}$ Aber er spielte General; ${ }^{503}$ und wenn ihm nicht wegen seiner Dummheit ungezügeltes Schwätzertum angehaftet hätte, wäre er nicht als „Zuckerhut-Kopf" und Kahlkopf verleumdet worden.

32.7. Alle, die philosophieren wollen tbei uns Menschent ${ }^{504}$ wir beurteilen nicht das, was man sehen kann, und bewerten auch nicht diejenigen, die zu uns kommen, nach ihrer äußeren Erscheinung; wir sind nämlich der wohldurchdachten Meinung, dass ein solider Verstand bei allen sein kann, auch wenn sie körperlich schwach sind. Eure Meinungen aber sind voll von Neid und Dummheit.

33.1. Deshalb ging es mir darum, ausgehend von den Dingen, die bei euch als wertvoll gelten, darzutun, dass unsere Sitten von Beherrschtheit geprägt, eure ${ }^{505}$ dagegen mit vielem Wahnsinn behaftet sind. Ihr, die ihr behauptet, dass wir bei Frauen und jungen Burschen, Jungfrauen und alten Frauen Unsinn reden, und die ihr uns verspottet, weil wir nicht mit euch konform gehen, hört das unsinnige Geschwätz, ${ }^{506}$ das die bei den Griechen üblichen Dinge darstellen! Denn Unsinn stellen - noch mehr durch den vielen Ruhm, in dem sie stehen - die Gepflogenheiten eurer Sitten dar und zeigen ein peinliches Fehlverhalten quer durch die Frauengemächer. 


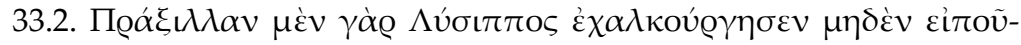

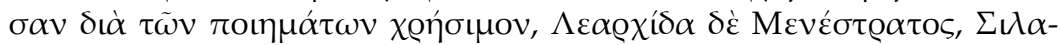

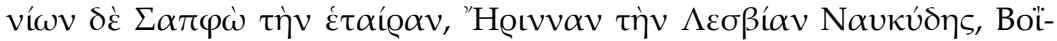

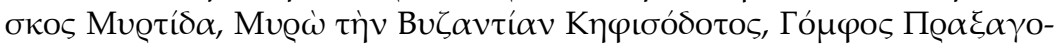

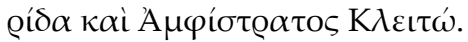

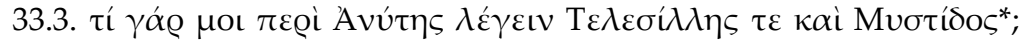

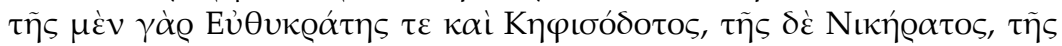

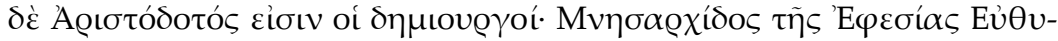

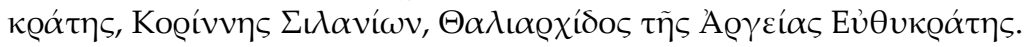

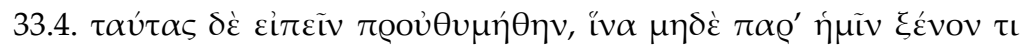

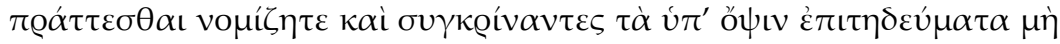

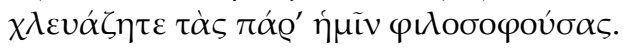

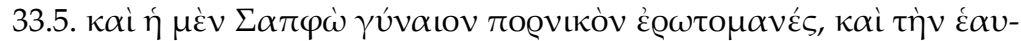

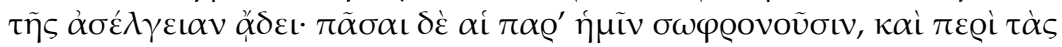

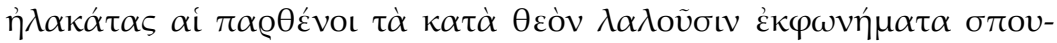

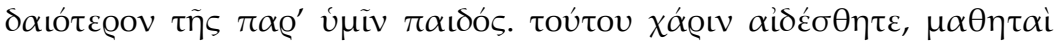

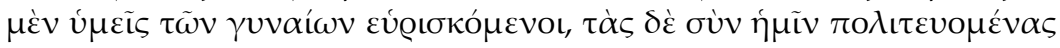

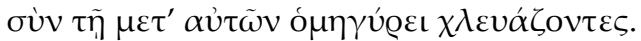

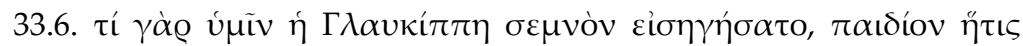

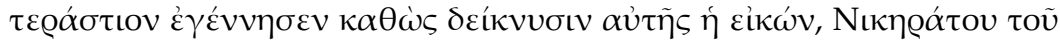

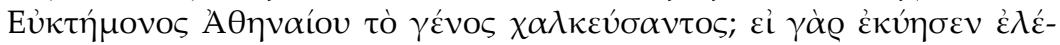

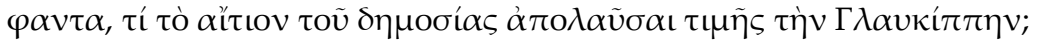

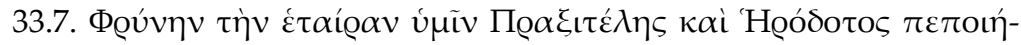

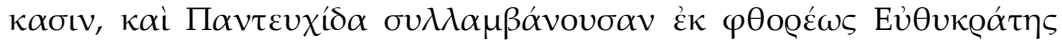

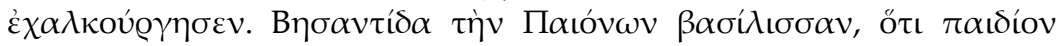

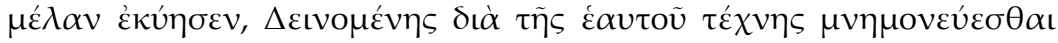
$\pi \alpha \varrho \varepsilon \sigma \kappa \varepsilon v ́ \alpha \sigma \varepsilon v$.

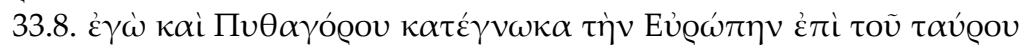

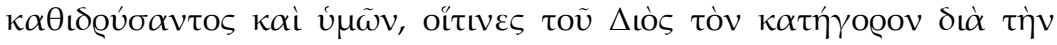

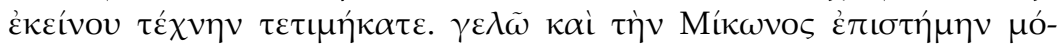

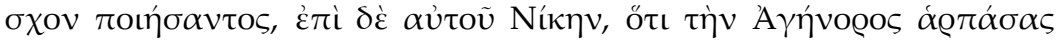

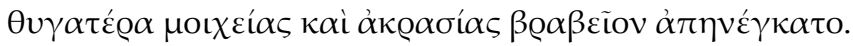

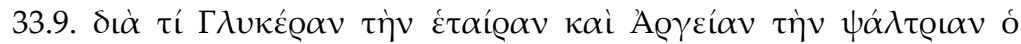

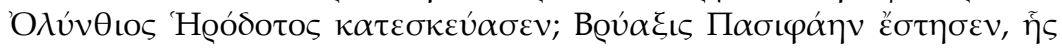


33.2. Praxilla ${ }^{507}$ wurde von Lysipp in Bronze dargestellt, obwohl sie in ihren Gedichten nichts Nützliches gesagt hatte, Learchis ${ }^{508}$ von Menestratos, von Silanion die Hetäre Sappho, ${ }^{509}$ die Lesbierin Erinna ${ }^{510}$ von Naukydes, von Boiskos Myrtis, 511 die Byzantierin Myro ${ }^{512}$ von Kephisodotos, von Gomphos Praxagoris ${ }^{513}$ und von Amphistratos Kleito. ${ }^{514}$

33.3. Was hat es für einen Sinn, dass ich über Anyte ${ }^{515}$ rede und Telesilla516 und Mystis? ${ }^{517}$ Schöpfer der Darstellung der einen sind Euthykrates und Kephisodotos, der anderen Nikeratos, der dritten Aristodotos; Schöpfer der Darstellung der Mnesarchis ${ }^{518}$ von Ephesos ist Euthykrates, der Korinna ${ }^{519}$ Silanion, der Thaliarchis ${ }^{520}$ von Argos Euthykrates.

33.4. Es ging mir darum, diese zu nennen, damit ihr glaubt, dass auch bei uns nichts Merkwürdiges geschieht, und - indem ihr diese in die Augen fallenden Erzeugnisse vergleicht - nicht die Frauen verspottet, die bei uns philosophieren.

33.5. Sappho ist ein hurenhaftes liebestolles Weiblein und besingt ihre eigene Zügellosigkeit; alle Frauen bei uns aber sind züchtig, und an den Spindeln sprechen unsere Jungfrauen über die Gott betreffenden Äußerungen, und zwar in ernsthafterer Weise als das Mädchen bei euch. ${ }^{521}$ Deshalb zeigt einmal Scham! Es stellt sich (nämlich) heraus, dass ihr die Schüler dieser Weibsbilder seid, während ihr die Frauen, die bei uns leben, zusammen mit ihrer Gemeinde verspottet.

33.6. Denn was hat eure Glaukippe ${ }^{522}$ Ehrwürdiges in die Welt gebracht? Sie gebar ein Monstrum, wie es ihr Bild zeigt, da es der Athener Nikeratos, Sohn des Euktemon, in Bronze abbildete. Wenn Glaukippe nämlich einen Elefanten zur Welt brachte, was ist der Grund dafür, dass sie öffentliche Ehren genießt?

33.7. Die Hetäre Phryne ${ }^{523}$ haben euch Praxiteles und Herodotos im Bild dargestellt, und Panteuchis, ${ }^{524}$ die von einem Verführer geschwängert wurde, wurde von Euthykrates in Bronze dargestellt. Besantis, 525 die Königin der Paionen, wurde, weil sie ein schwarzes Kind zur Welt brachte, von Deinomenes mittels seiner Kunst verewigt.

33.8. Was mich betrifft, so verachte ich sowohl Pythagoras, ${ }^{526}$ der Europa auf den Stier montierte, als auch euch, die ihr diesen Ankläger des Zeus wegen seiner Kunst geehrt habt. Ich lache auch über die Fertigkeit des Mikon, ${ }^{527}$ der ein Kalb gebildet hat und auf ihm die Siegesgöttin, weil er (Zeus) die Tochter Agenors raubte und damit einen Siegespreis für Ehebruch und Zügellosigkeit davongetragen hat.

33.9. Weshalb wurde die Hetäre Glykera ${ }^{528}$ und die Zitherspielerin Argeia durch Herodotos von Olynth dargestellt? Bryaxis hat ein Stand- 


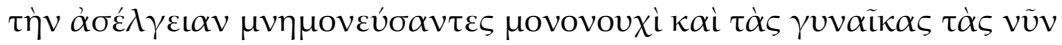

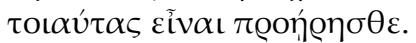

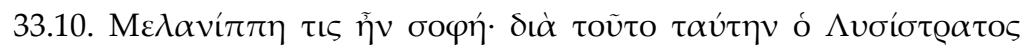

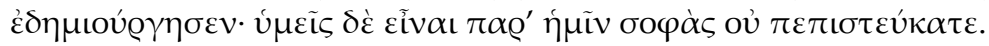

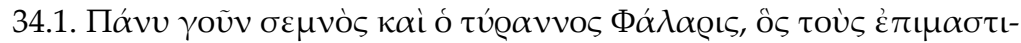

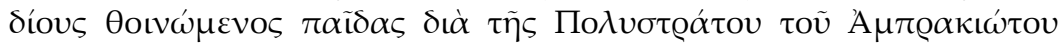

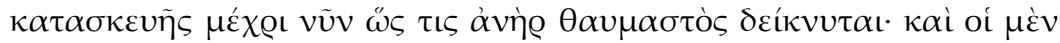

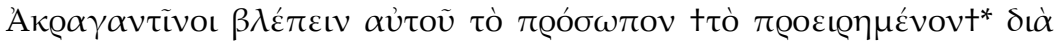

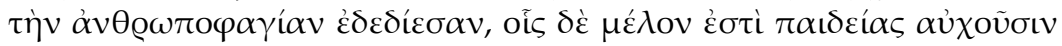

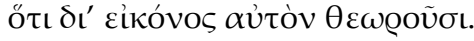

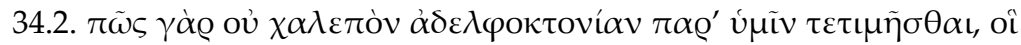

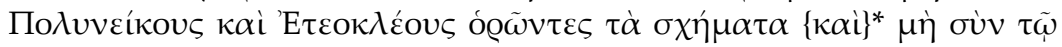

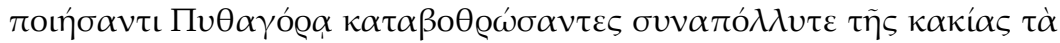

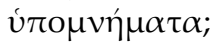

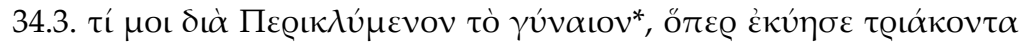

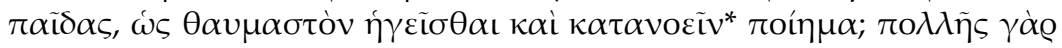

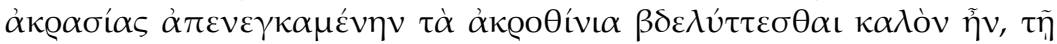

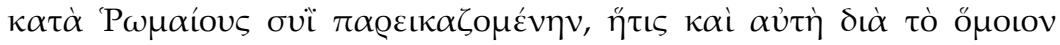

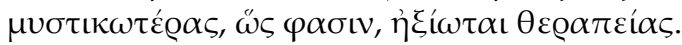

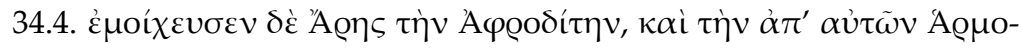

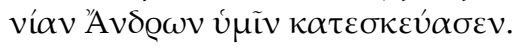

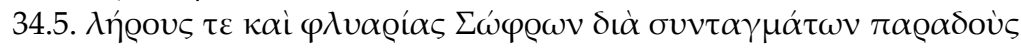

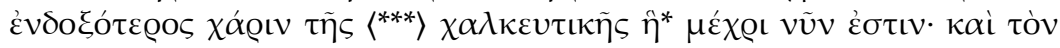

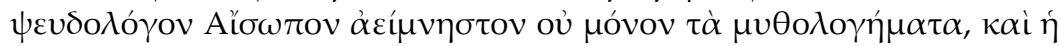

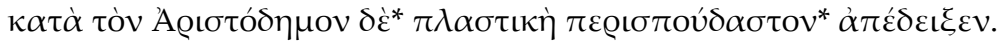

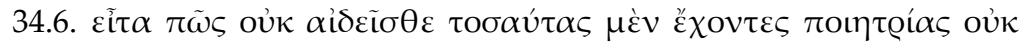

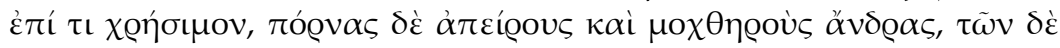

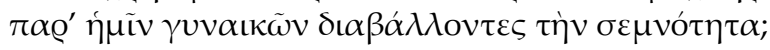

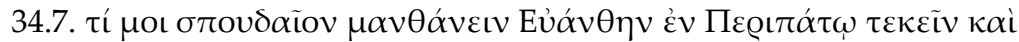

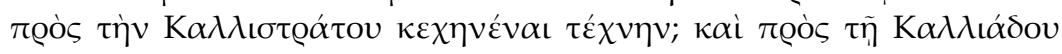


bild der Pasiphae ${ }^{529}$ aufgestellt, an deren Zügellosigkeit ihr euch (dadurch) erinnert und geradezu den Wunsch hegt, dass auch die heutigen Frauen von solcher Art seien.

33.10. Eine gewisse Melanippe war klug;,530 deshalb wurde sie von Lysistratos dargestellt; ihr aber glaubt nicht, dass es bei uns kluge Frauen gibt.

34.1. Ein sehr Ehrfurcht gebietender Mann ist ja auch der Tyrann Phalaris, ${ }^{531}$ der die noch an der Mutterbrust befindlichen Kinder zu seiner Speise machte und dank der Darstellung des Polystratos von Ambrakia bis heute wie ein wunderbarer Mann präsentiert wird; und die Einwohner von Akragas fürchteten sich wegen der Menschenfresserei, in das tvorerwähnte ${ }^{532}$ Gesicht dieses Mannes zu schauen - diejenigen aber, denen an „Bildung“ liegt, die finden es toll, dass sie ihn vermittels seines Bildes noch betrachten können.

34.2. Wie nämlich ist es nicht ärgerlich, dass der Brudermord bei euch in Ehren steht, die ihr, da ihr die Gestalten des Polyneikes und Eteokles $^{533}$ vor euch seht, ${ }^{534}$ sie nicht zusammen mit ihrem Schöpfer Pythagoras in einen Abgrund versenkt und auf diese Weise die Denkmäler der Schlechtigkeit mit vernichtet?

34.3. Was soll es mir, wegen Periklymenos das Weiblein, ${ }^{535}$ das dreiBig Kinder zur Welt brachte, als ein wundersames Erzeugnis anzusehen und aufzufassen?536 Da sie nämlich (lediglich) die Früchte einer großen Promiskuität davontrug, wäre es schön, sie zu verabscheuen; sie lässt sich ja der bei den Römern berühmten $\mathrm{Sau}^{537}$ vergleichen, die auch ihrerseits wegen einer ähnlichen Leistung einer recht mysteriösen Verehrung, wie man sagt, gewürdigt worden ist.

34.4. Ehebruch trieb Ares mit Aphrodite, und die von ihnen hervorgebrachte Harmonia ${ }^{538}$ hat euch Andron dargestellt.

34.5. Obwohl er (nur) Schwätzereien und Unsinnsreden in seinen Werken der Nachwelt vermittelt hat, ist Sophron ${ }^{539}$ ziemlich berühmt wegen der Metallbearbeitungskunst des $\langle * * *, 540$ die bis jetzt existiert; und dem Lügenerzähler Aesop haben immerwährende Erinnerung nicht nur seine Fabeln gebracht, auch ${ }^{541}$ die Bildhauerkunst des Aristodemos hat ihn zum Gegenstand des Interesses gemacht. ${ }^{542}$

34.6. Wie schämt ihr euch da nicht, einerseits so viele Dichterinnen zu nichts Nützlichem und unzählige Huren und schlechte Kerle ${ }^{543} \mathrm{zu}$ haben, andererseits aber die Sittsamkeit unserer Frauen zu verleumden?

34.7. Was soll es für mich wichtig sein zu erfahren, dass Euanthe ${ }^{544}$ im Peripatos (ein Kind) geboren hat, und vor der Kunst des Kallistratos den Mund aufzusperren? Und darüber hinaus auf die Neaira ${ }^{545}$ des Kal- 


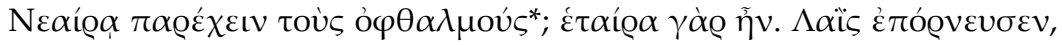

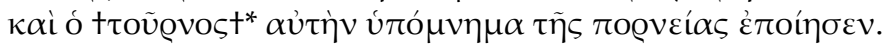

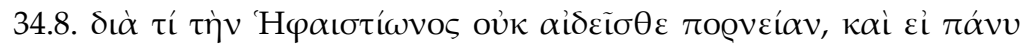

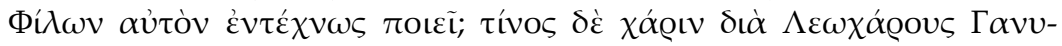

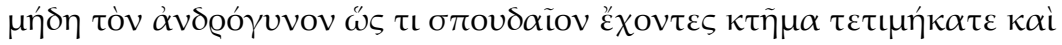

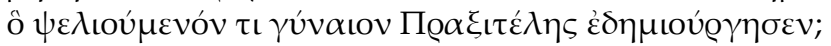

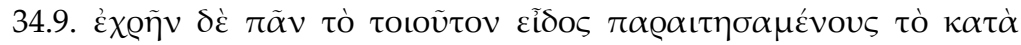

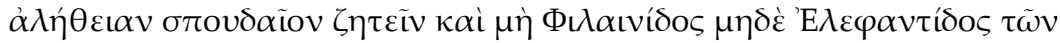

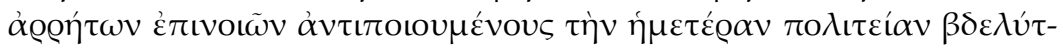
$\tau \varepsilon \sigma \theta \alpha \mathrm{L}$.

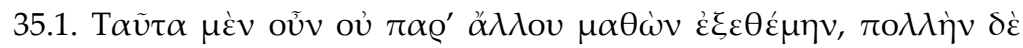

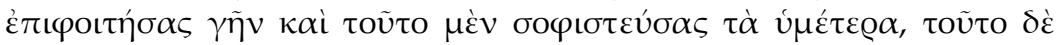

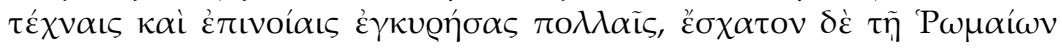

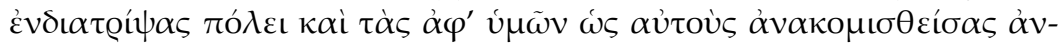

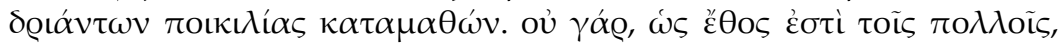

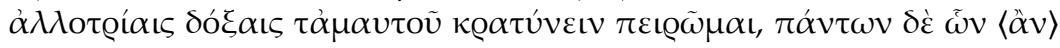

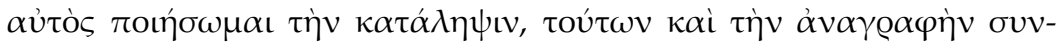

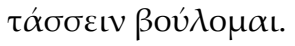

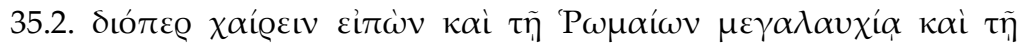

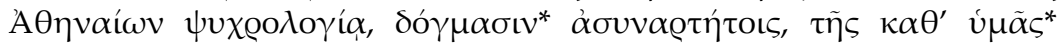

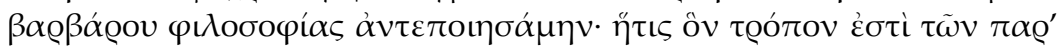

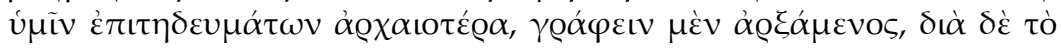

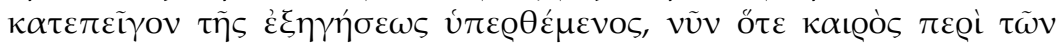

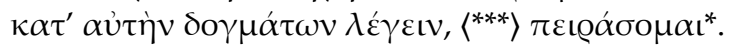

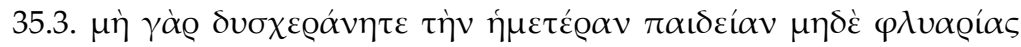

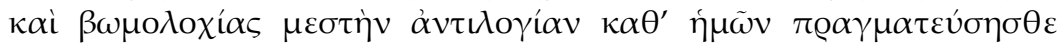

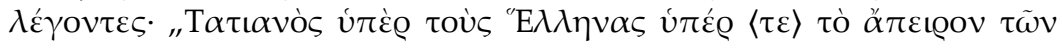

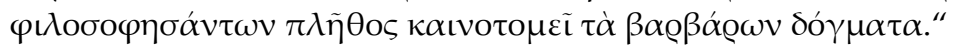

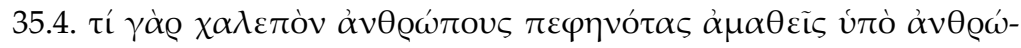

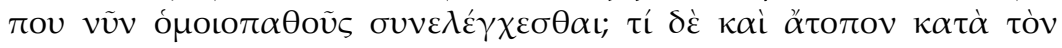

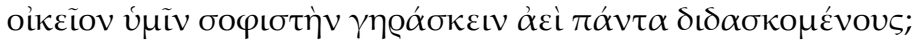


liades meine Augen zu richten? Denn sie war (doch nur) eine Hetäre. Lais hat Unzucht getrieben, und + Turnus ${ }^{546}$ hat sie noch $z u$ einem Denkmal der Hurerei gemacht!

34.8. Warum schämt ihr euch nicht der Hurerei Hephaistions, ${ }^{547}$ auch wenn ihn Philon ausgesprochen kunstgerecht darstellt? Und aus welchem Grund habt ihr dem androgynen Ganymedes ${ }^{548}$ durch Leochares Ehre zukommen lassen, als wenn ihr an ihm einen wertvollen Besitz hättet, und auch dem Weiblein mit Armband, ${ }^{549}$ das Praxiteles dargestellt hat?

34.9. Man sollte jedes derartige Bild von sich weisen und das in Wahrheit Edle suchen und nicht nach den unsäglichen Einfällen einer Philainis oder Elephantis ${ }^{550}$ trachten und unsere Lebensweise verabscheuen!

35.1. Dies nun habe ich nicht, weil ich es von einem anderen lernte, (hier) ausgebreitet, sondern nachdem ich (selbst) ein großes Stück Erde bereist und zum einen mir eure sophistischen Künste erworben habe, zum anderen aber auch vielen (anderen) Künsten und Vorstellungen begegnet bin und mich zuletzt auch in der Stadt der Römer aufgehalten und die von euch (Griechen) zu ihnen gebrachten vielfältigen Statuen kennengelernt habe. Denn nicht versuche ich - wie es die meisten zu tun pflegen - meine eigene Weltanschauung durch fremde Meinungen $\mathrm{zu}$ stärken, sondern von allem, was auch immer ich selbst erfassen kann, davon will ich auch eine schriftliche Dokumentation erstellen.

35.2. Deshalb habe ich sowohl der Prahlerei der Römer als auch der kalten Klügelei der Athener - Meinungen ohne sinnvollen Zusammenhang ${ }^{551}$ - Lebewohl gesagt und mich einer Philosophie zugewandt, die ihr ${ }^{552}$ für , barbarisch' haltet. Auf welche Weise diese (jedoch sogar) älter ist als die (geistigen) Tätigkeiten, denen ihr nachgeht, hatte ich zwar bereits darzulegen begonnen, dann aber wegen dringend erforderlicher (anderer) Darlegung aufgeschoben; nun, da es an der Zeit ist, über die Grundsätze unserer Philosophie zu sprechen, werde ich versuchen $<* * * .553$

35.3. Weist nämlich unsere Paideia nicht mit Verachtung von euch und strengt auch keine Gegenrede an - sie kann nur voll von Geschwätz und Possenreißerei sein -, indem ihr sagt: „Tatian lässt die Griechen und die unendliche Schar derer, die Philosophie betrieben haben, hinter sich und führt neu die Lehrsätze der Barbaren ein!“

35.4. Denn was wäre schlimm daran, dass Menschen, die sich als ungelehrt erwiesen haben, von einem Menschen, dem soeben das Gleiche widerfahren ist, widerlegt werden? Und was wäre daran fehl am Platz, 


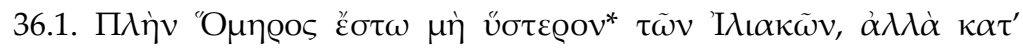

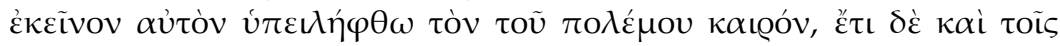

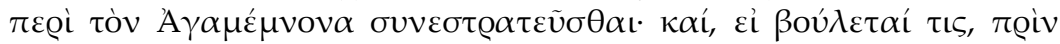

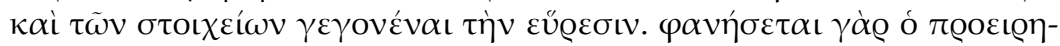

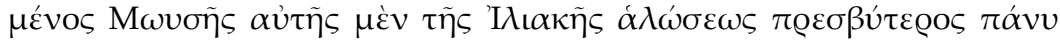

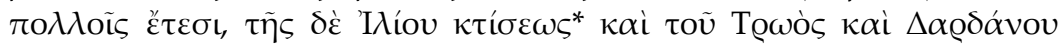

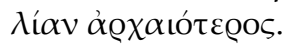

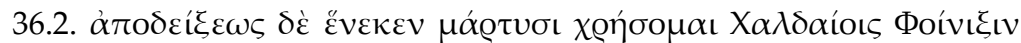

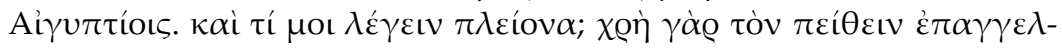

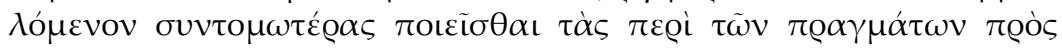

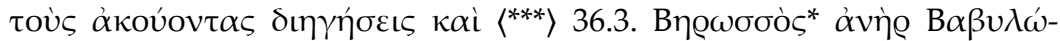

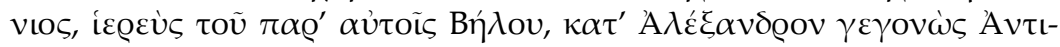

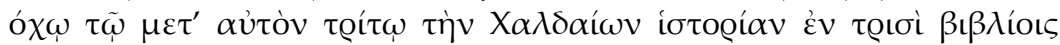

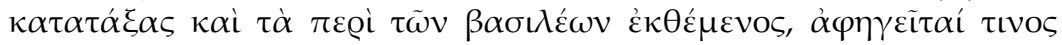

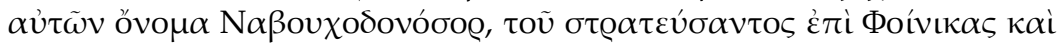

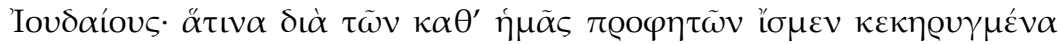

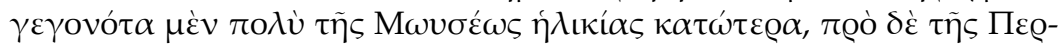

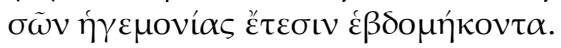

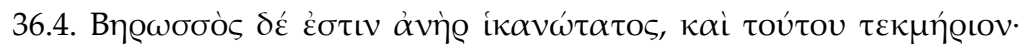

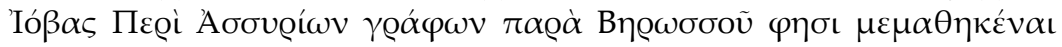

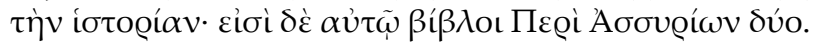

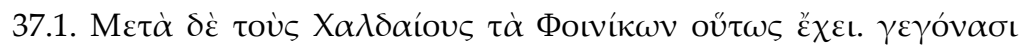

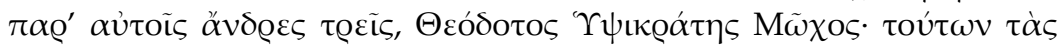

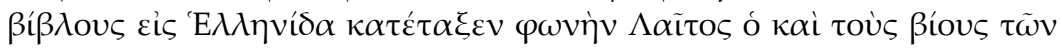

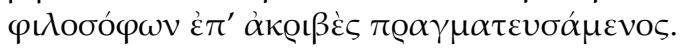

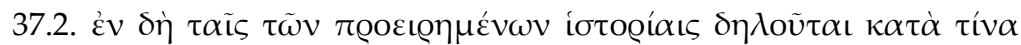

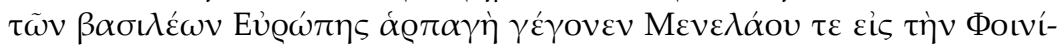

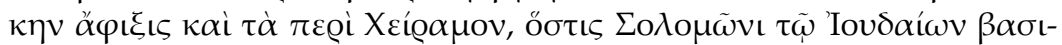

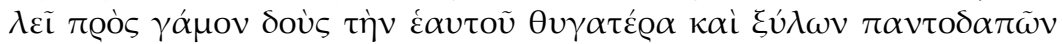

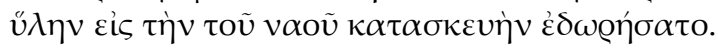


dass man - wie euer eigener Sophist ${ }^{554}$ sagt - ,auch im Alter noch ständig alles Mögliche (hinzu)lernt“?

36.1. ${ }^{555}$ Wohlan: Homer sei nicht später ${ }^{556}$ als die Ereignisse um Ilion angesetzt, sondern man nehme seine Existenz zur Zeit jenes Krieges selbst an, und ferner, dass er zusammen mit Agamemnon ins Feld gezogen sei,;57 und wenn jemand will, soll er auch gelebt haben, noch bevor es zur Erfindung der Buchstaben kam. ${ }^{558}$ Es wird sich nämlich zeigen, dass der schon genannte Moses einerseits im Vergleich zur Eroberung von Ilion älter ist, und zwar um viele Jahre, dass er aber andererseits auch im Vergleich mit der Gründung ${ }^{559}$ Ilions $^{560}$ und mit Tros und Dardanos $^{561}$ noch bedeutend älter ist.

36.2. Zum Beweis werde ich als Zeugen Chaldäer, Phönizier und Ägypter ${ }^{562}$ heranziehen. Und was soll ich noch mehr anführen? Derjenige, der sich einer überzeugenden Beweisführung anheischig macht, sollte seine Darlegung der Dinge gegenüber seinem Publikum kürzer gestalten und ${ }^{563}<^{* * *}>36.3$. Berossos aus Babylon,, 564 ein Priester des babylonischen Gottes Belos, ${ }^{565}$ lebte zur Zeit Alexanders, verfasste für Antiochos, den nach Alexander dritten König, ${ }^{566}$ seine Geschichte der Chaldäer in drei Büchern und legt auch ihre Königsgeschichte dar; er beginnt mit einem von ihnen namens Nabuchodonosor, ${ }^{567}$ der gegen Phönizier und Juden zu Felde zog. ${ }^{568}$ Von diesen Ereignissen wissen wir - da sie durch unsere Propheten verkündet wurden -, dass sie lange nach der Zeit des Moses stattfanden, aber siebzig Jahre vor der Herrschaft der Perser.

36.4. Berossos ist ein außerordentlich kompetenter Mann; ein Indiz dafür ist, dass Iuba, ${ }^{569}$ der „Über die Assyrer" geschrieben hat, angibt, er habe diese Geschichte von Berossos gelernt. 570 Sein Werk „Über die Assyrer" umfasst zwei Bücher.

37.1. Nach den Chaldäern verhält es sich mit den Zeugnissen der Phönizier folgendermaßen: Bei ihnen hat es drei Männer gegeben: Theodotos, Hypsikrates und Mochos. ${ }^{571}$ Ihre Bücher hat Laitos ${ }^{572}$ in die griechische Sprache übersetzt; er hat auch die „Lebensbeschreibungen der Philosophen" sorgfältig ausgearbeitet.

37.2. In den Geschichtswerken der gerade Genannten nun wird dargelegt, unter welchem von den Königen sich der Raub der Europe zutrug und die Ankunft des Menelaos in Phönizien ${ }^{573}$ sowie die mit Hiram $^{574}$ zusammenhängenden Ereignisse, der Salomon, dem König der Juden, seine eigene Tochter zur Ehefrau gab und dazu auch eine Menge mannigfaltiger Hölzer für den Bau des Tempels spendete. 


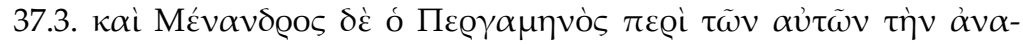

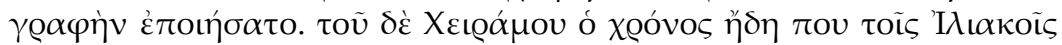

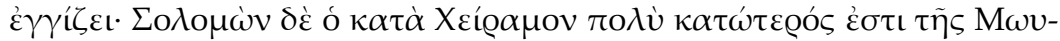

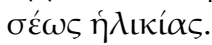

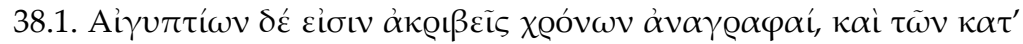

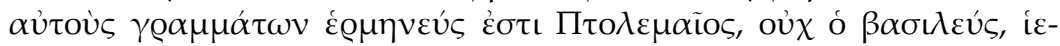

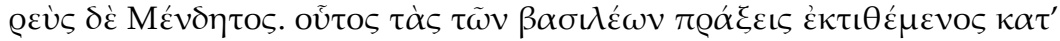

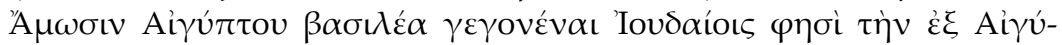

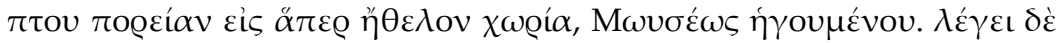

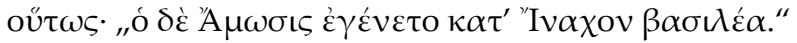

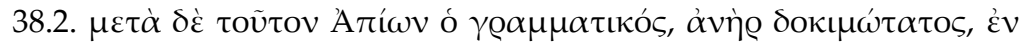

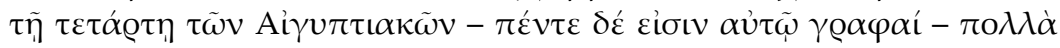

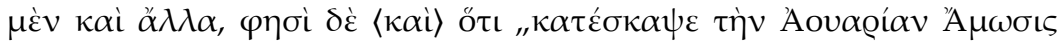

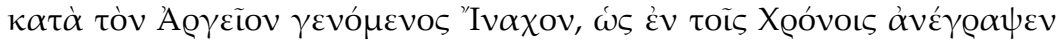

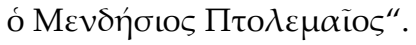

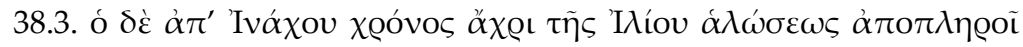

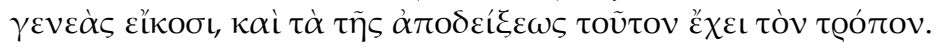

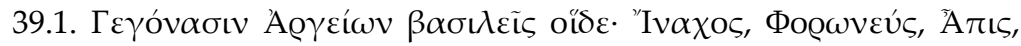

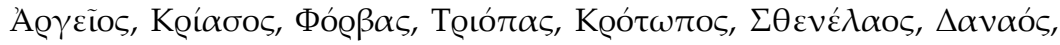

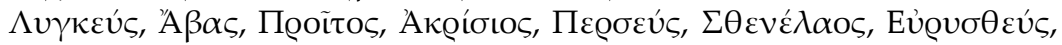

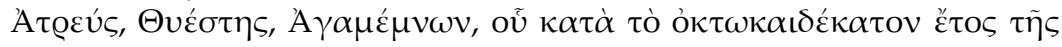

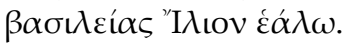

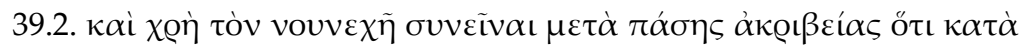

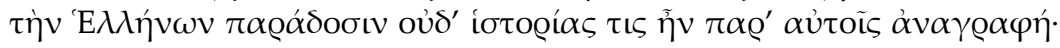

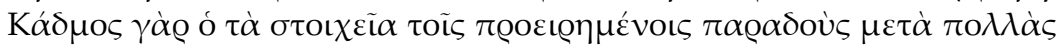

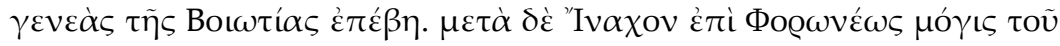

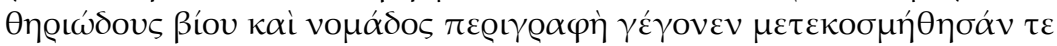

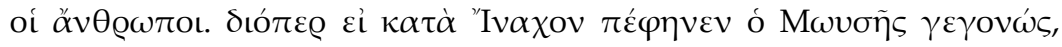

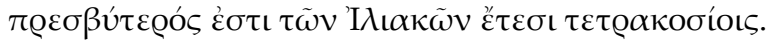

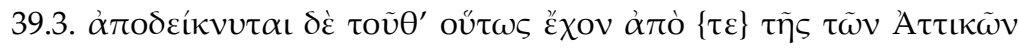

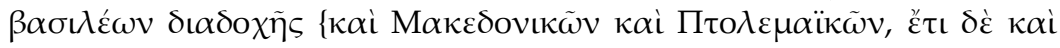

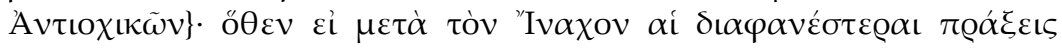


37.3. Auch Menander von Pergamon ${ }^{575}$ hat die gleichen Dinge schriftlich dargestellt. Die Zeit des Hiram ist den Ereignissen um Ilion bereits ziemlich nah; ${ }^{576}$ Salomon aber, der zur Zeit Hirams lebte, kommt erst lange nach der Zeit des Moses.

38.1. Von den Ägyptern aber gibt es genaue chronologische Aufzeichnungen, und ein Vermittler ihrer Schriften ist Ptolemaios, nicht der König, sondern ein Priester aus Mendes. ${ }^{577}$ Dieser stellt die Taten der Könige dar und sagt, dass zu der Zeit, als Ahmose ${ }^{578}$ König Ägyptens war, der Auszug der Juden aus Ägypten in die Gegenden, nach denen sie strebten, unter Führung des Moses stattgefunden habe. Er sagt aber wörtlich: „Ahmose aber lebte zur Zeit des Königs Inachos."

38.2. Nach ihm aber sagt der Grammatiker Apion, ein außerordentlich anerkannter Mann, ${ }^{579}$ im vierten Buch seiner "Ägyptischen Geschichte“ (sein Werk hat fünf Bücher), neben vielem Anderen auch: „Es zerstörte die Stadt Avaris Ahmose, der zur Zeit des Argivers Inachos lebte, wie in seinen ,Chronoi' Ptolemaios von Mendes aufgeschrieben hat."

38.3. Die Zeit von Inachos aber bis zur Eroberung von Ilion umfasst zwanzig Generationen, und der Nachweis hierzu ergibt sich auf folgende Weise:

39.1. Es hat folgende Könige der Argiver gegeben: ${ }^{580}$ Inachos, Phoroneus, Apis, Argeios, ${ }^{581}$ Kriasos, Phorbas, Triopas, Krotopos, Sthenelaos, Danaos, Lynkeus, Abas, Proitos, Akrisios, Perseus, Sthenelaos, ${ }^{582}$ Eurystheus, Atreus, Thyestes und Agamemnon, in dessen achtzehntem Herrschaftsjahr Ilion erobert wurde.

39.2. Auch muss jeder, der Verstand hat, mit aller Sorgfalt begreifen, dass es gemäß der Überlieferung der Griechen bei ihnen auch (noch) keine schriftliche Aufzeichnung von Geschichte gab; ${ }^{583}$ Kadmos nämlich, der den gerade Genannten die Buchstaben vermittelte, betrat erst viele Generationen später Boiotien. ${ }^{584}$ Nach Inachos aber, unter Phoroneus, ${ }^{585} \mathrm{kam}$ es mit mancher Mühe zu einer Eindämmung des noch tierisch-wilden und unsteten Lebens, und die Menschen gelangten $\mathrm{zu}$ neuer Gesittung. Wenn sich daher erwiesen hat, dass Moses zur Zeit des Inachos lebte, dann ist er vierhundert Jahre älter als die Ereignisse um Ilion. ${ }^{586}$

39.3. Der Beweis aber, dass sich dies so verhält, wird aus der Abfolge der attischen Könige ${ }^{587}$ erbracht (wenn daher erst nach Inachos die be- 


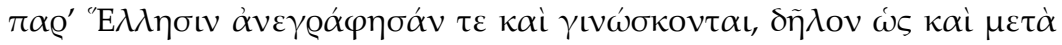
M $\omega v \sigma \varepsilon ́ \alpha$.

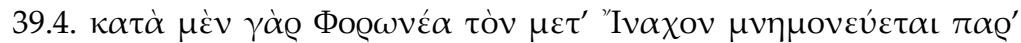

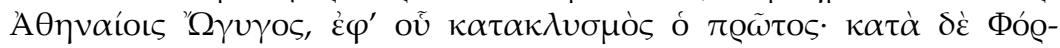

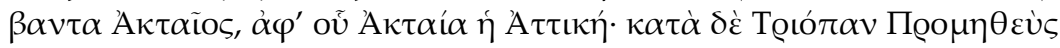

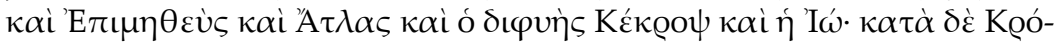

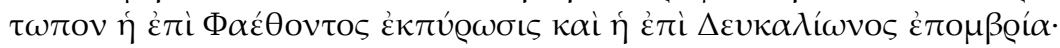

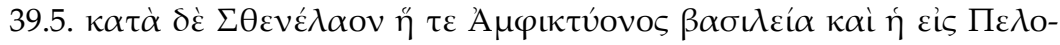

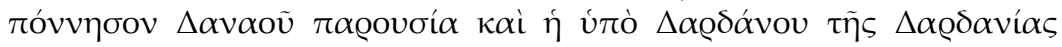

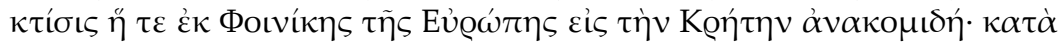

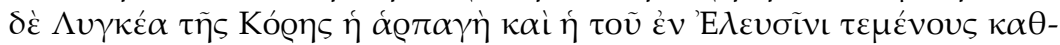

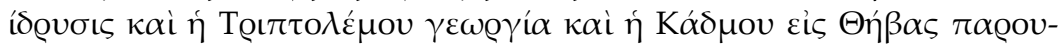

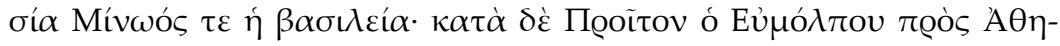

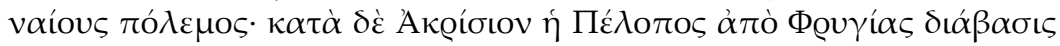

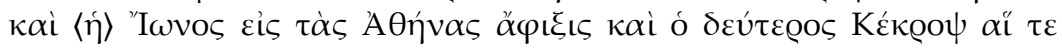

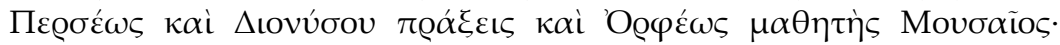

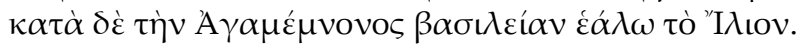

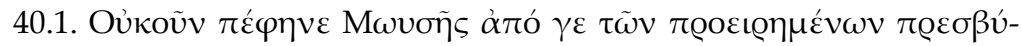

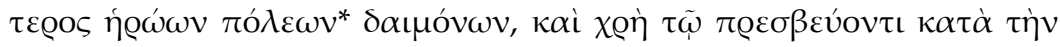

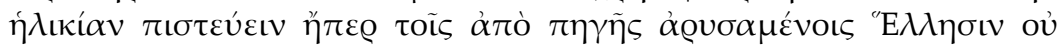

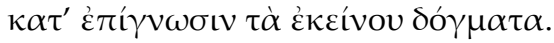

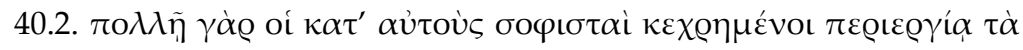

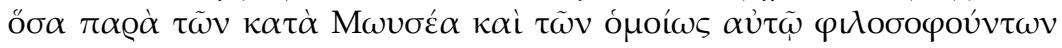

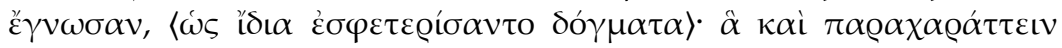

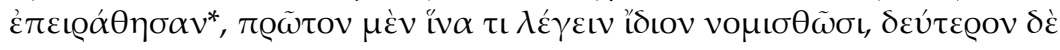

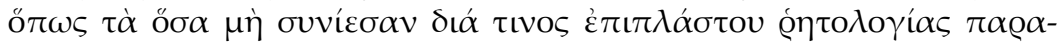

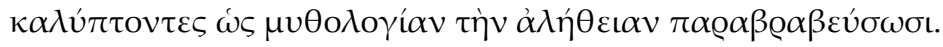

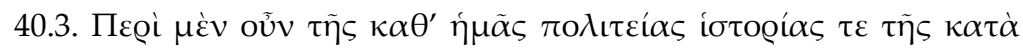

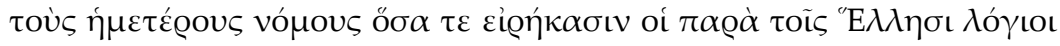

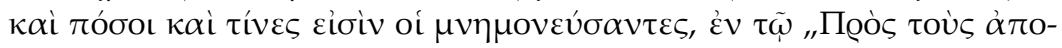

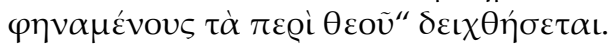


rühmteren Taten bei den Griechen aufgezeichnet wurden und dadurch bekannt sind, so bedeutet dies auch: erst nach Moses): ${ }^{588}$

39.4. Zur Zeit des Phoroneus nämlich, des Nachfolgers des Inachos, wird bei den Athenern Ogygos ${ }^{589}$ erwähnt, unter dem es zur ersten Überschwemmung kam; zur Zeit des Phorbas lebte Aktaios, ${ }^{590}$ nach dem Attika den Namen Aktaia erhielt; zur Zeit des Triopas lebten Prometheus, Epimetheus, Atlas, der aus zwei Gestalten bestehende Kekrops und Io; ${ }^{591}$ zur Zeit des Krotopos gab es den Weltbrand Phaethons und die große Flut Deukalions; ${ }^{592}$ 39.5. zur Zeit des Sthenelaos gab es das Königtum des Amphiktyon, 593 das Erscheinen des Danaos auf der Peloponnes, die Gründung von Dardania durch Dardanos ${ }^{594}$ und die Verschleppung der Europa aus Phönizien nach Kreta; zur Zeit des Lynkeus kam es zum Raub der Kore, zur Errichtung des Heiligtums in Eleusis, zur Begründung des Ackerbaus durch Triptolemos, ${ }^{595}$ zum Erscheinen des Kadmos in Theben und zur Herrschaft des Minos; ${ }^{596}$ zur Zeit des Proitos fand der Krieg des Eumolpos gegen die Athener statt; ${ }^{597}$ zur Zeit des Akrisios gab es den Übergang des Pelops aus Phrygien (nach Muttergriechenland), die Ankunft des Ion in Athen, den zweiten Kekrops, ${ }^{598}$ die Taten des Perseus und des Dionysos ${ }^{599}$ und Musaios als Schüler des Orpheus; ${ }^{600}$ zur Zeit der Königsherrschaft Agamemnons ${ }^{601}$ aber wurde Ilion erobert.

40.1. So also ist aufgrund jedenfalls des gerade Ausgeführten klar, dass Moses älter als die (genannten) Helden, Städte ${ }^{602}$ und Dämonen ist, und man muss dem, der an Alter voransteht, (mehr) Vertrauen schenken als den Griechen, die aus der Quelle die Lehrmeinungen jenes Mannes geschöpft haben, ohne ihn (entsprechend) anzuerkennen.

40.2. Denn ihre Sophisten legten sich sehr ins Zeug und eigneten sich alles, was sie von Moses $^{603}$ und denen erfuhren, die ähnlich wie er philosophierten, wie eigene Lehrsätze an; ${ }^{604}$ diese unternahmen sie dann aber auch (noch) zu entstellen, erstens damit man glaube, sie sagten etwas Eigenes, und zweitens, um alles, was sie nicht verstanden, durch eine dick aufgetragene Rhetorik zu verhüllen und die Wahrheit wie einen Mythos zu verfälschen.

40.3. Was nun unsere Lebensweise und Geschichte gemäß unseren Gesetzen betrifft, soviel darüber die Gelehrten bei den Griechen gesagt haben und wieviele und welche es waren, die davon sprachen, wird in der Schrift "An diejenigen, die die Dinge über Gott dargelegt haben" dargestellt werden. 


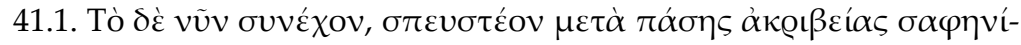

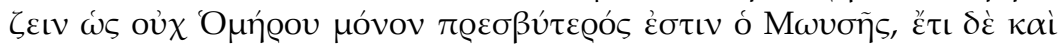

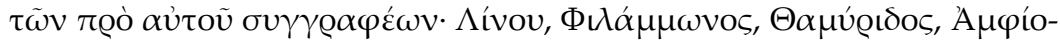

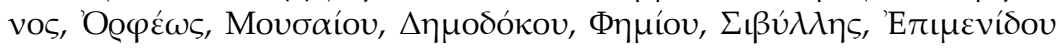

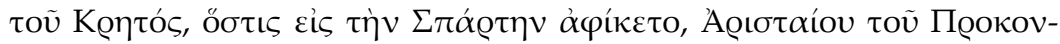

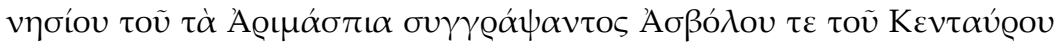

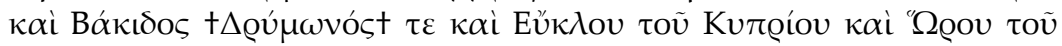

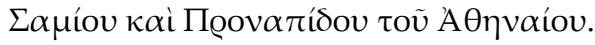

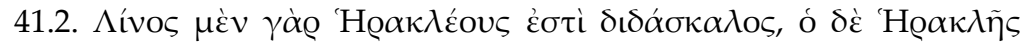

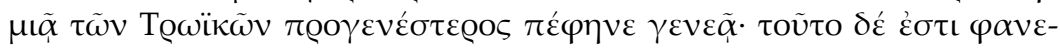

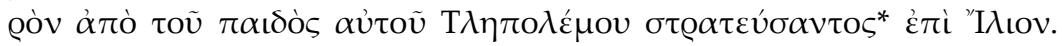

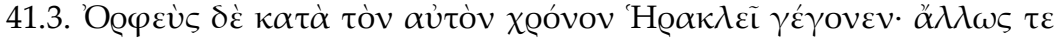

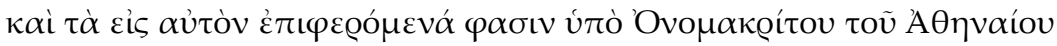

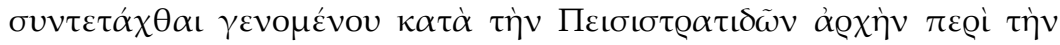

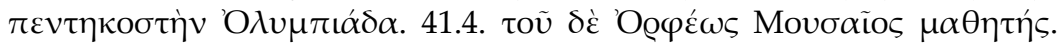

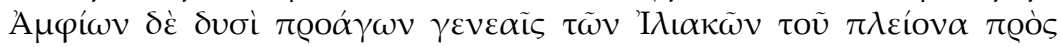

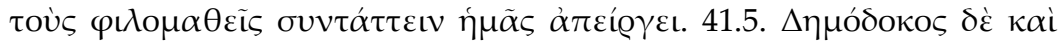

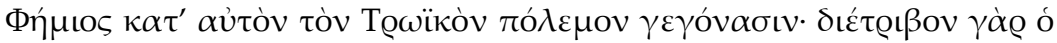

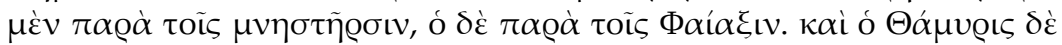

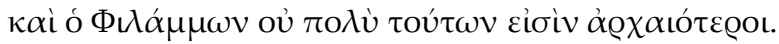

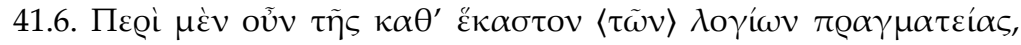

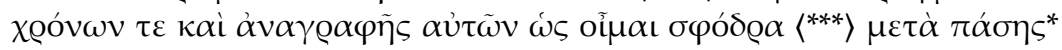

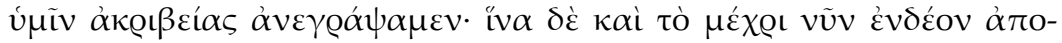

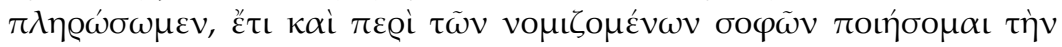

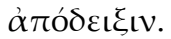

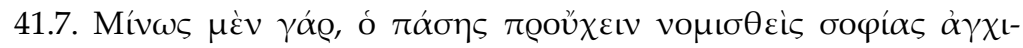

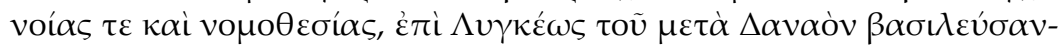

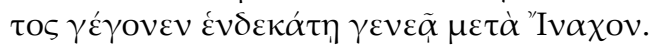

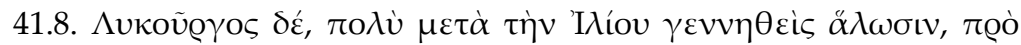

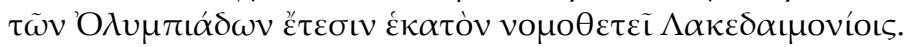

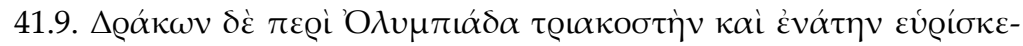

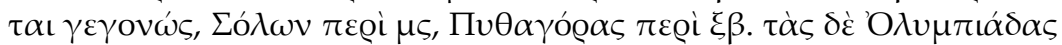

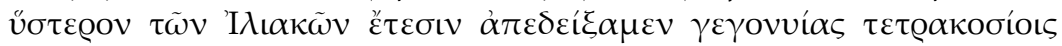
$\varepsilon \dot{\tau} \tau \dot{\alpha}$. 
41.1. Was aber jetzt die Hauptsache ist: Ich muss mich mit aller Genauigkeit bemühen klarzumachen, dass nicht nur im Vergleich mit Homer Moses der ältere ist, sondern auch im Vergleich zu den vor Homer lebenden Autoren: ${ }^{605}$ Linos, ${ }^{606}$ Philammon, ${ }^{607}$ Thamyris, ${ }^{608}$ Amphion, ${ }^{609}$ Orpheus, ${ }^{610}$ Musaios, ${ }^{611}$ Demodokos, ${ }^{612}$ Phemios, ${ }^{613}$ die Sibylle, ${ }^{614}$ Epimenides von Kreta, der nach Sparta kam, ${ }^{615}$ Aristeas von Prokonnesos, der das Arimaspen-Epos schrieb, ${ }^{616}$ der Kentaure Asbolos ${ }^{617}$ und Bakis, ${ }^{618}$ tDrymont 619 und Euklos von Zypern ${ }^{620}$ und Horos von Sa$\operatorname{mos}^{621}$ und Pronapides von Athen. ${ }^{622}$

41.2. Linos $^{623}$ ist nämlich der Lehrer des Herakles, von Herakles aber ist klar, dass er eine Generation älter ist als die Ereignisse um Troja; dies ist dadurch offenkundig, dass sein Sohn Tlepolemos ${ }^{624}$ gegen Ilion zu Felde zog. ${ }^{625}$ 41.3. Orpheus aber hat zur gleichen Zeit wie Herakles gelebt; zumal man sagt, dass die ihm zugeschriebenen Werke von Onomakritos $^{626}$ aus Athen verfasst worden sein sollen, der zur Zeit der Herrschaft der Peisistratiden, um die 50. Olympiade, lebte. 41.4. Schüler des Orpheus aber war Musaios. Der Umstand, dass Amphion um zwei Generationen den Ereignissen um Ilion voranging, hält mich davon $a b$, mehr (über ihn) für die Wissbegierigen (hier) zusammenzustellen. 41.5. Demodokos und Phemios haben gerade zur Zeit des Trojanischen Kriegs gelebt; denn der eine hielt sich bei den Freiern auf, der andere bei den Phaiaken. ${ }^{627}$ Auch Thamyris aber und Philammon ${ }^{628}$ sind nicht viel älter als diese.

41.6. Was nun die Behandlung eines jeden der gelehrten Männer betrifft, ihre Zeiten und ihre schriftliche Aufzeichnung, so habe ich, wie ich glaube, sehr $<* * * 629$ mit jeglicher Sorgfalt für euch aufgeschrieben. Um aber auch das bis jetzt noch Fehlende nachzutragen, werde ich auch noch über diejenigen, die als weise gelten, ${ }^{630}$ (hier) eine Darlegung geben.

41.7. Minos nämlich, der als herausragend an jeglicher Weisheit, Intelligenz und Gesetzgebungsfähigkeit gilt,,631 lebte zur Zeit des Lynkeus, ${ }^{632}$ der nach Danaos König war, in der elften Generation nach Inachos.

41.8. Lykurgos, erst lange nach der Eroberung Trojas auf die Welt gekommen, gab hundert Jahre vor dem Beginn der Olympiaden den Spartanern Gesetze. 633

41.9. Von Drakon findet man, dass er um die 39. Olympiade lebte, von Solon, um die 46., von Pythagoras, um die 62. Dass die Olympiaden (erst) 407 Jahre nach den Ereignissen um Ilion einsetzten, habe ich (bereits) gezeigt. ${ }^{634}$ 


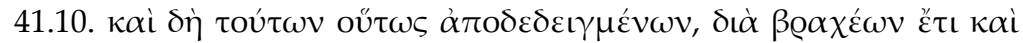

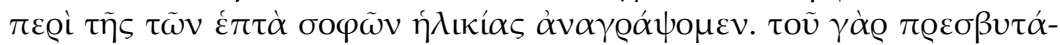

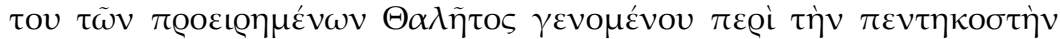

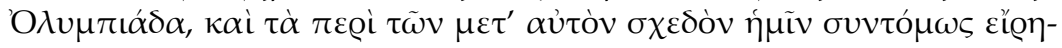
$\tau \alpha \mathrm{t}$.

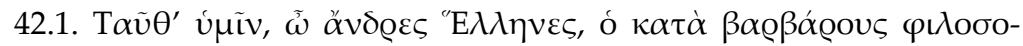

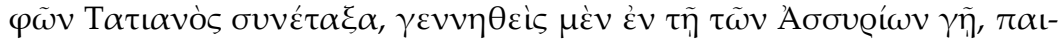

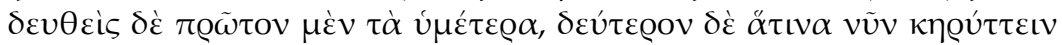
$\dot{\varepsilon} \pi \alpha \gamma \gamma \varepsilon \dot{\lambda} \lambda \lambda \mathrm{o \mu \alpha \textrm {t } .}$

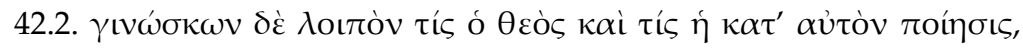

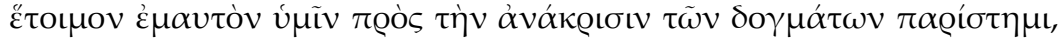

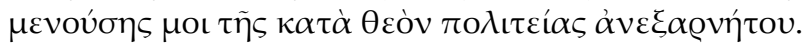


41.10. Und nachdem also diese Dinge so erwiesen sind, will ich in Kürze auch noch die Zeit der sieben Weisen notieren: Da nämlich der älteste der gerade Genannten, Thales, ${ }^{635}$ um die 50. Olympiade lebte, habe ich damit in ungefährer Weise auch die Zeitumstände der nach ihm Kommenden kurz angegeben.

42.1. Dies ist es, was ich, der nach der Weise der Barbaren philosophierende Tatian, für euch, ihr Griechen, zusammengestellt habe; geboren wurde ich im Land der Assyrer ${ }^{636}$ und lernte zuerst eure Bildung kennen, danach aber die, die zu verkünden ich mich jetzt anheischig mache.

42.2. Da ich aber erkannt habe, wer Gott ist und was die von ihm gestaltete Schöpfung, stelle ich mich euch bereitwillig zur Prüfung meiner Überzeugungen zur Verfügung - wobei mir der Lebenswandel gemäß den Geboten Gottes (stets) unverleugnet bleiben wird. 


\section{Anmerkungen zur Übersetzung}

* Der Asteriskos im griechischen Text bezieht sich auf die Liste der Textvarianten am Ende der Einführung.

1 Zum Verhältnis des nun folgenden Katalogs von Erfindungen durch Nichtgriechen zu einem Textabschnitt in den Stromateis des Clemens von Alexandria, der die gleiche These entwickelt (Strom. I 74,1: „Erfinder nicht nur der Philosophie, sondern mehr oder weniger jeder Kunst sind Nichtgriechen") vgl. die Einführung, oben S. 20. In Strom. I 77,1 nennt Clemens eine Reihe von Autoren, die solche Kataloge von Erfindungen zusammenstellten, aus denen wohl auch Tatian geschöpft hat: „Skamon von Mytilene und Theophrast von Eresos, ferner Antiphanes, Aristodemos und Aristoteles, zusätzlich Philostephanos, aber auch Straton der Peripatetiker haben in ihren Büchern ,Über Erfindungen' dies dargelegt."

Sind mit den der mantischen Traumdeutung Kundigen Bewohner der Stadt Telmissos (so die Tatian-Handschriften sowie Marcovich und Trelenberg: Te $\lambda \mu \iota \sigma \sigma \varepsilon ́ \omega \nu$ ) in Karien oder Bewohner der Stadt Telmessos (so konjizierte Schwartz und ihm

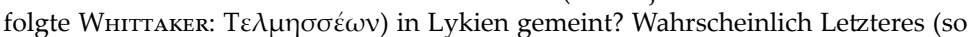
auch Di CRISTINA ad loc.). Schon Herodot (I 78,2f. und 84,3) kennt die mantischen Fähigkeiten der Telmessier, die dann auch von Cicero bestätigt werden (Div. I 91: Telmessus ..., qua in urbe excellit haruspicum disciplina, „die Stadt Telmessos ..., in der die Kunst der Eingeweideschauer hervorragt “). In Fr. 554 PCG des Komödiendichters Aristophanes scheinen die Telmessier mit Eingeweideschau in Verbindung gebracht zu werden. Der von Trelenberg angeführte Tertullian (De an. 46,3) spricht ebenfalls von Leuten aus Telmessos: Telmessenses nulla somnia euacuant ... ( „Die Einwohner von Telmessos halten keine Träume für leer ..."). Schon Cicero ist freilich auch ein guter Zeuge für die bereits in der Antike vorkommende Verwechslung: In Div. I 91 und 94 lokalisiert er Telmessos in Karien (wo also eigentlich Telmissos liegt), beschreibt aber seine Lage so, dass sie nur auf das an der Westgrenze Lykiens gelegene Telmessos (heute Fethiye) zutreffen kann (vgl. bereits WhitTAKER ad loc.). Da Tatian außerdem gleich im Anschluss von den Karern spricht, ist unwahrscheinlich, dass er auch bei den Traumdeutern das karische Telmissos im Auge hat. Der

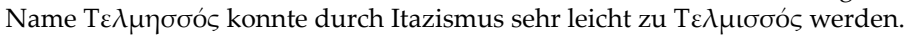

Karien ist eine Landschaft im Südwesten des antiken Kleinasien (mit Halikarnass als eine seiner wichtigsten Städte); gleich östlich davon schließt sich Lykien an, dem die kurz zuvor von Tatian genannten Einwohner von Telmessos zuzurechnen sind (vgl. die vorangehende Anm.).

Phrygien heißt in der Antike ein Gebiet im nördlichen Zentral-Kleinasien, südlich von Bithynien und östlich von Lydien.

Isaurien ist in der Antike ein Berggebiet im südlichen Zentral-Kleinasien, zwischen (dem südlich angrenzenden) Pisidien und (dem nordöstlich sich anschließenden) Lykaonien.

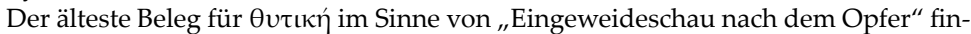
det sich bei Diodor (I 53,8: die Tochter des Pharao Sesoosis habe ihrem Vater unter

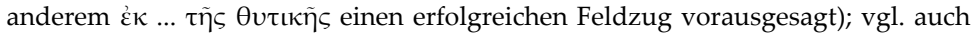

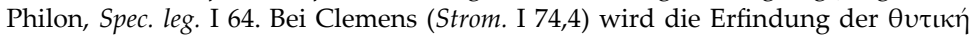
den „Tuskoi“ (= Etruskern) zugeschrieben.

7 Orpheus, eine zentrale Figur der griechischen Mythologie, gilt also nicht als Grieche, und zwar deshalb, weil er nach verbreiteter Bezeugung (ältester Beleg: Pindar, Fr. 128c,11f. SNell-MaeHLeR; Apollonios Rhodios, Arg. I 23-25.570; II 703; IV 905) 
Sohn des thrakischen Königs Oiagros ist. Zwar stammt er nach anderer Version direkt von Apollon ab (vgl. Apollod. Bibl. I 14 = I 3,2), doch wird diese Version von Tatian aus verständlichen Gründen hier ignoriert.

Wenn man Tovok $\alpha$ voí mit „Etrusker“ wiedergibt (so WhITTAKer, Di CRISTINA und TrelenberG; Fermi schreibt „Toscani“), fragt sich, wer dann die wenige Zeilen später genannten „Tyrrhener“ (Tv@@ұvoú ist spätestens seit Herodot die übliche griechische Bezeichung für Etrusker) sind. Clemens lässt in seinem Katalog sogar die „Tuskoi“ (Strom. I 74,5), „Tyrrhenoi“ (I 74,6) und „Tuskanoi“ (I 75,7) nebeneinander stehen. Trelenberg 2012, 85 Anm. 9 beruft sich in diesem Zusammenhang auf Puech 1903, 38 für die Meinung, „dass Tatian in der Kompilation ... auf mehrere literarische Vorlagen zurückgreift“; PuEch drückt sich jedoch etwas anders aus: „la double appellation des Etrusques (...) indique que tout dans le morceau n'a pas la même origine; mais il peut se faire que cette disparate fût déjà dans la compilation dont Tatien s'est servi.“ Genau dafür spricht, dass Clemens in der gleichen „compilation“ offenbar sogar drei Erfindungen der Etrusker (unter jeweils verschiedenen Bezeichnungen der Erfinder, was für verschiedene Quellenherkunft spricht) fand, wovon Tatian eine weggelassen hat.

9 Trelenberg 2012, 85 lässt in seiner Übersetzung die Phryger Marsyas und Olympos sowohl das „Flötenspiel“ (richtiger wäre „Aulosspiel“; ein Aulos ist keine Flöte) als auch das Spiel auf der Syrinx erfinden; sonst aber wird in diesem Katalog den Vertretern jeder Volksgruppe immer nur eine bestimmte Erfindung zugewiesen, und Aulos und Syrinx sind zwei recht verschiedene Instrumente, also auch

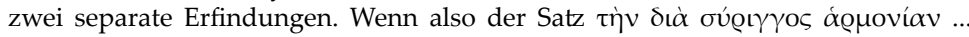

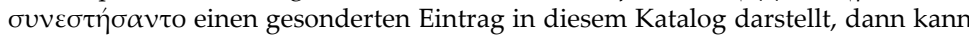

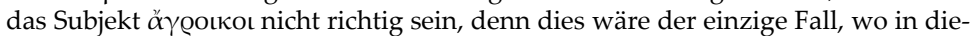
ser Aufzählung eine Erfindung irgendwelchen „Landleuten“ und nicht einem bestimmten nichtgriechischen Volk zugewiesen würde. Vielleicht hilft hier ein Blick auf die betreffende Stelle in einem analogen Katalog bei Clemens, Strom. I 76,5: $\varphi \alpha \sigma i$

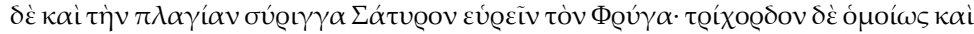

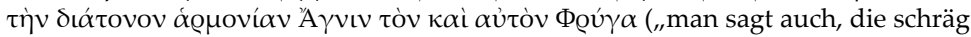
zulaufende Syrinx habe der Phryger Satyros erfunden; und in ähnlicher Weise die Leier mit drei Saiten und die diatonische Harmonie Agnis, der ebenfalls ein Phryger war"). Vielleicht könnte man also den Tatian-Text hier folgendermaßen korrigie-

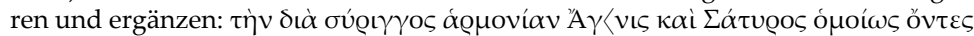
$\Phi\rangle$ @ú

10 Zur möglichen Doppelung der hier genannten „Tyrrhener“ mit den bereits genannten „Tuskanern“ vgl. oben Anm. 8.

11 Es ist höchst bemerkenswert, dass Tatian unter den nichtgriechischen Urhebern von Erfindungen auch „Kyklopen“ aufführt, so als seien dies Nichtgriechen wie alle anderen auch. Wie kommt Tatian dazu, hier den Kyklopen als barbarischem Volk die Erfindung der Erzbearbeitung zuzuschreiben? Es scheint in der antiken Literatur nur zwei direkte Parallelen zu geben: Der Kallimachos-Schüler Istros verzeichnet die Nachricht, dass Erzwaffen zuerst von Kyklopen auf Euboia geschaffen worden seien (FGrHist 334 F 71), und in einem längeren Katalog von Erfindungen schreibt der Ältere Plinius ebenfalls Kyklopen die Erfindung der Erzschmiedekunst zu (Nat. VII 197: aerariam fabricam [scil. monstrasse] alii Chalybas, alii Cyclopas [scil. putant], „von der Erzbearbeitung glauben die einen, dass sie die Chalyber, die anderen, die Kyklopen ans Licht gebracht hätten“); in VII 198 wird ihnen auch die Erfindung der Eisenschmiedekunst zugesprochen).

Möglicherweise liegt hier eine Kombination von verschiedenen Vorstellungen vor, die in der Antike mit „Kyklopen“ verbunden wurden. Drei verschiedene Arten von Kylopen hat vielleicht als erster der Geschichtsschreiber Hellanikos (späteres 5. Jh. v. Chr.; vgl. auch unten Anm. 12) zusammengestellt (FGrHist 4 F 88: „... Von Ky- 
klopen gibt es drei Arten: die Kyklopen, die Mykene mit Mauern umgaben, das Volk des Polyphem, und die eigentlichen Götter"). Zum einen sind drei göttliche Kyklopen (Brontes, Steropes und Arges, Söhne von Uranos und Gaia und damit direkte Geschwister der Titanen, die noch eine Generation vor den olympischen Göttern kommen) bereits bei Hesiod (Theog. 139-141) als Schmiede tätig, da sie für Zeus den Blitz anfertigen (vgl. auch Apollonios Rhodios, Arg. I 730-734); als Helfer des Schmiedegotts Hephaistos finden wir sie im Artemis-Hymnos des Kallimachos (V. 46-61) und in den Georgica (IV 170-175) und der Aeneis (VIII 416-453) Vergils. Zweitens führt die homerische Odyssee (IX 106-115) Kyklopen als „barbarische Ureinwohner" der Insel Thrinakia (die später in der Regel mit Sizilien identifiziert wurde) ein; zu ihnen gehört der ungeschlachte Polyphem, mit dem es Odysseus zu tun bekommt. Diese Kyklopen - die freilich nichts mit Metallverarbeitung zu tun haben, sondern primitive, in Höhlen wohnende Ziegen- und Schafhirten sind ohne auch nur einen Anflug höherer Zivilisation - werden später „historisiert" und z.B. von Thukydides (VI 2,1) als mutmaßliche erste Bewohner Siziliens eingeführt; vgl. auch Strabon I 2,9 und Heraclitus, Paradox. 11 (Mythogr. Gr. III 2 Festa). Schließlich gibt es noch eine dritte Kyklopen-Kategorie, die vor allem als Baumeister der „kyklopischen“ Mauern z.B. von Mykene und Tiryns auftraten (vgl. Paus. II 16,5; 20,7; 25,8); erste Belege zu ihnen finden sich bei Pindar (Fr. 70a, 6 und 169a,7 SNELLMaeHLeR), Bakchylides (Epin. 11,77) und Sophokles (Fr. 227 RadT). Laut Strabon (VIII 6,11; vgl. auch Apollod. Bibl. II $25=$ II 2,1) kamen diese Kyklopen aus dem kleinasiatischen Lykien, laut Schol. Eur. Or. 965 aus Thrakien; jedenfalls sind sie als "Nichtgriechen" ausgewiesen.

Die bei Istros, dem Älteren Plinius und Tatian zu findenden Kyklopen als erste Erzschmiedemeister sind vielleicht eine Kombination aus allen drei Kyklopenarten: Nr. 1 lieferte die Schmiedekunst, Nr. 2 und 3 die Identifikation als nichtgriechisches Volk. Anders als Tatian nennt Clemens (Strom. I 76,2) als erste Bearbeiter von Erz und Eisen nicht Kyklopen, sondern "Noroper", die er im späteren Noricum ansiedelt.

WhitTAKer 1982, 3 Anm. d weist zu Recht darauf hin, dass es sich bei dieser Atossa nicht um die Tochter des persischen Reichsgründers Kyros, Frau des Königs Dareios und Mutter des Königs Xerxes handelt, die eine tragende Rolle in Aischylos' Persern spielt, sondern um eine frühere Atossa, die der von Tatian zitierte Hellanikos (FGrHist 4 F 178ab = FGrHist 687a F 7ab, aus Hellanikos' Persika) als Tochter eines Königs Ariaspes nennt, dessen Herrschaft sie erbte, und die deshalb von Tatian hier auch korrekt als Herrscherin der Perser (was die Kyros-Tochter Atossa nie war) eingeführt wird. Weil diese Atossa als Mann erscheinen wollte (weil sie sonst offenbar nicht hätte herrschen können), trug sie entsprechende Kleidung und machte ihre herrscherlichen Verlautbarungen nicht persönlich, sondern durch Schrift-

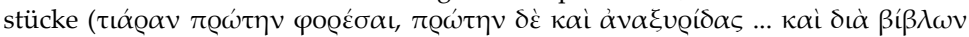

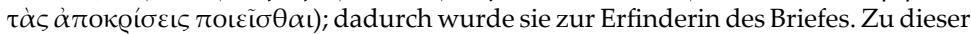
Semiramis-artigen Atossa vgl. D. L. Gera, Warrior Women: The Anonymous Tractatus De Mulieribus (Leiden 1997) 141-150, und Brown 2002, 97-100 (in seiner 9. Dihegesis vergleicht der Mythograph Konon die berühmte Semiramis explizit mit der „Assyrerin Atossa").

13 In der überlieferten Form (die von Whittaker und Trelenderg beibehalten wird)

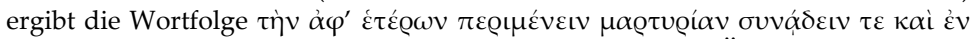

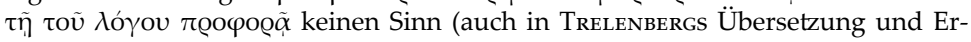
läuterung nicht, denn es deutet im Text nichts darauf hin, dass hiermit auf Tatians eigene Rede an die Griechen angespielt wäre). Schwartz hat daher zu Recht ad loc.

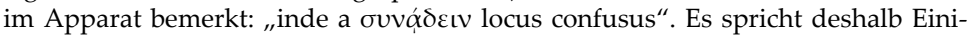

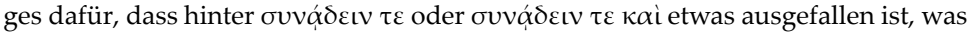

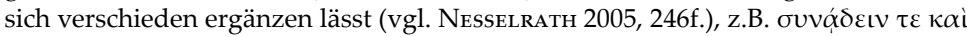




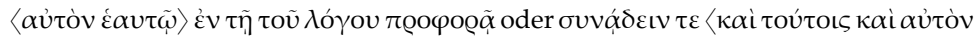

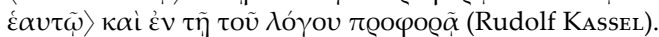

Mit „Dorern“, „Leuten aus Attika“, „Aiolern“ und „Ioniern“ sind die Vertreter der vier literarischen Hauptdialekte des antiken Griechisch (Dorisch, Attisch, Aiolisch, Ionisch) benannt, die sich in der griechischen Literatur niedergeschlagen haben (Dorisch vor allem in der Chorlyrik, Attisch vor allem in der Prosa, Aiolisch in der monodischen Lyrik, Ionisch im Epos und in der älteren wissenschaftlichen Prosa); dabei ist Attisch eigentlich eine (freilich deutlich erkennbare) Unterart des Ionischen.

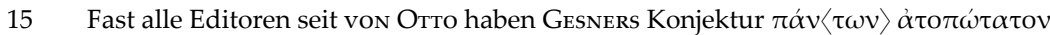
für das einhellig überlieferte $\pi \tilde{\alpha} v$ $\alpha \tau o \pi \omega \tau \alpha \tau o v$ übernommen; lediglich GooDSPEED ist mit seinem Vorschlag $\pi \alpha v \alpha \tau$ To $\omega \tau \alpha \alpha \tau$ im Prinzip bei dem überlieferten Wortlaut geblieben. Nun ist dieses Wort zwar nirgendwo sonst in der griechischen Literatur noch zu finden, aber es wäre nicht das einzige Hapax legome-

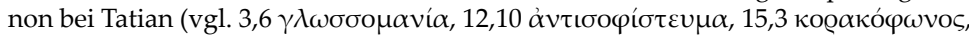

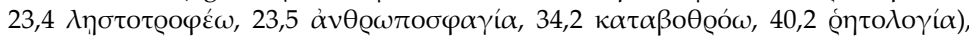
und es wäre auch ohne Anstöße gebildet, denn es gibt noch eine Reihe weiterer Adjektive (auch Superlativformen), die durch vorangestelltes $\pi \alpha v$ - gestei-

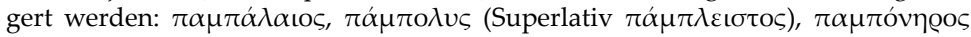

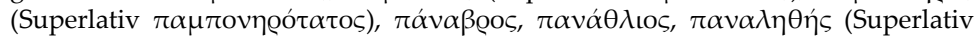

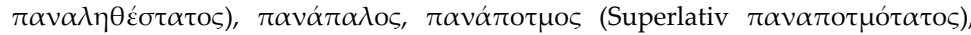

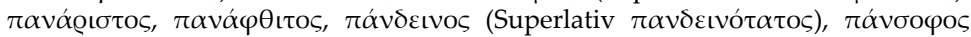
(Superlativ $\pi \alpha v \sigma o \varphi \omega ́ \tau \alpha \tau o \varsigma), \pi \alpha v v ́ \sigma \tau \alpha \tau o \varsigma$.

16 Dieser Satz ist auf zwei ganz verschiedene Arten verstanden worden: so wie hier von Oтто („,quamvis omnino spectatus aliquis in ea essem“), HARnAck (,war ich gleich ein hochangesehener in ihr"), WHItTAKER (,even though I was myself very distinguished in it") und ebenso Di CRISTINA, dagegen mit $\eta^{\prime \prime} v$ als 3. Person Singular von KuKula („,obwohl darin mancher von uns einen großen Ruf genoß“), von FERmi (die aber den $\tau \iota \varsigma$ gleichwohl auf Tatian bezieht) und zuletzt von Trelenberg (, auch wenn vielleicht sich manch einer durchaus achtbar in ihr zeigte ${ }^{\prime \prime}$. KuKula sieht hier eine Anspielung auf Tatians Lehrer Justin (vgl. unten 18,6), wofür Wortlaut und Kontext aber kaum einen Anhaltspunkt bieten. Es ist das natürlichste, die 1. Person (wenn auch Plural) im vorangehenden Hauptsatz $(\dot{\alpha} \pi \varepsilon \tau \alpha \xi \dot{\alpha} \mu \varepsilon \theta \alpha)$ im gleich angeschlossenen Nebensatz fortgesetzt zu sehen.

17 Zitat von Aristoph. Ran. 92f. mit leicht veränderter Wortstellung im ersten Vers

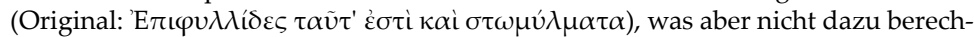
tigt, mit MARCovich (dem TrelenberG folgt) die originale Wortstellung hier hineinzukonjizieren. Mit den hier zitierten Worten charakterisiert der große EuripidesVerehrer Dionysos in Aristophanes' Fröschen die zeitgenössischen Tragödiendichter in Athen, die er nur für minderwertige Epigonen des Euripides hält; Tatian überträgt diese Charakterisierung auf die griechischen Sophisten seiner Zeit.

18 Anspielung auf Pindar, Ol. 2,85-88, wo krächzende Raben ein Bild für schlechte nachahmende Lernende (im Vergleich zu einem wahrhaft begabten Dichter) sind; vgl. auch Aristid. Or. 2,109; Clem. Alex. Strom. VI 151,4. Das Bild wird noch einmal in 15,3 aufgegriffen.

19 Whittaker 1982, 5 Anm. b und Trelenberg 2012, 87 Anm. 18 glauben, dass Tatian hier auf die Gesandtschaft griechischer Philosophen in Rom 155 v. Chr. anspielt, während deren Karneades zuerst eine Rede für und am Tag danach gegen die Gerechtigkeit hielt; bereits Gesner, dann auch von Otto und FERmi jeweils ad loc. hatten an den Wettkampf zwischen dem gerechten und dem ungerechten Logos in

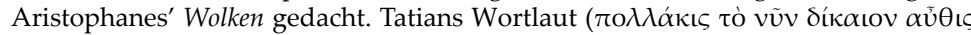

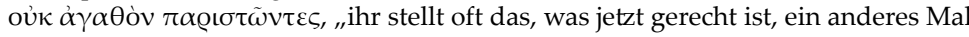
als nicht gut hin") scheint jedoch gar nicht auf einen bestimmten (historischen oder 
literarischen) Einzelfall zu gehen, sondern generell die unethische Prinzipienlosigkeit der Rhetorik anzuprangern, die bereits Sokrates im platonischen Gorgias dem Titelhelden dieses Dialogs vorhält.

Diese Kritik an den verwerflichen Inhalten der Dichtung geht bereits auf Platons Staat (II 377b-III 391b) und letztlich sogar schon auf den Vorsokratiker Xenophanes zurück (21 B 1,21f. und 11,1-3 DK); vgl. auch Lukian, der seinen Menipp ähnliche Vorwürfe gegen die Dichter äußern lässt (Nec. 3).

21 Tatian gibt hier die bekannteste Variante vom Tod des Kynikers Diogenes wieder; vgl. Lukian, Vit. Auct. 10; Diog. Laert. VI 76; Julian, In Cyn. inerud. 1, 181A; 12, 191C.

22 Der in diesem Satz zutage tretende Gegensatz zwischen dem "glaubwürdigen Schwelger" Aristipp und dem bei dem syrakusanischen Tyrannen Dionysios völlig erfolglosen Platon hat bemerkenswerte Ähnlichkeit mit der Schilderung, die Lukian in seinem Parasitendialog dem sehr unterschiedlichen Geschick dieser beiden Sokrates-Schüler bei Dionysios widmet (Luc. Par. 33f.; vgl. dazu Nesselrath 1985, 376-382): Während der sich aufs luxuriöse Leben sehr gut verstehende Aristipp bei dem Tyrannen aufs schönste reüssiert, erweist sich Platon als völliger Versager und verliert Dionys' Gunst sogar zweimal; er wird hier als außerordentlich erfolgloser Parasit gebrandmarkt, und ähnlich scheint ihn auch Tatian anzusehen (vgl. das Stichwort „Gefräßigkeit“).

23 Bemerkenswert umfangreich (im Vergleich zu den anderen in diesem Kapitel genannten Philosophen) fällt Tatians Kritik an Aristoteles aus; zu solcher Kritik in der Antike vgl. Nesselrath 1985, 387f.

24 Aristoteles' „der Vorsehung eine Grenze setzen“ wird unten in 2,3 näher erläutert. 25 Dass Aristoteles des Menschen Glückseligkeit nicht nur durch innere Werte (wie z.B. die Stoa) definierte, sondern auch durch das Vorhandensein angenehmer äußerer Umstände, bringt Lukian in Vit. Auct. 26 auf den Punkt: Dort werden drei Kategorien von Gütern genannt, die für Aristoteles und seine Schule Bestandteile des Glücks sind; sie liegen „,in der Seele, im Körper, in den äußeren Dingen“. Vgl. ferner wieder unten $(2,3)$.

26 Das Nahverhältnis zu Alexander d. Gr. stellte auch sonst einen wesentlichen Punkt in der antiken Aristoteles-Kritik dar; in Lukians Totengesprächen (Dial. Mort. 13,5) bezeichnet Alexander selbst Aristoteles einmal als „vermaledeitesten aller Schmeichler".

27 Gemeint ist Aristoteles' Großneffe Kallisthenes, der Alexander als Hofgeschichtsschreiber begleitete (FGrHist 124), bis er bei Alexander in Ungnade fiel, beschuldigt wurde, an der sogenannten „Pagen-Verschwörung“ gegen den König teilgenommen zu haben, und nach Folterung den Tod erlitt (die ganze Geschichte der zunehmenden Entfremdung zwischen Alexander und Kallisthenes bei Plut. Alex. 52-55= FGrHist 124 T 7; vgl. auch Arrian, Anab. IV 10-14; Curt. Ruf. VIII 8,21f.). Das Detail seiner Käfighaft findet sich auch bei Diog. Laert. V 5 (,er wurde in einem eisernen Tierkäfig mitgeführt, von Ungeziefer befallen und vernachlässigt; schließlich wurde er einem Löwen vorgeworfen und kam auf diese Weise ums Leben“). Zum Tod des Kallisthenes als einem besonders schwerwiegenden Teil von Alexanders Sündenregister vgl. Seneca, Nat. VI 23,2f.

28 An dieser Stelle schiebt Tatian eine sarkastische Bewertung des Aristoteles-Schülers Alexanders d. Gr. ein. Zu Alexander-Kritik (vor allem von Philosophen) in der Antike vgl. R. Stoneman, „The Legacy of Alexander in Ancient Philosophy“, in: J. Roisman (Hg.), Brill's Companion to Alexander The Great (Leiden 2003) 325-345 (vor allem 336-338 zu kritischen griechischen und römischen stoischen Stimmen; 344 Anm. 67 zu kritischen Äußerungen bei christlichen Autoren).

29 Alexanders zu große Freude an Trinkgelagen ist auch sonst Quelle herber Kritik an ihm, vgl. Seneca, Ep. 83,19.23; Arr. Anab. IV 8,2. Bei Plutarch (Alex. 75,3-5) und Arrian (Anab. VII 24,4-25,1) leitet ein solches Trinkgelage die Handlungssequenz ein, 
die zu Alexanders Tod führt. - Das durch einen Korrektor in der jungen Handschrift

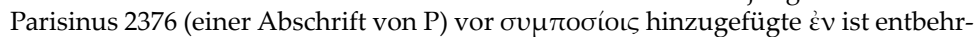
lich, und Trelenberg hat es zu Recht weggelassen, während SchwArtz, Whittaker und Marcovich es aufgegriffen haben.

30 Gemeint ist der makedonische Offizier Kleitos, der Alexander in der Schlacht am Granikos 334 v. Chr. das Leben gerettet hatte, ihn aber sechs Jahre später bei einem Gelage so gegen sich aufbrachte, dass Alexander ihn durch den geschilderten Lanzenwurf tötete; vgl. Plut. Alex. 50,1f.8-11; 51,1-9; Arrian, Anab. IV 8; Curt. Ruf. VIII 1,28-52; Sen. De ira III 17,1.

31 Alexanders Todeswunsch nach der Tötung des Kleitos wird von der Mehrzahl der Quellen (Plut. Alex. 51,10-52,2; Arr. Anab. IV 9,2-4; Curt. Ruf. VIII 2,4f. 10f.; vgl. Cic. Tusc. IV 79: cum interemisset Clitum familiarem suum, vix a se manus abstinuit; tanta vis fuit paenitendi, „als er seinen vertrauten Freund Kleitos umgebracht hatte, konnte er sich kaum davon abhalten, an sich selbst Hand anzulegen; so groß war die Wucht seiner Reue"; Seneca, Ep. 83,19: Clitum carissimum sibi ac fidelissimum inter epulas transfodit et intellecto facinore mori voluit, certe debuit, „Kleitos, seinen liebsten und treuesten Freund, durchbohrte er während des Mahls, und nachdem er seine Untat eingesehen hatte, wollte er sterben und hätte dies sicher gesollt"; Ep. 113,29) als echte Reue und nicht, wie hier von Tatian, als Heuchelei bewertet.

32 Hier wird die in 2,2 gegebene allgemeine Kritik an Aristoteles' Begrenzung der Vorsehung (vgl. oben Anm. 24) präzisiert, nämlich die sublunare Sphäre von deren Walten ausgenommen. Vgl. hierzu P. Moraux, Der Aristotelismus bei den Griechen, Bd. 2: Der Aristotelismus im 1. und 2. Jh.n. Chr. (Berlin / New York 1984) 578 (zu Atticus, Fr. 8,7-17 des Places).

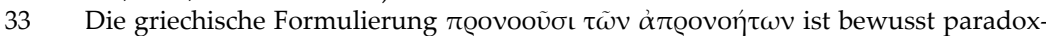
pointiert: „Sie sehen für Un-Vorsehungs-Dinge vor."

34 Zu den körperlichen und äußerlichen Faktoren, die laut Aristoteles das Glück eines Menschen mitbestimmen, vgl. oben Anm. 25.

35 In allen anderen Erwähnungen dieses Heraklit-Zitats (22 B 101 DK) steht nicht

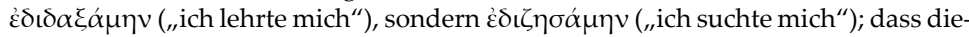
ses Zitat jedoch in Tatians Sinn verstanden wurde (oder zumindest werden konn-

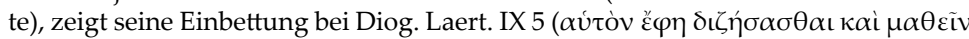

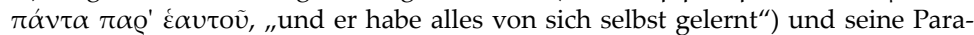

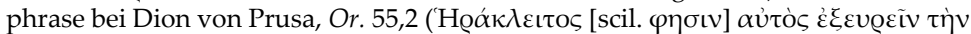

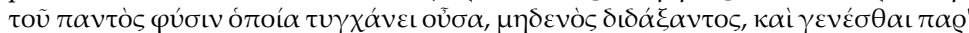

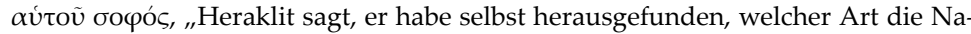
tur des Alls ist, ohne dass ihn jemand unterrichtet hätte, und sei durch sich selbst weise geworden“); bei Plutarch (Fr. 216*g SANDBACH) wird Heraklit in einer Reihe

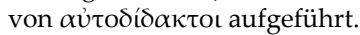

36 Bei Diogenes Laertios IX 6 heißt es, Heraklit habe sein Werk in den Artemis-Tempel

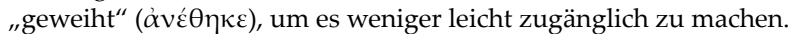

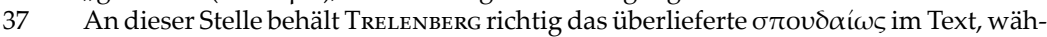

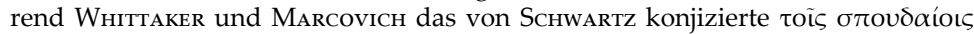
übernehmen.

38 Dass Euripides sich das Werk Heraklits besorgte und nach Athen brachte, ist zuerst von dem Peripatetiker Ariston von Keos (Fr. 29f. WehrLI = Diog. Laert. II 22 und IX 11) bezeugt. Überhaupt sah die Antike Euripides gern als „Philosophen auf der Bühne" an (vgl. Nesselrath 1985, 384f.).

39 Diogenes Laertios (IX 3) berichtet, dass Heraklit sich die Wassersucht zugezogen habe, als er sich aus der Stadt auf die Berge zurückzog und sich dort nur noch von Pflanzen ernährte.

40 Gemeint ist: als Autodidakt und mit dementsprechend hohem medizinischen Risiko. 
41 Laut dem Kallimachos-Schüler Hermipp (Fr. 29 WeHrLI, zitiert bei Diog. Laert. IX 4) ließ sich Heraklit durch Kinder mit Kuhfladen zupflastern. Aus dem Historiker und Biographen Neanthes von Kyzikos (FGrHist 84 F 25, ebenfalls zitiert bei Diog. Laert. IX 4) stammt als weiteres skurriles Detail dieser Todesgeschichte, dass Heraklit sich die Kuhfladen nicht mehr habe abnehmen können und dann aufgrund seiner Unkenntlichkeit von Hunden aufgefressen worden sei. Die von Tatian zum Besten gegebenen Details dürften aus einer ähnlichen Schilderung stammen.

Bei seiner Kritik an Zenon, dem Begründer der Stoa, konzentriert sich Tatian ganz auf dessen Lehre von der „Ekpyrosis“ (derzufolge sich der ganze Kosmos periodisch in das eine Element, Feuer, verwandelt, danach aber in genau der gleichen Gestalt wieder ,neu' geboren wird) und dessen absurde Konsequenzen (d.h. die nie endende Rückkehr der stets gleichen Konstellationen in der Welt- und Menschengeschichte), die er an einigen besonders eingängigen Beispielen demonstriert.

Tatian nennt hier bewusst mehr "Böse“ (die aus Platons Apologie einschlägig bekannten Sokrates-Ankläger Anytos und Meletos sowie den mythischen ägyptischen König Busiris, der aus in sein Land kommenden Fremden Menschenopfer machte, bis er von Herakles getötet wurde; vgl. dazu Isocr. Or. 11 [Busiris],36; Diod. IV 18,1; Apollod. Bibl. II 116f. = II 5,11) als "Gute“ (den mythischen Menschheits-Wohltäter Herakles), um die Aussage seines nächsten Satzes vorzubereiten.

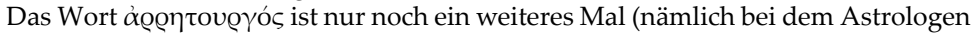
Hephaistion, späteres 4. Jh. n. Chr.) belegt.

Das zweite Detail, auf das Tatian die Philosophie des Stoa-Begründers Zenon reduziert, ist der stoische Pantheismus (d.h. in allen Elementen des Kosmos ist göttliches Pneuma zu finden), der hier jedoch an einem bewusst skurrilen und unappetitlichen Detail demonstriert wird.

Laut dem hellenistischen Philosophiehistoriker Hippobotos (zitiert bei Diog. Laert. VIII 69) soll Empedokles in einen Ätna-Krater gesprungen sein, um durch sein Verschwinden die Kunde zu unterstützen, er sei zu einem Gott geworden; doch wurde dann eine seiner Sandalen am Kraterrand gefunden. Auch bei Lukian ist der angebliche Ätna-Sprung des Empedokles mehrmals Gegenstand des Spotts; vgl. Luc. VH II 21, Icar. 13, Peregr. 1, Fug. 2, Dial. Mort. 6,4.

Was genau mit den „Ammenmärchen“ ( $\gamma \varrho \alpha \circ \lambda \circ \gamma^{\prime} \alpha$ ) des Pherekydes von Syros (frühes 6. Jh. v. Chr.; laut Diog. Laert. I 13 und 42 wurde er gelegentlich zu den Sieben Weisen gerechnet; vgl. auch Clem. Alex. Strom. I 59,5) gemeint ist, lässt Tatian offen; vielleicht handelt es sich um die Seelenwanderungslehre, die Pherekydes als erster vertreten haben soll (vgl. Suda $\varphi$ 214; Porph. Antr. 31 = Pherekyd. 7 B 6 DK). In Tusc. I 38f. entwickelt Cicero eine Traditionslinie Pherekydes - Pythagoras - Platon, aber nur in Hinsicht auf den Glauben an die Unsterblichkeit der Seele; von Seelenwanderung ist hier nicht die Rede. (Clem. Alex. Strom. VI 27,2 entwickelt demgegenüber zur Unsterblichkeit der Seele eine Traditionslinie Ägypter - Pythagoras Platon.)

48 Als Vorläufer oder Lehrer des Pythagoras wird Pherekydes bei Cic. Tusc. I 38; Diod. X 3,4; Dio Prus., Or. 55,1; Diog. Laert. I 13.15.119; VIII 2; Ael. VH V 2; Clem. Alex. Strom. I 61,4; 63,1 eingeführt; laut Aristoxenos, Fr. 14 und 18 WeHrLi wurde Pherekydes von Pythagoras auf Delos begraben. In 25,3 weist Tatian noch einmal auf die Beerbung des Pherekydes durch Pythagoras hin. Das ,Erbe' dürfte dabei vor allem in der auch von Pythagoras vertretenen Seelenwanderungslehre bestehen (vgl. die vorangehende Anm.).

49 WhitTAKer und TreLenberg behalten das überlieferte $\pi \varepsilon \rho i$ toútov (bezogen auf die vorher genannte Lehre, $\delta o ́ \gamma \mu \alpha$ ), während Marcovich das von SchwarTz konjizierte, aber unnötige $\pi \varepsilon \rho i$ toútous (wohl bezogen auf Pherekydes und Pythagoras) in den Text setzt. 
50 Platon wurde verschiedentlich Aneignung und sogar Plagiierung der Lehre des Pythagoras nachgesagt (vgl. Aristoxenos, Fr. 68 WeHrLI; Cic. Rep. I 16; Gell. NA III 17,5; Diog. Laert. VIII 54 = Neanthes von Kyzikos, FGrHist 84 F 26; Anonymus Photii 238,17f. Thesleff; Hippol. Ref. haer. VI 21,1; Eus. Adv. Hierocl. 380,8-10 Kayser; PE XIV 5,7-9 = Numen. Fr. 24, Z. 57-79 des Places): Er soll die erste schriftliche Niederlegung der pythagoreischen Lehre durch Philolaos für hundert Minen gekauft haben (Timon, SH 831 bei Gell. NA III 17,1; Diog. Laert. III 9; VIII 15.84; Iambl. VP 199). Andere sprachen etwas wohlwollender von einer Weiterentwicklung der Lehren des Pythagoras durch Platon (z.B. Cic. Tusc. I 39; Galen, Plac. Hipp. et Plat. IV 7,39, CMG V 4,1.2 = Poseidonios, Fr. 410, Z. 141-144 Theiler; Simpl. In Arist. Phys. I 7,10-15 Diels = Eudemos, Fr. 31 Wehrli; Eus. PE X 14,16).

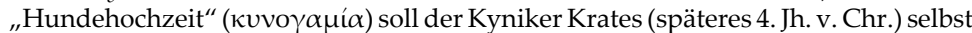
laut Suda к 2341 die unkonventionelle Beziehung zu seiner Lebensgefährtin Hipparcheia genannt haben, die von Diog. Laert. VI 97 beschrieben wird.

"Zungenwahnsinn" ( $\gamma \lambda \omega \sigma \sigma o \mu \alpha v i ́ \alpha)$ kommt offenbar nur hier in der griechischen Literatur vor und könnte eine eigene Prägung Tatians sein.

53 Hier übernimmt Trelenberg das von MARCovich (aus dem in M und V überlieferten

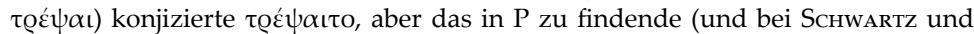

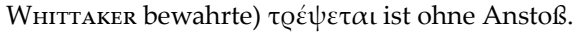

54 Das Wortspiel mit $\varphi \iota \lambda о \psi o ́ \varphi \omega v$ geht offenbar auf Tatians Lehrer Justin zurück (2 Apol. 3,1f.; zwar ist in den Tatian-Handschriften $\varphi$ גобó $\varphi \omega v$ überliefert und $\varphi \iota \lambda o \psi o ́ \varphi \omega v$ erst eine Konjektur von Styan Thirlby in seiner Ausgabe der Justini Philosophi et Martyris Apologiæ duæ von 1722, doch ist die evidente Richtigkeit dieser Konjektur seit SchwARTz allgemein anerkannt). Das Wort kommt nur bei Justin und (wenn richtig konjiziert) bei Tatian vor und spricht für die enge Verbindung zwischen beiden (vgl. Trelenberg 2012, 196-203).

55 Der Widerspruch zwischen Leben und Lehre ist auch einer der Lieblingsvorwürfe, die Tatians Zeitgenosse und Landsmann Lukian den Philosophen macht (vgl. vor allem dessen Schriften Symposion, Fugitivi und Piscator und die bei Nesselrath 1985, 418 angeführten Stellen).

56 Auch die sich in ständigem Streit äußernde gegenseitige Abneigung der Philosophen ist ein Lieblingstopos Lukians (vgl. Nesselrath 1985, 314. 361f.).

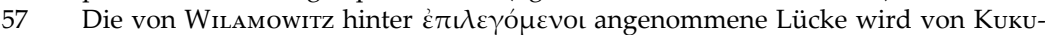
La, WhitTaker und Trelenberg nicht akzeptiert, aber ihre je ganz unterschiedliche Übersetzung dieser Stelle (Puech: „ils ... se choisissent les places éminentes“; KUKULA: „,indem sie sich marktschreierisch zu den Thronen drängen“; Fermi: „si cercano sempre i posti eminenti“; WHITTAKER: „each taking up an exaggerated position out of self-importance“; DI CRISTINA: „,adottando posizioni esagerate per pura vanità"; Trelenberg: ,in ihrer Eitelkeit suchen sie sich die ersten Plätze aus“; vgl. bereits von Отто: „propter arrogantiam loca eligentes praestantia“), zeigt, wie unklar der Text hier ist. Möglicherweise hat Tatian hier so etwas vorgeschwebt, wie es Lukian in seinem Symposion (Kap. 9) plastisch beschreibt: Bei einem Gastmahl machen sich die eingeladenen Philosophen verschiedener Schulen eifersüchtig die besten Plätze streitig.

58 Text und Übersetzung greifen hier die Konjektur von Oттоs auf, der vorschlug,

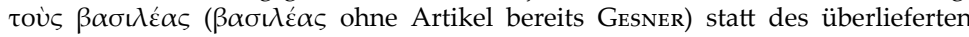
$\beta \alpha \sigma \lambda \lambda \varepsilon i ́ \alpha \varsigma$ zu lesen; ferner ist (wie bei von Отто) in den Text das in V überlieferte

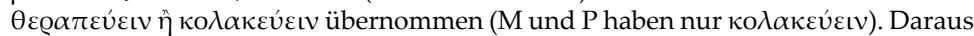

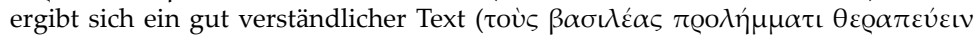

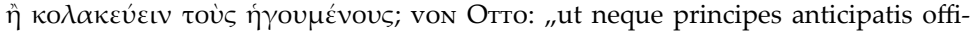
ciis colerent neque proceribus assentarentur"), während das seit ScHWARTz edierte

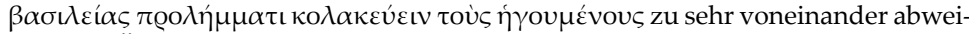
chenden Übersetzungsversuchen geführt hat, die - vielleicht notwendigerweise - 


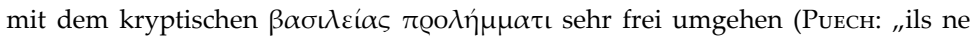
devraient pas flatter les gouvernants, fût-ce par la raison qu'ils règnent"; KUKULA: „Anständig aber wäre es, just wenn sie von eines Königs Majestät so hohe Meinung hegen, nicht den Herrschern zu schmeicheln“; FERMI: „,non dovrebbero invece adulare i sovrani, per accaparrarsi il governo"; WhitTAKeR: "they ought not to have kowtowed to the eminent in anticipation of their elevation to sovereignty"; DI CRISTINA: „sarebbe ... opportuno che essi non adulassero le personalità eminenti con l'anticiparne l'elevazione al regno“; TreLEnBERG: „Sie sollten den Machthabern auch nicht mit dem Blick auf eine zukünftige Königswürde schmeicheln“).

Das bei den Attizisten (vgl. Phryn. Ecl. 170) verpönte $\mu \varepsilon \gamma \iota \sigma \tau \tilde{\alpha} v \varepsilon \varsigma$ („Großkopfete"), dessen ältesten Beleg der Komödiendichter Menander bietet (Fr. 584 PCG), ist bereits sehr häufig in der Septuaginta (und im NT zweimal in der JohannesApokalypse) anzutreffen.

60 Der Ausdruck $\tau \dot{\alpha} \varsigma \pi \mathrm{o} \lambda \iota \tau \varepsilon \dot{\alpha} \alpha \varsigma$ wird in früheren Übersetzungen sehr verschieden wiedergegeben (von Отто: „Instituta“; Kuкula: „die Staatsgesetze“; Fermi: „vostre istituzioni“, ebenso Di Cristina; WhitTAKer: „society“; Trelenberg: „die Bürger-

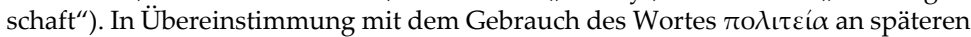
Stellen dieser Schrift $(9,1 ; 27,6 ; 28,1 ; 34,9 ; 40,3 ; 42,2)$ könnte man mit Harnack hier auch "die verschiedenen Lebensweisen“ verstehen. Auf jeden Fall geht es hier um die Schwierigkeiten der Einfügung christlicher Gemeinden in ihre pagane Umwelt, die mit zunehmender Sichtbarkeit dieser Gemeinden immer mehr zunahmen.

61 Mit der expliziten Erklärung seiner Loyalität als Untertan des Römischen Reiches steht Tatian in guter neutestamentlicher Tradition (vgl. Mt 22,15-22; Mk 12,13-17; Lk 20,20-26; Röm 13,6f.).

62 Vgl. 1 Petr 2,17 (

63 Mit der klaren Unterscheidung einer staatlich-irdischen Ordnung und einer transzendent-göttlichen leitet Tatian zu den in 4,3 beginnenden Ausführungen über Gott über. Vgl. auch 42,2, wo Tatian mit dem Vorbehalt einer höheren göttlichen Ordnung endet.

64 Die Worte $\pi v \varepsilon \tilde{v} \mu \alpha$ ó $\theta \varepsilon$ ćs sind wörtliches Zitat von Joh 4,24.

65 Damit wird die immanente Gottesvorstellung der Stoiker zurückgewiesen (vgl. Clem. Alex. Protr. 66,3: тoù

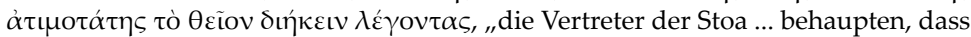
das Göttliche die gesamte Materie, und zwar auch die ehrloseste, durchdringe" = SVF II 1039). In 4,4 bezeichnet Tatian den "Geist, der die Materie durchdringt" (also

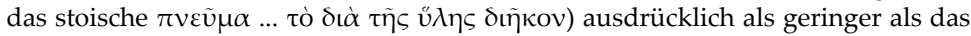
"göttlichere" $\pi v \varepsilon \tilde{v} \mu \alpha$.

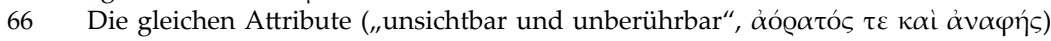
weist auch Maximos von Tyros dem Inbegriff von Gottheit zu (Dial. 11,9d: Tò $\delta \dot{\varepsilon}$

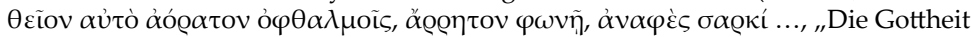
selbst ist aber nicht sichtbar den Augen, nicht aussprechbar der Stimme, nicht fühlbar dem Fleisch“), während der Platoniker Albinos diese Eigenschaften der Welt-

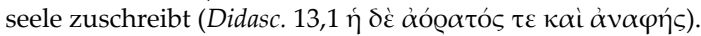

67 Vgl. Paulus in Röm 1,20, aber auch bereits Weish 13,5 (,, aus der Größe und Schönheit ja der Geschöpfe lässt sich in entsprechender Weise ihr Schöpfer wahrnehmen“). Hier steht im Hintergrund der Schöpfungsbericht der Genesis, in dem zuletzt der Mensch als „Krone der Schöpfung“ erscheint. Vgl. wiederum Weish 13,1-2.

69 Anspielung auf die aus Holz und Stein gefertigten Götterbilder der paganen Umwelt, über die sich ebenfalls bereits die Sapientia Salomonis ausführlich mokiert $(13,10-14,21 ; 15,8-17)$.

70 Gemeint ist die dem Menschen innewohnende niedere Seele, auf die Tatian ausführlich in 13,1 eingeht (vgl. schon 12,1). - Wie GoodsPeEd und Trelenberg akzeptiert die vorliegende Ausgabe hier das einhellig überlieferte $\psi v \chi \tilde{\eta} \pi \alpha \varrho \omega \mu \circ \omega \mu \mu \varepsilon v o v, ~ z u$ 
dem immer wieder Änderungsvorschläge gemacht wurden ( $\tau \tilde{\eta} \tilde{u} \lambda \eta \pi \alpha \varrho$. ScHWARTz

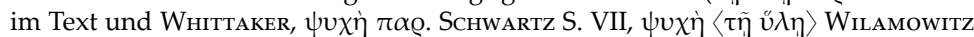
und Marcovich), die aber aufgrund der schon erwähnten Parallelisierung, die Tatian zwischen dem niederen und der niederen Menschenseele vornimmt, unnötig sind.

71 Während Schwartz, Whittaker und die vorliegende Ausgabe mit der Handschrift

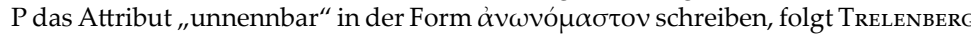
den Handschriften M und V sowie Marcovich mit der Schreibweise àvovó $\mu \alpha \sigma \tau o v$. Für die erstere Schreibweise spricht, dass auch Tatians Lehrer Justin (1 Apol. 63,1) und Clemens von Alexandria (Paed. I 57,2) sie in Verbindung mit $\theta$ có ৎ verwenden. Sachlich im Hintergrund steht die Vorstellung vom besonderen (Nicht-)Namen Gottes im Buch Exodus (3,13f.; vgl. 6,3).

72 Die Eigenschaft völliger Bedürfnislosigkeit wird Gott auch von Philon von Alexan-

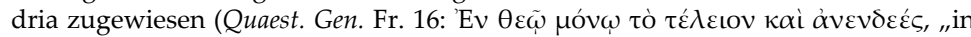
Gott allein ist das Vollkommene und keiner anderen Sache Bedürftige ${ }^{\prime \prime}$ ), doch findet sich die Vorstellung sogar schon im Herakles des Euripides (V. 1345f.): „Denn

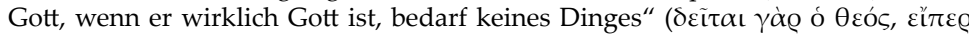

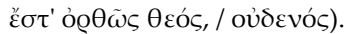

73 Mit den ersten Worten von 5,1 bezieht sich Tatian klar auf den Beginn des Johannes-

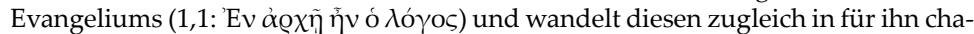
rakteristischer Weise ab, indem er $\lambda$ ó $\gamma o \varsigma$ durch $\theta \varepsilon$ co s ersetzt, der damit hierarchisch höher steht (vgl. 5,2).

74 Zu der hier und im Folgenden $(7,1.3 .4 ; 18,5)$ mehrfach erscheinenden Junktur „Kraft

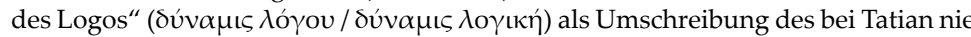

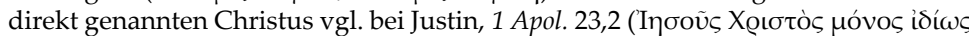

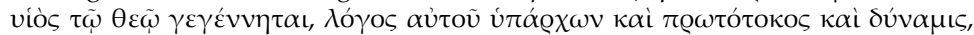
„Jesus Christus allein ist in individueller Weise von Gott als Sohn hervorgebracht, wobei er als sein Logos und sein Erstgeborerenr und seine Kraft besteht" ); Dial. 61,1

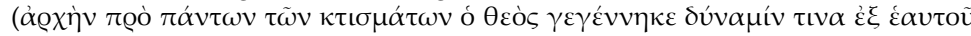

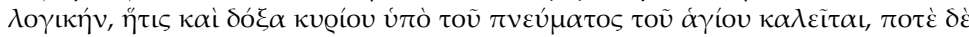
viós, „,als Anfang vor allen Geschöpfen hat Gott eine Kraft des Logos aus sich selbst hervorgebracht, die auch Ruhm des Herrn vom Heiligen Geist genannt wird, dann

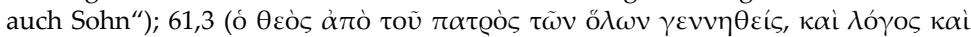

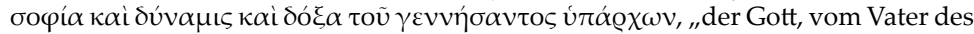
Alls hervorgebracht, der auch als Logos und Weisheit und Kraft und Ruhm dessen,

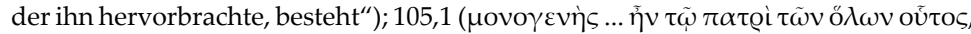

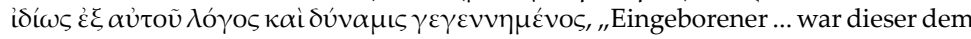
Vater des Alls, in individueller Weise aus ihm als Logos und Kraft hervorgebracht"), wobei Justin die Junktur selbst nur einmal verwendet (in Dial. 61,1), sonst aber stets

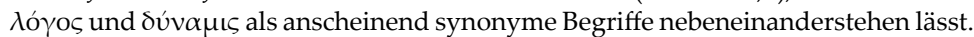

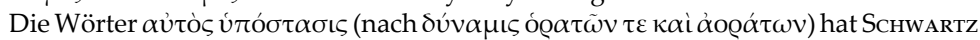
zu Recht getilgt, denn sie sehen sehr nach einer erklärenden Randglosse aus, und Puech, Whittaker und Marcovich sind ihm darin gefolgt, Trelenberg behält sie im Text, aber seine daraus resultierende Übersetzung (,,Sofern aber alle Macht bei ihm lag und er selbst der Grund sowohl des Sichtbaren als auch des Unsichtbaren war") ist ein weiteres Argument für ihre Tilgung, denn sie wird weder dem Wortlaut (das „und“ nach „,bei ihm lag“ ist im griechischen Text nicht vorhanden) noch der Wortstellung des griechischen Originals gerecht.

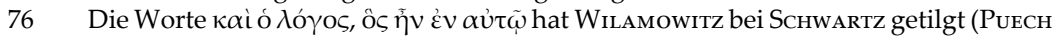
und Marcovich schließen sich an), doch werden sie von Whittaker und TrelenBERG im Text gehalten (auch von Di CRISTINA, wie seine Übersetzung ausweist). Dadurch aber würde die Rolle des Logos (Christus) in diesem Satz verdoppelt: Einmal wäre er das Instrument Gottes ( 


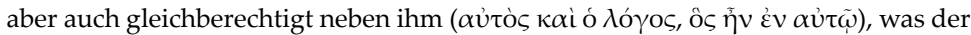
sonst bei Tatian anzutreffenden klaren Hierarchisierung zwischen Gott (Vater) und

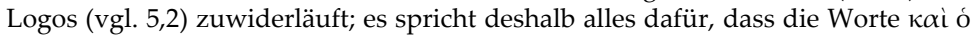

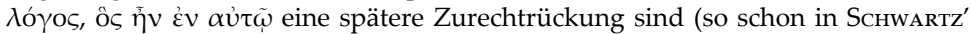
Apparat als Wilamowitz' Argument für die Tilgung: „ex seriore fide interpolata“), um Gott Vater und Sohn gleichberechtigt erscheinen zu lassen.

Zu der (Mit-)Schöpferrolle des Logos vgl. Weish 9,1 („Gott der Väter ..., der du das

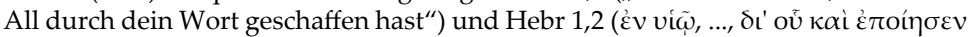
toù $\alpha \hat{i} \tilde{\omega} v \alpha \varsigma)$.

Tatians Formulierung erinnert stark an eine Justins (Dial. 128,3): „,So lässt der Vater, wann immer er will, ... seine [d.h. des Logos, kurz zuvor in 128,2 erwähnt] Kraft her-

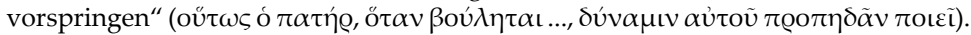
Eine ähnliche Formulierung scheint bei keinem anderen der zeitgenössischen Apologeten zu finden zu sein.

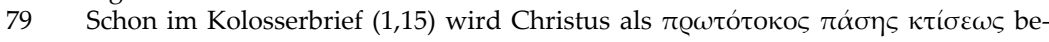
zeichnet, freilich nicht als čoyov des Vaters; die hier von Tatian vertretene Meinung kennzeichnet Gregor von Nyssa zweihundert Jahre später als Häresie (De perfectione

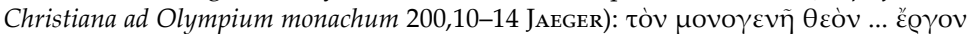

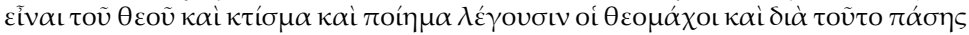

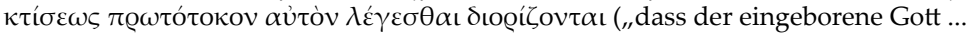
ein Werk Gottes sei und ein Geschöpf und Geschaffenes, sagen die, die gegen Gott kämpfen, und deswegen definieren sie, er sei der erstgeborene aller Schöpfung“").

80 Die gleiche bildliche Erläuterung der Vorstellung, dass es zwischen Gott Vater und Logos keine "Abtrennung" gibt, durch das Bild eines Feuers, von dem sich viele weitere anzünden lassen, ohne das ursprüngliche zu vermindern, findet sich bei Justin (Dial. 61,2).

81 Mit „Wiedergeburt“ ist die Bekehrung zum Christentum (hier gleichgesetzt mit der Erlangung der "Wahrnehmung des Wahren") gemeint. Vorgeprägt ist der Gedanke

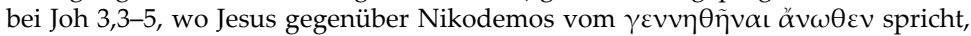
und ausformuliert (mit wiederholter Verwendung des auch von Tatian benutzten $\dot{\alpha} v \alpha \gamma \varepsilon v v \tilde{\alpha} \sigma \theta \alpha \mathrm{L})$ bei Justin, 1 Apol. 61,3f.

82 Damit widerspricht Tatian einer wichtigen Grundauffassung der paganen Philosophie: Sowohl der zeitgenössische Platonismus vertritt die These, dass die Materie gleich ewig ist wie Gott (Apul. De Plat. I 5: Initia rerum esse tria arbitratur Plato: deum

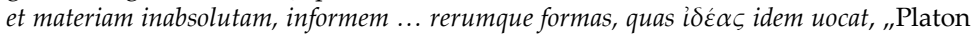
glaubt, dass es drei Anfänge der Dinge gibt: Gott und die undifferenzierte und ungeformte Materie ... und die Gestalten der Dinge, die er ,Ideen' nennt"); vgl. Aëtios,

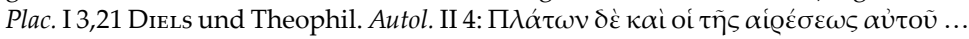

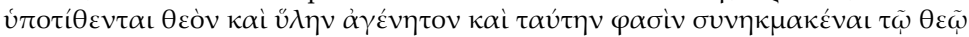
(„Platon und die Vertreter seiner Schulrichtung ... postulieren einen Gott und eine ungewordene Materie und sagen, dass diese zugleich mit Gott in Blüte gestanden

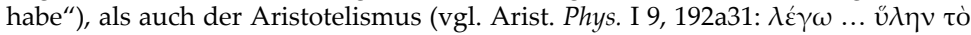

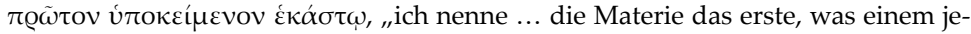
den zugrundeliegt"; Aëtios, Plac. I 3,22 Diess) und die Stoa (vgl. Aëtios, Plac. I 3,25). Demgegenüber nennt Tatian die Materie explizit eine Hervorbringung Gottes (vgl. auch 12,2).

83 Vor íoớva $\mu$ os hat Wilamowitz (dem Schwartz, Goodspeed und Marcovich fol-

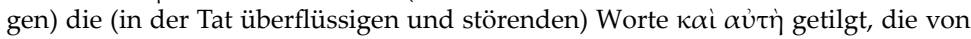
WhitTAKER und Trelenberg im Text gehalten werden.

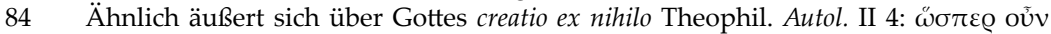

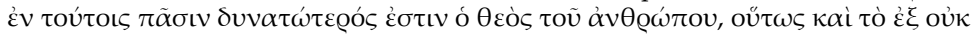

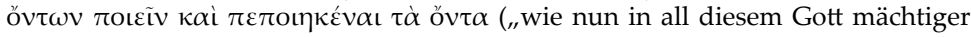
ist als der Mensch, so auch darin, dass er aus nicht Seiendem das Seiende schafft 
und geschaffen hat"). Vgl. auch unten 12,2. Zu Tatians Beitrag zur Entwicklung der kirchlichen Lehre der creatio ex nihilo vgl. G. MAY, Schöpfung aus dem Nichts. Die Entstehung der Lehre von der creatio ex nihilo (Berlin / New York 1978 [engl. Übers. 1994]) 151-157; J. C. O'NeILl, "How Early is the Doctrine of Creatio ex Nihilo?" , JTS, N.S. 53 (2002) 449-465.

Vgl. dazu bereits oben 3,3.

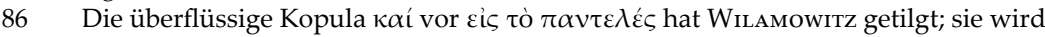
von WhitTAKer und Trelenberg beibehalten (aber von beiden nicht wirklich übersetzt) und MARCOvich sogar noch um ein vorangestelltes $\alpha ँ \pi \alpha \xi$ erweitert.

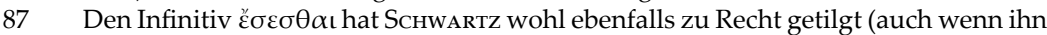
Whittaker und Trelenberg im Text halten - erneut, ohne ihn zu übersetzen). Er ließe sich allenfalls dann halten, wenn man ihn mit dem vier Zeilen weiter oben stehenden $\pi \varepsilon \pi \iota \sigma \tau \varepsilon v ́ \kappa \alpha \mu \varepsilon v$ verknüpft (doch hat der Satz inzwischen eine ganz andere Entwicklung genommen). Diese Verknüpfung hat wohl MarcovicH vorgeschwebt,

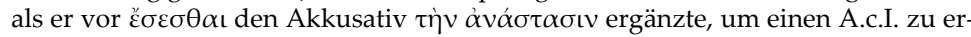
halten - der brachiale Eingriff zeigt gerade, wie verloren der Infinitiv hier steht. Mit richterlichen Funktionen in der Unterwelt taucht der Zeus-Sohn Minos zuerst in der homerischen Odyssee auf, wo ihn Odysseus bei seinem Unterweltsbesuch erblickt (Od. XI 568-571); dagegen ist bei der Erwähnung des Rhadamanthys auf dem Elysischen Feld in Od. IV 564 (von Trelenberg ad loc. zitiert) von irgendeiner richterlichen Funktion nicht die Rede. Für ein regelrechtes Totengericht gibt es in der griechischen Literatur Belege erst seit dem 5. Jh. v. Chr.: In der zweiten Olympischen Ode Pindars (für den Tyrannen Theron von Akragas, von 476 v. Chr.) heißt

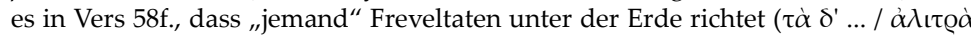
$\kappa \alpha \tau \dot{\alpha} \gamma \tilde{\alpha} \varsigma \delta \iota \kappa \alpha ́ \zeta \varepsilon \iota \tau \iota \varsigma)$; in den Schutzflehenden des Aischylos (aufgeführt wahrscheinlich 463 v. Chr.) ist vermerkt, dass im Hades "ein anderer Zeus" (gemeint ist der Unterweltsherrscher Pluton/Hades, ein Bruder des Zeus) die Freveltaten der Ver-

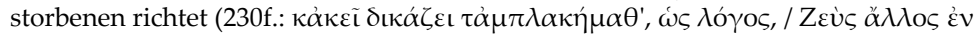
$\kappa \alpha \mu o \tilde{\sigma} \sigma \iota v)$, und die gleiche Vorstellung taucht fünf Jahre später auch in Aischylos' Eumeniden auf (vgl. A. M. RITTER, "Jenseits, Jenseitsgericht und Jenseitsstrafen im Denken des antiken Griechentums", in: K. Luchner [Hg.], Synesios von Kyrene. Polis - Freundschaft - Jenseitsstrafen. Briefe an und über Johannes. SAPERE 17 [Tübingen 2010] [151-166] 157 Anm. 24). Die hier von Tatian genannten Totenrichter Minos und Rhadamanthys (beide Söhne des Zeus) tauchen namentlich zuerst in Platons Apologie auf (41a), wo neben ihnen freilich noch andere genannt sind (Aiakos, Triptolemos „und andere, soviele von den Halbgöttern Gerechte wurden in ihrem [irdischen] Leben“); erst in Platons Gorgias (523e-524a) werden genau drei Totenrichter aufgeführt (alle Zeus-Söhne): Rhadamanthys für die Toten aus Asien, Aiakos für die Toten aus Europa (hier liegt die Vorstellung zugrunde, dass die Oikumene sich in diese beiden Kontinente gliedert) und als ihr „Vorgesetzter" Minos. In späterer Literatur wird diese Dreizahl öfter auf Minos und Rhadamanthys reduziert, z.B. im ps.-platonischen Axiochos (371c), bei dem Mythographen Apollodor (Bibl. III $6=$ III 1,2), bei Lukian (De luctu 7), dann auch bei den Apologeten Justin (1 Apol. 8,4) und Athenagoras (Leg. 12,2).

89 Tatsächlich wird die Einsetzung der Totenrichter Minos, Rhadamanthys und Aiakos im Mythos des platonischen Gorgias als Ergebnis einer ,Reform' vorgestellt, mit der Zeus die Beurteilung der Menschen nach ihrem Leben gerechter machen wollte (Plat. Gorg. 523b-524a).

90 Mit $\sigma \pi \varepsilon Q \mu о \lambda o ́ \gamma o u \varsigma$ greift Tatian eine verächtliche Bezeichnung auf, die die athenischen Philosophen auf den Apostel Paulus angewendet hatten (Apg 17,18).

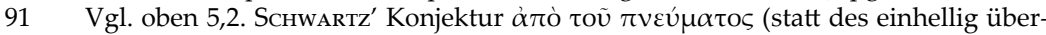

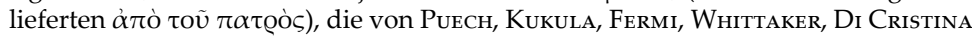
und MARCOvich aufgegriffen wird, ist attraktiv, aber nicht zwingend. 
92 Dass der Logos in „Nachahmung“ der Schöpfungstätigkeit des Vaters (die den Logos selbst hervorgebracht hat) den Menschen als "Abbild“ seiner eigenen Unsterblichkeit hervorbringt, um ihm auf diese Weise eine "Teilhabe“ an Gottes Wesen zu verschaffen, klingt zum einen bemerkenswert platonisch, hat aber auch ein Vorbild in Weish 2,23, wo es heißt: „Gott hat den Menschen geschaffen zur Unvergäng-

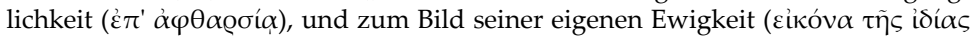

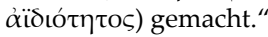

93 Statt des in den Handschriften überlieferten ô $\pi \lambda \eta \dot{v}$ (was Schwartz zur Annahme einer Lücke vor $\pi \lambda \eta \dot{v}$ veranlasste) konjizierte von Отто plausibel ö $\pi \varepsilon Q$, was WнітTAKER und TRELENBERG übernommen haben.

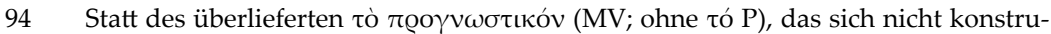

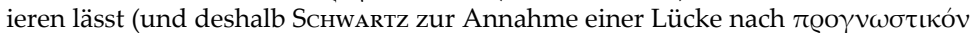

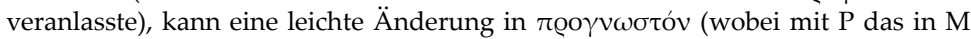
und V vorangestellte tó wegzulassen ist) die Syntax wieder einrenken (vgl. NESSELRATH 2005, 247f.).

95 „Am klügsten im Vergleich zu allen Tieren auf der Erde“ (

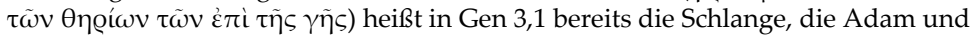
Eva im Paradies verführt, und mit dieser Schlange ist der Drache gleichgesetzt, der

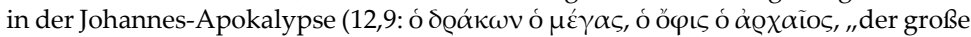
Drache, die alte Schlange") aus dem Himmel gestürzt wird.

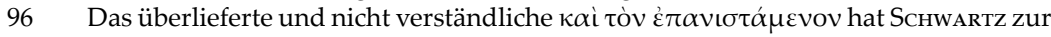

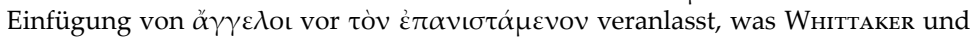
Trelenkerg übernommen haben (ebenso Fermi und Di CRistinA; zurückhaltender Puech); der Satz lässt sich jedoch wesentlich gelinder heilen, wenn man к $\alpha$ íto statt кoi tóv liest (vgl. Nesselrath 2005, 249f.).

97 Gemeint ist der Mensch (vgl. oben 7,1).

98 Vgl. zu dieser Trennung unten 12,1 und vor allem 13,4.

99 Alle modernen Ausgaben (mit Ausnahme von Мarcovich, der aber die Wortfolge

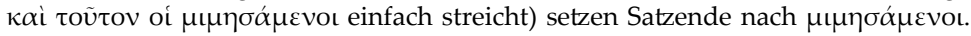

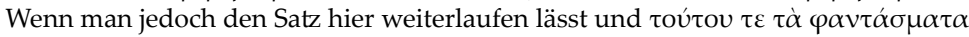
( $\tau \varepsilon$ wurde von Schwartz nachträglich konjiziert) noch als weiteres Objekt zu $\mu \iota \eta \eta \sigma \alpha ́ \mu \varepsilon v o l$ auffasst, ergibt sich ein erheblich besserer Sinn (vgl. die hier vorgelegte Übersetzung und Nesselrath 2005, 250f.). So hat auch bereits Puech verstanden

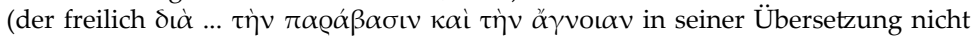
wiedergibt): „le premier-né est devenu démon, et ceux qui l'ont imité, lui et ses prodiges, ont formé l'armée des démons."

100 Damit sind die Engel gemeint, die sich dem rebellischen „Erstgeborenen“ angeschlossen haben; weitere Auskünfte über ihre Identität erhalten wir unten in 8,2.

101 Ein ähnlicher Vergleich erscheint in 9,2 (,wie die, die sich mit den Brettspielen vergnügen“): Die Dämonen ,spielen' mit dem Leben auf der Erde.

102 Heimarmene ist der vor allem in der Stoa (vgl. z.B. Diog. Laert. VII 149) gebräuchliche Ausdruck für das als unabwendbar angesehene Schicksal, den die Stoiker aber wohl von Heraklit (vgl. Diog. Laert. IX 8) übernahmen.

103 Zwei der Totengespräche Lukians bieten eine plastische Illustration dieser Aussage: In Dial. Mort. 27 kommt der homerische Held Protesilaos zu der Einsicht, dass an seinem frühen Tod (gleich bei der Landung des griechischen Heeres an der Küste Trojas) keine Helena, kein Menelaos und kein Paris verantwortlich sind, sondern nur das Schicksal; und in Dial. Mort. 24 weist der Raubmörder Sostratos keinem Geringeren als dem Totenrichter Minos selbst nach, dass auch für seine (Sostratos') Verbrechen niemand anders als die Schicksalsmoira verantwortlich zu machen ist.

104 Der Vers findet sich zweimal in den homerischen Epen: In Ilias I 599 lachen die Götter auf dem Olymp über Hephaistos' unbeholfene Mundschenkdienste, und in Odyssee VIII 326 erregt ihre Heiterkeit, wie geschickt der gleiche Hephaistos es ver- 
standen hat, seine Frau Aphrodite zusammen mit ihrem Liebhaber Ares auf dem Bett, auf dem sie ehebrecherisch zugange waren, zu fesseln. Die Theatersituation, die Tatian hier skizziert, ist freilich eher dort gegeben, wo Zeus vom Idagebirge aus mit durchaus voyeuristischer Lust beobachtet, wie sich Griechen und Trojaner im Kampf gegenseitig abschlachten (vgl. z.B. Hom. Il. VIII 47-52).

105 Hier wird klar, dass Tatian die Engel, die sich gegen Gott erhoben haben und dadurch zu „Dämonen“ geworden sind (vgl. oben 7,5), vor allem mit den Göttern seiner paganen Umwelt gleichsetzt.

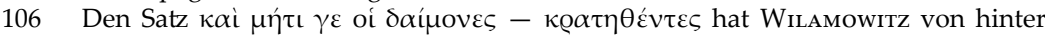

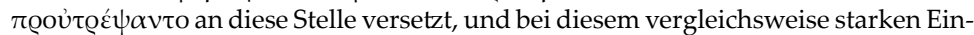
griff sind ihm Puech, Fermi und Marcovich gefolgt; tatsächlich scheint sich mit dieser Umstellung ein wesentlich besserer Gedankenablauf erzielen zu lassen.

Dafür, dass die Götter unter ihrem Herrscher Zeus „,von den gleichen Leidenschaften beherrscht werden wie auch die Menschen ", also völlig anthropomorph gedacht sind, bietet die griechische Mythologie reiches Anschauungsmaterial.

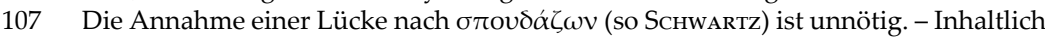
ist hier wieder an die homerischen Götter zu denken, von denen die einen (vor allem Hera, Athena, Poseidon) die griechische Seite im Kampf um Troja favorisieren, die anderen (vor allem Zeus, Apollon, Ares, Aphrodite) die trojanische; in Ilias-Buch XXI geraten die beiden Seiten schließlich sogar in der sogenannten „Götterschlacht" (385-520; mit Vorspiel in XX 4-40; 67-74; 132-152) handgreiflich aneinander.

108 Als Päderast und notorischer Frauenheld ist im griechischen Mythos vor allem wieder Zeus bekannt (mit schönen Illustrationen in Lukians Göttergesprächen; vgl. Dial. Deor. $4 ; 6 ; 7 ; 8 ; 10 ; 14)$.

109 Bei Göttern, die von Menschen verwundet werden und vor ihnen Reißaus nehmen, ist vor allem an das fünfte Buch der Ilias zu denken, in dem der griechische Held Diomedes (freilich mit tatkräftiger Unterstützung der Göttin Athena) nicht nur die Liebesgöttin Aphrodite, sondern sogar den Kriegsgott Ares zuerst verwundet und dann in die Flucht schlägt (V. 330-367; 846-870). Dagegen ist die von Marcovich und Trelenberg (im Gefolge von Theophil. Ad Autol. I 9) herangezogene Partie des XXI. Ilias-Buches, in der Apollon vor Achill flüchtet, durchaus anders zu bewerten, denn hier hat Apollon menschliche Gestalt angenommen und nimmt vor Achill nur deswegen Reißaus, um ihn von den in die Stadt fliehenden Trojanern abzulenken (V. 599-611; XXII 7-20).

110 Zur Sterblichkeit der Dämonen vgl. unten 14,3-5.

111 Tatian konstruiert im Folgenden eine Reihe von Gegensatzpaaren, um die „Zuständigkeiten“ der griechischen Götter (= Dämonen) ad absurdum zu führen.

112 Rhea, Schwester und Gemahlin des Titanen Kronos, ist die Mutter der älteren Generation der olympischen Götter (also der Göttinnen Hestia, Demeter und Hera sowie der Götter Hades, Poseidon und Zeus) und wird darum auch generell gern als ,Göttermutter' bezeichnet. Ihre Identifikation mit der in Phrygien (vgl. oben Anm. 4) beheimateten Muttergöttin Kybele ist seit Strabon (X 3,12) explizit belegt, geht aber sicher in frühere Zeiten zurück. Die Geschichte ihres Geliebten Attis (im Griechi-

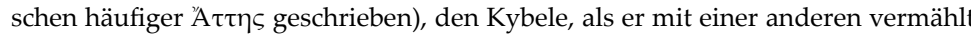
werden sollte, in den Wahnsinn trieb, so dass er sich entmannte, ist bei dem Periegeten Pausanias zu finden (VII 17,11f.), der auch noch andere Versionen kennt (vgl. auch Luc. Dea Syr. 15, Dial. Deor. 20,1). Das „Gesetz“ des „Abschneidens von Schamteilen“ bezieht sich auf die Priester der Kybele, die sogenannten Galloi, die sich im Verlauf ekstatischer Feste selbst öffentlich entmannten (im Rahmen des Kultes der Syrischen Göttin beschrieben bei Lukian, Dea Syr. 51; als schmierige Bettelpriester treten solche Galloi im pseudo-lukianischen Eselsroman auf, Kap. 35-39). 
113 Aphrodite ist eigentlich mehr die Göttin der sexuellen Vereinigung, aber hier betont Tatian die „ehrbare“ Seite der Sexualität, um einen scharfen Kontrast zu den unappetitlichen Vorlieben der Rhea/Kybele erzeugen zu können.

114 Tatian kostet hier die Pointe aus, dass gerade die göttlichen Geschwister Artemis und Apollon so verschiedene Metiers betreiben, wobei Artemis hier mit Hekate gleichgesetzt wird (dies geht bereits auf die attischen Tragödiendichter zurück, vgl. Aesch. Suppl. 676; Eur. Phoen. 110, Fr. 62h KanNicht), die gerade in der Kaiserzeit die Zaubergöttin par excellence ist. Wenn man freilich bedenkt, dass das griechi-

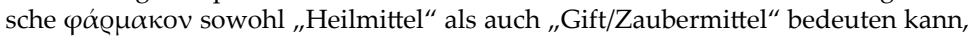
liegen die Metiers der Artemis und des Apollon gar nicht so weit auseinander.

115 Bevor er zum nächsten Gegensatzpaar (betreffend den ganz unterschiedlichen Gebrauch, den die Gottheiten Athena und Asklepios vom Blut der Gorgo Medusa machen) gelangt, schiebt Tatian noch einen Exkurs über Medusa ein: Als der griechische Held Perseus sie enthauptete, sprangen aus ihrem Hals das Flügelpferd Pegasos und der Krieger Chrysaor hervor; der Grund dafür war, dass sie zuvor vom Meergott Poseidon in Gestalt eines Hengstes geschwängert worden war. TRELENBERG 2012, 104f. Anm. 88 sieht hier (im Gefolge von Marcovich) wörtliche Anklänge an die entsprechende Stelle in Hesiods Theogonie (V. 280f.), doch zeigt das Referat beim Mythographen Apollodor (Bibl. II $42=$ II 4,2) sogar noch mehr wörtliche Anklänge (hier unterstrichen: $\alpha \pi 0 \tau \mu \eta \theta \varepsilon i ́ \sigma \eta \varsigma \delta \dot{\varepsilon} \tau \tilde{\eta} \varsigma \kappa \varepsilon \varphi \alpha \lambda \tilde{\eta} \varsigma, \dot{\varepsilon} \kappa \tau \tilde{\eta} \varsigma$

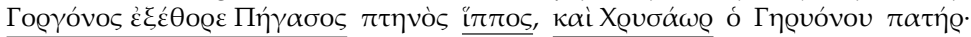

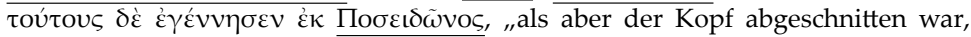
sprang aus der Gorgo das geflügelte Pferd Pegasos heraus und Chrysaor, der Vater des Geryones; diese hatte sie von Poseidon empfangen"; vgl. II $46=$ II 4,3:

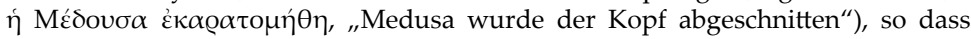
Tatian wohl nicht auf Hesiod zurückgegriffen haben muss. Als "Geliebte Poseidons" kann Medusa freilich nur von einem Zyniker bezeichnet werden: Laut Ovid (Met. IV 794-801), der wahrscheinlich auf eine hellenistische Erzählung zurückgreift, wurde Medusa, einst eine von vielen begehrte Schönheit, von Poseidon ausgerechnet in einem Athena-Tempel vergewaltigt, und die erzürnte Göttin verlieh ihr daraufhin das Angesicht, das fortan alle zu Stein verwandelte.

In den uns noch bekannten Quellen funktioniert die Aufteilung des Blutes der Medusa nicht ganz so wie hier von Tatian beschrieben: Bei Euripides (Ion 999-1005) gibt Athena dem frühen attischen König Erichthonios zwei Tropfen des Gorgonenblutes, von denen der eine tödlich und der andere heilbringend ist; beim Mythographen Apollodor (III $120=$ III 10,3) empfängt Asklepios ebenfalls von Athena beide „Blutsorten“ der Gorgo und kann damit Lebende zum Tod befördern und Tote wieder ins Leben rufen. Wahrscheinlich hat Tatian hier nicht genau genug abgeschrieben.

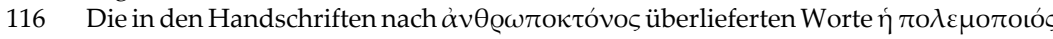
hat SchwarTz zu Recht getilgt, denn sie sehen ganz nach einer ursprünglichen Randglosse aus, um $\alpha \dot{v} \theta \varrho \omega \pi$ токо́voৎ zu erläutern. Das zuerst bei Aristoteles

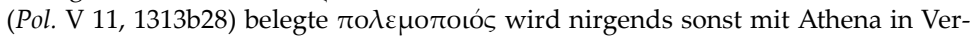
bindung gebracht.

117 Das Stichwort „Athena“ führt Tatan nunmehr zu einem Exkurs über diese Göttin.

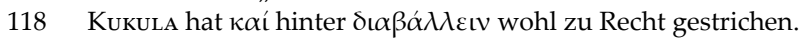

119 Laut dem Mythographen Apollodor (III 188 = III 14,6) machte Hephaistos, von seiner Frau Aphrodite verlassen, der jungfräulichen Athena Avancen, die Athena wenig schätzte; als Hephaistos handgreiflich wurde, wehrte sich Athena und wischte Hephaistos' Sperma, das ihr auf den Schenkel getropft war, voller Ekel mit einem "Wollknäuel“ (દ̣̌ıv) ab und warf dieses auf die „Erde“ ( $\chi \theta \omega \omega v)$, die daraufhin den attischen Urkönig Erichthonios hervorbrachte. Die Geschichte ist sehr dezent in Platons Kritias angedeutet (109c6-8; vgl. dazu Nesselrath 2006, 138f.); Tatian gestaltet 
sie eindeutig in malam partem aus (vgl. Clem. Alex. Protr. 27,5, wo ebenfalls eine sexuelle Beziehung zwischen beiden konstatiert und hinzugefügt wird: „da ist Athena natürlich keine Jungfrau mehr"; ähnlich wird die Geschichte bei Lactanz, Div. Inst. I 17,11-14 und Augustinus, CD XVIII 12 interpretiert: Erichthonii regis Atheniensium ... Vulcanus et Minerua parentes fuisse dicuntur. sed quoniam Mineruam uirginem uolunt, in amborum contentione Vulcanum commotum effudisse aiunt semen in terram ...., „die Eltern des Erichthonios, des Königs der Athener, ... sollen Hephaistos und Athena gewesen sein. Aber weil es ihnen darum geht, dass Athena eine Jungfrau sei, behaupten sie, dass Hephaistos, beim Kampf beider erregt, seinen Samen auf die Erde vergossen habe ...").

120 Die jungfräuliche Jägerin Atalante nahm als einzige Frau an der berühmten Jagd auf den Kalydonischen Eber teil, und bei dieser Gelegenheit soll sich Meleager, der Anführer und Organisator der Jagd, in sie verliebt haben (vgl. Diod. IV 34,4; Apollod. Bibl. I $69=\mathrm{I} 8,2)$; dass sie jedoch miteinander geschlechtlich verkehrt hätten, liest man sonst nur noch in den Fabulae des Hyginus (Nr. 70: einer der Sieben Feldherren gegen Theben ist Parthenopaios, Meleagri filius ex Atalanta; ebenso in Nr. 99).

121 Bereits William WorTh konjizierte in seiner 1700 erschienenen Tatian-Ausgabe

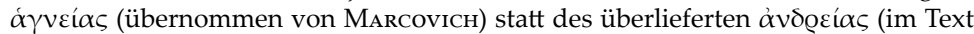
behalten von Schwartz, Goodspeed, Whittaker und Trelenberg; auch von den Übersetzern Puech, Fermi und Di Cristina), das keinen wirklichen Sinn ergibt.

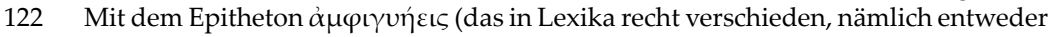
als „,beidseitig geschickt“ oder „,auf beiden Seiten mit krummen Gliedern / mit zwei krummen Beinen“ gedeutet wird; antike Erklärer deuteten es als „, auf beiden Seiten lahm“, z.B. Schol. Hom. Il. I607b, und so versteht es sicher auch Tatian) wird in den homerischen Epen insgesamt elfmal der Schmiedegott Hephaistos bezeichnet. Die von Hephaistos hergestellten "Spangen“ und "gekrümmten Ohrringe“ sind direktes Zitat aus dem Ilias-Vers XVIII 401 (dessen originaler Kontext freilich mit Athena nichts zu tun hat).

123 Diese despektierliche Kennzeichnung von Athena verweist darauf, dass sie nicht auf natürliche Weise von einer Mutter, sondern aus Zeus' Kopf geboren wurde (die Göttin Metis, die Athenas Mutter geworden wäre, hatte Zeus zuvor verschlungen, weil ihm geweissagt worden war, dass Metis zuerst eine Zeus ebenbürtige Tochter und danach einen Zeus überlegenen Sohn gebären würde (vgl. Hes. Theog. 886-890; Apollod. Bibl. I 20 = I 3,6). Vgl. auch unten 25,5.

124 Dionysos als „Tyrannen“ oder Herrscher über Theben zu bezeichnen ist eigenartig; in Euripides' Bakchen setzt sich Dionysos erfolgreich gegen die Anfeindungen des thebanischen Herrschers Pentheus zur Wehr, tritt aber selber keine Herrschaft über Theben an.

125 Kronos als Tyrannentöter darzustellen ist zumindest schief: Kronos entmannte seinen Vater Uranos und setzte sich als Herrscher an seine Stelle (Hesiod, Theog. 168-181; Apollod. Bibl. I 3). Freilich stellt auch Justin (1 Apol. 21,5) Kronos (wie seinen Sohn Zeus, wo dies ebenfalls nicht zutrifft) als „Vater-Töter"

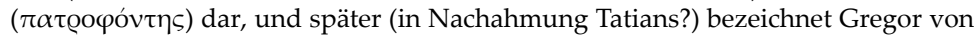

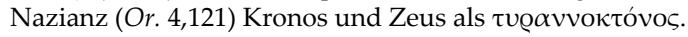

126 Im Hintergrund dieses neuerlichen Skandalons, das Tatian zu berichten weiß (über den Inzest des Zeus mit seiner Tochter Persephone und den daraus hervorgegangenen Dionysos Zagreus) stehen offenbar orphische Traditionen (Orph. Fr. 59, 140 Kern; vgl. Fr. 210, 230 KerN); vgl. aber auch Photios, $\zeta 3$ Theodoridis; Schol. Lycophr. 355. Die Geschichte wurde auch von anderen Apologeten der Zeit Tatians als weiteres ,Beweisstück' gegen die unmoralischen griechischen Götter verwendet

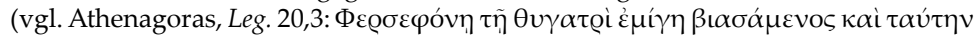

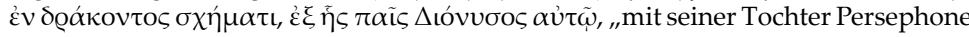
hatte er Geschlechtsverkehr und vergewaltigte sie in der Gestalt einer Schlange; aus 
ihr wurde ihm dann als Sohn Dionysos geboren“; Clem. Alex., Protr. 16,1: $\mu$ í $\gamma v v \tau \alpha$ เ

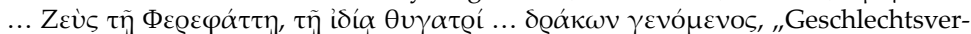
kehr hatte ... Zeus mit Persephone, seiner eigenen Tochter ..., nachdem er sich in eine Schlange verwandelt hatte").

127 Zum Zeugen für die gerade zum Besten gegebene Ungeheuerlichkeit (den Inzest des Zeus mit seiner Tochter Persephone) ruft Tatian nun Phänomene an, die mit orphischen Traditionen verbunden sind: Die Eleusinischen Mysterien gelten zum Teil als von Orpheus gegründet (Orph. test. 102-104 KERN; vgl. Aristoph. Ran. 1032; Ps.Eur. Rhes. 943f.; 966; Ps.-Dem. Or. 25,11; dazu F. Graf, Eleusis und die orphische Dichtung Athens in vorhellenistischer Zeit [Berlin 1974] 2 Anm. 7 und 22-39; M. L. WEST, The Orphic Poems [Oxford 1983] 24), die "mystische Schlange“ evoziert die Gestalt, in der Zeus seiner Tochter beiwohnte (vgl. die vorangehende Anm. und unten Anm. 160

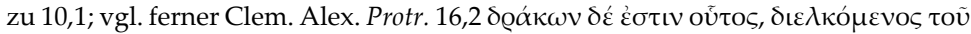

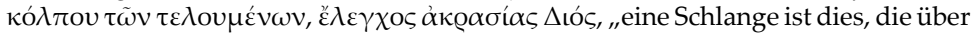
den Busen derer kriecht, die sich einweihen lassen, eine Entlarvung der Zügellosig-

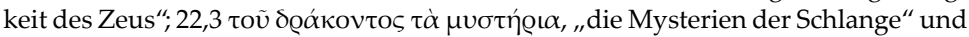

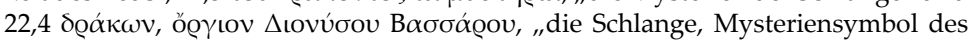
Dionysos Bassaros"), und dann wird der "Urheber" dieser Traditionen, Orpheus, selbst genannt. Den ihm zugeschriebenen Spruch zitiert Tatian freilich in einer Variante (mit dem Dativ $\beta \varepsilon \beta \eta$ ioıs), die sich nur in einer Minderheit der Zeugnisse findet (Olympiod. In Arist. Cat. 12,12 Busse; Elias, In Arist. Cat. 125,3 Busse); in der Regel steht hier der Vokativ $\beta \varepsilon \beta \eta$ \ol, mit dem die „Unreinen“ selbst aufgefordert werden, ihre Türen vor den heiligen Handlungen zu schließen (Orph. Fr. 334 KERN; vgl. Clem. Alex. Protr. 74,4; Ps.-Justin, Coh. 15,1; Eus. PE XIII 12,2; Theodoret, Graec. aff. cur. I 86.115; Cyrill. Contra Iul. I 35; erste Anspielung bereits bei Plat. Symp. 218b:

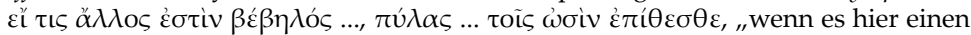
anderen Unreinen gibt ..., macht die Tore vor euren Ohren $\left.\mathrm{zu}^{\prime \prime}\right)$.

128 Hier erzählt Tatian in wenigen Worten die ,gängigere' Geschichte (im Vergleich zum orphischen Inzestmythos) vom Raub der Persephone durch den Unterweltsherrscher Hades (den Tatian hier mit seiner epischen Namensform "Aïdoneus" nennt, die in der homerischen Ilias und in Hesiods Theogonie erscheint, vor allem aber auch - und zwar insgesamt viermal - im homerischen Demeterhymnus, der ältesten ausführlichen Darstellung des Raubes). Vgl. Clem. Alex. Protr. 17,1:

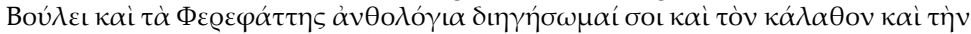

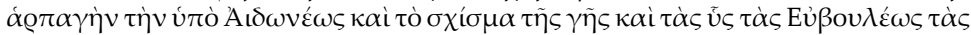

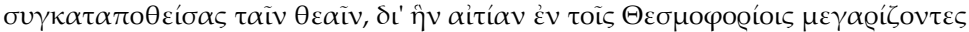

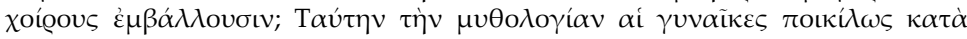

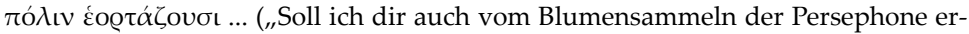
zählen und von ihrem Korb und dem Raub durch Aïdoneus und dem Spalt in der Erde und den Schweinen des Eubuleus, die mit den Göttinnen verschlungen wurden, weshalb man am Thesmophorienfest Gruben vorbereitet und Ferkel hineinwirft? Diese Mythengeschichte feiern die Frauen auf schillernde Weise in der Stadt ...")

129 Kore („das Mädchen“, als Tochter der Demeter) ist der vor allem in Attika gängige Name der Persephone, im Kultzusammenhang mit Demeter, der im attischen Thesmophorien-Fest und in den Eleusinischen Mysterien präsent ist.

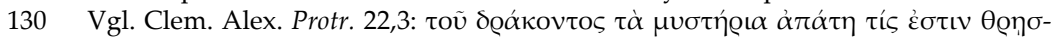

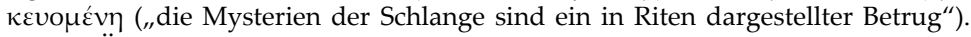
Tatians Äußerung bezieht sich wohl darauf, dass auch viele Nicht-Athener sich in die Eleusinischen Mysterien einweihen ließen; vgl. H. Bowden, Mystery Cults of the Ancient World (Princeton 2010) 33.

131 Die folgenden Ausführungen sind dem Gott Apollon (Sohn der Leto) gewidmet. Sie wirken sprunghaft: Von einer Einzelheit in Apollons heiligem Bezirk und Ora- 
kelheiligtum in Delphi (dem Nabel) gelangt Tatian im nächsten Satz zu Apollons unerfüllter Liebe zu Daphne, die ihn zum einen als sexhungrig darstellen und zum anderen seine defizitäre Seherkunst entlarven soll, und gleich darauf zu seiner ebenso unglücklichen Liebe zu Hyakinthos, die ähnliche Defizite (homosexuelle Neigung und erneutes Nichtvoraussehenkönnen der unglücklichen Wendung) offenlegt. Angestrebt scheint eine knappe, aber umfassende Demontage dieses außerordentlich prominenten Gottes der Griechen. Vgl. auch die entsprechenden Bemerkungen bei Ps.-Justin, Coh. 38E und Theophilos, Autol. I 9.

132 Bei dem hier erwähnten "Grab des Dionysos" handelt es sich um die Bestattung des ,ersten' Dionysos (Dionysos Zagreus), des Sohnes des Zeus und der Persephone (vgl. oben Anm. 126 und 127), dessen Überreste Zeus (nach Züchtigung der Titanen, die diesen Dionysos zerrissen hatten) dem Apollon zur Bestattung in Delphi übergab (vgl. Clem. Alex. Protr. 18,2; vgl. Kallimachos, Fr. 643 Pfeiffer). Nur hier bei Tatian scheint dieses Grab mit dem berühmten Omphalos von Delphi (vgl. Paus. X 16,3) identifiziert zu werden.

133 Dass die Seherkunst Apollons gerade bei seiner Liebe zu Daphne scheiterte, bemerkt auch Ovid bei seiner Darstellung der Geschichte (Met. I 490f.: Phoebus amat visaeque cupit conubia Daphnes, / quodque cupit, sperat, suaque illum oracula fallunt, „Apollon liebt und wünscht die Ehe mit der von ihm erblickten Daphne, / und was er wünscht, erhofft er, und seine eigene Orakel täuschen ihn").

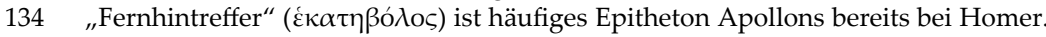
TreLEnBerg 2012, 107 Anm. 100 will die Bedeutung ,fernhintreffend“ durch ",treffsicher" ersetzen (ohne dazu eine Quelle anzugeben); aber die antiken Erklärungen (z.B. Apollonios Sophistes, Lex. Hom. S. 65,14 BекKER; Hesych $\varepsilon$ 1266) erläutern das Wort immer als ",fernhintreffend“, und so dürfte es auch Tatian verstanden haben.

$135 \mathrm{Zu}$ dem durch Zephyros verursachten Tod des von Apollon geliebten Hyakinthos vgl. Lukian, Salt. 45 und Dial. deor. 16,1f.; 17,2; Apollod. Bibl. I 17 = I 3,3; III $116=$ III 10,3; Philostr. Im. I 24,3f.; Philostr. iun. Im. S. 886,4-9.

136 Ein iambischer Trimeter eines unbekannten Tragödiendichters (TrGF adesp. Fr. 565 KaNNICHT-SNELL), nur hier bei Tatian überliefert.

137 Die von Schwartz (dem Marcovich folgt) vorgenommene Tilgung von oũtot ist unnötig.

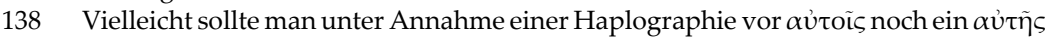

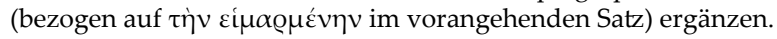

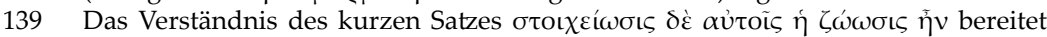
große Schwierigkeiten und hat dementsprechend auch zu ganz verschiedenen Übersetzungsversuchen geführt (WORTH versteht: „Principium cui fatidicam suam doctrinam superstruebant fuisse animalium in coelo collocationem"; von OTто: „Elementum autem iis [i.e. daemonibus] fuit animalium in coelo collocatio“; HARNACK: „Ihr Hauptgeschäft aber war, dass sie Tiere an den Himmel versetzten“; Kukula: „für deren [scil. der von den Dämonen festgelegten Tafel des Fatums] Feder ihnen das Tierreich die Zeichen liefern mußte“; Whittaker: „Their basic principle was the giving of life“; TreLEnBERG: „Zu seiner [scil. des Schicksals] Bezeichnung diente ihnen das Tierreich"). Die Schwierigkeiten liegen im Verständ-

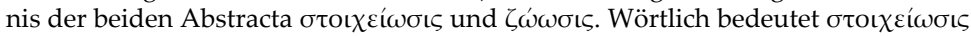
"Elementarunterweisung" oder „Lehre von den Elementen“, $\zeta \omega \omega \sigma \iota \varsigma$ „Belebung / Lebendigmachung"; setzt man diese Bedeutungen jedoch in Tatians Satz ein, ergibt sich kein Sinn. Er muss die beiden Begriffe als Zusammenfassung der sich hinter

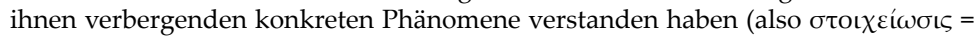
die Gesamtheit der Elemente, $\zeta \omega \omega \sigma \iota \varsigma=$ die Gesamtheit der Tiere), und so ist hier übersetzt. 
140 Die Dämonen, so Tatian, griffen also zum Mittel der Verstirnung von Tieren (gemeint sind hier vor allem die gleich in 9,2 genannten Tierkreiszeichen), um eine Art Logos-Ordnung zu simulieren, als deren Urheber sie selber erscheinen wollten.

141 Der Text folgt dem Vorschlag GesNERs, vor dem einhellig überlieferten $\dot{\alpha} \pi^{\prime} \alpha \dot{v} \tau \tilde{\omega} v$

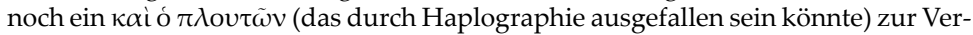
vollständigung des Gegensatzpaars mit ó $\pi \tau \omega \chi \varepsilon v ́ \omega \omega v$ zu ergänzen. Dagegen ersetzen Schwartz und in seinem Gefolge WhitTAKER und TreLEnberg das überlieferte

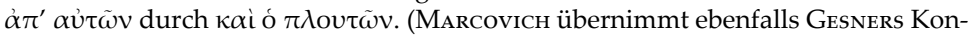
jektur, verändert aber dann unnötigerweise $\dot{\alpha} \pi^{\prime} \alpha \dot{v} \tau \tilde{\omega} v \dot{\varepsilon} \sigma \tau \mathrm{zu}$ zu $\alpha \dot{\mathrm{o}}\langle\tau \tilde{\omega} v\rangle \alpha \dot{v} \tau \tilde{\omega} v$ $\dot{\varepsilon} \sigma \tau \iota\langle\theta \varepsilon \tilde{\omega} v\rangle$.)

142 Damit erteilt Tatian der astrologischen Lehre, dass die Sternkonstellation bei der Geburt eines Menschen (die sogenannte ,Nativität') über seinen Charakter entscheidet, eine Absage.

143 Die sieben Planetengötter sind der Mond/Luna/Selene, die Sonne/Sol/Helios/Apollon, Merkur/Hermes, Venus/Aphrodite, Mars/Ares, Jupiter/Zeus und Saturn/Kronos (die Planeten Uranus, Neptun und Pluto waren in der Antike noch nicht bekannt). - Die Ansetzung einer Lücke durch Schwartz (dem GoodsPEEd folgte) nach $\pi \lambda \alpha v \tilde{\eta} \tau \alpha$ เ ist unnötig; vgl. KuKULA 1900, 24.

144 Hierzu gibt Kuкula ad loc. eine hilfreiche Erklärung: „Der Zodiakus ist also mit einer Art von Schachbrett ... verglichen, dessen zwölf Felder die bekannten Kalenderzeichen für $\uparrow$ Widder, $\measuredangle$ Stier, $\amalg$ Zwillinge usw. aufzeigen; als Figuren dienen die diesen Feldern entsprechenden zwölf Zodiakalgötter, Spieler aber sind die sie-

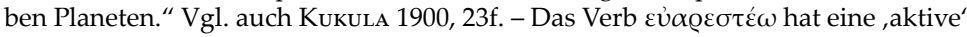
(„Gefallen an etwas haben“) und eine ,passive' (,jemandem gefallen“) Bedeutung. Für die zweite Bedeutung (dass die sieben Planeten-Götter hier jemand anderem gefallen) plädierten Worth und MARAN (und WHITTAKER übersetzt entsprechend: "The seven planets ... amuse them", mit der Erklärung: "The gods enjoy watching the game in which the planets control men's lives ..."), für die erste Bedeutung bereits Konrad Gesner (der übersetzte: „Delectantur ... his Zodiaci picturis Planetae septem"), vом Отто (der zu Recht die hier genannten Planeten mit ihren Göttern [vgl. die vorangehende Anm. und 9,3 $\pi \lambda \alpha v \eta \tau \tilde{\omega} v \delta \alpha \mu \mu o ́ v \omega v]$ gleichsetzt) und auch die Übersetzungen von KuKula (sowie Kukula 1900, 23f.) und Trelenberg.

145 Im Folgenden kommentiert Tatian kritisch einige besondere Sternzeichen; die gemeinsame Pointe ist (vgl. 9,5), dass es absurd ist zu glauben, dass die betreffenden Sterne erst nach dem jeweiligen Verstirnungs-Mythos entstanden wären und nicht schon vorher existiert hätten.

146 Triptolemos, ein Angehöriger des Königsgeschlechts von Eleusis, ist im griechischen (genauer: attischen) Mythos der erste Mensch, der von Demeter die Gabe der Getreide-Saat empfängt und diese mithilfe eines geflügelten Wagens über die ganze Erde verbreitet (vgl. Apollod. Bibl. I 32 = I 5,2); zur Entwicklung dieses Mythos vgl. jetzt H.-G. Nesselrath, „Triptolemos - ein mythischer Kulturheld im Wandel der Zeiten“, in: A. Zgoll / R. G. Kratz (Hg.), Arbeit am Mythos. Leistung und Grenze des Mythos in Antike und Gegenwart (Tübingen 2013) 195-216.

147 Demeter übergab dem Triptolemos die Getreidesaat, nachdem sie ihre Tochter Persephone aus der Unterwelt zurückerhalten hatte (vgl. oben Anm. 128). Es gibt Deu-

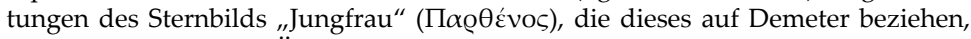
weil die Jungfrau eine Ähre hält: vgl. Arat. Phaen. 97 mit Ps.-Eratosth. Catast. 9 (oi

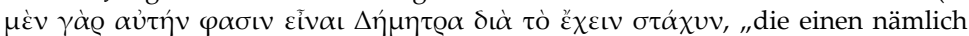
sagen, es sei Demeter, weil sie eine Ähre hält“).

148 Erigones traurige Geschichte ist kurz beim Mythographen Apollodor (Bibl. III 192 $=$ III 14,7) und in Fabula 130 des Hyginus geschildert: Ihren Vater Ikarios, dem Dionysos die Gabe der Weinherstellung vermittelt hatte, hatten Bauern getötet, die sich von dem ihnen unbekannten Wein zunächst vergiftet glaubten. Erigone wurde 
von ihres Vaters Hündin Maira zu dessen Leichnam geführt und erhängte sich aus Schmerz; Maira aber harrte bei der toten Erigone bis zu ihrem eigenen Tod aus (vgl. Aelian, Nat. VII 28). Alle drei wurden von einem mitleidigen Zeus unter die Sterne versetzt (Hyg. Astron. II 4,4). Ausführlich dargestellt ist die Geschichte im 47. Buch der Dionysiaka des Nonnos (V. 34-262).

Über den Hund der Erigone als Sternzeichen mokiert sich auch Lukian in einer Weise, die der Tatians recht ähnlich ist (Deor. conc. 5, wo Momos sagt: „Und was von allem das lächerlichste ist, ihr Götter, auch den Hund der Erigone, auch den hat er [scil. der vergöttlichte Dionysos] mit heraufgebracht, damit das Mädchen nicht bekümmert sei, wenn es im Himmel nicht sein gewohntes und geliebtes Hündchen habe").

149 Artemis gewann den Skorpion als Helfer gegen den Jäger Orion, der sie bedrängt hatte (vgl. Nikander, Ther. 13-20 und Ps.-Eratosth. Catast. 7); sowohl Orion als auch der Skorpion wurden verstirnt.

150 Zeus soll Cheiron verstirnt haben, nachdem er versehentlich durch einen Giftpfeil des Herakles ums Leben gekommen war (Ps.-Eratosth. Catast. 40).

151 Für die Verstirnung der Argo, des ersten mythischen Hochseeschiffes, soll die Göttin Athena gesorgt haben, die auch an seiner Erbauung maßgeblich mitwirkte (Apoll. Rhod. Arg. I 18f.; Apollod. Bibl. I 110 = I 9,16); freilich wurde nur die hintere Hälfte des Schiffs, vom Mast bis zum Heck mit den Steuerrudern, verstirnt (Ps.-Eratosth. Catast. 35).

152 Die Geschichte der Kallisto ist am ausführlichsten bei Ovid (Met. II 405-507; Fast. II 156-190) und in den Astronomica Hygins (II 1) dargestellt: Kallisto, eine Tochter des arkadischen Königs Lykaon, war eine Begleiterin der Jagdgöttin Artemis und erregte als solche die Begierde des Zeus, der sich ihr in Gestalt der Artemis näherte und sie schwängerte. Als Artemis den Verlust der Jungfräulichkeit der Kallisto entdeckte, verwandelte sie sie zur Strafe in eine Bärin (wobei es mehrere Versionen von dieser Bären-Verwandlung gibt). Als Bärin gebar Kallisto den Arkas (den Namengeber der Arkader); als sie ihm fünfzehn Jahre später begegnete, wäre sie fast von ihm getötet worden, doch wurden beide noch rechtzeitig als Ursa Maior und Minor (oder als Arktos und Arktophylax, vgl. Hyg. Astr. II 4,1) an den Himmel versetzt.

153 Beide hier von Tatian erwähnten Deutungen des Sternbilds „Dreieck“ (Deltoton, Trigonon, Triangulum) erscheinen auch bei Hygin (Astr. II 19); bei Ps.-Eratosthenes (Catast. 20) fehlt die mit Sizilien. Delta als erster Buchstabe des Namens des Zeus erklärt sich aus den üblichen obliquen Casus des Zeus-Namens (Zev́s, $\Delta$ tós, $\Delta$ uí, $\Delta$ í $\alpha$ ).

154 Brüder des Zeus sind Poseidon als Herrscher über das Meer und Hades/Pluton als Herrscher über die Unterwelt; zur Aufteilung der Herrschaftsbereiche unter den dreien vgl. Apollod. Bibl. I 7 = I 2,1 (und bereits Hom. Il. XV 187-192).

155 Die Annahme einer Lücke vor $\gamma \varrho \alpha \mu \mu \alpha ́ \tau \omega \nu$ (die Worth - dem Marcovich und TRE-

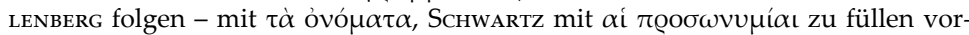
schlägt) ist unnötig, wenn man statt $\sigma \chi \eta \mu \alpha$ tov@ $\gamma$ '́ $\alpha$ mit MARAN (und von OtTo und KuKULA) $\sigma \chi \eta \mu \alpha \tau O v Q \gamma$ í $\alpha$ l liest.

156 Seit Schwartz nehmen alle Tatian-Editionen das von Nauck konjizierte $\kappa \alpha \tau \eta \sigma \tau \varepsilon-$

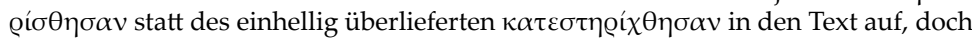
scheint dies nicht unbedingt nötig, denn aus dem ganzen Zusammenhang geht her-

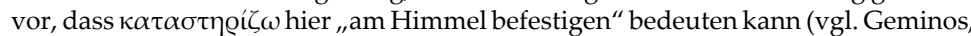

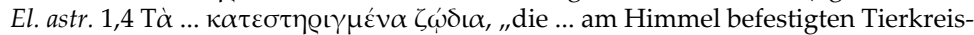

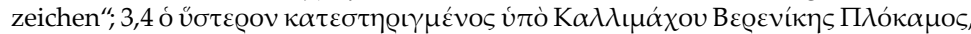
„die später von Kallimachos am Himmel befestigte Locke der Berenike“; Kleitony-

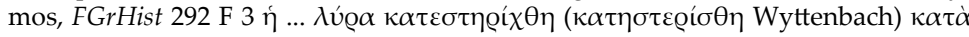

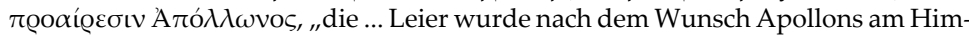




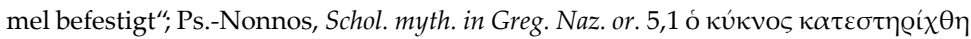

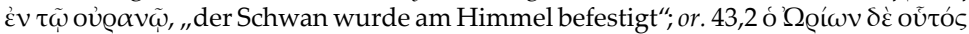

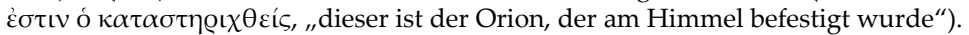

157 Kronos und seine Geschwister, die Titanen, wurden von Zeus und seinen Geschwistern besiegt und anschließend im unterweltlichen Tartaros eingekerkert; vgl. Hes. Theog. 501-506; 617-733; Apollod. Bibl. I 6f. = I 2,1.

158 Mit dieser Frage weist Tatian auf den Widerspruch hin, dass Kronos, obwohl im Tartaros gefangen (vgl. die vorangehende Anm.), zugleich einer der sieben Planetengötter sein soll, die durch ihr ,Spiel' mit den Tierkreiszeichen (vgl. 9,2) über das Schicksal bestimmen. Übrigens thematisiert Lukian in seinen Saturnalia einen ganz ähnlichen Widerspruch, da er zur Saturnalienzeit einen Priester den Kronos höchstpersönlich fragen lässt, ob es denn wahr sei, dass er seine Kinder verschlungen habe, dann von Rhea (die ihm anstelle des kleinen Zeus einen Stein zum Verschlingen gab) getäuscht und von Zeus gewaltsam aus der Herrschaft vertrieben und im Tartaros angekettet worden sei, woraufhin Kronos sehr unwirsch darauf verweist, dass er jetzt ja vor ihm stehe, also nicht im Tartaros gefangen sein könne (Luc. Sat. 5f.).

159 Es ist unklar, auf welche Geschichte Tatian hier anspielt. Die von TreLEnBERg im Gefolge von Marcovich genannten Stellen helfen nicht weiter: In Ovid, Met. X 103-105 wird kurz berichtet, dass sich der von der Göttermutter Rhea/Kybele geliebte Attis (vgl. oben Anm. 112) in eine "Kiefer" (pinus) verwandelt hat, und deren „Nüsse“ werden bei Martial, Epigr. XIII 25 als „Früchte der Kybele“ bezeichnet; damit ist aber über eine Verwandlung der Göttermutter selbst in einen Baum nichts gesagt.

160 Phersephassa ist eine Namensform der Persephone, die vor allem in der attischen Tragödie belegt ist (Aesch. Fr. 451s RadT; Soph. Ant. 894; Eur. Hel. 175). Dazu, dass sich Zeus in eine Schlange verwandelte, um mit seiner Tochter Persephone zu schlafen, vgl. oben Anm. 126 und 127 (zu 8,6).

161 Schwartz fügte nach $\alpha$ í $\gamma \varepsilon$ เooı die Kopula $\tau \varepsilon$ ein (nicht zuletzt um den Hiat zu vermeiden); ihm folgen Whittaker und Marcovich, nicht aber Trelenberg. Da Tatian auch sonst asyndetisch formulieren kann (und nicht so sehr auf Hiatvermeidung geachtet hat, wie Schwartz glaubte), ist die Einfügung nicht zwingend.

162 Die Verwandlung der um ihren Bruder Phaëthon, der mit dem Himmelswagen des Sonnengottes zu Tode stürzte, trauernden Schwestern (der sogenannten Heliaden = Töchtern des Helios) zu Pappeln (die immer noch Bernstein als Tränen vergießen) wird bei Ovid (Met. II 340-366) und in den Fabulae Hygins (154,3f.) dargestellt. Eine ironische Beleuchtung der Geschichte findet sich im Anfangsteil von Lukians Prolalia Electrum („Der Bernstein“).

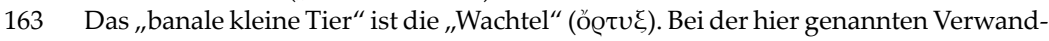
lung liegt ein Irrtum Tatians vor: Nach den gängigen mythographischen Quellen (Apollod. Bibl. I 21 = I 4,1; Hygin, Fab. 53; vgl. Schol. Apoll. Rhod. 35,8-10 Wendel und Schol. Lycophr. 401) ist es nicht Leto, sondern Letos Schwester Asteria, die sich auf der Flucht vor Zeus in eine Wachtel verwandelt und ins Meer stürzt; hier wird sie zu einer Insel, die zunächst Asteria heißt (so noch mehrfach in Kallimachos' Hymnos auf Delos, vor allem V. 36-38), dann von Asterias Verwandlung in eine Wachtel den Namen Ortygia bekommt und schließlich - nachdem die von Zeus geschwängerte Leto auf ihr Apollon und Artemis zur Welt bringt - Delos heißt (übrigens ist im Lykophron-Scholion der Wortlaut bemerkenswerterweise zum Teil so zweideutig, dass man hier tatsächlich Leto mit Asteria verwechseln könnte, und vielleicht ist Tatians Irrtum auf einen solchen unklar formulierten Text zurückzuführen).

164 Die beiden in diesem Satz genannten Verwandlungen beziehen sich auf Zeus: Der schönen Leda (Frau des spartanischen Königs Tyndareos) wohnte Zeus in Gestalt eines Schwans bei, den schönen trojanischen Hirtenknaben Ganymedes (Sohn des Königs Tros) holte er höchstpersönlich auf den Olymp, nachdem er sich zuvor in 
einen Adler verwandelt hatte. Ähnliche Aufzählungen wie hier bietet Lukian in seinem Pamphlet Über die Opfer, Kap. 5 („Einige Bastarde hat er auch aus dem sterblichen und irdischen Geschlecht produziert, indem der wackere Kerl sich bald in Gold verwandelte, bald in einen Stier oder einen Schwan oder einen Adler ...") oder in seinem 6. Göttergespräch (wo Zeus direkt zu Eros spricht: „Nichts gibt es, was du nicht aus mir gemacht hast: Satyr, Stier, Gold, Schwan, Adler!“ [Kap. 1]). Auch bei christlichen Apologeten sind solche Kataloge beliebt (vgl. Athenagoras, Leg. 9,7; Greg. Naz. Carm. mor. PG 37, 618,1 und 740,10).

165 Hier könnte Tatian an Geschichten wie die bereits im 9. Buch der Ilias (V. 533-542) erzählte von der Göttin Artemis denken, die von dem König Oineus von Kalydon bei einer großen Opferfeier versehentlich "vergessen" wurde und daraufhin voller Zorn einen riesigen Eber schickte, der die Felder Kalydons verwüstete. Bereits Platon kritisiert ein solches Götterverständnis, das die Götter für „bestechlich“ hält (Leg. X 885b8f.; 905d-907b).

166 Vgl. zu diesem Satz oben 9,2f. mit Anm. 143f.

167 Erneut macht sich Tatian eines Fehlers schuldig: Laut den maßgeblichen Erzählungen (Kallimachos behandelte die Verstirnung der "Locke der Berenike“ am Ende des 4. Buches seiner Aitien, und Catull übertrug diese Darstellung in seinem 66. Gedicht ins Lateinische) wurde die Locke der ptolemäischen Königin Berenike II. (Frau des Ptolemaios III. Euergetes) nicht erst nach ihrem Tod als Sternzeichen an den Himmel versetzt, sondern bereits kurz, nachdem die Königin ihre Locke den Göttern geweiht hatte, um eine glückliche Rückkehr ihres Mannes aus dem 3. Syrischen (oder „Laodike-“)Krieg zu erreichen - jedenfalls war dies (laut Kallimachos) die Erklärung des ptolemäischen Hofastronomen Konon von Samos, als die Locke auf mysteriöse Weise aus dem Tempel verschwunden war.

168 Antinoos, der jugendliche Geliebte des Kaisers Hadrian, kam 130 n. Chr. in den Fluten des Nil ums Leben (vielleicht durch Selbstmord) und erhielt danach viele göttliche Ehren zugesprochen. Dass Tatian ihn hier gewissermaßen als „Mann im Mond" apostrophiert, kann mit archäologischen (auch numismatischen) Zeugnissen zusammenhängen, die den vergöttlichten Antinoos mit dem Mondgott identifizieren (vgl. H. Meyer, Antinoos. Die archäologischen Denkmäler unter Einbeziehung des numismatischen und epigraphischen Materials sowie der literarischen Nachrichten [München 1991] 171f.).

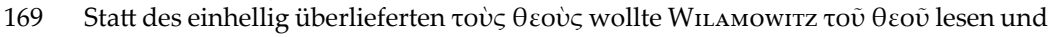
fand damit Anklang bei Schwartz, Whittaker und Marcovich, während TrelenBERG die Überlieferung hält; bereits KuKULA 1900, 19 Anm. 1 verteidigte den Akku-

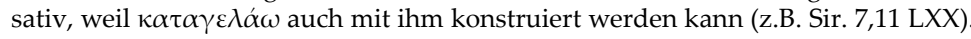
Auch inhaltlich hat der Plural („,die Götter“) mehr Pointe: Die hier geschilderte Divinisierungs-Inszenierung (vgl. die folgende Anm.) ist sogar für heidnische Götter eine Beleidigung.

170 Hier spielt Tatian auf das bei der Divinisierung von römischen Kaisern übliche Phänomen an, dass sich ein Augenzeuge zu finden pflegte, der behauptete, er habe den abgelebten Kaiser in den Himmel auffahren sehen (vgl. etwa zu Augustus Suet. Div. Aug. 100,4). Lukian parodiert das Phänomen, indem sein Ich-Erzähler gegen Ende von De morte Peregrini selbst als Augenzeuge dafür posiert, dass er den Peregrinos nach seinem Feuertod als Geier auf dem Scheiterhaufen habe auffahren sehen (Peregr. 39), und gleich darauf noch ein anderer berichtet, er sei dem weißgewandeten Peregrinos in einer Wandelhalle begegnet (Peregr. 40; vgl. P. Pilhofer, Anm. 126, 129 und 131 auf S. 87-90 in: P. Pilhofer u. a. [Hg.], Lukian. Der Tod des Peregrinos. Ein Scharlatan auf dem Scheiterhaufen. SAPERE 9 [Darmstadt 2005]). Im Fall des Antinoos war laut Cassius Dio LXIX 11,4 Hadrian selbst Zeuge für die Verstirnung seines jungen Geliebten. 
171 Schaf (bzw. Widder) und Stier sind sowohl häufig verwendete Opfertiere in den griechisch-römischen Götterkulten als auch am Himmel stehende (und damit vergöttlichte) Zeichen des Tierkreises: Der Widder soll der verstirnte Träger des Goldenen Vlieses gewesen sein, der den jungen Phrixos nach Kolchis trug, der Stier das verstirnte Abbild entweder des Stieres, der Europa nach Kreta trug, oder der in eine Kuh verwandelten Io (vgl. Ps.-Eratosth. Catast. 19 und 14).

172 Bei den nächsten drei Sternzeichen, die Tiere zeigen (Drache, Adler und Schwan), kommt es Tatian auf die Pointe an, dass alle diese Tiere in fragwürdige Mythen (der Drache ist der böse Gegner eines großen Helden; der Adler ist der Quäler eines Wohltäters der Menschheit; der Schwan ist das Werkzeug eines göttlichen Ehebruchs) verstrickt sind, weshalb sie eine solche „Belohnung“ durch Verstirnung keineswegs verdient haben.

173 Das „,böse Tier" ist das verstirnte Abbild („Drakon“, auch „Ophis“) des riesigen Drachen (bei Apoll. Rhod. Arg. IV 1396 heißt er Ladon), der die goldenen Äpfel der Hesperiden zu bewachen hatte, deren Beschaffung eine der zwölf Aufgaben des Herakles war; dazu musste er (zumindest in einer Version der Geschichte; vgl. Apoll. Rhod. Arg. IV 1400-1405; 1432-1440; Diod. IV 26,4) den Drachen töten, und das Sternbild „Engonasin“ (,,[Der] auf den Knien“) zeigt nach antiker Interpretation (vgl. Ps.-Eratosth. Catast. 4; Hygin. Astr. II 6,1), wie Herakles, mit dem einen Bein knieend, mit dem anderen Fuß den Drachen niederdrückt und mit seiner Keule in der rechten Hand zum Schlag ausholt.

174 Das von Schwartz vor tòv $\alpha \dot{v} \theta \varrho \omega \pi$ oтolóv ergänzte $\langle\dot{o}\rangle$ steht vielleicht besser vor

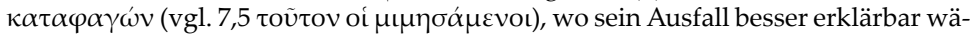
re.

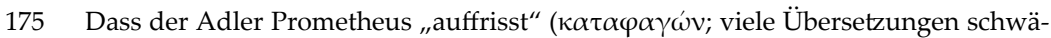
chen das Verb ab: Harnack, Kukula und Trelenberg geben es mit „zerfleischen“ wieder, Whittaker mit „,feed on“; richtig dagegen Puech: „dévore“, Di Cristina: "divora“; etwas zuviel des Guten Fermi: „ha divorato"), ist natürlich eine (von Tatian gewollte?) Übertreibung: Zeus bestrafte den Titanen Prometheus, der sich durch wiederholte Begünstigungen der von ihm geschaffenen Menschen (er sorgte dafür, dass sie bei Tieropfern bessere Teile erhielten als die Götter, und er verschaffte ihnen das Feuer; vgl. Hes. Theog. 535-569) beim olympischen Götterherrscher unbeliebt gemacht hatte, vielmehr dadurch, dass er dem an einen Kaukasusfelsen Angeketteten täglich einen Adler schickte, der ihm die Leber zerfressen sollte (die dann bis zum nächsten Tag wieder nachwuchs; Hes. Theog. 521-525; Apollod. Bibl. I 45=I 7,1). Der Adler (der später von Herakles getötet wird, vgl. Hes. Theog. 526-528; Apollod. Bibl. II $119=$ II 5,11) heißt übrigens nicht „Ethon“, wie falsch von der deutschsprachigen Wikipedia (s. v. „Prometheus" und "Ethon“, konsultiert am 18. 08. 2013) und von Trelenberg 2012, 113 Anm. 126 behauptet wird, sondern Aithon („der Flammende/Gelbbraune", bei Hygin Fab. 31,5 latinisiert zu Aethon).

176 Zum Sternbild „Adler“ vgl. Ps.-Eratosth. Catast. 30, wo der verstirnte Adler freilich nicht derjenige ist, der täglich Prometheus' Leber wegfraß (vgl. die vorangehende Anm.), sondern derjenige, der den jungen Ganymedes auf den Olymp trug (vgl. oben 10,1 mit Anm. 164).

177 Noch einmal (vgl. oben 10,1 mit Anm. 164) spielt Tatian hier auf den Ehebruch des in einen Schwan verwandelten Zeus mit der spartanischen Königsgemahlin Leda an. Zum Sternbild des Schwans (Cygnus) vgl. Ps.-Eratosth. Catast. 25, wo das Objekt von Zeus' sexueller Begierde freilich nicht Leda, sondern die Göttin Nemesis ist.

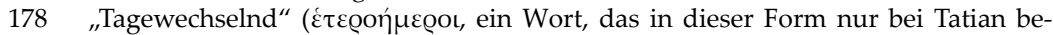
legt ist; bereits in Hom. Od. XI 303 tritt die - in den Hexameter passende - Form

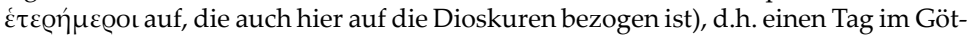
terhimmel und den nächsten in der Unterwelt bei den Toten verbringend, heißen die Dioskuren Kastor und Polydeukes (lat. Pollux), weil der von Zeus und Leda 
stammende (und daher für die Unsterblichkeit bestimmte) Polydeukes dieses Los erbat, als sein (von Tyndareos und Leda, d.h. nur von sterblichen Menschen stammende und daher zum Tod verurteilte) Halbbruder Kastor tödlich verwundet war; auf diese Weise konnte Polydeukes seinem Halbbruder die Hälfte seiner Unsterblichkeit abgeben (vgl. die nächste Anm.).

179 Mit dem Hinweis auf den Raub der Töchter des Leukippos greift Tatian zielsicher den vielleicht einzigen schwarzen Fleck auf der sonst „weißen Weste“ der Dioskuren auf: Hilaeira und Phoibe, Töchter des Leukippos, waren bereits den Helden Lynkeus und Idas zur Ehe versprochen, wurden dann aber von den Dioskuren geraubt; es kam deshalb zu einer Auseinandersetzung zwischen den beiden Brüderpaaren, in deren Verlauf Idas und Lynkeus, aber auch Kastor getötet wurden und dieser dann nur zu einer ,halben' Unsterblichkeit wiedererweckt werden konnte, weil Polydeukes eine Hälfte der seinigen aufgab (vgl. die vorangehende Anm.). Vgl. hierzu die 10. Nemeische Ode Pindars (V. 54-90), Theokrits Dioskuren-Hymnos, Id. 22,135-211 und das knappe Referat (in dem manches etwas anders dargestellt wird) in Apollod. Bibl. III 134-137 = III 11,2.

180 Auf die schöne Helena zu sprechen zu kommen, liegt wohl deshalb für Tatian hier so nahe, weil sie die Tochter der Leda ist, der Zeus als der gerade erwähnte Schwan beiwohnte, und die Schwester der ebenfalls gerade genannten Dioskuren.

181 Während Helenas Ehemann Menelaos in den homerischen Epen recht oft als "blond“ ( $\xi \alpha v \theta o ́ s)$ bezeichnet wird (16mal in der Ilias und 14mal in der Odyssee),

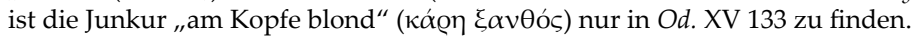

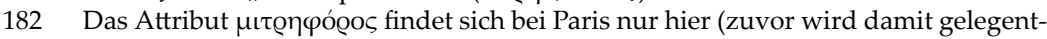
lich Dionysos charakterisiert, einmal auch der verweichlichte orientalische König

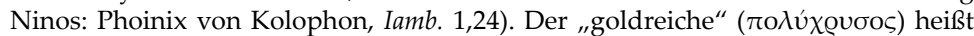
Paris ebenfalls nur hier (in Eur. Hec. 492 sind die Trojaner mit diesem Attribut gekennzeichnet, in Eur. Hel. 928 ihre Häuser, in Hom. Il. XVIII 289 die ganze Stadt Troja; bei Quintus Smyrn. III 652; IX 40; X 21.360 wird Paris' Vater Priamos so genannt). Ähnliche Beschreibungen des Paris, der mit seinem aufgeputzten Äußeren in Sparta Helena verführt, gibt es schon bei Euripides (Troad. 991f.; IA 73f., zitiert von Clem. Alex. Paed. III 13,1).

183 In Hom. Od. IV 561-569 sagt der alte Meergott Proteus dem Menelaos voraus, er werde nach seinem irdischen Leben einmal ins 'H der Gatte der Helena sei; dabei ist anzunehmen, dass sich auch Helena dort selber an der Seite ihres Mannes finden wird. In Lukians Wahren Geschichten (II 8, vgl. 26) sind sie und Menelaos jedenfalls auf der "Insel der Seligen“.

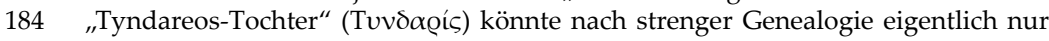
Helenas Schwester Klytaimnestra genannt werden (und wird so genannt Eur. El. 60; Hec. 1278; IT 806; Or. 826), denn Helena ist ja eine Tochter des Zeus (vgl. oben

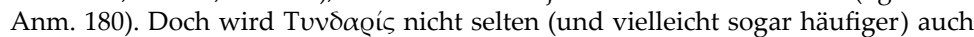
auf Helena angewandt (vgl. Eur. Andr. 898; Hec. 269; Troad. 34; Hel. 472; 614; 1179; 1546; Or. 1154; IA 61; 1335; 1417). Bei der vorliegenden Stelle sind sich die Kommentatoren seit Gesner und Worth uneins, ob Helena (so Gesner; dann Kukula, Whittaker, Di Cristina, Marcovich; vgl. auch Puech 1903, 122) oder Klytaimnestra (so Worth) gemeint ist (Trelenberg 2012, 113 Anm. 133 lässt beide Möglichkeiten offen; auch von Отто trägt beide Möglichkeiten vor). Für Klytaimnestra spricht, dass man Tatian dann nicht erneut einen Fehler in seiner Mythenkenntnis vorhalten müsste, denn Orest tötet seine Mutter Klytaimnestra tatsächlich in der Elektra des Euripides (nicht im Orest, wie man bei WоRтн und von Отто lesen kann); dagegen trachtet er der Helena zwar im Orest des Euripides nach dem Leben, doch wird diese von den Göttern entrückt, bevor er die Tat ausführen kann.

185 In diesem Satz zählt Tatian die Wünsche und Situationen auf, die Menschen dazu veranlassen könnten, den Willen des Schicksals in Erfahrung zu bringen (Herr- 
schaft, Reichtum, Heldentum, Erfüllung der Lüste, Ehrgeiz in Sportwettkämpfen, Ruhmsucht, Angst vor Tod und Krankheit). Daraus ergibt sich ein Ideal der Bedürfnislosigkeit, das stoisch oder eher sogar kynisch wirkt.

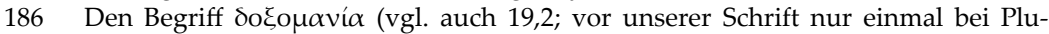
tarch, Sulla 7,1 belegt) scheint Tatian in die christliche Literatur eingeführt zu haben (nächster Beleg ist Clem. Alex. Paed. II 125,1; dann Belege bei Gregor von Nyssa, Basileios von Kaisareia und vor allem Johannes Chrysostomos). Das Adjektiv

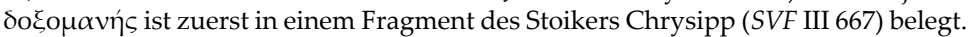

187 Hier könnte Mt 5,45b im Hintergrund stehen: Gott Vater lässt seine Sonne über Böse und Gute aufgehen (

188 Vgl. zu dem uralten Topos, dass allen Menschen der Tod gemeinsam ist (vgl. bereits Hom. Il. VI 486-489), H. WANKEL, „,'Alle Menschen müssen sterben.' Variationen eines Topos der griechischen Literatur", Hermes 111 (1983) 129-154.

189 Bereits in Solons Musenelegie heißt es, dass diejenigen, die schon am meisten haben, das Doppelte begehren (Fr. 13,72f. WEST): oî $\gamma \dot{\alpha} \varrho$ vĩv $\dot{\eta} \mu\langle\dot{\varepsilon} \omega\rangle \nu \pi \lambda \varepsilon \tilde{\imath} \sigma \tau$ tov $\varepsilon^{\prime} \chi 0 v \sigma \iota$

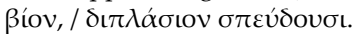

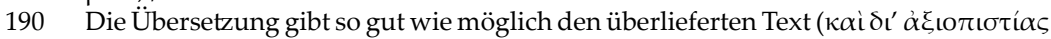

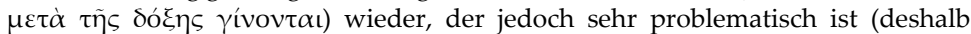
hier auch in Cruces gesetzt wurde) und eine Reihe von Verbesserungsvorschlägen hervorgerufen hat, die jedoch alle nicht überzeugen können (MARAN: Kä̀ $\delta \iota^{\prime}$

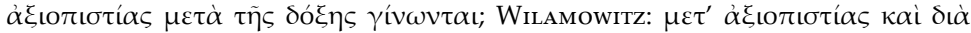

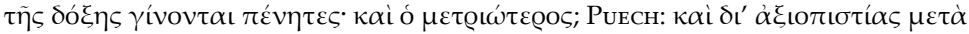

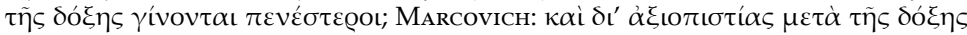

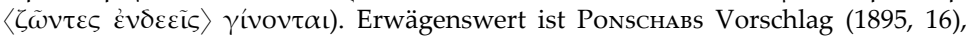

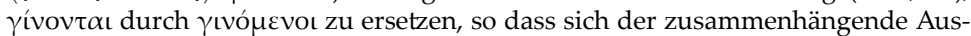

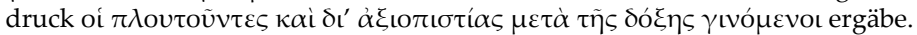

191 Tatian gibt zu verstehen, dass die die Menschen plagenden Begierden (darunter auch die Habgier) eine Folgeerscheinung der von den Dämonen kreierten Heimarmene ( $\left.\kappa \alpha \theta^{\prime} \varepsilon \dot{\varepsilon} \mu \alpha \varrho \mu \varepsilon ́ v \eta v\right)$ sind; sagt man sich von dieser frei, kann man sich auch von den Begierden befreien. - Den schlaflosen Habgierigen / Geizigen karikiert sehr plastisch Lukian in seinem Gallus (29f.).

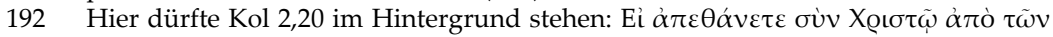

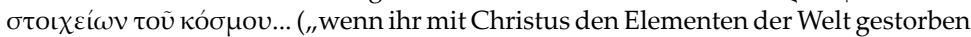

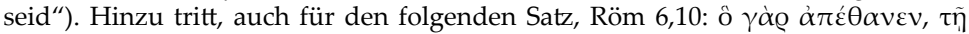

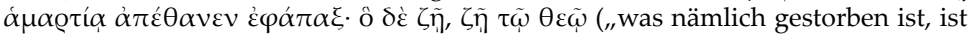
ein für allemal der Sünde gestorben; was aber lebt, lebt für Gott").

193 Die $\pi \alpha \lambda \alpha \iota \dot{\alpha} \gamma \varepsilon \dot{v} v \varepsilon \sigma \iota \varsigma$ lässt an Röm 6,6, Eph 4,22 (wo jeweils vom $\pi \alpha \lambda \alpha$ ıò $\alpha \ddot{v} \theta \varrho \omega \pi 0 \varsigma$ die Rede ist) denken.

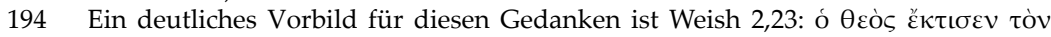

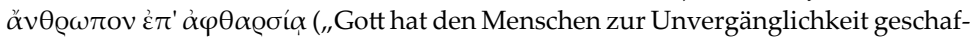
fen").

195 Mit der „Freiheit" ( von Gott gemeint, der in 7,4 geschildert wurde (in 7,2 und 7,3 war ebenfalls vom

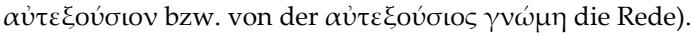

196 Etwas anders pointiert („,unter die Sünde verkauft“), aber jedenfalls Inspiration für

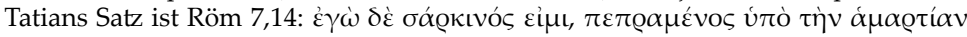
(„,ich aber bin aus Fleisch, verkauft unter die Sünde“).

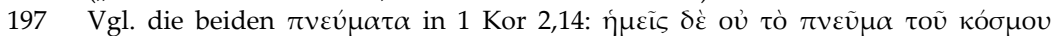

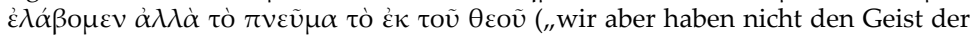
Welt empfangen, sondern den Geist, der von Gott stammt ${ }^{\prime \prime}$ ).

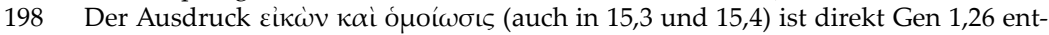
nommen, wo Gott den Beschluss fasst, den Menschen zu erschaffen (Поэฑ $\sigma \omega \mu \varepsilon v$ 


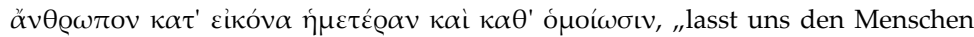
schaffen nach unserem Bild und Gleichnis“").

199 Zur creatio ex nihilo der Materie vgl. oben 5,7 mit Anm. 84.

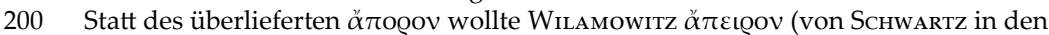
Text aufgenommen) und Schwartz (S. VIII in seiner Praefatio) ă totov lesen (von Puech 1903, 123 befürwortet und von Marcovich übernommen). Für die Junktur von beiden Vorschlägen mit $\alpha \sigma \chi \eta \mu \alpha ́ \tau \tau$ $\sigma \tau o v$ in Bezug auf die Materie gibt es Belege:

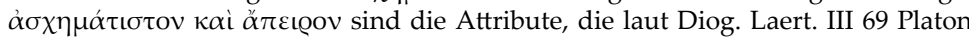
der Materie gibt; dagegen soll Platon laut Aëtios, Plac. 308,5-7 Diels die Materie

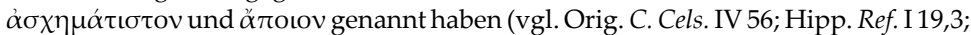
V 17,2). Doch scheint auch das für Tatian überlieferte $\alpha$ żo@ov durchaus einen Sinn zu ergeben (die Materie ist "hilflos“, weil sie völlig passiv ist und eines formenden Gestalters bedarf) und braucht deshalb nicht geändert zu werden.

201 Für die "zweite Stufe der Schöpfung", die Ordnung und Gestaltung der vorher indiskreten und gestaltlosen Materie, ist laut 5,6 der Logos verantwortlich.

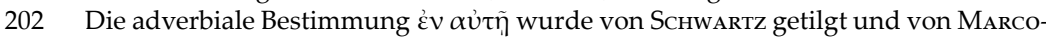

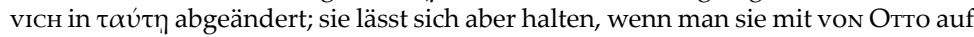

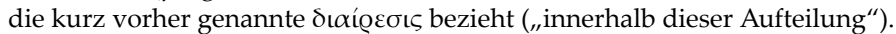

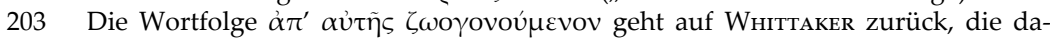
mit eine Konjektur von Schwartz teilweise aufnimmt (überliefert ist $\dot{\alpha} \pi^{\prime} \alpha \hat{\tau} \tilde{\eta} \varsigma$

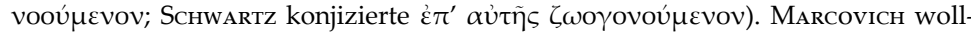

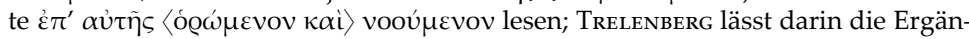

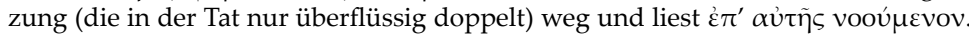
Vielleicht könnte man die Tilgung der Präposition erwägen und einfach $\alpha \hat{v} \tau \tilde{\eta} \varsigma$ vooú $\mu \varepsilon v o v$ lesen (vgl. HARNACKs Übersetzung: „was zu ihr gehört“); möglicherweise hat auch Di CRISTINA den Text so gedeutet (,,tutto ciò che conosciamo di essa [scil. della terra]").

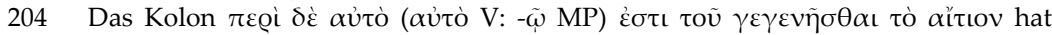
Puech 1903, 124 zu Recht als „phrase ... très obscure“ bezeichnet, und dies bildet sich auch in den Übersetzungen ab (GESNER: „Quemadmodum enim corporis animalis constitutio, unius gubernationis est, et ad unum finem, cuius gratia genitum est, refertur"; vом Отто: "Quemadmodum enim corporis constitutio unius est descriptionis, et circa illud versatur nascendi causa"; HARNACK: „Wie nämlich der Leib einheitlich organisiert ist und diese seine Einheitlichkeit von der Geburt an besteht"; Puech: „,comme la constitution du corps a son unité qui repond à un plan, - c'est là qu'est le principe de son existence - ...“; KuKula: „wie die Zusammensetzung des menschlichen Körpers einheitlich und maßgebend für seine Existenz ist“; FermI: „È come nel corpo umano: vi è in esso un'armonia generale di funzionamento, sulla quale si fonda il principio della vita"; WHITTAKER: "the structure of the body results from a single plan, and the reason for its creation is connected with it"; Di CRISTINA: „Come infatti la struttura del corpo obbedisce a un unico piano - il che è determinante per il venire all'esistenza“; TrelenberG: „wie nämlich der Bau des menschlichen Körpers einen einheitlichen Plan besitzt, welcher für die Existenz desselben ursächlich und maßgebend ist"). Wenn der überlieferte Text gehalten werden soll (SchwARTz' sehr starker Eingriff ist nicht überzeugend und auch die weniger star-

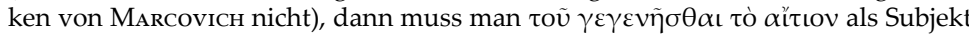
des Kolons auffassen und kann $\pi \varepsilon \varrho i$... $\alpha$ ủंó nur auf den voranstehend erwähnten Körper $(\sigma \tilde{\omega} \mu \alpha)$ beziehen. Dann ist hier gesagt, dass der Körper in seinem Zusammenhalt den Grund dafür bildet, dass er so geworden ist, wie er ist, und seine einzelnen Teile einem einheitlichen Plan unterworfen sind.

Elze 1960, 87 schlug vor, $\pi v \varepsilon \tilde{v} \mu \alpha$ anstelle von $\pi \varepsilon$ Qí zu lesen, was Di CRISTINA „,allettante" findet, der freilich seinerseits das konjizierte $\pi v \varepsilon \tilde{v} \mu \alpha$ durch $\psi v \chi \eta \dot{~ e r s e t z e n ~}$ 
möchte und dann versteht: „Come infatti la struttura del corpo obbedisce a un unico piano, ed è l'anima la sua ragion d'essere ..."

205 Eine ähnliche Analogie zwischen den Gliedern eines einzelnen Körpers und den

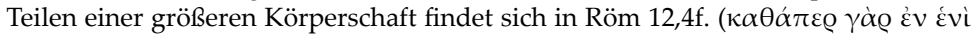

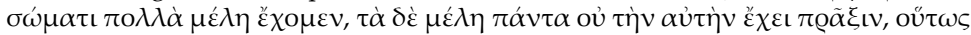

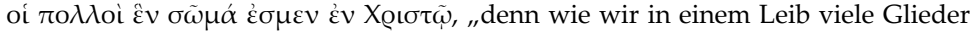
haben, die Glieder aber alle nicht die gleiche Tätigkeit haben, so sind wir vielen ein Leib in Christus"; vgl. 1 Kor 12,12). Freilich geht Tatians Gedanke noch weiter und setzt die Ordnung des Mikrokosmos im menschlichen Körper gleich mit der des Makrokosmos der großen Welt. Vgl. zu dieser Denkfigur A. Meyer, Wesen und Geschichte der Theorie vom Mikro- und Makrokosmos, Diss. (Bern 1900): Erste Spuren finden sich bereits bei den Vorsokratikern (4-15; vgl. vor allem Demokrit, 68 B 34 DK:

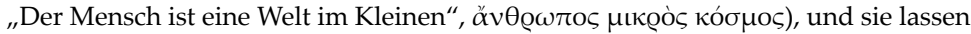
sich über Platon (18-24), Aristoteles (26-30), die Stoiker (31-35) und die Neupythagoreer (36-38) bis in die Kaiserzeit verfolgen (38-45). Zum Beitrag der Medizin in dieser Diskussion F. LE BLAY, „Microcosm and Macrocosm: The dual direction of analogy in Hippocratic thought and the meteorological tradition", in: P. VAN DER EIJK (Hg.), Hippocrates in Context (Leiden / Boston 2005) 251-269. Ferner: G. LANCZKOWSKI / W. JANKE / G. SiegmanN, „Makrokosmos/Mikrokosmos“, in: TRE 21 (1991) [745-754] 748-750, sowie M. Gatzemeier, „Makrokosmos/Mikrokosmos. I. Antike und Mittelalter", in: HWPh 5 (1980) 640-643.

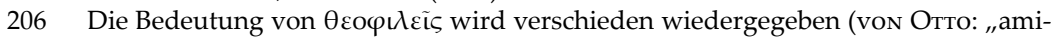
cos deo“; Harnack und Kukula: „Freunde Gottes“; Whittaker: „lovers of God“; TreLEnBERG: „Gottesverehrer"). Die häufigere und ältere Bedeutung (vgl. LSJ s. v. $\theta \varepsilon o \varphi \iota \lambda \eta ́ \varsigma$ I) ist die passive („,dem Gott lieb / von Gott geliebt“).

207 Statt des überlieferten ö $\mu \omega \varsigma$ hat KuкULA ó $\mu \tilde{\omega} \varsigma$ konjiziert (Marcovich präferiert das von de ZwaAn konjizierte ó $\mu\langle$ ó́ $\rangle \omega \varsigma$ mit dem gleichen Sinn).

208 Damit spielt Tatian darauf an, dass im Griechischen $\delta \alpha i ́ \mu \omega v$ seit jeher (vgl. bereits z.B. Hom. Il. I 222) ein Synonym für $\theta \varepsilon$ có ist (oder zumindest sein kann).

209 Die „spirituelle Konstitution“ der Dämonen ist also grundsätzlich die gleiche wie die der Menschen; sie sind ja auch beide (die Dämonen als frühere Engel) Geschöpfe des Logos (vgl. oben 7,2).

210 Bemerkenswerterweise differenziert Tatian bei den Dämonen zwischen mehr und weniger Materie-Orientierten; dafür gibt es Parallelen in paganer Dämonologie: Schon der Platoniker Xenokrates (bei Plut. De Is. 25, 360E) unterschied verschiedene Grade von Tugend und Laster bei den Dämonen, und Reflexe einer solchen differenzierenden Dämonen-Lehre finden sich auch im Timaios-Kommentar des Calcidius (Kap. 133 und 135; vgl. Dillon 2004, 130 und 140).

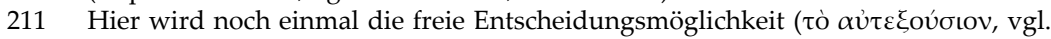
oben 11,4 mit Anm. 195 sowie 7,2f.) betont, die die Dämonen aufgrund ihrer Dummheit $\left(\dot{\alpha} \beta \varepsilon \lambda \tau \varepsilon Q \alpha_{1} \alpha\right.$, so auch schon 7,5$)$ zu ihrem eigenen Verderben ausgeübt haben.

212 Vgl. 7,4f.; doch während dort nur davon die Rede ist, dass der rebellierende „Erstgeborene" der Engel sich zum Gott erklären lässt, wird hier allen abgefallenen Engeln (= Dämonen) die Begierde zugeschrieben, göttlichen Status zu beanspruchen - womit sie bei den Menschen, die sie als Götter verehren, ja auch Erfolg haben.

213 Statt des überlieferten $\dot{\varepsilon} \varphi$ lé $\mu \varepsilon v o t$ hat Schwartz $\dot{\alpha} \varphi$ lé $\mu \varepsilon v o l$ konjiziert. WhitTaker und TreLENBERG versuchen das Überlieferte zu halten, zeigen aber durch ihre Übersetzung, dass das nicht gut aufgeht (WHITTAKER: ,,who through the demons' revolt long for knowledge of the perfect god" - aber die "demons' revolt" hat die Menschen doch gerade von Gott abgebracht; Di CRISTINA: "gli uomini che in mezzo alla

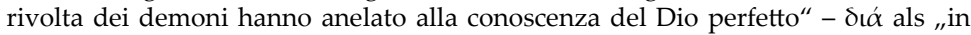
mezzo“?; Trelenberg: "die während des Aufstands der Dämonen dennoch nach der Erkenntnis des vollkommenen Gottes strebten" (so auch bereits FERMI) - aber 
weder „während“ noch „dennoch" sind durch den griechischen Wortlaut gedeckt).

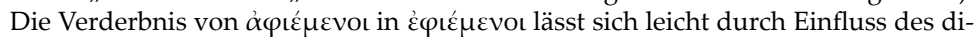

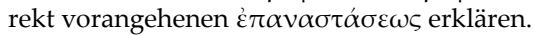

214 Die Vorstellung von einem alles durchwaltenden $\pi v \varepsilon \tilde{v} \mu \alpha$ erinnert an die Stoa, doch ist das hier von Tatian gemeinte von deutlich niedrigerer Natur als das stoische.

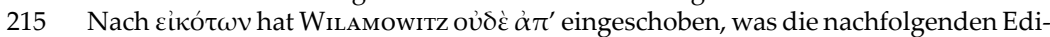

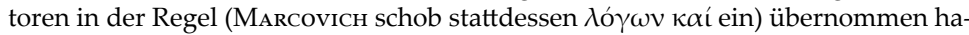

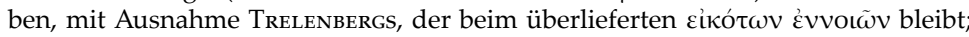
dies geht jedoch schon sprachlich nicht, weil das Attribut beim Femininum $\varepsilon v v$ vot $\tilde{v} v$

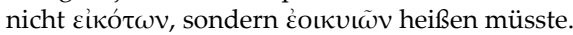

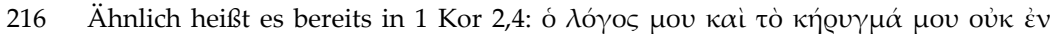

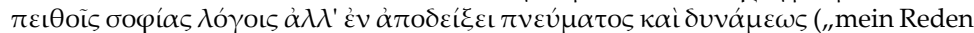
und meine Verkündigung liegen nicht in plausiblen Worten menschlicher Weisheit, sondern in der Darlegung des Geistes und der Kraft [scil. Gottes]“).

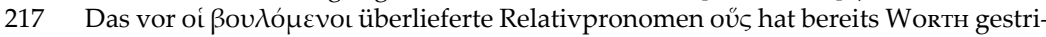
chen, weil diese Satzperiode sonst gar keinen Hauptsatz hätte, und alle neueren Editoren sind ihm gefolgt, mit Ausnahme Trelenbergs, der es jedoch bezeichnenderweise nicht übersetzt.

218 Der Skythe Anacharsis (erwähnt zuerst bei Herodot IV 46,1 und IV 76f.) avancierte in der griechischen Überlieferung zum Muster eines „Barbaren“, der sich griechische Kultur aneignete (er soll zur Zeit Solons nach Athen gekommen sein: Diog. Laert. I 101f.) und den Griechen als ebenbürtig erwies. Diverse Autoren rechneten ihn zu den Sieben Weisen (vgl. Diog. Laert. I 13; 41f.), und Diogenes Laertios widmete ihm in seiner Philosophiegeschichte einen eigenen Abschnitt (I 101-105) zwischen den zu den Sieben Weisen gerechneten Griechen Periander und Myson. Die Reputation des Anacharsis zur Zeit der Zweiten Sophistik zeigt vielleicht am besten Lukians Dialog Anacharsis oder: Über die Wettkampfstätten, in dem Anacharsis im Gespräch mit Solon ein zentrales Phänomen der griechischen Kultur (die sportlichen Wettkämpfe) einer geistreichen Kritik unterzieht und sich dabei seinem Gegenüber Solon als völlig ebenbürtig erweist.

219 Ein Hinweis auf die Popularität der aus Babylonien stammenden „chaldäischen" Astrologie im griechisch-römischen Mittelmeerraum (vgl. Diod. II 29,2; 31,8; Strab. XVII 1,29; Sext. Math. V 2).

220 Gemeint ist die Orakeleiche von Dodona, die zum ersten Mal in der Odyssee erwähnt wird (Od. XIV 327-330 = XIX 296-299; in Il. XVI 233-235 ist zwar von Dodona, aber noch nicht von der Eiche die Rede).

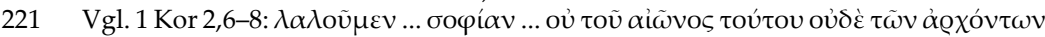

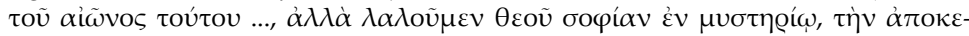

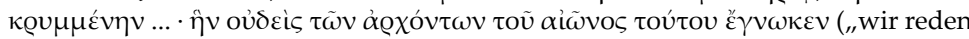
... Weisheit ... nicht dieser Welt und auch nicht die der Herrschenden dieser Welt ..., sondern wir reden Gottes Weisheit im Mysterium, die verborgene ...; welche niemand von den Herrschenden dieser Welt erkannt hat"). Ferner Justin, 2 Apol. 15,3:

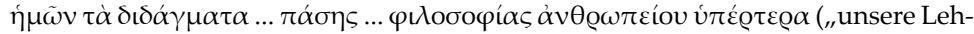
ren ... stehen höher als jede menschliche Philosophie“).

222 Mit dieser Aussage widerspricht Tatian einem zentralen Postulat platonischer und pythagoreischer Philosophie (außer den einschlägigen Partien in Platons Phaidon, Phaidros und Menon vgl. Diog. Laert. III 67 [Referat über Platon], VIII 28 [Referat über Pythagoreer], Clem. Alex. Strom. VI 27,2: die Lehre über die Unsterblichkeit der Seele kam von den Ägyptern über Pythagoras zu Platon).

$223 \mathrm{Zu}$ dieser paradoxen These, dass die Seele nicht unsterblich ist, aber den endgültigen Tod vermeiden kann, ,wenn sie sich die Erkenntnis Gottes zueigen gemacht hat", vgl. Theophil. Autol. II 27: „Weder nun hat Gott ihn [scil. den Menschen] unsterblich gemacht noch sterblich, sondern ... fähig, beides zu empfangen, damit er, 
wenn er das Gebot Gottes beachtet und sich den Dingen der Unsterblichkeit zuneigt, als Lohn von ihm die Unsterblichkeit empfängt und zum Gott wird, wenn er aber andererseits sich den Werken des Todes zuwendet und Gott missachtet,

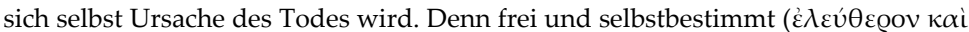

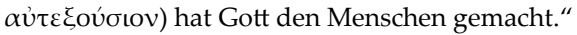

224 Vgl. oben 6,1 („nachdem ein einziges Mal die uns betreffenden Zeitläufte vollständig vollendet sind“) und 12,7 („bis der Kosmos sein Ende nimmt, aufgelöst wird und der Richter sich einfindet").

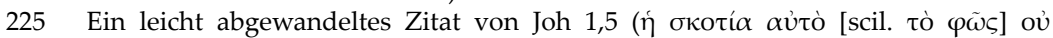
$\kappa \alpha \tau \varepsilon ́ \lambda \alpha \beta \varepsilon v$, „die Dunkelheit aber hat es [= das Licht] nicht ergriffen“).

226 Das $\pi v \varepsilon \tilde{v} \mu \alpha$, von dem hier (und in 13,4) die Rede ist, ist das "göttliche" (vgl. $\theta \varepsilon i ́ o v$ $\pi v \varepsilon v ́ \mu \alpha \tau o \varsigma$ in 13,3 und die Unterscheidung der beiden $\pi v \varepsilon v ́ \mu \alpha \tau \alpha$ in 12,1), während Tatian in 12,3 und 12,5 vom $\pi v \varepsilon \tilde{v} \mu \alpha$ ú $\lambda$ เкóv spricht, das den Kosmos durchwaltet (vgl. auch 12,8: es ist in allen Wesen des Kosmos, auch in den Menschen) und an dem auch die Dämonen Anteil haben. In 12,1 hat Tatian das niedere $\pi v \varepsilon \tilde{v} \mu \alpha$ direkt als „Seele“ ( $\psi v \chi \eta ́)$ bezeichnet, wozu seine hier gemachte Gegenüberstellung zwischen $\psi v \chi \eta ́$ und (höherem) $\pi v \varepsilon \tilde{v} \mu \alpha$ passt.

227 Auch die Verbindung von Logos und Licht erinnert an den Prolog des JohannesEvangeliums, wobei die Verbindung dort (Joh 1,3f.) über mehr Stationen stattfindet als hier.

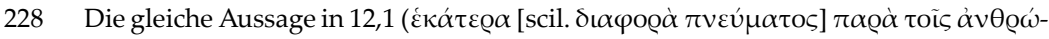

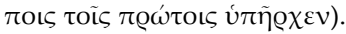

229 Tatian muss hier einen gewissen Widerspruch in Kauf nehmen (obwohl der göttliche Geist die menschliche Seele verlassen hat, da sie ihm nicht folgen wollte - vgl. oben 7,4 -, ist ein Funke dieses Geistes in ihr verblieben), um die Entstehung des Glaubens an viele Götter (die Dämonen) statt des einen Gottes zu erklären.

230 An dieser Stelle behält TRELENBERG zwar zu Recht das überlieferte $\kappa \alpha \tau \alpha \gamma o ́ \mu \varepsilon v o v$ im Text (für das die Bedeutungen „einkehren bei / Wohnstatt nehmen bei“ gut belegt sind; vgl. Nesselrath 2005, 251); die von Schwartz in den Text gesetzte Konjek-

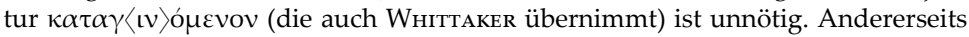

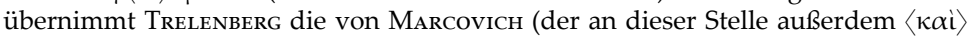
$\kappa \alpha \tau \alpha \gamma\langle\iota v\rangle$ ó $\mu \varepsilon v o v$ lesen wollte) eingeführte Satzpause vor $\kappa \alpha \tau \alpha \gamma o ́ \mu \varepsilon v o v$, obwohl der Satz viel besser und völlig glatt einfach durchläuft.

231 Der Satz erklärt das Auftreten von Propheten Gottes unter den Menschen. Vgl. Theophil. Autol. II 10: „Dieser also [scil. der Logos als ,Gehilfe' Gottes], der ,Geist

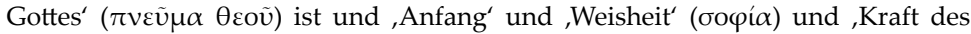
Höchsten', kam herab auf die Propheten und legte durch sie die Verhältnisse über die Erschaffung der Welt und aller übrigen Dinge dar."

232 Die Verbindung von Weisheit und göttlichem Geist lässt an Vorstellungen der Sapientia Salomonis denken; vgl. dort 7,7-15.24-28; 8,3f.21-9,4; 10. Bei anderen Apologeten nimmt die Sophia in der göttlichen Trinität die Stelle des Heiligen Geistes ein

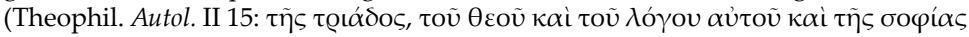

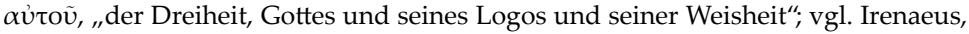
Adv. haer. IV 7,4).

233 Als „Diener des Gottes, der gelitten hat" wird hier offenbar das gleiche verstanden wie die Weisheit im vorangehenden Satz; dann ließe sich auch bei diesem Diener an den Heiligen Geist denken (vgl. von Отто und Di Cristina ad loc.). - „Der Gott, der gelitten hat" ist eine der wenigen Anspielungen Tatians auf das irdische Leben Christi (vgl. 21,1).

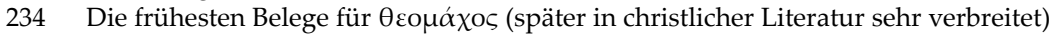
finden sich in Ps.-Skymnos, Ad Nicom. Reg. 637 (späteres 2. Jh. v. Chr.), bei dem Stoiker Herakleitos, Hom. Alleg. I 2 (um 100 n. Chr.) und im Neuen Testament (Apg 5,39). 
235 Der Begriff „Vielherrschaft" ( schen Form belassen) spielt auf eine berühmte Sentenz in der Ilias an (II 204: „Nicht etwas Gutes ist die Vielherrschaft!") und macht die Pointe, dass die Griechen mit ihrem Polytheismus diese Sentenz gerade nicht beherzigt haben.

236 Seit von Otтo verweisen alle Kommentatoren zu dieser Stelle auf Mt 12,29 (TrelenBERG auf die gesamte Partie 12,22-30), wo Jesus die Vorwürfe der Pharisäer, er treibe Dämonen im Namen Beelzebubs aus, zurückweist und danach mit dem Gleichnis,

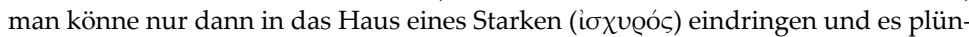
dern, wenn man den Starken fessele, antwortet und damit darauf hinweist, dass er mit seiner Dämonenaustreibung auf jeden Fall gegen solche finsteren Mächte vorgehe. Wenn Tatian bei seinem Satz wirklich an diese Stelle gedacht hat (was mir nicht sicher scheint), dann hat er ihre Aussage deutlich geändert, denn während er den Dämonen nur vermeintliche Stärke zuweist, ist der Dämon in Jesus' Gleichnis tatsächlich íoxv@ós.

237 Vgl. dazu 13,4: "der Geist ... hat sie, da sie ihm nicht folgen wollte, verlassen.“

238 Das vorliegende Satzgefüge enthält mindestens eine größere Störung. SchwarTz

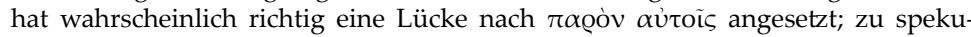
lativ jedoch ist es, zwei Worte vor dieser Lücke mit WiLAmowitz ra@óv durch

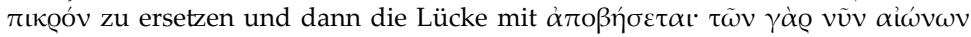
$\pi \alpha \varrho \varepsilon \lambda \eta \lambda v \theta$ ó $\tau \omega \nu$ zu füllen.

Die Versuche, ohne die Annahme einer solchen Lücke auszukommen, schlagen

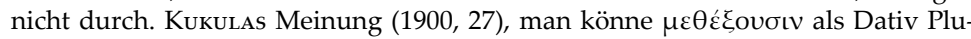
ral eines Partizips auffassen und direkt auf das vorangehende aùtoĩ beziehen,

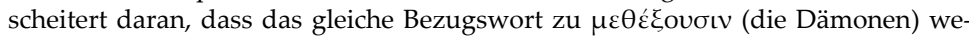

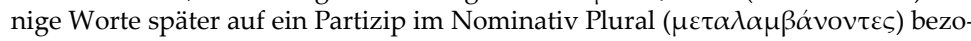
gen werden müsste und damit ein unerträglich hartes Anakoluth ergäbe. Auch die Übersetzungen von WhitTAKer und TreLENBERg zeigen, dass es ohne Lücke nicht geht: WhitTAKer übersetzt etwas, was nicht im Text steht (,instead of death they [i. e. the demons] will receive torment that is deathless" - von "torment" steht nichts im Text), und TRELENBERG produziert einen inhärenten Widerspruch („So kommt es, dass das, was sie [= die Dämonen] ihnen [= den Menschen] momentan voraushaben, nämlich nicht wie die Menschen zu sterben, ihnen dereinst zustößt" - d.h. weiterhin „nicht wie die Menschen zu sterben“? dies wäre jedenfalls die aus dem Vorangehenden zu folgernde Implikation; aber der weitere Text sagt genau das Gegenteil).

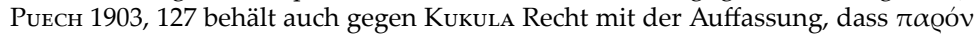

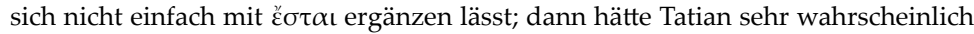
einfach $\pi \alpha \varrho \varepsilon ́ \sigma \tau \alpha$ เ geschrieben. PUeCh dürfte ferner Recht damit haben, dass $\pi \alpha \varrho o ́ v$ ein Partizip im Akkusativ Absolutus (wie ċłóv) darstellt; doch ist auf $\pi \alpha \varrho o ́ v ~ n i c h t$ notwendig das ó $\pi$ ó $\alpha v$ vorangehende $\tau o \tilde{~} \theta^{\prime}$ zu beziehen; vielmehr ist die Ergänzung von $\pi \alpha$ @óv wahrscheinlich in der Lücke verschwunden.

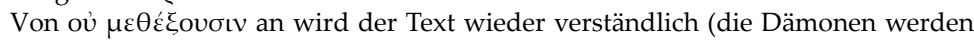
keinen Anteil am ewigen Leben haben), doch ist hier wahrscheinlich noch ein kleinerer Eingriff vorzunehmen, weil dem Partizip $\mu \varepsilon \tau \alpha \lambda \alpha \mu \beta \alpha ́ v$ ov $\tau \varepsilon \varsigma$ sonst die notwendige Ergänzung fehlt. Bereits Harnack (dem Trelenberg folgt) hatte vorge-

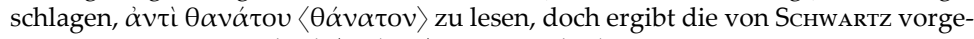

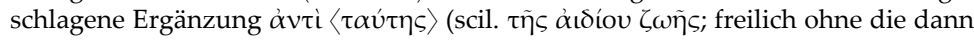
von ihm vorgenommene Wort-Umstellung) einen pointierteren Gegensatz: Statt ewigen Lebens erhalten die Dämonen einen ewigen Tod.

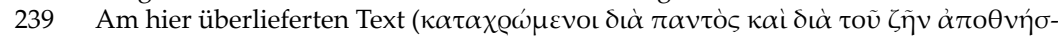

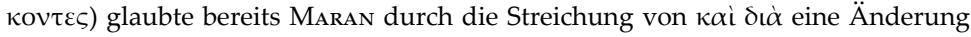

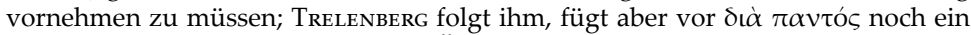

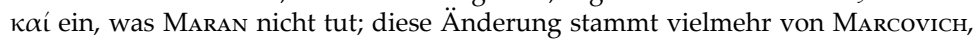




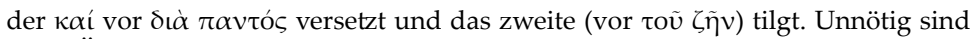
beide Änderungsvorschläge.

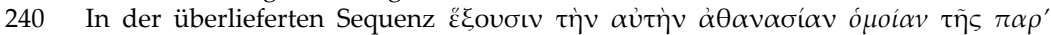

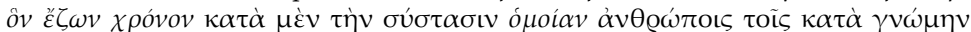

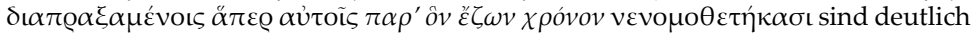
Doppelungen erkennbar (hier kursiv hervorgehoben). Die Stelle hat nicht überraschend eine Reihe von Änderungsvorschlägen hervorgerufen: SchwARTz wollte

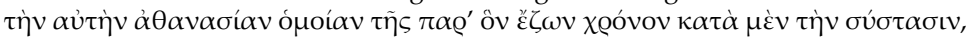

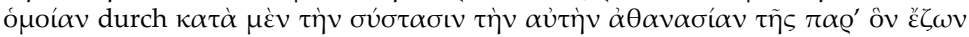

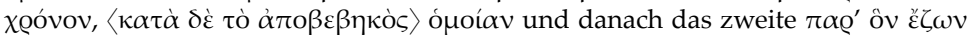

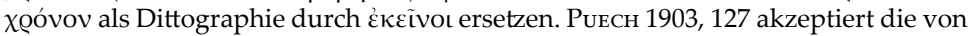

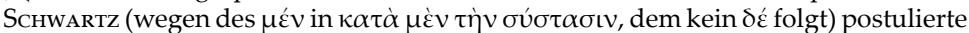
Lücke (die Kukula 1900, 28 abgelehnt hatte) und nimmt an, dass nach dem zweiten ó $\mu$ oí $\alpha v$ noch eine Zeile ausgefallen ist, die er exempli gratia folgendermaßen

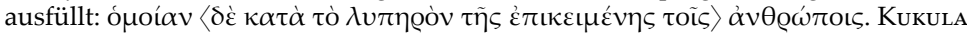

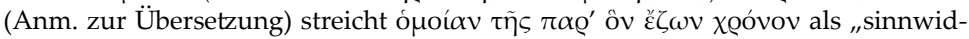

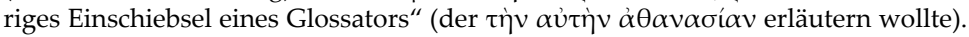
WhitTAKer bleibt beim überlieferten Wortlaut. Marcovich übernimmt KuKUlas

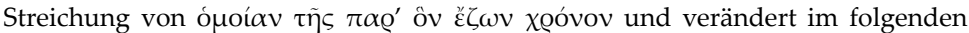

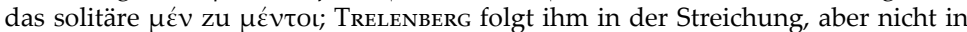
der Änderung von $\mu \varepsilon ́ v$, das er als explikatives „und zwar" verstehen möchte (was nirgends belegt ist). Der hier vorgelegte Text kommt mit der von KuKula vorgeschlagenen Streichung und einer kleinen, leicht durch Haplographie begründbaren

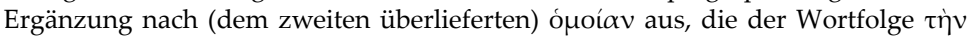

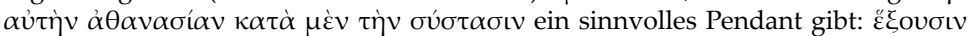

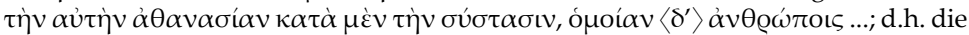
Dämonen und die Menschen, die ihnen freiwillig folgten, werden eine vergleichbare ewige Bestrafung erleiden.

241 Die Ergänzung von $\mu \varepsilon ́ v$ nach toĩ n nahm bereits GeSNER vor, die Änderung des zweiten toís in $\langle\alpha \hat{u}\rangle$ toĩ SCHWARTz.

242 Die Ansicht, dass die Seele mehrteilig sei, findet sich bereits bei Platon (vgl. das Bild vom Wagenlenker und seinem Rossegespann in Phaidr. 246a-b), dann auch bei den Stoikern (SVF II 824; Tert. De an. 14,2). Vgl. auch Tatians ungefähren Zeitgenossen Maximos von Tyros (Dial. 11,7a) und als spätantiken Zeugen für die Auffassungen Platons und der Stoiker Themistios (In Arist. de an. paraphr. 3,13-15 Heinze).

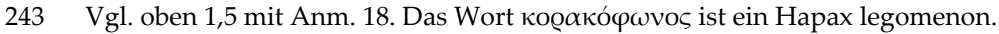

244 Eine weitverbreitete antike Definition des Menschen, die außer hier bei Tatian erstmals in den pseudogalenischen Definitiones medicae (XIX, 355,7f. KüHN) und mehrfach bei Sextus Empiricus (z.B. Pyrrh. Hyp. II 26; Math. VII 269) zu finden ist.

245 Dies gegen stoische Auffassungen (die nur Menschen und Göttern Vorhandensein und Gebrauch des Logos zubilligen; vgl. WILDBERGER 2006, 254-257) zu zeigen, ist etwa ein Anliegen von Plutarchs Schriften Welche von den Tieren sind klüger, Land-

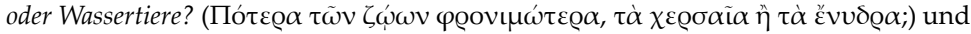

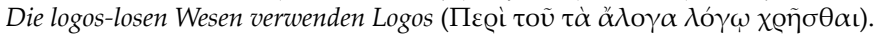

246 Vgl. oben 12,1 mit Anm. 198.

$247 \mathrm{Zu}$ diesem und anderen von Tatian nicht erhaltenen Werken vgl. die Einführung, oben S. 7.

248 Als „unvergleichbar“ wird Gott bereits bei Philon bezeichnet (Fug. 141: $\tau$ oṽ $\tau \tilde{\omega} v$

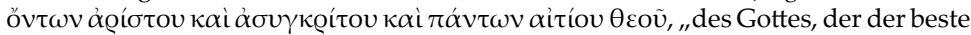
der Seienden und unvergleichbar und Urheber von allem ist"; vgl. Mut. nom. 3: tò

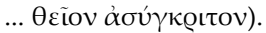

249 „Das Seiende selbst“ („ipsum ens“ bei Worth und von Отто; nicht „das Sein“ oder "l'être“, wie Harnack, Puech und Trelenberg übersetzen), eine deutlich platonisie- 
rende Formulierung (vgl. Plat. Rep. VII 537d) ist Gott (vgl. Clem. Alex. Strom. V 82,1:

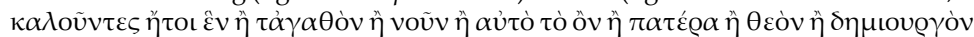

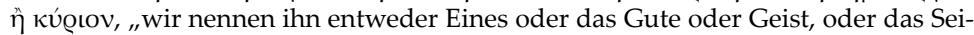
ende selbst oder Vater oder Gott oder Schöpfer oder Herrn“). In der Septuaginta

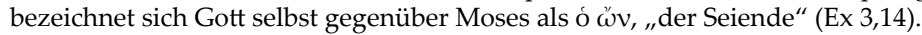

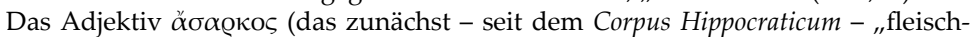
los" im Sinne von "mager" bedeutet) wird im Sinne von „unkörperlich“ offenbar erstmals von Philon verwendet (hier aber noch meist im Verbund mit $\alpha \sigma \omega \mu \alpha \tau o s:$ Gig. 31; Ebr. 87; Fug. 59). Möglicherweise ist Tatian der erste, der das sehr plastische Wort („,unfleischlich“) auf Gott bezieht. Dass Gott $\dot{\alpha} \sigma \omega \dot{\mu} \alpha \tau \tau$ to ist, ist alte philosophische Lehre (vgl. Clem. Alex. Strom V 109,1 = Xenophanes, 21 B 23 DK zu Xenophanes; Diog. Laert. III 77 zu Platon, V 32 zu Aristoteles), während die Stoiker Gott einen Körper zugewiesen hatten (SVF I 153; vgl. Plut. Comm. not. 48, 1085C; Sext. Pyrrh. Hyp. III 218).

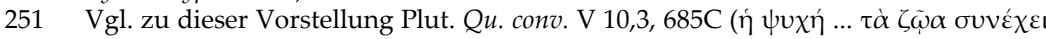

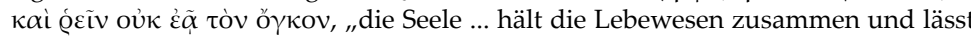
ihre Körpermasse nicht zerfließen“), nicht dagegen die von TRELENBERG angegebene Stelle Plat. Phaid. 99c, wo von einer den Körper zusammenhaltenden Seele nicht die Rede ist.

252 Zu der unterstützenden Rolle des Fleisches für das Handeln des Menschen vgl. Plat.

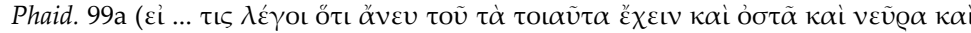

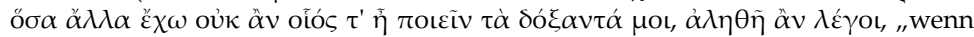
jemand sagte, dass ich, ohne solches zu haben und Knochen und Sehnen und alles andere, was ich habe, nicht in der Lage wäre zu tun, was mir gut scheint, würde er wohl die Wahrheit sagen").

253 Die Tempelvorstellung ist mehrfach in den Briefen des Neuen Testaments zu finden;

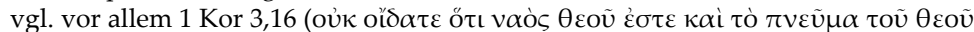

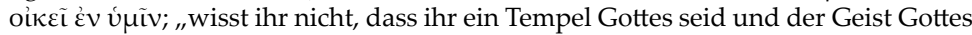

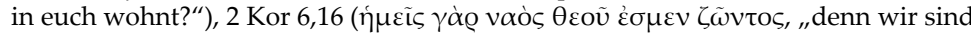
ein Tempel des lebendigen Gottes").

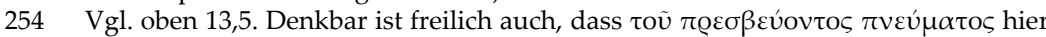

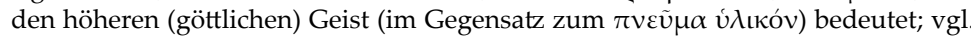

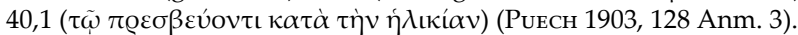

255 Der Gebrauch von $\sigma \kappa \eta ́ v \omega \mu \alpha$ (,"Zelt des Körpers“) erinnert an 2 Petr 1,13.

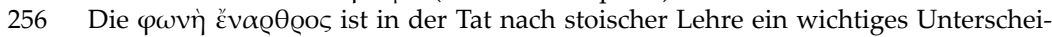
dungsmerkmal des Menschen vom Tier (SVF III 17 = Diog. Laert VII 55; vgl. Phil.

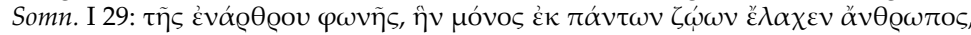
"der artikulierten Stimme, welche allein der Mensch von allen Lebewesen erlangt hat"; Ael. Nat. IV 46).

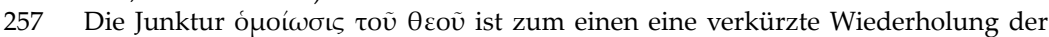

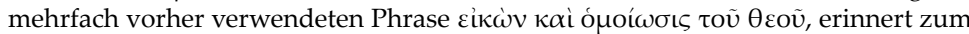
anderen aber auch an das, was in platonischer Philosophie als ein Telos des Men-

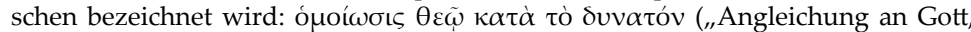

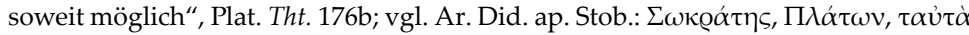

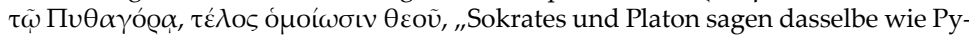

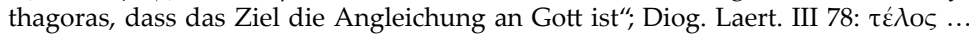

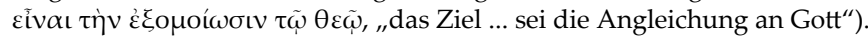

258 Vgl. oben 14,3 („, sie haben ... keinen Anteil am Fleisch“).

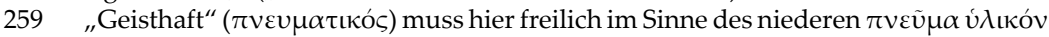
gemeint sein (vgl. oben 12,5), sonst hätten die Dämonen - da sie ebenfalls ohne Fleisch sind - die gleiche Konstitution wie der wahre Gott. Vgl. auch unten 15,8: "Denn sie sind (nur) Ausstrahlungen von Materie und Schlechtigkeit." 
260 Gemeint sind die Menschen, die das höhere $\pi v \varepsilon \tilde{v} \mu \alpha$ verlassen hat; vgl. oben

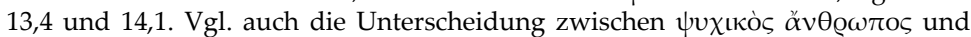

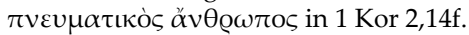

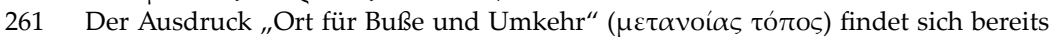
in Weish 12,10 und in Hebr 12,17.

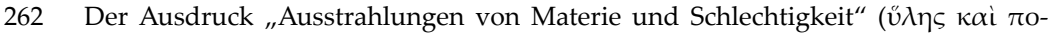

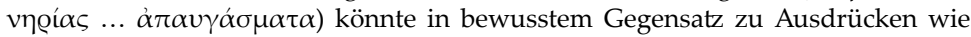

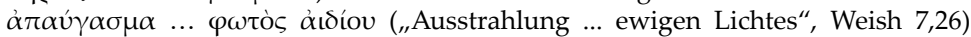

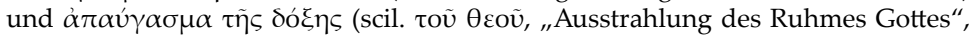
Hebr 1,3) gewählt sein.

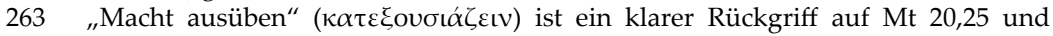
Mk 10,42, denn das Verb ist sonst vor Tatian nicht belegt.

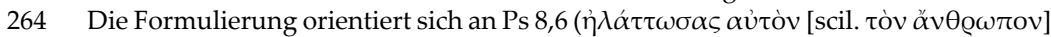

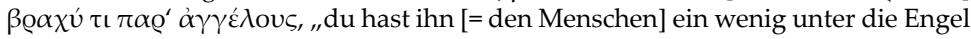
gesetzt"), was in Hebr 2,7 zitiert ist.

265 Die von WоRтн vorgeschlagene Änderung des einhellig überlieferten $\pi \alpha \varrho \alpha t-$

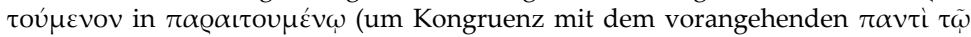

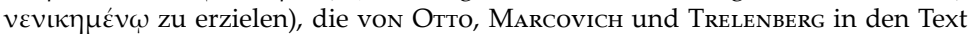
aufnehmen, ist unnötig, da sich $\pi \alpha \varrho \alpha ı \tau o u ́ \mu \varepsilon v o v$ als auf einen gedachten Subjektsakkusativ zu vıкã $v$ bezogen verstehen lässt.

266 Die hier erwähnten „,anderen Darlegungen“ sind nicht erhalten (vgl. oben Einführung, S. 8).

267 Dass die Seele sich erst dann richtig entfalten kann, wenn sie nicht mehr im Körper steckt, ist freilich schon eine bei Platon vertretene Auffassung (Phaid. 66b-68b).

268 Vgl. oben 13,3: Die Menschenseele „strebt ..., wenn sie allein ihr Leben verbringt, abwärts zur Materie“.

269 Die Editoren sind sich einig, dass hier das substantivische Bezugswort zu $\dot{\alpha} \pi \alpha \theta \alpha$ -

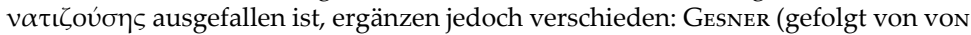

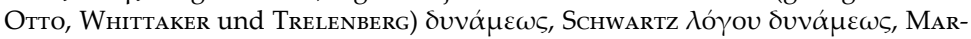

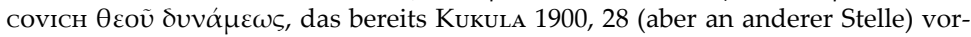

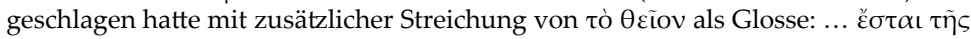

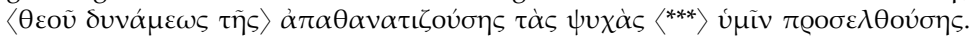

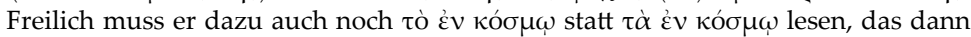

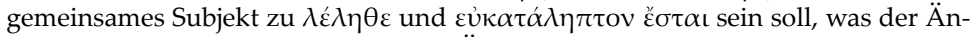
derungen doch etwas viel ist. In seiner Übersetzung will KuKuLA offenbar nur noch

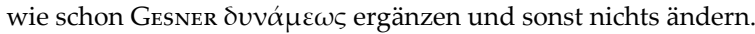

270 Damit korrigiert Tatian die in 15,7 gemachte Aussage, dass die $\psi v \chi$ Łкoí die Dämonen nicht erblicken können; diese können, wenn sie es wollen, sich aus den im Text genannten Gründen zeigen.

271 Die Metaphorik der geistlichen Waffenrüstung ist in mehreren Paulus-Briefen vor-

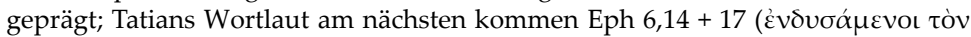

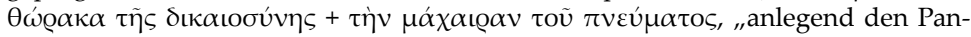
zer der Gerechtigkeit / (aufnehmend) das Schwert des Geistes") und 1 Thess 5,8

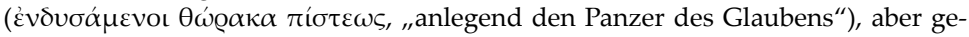
nauere Entsprechungen als die zitierten finden sich nicht.

272 Es geht um Exorzismus, vgl. Justin, 2 Apol. 6,6; Dial. 30,3; 85,2.

273 Hinter dem hier genannten Demokrit verbirgt sich in Wahrheit ein Autor namens Bolos von Mendes (3. oder 2. Jh. v. Chr., vgl. Suda $\beta 481$ und 482; in 481 wird

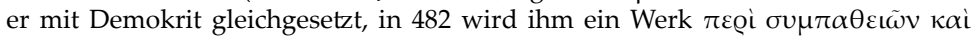

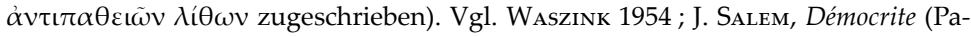
ris 2002) 366-368.

274 Demokrit stammte aus Abdera (einer griechischen Stadt an der Nordküste der Ägäis), und die Abderiten waren schon in der Antike für ihre Einfältigkeit verschrieen 


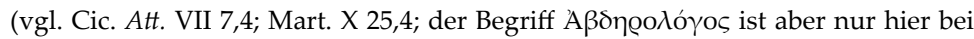
Tatian belegt).

$275 \mathrm{Zu}$ Ehren seines Begleiters Abderos (ein Sohn des Hermes), der von den Rossen des thrakischen Königs Diomedes getötet worden war (die Herakles als seine achte Aufgabe seinem Herrn Eurystheus zu beschaffen hatte), gründete Herakles die Stadt Abdera (vgl. Apollodor, Bibl. II $97=$ II 5,8).

276 Der iranische Magier Ostanes soll zur Zeit des Xerxes die Magie nach Griechenland importiert und unter seinen Schülern auch Demokrit gehabt haben (vgl. Plin. Nat. XXX 8-11). Laut Syncell. Ecl. 297,23-28 Mosshammer (= Demokrit, 68 B 300,16 $D K)$ soll Demokrit in Ägypten auf ihn getroffen sein und sich dort von ihm haben unterrichten lassen (vgl. А. Авт, Die Apologie des Apuleius von Madaura und die antike Zauberei [Gießen 1908] 251; M. Martelli, Pseudo-Democrito. Scritti alchemici [Paris / Milano 2011] 166-172: „Lo Pseudo-Democrito e Ostane“).

277 Vgl. oben 6,1 und 13,1.

278 Eine mögliche, aber nicht zwingende Anspielung auf Demokrit, den „lachenden Philosophen" (vgl. seine Präsentation in Lukians Vitarum Auctio, Kap. 13).

279 „Von der Höhe“ kann auf mehreres anspielen: zum einen auf neutestamentliche Aufforderungen, etwas „,von den Dächern“ zu rufen (Mt 10,27; vgl. bereits Jer 50,2), aber auch auf die gern von Kynikern eingenommene Beobachtungswarte auf einem erhöhten Punkt (Luc. Pisc. 15; vgl. R. Helm, Lucian und Menipp [Leipzig 1906] 90f.). Puech 1903, 130 Anm. 5 hat ferner auf eine Partie des (ps.-?)platonischen Kleitophon hingewiesen, wo Sokrates als ein solch erhöht stehender Rufender vorgestellt wird

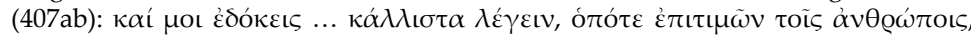
 („und du schienst mir ... wunderschön zu sprechen, als du den Menschen, wie ein Gott auf einer tragischen Bühnenmaschine, Vorhaltungen machtest und hymnisch riefst: ,Wo eilt ihr hin, ihr Menschen?' ...").

280 Gemeint sind Amulette (vgl. z.B. Artemidor, Onirocr. V 26, wo ein Lederamulett mit dem Namen des Sarapis beschrieben ist; Iul. Afr. Cest. I 3 erwähnt in Lederriemen eingewickelte wundertätige Steine).

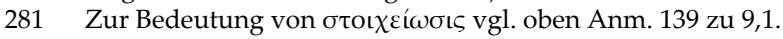

282 Anspielung auf Liebeszauber.

283 Anspielung auf Fluchtäfelchen.

284 Hier treffen sich der Schöpfungsoptimismus der Genesis $(1,31)$ und der heidnischen Philosophie (vgl. z.B. Plat. Tim. 29d; zum Glauben der Stoa an die Vollkommenheit der Welt vgl. Wildberger 2006, 49f.).

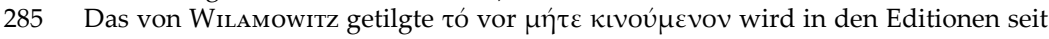
SCHWARTz lediglich von TRELENBERG im Text gehalten.

286 Whittaker und Trelenberg beziehen diese Äußerung auf die Anfänge des christlichen Reliquienkults, und eine (bei von Отто ad loc. zitierte) Randnotiz zu dieser Stelle im Codex P tadelt Tatian dafür, dass er hier gegen die wunderkräftigen

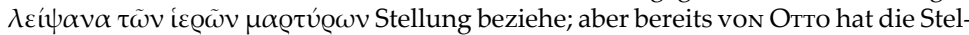
le wahrscheinlich richtiger auf magische (heidnische) Praktiken bezogen, in denen Leichenteile Verstorbener verwendet werden.

287 Anspielung auf den weitverbreiteten Glauben, dass Menschen, die eines gewaltsamen und ungesühnten Todes gestorben waren, in der Nähe ihrer Todesstätte als böse Gespenster verblieben und entsprechend von Zauberern eingesetzt werden konnten; vgl. J.H. WAsziNK, „Biothanati“, RAC 2 (1954) 391f. Eine Geschichte vom nächtlichen Umgehen eines solchen $\beta \mathrm{l}(\alpha \mathrm{\iota}) \mathrm{o} \theta \alpha \dot{v} v \alpha \tau \mathrm{c} \varsigma$ in dem Haus, in dem er ermordet wurde, findet sich Luc. Philops. 30f.

288 Bei seinem hier folgenden Angriff auf die Medizin macht Tatian sich die Doppeldeutigkeit des Wortes $\varphi \alpha \varrho \mu \alpha ́ \kappa \varepsilon \iota \alpha$ (das auch „Benutzung von Zaubermitteln“ und damit „Hexerei“ bezeichnen kann) zunutze. 
289 Ist hier die Verbindung von mehreren „schlechten“ Mitteln gemeint (so TreLeNBERG und WHITTAKER in ihren Übersetzungen, anscheinend auch schon HARNACK) oder die eines „schlechten“ Mittels mit einem „guten“ (so KuкuLA - vgl. auch KuкuLA 1900, 28f. - und auch Puech; nicht eindeutig Di CRIstina: „mescolando insieme un elemento cattivo con un altro")? Die zweite Möglichkeit erscheint im Kontext logischer: Während Tatian (,wir $\left.{ }^{\prime \prime}\right)$ in Heilungsversuchen Mittel der Materie insgesamt als schlecht ablehnt, gibt es andere, die Kompromisse machen und auch Dinge der schlechten Materie in ihre Heilungsversuche integrieren. Auch der nächste Satz spricht dafür, dass Tatian hier an die (von ihm für untauglich gehaltene) Verbindung von etwas Gutem mit etwas Schlechtem denkt.

290 Hier übersetzen Harnack, Kukula, Fermi, Di Cristina und Trelenberg final („um es zu vermeintlich Gutem zu gebrauchen / zu verwenden"), d.h. so als ob nicht

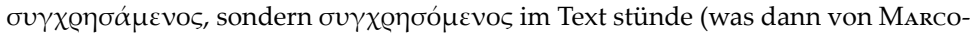
vicH in den Text gesetzt wird). Es geht jedoch nicht um die bloße Absicht, sondern die tatsächliche Ausführung (so wie hier übersetzt wird; so auch bereits Puech: „,'s'en servant en vue de ce que l'on juge bon“), für die laut Tatian dann auch die Strafe Gottes folgt.

291 Die hier aufgeführten Weisen, wie Tiere sich selbst zu heilen versuchen, sind bei verschiedenen antiken Schriftstellern überliefert: Dass der Hund Gras frisst, liest man bei Plutarch, Soll. an. 20, 974B; Aelian, Nat. V 46 und Sextus, Pyrrh. Hyp. I 71. Dass der Hirsch sich durch eine Schlange kuriert, ist freilich in dieser Form anderswo nicht zu finden; sondern dass Hirsche Schlangen zur Strecke bringen, steht bei Plinius d. Ä., Nat. VIII 118 und XXVIII 149f. (hier wird auch gesagt, dass bestimmte Hirschteile gut seien, um Schlangen zu vertreiben oder fernzuhalten) sowie bei Plutarch, Soll. an. 24, 976D und bei Aelian, Nat. II 9, V 48 und VIII 6. Dass Schweine sich mit Hilfe von Flusskrebsen heilen, liest man bei Plinius d. Ä., Nat. XXXII 55 und Plutarch, Bruta an. 9, 991E. Dass Löwen sich von Übersättigung durch Affenfleisch kurieren, ist bei Plinius d. Ä., Nat. VIII 52 und Aelian, Nat. V 39 und XV 17 zu finden.

292 Vgl. oben $17,5$.

293 Diesen Satz zitiert Eusebios in seiner Kirchengeschichte (IV 16,7; vgl. Einführung S. 19 Anm. 59). Mehrere Kommentatoren (Puech, Whittaker, Di Cristina, Trelenberg) vermerken, dass Justins Äußerung in keinem seiner erhaltenen Werke zu finden ist; Tatian kann ihn natürlich auch mündlich von Justin gehört haben (so bereits FERMI; vgl. LAmpe 1989, 245 Anm. 468).

294 Damit könnte auf den Heilschlaf („Inkubation“) in Heilheiligtümern (z.B. dem Amphiareion von Oropos oder den Asklepieia von Epidauros oder Pergamon) angespielt sein: Kranke schliefen in diesen Heiligtümern, um durch Träume, in denen ihnen die zuständige Gottheit erschien, sich Wege zur Heilung anzeigen zu lassen. Vgl. etwa die Träume, die Aelius Aristides in seinen Hieroi Logoi erzählt.

295 Heilungen wurden durch die Aufstellung von Weihreliefs oder Inschriften mit Heilungsberichten für die Mit- und Nachwelt festgehalten; vgl. B. BÄBLER, „Healing Cults", in: G. SPEAKe (Hg.), Encyclopedia of Greece and the Hellenic Tradition, Bd. I (London 2000) 714.

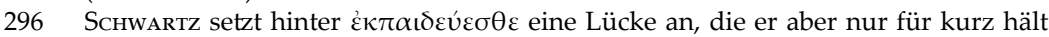
(im Apparat schlägt er die Ergänzung von $\pi \alpha u ́ \varepsilon \sigma \theta \varepsilon \delta \varepsilon \dot{~ v o r, ~ w a s ~ o f f e n b a r ~ i n ~ F e r m i s ~}$ Übersetzung „non dite più" aufgegriffen ist). KUKUla, WhitTaKer, Di CRISTINA (der immerhin auf den abrupten Wechsel der Gedanken hinweist) und Trelenberg übersetzen, ohne eine Lücke erkennen zu lassen (Marcovich nimmt eine Umstellung der Kola des Satzes vor, rechnet also auch nicht mit einem Textausfall); lediglich Puech 1903, 132 Anm. 4 hält den Satz ohne die Lückenannahme für "trop concise et obscure“. Bereits H. Deмвоwsкi, Die Quellen der christlichen Apologetik des zweiten Jahrhunderts, Teil I: Die Apologie Tatian's (Leipzig 1878) 48f. und 56 hatte hier einen „Riss im straffen Zusammenhange“ (56) festgestellt (der freilich von KuкuLA 1900, 5 
entschieden bestritten wird; doch fügt KUKULA in seiner an dieser Stelle gegebenen Übersetzung eine Ergänzung ein, die so eben bei Tatian nicht steht).

In der Tat ist nach $\varepsilon \kappa \tau \alpha \iota \delta \varepsilon v ́ \varepsilon \sigma \theta \varepsilon$ von einem völlig anderen Thema die Rede (die vermeintliche Todesverachtung der paganen Philosophen) als vorher (wo es um die üblen Tricks der Dämonen bei Krankheitsfällen geht), so dass die Lücke wahrscheinlich sogar größer anzusetzen ist, als von ScHwARTz angenommen wurde.

Die hier gemachte Angabe über die kaiserliche Besoldung der Philosophen stimmt (wie Whittaker 1982, 39 Anm. a richtig bemerkt) weder mit der von TrelenberG herangezogenen Stelle aus Suet. Vesp. 18 überein (wo es überdies nicht um Philosophen, sondern um Rhetoren, Dichter und bildende Künstler geht) noch mit der über die von Marc Aurel besoldeten Philosophie-Lehrstühle in Athen (vgl. Luc. Eun. 3 und 8; die hier genannten ,zehntausend“ sind Drachmen oder Denare, die $400 \mathrm{Au}$ rei $=$ Goldstücken entsprechen). Besser ist Kukulas Hinweis auf die Angabe in der Historia-Augusta-Vita des Antoninus Pius (SHA, Anton. Pius 11,3), wonach der Kaiser überall im Reich für Rhetoren und Philosophen Ehrenstellen und Saläre bereitgestellt habe (Rhetoribus et philosophis per omnes provincias et honores et salaria detulit); doch sind hier keine Zahlen genannt.

298 SchwARTz hatte hier vor ö $\pi \omega \varsigma$ ein ทे ergänzt („, für keinen nützlichen Zweck als dem, dass ..."); aber wäre es ein nützlicher Zweck, dass die Philosophen „nicht einmal ihren herabwallenden Bart umsonst haben“? Eher könnte man an die Einfügung eines

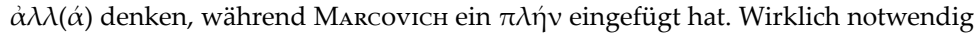
ist beides nicht.

299 Der lange Bart ist typisches Philosophen-Kennzeichen auch bei Lukian; vgl. NesSELRATH 1985, 451.

300 Der kynische Philosoph Crescens ist außer dieser Vorstellung durch Tatian vor allem durch Justin bekannt, der in seiner Zweiten Apologie zweimal auf ihn zu sprechen kommt: In 3,1f. erwartet er von Crescens einen Anschlag (Denunziation?) ge-

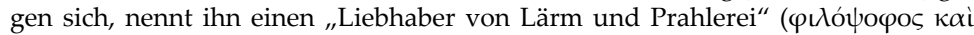

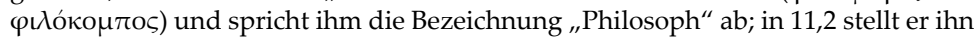

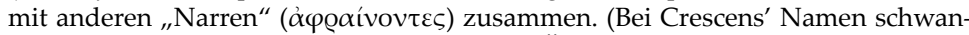
ken sowohl die Tatian- als auch die Eusebios-Überlieferung zwischen den Formen

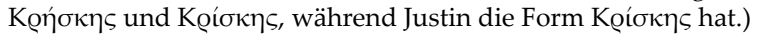

301 Die hier gegen Crescens geäußerten Vorwürfe pflegt auch Lukian gern gegen zeitgenössische Philosophen zu richten, und sie sind auch schon in früherer Literatur zu finden (zur Päderastie von Philosophen vgl. Nesselrath 1985, 423. 469f.; zu ihrer Geldgier vgl. Nesselrath 1985, 338. 464f. 466f.).

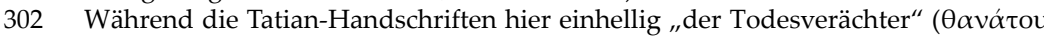

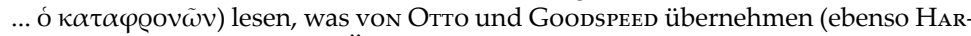
NACK und Kukula in ihren Übersetzungen), liest man in der Sekundärüberliefe-

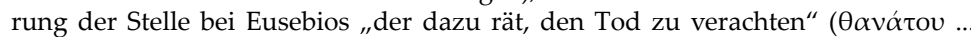

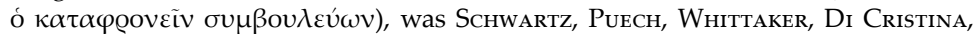
Marcovich und Trelenberg für die bessere Variante halten (anders dagegen Fermi: „col suo disprezzo della morte“). Zwar entspricht der Text bei Eusebios etwas mehr der in 19,1 skizzierten Haltung der Philosophen (sie sagen, sie verachteten den Tod

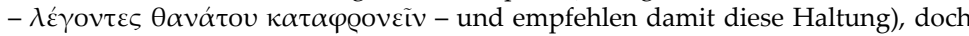

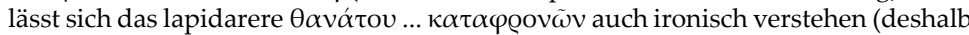
setzt HARNACK "der Todesverächter“ in Anführungszeichen, und KuKula verfährt genauso) und braucht daher nicht geändert zu werden.

303 Eusebios hat an dieser Stelle $\alpha u ̛$ tós (übernommen von HARNAcK - der es aber auf den folgenden Teilsatz bezieht: „er fürchtete den Tod so sehr, dass er selbst dem Justinos ... ihn ... zu bereiten suchte“ - sowie von Schwartz, Puech, Whittaker und

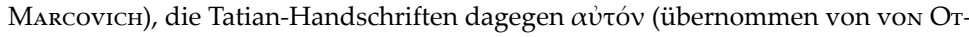
to, Kukula und Trelenberg). Mehr Pointierung bietet zweifellos aủ tós. 
304 Die kurze Bemerkung „,als auch mich“ ist in der Vergangenheit verschiedentlich als Interpolation (so FUNK 1883, 221-223) oder Teil einer Interpolation (so R. WEIJENBORG, „Die Berichte über Justin und Crescens bei Tatian“, Antonianum 47 [1972] 372-390) aufgefasst worden; auch Marcovich und Trelenberg 2012, 136 folgen hier Eusebios, in dessen Zitat dieses Passus (in HE IV 16,8f.) die in den Tatian-

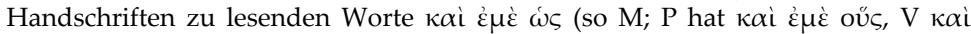
$\varepsilon \dot{\varepsilon} \dot{\varepsilon}$ oíov) durch $\mu \varepsilon \gamma \alpha \dot{\alpha} \lambda \omega$ ersetzt sind. Aber warum hätte hier jemand eine SelbstErwähnung des Autors nachträglich einfügen sollen? Es ist eher vorstellbar, dass Eusebios dem schon seit Irenaeus als Häretiker geltenden Tatian nicht die Ehre eines Beinahe-Martyriums (noch dazu im Gefolge des Justin) zukommen lassen wollte und deshalb den Text änderte (vgl. bereits von Oтто ad loc.: „Eusebius de industria videtur locum isto modo dedisse").

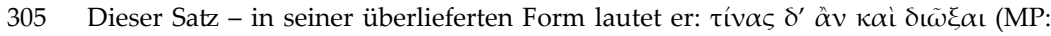

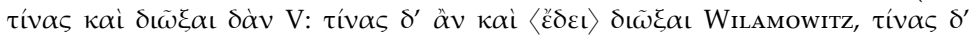

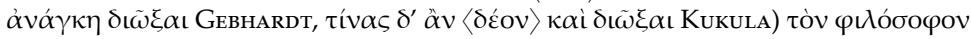

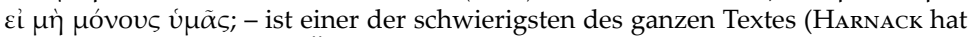
deswegen sogar auf eine Übersetzung verzichtet). Die Konjekturen von WiLAmowitz, GEBHARDT und KuKULA sind nur im Wortlaut verschieden, in ihrer Bedeutung dagegen gleich; alle fügen ein ,ist / wäre notwendig“ ein, um den Satz zu vervollständigen, doch ergibt sich bei allen auch eine unschöne Doppeldeutigkeit: Wer (Subjektsakkusativ) soll hier wen (Objektsakkusativ) verfolgen? Bei KuKULA bildet

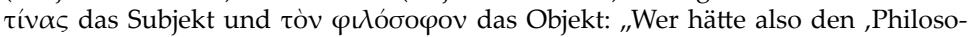
phen' [= Crescens] geradezu vor Gericht zu ziehen, als einzig und allein ihr [die von Tatian angeredeten Griechen]?“ Dagegen versteht Puech 1903, 133 genau andersherum: "C'est bien plutôt vous seuls que le philosophe eût dû poursuivre!" Fermi, Whittaker und Di Cristina folgen der Deutung von Puech, während TreLENBERG sich Kukula anschließt. Bereits Funk 1883, 223-225 sah als Subjekt („Verfolger“) dieses Satzes den „Philosophen“ Crescens an, wollte jedoch am Ende $\dot{\eta} \mu \tilde{\alpha} \varsigma$ statt $\dot{v} \mu \tilde{\alpha} \varsigma$ lesen.

Akzeptiert man eine der drei genannten Konjekturen dennoch (wobei die von $\mathrm{W}_{\mathrm{I}}$ LAMOWITz sich am glattesten einfügt und auch den besten Sinn ergibt), dann hat im Kontext der Argumentation die Deutung Puechs mehr für sich als die Kukulas: Crescens verfolgte Justin (und wohl auch Tatian), um ihnen mit dem Tod das größte Übel anzutun, verfehlte jedoch sein Ziel, denn nicht die Christen fürchten den Tod als Übel, sondern ihre heidnischen Zeitgenossen; also hätte Crescens nur ihnen mit entsprechender Verfolgung das beabsichtigte Übel antun können.

306 Der Philosoph Anaxarchos von Abdera lebte in den mittleren Jahrzehnten des 4. Jh.s v. Chr., war einer der Lehrer des Skeptikers Pyrrhon von Elis (beide begleiteten Alexander d.Gr. auf seinen Feldzügen) und war in der Antike vor allem wegen der Standhaftigkeit berühmt, die er zeigte, als der mit ihm verfeindete Fürst Nikokreon von Zypern ihn zu Tode foltern ließ (vgl. Cic. Tusc. II 52, Nat. III 82; Val. Max. III 3ext.,4; Dio Prus. Or. 37,43; Clem. Alex. Strom. IV 55,4; Diog. Laert. IX 59). Gerade diesen Tod macht Tatian hier verächtlich und schreibt ihn verrückter Ruhmsucht zu.

307 Vgl. Weish 1,14: „Auf Heil hin angelegt sind die Geschöpfe der Welt, und nicht gibt es in ihnen ein Gift des Verderbens."

308 Der Vergleich des Lebens mit einem Fest ist bereits bei dem Komödiendichter Menander zu finden (Fr. 871,1f. PCG mit Hinweisen zu weiteren Stellen); zur Präsenz des Gedankens in philosophischen Texten vgl. Nesselrath 1985, 333.

309 Die Bedeutung des Verbes $\theta \varepsilon \alpha \tau$ фоко $\pi \varepsilon \dot{\omega} \omega$ ist wegen seiner Seltenheit (es ist außer an dieser Stelle nur noch Orac. Sib. V 142 belegt) nicht ganz sicher; die Übersetzer schwanken zwischen "Beifall erhalten / sich spenden lassen“ (von Otто, НARnack, Kukula, Puech, Fermi, Di Cristina, Trelenberg) und „sich um Beifall bemühen“ 
(WhitTAKeR). Nach Tatians vorangehender Geißelung verrückter Ruhmsucht ist die zweite Bedeutung die näherliegende.

310 Apollon ist hier der Orakelgott par excellence.

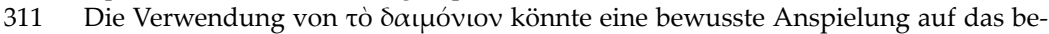
rühmte Daimonion des Sokrates sein, das gewissermaßen als sein individuelles Orakel fungierte, indem es ihm von bestimmten Handlungen abriet (vgl. Plat. Apol. 31c-d; Euthyphr. 3b-c; Xen. Mer. I 1,2f.; Apol. Socr. 12f.). Dass auch in der Kaiserzeit dieses Daimonion noch Gegenstand großen Interesses war (und damit auch eine Zielscheibe von Tatians Spott sein konnte), zeigen Plutarchs Schrift De genio Socratis und Apuleius' De deo Socratis.

312 In Hom. Il. II 372 wünscht sich Agamemnon zehn Ratgeber von der Qualität des alten Nestor, um Troja möglichst rasch in seine Gewalt bringen zu können.

313 Hier sind mehr oder weniger alle wesentlichen Fälle aufgezählt, in denen Griechen ein Orakel zu Rate zogen: vor größeren politischen oder militärischen Unternehmungen, zur Förderung persönlicher Wünsche, zur Wiedererlangung von Gesundheit.

314 Hier ist mit ziemlicher Sicherheit die delphische Pythia gemeint: Lukian, JTrag. 30 erwähnt Weihrauch und Kastalische Quelle als Voraussetzung für die delphische Mantik, Bis Acc. 1 und Hermot. 60 das "heilige Wasser".

315 Vgl. oben 8,9 mit Anm. 133.

316 Vgl. oben 12,10 mit Anm. 220.

317 Auf die Erfindung der Weissagekunst, die sich des Vogelflugs bedient, hat Tatian bereits in 1,1 hingewiesen.

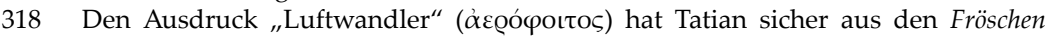
des Aristophanes (V. 1291), aus denen bereits ein Zitat in 1,5 stammt (vgl. oben Anm. 17). Ursprünglich stammt der Ausdruck aus einem Aischylos-Vers (Fr. 282 RADT), den Aristophanes parodistisch in seine Frösche eingebaut hat.

319 Auch die Orakel sind in Tatians Deutung also nur Mittel, mit denen die Dämonen die Menschen täuschen und unterjochen.

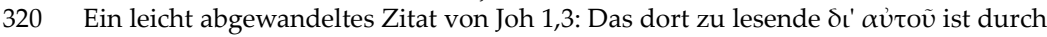
$\hat{v} \pi^{\prime} \alpha \hat{\tau} \tau o \tilde{v}$ ersetzt, weil Tatian unmittelbar vorher vom „einzigen Gott“ (und nicht wie Johannes vom Logos) gesprochen hat.

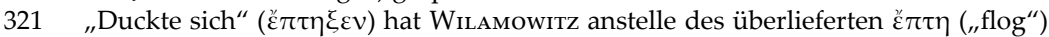
konjiziert, was von Schwartz, Puech und Marcovich akzeptiert wurde.

322 Tatian bietet hier eine christliche Umdeutung des in Platons Phaidros (246a-248d) erzählten Mythos, wie die von der Schau des Göttlich-Ewigen beflügelte Seele aufgrund der Teile von ihr, die nach unten drängen, ihre Flügel verliert und auf die Erde stürzt.

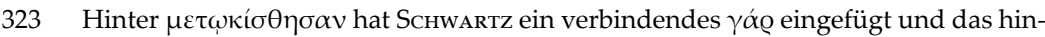
ter $\dot{\varepsilon} \xi \omega \varrho i ́ \sigma \theta \eta \sigma \alpha \nu$ von zwei (M und V) der drei Handschriften überlieferte $\gamma \alpha \dot{Q} Q$ durch $\delta \varepsilon ́$ ersetzt; denkbar und mit Tatians Stil gut vereinbar wäre jedoch auch eine asyndetische Reihung der beiden parallelen Teilsätze, die zumindest in Handschrift $P$ auch so überliefert ist.

324 Mit den „zuerst Geformten“ sind die ersten Menschen gemeint (vgl. Weish 7,1; Phil. Quaest. in Gen. et Ex. I Fr. 32; II Fr. 46); zu ihrer und der Dämonen Verbannung aus der Nähe Gottes wegen ihrer Rebellion vgl. 7,4f.

325 Hier ist zum einen an das (irdische) Paradies gedacht, aus dem die ersten Menschen nach ihrem Sündenfall vertrieben wurden (Gen 3,23f.); zum anderen findet sich die Vorstellung einer „besseren Erde“ als die hier und jetzt von Menschen bewohnte auch in Platons Phaidon (vgl. dort 110a-111c).

326 Die Beschreibung der besseren $\alpha i \tilde{\omega} v \varepsilon \varsigma$ jenseits des (von der Erde aus sichtbaren) Himmels erinnert zum einen an christliche Texte wie 1 Tim 6,16 (hier ist vom göttlichen Herrscher die Rede, „der ein unzugängliches Licht bewohnt und den keiner 
von den Menschen ... sehen kann“); zum anderen tauchen wichtige Elemente dieser Beschreibung bereits in homerischen Schilderungen ,jenseitiger" Orte auf: die Abwesenheit störender klimatischer Erscheinungen im „Elysischen Feld“ am Rand der Erde (Hom. Od. IV 565-568), das Gleiche sowie ein besonderes Licht auf dem Olymp der Götter (Hom. Od. VI 42-46).

327 Die Gezeiten sind in der Tat ein Phänomen der „äußeren“ Meere; im Mittelmeer (dem zentralen Meer der antiken Oikumene) sind Ebbe und Flut kaum vorhanden.

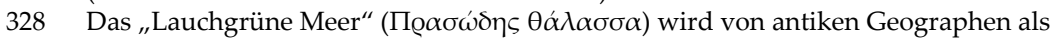
Teil des Indischen Ozeans südlich und östlich von Indien lokalisiert und soll sich bis an die Küste eines unbekannten Südkontinents erstrecken: vgl. Anon. Geogr. exp. comp. 32 Müller; Ptol. Geogr. VII 2,1; 3,6; Marcian. Peripl. ext. I 12; 44.

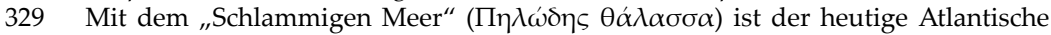
Ozean westlich von Gibraltar und Afrika gemeint, der den Griechen seit dem 5. Jh. v. Chr. als seicht und verschlammt galt (was dann Platon dazu inspirierte, diesen Schlamm als Indiz für sein versunkenes Atlantis zu verwenden: Tim. 25c6-d6 und Kritias 108e7-109a2); vgl. Hdt. IV 43; Aristot., Meteor. II 1, 354a22; Avienus, Ora maritima 114-129; 375-389; 406-415 und H.-G. NesSELrath, ,,,Where the Lord of the Sea Grants Passage to Sailors Through the Deep-Blue Mere No More': The Greeks and the Western Seas“, Greece \& Rome 52 (2005) [153-171] 160f.

330 In diesen Worten ist die seit dem Hellenismus gängige Vorstellung angedeutet, dass die als Kugel gedachte Erde sich in verschiedene Klimazonen („Gürtel“) aufteilt, wobei unsere "bewohnte Welt" (Oikumene) - auf der nördlichen Hemisphäre - sich in einem „Streifen“ befindet, der im Norden von einem Frost- und im Süden von einem Hitzegürtel begrenzt wird; vgl. etwa die Beschreibung der Erde die Cicero im Somnium Scipionis dem Scipio Africanus maior in den Mund legt (Rep. VI 21): Die Gebiete um die beiden Pole sind von Frost erstarrt (obriguisse pruina), während ein großer Mittelgürtel (zu beiden Seiten des Äquator) von der Glut der Sonne ausgedörrt ist (solis ardore torreri). Zwischen den frostkalten und glutheißen Gebieten liegen zwei gemäßigte Zonen: die antike Oikumene auf der Nordhalbkugel und die Zone der "Antipoden“ (in quo qui insistunt, adversa vobis urgent vestigia, "diejenigen, die in dieser Zone stehen, drücken euch ihre Fußspuren entgegen") auf der Südhalbkugel.

Die von Wilamowitz vorgeschlagene und von Schwartz übernommene Tilgung des Präfixes $\delta \iota \alpha$ von $\delta\llcorner\alpha \pi \varepsilon \pi \eta \gamma o ́ \varsigma$ ist unnötig (vgl. Aristot. mir. 835a30).

331 Vgl. oben 13,5 mit Anm. 231. Dem spekulativen „Weltwissen“ der Griechen wird die den Christen durch prophetische Offenbarung zuteilgewordene Kenntnis des einzig Wichtigen und Wahren gegenübergestellt.

332 Zur Textgestaltung in dieser Parenthese vgl. Nesselrath 2005, 252-254. Die Übersetzungen (Harnack, Kukula, Puech, Whittaker, Trelenberg) verstehen den über-

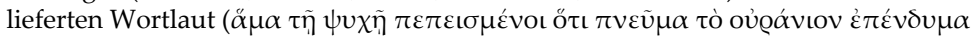

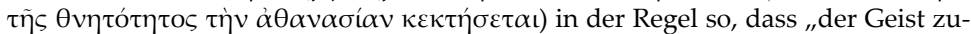
sammen mit der Seele die Unsterblichkeit, die himmliche Überkleidung der Sterblichkeit, erwerben werde" (so zuletzt TRELENBERG; fast genauso bereits HARNACK). Aber das $\pi v \varepsilon \tilde{v} \mu \alpha$ ist ja bereits unsterblich (vgl. oben 12,1 und 13,3); was hier vielmehr die Unsterblichkeit wiedererlangen muss, ist die Seele, die daher Subjekt des ótı-Satzes sein muss (so bereits Ponschaв 1895, 17, der aber nichts am Text änderte). Um dies zu erreichen, muss man $\tau \tilde{\eta} \psi v \chi \chi \tilde{\eta}$ in $\tau \dot{\eta} v \psi v \chi \eta \dot{v} v$ ändern (der überlieferte Dativ lässt sich als Angleichung an das vorangehende ó $\mu \alpha$ erklären) und als Prolepse des Subjekts des Relativsatzes verstehen. Ferner spricht viel dafür, dass $\tau \grave{\eta} v$

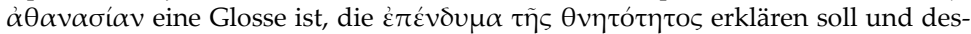
halb zu streichen ist. Aus diesen Elementen ergibt sich der hier vorgeschlagene Text.

$\mathrm{Zu}$ der geradezu poetischen Vorstellung, dass die Seele eine „Umhüllung ihrer 
Sterblichkeit" durch den himmlischen Geist (und damit die Unsterblichkeit) erhalten soll, vgl. oben 16,7, wo der Mensch "mit dem Panzer des himmlischen

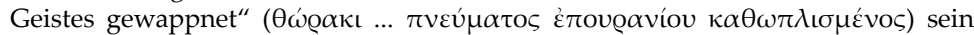
soll. Demgegenüber ist die von mehreren Kommentatoren (Puech, Di Cristina, Marcovich, Trelenberg) hier angeführte Stelle 1 Kor 15,53f. nur bis zu einem gewissen Punkt vergleichbar, denn hier ist lediglich allgemein davon die Rede,

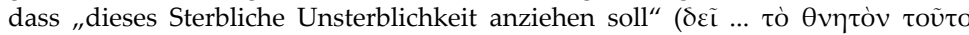
$\dot{\varepsilon} v \delta \dot{\sigma} \sigma \alpha \sigma \theta \alpha \mathrm{\iota} \dot{\alpha} \theta \alpha v \alpha \sigma i ́ \alpha v)$ soll. Eher ist Tatian von 2 Kor 5,1-4 inspiriert, wo das Verb غ̇ $\pi \varepsilon v \delta u ́ \sigma \alpha \sigma \theta \alpha$ เ zweimal vorkommt und Paulus sagt, dass wir Menschen uns „im gegenwärtigen Zustand“ danach sehnen, „mit dem himmlischen Haus über-

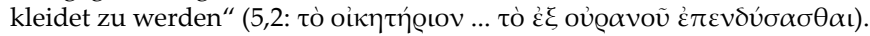

Auch dies erinnert an die gerade genannte Paulus-Passage (2 Kor 5,3: „So bekleidet, werden wir nicht nackt erscheinen").

334 Im folgenden führt Tatian kurz Geschichten von Göttern an, die sich in Menschen verwandeln, die sterben und die schreckliche Qualen erleiden; damit will er zeigen, dass auch der griechische Mythos wesentliche Elemente der Christusgeschichte kennt, über die die Griechen sich daher nicht mokieren sollten.

335 In Hom. Il. XXII 226f. nimmt Athena die Gestalt des Deïphobos (eines Bruders Hektors) an und tritt auf Hektor zu, um diesen dazu zu ermuntern, sich Achill (vor dem er bisher davongelaufen ist) im Kampf zu stellen.

336 Weil Phoibos Apollon aus Zorn darüber, dass Zeus seinen Sohn Asklepios getötet hatte, seinerseits die Kyklopen des Zeus (vgl. oben Anm. 11) tötete, musste er zur Strafe ein Jahr lang die Rinder des Königs Admetos von Pherai (in Thessalien) hüten; vgl. Eur. Alc. 1-8; Apollod. Bibl. III 122 = III 10,4.

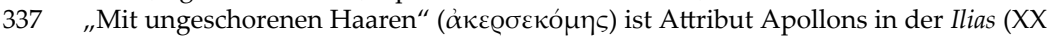
39), in Hesiod-Fragmenten (Fr. 60,3 und 171,8 Меrкеlвасн-West) und bei Pindar (Pyth. 3,14; Isthm. 1,7).

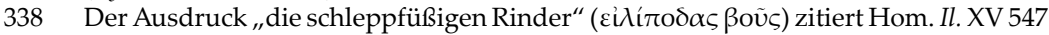
(vgl. IX 466; XXI 448 - direkt auf Apollon bezogen, aber auf sein Weiden der Rinder

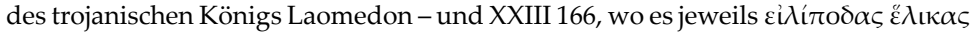
ßoũ heißt).

339 Hera verwandelt sich in eine alte Dienerin der thebanischen Prinzessin (Tochter des Kadmos) Semele, die Zeus' erotische Aufmerksamkeit erregt hat. In dieser Gestalt gibt sie Semele den verderblichen Rat, sie solle sich von Zeus wünschen, dass er ihr in seiner ganzen göttlichen Pracht erscheine - was dazu führt, dass Semele von dieser Pracht den Feuertod erleidet. Vgl. Ovid, Met. III 274-286.

340 Zum Tod des Asklepios vgl. oben Anm. 336.

341 Der Entjungferer der fünfzig Töchter des Thespios ist Herakles; dass er dies in einer einzigen Nacht getan habe, liest man bei Pausanias IX 27,6f. (in zwei leicht voneinander abweichenden Varianten), während der Mythograph Apollodor berichtet, Herakles habe pro Nacht mit einer geschlafen, jedoch in dem Glauben, es handle sich jedesmal um die gleiche (Apollod. Bibl. II $66=$ II 4,10).

342 Herakles ließ sich auf einem Scheiterhaufen auf dem Berg Oita lebendig verbrennen, weil er die Qualen nicht mehr aushielt, die ihm das mit dem giftigem Blut des Kentauren Nessos bestrichene Gewand bereitete, das ihm seine Frau Deianira (die aber von den todbringenden Eigenschaften des Gewandes nichts wusste) geschickt hatte. Die Geschichte ist in den Trachinierinnen des Sophokles dargestellt.

343 Tatians kurze Zusammenfassung der Prometheus-Geschichte ist so gehalten, dass die Ähnlichkeiten zur Christusgeschichte deutlich hervortreten: Prometheus wird zu langdauernden Qualen (Ankettung am Kaukasos; vgl. auch oben Anm. 175 mit den dort angegebenen Stellen) verurteilt, weil er ein Wohltäter der Menschen war.

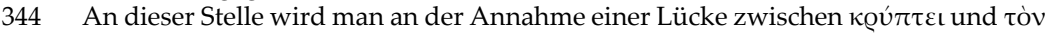
ǒveıov kaum vorbeikommen, denn dafür, dass Zeus „den [welchen?] Traum“ ver- 
borgen habe, gibt es keinerlei Belege in irgendeinem Mythos, und die Übersetzungen, die ohne Lückenannahme auszukommen versuchen (НARNACK: „verbirgt den Menschen die Deutung des Traums"; Puech: „,il cache le sens du songe qu'il envoie“; KUKUlA: ,,schickt dunkle Träume“; Di CRISTINA: „tiene celato il significato dei sogni“" [ähnlich bereits Fermi]; Trelenberg: „schickt einen dunklen Traum“), müssen alle Ergänzungen zum griechischen Wortlaut oder Veränderungen an der Bedeutung des Verbs к@ú $\pi \tau \varepsilon \iota v$ vornehmen, die nicht belegt sind. WiLAmowitz' knapper Er-

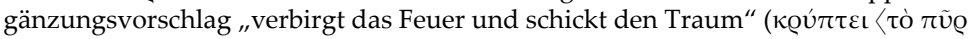

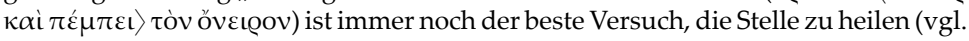
dazu jetzt auch S. FREUND, ,,, Und wunderbar sind auch eure Dichter, die da lügen ...' [Tat., orat. 22,7]. Beobachtungen zu Gestalt, Auswahl und Funktion von Dichterzitaten in der griechischen Apologetik am Beispiel Tatians", in: Ch. Schubert [Hg.], Ad veram religionem reformare. Frühchristliche Apologetik zwischen Anspruch und Wirklichkeit [Erlangen 2006] [97-121] 109f.). WiLamowitz' Vorschlag würde den „Neid“ des Zeus mit zwei markanten Beispielen belegen: Zeus verbarg das Feuer vor den Menschen (vgl. Hes. Theog. 562-654; Op. 47-50), um ihnen auf diese Weise die Möglichkeit zu kultureller Höherentwicklung zu nehmen, und er schickte vor Troja dem griechischen Oberfeldherrn Agamemnon einen verderblichen Traum, der diesen zum Kampf aufreizen und damit vielen Kämpfern den Tod bringen sollte (Hom. Il. II 3-6).

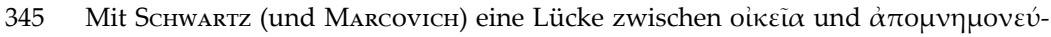
$\mu \alpha \tau \alpha$ anzunehmen ist unnötig.

346 Tatian führt hier gegen den griechischen Mythos eine seit Parmenides (28 B 8,3.21 DK; vgl. Plat. Phaidr. 245c5-e2) entwickelte These der griechischen Philosophie ins Feld, derzufolge alles, was unsterblich ist, weder einen Anfang noch ein Ende hat. Explizit auf die Götter angewendet findet sich diese These bei Cicero, Nat. I 68: si ortus est deorum, interitus sit necesse est (,,wenn es ein Entstehen der Götter gibt, muss es auch einen Untergang geben").

347 Es ist nicht ohne Ironie, dass Tatian sich gerade bei Hera darüber wundert, dass sie keine Kinder mehr hervorbringt, denn gerade Hera ist im Mythos nicht für „produktive Seitensprünge“ bekannt (GEFFCKEN 1907, 112 Anm. 3 vergleicht hierzu Seneca, Fr. 119 HAASE = Lact. Div. Inst. I 16,10, der sich darüber wundert, dass Heras Ehemann Zeus, der apud poetas salacissimus, offenbar auch nicht mehr für weiteren illegitimen Nachwuchs sorgt). Vgl. jedoch Minucius Felix, Oct. 21,11 (Nisi forte iam Iuppiter senuit et partus in Iunone defecit, „es sei denn, Zeus ist alt geworden, und die Gebärkraft in Hera ist versiegt"); Theophilos, Autol. II 3 wundert sich ingesamt darüber, dass die Götter keine Nachkommen mehr hervorbringen; offenbar sind sie zu alt geworden oder gar verstorben.

348 Die Kritik Tatians und der anderen christlichen Apologeten an den griechischen Göttern steht und fällt damit, dass man deren mythische Geschichten wörtlich nimmt; eine allegorische Deutung würde eine solche Kritik ins Leere laufen lassen.

349 Metrodor von Lampsakos (61 DK; nicht zu verwechseln mit dem gleichnamigen Schüler Epikurs) wird zuerst in Platons Dialog Ion erwähnt, wo ihn die Titelfigur mit anderen Homer-Interpreten (Stesimbrotos von Thasos und Glaukos von Rhegion oder Teos) zusammenstellt (530c). Laut Diog. Laert. II 11 war er ein Schüler des Anaxagoras von Klazomenai. Vgl. J. Hammerstaedt, „Die Homerallegorese des älteren Metrodor von Lampsakos“, ZPE 121 (1998) 28-32; P. P. Fuentes González, „Métrodore de Lampsaque“, in: DPhA 4 (2005) 508-514.

350 Vgl. oben 12,5, wo die Dämonen als Wesen aus Materie bezeichnet werden; ferner 3,3, wo der Gott der Stoiker als „,in Kloaken und Würmern und Unholden“ wohnend dargestellt wird.

351 Das Wort $\delta \iota \delta \alpha \gamma \mu \alpha \tau \alpha$ wird gelegentlich in der theatertechnischen Bedeutung von $\delta เ \delta \alpha \sigma \kappa \alpha \lambda i ́ \alpha \iota$ verstanden (Kukula: „Theaterwesen“; TRELEnberG: „Theaterauffüh- 
rungen"), doch scheinen sich für eine solche Verwendung von $\delta i ́ \delta \alpha \gamma \mu \alpha$ keine Parallelen finden zu lassen, so dass man es wohl bei der Grundbedeutung „Lehrgegenstände/Unterweisungen“ belassen sollte (vgl. von Отто: "disciplinae“; НARNAcк: „Unterweisungen“; PUech: „enseignements“; Whittaker: „teaching“; Di CRistina: ",insegnamenti“), die aber wahrscheinlich ironisch gemeint ist.

Vgl. etwa Justin, 1 Apol. 4,9, wo von den $\delta\llcorner\delta \alpha ́ \gamma \mu \alpha \tau \alpha$ der Dichter die Rede ist, unter denen auch Theater-Dichter gemeint sein könnten.

352 Die öffentlichen Feste einer griechischen Polis werden in der Tat alle zu Ehren bestimmter Götter veranstaltet (vgl. in Athen die Großen Dionysien zu Ehren des Dionysos, die Panathenäen zu Ehren Athenas etc.). Den Ablauf des jährlichen Festkalenders von Athen beschreibt F. Graf, ,"Griechische Religion “, in: H.-G. Nesselrath, Einleitung in die Griechische Philologie (Stuttgart / Leipzig 1997) [457-504] 489f.

353 Die von Schwartz vorgenommene Ergänzung des Artikels tóv vor $\alpha \beta$ Q ist unnötig.

354 Die hier beschriebene Darbietung ist die eines pantomimischen Solotänzers (vgl.

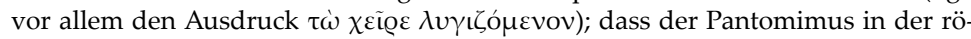
mischen Kaiserzeit eine sehr populäre Theaterform war, belegen Schriften wie Lukians Dialog De saltatione und Libanios' Rede „An die Adresse des Aristeides zur Verteidigung der Pantomimentänzer“. Eine ähnlich negative Perspektive auf den pantomimischen Tanz wie hier findet sich Luc. Salt. 5.

355 Die hier gegebene Aufzählung spiegelt die Themen wider, die in der im ganzen Römischen Reich populären Theaterform des Mimus (den Tatian hier mit dem Pantomimus zusammenstellt, ohne sich um die Unterschiede beider Formen zu kümmern) geboten wurden: Burlesken und Travestien von Götter- und Heldenmythen, Abenteuer- und Ehebruchsgeschichten (,Sex and Crime“). Zum Mimus vgl. H. Wiemken, Der griechische Mimus. Dokumente zur Geschichte des antiken Volkstheaters (Bremen 1972).

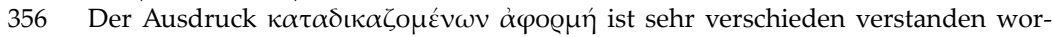

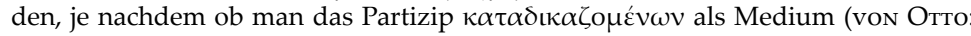
„sententiarum capitalium occasionem“; РuEch: „prétexte à condannations capitales"; Kukula: „Vorbild für ungerechte Richter", ähnlich bereits Harnack; Fermi: „un'occasione per emanare sentenze capitali“) oder als Passiv (WHITTAKER: „,instigator of condemned criminals“; Di CRISTINA: „istigatore di delinquenti“; TRELENBERG: „Hilfe für Kriminelle“) versteht. Das zweite scheint im Kontext besser: Der unmoralische Mimen-Darsteller liefert eine Inspiration ( $\dot{\alpha} \varphi$ oQ $\mu \eta ́$, wörtlich „Ausgangspunkt") für Leute, die sich durch das Vorgeführte zu kriminellen Handlungen verleiten lassen und dann vor Gericht dafür verurteilt werden.

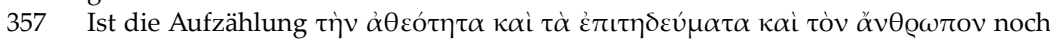
Objekt zu $\pi \alpha \varrho \eta \tau \eta \sigma \alpha ́ \mu \eta v$ (so von OtTo, НARNack, Schwartz; wohl auch WhitTaKer, Di Cristina und Trelenberg) oder zu $\psi \varepsilon v \delta o ́ \mu \varepsilon v o v$ (und würde damit $\pi \alpha ́ v \tau \alpha$ entfalten; so Kukula 1900, 30 und in seiner Übersetzung; Puech 1903, 137 mit Anm. 2; Fermi)? Es spricht wohl mehr für die erste Auffassung: Eine echte Gottlosigkeit ist sicher stärker abzulehnen als eine nur vorgespielte.

358 Hier scheinen Darbietungen von Chören anvisiert zu sein.

359 Hier geht es noch einmal um den Pantomimentänzer (vgl. oben Anm. 354).

360 Das Verb @́เv $\alpha \cup \lambda \varepsilon ́ \omega$ („,durch die Nase blasen“) ist sonst nur bei Tatians Zeitgenossen Lukian belegt (Lexiph. 19), wo es ein verächtliches Schnauben bezeichnet. Zur bei Tatian gemeinten Sache vgl. Clem. Alex. Paed. III 29,2f., wo diese Geräusche von männlichen Prostituierten ( $\kappa i ́ v \alpha \iota \delta o t)$ hervorgebracht werden.

361 Warnungen vor den Anreizen zur Unzucht, die das Theater bietet, sind ein ständig wiederkehrender Topos bei der Kirchenväterkritik am antiken Drama; vgl. T. D. Barnes, "Christians and the Theater", in: W. J. Slater (Hg.), Roman Theater and Society (Ann Arbor 1996) 161-180; R. Wевв, Demons and Dancers: Performance in La- 
te Antiquity (Cambridge/Mass. 2008) (zum Pantomimus 58-94, zum Mimus 55-138; zu Tatian über den Pantomimus 86f. 149. 166. 184f.); L. Lugaresi, Il teatro di Dio: il problema degli spettacoli nel cristianesimo antico (II-IV secolo) (Brescia 2008) (zu Tatian 360-366).

362 Gemeint sind hier die Odeen (z.B. das des Agrippa und das des Herodes Atticus in Athen), in denen die „Konzertredner" der Zweiten Sophistik ihre rhetorischen Darbietungen zum Besten gaben; zu ihnen gehörten auch fiktive Gerichtsreden, in denen unter anderem auch zum Teil pikante innerfamiliäre Streitigkeiten (Enterbungen, Ehebrüche u.ä.) eine Rolle spielten.

363 Kritik an Athleten, die sich mästen, um Muskelmasse aufzubauen, ist schon lange vor Tatian in der griechischen Literatur zu finden: Bereits Xenophanes (21 B 2 $D K)$ kritisiert, dass Athleten in höherem Ansehen stehen als Männer, die sich um das Wohl der Polis bemühen; in der Athletenkritik des Euripides (Fr. 282 KanNicht) wird dann auch explizit die Gefräßigkeit solcher Athleten hervorgehoben. Im zehnten Buch seiner Deipnosophistai präsentiert Athenaeus einen kleinen Katalog solcher gefräßiger Athleten (412d-413c). Auch dem Skythen Anacharsis (vgl. oben 12,10 mit Anm. 218) werden kritische Äußerungen über das griechische Athletenwesen zugeschrieben (Dio Prus. Or. 32,44; Diog. Laert. I 103), die dann Lukian als Ausgangspunkt für seinen Dialog des Anacharsis mit Solon über das griechische Sportwesen dienten.

364 In diesem Satz geht Tatian von den "geringeren Übeln“ (d.h. den in seinen Augen unsinnigen griechischen Sportwettkämpfen, vor allem im Ringen und im Pankration) zu den "größeren“ (d.h. den römischen Gladiatorenspielen, die inzwischen auch im griechischen, d.h. östlichen Teil des Mittelmeerraums populär geworden waren, vgl. Dio Prus. Or. 31,121; Luc. Demon. 57) über, ohne dies freilich sprachlich sehr deutlich zu machen (vgl. unten Anm. 366).

365 Zur Kritik an Gladiatorenspielen als Tötungsorgien (mit bösen Folgen auch für die psychische Konstitution der Zuschauer) vgl. auch Seneca, Ep. 7,3-5.

366 Die eigenartige sprachliche Formulierung dieses Satzes ( $\mu$ ovo $\mu \alpha \chi 0 \tilde{v} \sigma \iota$ weist auf

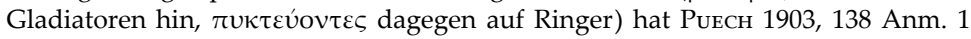
veranlasst, ihn direkt auf $\S 1$ folgen zu lassen, wo von griechischen Ringern, Boxern und Pankratiasten die Rede ist; in dieser Umstellung ist ihm jedoch nur MARcovich gefolgt. Möglicherweise hat Tatian (der hier ja auch mehr die Zuschauer als die Akteure im Blick hat) hier bewusst die Unterschiede verschwimmen lassen, um anzudeuten, dass das Zuschauen bei aller Art von Kampfspielen in seinen Augen gleichermaßen verwerflich ist.

367 Der Satz klingt nach einer generellen Kritik am Fleischverzehr (so haben ihn HARNACK und KuKula verstanden, und KuKUla hat deswegen Tatian sogar bereits in seiner enkratitischen Phase gesehen, als er diesen Satz niederschrieb; auch spätere christliche Autoren haben die Bemerkung offenbar mit Tatians Häresie in Verbindung gebracht: vgl. Tertullian, Ieiun. 15,1; Hieron. Ad Iovinian. 1,3).

368 An dieser Stelle bieten die Ausgaben von Schwartz, Goodspeed und Whittaker das Wort $\alpha \dot{\alpha} \theta \varrho \omega \pi$ o $\varphi \varphi \alpha \gamma^{\prime} \alpha v$ („,Menschenschlachtung“), die Ausgaben von von Отto, Marcovich und Trelenberg dagegen d $\alpha \theta \emptyset \omega \pi$ o $\alpha \alpha \gamma$ í $\alpha v$ („Menschenfresserei“); keine der Ausgaben jedoch verzeichnet eine Variante in den Handschriften. Die Übersetzungen sind in ähnlicher Weise gespalten: Риech (,la vue d'hommes qui s'égorgent entre eux“), Fermi („uccisioni umane“), Whittaker („human slaugh-

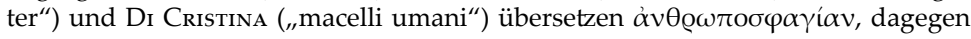
von Отто („epulum humanae carnis“), НаRnack („um Menschenfleisch zu fressen“), Kukula („Menschenfleisch zum Fraße“) und Trelenberg („Menschenfraß“) $\dot{\alpha} v \theta \varrho \omega \pi$ о $\rho \alpha \gamma \dot{\alpha} \alpha \nu$. Deutlich seltener belegt von den beiden ist $\dot{\alpha} v \theta \varrho \omega \pi о \sigma \varphi \alpha \gamma^{\prime} \alpha$, nämlich nur hier bei Tatian (wenn denn richtig gelesen). Tatian könnte das Wort

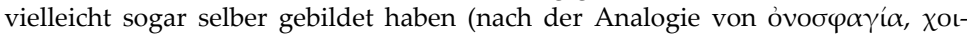




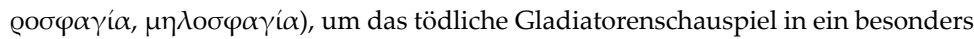
drastisches Wort zu fassen.

369 Alkmaion ist der Sohn des Sehers Amphiaraos; dieser sollte am Feldzug der Sieben gegen Theben (der den von dort vertriebenen Ödipus-Sohn Polyneikes wieder in seine Herrschaft einsetzen sollte) teilnehmen, wollte dies aber nicht, weil er den Tod aller sieben Anführer (also auch seinen eigenen) mit Ausnahme des Oberfeldherrn Adrastos voraussah. Amphiaraos hatte sich aber verpflichtet, bei Disputen zwischen sich und Adrastos seiner Frau Eriphyle (der Schwester des Adrastos) die Entscheidung zuzugestehen, und Eriphyle - von Polyneikes durch ein kostbares Halsband bestochen - hatte im Sinne ihres Bruders für den Feldzug entschieden. Amphiaraos fügte sich, trug aber seinen Söhnen (darunter Alkmaion) auf, ihre Mutter Eriphyle zu töten, sobald sie erwachsen seien, und ihren Vater durch einen neuen Feldzug gegen Theben zu rächen (Apollod. Bibl. III 60-62 = III 6,2). Der Feldzug scheiterte, wie von Amphiaraos vorausgesehen, und Amphiaraos selbst kehrte nicht lebend zurück. Zehn Jahre später unternahmen die Söhne der umgekommenen Heerführer unter der Führung Alkmaions einen neuen, diesmal erfolgreichen Feldzug; vor diesem hatte sich seine Mutter Eriphyle übrigens ein weiteres Mal (diesmal von Polyneikes' Sohn Laodamas) bestechen lassen, um auch ihre Söhne in den Kampf zu schicken (Apollod. Bibl. III 80-85 = III 7,2-4). Nach der Eroberung Thebens kehrte Alkmaion zurück und tötete seine Mutter, legitimiert durch ihre beiden Intrigen und auch noch durch einen Orakelspruch Apollons; dennoch suchten ihn nach der Tat die Erinnyen heim und trieben ihn auf eine längere Flucht (mit mehreren Stationen), bis er schließlich einen gewaltsamen Tod fand (Apollod. Bibl. III 86-90 = III 7,5).

Alkmaions Schicksal war Gegenstand mehrerer Tragödien, darunter zweier des Euripides (Alkmaion in Psophis, Alkmaion in Korinth; vgl. TrGF V 1, 205-218 KANNICHT; unsere Tatian-Stelle ist test. iii zum Alkmaion in Psophis, in dem der Muttermord wahrscheinlich eine größere Rolle spielte als im Alkmaion in Korinth); der genaue Handlungsverlauf der beiden Stücke lässt sich aufgrund der wenigen erhaltenen Fragmente und Zeugnisse (viele davon sind nicht einmal mehr einem der Stücke sicher zuzuordnen) nicht mehr erkennen.

Was Tatian hier schildert, ist offenbar die Vorführung eines Botenberichts aus dem Alkmaion in Psophis (?), in dem Alkmaions Muttermord sehr packend geschildert war (vgl. den Botenbericht des sophokleischen König Ödipus, der die Selbstblendung des Ödipus darstellt). Die Vorführung solcher ,Auszüget aus Tragödien ist eine für die Kaiserzeit typische Darbietung (vgl. die Schilderung, die Lukian am Beginn von De historia conscribenda über eine Darbietung von Partien aus der euripideischen Andromeda gibt). Trelenberg 2012, 149 versteht die Tatian-Stelle falsch, da er Tatian von zwei agierenden Schauspielern sprechen lässt (, der rasende Schauspieler bei Euripides sowie derjenige, der den Muttermord des Alkmaion verkündet"); „rasend" heißt der Schauspieler nicht in Bezug auf den Wahnsinn des Alkmaion, sondern weil seine Darstellung offenbar sehr expressiv und exaltiert war.

$370 \mathrm{Zu}$ dieser Schilderung eines tragischen Schauspielers und seines Auftretens gibt es mehrere Parallelen bei Lukian (Salt. 27; Gall. 26).

371 Der hier erwähnte Hegesias könnte mit dem identisch sein, den Gellius in einer Gruppe von Autoren aufführt, die über miracula und fabulae schrieben (Gell. NA IX 4,3: libri Graeci miraculorum fabularumque pleni, ... scriptores ueteres non paruae auctoritatis: Aristeas Proconnesius et Isigonus Nicaeensis et Ctesias et Onesicritus et Polystephanus et Hegesias = Hegesias, FGrHist 142 T 9a [,griechische Bücher voller Wundergeschichten, ... alte Schriftsteller nicht geringer Autorität: Aristeas von Prokonnesos und Isigonos von Nikaia und Ktesias und Onesikritos und Polystephanos und Hegesias"]). 
372 Menander ist der berühmteste Dichter der attischen Neuen Komödie, der gerade in der Kaiserzeit der meistgelesene Autor seines Genres war (vgl. H.-G. NesSELRATH, „Menander and his Rivals: New Light from the Comic Adespota?", in: D. Оввгnк / R. Rutherford [Hg.], Culture In Pieces: Essays on Ancient Texts in Honour of Peter Parsons [Oxford 2011] [119-137] 120-122).

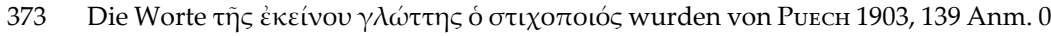
für unverständlich gehalten („Le texte doit être altéré, sans que je voie exactement comment“; vgl. auch Di CRISTINA 1991, 106 Anm. 192). WhitTAKER übersetzt „,who used the same tongue“ (ähnlich Di Cristina und TrelensberG; Fermi versuchte mit "versificatore dello stesso genere" durchzukommen) und bezieht "the same" offenbar auf Hegesias (so auch Kukula, der aber „Hegesias“ zu „Hegesippos“ ändert,

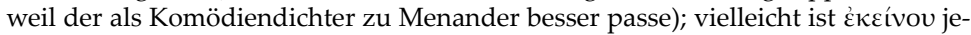
doch eher auf den im vorangehenden Satz geschilderten Schauspieler zu beziehen, der neben Partien aus Euripides sicher auch Partien aus Menander zum Besten geben konnte.

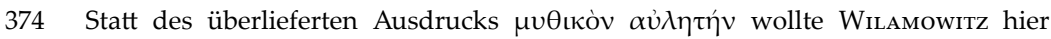

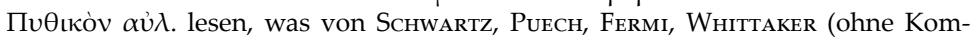
mentar), Di CRISTINA (der darunter Apollon versteht; aber Apollon spielt nicht den Aulos, sondern die Leier) und Marcovich übernommen wird. Dagegen bleibt KuKULA beim überlieferten Text und will unter dem „mythischen Flötenspieler“ den Marsyas verstehen, der mit Apollon in einen Wettkampf eintrat, verlor und zur Strafe lebendig gehäutet wurde (vgl. Apollod. Bibl. I 24 = I 4,2); TreLenberg hat diese Deutung übernommen. Es fragt sich freilich, warum gerade der arme Marsyas Gegenstand einer Bewunderung sein soll, die Tatian ablehnt; hier ist die richtige Erklärung also vielleicht noch nicht gefunden.

375 Der Aristoteles-Schüler Aristoxenos (späteres 4. Jh. v. Chr.) verfasste neben ande-

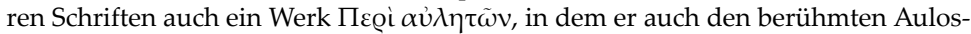
Spieler Antigenides von Theben (früheres 4. Jh. v. Chr.) behandelte (Fr. 77 WeHrLI $=$ Fr. II 3,15 [p. 17] KAISER).

376 Die Überlieferung ist zwischen „euren“ ( $\mu \tilde{\omega} \nu \mathrm{M} \mathrm{P}^{1}$ ) und „unseren“ ( $\dot{\eta} \mu \tilde{\omega} \nu \mathrm{P}^{2} \mathrm{~V}$ ) „Lehren“ gespalten; die Editionen optieren in der Regel für v́ $\mu \tilde{\omega} v$ (außer TreLENBERG), die Übersetzungen dagegen meist für $\eta \mu \tilde{\omega} v$ : „Unsere“ findet sich bei von OTto, Harnack, Puech, Kukula, Fermi, Di Cristina und Trelenberg, „eure“ nur bei WhitTAKER. Die Aufforderung muss mit der im folgenden formulierten Alternative zusammengenommen werden, die aber ebenfalls zum Teil recht unterschiedlich verstanden wird: ",similiter nobis a vestris decedite“ (vоN Oтто); „,oder (ihr mögt) ... uns die unsrigen (Lehren) preisgeben“ (НARNACK); „,ou, comme nous vous cédons les vôtres, cédez nous les nôtres" (Рuech); „,oder ... lasst unsere Sache ungeschoren“

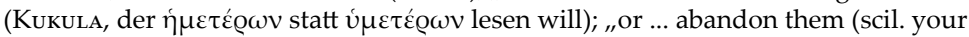
doctrines)“ (WHITTAKER); ",oppure lasciarle a noi [scil. le nostre dottrine], come noi facciamo per le vostre“ (Di CRISTINA, ähnlich bereits Fermi); ,,oder geht uns, wie wir es mit euren Lehren tun, aus dem Wege" (TrelenberG). Nach dem vorangehenden Satz („Wir überlassen euch das nutzlose Zeug“) lässt sich jedoch der ersten Aufforderung ("Glaubt ... euren Lehren“, mit v́ $\mu \tilde{\omega} v)$ durchaus ein Sinn abgewinnen (nämlich der: "glaubt doch, was ihr wollt!“), wozu dann das Folgende (mit dem

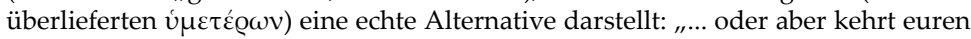
Lehren den Rücken, wie wir es getan haben!"

377 Mit einer freien Schulter wird der Kyniker Diogenes in Lukians Vitarum Auctio (7) eingeführt.

378 Das von Schwartz hinter кó $\mu$ v eingefügte $\tau \varepsilon$ hilft, die Periode besser zu gliedern;

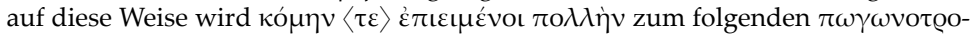

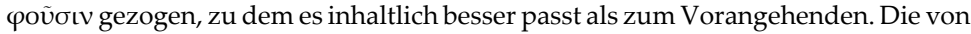


Marcovich in diesem Satz vorgenommene Umstellung weist Trelenberg 2012, 150 Anm. 264 zu Recht zurück.

379 Zum Bart als Philosophenkennzeichen vgl. oben Anm. 299.

380 Peregrinos Proteus scheint im Römischen Reich der mittleren Jahrzehnte des 2. Jh.s n. Chr. eine notorische Figur gewesen zu sein: Erst Christ, dann Kyniker, beendete er sein Leben an den Olympischen Spielen von 165 durch einen selbstgewählten Feuertod. Während der römische Buntschriftsteller Aulus Gellius in Athen von ihm einen guten Eindruck gewann (vgl. NA XII 11,1), ließ Lukian in seiner satirischen Darstellung von Peregrinos' Ende kein gutes Haar an ihm. Als kynischer Straßenprediger hatte Peregrinos auch einmal Rom besucht und hier durch Tiraden gegen den regierenden Kaiser Antoninus Pius Aufsehen erregt (vgl. Luc. Peregr. 18); aus dieser Zeit könnte die christliche Gemeinde in Rom noch direkte Erinnerungen bewahrt haben.

381 Der Ranzen ist ebenfalls typisches Philosophenkennzeichen, vor allem bei den Kynikern; vgl. Lukian, Demon. 48; Catapl. 3; Tim. 57; VA 7; 9; Pisc. 42; 45; Bis Acc. 6; Peregr. 15; Fug. 14; 20.

382 Auch der Stock ist festes Accessoire vor allem bei kynischen Philosophen; vgl. NesSELRATH 1985, 475f.

383 Zur Gefräßigkeit der Philosophen vgl. Nesselrath 1985, 371 .

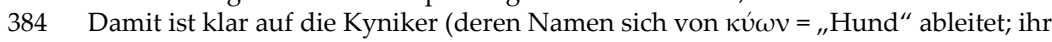
Gründungsheros Diogenes wird gern als „der Hund“ apostrophiert; vgl. Dio Prus. Or. 64,18; Plut. Ex. 7, 602A; Diog. Laert. I 15; VI 60; Aesop. Fab. 65) angespielt.

385 Das Bild des in der Öffentlichkeit lautstark auftretenden und alle beschimpfenden Kynikers hat Lukian vor allem am Beispiel des schon erwähnten Peregrinos Proteus vorgeführt, vgl. Luc. Peregr. 18f. Weitere Beispiele für krakeelende Kyniker finden sich VA 10f.; Pisc. 45; Fug. 14.

386 Wiederum Lukian präsentiert nicht wenige Beispiele für Philosophen, die aus ihrer Philosophie ein Geschäft machen; vgl. Nesselrath 1985, 464f. 466f.

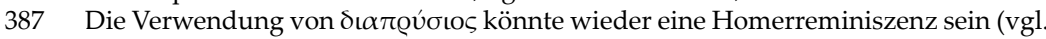
Ilias VIII 227 und fünf weitere Stellen, an denen Helden durchdringend schreien, um ihre Leute zu intensiverem Kampf aufzufordern).

388 Auch die unaufhörlichen Streitigkeiten der philosopischen Sekten untereinander sind ein bei Lukian oft zu findendes Thema; vgl. Nesselrath 1985, 314. 361f.

389 Darüber, dass Pythagoras behauptete, eine Reinkarnation des im Trojanischen Krieg auf der Seite der Trojaner kämpfenden Euphorbos zu sein (der an der Tötung des Patroklos beteiligt ist, vgl. Hom. Il. XVI 806-815, und dann von Menelaos getötet wird, Il. XVII 59f.), macht sich Lukian in Gall. 4; 13; 15f.; 17; VH II 21 und Dial. Mort. 6,3 lustig; eine ganze Reihe älterer Reinkarnationen des Pythagoras bietet Diog. Laert. VIII $4 \mathrm{f}$.

390 Bereits in 3,5 (oben Anm. 47 und 48) wird Pythagoras als Erbe des Pherekydes eingeführt.

391 Laut Aristoteles' Schrift De anima ist die Seele vom Körper nicht trennbar (II 1,413a4) und kann damit natürlich auch nicht als selbständiges Wesen unsterblich sein. Spätere Peripatetiker, z.B. Alexander von Aphrodisias in seiner Schrift über die Seele blieben auf dieser Linie und formulierten noch direkter, die Seele sei sterblich (vgl. Alex. Aphr. De an. S. 17,10-15; 21,22-24). Bereits der Aristoteles-Schüler Dikaiarch hatte die These vertreten, dass die Seele nur eine Funktion des Körpers sei (Fr. 7 und 9 WeHRLI).

392 Körperlichkeit wird Gott oder Gottheiten von den Stoikern und Epikureern zugewiesen.

393 Die Lehre von der Unvergänglichkeit der Welt wird bereits Xenophanes (Aët. Plac. 323,2-4 Diels = 21 A 37 DK) und Platon zugeschrieben (Diog. Laert. III 72); auch Aristoteles (De caelo I3, 270a13f.) hat sie vertreten, und sie bleibt bis zum spät- 
antiken Neuplatonismus (Proklos, gegen den sich Johannes Philoponos mit seiner Schrift De aeternitate mundi wendet) fester Bestandteil paganer Philosophie.

394 Zur Ekpyrosis-Vorstellung der Stoiker vgl. oben 3,3 und 6,1.

$395 \mathrm{Zu}$ den Totenrichtern Minos und Rhadamanthys vgl. oben 6,2 mit Anm. 88 und 89.

396 Zur Auferstehung auch des Leibes vgl. oben 13,1 und 15,2.

397 Zu Vorwürfen (aufgrund des falsch verstandenen Ritus der Eucharistie), die Christen praktizierten Kannibalismus, vgl. A. Henrichs, „Pagan Ritual and the Alleged Crimes of the Early Christians", in: P. Granfield / J. A. Jungmann (Hg.), Kyriakon. FS Johannes Quasten (Münster 1970) 18-35. Ein generelles odium generis humani wird den Christen bereits bei Tacitus (Ann. XV 44) zugeschrieben.

398 Als Geliebter des Poseidon wird Pelops, der Sohn des Königs Tantalos, zuerst in Pindars 1. Olympischer Ode dargestellt (V. 25; 36-42); die Geschichte, dass Tantalos seinen Sohn den Göttern zur Speise vorsetzte, deutet Pindar nur an (V. 25-27; vgl. aber Hygin. Fab. 83).

399 Der (nach seinem Vater Uranos, den er gestürzt hatte, zweite) Götterherrscher Kronos verschlang seine Kinder, weil er befürchtete, von ihnen in ähnlicher Weise entthront zu werden, wie er es mit seinem Vater getan hatte. Vgl. Hes. Theog. 453-467; Apollod. Bibl. I 4 = I 1,5.

400 Metis, Tochter des Okeanos, half Zeus bei der „Rückgewinnung“ seiner Geschwister aus dem Bauch des Kronos (vgl. die vorangehende Anm.), indem sie Kronos ein Brechmittel einflößte (Apollod. Bibl. I 6 = I3,2). Später wurde sie die erste Gemahlin des Zeus, doch überlebte sie diesen Eheschluss nicht einmal bis zur Geburt ihres ersten Kindes; Zeus hatte nämlich die Weisagung erhalten, dass Metis zuerst eine Tochter gebären werde, ",die an Weisheit und Kraft so stark wie ihr eigener Vater" (Hes. Theog. 896) sein würde, und danach sogar „,den König der Götter und Menschen" (Hes. Theog. 897f.). Da Zeus nicht seinen eigenen Entmachter in die Welt setzen wollte, griff er auf das alte Mittel seines Vaters Kronos zurück und verschlang Metis, als sie mit der erwähnten Tochter schwanger war, die dann später als Athena aus Zeus' Kopf zur Welt kam (vgl. Hes. Theog. 886-900; bei Apollod. Bibl. I 20 = I 3,6 dagegen will sich Metis nicht mit Zeus vereinigen - wohl weil sie bereits ihr späteres Schicksal kennt).

401 Die Geschichte, wie die Dohle sich mithilfe der Federn anderer Vögel schöner und größer zu machen versucht, jedoch rasch von den übrigen Vögeln enttarnt wird, die ihr die fremden Federn wieder wegnehmen, ist fester Bestandteil antiker Fabelsammlungen (vgl. Aes. Fab. 103; Babr. I 72).

402 Hier macht sich Tatian die am Apollon-Tempel in Delphi (vgl. Paus. X 24,1; Plut. De E 2, 385D; 17, 392A; 21, 394C) angebrachte Mahnung „Erkenne dich selbst!“ zunutze (vgl. H. TRÄNKLE, „"Gnothi seauton. Zu Ursprung und Deutungsgeschichte des delphischen Spruchs", Würzburger Jahrbücher für die Altertumswissenschaft NF 11 [1985] [19-31] 20f.).

403 Anspielung auf die zuerst in Platons Theaitetos (174a) überlieferte Geschichte, der Philosoph Thales von Milet sei, während er angestrengt zum Himmel aufschaute, in eine Grube gestürzt und dadurch zum Gespött einer thrakischen Magd geworden.

404 Mit dem Bild vom Labyrinth suggeriert Tatian, dass die Griechen eine so verwirrende Fülle von Schrifttum produziert (und - vgl. die folgende Anm. - in ihren Bibliotheken gesammelt) haben, dass man sich darin heillos verirren und verlieren muss. Vielleicht hat Tatian hier auch die resignierende Feststellung von Kohelet 12,12 vorgeschwebt: „Des vielen Büchermachens ist kein Ende.“

405 Das überlieferte $\alpha \dot{\alpha} v \alpha \theta \varepsilon \dot{\varepsilon} \sigma \varepsilon \varsigma$ ist verschiedentlich angezweifelt worden. Ältere Übersetzungen wollten es als „editiones“ (WоRTH), „pertractationes“ (MARAN, von OTTo), „Inhalt" (Harnack; vgl. „contenuto“ bei Fermi) oder "exposés“ (Puech, der aber auch an "amas" = "Anhäufung“ dachte) verstehen, aber das gibt die Grundbedeutung von $\alpha \dot{v} \alpha \dot{\theta} \theta \varepsilon \sigma \iota \varsigma$ kaum her. KuKULA wollte $\alpha \dot{v} \tau \imath \theta \varepsilon \dot{\sigma \varepsilon \varepsilon \varsigma}$ lesen und als „Wi- 
dersprüche in eueren Büchern“ verstehen, aber da liegt der Vergleich mit Labyrinthen (vgl. die vorangehende Anm.) kaum nahe. Richtiger sind WHITTAKERS „bookstacks“ (",scaffali dei vostri libri“ Di CRIstina). In diese Richtung geht auch TrELENBERG, übernimmt dafür aber MARcovichs Konjektur $\alpha \dot{\pi}$ to

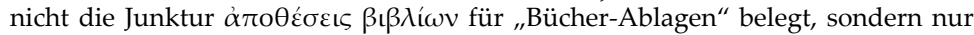
$\alpha \dot{\pi} \operatorname{0\theta } \tilde{\eta} \kappa \alpha \iota ~ \beta \iota \beta \lambda i ́ \omega v$ (Luc. Adv. Ind. 5; Cass. Dio XLII 38,2; XLIX 43,8; LIII 1,3); andererseits kommt die Junktur $\alpha \dot{v} \alpha \dot{\theta} \theta \varepsilon \sigma \iota \varsigma \beta \iota \beta \lambda i ́ \omega v$ vor (Aristid. Or. 51,63; vgl. Eus. HE II 18,8), so dass eine Änderung nicht nötig scheint.

406 Die Danaiden $=$ Töchter des Königs Danaos mussten zur Strafe für den von ihnen (freilich auf Geheiß ihres Vaters) noch in der Brautnacht begangenen Mord an ihren Ehemännern in der Unterwelt Wasser in ein durchlöchertes Fass schöpfen (vgl. Hygin. Fab. 168), und diese Strafe wurde schon bald sprichwörtlich (Zenob. Paroem. II 6; vgl. Plat. Gorg. 493b-c; Luc. Tim. 18; Hermot. 61). So sinnlos wie diese „DanaidenArbeit" ist laut Tatian auch das Lesen der unzähligen griechischen Bücher.

407 Tatian reißt hier kurz die zwischen Platonikern und Stoikern (vgl. Plut. Comm. not. 41, 1081C-1082A = SVF II 517-519) geführten Diskussionen darüber an, wie weit (und ob überhaupt) Zeiteinteilungen wie „Vergangenheit" , ,Gegenwart" , ,Zukunft" realen Phänomenen entsprechen.

408 Der Vergleich der Zeit mit dem sich bewegenden Schiff dürfte damit zusammenhängen, dass die Stoiker die Zeit mit einer Bewegung und der durch sie zurückgelegten Distanz zusammenbringen (vgl. SVF II 509-515). Der Vergleich mit der falschen Wahrnehmung der auf dem Schiff Fahrenden intendiert, dass die von Tatian angeredeten "Griechen“ einen grundsätzlichen Perspektivwechsel vornehmen müssten, um die wahren Verhältnisse zu erkennen.

409 Schon in 11,12 hebt Tatian die grundsätzliche Gleichheit aller Menschen hervor (vgl. dort auch Anm. 187 und 188).

410 Tatians Vorwurf gegen die „Grammatiker“, d.h. die professionellen Lehrer höherer Bildung, scheint ähnlich demjenigen Senecas (vgl. Ep. 88,39) zu sein: Sie vermitteln zu viel unnützes Einzelwissen, also eben "Geschwätz".

411 Die wahre Weisheit ist die von Gott geoffenbarte; die "Griechen“ dagegen haben in Tatians Augen nur partikulare Weisheiten, die sich in den philosophischen Sekten manifestieren, die in der Regel nach ihren Gründern benannt sind (Pythagoreer, Platoniker, Aristoteliker, Epikureer). Der Kontrast zwischen der „einen“ wahren Weisheit oder Philosophie und ihren vielen Teilausprägungen wird auch bei Lukian thematisiert (vgl. Pisc. 13; Par. 27f.; Hermot. 14).

412 Zum massiven Dissens der griechischen Philosophen untereinander vgl. bereits

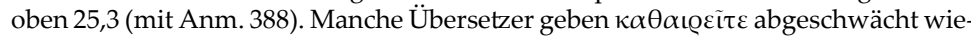
der (Worth: „VOs ipsi mutuis contentionibus atteritis“; PUECH: „vous vous ruinez mutuellement", so auch Fermi; KuкuLA: „so bekämpft und verurteilt ihr euch untereinander"; TRELENBERG: „,ihr ... verdammt euch gegenseitig“), doch ist es fraglich, ob Tatian das Wort nicht in aller Schärfe verstanden wissen wollte (und sei es nur in satirischer Zuspitzung; man vergleiche, wie die sich gegenseitig befeindenden Philosophen am Ende von Lukians Symposion massakrieren).

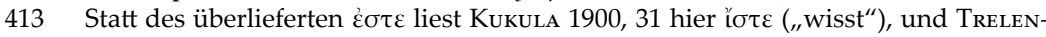
BERG folgt ihm; doch ist „,ihr seid nichts“ eine stärkere (und damit für Tatian wahrscheinlichere) Verdammung als "ihr wisst nichts“.

414 Der Gegensatz zwischen Taten und Worten der Philosophen ist auch bei Lukian ein gern und oft behandeltes Thema; vgl. Nesselrath 1985, 418. 465.

415 Vielleicht ist hier im Text ein Objekt zu $\pi$ ou $\pi \varepsilon v \varepsilon \varepsilon \varepsilon$ verlorengegangen; SchwarTz (IX) versucht es aus dem folgenden toù $\delta \dot{\varepsilon} \lambda$ ó $\gamma$ ouৎ zu gewinnen, muss dafür aber das eingebettete $\delta \varepsilon ́$ streichen und nach $\lambda$ ó $\gamma$ ouৎ eine Lücke postulieren, weil er noch ein weiteres Objekt zu ảंок९ú $\pi \tau \varepsilon \tau \varepsilon$ braucht. 
416 Schon im platonischen Gorgias (485d) wirft der Sophist Kallikles dem Sokrates vor, dass er als Philosoph sich flüsternd in einem Winkel mit ein paar Jünglingen aufhalte, anstatt eines freien Bürgers würdige Worte mitten auf der Agora zu sprechen.

417 Der „Krieg der Buchstaben“ erinnert an den sehr vergnüglich zu lesenden Prozess der Konsonanten (Lis consonantium = Iudicium vocalium), in dem Lukian sich das Sigma vor einem aus Vokalen bestehenden Richtergremium über die unverschämten Übergriffe beschweren lässt, mit denen das attizistische Tau es aus seinen ange-

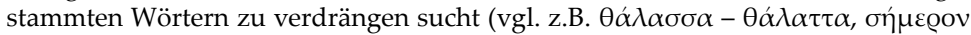
$-\tau \eta \dot{\mu \varepsilon \rho o v) . ~}$

418 Auch Lukian prangert den übertriebenen Attizismus seiner Zeit in mehreren Schriften an, neben dem schon erwähnten Lis consonantium im Lexiphanes und im Rhetorum praeceptor.

419 Ähnliche Beanspruchungen des Rechts, selbst gewählten Lehren (dafür, das über-

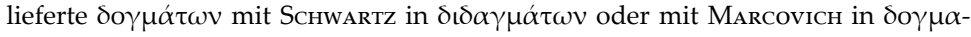
$\tau \iota \sigma \tau \tilde{\omega} \nu \mathrm{zu}$ ändern, gibt es keinen Grund) zu folgen, findet sich oben in 21,1.4; 22,4; 24,3 .

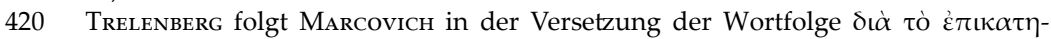

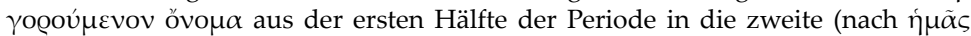
$\delta \varepsilon \dot{\varepsilon})$, aber Tatians Aussage ist durch die Beibehaltung der Überlieferung besser gedient als durch die Umstellung. Es geht hier um eine möglichst exakte Parallelisierung: Kein Räuber würde lediglich durch eine Beschuldigung, er sei „Räu-

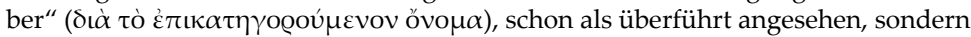
es bedarf immer noch einer wahrheitsgemäßen Feststellung der ihm vorgeworfenen Sachverhalte; bei Christen jedoch reicht die im Vorhinein als Schmähung ge-

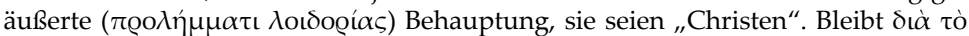

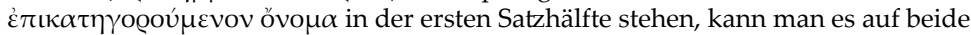
Satzhälften beziehen; diese Parallelität ginge durch die Umstellung verloren.

421 Diagoras von Melos (etwa 475-nach 415 v. Chr.) war einer der bekanntesten Atheisten der klassischen Antike; die Testimonien zu seinem Leben und die (wenigen) Fragmente aus seinen dichterischen Werken sind gesammelt bei M. WINIARCZYK, Diagorae Melii et Theodori Cyrenaei reliquiae (Leipzig 1981).

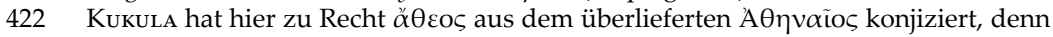
obwohl Diagoras offenbar einige Jahre seines Lebens in Athen verbracht hat, war er nie athenischer Bürger; ferner ist $\ddot{\alpha} \theta \varepsilon \circ \varsigma$ in vielen Testimonien festes Epitheton des Diagoras (vgl. T 5A/B. 8. 9A/B. 17. 41. 43. 45. 51. 57. 67A. 74 WINIARCZYK).

423 Die Profanation der Eleusinischen Mysterien (vgl. T 6A/B. 7A. 11. 16. 18A/B. 20. 27 WiNIARCZYK) war der schlimmste Diagoras gemachte Vorwurf und trug ihm $415 \mathrm{v}$. Chr. in einem Asebie-Prozess die Todestrafe ein, der er sich durch Flucht entzog (vgl. T 10. 17. 22A/B WiniARCZYK).

424 Das überlieferte $\tau \varepsilon \tau \iota \mu \omega \varrho \eta ́ \kappa \alpha \tau \varepsilon$ („,habt ihr zur Rechenschaft gezogen / bestraft“) lässt sich innerhalb des Argumentationsduktus dieses Satzes kaum halten, denn es soll ja gerade das völlig widersinnige und unlogische Verhalten der Griechen gegenüber Diagoras im Vergleich zu ihrem Verhalten gegenüber den Christen illustriert werden. Deswegen spricht einiges für Marans Änderung von $\tau \varepsilon \tau \tau \mu \omega \varrho \eta ́ \kappa \alpha \tau \varepsilon$ in $\tau \varepsilon \tau \iota \mu \eta ́ \kappa \alpha \tau \varepsilon$, die auch KuKula und TRelenberg (sonst aber offenbar niemand) übernommen haben. Zwar scheint die Änderung auf den ersten Blick der Überlieferung, dass die Athener Diagoras für seinen Frevel zur Rechenschaft zogen (bzw. zu ziehen versuchten) zu widersprechen; aber Tatian spricht hier nicht vom athenischen, sondern vom gemeingriechischen Standpunkt: Die "Griechen“ (insgesamt) halten Diagoras noch immer in Ehren, indem sie ihn nicht der damnatio memoriae anheimfallen ließen und sogar noch seine Bücher lesen.

425 Außer an dieser Stelle (= T 68 WiniarczYK) wird diese Schrift noch in einem auf Arabisch erhaltenen Bericht über Diagoras' Leben (= T 10 WINIARCZYK) erwähnt. 
426 Leon von Pella, auch „der Ägypter“ genannt, lebte zur Zeit Alexanders d. Gr. und soll bereits eine sehr ähnliche Lehre wie einige Jahrzehnte später Euhemeros vertreten haben, dass nämlich die Götter (die griechischen, aber auch die ägyptischen) einst bedeutende Menschen gewesen seien. Die Nachrichten zu Leons Leben und Schriften sind in FGrHist 659 gesammelt; das Werk (oder die Werke?), in dem (oder denen) er seine Götterlehre darstellte, wird (oder werden) mit verschiedenen Titeln

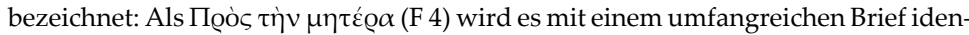
tifiziert, den Alexander d. Gr. an seine Mutter Olympias geschrieben habe (und in dem Darlegungen des hochrangigen ägyptischen Priesters Leon enthalten gewesen

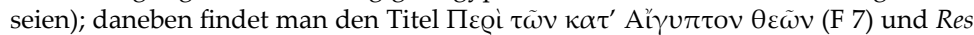
Aegyptiae (F 9a), was auf Griechisch mit Ai $\gamma v \pi \tau \iota \alpha \kappa \alpha ́$ wiederzugeben wäre.

427 Der im ausgehenden 1. Jh. v. Chr. und in der ersten Hälfte des 1. Jh.s n. Chr. lebende Grammatiker, Rhetor und Publizist Apion wuchs in Alexandria auf und brachte es dort bis zum Oberhaupt der Grammatikerschule; in späteren Lebensabschnitten lehrte er in Rom, wo er offenbar große Aufmerksamkeit erregte (laut Plin. Nat. praef. 25 nannte ihn Kaiser Tiberius ein cymbalum mundi, und Plinius fügt sarkastisch hinzu: $<c>$ um $<$ pro $>$ pr $<i>a e$ famae tympanum potius videri posset, , "während er eher als eine Trommel seines eigenen Ruhmes erscheinen konnte“; laut Seneca, Ep. 88,40 machte Apion auch in Griechenland sehr publikumswirksame Tourneen). Die Äußerungen Apions über die ägyptischen Götter dürften Teil seiner fünf

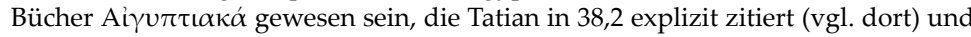
deren Fragmente in FGrHist 616 gesammelt sind (die Stelle hier in 27,3= F 18). Ein Beispiel für diese - Tatian offenbar absurd erscheinenden - Äußerungen hat wiederum der Ältere Plinius bewahrt (Nat. XXX 99 = FGrHist 616 F 19): Dort heißt es, die Ägypter würden den Skarabäus deswegen als Gottheit verehren, weil seine Tätigkeit der der Sonne ähnlich sei (... curiosa Apionis interpretatione, qua colligat Solis operum similitudinem huic animali esse).

428 Ein "Grab des Zeus" auf Kreta wird zum ersten Mal in der griechischen Literatur im Zeus-Hymnos des Kallimachos (V. 8f.) erwähnt und dort auch gleich mit dem Hinweis abgetan, dass die Kreter ja stets Lügner seien (die dichterische Fassung dieses Sprichworts, Kõ̃ $\tau \varepsilon \varsigma \dot{\alpha} \varepsilon \grave{\psi} \psi \varepsilon \tilde{v} \sigma \tau \alpha \iota$ [vgl. dazu die nächste Anm.] konnte Tatian wenn nicht aus Kallimachos selbst, so aus dem neutestamentlichen Titusbrief $[1,12]$ bekannt sein). Das Zeus-Grab taucht als götterkritisches Motiv auch mehrfach bei Tatians Zeitgenossen Lukian auf: JTr 45; Tim. 6; Sacr. 10; Philops. 3; Deor. Conc. 6.

429 Die älteste Fassung dieser sprichwörtlich gewordenen Wendung - Kallimachos hat sie in seinen Zeus-Hymnos integriert (vgl. die vorangehende Anm.) - wird auf den alten kretischen Seher und Philosophen Epimenides [zu ihm vgl. unten Anm. 615] zurückgeführt: 3 B 1 DK = FGrHist 457 F 2.

430 Obwohl Epikur die Existenz von Göttern nicht leugnet, gilt er dennoch vielen in der Antike de facto als Atheist, weil seine Götter keine im Gang der Welt eine Rolle spielende Macht darstellen (vgl. Cic. Nat. I 85: nonnullis videri Epicurum ... verbis reliquisse deos, re sustulisse, „einigen Leuten scheint es, dass Epikur ... die Götter zwar nominell belassen, de facto aber beseitigt hat"). In seinem Zeus Tragodos führt Lukian den Epikureer Damis als souveränen Götterleugner ein, der dem für Existenz und Walten der Götter argumentierenden Stoiker Timokles intellektuell weit überlegen ist.

431 Obwohl die Epikureer die Götter als für die Lebenswelt der Menschen eigentlich irrelevante Phänomene betrachteten (vgl. die vorangehende Anm.), schloss dies nicht aus, dass sie doch an den traditionellen religiösen Kulten der Polis teilnahmen; vgl. hierzu Epic. Fr. 142; 157; 169; 387 Usener; in Lukians Symposion (Kap. 9) ist der Epikureer Hermon selber Priester eines angesehenen Kults. Tatian spitzt die Spannung zwischen der epikureischen Göttervorstellung und der Teilnahme am Kultleben zu, indem er Epikur geradezu zum Daduchos, also einem der wichtigsten Kultfunktio- 
näre bei der eleusinischen Mysterienfeier, macht. Es spricht auf jeden Fall nichts dafür, das Prädikat $\delta \alpha \delta o v \chi \tilde{\eta}$ mit KuKULA („,mag auch der Götterverächter Epikur hier die Fackel vorantragen“) und Trelenserg (,Zugegeben, dass schon deren Verächter Epikur diese Tatsache wie mit einer Fackel erhellt") hier metaphorisch (Epikur als „erleuchtender Aufklärer“ dunklen Götterglaubens) zu verstehen, denn ein solcher Wortgebrauch ist nicht belegt.

432 Wilamowitz' Ergänzung бé $\beta \omega$ scheint immer noch die beste Möglichkeit, mit den textlichen Schwierigkeiten dieser Stelle einigermaßen fertigzuwerden (da für Tatian das, was eigentlich zählt, seine Verehrung für Gott ist, scheint $\sigma \varepsilon ́ \beta \omega$ angemessener als das von Di CRISTINA vorgeschlagene $\varepsilon \check{\chi} \omega$ und das von MarCovich vorgeschlagene und von TreLEnberg übernommene $\tau \mu \mu \tilde{\omega})$. Inhaltlich bietet die Aussage den Gegenpol zu dem gerade zuvor geschilderten widersprüchlichen Verhalten Epikurs: Während dieser aus Furcht vor den staatlichen Behörden (so interpretieren z.B. Äußerungen Ciceros - Nat. I 85; III 3 - dieses Verhalten) den offiziellen Kulten nicht fern zu bleiben wagte, ist der Christ Tatian bereit, entsprechende Risiken einzugehen.

433 Einen ähnlichen Widerspruch zwischen Wort (Behauptung, den Tod zu verachten) und Tat (Bemühen, den Tod zu vermeiden) hat Tatian oben in 19,2 bei dem Kyniker Crescens konstatiert.

434 In Hom. Il. I 225 beschimpft der in Zorn geratene Achill seinen Oberfeldherrn mit

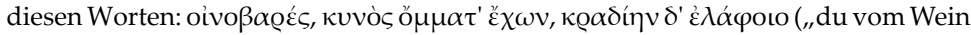
berauschter, mit den Augen eines Hundes und dem Herzen eines Hirsches!“).

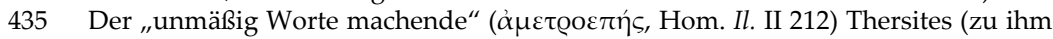
auch unten 32,6 mit Anm. 503) ist eine der negativsten Figuren der Ilias; mit Thersites' ungeordnetem Keifen die griechische Rhetorik zu vergleichen, ist eine bemerkenswerte Provokation.

436 Die hier zitierten Behauptungen gehen auf das Konto des vorsokratischen Philosophen Anaxagoras (vgl. Diog. Laert. II $8=59$ A 1 DK); zuerst belegt sind sie in Platons

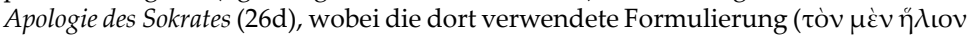

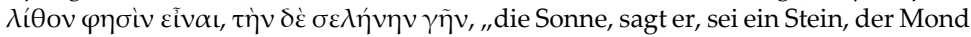
aber eine Erde") mit der bei Tatian zum Teil identisch ist, so dass Tatian diese Stelle hier sicher vor Augen gestanden hat. Auch Lukian macht sich mehrfach über diese Thesen des Anaxagoras lustig (Icar. 7. 20).

437 Der Ausdruck $\alpha \lambda \eta \theta \varepsilon i ́ \alpha \varsigma \delta \iota \alpha \kappa o ́ \sigma \mu \eta \sigma \iota \varsigma$ ist sehr verschieden verstanden worden: „,veritatis illustratio“ (vоN Отто); "gewissenhaft bedachte Wahrheit“ (НАRnAcк); ,erwiesene Tatsachen“ (KuKula); "conformité à la vérité" (Рuech); „orderly exposition of the truth“ (WhitTAKer); „esposizioni ordinate della verità" (Di CRISTINA; ähnlich vorher bereits FeRMI); ,ordnungsgemäß aufgestellte Wahrheitsaussagen“

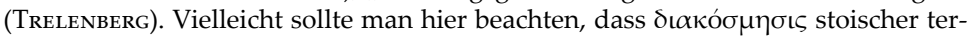
minus technicus für die geordnete Welt zwischen zwei Ekpyroseis ist (vgl. WiLDBERGER 2006, II 478 Anm. 93); dementsprechend ist hier übersetzt.

438 Der Mythograph Herodoros von Herakleia (um 400 v. Chr.; Testimonien und Fragmente gesammelt in FGrHist $31=$ R. L. Fowlen, Early Greek Mythography I [Oxford 2000] 232-257) verfasste neben anderen Werken auch eine wenigstens sieb-

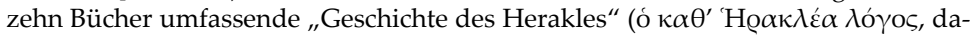
zu Fowlens Kommentarband [Early Greek Mythography II: Commentary, Oxford 2013] 260-333).

439 Aus Herodors Mitteilungen über die „obere Erde“ sind außer Fr. 4 JACOBY / FowLER (= unsere Tatianstelle) Fr. 21 (über die fünfzehnmal so großen Mondbewohner, deren Frauen Eier gebären) und Fr. 22 (über die Geier, die angeblich nicht auf der Erde, sondern auf einem anderen Himmelskörper nisten) erhalten. Dass der von Herakles getötete nemeische Löwe vom Mond stamme, wird schon in Versen behauptet, die 
dem Epimenides (vgl. oben Anm. 429 und unten Anm. 615) zugeschrieben werden (3 B 2 DK = FGrHist 457 F 3) und bei Aelian (Nat. XII 7) überliefert sind.

440 Das Wort $\sigma \omega \varrho \varepsilon i ́ \alpha$ spielt auf das sogenannte Sorites-Schlussverfahren an, das Cicero in Luc. 49 tadelt (captiosissimo genere interrogationis ..., quom aliquid minutatim et gradatim additur aut demitur: soritas hoc vocant, qui acervum efficiunt uno addito grano, „, mit einer völlig trügerischen Form der Befragung ..., wenn etwas in kleinsten Mengen oder Schritten hinzugefügt oder weggenommen wird: ,Haufenschlüsse' nennt man das, die einen Haufen erzeugen durch die (jeweilige) Hinzufügung eines einzigen Korns").

441 Die Verschiedenheit menschlicher Sitten thematisiert bereits Herodot (III 38: Der persische Großkönig Dareios lässt Inder und Griechen aufeinandertreffen, die diametral verschiedene Bestattungssitten haben). Tatian bringt im folgenden zwei besonders drastische Beispiele.

442 Dass Inzest mit der Mutter oder Tochter für die persischen Magier ő tet auch Diog. Laert. I 7 unter Berufung auf Sotion (Fr. 36 WeHrLI); vgl. Plut. Alex. fort. 5, 328C.

$443 \mathrm{Zu}$ den „Herden von Knaben“ bietet Justin, 1 Apol. 27,1 ein deutliches Vorbild (ôv

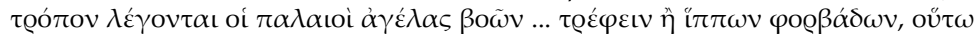

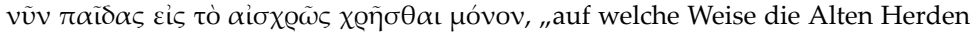
von Rindern ... oder Weidepferden ernährt haben sollen, so (halten sie) jetzt Knaben nur, um sie auf schändliche Weise zu missbrauchen“). - Die Änderung des überlie-

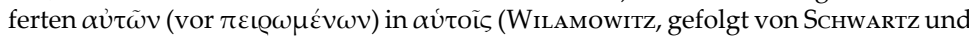
MarCovich) ist unnötig.

444 Gemeint sind Kulte für die Große Mutter (Kybele/Rhea) und die Dea Syria, die von entmannten Priestern (Galli) betreut wurden, z.T. stationär in bestimmten Heiligtümern (vgl. etwa Lukian, De Dea Syria 15; 22; 27; 50-53), z.T. auch von umherziehenden Bettelpriestern (dazu bietet eine sehr schillernde Vignette Ps.-Lukian, Asin. 35-39).

445 Iuppiter Latiaris war die Schutzgottheit des alten Bundes der Latinerstädte (in dem Rom dann eine führende Stellung übernahm); sein Kultort befand sich auf dem Mons Albanus. Die älteste Erwähnung angeblicher Menschenopfer in diesem Kult findet sich bei Justin (2 Apol. 12,5, ohne explizite Nennung des Jupiter Latiaris), die erste explizite Verbindung mit dem Kult des Latiaris bei Minucius Felix (Oct. 30,4, vgl. 23,6). Immerhin notiert sogar eine pagane Quelle (Porph. Abst. II 56,9), dass beim Fest des „Zeus Latiarios“ ein Mensch geschlachtet werde. Zur Bewertung dieser Nachrichten vgl. I. GRADEL, "Jupiter Latiaris and Human Blood - Fact or Fiction?", Classica et Mediaevalia 53 (2002) 235-253.

446 Für den Kult der Diana Nemorensis von Aricia (einer kleinen Stadt etwa 26 km südöstlich von Rom) ist überliefert, dass sein Zentrum, eine heilige Eiche, vom sogenannten rex Nemorensis bewacht wurde, der ein entlaufener Sklave war; dieser verlor jedoch sein Amt, wenn es einem anderen entlaufenen Sklaven gelang, einen Ast von der Eiche abzubrechen und dann den rex Nemorensis im Duell zu töten. In dieser Form schildert der Vergil-Kommentator Servius den Ritus (in Verg. Aen. VI 136; vgl. Suet. Cal. 35,3; Strab. V 3,12, S. 239; Paus. II 27,4).

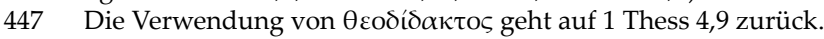

448 Die von Marcovich vorgenommene (und von Trelenberg übernommene) Erset-

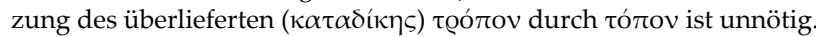

449 Bereits oben in 14,1 hat Tatian darauf hingewiesen, dass die Griechen sich durch ihren Polytheismus eine "Vielherrschaft" bereitet haben.

450 Vgl. oben 13,$4 ; 15,1 ; 20,2$.

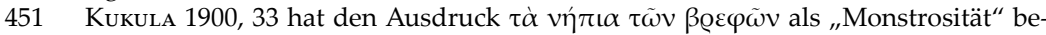

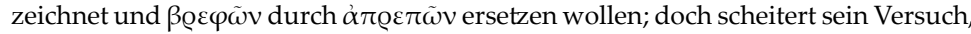

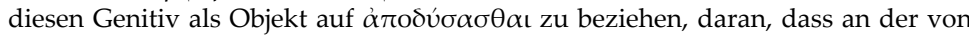


ihm angeführten Aristophanes-Stelle (Thesm. 656) der Genitiv wohl als Partitivus zu werten ist (vgl. LSJ s. v. $\dot{\alpha} \pi 0 \delta v ́ \omega$ II 1) und dieses Verb sonst nur Akkusativ-Objekte hat. Übrigens findet sich der Ausdruck $\tau \dot{\alpha} v \eta \dot{\tau} \tau \iota \alpha \tau \tilde{\omega} v \beta \rho \varepsilon \varphi \tilde{\omega} v$ auch bei Diod. II 58,5 und bedeutet dort genau das, was er wohl auch hier heißt: die ganz kleinen unter den Kindern.

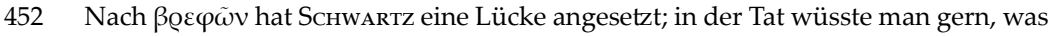
die kleinen Kinder abstreifen (Windeln? Torheiten? DI CRISTINA ergänzt „giocattoli“, also Spielsachen) und wovon im Vergleich dazu Tatian sich durch seine Konversion zum Christentum befreien möchte. РUECH hat versucht, $\dot{\alpha} \pi$ rodv́ $\sigma \alpha \sigma \theta \alpha \iota$ intransitiv zu verstehen (,,je veux me mettre nu comme les jeunes enfants“; ähnlich FERMI), aber dann bleibt der Vergleich zu offen und unscharf.

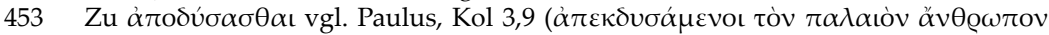

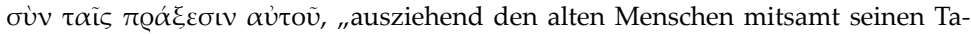
ten").

454 Bei den „kleinsten Samen“, die stark wachsen können, lässt sich zum einen an das in Mt 13,32 erwähnte Senfkorn denken, zum anderen aber auch an den unkrautartigen

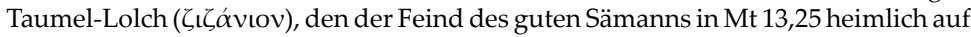
dessen Acker ausbringt.

455 Das Pronomen toútou muss sich (auch wenn dies syntaktisch hart ist) auf die vor-

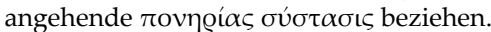

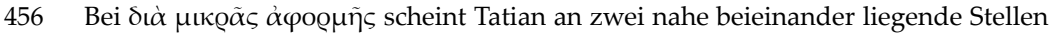

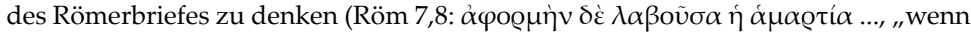

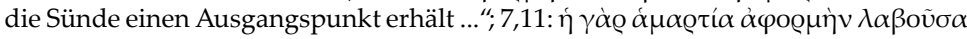
..., „,die Sünde nämlich, wenn sie einen Ausgangspunkt erhält ...“).

457 Deutlicher Anklang an das Gleichnis vom verborgenen Schatz in Mt 13,44 ('Ouoí $\alpha$

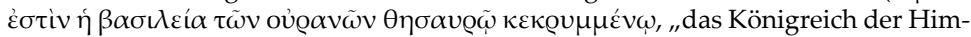
mel ist gleich einem verborgenen Schatz").

458 Marans Konjektur $\pi \alpha \varrho \varepsilon ́ \sigma \chi O \mu \varepsilon v$ (statt $\pi \alpha \varrho \varepsilon ́ \chi O \mu \varepsilon v)$, übernommen von SchwarTz, GoodsPeEd und Marcovich, ist unnötig.

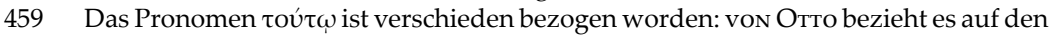
Schatz (so auch Fermi und WhitTAKer); Harnack versteht "dem staubgeborenen Menschen“; Puech bezieht es auf den „Logos Gottes“ (ebenso Kukula); TrelenberG legt sich nicht fest.

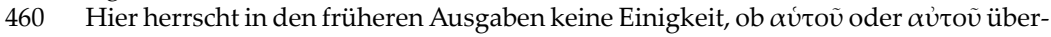
liefert ist: Schwartz druckt aútoṽ im Text und sagt nichts im Apparat, sieht also

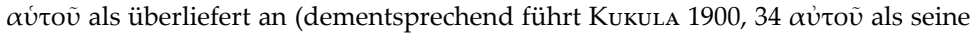
Konjektur an); dagegen betrachten Whittaker, Di Cristina, Marcovich und Tre-

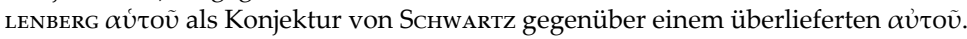
Wie dem auch sei, im vorliegenden Kontext scheint $\alpha \hat{v} \tau o \tilde{v}$ angebrachter, denn es würde noch einmal auf den Logos zurückverweisen, durch dessen Besitz man noch „kostbareren Reichtum“ (das Himmelreich) erwirbt.

461 Hier spielt Tatian auf die Entstehung der Sprachenverwirrung durch den Turmbau zu Babel an (Gen 11,1-9); aufgrund dieser Geschichte lassen sich alle Sprachen als gleich ansehen und jedenfalls kein Superioritätsanspruch der Griechen ableiten.

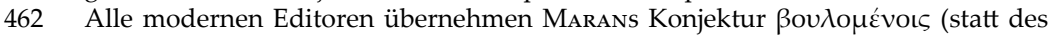
überlieferten $\beta$ ovגó $\mu \varepsilon v o \varsigma$ ), und Schwartz fügt davor noch den bestimmten Artikel toĩ vorneweg hinzu. Es ist jedoch zu erwägen, ob die Überlieferung nicht doch

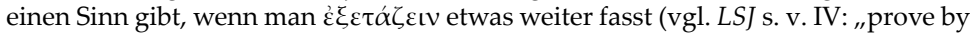
scrutiny or test"). Wenn man so hier versteht, ergibt sich eine ähnliche Aussage wie die, mit der Tatian in 42,2 seinen Text beschließt.

463 Kapitel 31 ist zur Gänze auch als Zitat in Eusebios' Praeparatio evangelica überliefert (vgl. oben Einführung S. 19). 


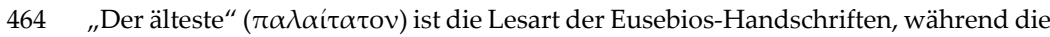
Tatian-Handschriften $\pi \alpha \lambda \alpha$ tó $\varepsilon £ \rho o v$ haben, was von den modernen Editionen nur TRELENBERG übernimmt, aber mit ,jeweils die ältesten“ übersetzt (vgl. dazu die folgende Anmerkung).

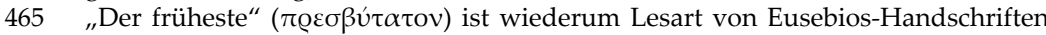
(diesmal freilich nicht von allen), während die Tatian-Handschriften erneut den Komparativ ( $\pi \rho \varepsilon \sigma \beta u ́ \tau \varepsilon \rho o v)$ bieten, was von den modernen Editionen wiederum nur TRELENBERG übernimmt (auch er übersetzt jedoch „der älteste“, mit der Begründung: „Der ... Komparativ ... ist sachlich mit dem Superlativ identisch“; dies wäre jedoch nur der Fall, wenn bei den „Dichtern und Geschichtsschreibern“ im griechischen Text ausdrücklich ,alle“ hinzugesetzt wäre).

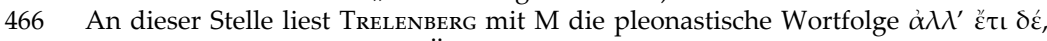
während $\mathrm{V}$ und die Eusebios-Überlieferung éc anderen modernen Editoren akzeptiert wurde. Auch an anderen Stellen folgt bei

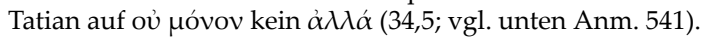

467 „Verwenden“: alle modernen Editoren haben sich für das bei Eusebios zu lesende

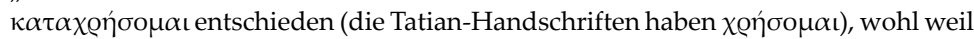
es stilistisch besser zu dem vorangehenden Kompositum $\pi \alpha \varrho \alpha \lambda \eta ́ \psi о \mu \alpha \iota$ passt.

„Weil man es auch von unserer Seite nicht akzeptieren dürfte“ gibt das in den

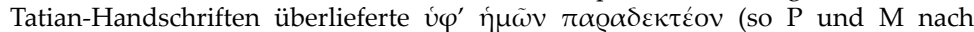
Korrektur; in der ursprünglichen Fassung von $\mathrm{M}$ und in $\mathrm{V}$ stand bzw. steht

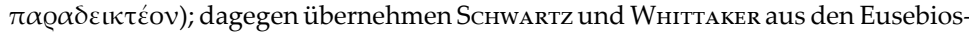
Handschriften $\pi \alpha \varrho \alpha \delta \varepsilon \kappa \tau$ tóv und Marcovich und Trelenberg sogar das nur in zwei von vier Eusebios-Handschriften zu findende v́ $\mu \tilde{\omega} v$ (wobei TreLEnBerg gleichwohl „weil nicht einmal bei uns beweiskräftig“ übersetzt). Vgl. zur Textherstellung hier im Übrigen NesSelRath 2005, 254f.

469 „Wenn“: Alle modernen Editoren (außer GoodsPEED) übernehmen ó $\pi$ „ót $\alpha v$ aus den Eusebios-Handschriften, während die Tatian-Handschriften ő $\alpha$ v nahelegen; dies dürfte richtig sein, weil der Kondizionalsatz nicht iterativ konnotiert ist.

470 „Bekomme“: Während Schwartz und Whittaker das in den Tatian-Handschriften überlieferte $\lambda \alpha \mu \beta \alpha ́ v \omega \omega$ drucken, bevorzugen Marcovich und Trelenserg das bei Eusebios zu findende $\pi \alpha \varrho \alpha \lambda \alpha \mu \beta \alpha ́ v \omega$.

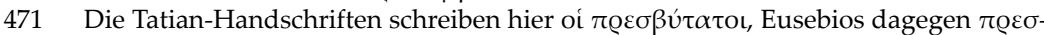

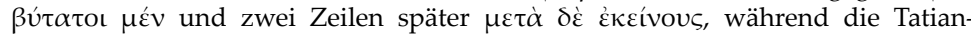
Handschriften dort $\delta \varepsilon ́$ weglassen; möglicherweise hat Eusebios in dieser Aufzählung bereits stilistisch geglättet. Von den modernen Editoren folgen SchwarTZ, Whittaker und Marcovich dem Eusebios-Text, während Trelenberg sich mit oí

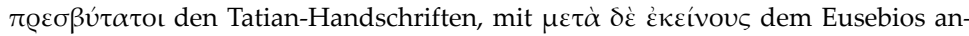
schließt. Ebenso übernehmen zu Beginn von $\S 4$ alle modernen Editoren aus Eu-

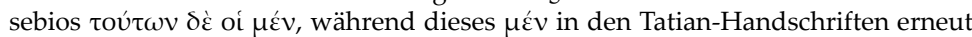
fehlt.

472 Theagenes aus Rhegion in Unteritalien ist ein griechischer Literat des späteren 6. Jh.s v. Chr.; zu seiner Beschäftigung mit Homer vgl. Pfeiffer 1970, $26 f$.

473 Kambyses: zweiter Perserkönig der Achaimeniden-Dynastie, regierte von 529 bis 522 v. Chr. Trelenberg 2012, 165 Anm. 327 dagegen glaubt, es handle sich um seinen Großvater (den Vater des Reichsgründers Kyros), der in der ersten Hälfte des 6. Jh.s unter medischer Oberherrschaft Fürst der Persis war; diese Identifikation kann jedoch nicht richtig sein, weil Theagenes von Rhegion (s. vorangehende Anmerkung) damit zu früh datiert würde. Theagenes dürfte mit seiner allegorischen Homerverteidigung auf Kritik an der ,unmoralischen' Götterdarstellung Homers reagieren, wie sie erstmals von Xenophanes von Kolophon im späteren 6. Jh. v. Chr. geäußert wurde. 
474 Stesimbrotos von der Insel Thasos ist ein griechischer Literat und Geschichtsschreiber des 5. Jh.s v. Chr. (Testimonien und Fragmente gesammelt in FGrHist 107). Zu seiner Beschäftigung mit Homer vgl. Pfeiffer 1970, 56. 67. - Zum Text der Stelle: Stesimbrotos wird in den Tatian-Handschriften mit nachgestelltem $\tau \varepsilon$ eingeführt, bei Eusebios dagegen mit vorangestelltem $\kappa \alpha$ í.

475 Antimachos (so richtig in den Tatian-Handschriften überliefert; bei Eusebios dage-

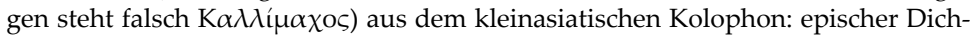
ter des späteren 5. und frühen 4. Jh.s (Testimonien und Fragmente gesammelt von V. J. Matrhews, Antimachus of Colophon. Text and commentary [Leiden 1996]), der außerdem erster namentlich bezeugter Editor einer Homer-Ausgabe ist (vgl. dazu Pfeiffer 1970, 121-123).

476 Herodot kommt in seinem Geschichtswerk in II 53,2 auf die Lebenszeit Homers zu sprechen: vierhundert Jahre vor seiner eigenen Zeit.

477 Ein Dionysios von Olynth wird nur an dieser Stelle als Autor, der sich mit Homer befasste, erwähnt.

478 Ephoros von Kyme war ein griechischer Universalhistoriker des 4. Jh.s v. Chr. (Testimonien und Fragmete zu ihm sind gesammelt in FGrHist 70; unsere Tatian-Stelle ist F 98); über Studien des Ephoros zu Homer ist sonst nichts bekannt.

479 Philochoros war ein athenischer Schriftsteller des 3. Jh.s v. Chr. (Testimonien und Fragmente zu ihm sind gesammelt in FGrHist 328; unsere Tatian-Stelle ist F 211a). Sein Hauptwerk ist eine Geschichte Attikas (Atthis) von den Anfängen bis in seine eigene Lebenszeit; er verfasste auch eine Reihe antiquarischer und literarhistorischer Schriften (Titelverzeichnis bei FGrHist, IIIb Suppl. [Textband] 242).

480 Von dem ins spätere 4. oder frühe 3. Jh. v. Chr. zu datierenden Megakleides wird verschiedentlich ein Werk Пвœi 'Ouń@ov (vgl. FHG IV 443) zitiert, das mindestens zwei Bücher umfasste (Schol. Hom. Il. XVI 140b; XXI 195b).

$481 \mathrm{Zu}$ dem Peripatetiker Chamaileon von Herakleia (späteres 4. und frühes 3. Jh. v. Chr.) vgl. die Testimonien- und Fragmentsammlung von F. WehrLi (Die Schule des Aristoteles, Bd. 9 [Basel ${ }^{2}$ 1969]; unsere Tatian-Stelle ist Fr. 14 WeHrLI). Er verfasste eine mindestens fünf Bücher umfassende Schrift „Über die Ilias“ (Fr. 22 WeHrLI) und wahrscheinlich auch ein Werk „Über die Odyssee“ (vgl. Fr. 21 WeHrLI).

482 Zenodot von Ephesos (um 330-um 260 v. Chr.) war der erste der großen alexandrinischen Philologen, der erste Direktor der von Ptolemaios I. gegründeten großen Alexandrinischen Bibliothek und Erzieher des Prinzen Ptolemaios II. Zu seinen Homerstudien vgl. Pfeiffer 1970, 136-150; K. Nickau, Untersuchungen zur textkritischen Methode des Zenodotos von Ephesos (Berlin / New York 1977), vor allem 253-259.

483 Aristophanes von Byzanz (etwa 255-180 v. Chr., ebenfalls Direktor der großen Alexandrinischen Bibliothek, und zwar als Nachfolger des Eratosthenes, vgl. unten Anm. 486) ist der nächste (nach Zenodot) große alexandrinische Homerphilologe; zu seinen Homerstudien vgl. Pfeiffer 1970, 216-220.

484 Kallimachos von Kyrene (geboren in den letzten Jahrzehnten des 4. Jh.s, gestorben nach 245 v. Chr.) ist als Philologe und Dichter wohl die beste Verkörperung des hellenistischen poeta doctus; er schuf nicht nur eines der bedeutendsten dichterischen Oeuvres des Hellenismus, sondern machte sich auch um die große Alexandrinische Bibliothek verdient, da er ihren ersten umfassenden Katalog schuf (vgl. unten). $\mathrm{Zu}$ seiner Beschäftigung mit Homer vgl. Pfeiffer 1970, 174-176.

Anstelle des einhellig sowohl in den Tatian-Handschriften als auch bei Eusebios

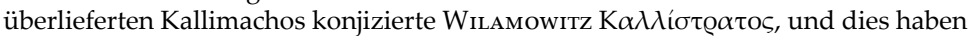
alle Editoren seit SchwARTz in den Text übernommen, vielleicht deshalb, weil der Grammatiker Kallistratos als Schüler des Aristophanes von Byzanz die chronologische Reihenfolge wahren würde, während Kallimachos - der um 240 v. Chr. starb und deutlich älter ist als der vor ihm genannte Aristophanes von Byzanz - diese Reihenfolge stören würde. Die Chronologie wird aber auch bei den vorhergehenden 
Namen nicht immer gewahrt (denn der als nächster genannte Krates von Mallos ist deutlich jünger als der nach ihm aufgeführte Eratosthenes), womit das Argument der Chronologie zur Beseitigung des überlieferten Kallimachos gegenstandslos wird. Kallimachos hat sich mit Sicherheit in seinen Pinakes, dem von ihm angelegten ersten großen Katalog der Bibliothek von Alexandria, auch zum Alter von Homer geäußert und passt damit durchaus in die hier von Tatian aufgezählte Reihe von Geistesgrößen, die sich mit dieser Frage beschäftigten; dagegen ist es sehr fraglich, ob der sonst nur aus einigen grammatikalischen Spezialschriften, Athenaios' Deipnosophistai und Homer-Scholien bekannte Kallistratos Tatian überhaupt ein Begriff war.

485 Der stoische Philosoph Krates von Mallos (geboren im späteren 3. Jh., gestorben um 145 v. Chr.) wurde von dem pergamenischen König Eumenes II. zum Gründer einer grammatisch-literarwissenschaftlichen Schule in Pergamon gemacht, die zu einer ernsten Rivalin der alexandrinischen Philologie wurde. Zu Krates' Homer-Studien vgl. Pfeiffer 1970, 291-294.

486 Eratosthenes von Kyrene (um 275-um 194 v. Chr.) war nicht nur Dichter, sondern auch vielseitiger (geradezu universaler) Gelehrter mit bedeutenden Leistungen vor allem in Geographie und historischer Chronologie (dazu auch Direktor der großen Alexandrinischen Bibliothek). Zu seinen Homer-Studien vgl. Pfeiffer 1970, 205. 207. 209.

487 Aristarch von Samothrake (um 216-um 144 v. Chr.) war (nach Zenodot, vgl. oben Anm. 482, und Aristophanes von Byzanz, vgl. oben Anm. 483) der dritte große (und vielleicht bedeutendste) alexandrinische Homer-Philologe; zu seinen HomerStudien vgl. Pfeiffer 1970, 262-269. 278-283.

488 Apollodor von Athen (um 180-nach 120/19 v. Chr.), Schüler des gerade genannten Aristarch, verfasste ein ,populärwissenschaftliches' chronologisches Werk in iambischen Versen (Chronika; hierzu Pfeiffer 1970, 309-312), ein umfangreiches Werk (in zwölf Büchern) über den Schiffskatalog in Buch II der Ilias und eine noch um-

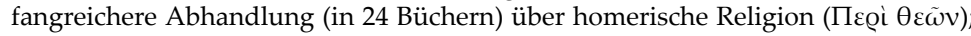
zu beiden vgl. Pfeiffer 1970, 312-319. Testimonien und Fragmente sind gesammelt in FGrHist 244.

489 Mit der periphrastischen Formel oí $\mu \varepsilon \grave{v} v \pi \varepsilon @ i$ K@ó $\tau \eta \tau \alpha$ ist letztlich nur Krates selber gemeint (so richtig von Отто, Fermi; dagegen Нarnacк: „die Anhänger des Krates“, Puech: "les disciples de Cratès“, Whittaker: "the school of Crates“, Di CrisTINA: „quelli della cerchia di Cratete“, Trelenderg: „die Schüler des Krates"), eben-

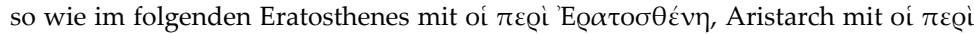

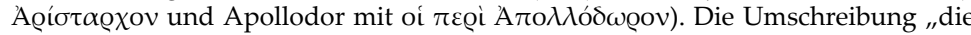
um $X^{\prime \prime}={ }^{\prime} X^{\prime \prime}$ grassiert besonders in kaiserzeitlichen griechischen Texten, beginnt zum Teil aber schon erheblich früher; vgl. dazu S. RADT, „OI (AI etc.) ПEPI + Acc. nominis proprii bei Strabon“, ZPE 71 (1988) 35-40; R. GoRMAN, „OI ПEPI TINA in Strabo“, ZPE 136 (2001) 201-213; ders., „,Polybius and the evidence for periphrastic hoi peri tina", Mnemosyne 56 (2003) 129-144.

490 Mit der „Rückkehr der Herakliden“ ist die (Rück-)Eroberung der Peloponnes durch die Nachkommen des Herakles gemeint (Herakles wäre rechtmäßiger König von Argos, des mythischen Hauptortes der Peloponnes, gewesen, wenn Hera nicht seine Geburt hinausgezögert hätte, so dass er nach Eurystheus geboren wurde; vgl. Apollod. Bibl. II 53 = II 4,5). Laut dem Gelehrten Apollodor (oben Anm. 488) fand diese Rückkehr - die dann auch gern mit der dorischen Einwanderung in die Peloponnes gleichgesetzt wurde - achtzig Jahre nach dem Fall Trojas (1184/3 v. Chr. vgl. Anm. 491), also im Jahr 1104/3 v. Chr., statt (vgl. Diod, I 5,1 = Apollodor FGrHist 244 F 61a).

491 An dieser und den folgenden Stellen ist das, eratosthenische ${ }^{`}$ Datum der Eroberung von Troja (1184/3 v. Chr.) als Fixpunkt zugrunde gelegt. 
492 Mit der "Ionischen Kolonisierung“ (140 Jahre nach dem Trojanischen Krieg = $1044 / 43$ v. Chr.) ist der halbmythische Vorgang gemeint, in dem von Athen aus unter Führung verschiedener Söhne des letzten attischen Königs Kodros Milet und andere bedeutende ionische Städte (insgesamt zwölf, die sogenannte ionische Dodekapolis) an der kleinasiatischen Küste gegründet worden sein sollen; vgl. Strabon VIII 7,1 und XIV 1,3.

Zum Teil die gleichen Daten für Homer wie Tatian in diesem Abschnitt bietet Clem. Alex. Strom. I 117,1-3: Aristarch zur Zeit der Ionischen Kolonisierung, Apollodor 100 Jahre nach der Ionischen Kolonisierung (= 944/3 v. Chr.); dagegen habe Philochoros ihn 180 Jahre nach der Ionischen Kolonisierung (=864/3 v. Chr.) angesetzt (das Intervall „180 Jahre“ erscheint auch bei Tatian, wird aber bei ihm vom Trojanischen Krieg aus gerechnet und führt damit auf das Jahr 1004/3 v. Chr.). Clemens führt noch weitere Datierungen (über Tatian hinaus) an und nennt dann in Strom. I 117,6f. auch eine ähnliche Datierung Homers wie Tatian für Krates (Zeit der Rückkehr der Herakliden; bei Tatian steht ,vor der Rückkehr der Herakliden“) und die gleiche Datierung für Eratosthenes (100 Jahre nach dem Fall Trojas = 1084/3 v. Chr.)

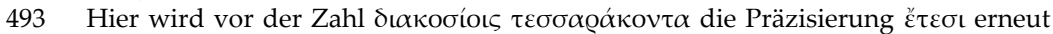
von allen modernen Editoren aus Eusebios übernommen, während sie in den Tatian-Handschriften fehlt; da Éं $\varepsilon \sigma \iota v$ jedoch nur eine halbe Zeile vorher bei einer gleichartigen Angabe steht, hat Tatian selbst es hier vielleicht einfach eingespart.

494 Hier übernehmen Marcovich und Trelenberg die Einfügung von $\mu$ ikoóv („,kurz“) durch Rudolf HeLm vor $\pi$ อò $\tau \tilde{\omega} v v^{\prime} \mathrm{O} \lambda v \mu \pi \mathrm{u} \alpha \dot{\delta} \omega \omega v$, was aber nicht unbedingt nötig ist, da ja gleich danach die Präzisierung „vierhundert Jahre nach der Einnahme von Ilion" erfolgt.

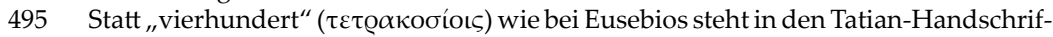

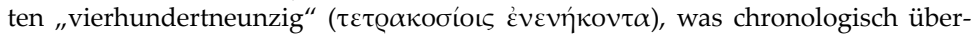
haupt nicht aufgeht. Zwischen 1183 und 776 v. Chr. (dem Beginn der Olympischen

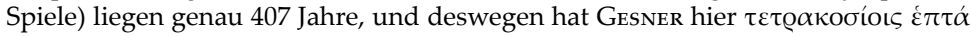
konjiziert, was MarCovich in seinen Text übernimmt, wozu dann freilich das eben-

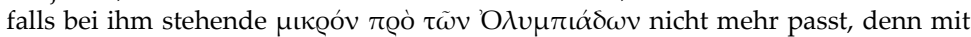
407 wären wir ja genau im Jahr des Olympiadenbeginns.

Die hier auf "einige" und „,andere“ zurückgeführten Datierungen werden bei Clemens (Strom. I117,8f.) zum Teil mit Namen versehen: Die Gleichzeitigkeit mit Archilochos (erste Hälfte des 7. Jh.s v. Chr., Dichter von Elegien und spöttischen Iamben), die auf einen Abstand von 500 Jahren nach dem Trojanischen Krieg führt, vertrat der Historiker Theopomp von Chios (FGrHist 115 F 205), die mit dem lydischen König Gyges (Begründer der Dynastie, deren letzter Vertreter der legendär reiche Kroisos war) der hellenistische Dichter und Gelehrte Euphorion.

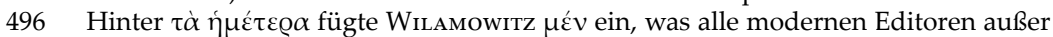
TRELENBERG übernehmen.

497 Anspielung auf eine Szene im 8. Buch der Ilias, in der Nestor, der älteste Heerführer der Griechen vor Troja, in Lebensgefahr gerät, weil er sich nicht schnell genug vor dem anstürmenden Hektor retten kann (Il. VIII 78-90); Tatians Wortfolge

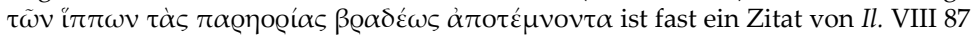

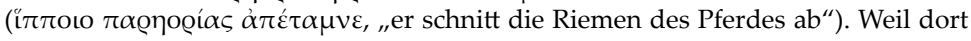

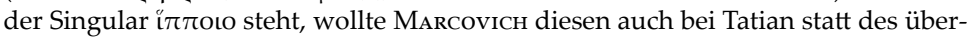
lieferten Plurals einsetzen; da jedoch im Vers vorher von „Pferden“ im Plural die Rede ist (und gleich im Anschluss wieder), ist diese Änderung unnötig. Als dann der junge Diomedes zur Rettung Nestors eingreift, hebt er dessen Alter sehr expli-

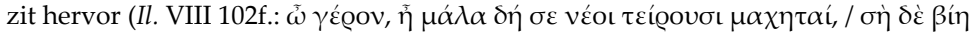

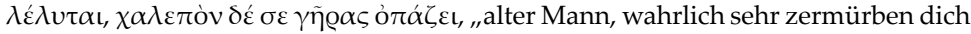
junge Kämpfer, deine Kraft ist gelöst, und das mühevolle Alter bedrängt dich“), 
und dies liefert den Aufhänger, um Nestor hier als für eine Schlacht eigentlich zu alt einzuführen.

Dass Nestor es sich nicht nehmen lässt, trotz seines Alters seine Truppen selbst in den Kampf zu führen, wird z.B. Hom. Il. X 77-79 ausdrücklich gesagt ( $\pi \dot{\alpha} \varrho \delta \dot{\varepsilon}$

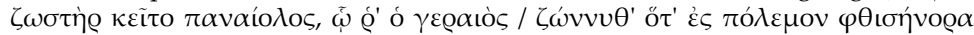

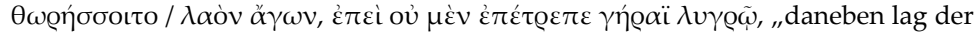
buntschillernde Gürtel, mit dem der alte Mann sich zu gürten pflegte, wenn er sich zum männerverderbenden Krieg rüstete und dabei seine Leute führte, da er sich nicht dem traurigen Alter überließ").

499 Amazonen als mythisches kriegerisches Frauenvolk sind in der griechischen Literatur seit Homer belegt (Il. III 184; VI 186); vgl. O. Wenskus, „Amazonen zwischen Mythos und Ethnographie“, in: S. KLettenhammer / E. Pöder (Hg.), Das Geschlecht, das sich (un)eins ist? Frauenforschung und Geschlechtergeschichte in den Kulturwissenschaften (Innsbruck 2000) 63-72; J. FornAsier, Amazonen. Frauen, Kämpferinnen, Städtegründerinnen (Mainz 2007); Ch. TAUBE, „Literarische Amazonenbilder der Antike“, in: Ch. Schubert / A. Weiss (Hg.), Amazonen zwischen Skythen und Griechen (Berlin / Boston 2013) 39-56.

500 Semiramis wurde vor allem von dem griechischen Geschichtsschreiber Ktesias bekannt gemacht (bei dem sie die Frau des assyrischen Königs Ninos und Begründerin von Babylon ist), dem dann Diodor seine umfangreiche Darstellung im zweiten Buch seiner Bibliotheke verdankt.

501 "Schwach“ war der griechische Held Philoktet, weil er noch vor der Ankunft in Troja auf der Insel Lemnos von einer Schlange gebissen wurde, deren Gift eine übel riechende und nicht heilen wollende Wunde verursachte, weshalb das griechische Heer ihn auf Lemnos zurückließ; da Philoktet jedoch den Bogen und die Pfeile des Herakles bei sich hatte und ein Orakel besagte, dass nur durch deren Anwendung Troja erobert werden könne, sahen sich die Griechen gezwungen, Philoktet im zehnten Kriegsjahr wieder zu holen. Die Geschichte war in den Kyprien und in der Kleinen Ilias behandelt (vgl. dazu jetzt West 2013, 112f. 181-185) und lieferte Stoff für mehrere attische Tragödien, von denen der Philoktet des Sophokles erhalten ist.

$502 \mathrm{Zu}$ Thersites vgl. oben 27,6 mit Anm. 435.

503 Dass Thersites im griechischen Heer vor Troja eine Generalsfunktion gehabt hätte, geht jedenfalls aus den einschlägigen Stellen der Ilias nicht hervor, sondern hier muss er sich von Odysseus sogar einmal sagen lassen, es gebe unter allen Grie-

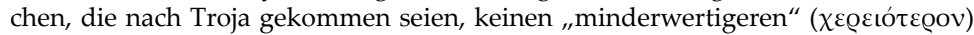
als ihn (Il. II 248f.). In späterer Literatur wird der homerische Thersites mit einem äolischen Thersites identifiziert, der ein Sohn des Agrios ist, welcher seinerseits ein Bruder des Königs Oineus von Kalydon ist, des Großvaters des homerischen Helden Diomedes (vgl. Quint. Sm. I 767-773; vgl. auch das von Libanios geschriebene "Lob des Thersites", Progymn. VIII 4, Kap. 2); als solcher würde Thersites zu den vor Troja versammelten griechischen Adligen gehören und könnte auch ein „Feldherr" gewesen sein. $\mathrm{Ob}$ diese Genealogie sich jedoch schon in der dem epischen Kyklos angehörenden Aithiopis fand, in der Thersites den Achill wegen seiner Liebe zu der getöteten Amazonenkönigin Penthesileia verspottet und daraufhin von ihm getötet wird, ist unklar (vgl. West 2013, 142, der darauf hinweist, dass der ätolische Thersites zum ersten Mal bei dem frühen Mythographen Pherekydes von Athen, FGrHist 3 F 123 = Fr. 123 Fowlen, erscheint). - Die Bezeichnungen des Thersites als „Zuckerhut-Kopf“ ( $\varphi$ oł́ós) und „Kahlkopf“ ( $\psi \varepsilon \delta v o ́ \varsigma)$ sind direkt Hom. Il. II 219 entnommen.

504 Der überlieferte griechische Text bietet an dieser Stelle schwere Probleme, und alle bisherigen Heilungsversuche müssen spekulativ bleiben. SchwARTz postulier-

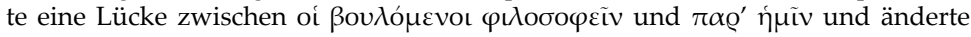

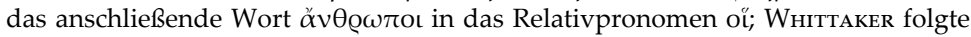


Schwartz mit dieser Änderung, aber nicht in der Annahme der Lücke; Marcovich setzte in die von Schwartz angenommene Lücke das Wort $\varphi$ ílot ein und über-

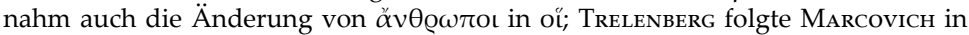
der Ausfüllung der Lücke, behielt aber das überlieferte äv $\theta \varrho \omega \pi$ ot. Keiner dieser Vorschläge dürfte das Richtige gefunden haben. Es wäre zu überlegen, ob der von

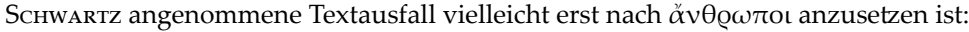
„Alle Menschen, die bei uns [= in unserer Gemeinschaft] philosophieren wollen ...; wir beurteilen ..."

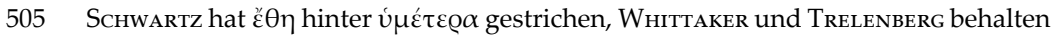

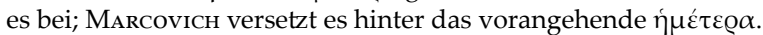

506 "Geschwätz" ist in den Tatian-Handschriften M und V sowie am Rand von P mit v̋ $\theta \lambda$ ov wiedergegeben, nur im Text von P mit $\lambda \tilde{n}$ oov, was alle Editionen mit Aus-

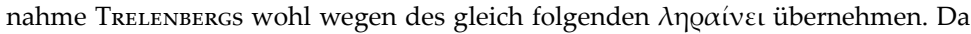

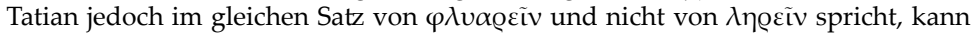

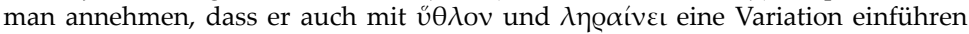
wollte.

$507 \mathrm{Zu}$ der im 5. Jh. v. Chr. tätigen lyrischen Dichterin Praxilla von Sikyon, die von ihrem Landsmann Lysipp, einem der berühmtesten Bildhauer des 4. Jh.s v. Chr., dargestellt wurde. vgl. Plant 2004, 38-40. Sie schrieb Trinklieder (Skolia), Hymnoi und Dithyramben (und nach ihr war sogar ein eigenes Metron, das Praxilleion, benannt); erhalten sind insgesamt nur acht Fragmente (PMG 747-754). Wahrscheinlich hat ihre Assoziation mit Trinkliedern (für Symposien, bei denen ehrbare Frauen normalerweise nicht zugelassen waren) zu Tatians moralischer Negativbewertung geführt.

508 Learchis wird nur in dieser Tatian-Stelle erwähnt; zu dem Bildhauer Menestratos, der sie dargestellt haben soll, vgl. A. BонNe, „Menestratos (I)“, in: VоцLкомMER 2001, 502f.

509 Die berühmte Dichterin Sappho als Hetäre darzustellen, geht wahrscheinlich auf die attische Komödie zurück, in der Sappho vor allem im 4. Jh. v. Chr. in mehreren Stücken (des Ameipsias, Antiphanes, Amphis, Ephippos, Timokles und Diphilos) Titelheldin war; vgl. auch PLANT 2004, 11 mit Anm. 17 (von einer zweiten Sappho von Lesbos, die tatsächlich Hetäre gewesen sein soll, spricht Ael. VH XII 19; Seneca, Ep. 88,37 behauptet, der Vielschreiber Didymos habe die Frage erörtert, ob Sappho eine „publica“ gewesen sei). Zu Silanion vgl. M. Weber, „Silanion“, in: VollкомMER 2001, 821-824; seiner Sappho-Statue hat namentlich Cicero (Verr. II 4,126) ein sehr positives Zeugnis ausgestellt. In 33,3 ist er auch als Schöpfer einer KorinnaStatue erwähnt (vgl. unten Anm. 519).

510 Zu der jung verstorbenen Erinna vgl. PLAnt 2004, 48-52; größere Teile ihres Gedichts "Die Spindel" sind dank einem Papyrus wieder ans Licht gekommen (jetzt SH 401). In diesem Werk gedenkt Erinna ihrer Jugendfreundin Baukis; möglicherweise ist dieses Thema der Grund dafür, dass Tatian Erinna als „Lesbierin“ bezeichnet, denn in anderen Zeugnissen werden ihr auch andere Heimatorte zugewiesen. Sie wird in der Regel ins mittlere 4. Jh. v. Chr. datiert; damit kann der Bildhauer Naukydes, der laut Tatian ihre Statue schuf, nicht der Künstler dieses Namens gewesen sein, der im 5. Jh. wirkte, sondern müsste ein jüngerer mit gleichem Namen sein (vgl. P. C. Bol , „Naukydes (I) und Naukydes (II)“, in: Vollкommer 2001, 546-548).

511 Zu der Dichterin Myrtis von Anthedon vgl. Plant 2004, 36f.; laut dem Suda-Lexikon ( $\kappa 2087$ und $\pi$ 1617) soll sie die Lehrerin Korinnas (vgl. unten Anm. 519) und Pindars gewesen sein. Verse von ihr sind nicht erhalten, immerhin jedoch ein Prosareferat Plutarchs (Qu. Gr. 40, 300d-f) über eine ihrer erzählenden Dichtungen. Zu Boiskos vgl. W. Müller, „'Boiskos“, in: Vollkommer 2001, 122. 
512 Zu der um 300 v. Chr. tätigen Myro (wie Pausanias, Tatian und das Suda-Lexikon sie nennen) oder Moiro (so heißt sie bei dem Epigrammatiker Meleager und bei Athenaios) vgl. PLANT 2004, 61f. Sie soll ein recht substantielles Oeuvre verfasst haben, von dem aber nur drei kurze Stücke erhalten geblieben sind. Zu Kephisodotos vgl. R. Vollkommer, „,Kephisodotos (II)“, in: Vollкомmer 2001, 410f.

513 Praxagoris wird nur hier erwähnt; zu dem ebenfalls sonst völlig unbekannten Gomphos vgl. R. Vollкомmer, "Gomphos“, in: Vollкомmer 2001, 270.

514 Welche Kleito hier gemeint ist, ist unklar (Kleito hieß die Mutter des Euripides, vgl. Philochoros, FGrHist 328 F 218; ferner nennt Platon, Kritias 113d so die sterbliche Frau, mit der Poseidon die ersten zehn Könige von Atlantis zeugte; vgl. NesSelrath 2006, 254f.). Zu Amphistratos vgl. E. Paul, „Amphistratos“, in: VollкомMER 2001, 34.

515 Zu der frühhellenistischen Dichterin Anyte von Tegea vgl. Plant 2004, 56-50; von 25 unter ihrem Namen in der Anthologia Palatina überlieferten Epigrammen werden heute 21 für echt gehalten, von der ihr ebenfalls zugeschriebenen lyrischen und epischen Dichtung hat nichts überlebt. Sie ist die einzige von Tatian genannte, von der gleich zwei Künstler eine Statue anfertigten: zu Euthykrates vgl. J. J. PollitT, „Euthykrates (I)“, in: Vollкommer 2001, 239f., zu Kephisodotos vgl. oben Anm. 512.

516 Die in der ersten Hälfte des 5. Jh.s v. Chr. lebende Telesilla von Argos (zu ihr vgl. PLANT 2004, 33-35) war nicht nur als Dichterin berühmt, sondern auch als martialische Verteidigerin ihrer Stadt gegen die Spartaner (vgl. Plut. Mul. Virt. 4, 245c-f), und vielleicht wurde ihr gerade deswegen noch im 2. Jh. v. Chr. von dem Bildhauer Nikeratos (zu ihm vgl. B. Andreae, „Nikeratos“, in: Vollкомmer 2001, 568-570) eine Statue gewidmet.

517 Statt der sonst unbekannten Mystis hat H. Brunn hier die Dichterin Nossis von Lokroi (zu ihr vgl. Plant 2004, 63-66) in den Text einsetzen wollen, was von Schwartz, Fermi (die versehentlich „Nasside“ schreibt), Whittaker, Di Cristina, Marcovich und TRELENBERg übernommen wird. Die Konjektur wird damit begründet, dass mit Nossis in Tatians Aufzählung in Or. 33,2f. alle neun Dichterinnen genannt wären, die der Epigrammdichter Antipater von Thessalonike in Anth. Pal. IX 26 als neun „irdische Musen“ verherrlicht. Aber auch dann bleiben bei Tatian immer noch fünf andere (Learchis, Praxagoris, Kleito, Mnesarchis und Thaliarchis) übrig, die bei Antipater nicht auftauchen, so dass es keineswegs zwingend erscheint, dass Tatian sich hier an Antipaters Katalog gehalten haben sollte (wenn er ihn überhaupt kannte). Der Künstler Aristodotos (zu ihm G. BRöKER, „AAristodotos“, in: VollKommer 2001, 86), der eine Statue der Mystis geschaffen haben soll, wird ebenfalls nur hier erwähnt.

Inzwischen aber gibt es archäologische Belege dafür, dass es eine Darstellung der Mystis des Aristodotos tatsächlich gegeben hat, denn eine entsprechende Statueninschrift wurde bereits vor einigen Jahrzehnten in der "Area sacra“ des Largo Argentina in Rom gefunden; vgl. hierzu Hinz 2001, 45 mit Angaben zu einschlägiger archäologischer Literatur in Anm. 45. Auf diese Weise ist wahrscheinlich geworden, „daß Tatian zumindest teilweise Statuen der Portikus des Pompeiustheaters beschrieb“, und so können ,sonst nicht bezeugte Angaben [scil. Tatians] nicht einfach mehr für erfunden erklärt werden" (Hinz 2001, 45f.).

518 Mnesarchis wird nur hier erwähnt; zu Euthykrates vgl. oben Anm. 515.

519 Zu der böotischen Dichterin Korinna von Tanagra vgl. Plant 2004, 92-98. Sie galt als Rivalin Pindars, gegen den sie einen Wettkampf (so Paus. IX 22,3) oder sogar mehrere (so Aelian, VH XIII 25) gewonnen haben soll. Zu Silanion vgl. oben Anm. 509.

520 Auch Thaliarchis wird nur hier erwähnt; zu Euthykrates vgl. oben Anm. 515.

521 „Das Mädchen bei euch“ dürfte eine Anspielung auf Erinna sein, deren Gedichttitel

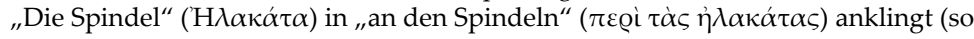
bereits Wilamowitz). 
522 Mit Glaukippe beginnt eine Aufzählung weiterer Frauen, die Gegenstand von Skulpturen wurden; diese Frauen sind keine Dichterinnen, sondern zeichnen sich durch etwas aus, was Tatian als skurril, grotesk, immer aber skandalös empfindet, was er auf die Kunstwerke überträgt. Glaukippes, Alleinstellungsmerkmal' ist, dass sie einen Elefanten geboren haben soll; ein solches Prodigium ist in anderen Quellen (Plin. Nat. VII 34) von einer Alkippe berichtet. Zu Nikeratos vgl. oben Anm. 516.

523 Phryne ist eine der berühmtesten athenischen Hetären des 4. Jh.s (sie findet auch in der zeitgenössischen Komödie manche Erwähnung: vgl. Anaxilas, Fr. 22,18 PCG, Timocl. Fr. 25. 27,3 PCG; Posidipp. Fr. 13 PCG); zu dem berühmten Prozess, in dem sie wegen Asebie angeklagt wurde und der attische Redner Hypereides als ihr Anwalt auftrat, vgl. J. Engels, Studien zur politischen Biographie des Hypereides (München 1989) 65-67. Der Bildhauer Praxiteles soll Phryne nicht nur als Modell für seine berühmte knidische Aphrodite verwendet, sondern auch von ihr selbst eine Statue angefertigt haben, die dann in Delphi stand (Ps.-Dio [= Favorinus], Or. 37,28; Paus. X 15,1; Ath. XIII 591b; Aelian VH IX 32). Dagegen nennt Clemens (Protr. 53,6) als Modell des Praxiteles für Aphrodite nicht Phryne, sondern Kratine; Phryne sei jedoch Aphrodite-Modell für alle Maler ihrer Zeit gewesen. Zu Herodotos vgl. R. Vollkommer, „Herodotos (II)“, in: Vollкомmer 2001, 314. Zu Phrynes Standbild in Delphi vgl. auch C. Keesling, „Heavenly Bodies: Monuments to Prostitutes in Greek Sanctuaries", in: Ch. Faraone / L. K. McClure (Hg.), Prostitutes and Courtesans in the Ancient World (Madison, Wis. 2006) [59-76] 66-71.

524 Panteuchis wird nur hier erwähnt; zu Euthykrates vgl. oben Anm. 515.

525 Auch Besantis wird nur hier erwähnt; zu Deinomenes vgl. R. Vollкомmer, „Deinomenes (I)“', in: VolLKommer 2001, 162f.

526 Mit dem als Skulptur dargestellten Raub Europas schiebt Tatian unvermittelt eine Episode aus dem griechischen Mythos ein, in der der Göttervater Zeus als Frauenentführer in Gestalt eines Stieres keine gute Figur macht. Zu dem im 5. Jh. v. Chr. tätigen Pythagoras vgl. M. Weber, „Pythagoras (I)“, in: VolLkommer 2001, $769 f$. Sein Werk „Europa auf dem Stier“ wird als in Tarent befindlich sowohl von Cicero (Verr. II 4,135) als auch von Varro (Ling.lat. V 32: Europa [scil. dicta est] ab Europa Agenoris, quam ex Ph<0>enice Manlius scribit taurum exportasse, quorum egregiam imaginem ex aere Pyt $<h>$ agoras Tarenti, „Europa ist benannt nach Agenors Tochter Europa, von der Manlius schreibt, ein Stier habe sie aus Phönizien weggetragen; ein auserlesenes Bronzebild dieser Gruppe hat Pythagoras in Tarent geschaffen") erwähnt.

527 An die Darstellung der Europa (die gleich als die "Tochter Agenors" bezeichnet werden wird) auf dem zum Stier gewordenen Zeus schließt Tatian die Darstellung eines Kalbes (oder jungen Stieres?) mit einer Nike darauf an, die er einem Künstler namens Mikon (die Handschriften haben Mík $\omega v 0 \varsigma$, was offenbar zuerst J. SiLlig, Catalogus Artificum [Dresden 1827] 275 in Mík $\omega v o \varsigma$ verbesserte) zuwies (in VollкоммеR 2001, 518-521 ist dieses Kunstwerk bei keinem der immerhin fünf Mikones aufgeführt). K. GESNER hatte hier „Myron“ statt „Mikon“ lesen wollen (wohl wegen der berühmten Kuh des Myron), und Kalkmann 1887, 490 hat dies übernommen (ohne darauf hinzuweisen, dass es eine Konjektur ist); auf S. 515 weist KalKmanN die Namensform Mikon explizit zurück und führt sogar aus, dass Tatian die auf dem Rindvieh reitende Nike erst selber erfunden habe, „denn jene Pointe auf Europa ist gar zu verlockend“. Dann hätte Tatian aber auch die Kuh zunächst in ein Kalb verwandelt - insgesamt sind hier der Hypothesen einfach zu viele.

528 Glykera galt als die Gefährtin des Komödiendichters Menander und ist als solche in den „Hetärenbriefen“ des Alkiphron literarisch verewigt (Alciphr. Ep. IV 2; 18; 19). Die Zitherspielerin Argeia scheint nur hier erwähnt zu sein. Zu dem die beiden darstellenden Künstler Herodotos vgl. oben Anm. 523.

529 Ein weiteres Mal mischt Tatian in seinen Katalog eine Figur aus dem Mythos ein: Pasiphae, die ihm wegen ihrer (freilich durch höhere Mächte induzierten) Liebe 
zu einem Stier besonders verwerflich erscheint. Zu dem im späteren 4 . Jh. tätigen berühmten Bildhauer Bryaxis vgl. R. Vollкommer, ",Bryaxis“, in: Vollkommer 2001, 122-125.

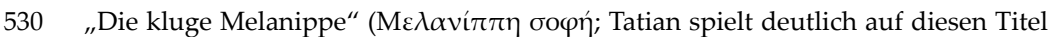
an) war ein recht bekanntes Stück des Euripides, von dem sich aber nur Fragmente erhalten haben (vgl. TrGF 5/1 Euripides, Fr. 480-488 Kannicht). Zu Lysistratos vgl. P. Schollmeyer, „Lysistratos“, in: Vollkommer 2001, 476.

531 Hinz 2001, 45 hebt zu Recht hervor, dass der berüchtigte Tyrann Phalaris von Akragas (= Agrigent) hier nicht wegen seines Stiers erwähnt wird, in dem er unliebsame Zeitgenossen zu Tode zu rösten pflegte (dies ist sonst seine bekannteste Grausamkeit, vgl. etwa Lukian, Phalaris I und II), sondern wegen seines angeblichen Verzehrs von Kindern, der auch an zwei Stellen von Aristoteles' Nikomachischer Ethik (VII 6, 1148b24 und 1149a13-15) und bei dem Peripatetiker Klearchos von Soloi (Fr. 61 WeHrLi) erwähnt wird (vgl. Hinz 2001, 59-62). Zu dem Künstler Polystratos vgl. R. Vollkommer, „Polystratos“, in: Vollkommer 2001, 734.

532 Die Bezeichnung von Phalaris' Gesicht als „vorerwähnt“ ist seltsam, da es als solches überhaupt noch gar nicht erwähnt wurde. MARCovicH wollte deshalb tò

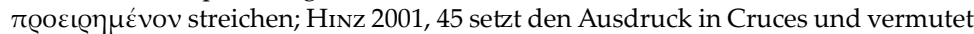
plausibel (Anm. 117), dass hier ursprünglich etwas wie „verfemt/abstoßend wegen

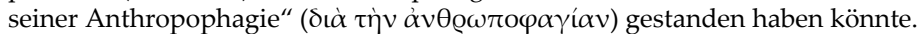

533 Erneut geht Tatian von einem historischen Beispiel eines unnatürlich grausamen Menschen (Phalaris) zu einem Greuel des griechischen Mythos über, dem Bruderkampf (den Tatian hier sofort in „Brudermord“ umdeutet) der Ödipus-Söhne Polyneikes und Eteokles um die Herrschaft in Theben, der in antiker Literatur u.a. Gegenstand der Tragödien Sieben gegen Theben des Aischylos und Phoinissen des Euripides war. Zu dem die beiden Brüder darstellenden Pythagoras vgl. oben Anm. 526.

534 Als einziger von den modernen Editoren belässt TrELENBERG das von SchwARTz hinter $\tau \dot{\alpha} \sigma \chi \eta \dot{\mu} \mu \alpha \tau \alpha$ gestrichene $\kappa \alpha$ í im Text, übersetzt aber dennoch so, als sei es gestri-

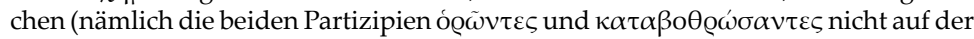

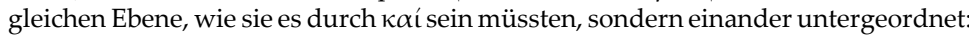
"da ihr beim Anblick ... nicht ... begrabt und gleich mitvernichtet" ).

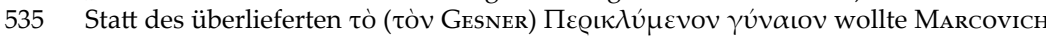

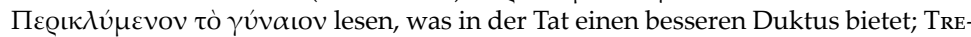
LENBERG ist ihm gefolgt.

Das bei Tatian namenlos bleibende „Weiblein“ könnte Eutychis sein (vgl. Plin. Nat. VII 34: Pompeius Magnus in ornamentis theatri mirabiles fama posuit effigies, ... inter quas legitur Eutychis ... enixa XXX partus, „Pompeius der Große stellte bei der Ausschmückung seines Theaters Bildwerke von bewundernswertem Ruhm auf, ... unter diesen wird Eutychis genannt .., die dreißig Kinder gebar" ${ }^{\prime \prime}$. Zu Periklymenos vgl. U. W. GotTschall, „Periklymenos“, in: Vollkommer 2001, 641.

536 Die vorliegende Übersetzung stützt sich vor allem darauf, anders als alle anderen

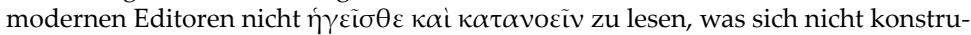
ieren lässt (Trelenbergs „Weshalb gebietet ihr mir ... zu betrachten“ weist í $\gamma \varepsilon \tilde{\sigma} \sigma \theta \varepsilon$ eine Bedeutung und Konstruktion zu, die das Verb nicht hat), sondern ๆ $\gamma \varepsilon \tilde{\tau} \sigma \theta \alpha \mathrm{\iota}$

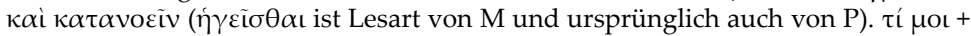
Infinitiv kommt bei Tatian noch öfter vor (vgl. Nesselrath 2005, 256), und damit bietet auch das kaí zwischen den beiden Infinitiven (das MARCovicH - neben anderen schwerwiegenden Eingriffen - hier streichen zu müssen glaubte) keinen Anstoß,

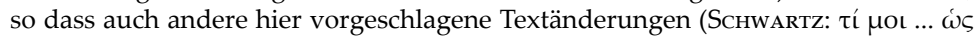

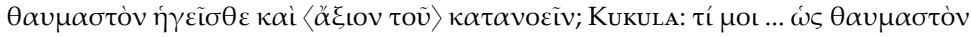

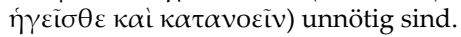

537 Bei seiner Ankunft in Latium soll Aeneas am Ufer des Tiber eine Muttersau mit dreißig Frischlingen entdeckt haben, und dieses Prodigium kündigte ihm an und 
deutete zugleich der Flußgott Tiberinus (vgl. Verg. Aen. VIII 43-49; eine Vorankündigung durch den Seher Helenus in III 388-393). Zur "recht mysteriösen Verehrung“ dieser Sau vgl. einen Hinweis in den Res rusticae des Varro (II 4,18), dass immer noch (jedenfalls zu Varros Zeit im 1. Jh. v. Chr.) bronzene Nachbildungen der Sau und ihres Nachwuchses öffentlich ausgestellt seien und der durch Einsalzen (salsura) haltbar gemachte Körper der Sau von Priestern gezeigt werde.

538 Wieder ein mythischer Skandal-Fall: Das ehebrecherische Verhältnis zwischen dem Kriegsgott Ares und der Liebesgöttin Aphrodite zulasten von Aphrodites Ehemann, dem Schmiedegott Hephaistos, ist seit der homerischen Darstellung, wie der gehörnte Ehemann die beiden Sünder in einem von ihm geschmiedeten Netz einfing und den übrigen Göttern in flagranti präsentierte (Hom. Od. VIII 266-366), berühmt; als Tochter von Ares und Aphrodite wird Harmonia erstmals in Hesiods Theogonie (V. 937) erwähnt. Zu Andron vgl. D. Rössler, „Andron (I)“, in: Vollкommer 2001, 43.

539 Sophron von Syrakus ist der erste bekannte Dichter sogenannter Mimoi, einer kleineren Form komischer Dramen, die bereits vorliterarisch verbreitet waren. Die Fragmente von Sophrons Stücken (die übrigens nicht in Versen, sondern in Prosa gefasst waren und deshalb keine „Komödien“ im landläufigen antiken Sinn sind) sind ediert in PCG I (2001) 187-253, einen Kommentar bietet J. H. Hordern, Sophron's Mimes. Text, Translation, and Commentary (Oxford 2004).

540 Marcovich hat zu Recht vermutet, dass zwischen $\tau \tilde{\eta} \varsigma$ und $\chi \alpha \lambda \kappa \varepsilon v \tau \iota \kappa \tilde{\zeta}$ der Name des bildenden Künstlers ausgefallen ist, der eine Bronzestatue Sophrons anfertigte, denn die Aussage „berühmter noch ist er [scil. der dargestellte Sophron] durch die Schmiedekunst, die bis heute existiert" (Übersetzung Trelenserg), wäre einfach nur banal, und die Übersetzung „,his reputation is all the greater because of the bronze statue of him which exists to the present day" (WhitTAKER) ist durch den Be-

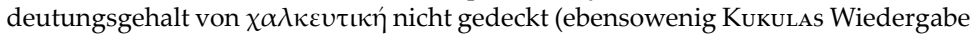
mit dem Plural „Erzbilder“). Es wäre dies zudem die einzige Stelle, an der Tatian in diesem „Künstlerkatalog“ den Namen des Künstlers ausgelassen hätte.

541 Marcovich wollte hier, eine sekundäre Korrektur in der Handschrift P aufgreifend, $\langle\dot{\alpha} \lambda \lambda \dot{\alpha}\rangle \kappa \alpha \grave{\imath}$ (naheliegend nach dem vorausgehenden oủ $\mu$ óvov) lesen und musste

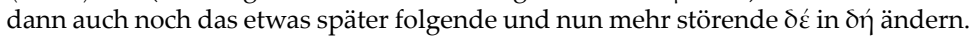

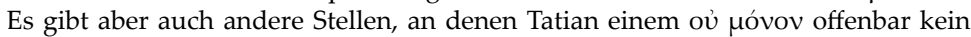

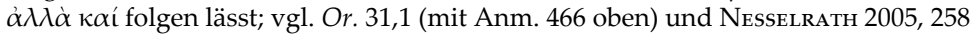
mit Anm. 31.

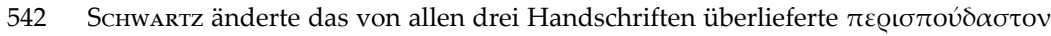
in den Nominativ, und dieser wurde von MARCovich und TRELENBERg übernommen (wobei TReLEnbergs Übersetzung $\pi \varepsilon \varrho \iota \sigma \pi o u ́ \delta \alpha \sigma \tau o v$ wiedergibt: „trug ... zu seiner Berühmtheit bei“). Die Änderung ist jedoch unnötig, da sich $\pi \varepsilon \varrho ı \sigma \tau o u ́ \delta \alpha \sigma \tau o v ~ s e h r$ gut immer noch auf Äsop beziehen lässt, der durch seine Darstellung in Bronze eben (zusätzliches) Interesse erfährt. Zu dem Bildhauer Aristodemos vgl. G. BRöKER, "Aristodemos (I)“, in: Vollкommer 2001, 85.

543 Ein kurzes Zwischenfazit: Die Griechen haben so viele schlechte Frauen und Männer in bildender Kunst verewigt, dasss sie sich hüten sollten, die Reputation christ-

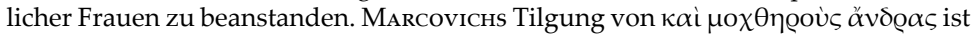
nicht berechtigt, denn es war ja bereits wirklich von "schlechten Kerlen“ die Rede (Phalaris, Sophron, Äsop; von den mythischen Figuren Zeus, Ares, Eteokles und Polyneikes nicht zu reden).

544 Euanthe ist eine uns aus keiner anderen Stelle der antiken Literatur bekannte Person, die durch eine Niederkunft in der Philosophenschule des Peripatos offenbar einen Skandal verursachte; mit Sicherheit ist mit dem Namen nicht die (göttliche) Mutter der drei Chariten gemeint (so aber TrelenberG), denn wieso sollte diese als menschliche Kindsgebärerin dargestellt werden? Zu Kallistratos vgl. Vоццком- 


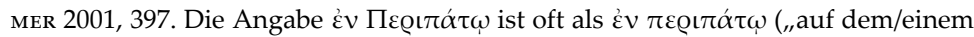
Spaziergang“, HaRnAcK, KuKula / TRElEnberG, der freilich in seinem griechischen

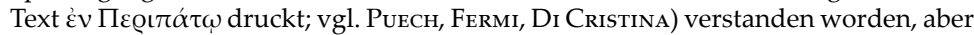
damit würde der Aussage ein erheblicher Teil des „Skandals" genommen.

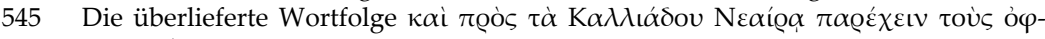
$\theta \alpha \lambda \mu$ oú $\varsigma$ hat syntaktisch immer Schwierigkeiten bereitet und ist deshalb vielfach

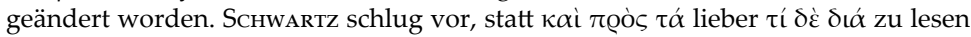
(aber müsste $\delta \iota \alpha ́ \alpha$ dann nicht auch mit dem Akkusativ stehen, „wegen Kalliades“?

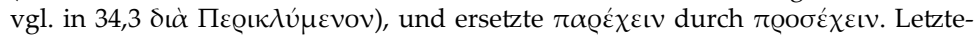

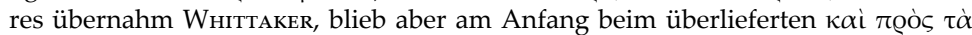

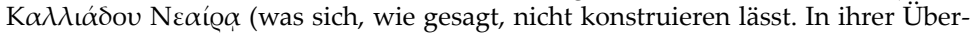
setzung ,"to glue my eyes to Calliades' Neaera“ tut WhitTAKer so, als stünde nicht

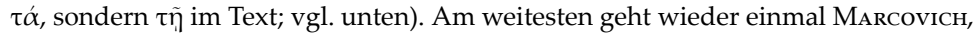

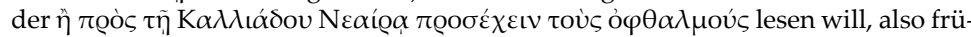

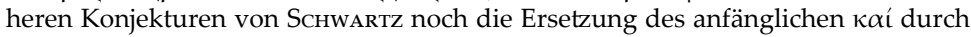
$\eta$ hinzufügt. Trelenberg liest so wie vor ihm bereits KuKula (obwohl er sich selbst

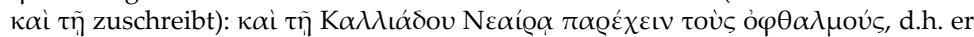

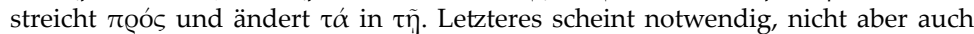
die Streichung von Tœós, wenn man es adverbial im Sinne von „darüber hinaus" versteht (vgl. dazu Nesselrath 2005, 258f.). Den so entstandenen Text (mit nur einer kleinen Änderung von $\tau \alpha ́$ in $\tau \tilde{\eta}$ ) liest man übrigens schon bei voN Отто (der reó $\varsigma$ freilich noch nicht adverbial verstanden zu haben scheint, jedenfalls nicht so übersetzt).

Neaira ist dank der Rede 59 im Corpus Demosthenicum (die jedoch nicht von Demosthenes, sondern von dem athenischen Redner und Politiker Apollodoros stammt; zu ihm vgl. J. ENGELs, „Apollodoros [1]“, DNP 1 [1999] 856f.) die wohl am besten bekannte Hetäre des klassischen Altertums. Zu Kalliades vgl. R. VolLKomMER, „Kalliades (I)“, in: Vollkommer 2001, 386.

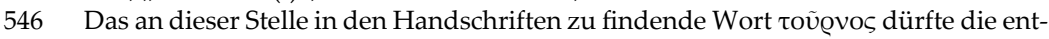
stellte Form des Namens des Künstlers sein, der die berühmte Lais (oder eine der Hetären dieses Namens, denn es gab wenigstens zwei berühmte; vgl. M. SтRотнMANN, "Lais $1+2$ ", DNP 6 [1999] 1067f.) in einem Kunstwerk verewigte und sie damit „,zu einem Denkmal der Hurerei“ machte. Alle bisherigen Versuche, die Korruptel zu verbessern, überzeugen nicht (vgl. dazu NesselRath 2005, 259): weder WI-

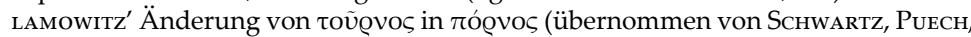
Fermi, Whittaker, Di Cristina und Trelenberg) noch Marcovichs Postulat einer Lücke nach diesem tó@vos.

547 Von Hephaistion wurde in der Antike vielfach angenommen, er habe eine homoerotische Beziehung zu Alexander d. Gr. gehabt wie im Mythos Patroklos zu Achill (vgl. Arr. Anab. I 12,1 in Verbindung mit Ael. VH XII 7; Plut. Alex. 39,8; Epistulae Diogenis 24); für Tatian ist so etwas natürlich ro@veí $\alpha$. Zu Philon vgl. VolLкоммer, „Philon (III)“, in: Vollkommer 2001, 681.

548 Leochares' (zu ihm vgl. P. Moreno, "Leochares“, in: Vollkommer 2001, [441-447] 444) Skulptur des Adlers, der den schönen jungen Ganymedes zum Göttervater Zeus bringt, erwähnt auch der Ältere Plinius (Nat. XXXIV 79). In Rom wurde eine Inschrift gefunden, die die Überführung dieser Leochares-Skulptur bezeugt (vgl. D. Mustilli, „Nuova iscrizione di Myron tebano“, Bullettino della commissione archeologica comunale di Roma 61 [1933] [207-210] 208f. mit Abb. 2); sie wird auch in einem Epigramm des Straton von Sardes (Anth. Pal. XII 221) beschrieben und von Juvenal (Sat. 9,22) erwähnt. Vgl. auch H. SichtermanN, "Ganymedes“, LIMC IV (1988) Nr. 200 (S. 164) und 251 (S. 166).

549 Die sogenannte pseliumene des Praxiteles erwähnt wiederum der Ältere Plinius (Nat. XXXIV 70). Warum Tatian auf die Darstellung zweier Fälle von in seinen Au- 
gen skandalöser Homosexualität zwischen Männern nun gerade diese PraxitelesSkulptur einer Frau folgen lässt, ist nicht klar.

550 Während die „Anaischyntographin“ (der Ausdruck findet sich bei Polyb. XII 13,1 für noch andere Vertreter dieser "Gattung“") Philainis recht häufig in antiker Literatur seit dem 4. Jh. v. Chr. evoziert wird (vgl. Klearchos, Fr. 63 WeHrli und Aischrion, $\mathrm{SH} 4$ mit weiteren Belegen), ist eine Autorin namens Elephantis in griechischer Literatur nur hier bei Tatian zu finden; sie könnte allerdings mit der im Suda-Lexikon ( $\alpha$ 4261) zitierten Elephantine identisch sein. In lateinischer Literatur: Plinius erwähnt Elephantis in Nat. I 28c als eine Quellenautorin und zitiert sie in XXVIII 81 als Autorität zu Abtreibungsmitteln. Elephantidos libelli werden in Carm. Priap. 4,2 und Mart. XII 43,4 erwähnt sowie in Suetons Tiberius-Vita als Vorlage für die Ausschmückung von Tiberius' Räumen mit lasziven Gemälden.

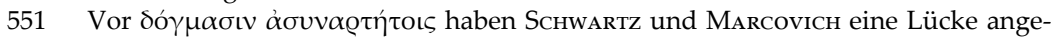
nommen und verschieden ausgefüllt, WHITTAKER und TRELENBERg kommen dagegen zu Recht ohne Lücke aus; vgl. Nesselrath 2005, 260.

552 Schwartz und Marcovich sind einer Konjektur Gesners gefolgt und wollten $\kappa \alpha \theta^{\prime}$ $\eta \tilde{\mu} \tilde{\alpha} \varsigma$ statt des einhellig überlieferten $\kappa \alpha \theta^{\prime} \dot{v} \mu \tilde{\alpha} \varsigma$ lesen; WHITTAKER und TRELENBERG sind zu Recht bei der Überlieferung geblieben (vgl. NesSELRATH 2005, 260).

553 An dieser Stelle findet sich in Schwartz' Text die Anzeige einer Lücke, die WiLamowitz durch den Infinitiv $\dot{\varepsilon} \kappa \theta \dot{\varepsilon} \sigma \theta \alpha$ เ ausfüllen wollte; KuKULAs Vorschlag $\pi \varepsilon Q \alpha i ́ v \varepsilon ı v$ erscheint besser (aber noch nicht ausreichend), da Tatian ja gerade auf den von ihm in Kap. 31 begonnenen Altersbeweis verwiesen hat, den er jetzt offenbar zu Ende führen möchte. Whittaker, Marcovich (!) und Trelenberg glauben ohne die Annahme einer Lücke auskommen zu können, aber der sich dann ergebende Text (,werde nun aber ... es in Angriff nehmen, über ihre [d.h. die christlichen] Lehren zu sprechen“, wie TRELENBERG übersetzt) lässt Tatian etwas ankündigen, was er gar nicht tun will, denn er will ja nicht über die Lehren der christlichen Philosophie als solche sprechen, sondern ihr hohes Alter erweisen, und etwas in diesem Tenor müsste hier gestanden haben.

554 Der hier gemeinte "Sophist" ist der berühmte athenische Staatsmann (und Dichter) Solon, der später als einer der Sieben Weisen galt, und sein von Tatian leicht abge-

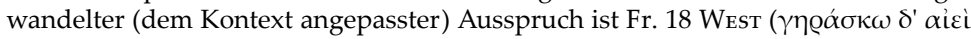
$\pi \circ \lambda \lambda \dot{\alpha} \delta เ \delta \alpha \sigma \kappa o ́ \mu \varepsilon v o \varsigma$, , ich werde alt und lerne dabei immer noch vieles"). Er wird

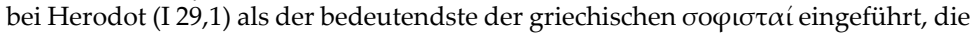
den steinreichen lydischen König Kroisos besuchen; bei Tatian hat die bei Herodot noch neutral verwendete Bezeichung „Sophist“ (= kluger Mann) eine deutlich negative Konnotation.

555 Vom Beginn dieses Kapitels an bis zum Ende der Schrift wird Tatians Text auch in Eusebios' Praeparatio evangelica als Auszug geboten (PE X 11,6-35) und steht damit in einem wichtigen weiteren Überlieferungsträger zur Verfügung.

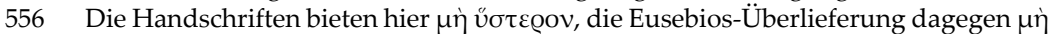

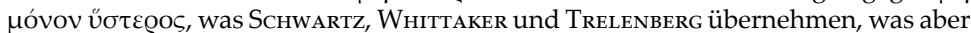
eher eine Verdunkelung des Gemeinten darstellt; denn was soll heißen, dass man annehmen soll, „Homer habe nicht $<$ bloß $>$ nach den Kämpfen um Troja, sondern zu genau jener Zeit des Krieges gelebt“, wie Trelenderg übersetzt? WhitTAKer gibt den Text mit "let us assume that Homer was not only no later than the Trojan War, but lived at the very same time" wieder und nimmt damit Marcovichs Ergänzung

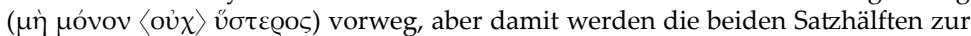
Tautologie („,nicht später als der Trojanische Krieg“ = zur genau gleichen Zeit wie der Trojanische Krieg"). Auch Kukula und Рuech bevorzugen die Lesart der Handschriften vor der Eusebios-Überlieferung.

557 Laut der dem Neuplatoniker Proklos zugeschriebenen Homer-Vita datierte der pergamenische Philologe Krates von Mallos Homer noch in die Zeit des Trojani- 


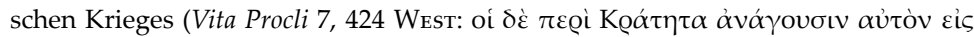

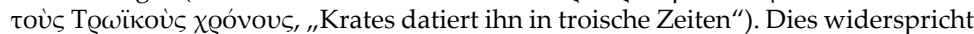
freilich Tatians eigener Aussage in 31,4 (,,innerhalb von achtzig Jahren nach dem Trojanischen Krieg“") und auch den Zeugnissen anderer Homer-Viten (Ps.-Plut. De

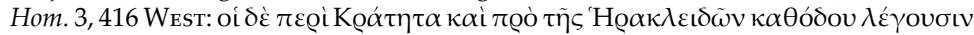

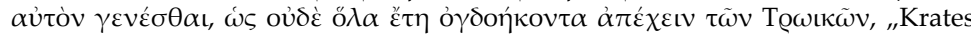
sagt, er habe sogar vor der Rückkehr der Herakliden gelebt, so dass er nicht einmal ganze achtzig Jahre vom Trojanischen Krieg entfernt war"; Vita Romana 4, 434 WEST:

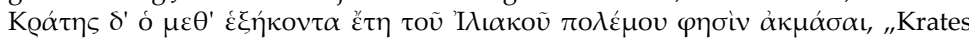
von Mallos sagt, er [= Homer] habe sechzig Jahre nach dem Trojanischen Krieg seine Blüte gehabt"). In jedem Fall sind die dem Krates zugeschriebenen Datierungen die frühesten; alle anderen antiken Homerforscher datierten Homer später.

558 Die Meinung, Homer sei des Schreibens noch nicht mächtig gewesen (weil dieses noch nicht erfunden war) und habe seine Gesänge nur mündlich hinterlassen, findet

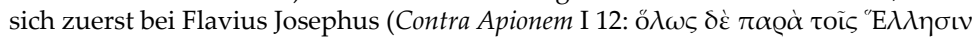

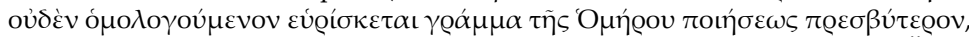

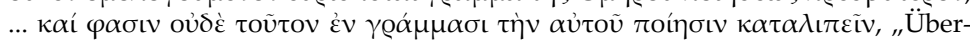
haupt aber findet sich bei den Griechen keine Schrift, bei der man sich einig wäre, dass sie älter als die Dichtung Homers ist, ... und man sagt, dass auch dieser seine Dichtung nicht schriftlich hinterlassen habe“; vgl. auch Scholia in Dion. Thr., GG III [Leipzig 1901] 179,11ff.; Schol. Hom. Il. VI 168 und VII 175).

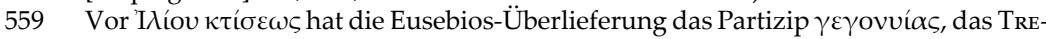
LENBERG (als einziger der modernen Editoren) in seinen Text übernimmt.

560 Ilion wurde von Ilos, dem Sohn des Tros (vgl. die nächste Anm.) gegründet (vgl. Apollod. Bibl. III 142f. = III 12,2f.).

561 Über die frühen troischen Könige Dardanos und Tros unterrichtet uns bereits ein ausführlicher Exkurs, den Aineias im 20. Buch der Ilias seinem Gegner Achill über seine Genealogie gibt (bevor er mit ihm in den Kampf eintritt): Der Zeus-Sohn Dardanos gründete Dardania als Vorgängerstadt Trojas (Il. XX 215-218; vgl. auch unten 39,5), und Tros, der Namensgeber der Trojaner, war Enkel des Dardanos (Il. XX 219.230) und seinerseits Urgroßvater des Priamos (Il. XX 231f.235f.), zu dessen Zeit Troja zerstört wurde; Dardanos lebte mithin fünf und Tros drei Generationen vor dem Trojanischen Krieg.

562 Bemerkenswerterweise führt Josephus, Contra Apionem I 215 genau die gleichen drei

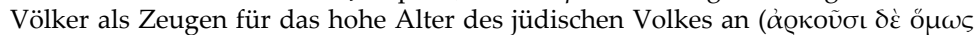

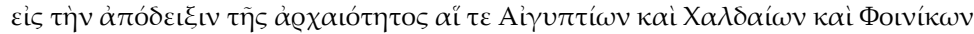
$\dot{\alpha} v \alpha \gamma \varrho \alpha \varphi \alpha \grave{\iota} \kappa \tau \lambda .$, ,es reichen jedoch zum Beweis des Alters die Aufzeichnungen der Ägypter und Chaldäer und Phönizier"); dies zeigt, dass Tatian mit seinem Altersbeweis in jüdischer Tradition steht.

563 An dieser Stelle ist in zwei der drei Tatian-Handschriften (M und V) der Text gestört, denn nach $\delta ı \gamma \eta \dot{\sigma \varepsilon ı \varsigma ~ \kappa \alpha i ́ ~ g e h t ~ e s ~ v o ̈ l l i g ~ a n d e r s ~ w e i t e r . ~ I n ~ d e r ~ H a n d s c h r i f t ~} \mathrm{P}$

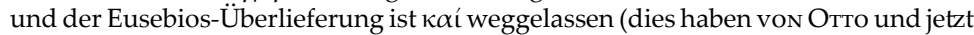
auch TrELENBERg in ihrem Text übernommen) und damit die Störung oberflächlich behoben; im folgenden Satz findet jedoch mit der Einführung des Berossos ein so abrupter Themenwechsel statt, dass es sehr schwer fällt zu glauben, hier sei nichts ausgefallen.

Als erster hat an dieser Stelle Schwartz eine Lücke angenommen; er hat jedoch gleichzeitig das vor dieser Lücke stehende $\kappa \alpha i ́$ in gehenden Komparativs $\sigma v v \tau o \mu \omega \tau \varepsilon \dot{0} \alpha \varsigma$ ) und im kritischen Apparat die Ergänzung

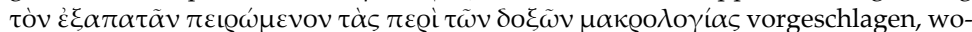
mit für einen besseren Übergang zum Folgenden freilich nichts getan ist. WHitTAKER hat das von SCHWARTz konjizierte ฑ und die Annahme der Lücke danach übernommen, auf Schwartz' Ergänzungsvorschlag jedoch verzichtet; MARCovich hat 
das überlieferte к $\alpha i ́$ zum Anfang des folgenden Satzes gezogen und geglaubt, den

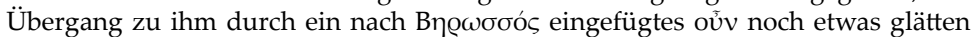
zu können; der inhaltliche Bruch ist damit jedoch nicht beseitigt, und dieser Bruch bleibt auch in TreLenbergs Textkonstitution (vgl. oben) bestehen.

Dass dieser Bruch ein wirklich tiefer ist, ergibt sich aus dem, was Tatian in 36,2 ankündigt, sein Text dann aber (jedenfalls zunächst) nicht einlöst: Angekündigt wurden Gewährsleute der Chaldäer, Phönizier und Ägypter, die zeigen sollten, dass die in 36,1 formulierte These, Moses habe viel früher nicht nur als der Trojanische Krieg, sondern auch als die Gründung Trojas gelebt, wahr ist; in den dann folgenden Ausführungen über Berossos gelangt Tatian dann aber mit dem Krieg des "Nabuchodonosor" gegen Juden und Phönizier (vgl. unten) gerade einmal an den Anfang des 6. Jh.s v. Chr. und bleibt damit über ein halbes Jahrtausend zeitlich diesseits der Zerstörung Trojas - was soll dies für das Alter des Moses beweisen? Entweder hat Tatian das von ihm selbst angekündigte Beweisziel eklatant verfehlt, oder zu Beginn seiner Ausführungen sind Dinge ausgefallen, die dieses Beweisziel stützen konnten. Wenn hier ein (vielleicht größerer) Textschaden vorliegt, ist er freilich schon entstanden, bevor dieser Text zu Eusebios kam, denn in dessen Zitierung wurde er nur ganz unzureichend behoben (vgl. oben).

Dass die babylonische bzw. assyrische Geschichte in der Tat als erheblich älter galt als die griechische und durch einen entsprechenden Synchronismus (der bei Tatian aber eben fehlt) das hohe Alter des Moses beweisen konnte, zeigt Clem. Alex.

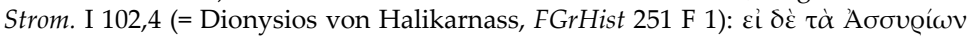

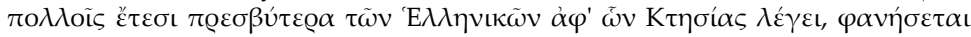

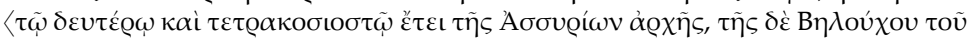

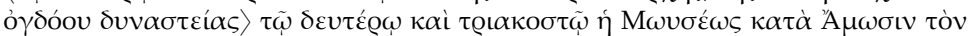

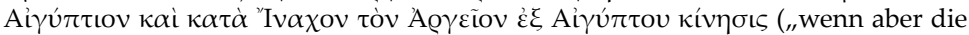
Geschichte der Assyrer viele Jahre älter ist als die griechische, aufgrund dessen, was Ktesias sagt, so wird sich zeigen, dass im 402. Jahr der assyrischen Herrschaft und im 32. Jahr der Herrschaft des Beluchos des Achten der Aufbruch des Moses aus Ägypten zur Zeit des Ägypters Ahmose und des Argivers Inachos erfolgt ist"). Etwas in dieser Art hätte hier eigentlich auch bei Tatian stehen sollen.

564 Die Fragmente des Berossos sind gesammelt in FGrHist 680.

565 Belos heißt der babylonische Hauptgott bereits bei Herodot (I 181,2), wo er mit Zeus identifiziert wird.

566 Antiochos I. (Mitregent seines Vaters Seleukos seit 294 v. Chr., Alleinregent 281-261 v. Chr.) ist der "dritte König“, wenn man von Alexander d. Gr. an inklusiv rechnet und eine direkte Abfolge Alexander - Seleukos - Antiochos postuliert.

567 Nabuchodonosor ist als Namensform für den neubabylonischen König Nebukadnezar II. (regierte 605-562 v. Chr.) seit der Septuaginta belegt und wurde aus ihr in spätere jüdische und christliche Literatur übernommen.

568 Von diesem Feldzug berichtet - mit gleicher Datierungs- und Quellenangabe -

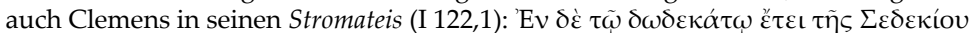

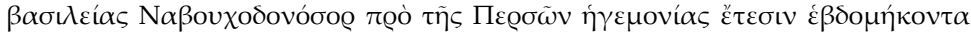

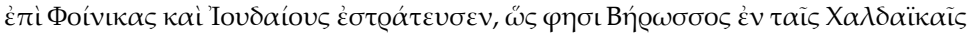

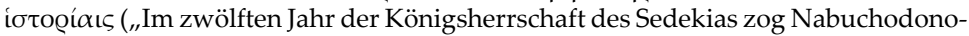
sor - siebzig Jahre vor der Herrschaft der Perser - gegen Phönizier und Juden zu Felde, wie Berossos in seiner ,Chaldäischen Geschichte' erzählt").

569 Die erhaltenen Fragmente aus dem schriftstellerischen Oeuvre Jubas II. sind in FGrHist 275 gesammelt.

570 Aus dieser Angabe (die eine deutliche Parallele in Clem. Alex. Strom. I 122,2 hat) ergibt sich mit ziemlicher Sicherheit, dass Tatian Berossos nicht direkt gelesen, sondern über Juba rezipiert hat. 
571 Mochos wird als Autor von Фоıvıкıкá auch von Flavius Josephus (AJ I 107) und bei Ath. III 126a erwähnt. Von diesem Mochos ist vielleicht noch wenigstens ein Homonymos zu unterscheiden, nämlich ein uralter Philosoph (dagegen nimmt R. LAQUeUR, "Mochos", RE XV 2 [1932] 2314 nur einen Mochos an): Laut Poseidonios (Fr. 57ab Theiler = FGrHist 87 F $67=$ Fr. 285 Edelstein-KIdD, zitiert von Strabon XVI 2,24, 757,25-27 RADT und Sextus Empiricus, Math. IX 363) soll ein Mochos von Sidon bereits vor dem Trojanischen Krieg gelebt und die Atomlehre aufgestellt haben (vielleicht ist auch der in Diog. Laert. I 1 erwähnte Phönizier Ochos, der hier als einer der ersten nichtgriechischen Philosophen präsentiert wird, richtig „Mochos“ zu lesen; vgl. FGrHist 784 F 2). Eudemos, Fr. 150 WeHrLI präsentiert eine

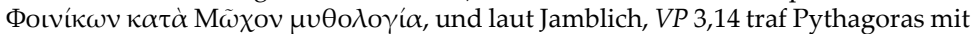

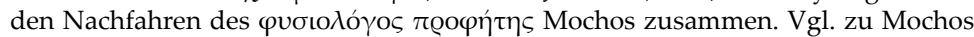
auch West 1994, 291-293.

$\mathrm{Zu}$ Hypsikrates finden sich keine weiteren Belege in der uns bekannten antiken Literatur (vgl. F. JАсовY, „Hypsikrates [2]“, RE VIII 2 [1914] 434); Theodotos könnte mit dem von Josephus, Contra Apionem I 216 genannten Autor identisch sein, der hier zusammen mit anderen als Gewährsmann für das hohe Alter des jüdischen Volkes angeführt wird (vgl. R. LAQueur, „Theodotos [20]“, RE V A 2 [1934] 1958).

572 Laitos' Фоเvıкıкá (deren Fragmente in FGrHist 784 gesammelt sind) werden sonst nur noch in Clemens' Stromateis (I 114,2, einer Stelle, die viele inhaltliche Übereinstimmungen mit unserer Tatian-Stelle hat; vgl. oben Einführung S. 23) erwähnt. Es ist auffällig, dass Laitos auch die Werke von zwei Autoren ins Griechische übersetzt haben soll, die selber rein griechische Namen tragen; vielleicht handelt es sich hier bereits ebenfalls um Übertragungen ursprünglich phönizischer Namen. Den Laitos möchte R. Laqueur („Laitos“, RE XII 1 [1924] 517f.) nicht erst ins 2. Jh. n. Chr., sondern bereits in hellenistische Zeit datieren; dagegen könnte jedoch der wahrscheinlich römische Name (= Laetus) sprechen, der kaum vor der Kaiserzeit im griechischen Osten denkbar ist (gegen die Annahme, dass Laitos römisch ist, jedoch West 1994, 292). Zu Laitos vgl. auch M. HaAke, Der Philosoph in der Stadt: Untersuchungen zur öffentlichen Rede über Philosophen und Philosophie in den hellenistischen Poleis (München 2007) 307-309, der die Identifizierung eines Akarnanen Laitos aus Stratos, dem eine delphische Ehreninschrift von etwa 275 v. Chr. gewidmet ist (FD III 1,106), mit dem von Tatian genannten Autor zu Recht zurückweist.

573 Ein kurzer Hinweis auf Menelaos' Besuch in Phönizien (während seiner Irrfahrten nach der Zerstörung Trojas) findet sich in Hom. Od. IV 83.

574 Die Lebens- bzw. Regierungsdaten des Königs Hiram I. von Tyros werden unterschiedlich angegeben, umfassen in der Regel aber die mittleren Jahrzehnte des 10. Jh.s v. Chr. (H. G. Niemeyer, „Hiram I.“, DNP 5 [1998] 612: 962-929 v. Chr.). Über die Mitwirkung Hirams an Salomons Tempelbau und die guten Beziehungen der beiden berichtet 1 Kön 5,15-32, ferner 9,10-14; 10,11 (von einer Verheiratung der Tochter Hirams mit Salomon ist in diesen Kapiteln freilich nicht die Rede).

575 Menander von Pergamon wird sonst nur bei Clem. Alex. Strom. I 114,2 als Autor erwähnt, in einer Partie, die so viele Gemeinsamkeiten mit der vorliegenden TatianStelle hat, dass ihr wohl die gleiche Quelle zugrunde liegt (vgl. oben Einführung S. 23). Bei Josephus (C. Ap. I 116) wird als Autor sowohl für griechische als auch nichtgriechische Geschichte ein Menander von Ephesos (FGrHist 783) zitiert; sowohl Josephus (C. Ap. I 116-121) als auch der Apologet Theophilos (Autol. III 22) zitieren (größtenteils gleich) ein längeres Referat Menanders über eine phönizische Königsreihe, in der auch Hiram erscheint (= FGrHist 783 F 1), und deshalb ist vermutet worden, dass Menander von Pergamon und Menander von Ephesos ein und dieselbe Person sind (JАСову in den FGrHist nimmt die Identität ohne weiteres an; vgl. auch R. Laqueur, "Menandros [10] von Ephesos“, RE XV 1 [1931] 762 und bereits von ОтTо ad loc.). 
576 Falls Tatian die gleichen Vorstellungen von der Chronologie Hirams (und Salomons) hatte wie wir Heutigen (also frühes bis mittleres 10. Jh.v. Chr.), dann ist „ziemlich nah“ recht großzügig bemessen, denn das eratosthenische Datum der Zerstörung Trojas (vgl. oben Anm. 491) liegt noch etwa zwei Jahrhunderte früher.

577 Etwas mehr zu diesem Ptolemaios, Priester einer Stadt im östlichen Nildelta (seine wenigen Fragmente sind in FGrHist 611 gesammelt), findet sich bei Clemens, Strom. I 101,5 (vor allem die Angabe, sein Werk habe drei Bücher umfasst). Zeitlich lässt er sich nur als früher als Apion (vgl. oben Anm. 427) bestimmen, der ihn benutzt hat. Wie gleich 38,2 zeigt, hat Tatian Ptolemaios' Werk sehr wahrscheinlich nicht direkt benutzt, sondern dessen Inhalt über Apion kennengelernt. - Statt

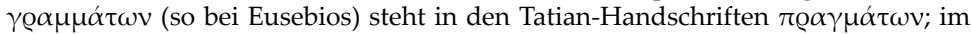
vorliegenden Kontext ist die bei Eusebios erhaltene Variante die wahrscheinlichere.

578 Ein ägyptischer König Ahmose/Amosis taucht in erhaltenem griechischen Schrifttum zuerst im 1. Buch Diodors auf, das hauptsächlich auf das Ägyptenbuch des frühhellenistischen Autors Hekataios von Abdera zurückgeht (Diod. I 64,13 = Hecat. FGrHist $264 \mathrm{~F} 25,13$ ).

579 In 27,3 war Tatians Bewertung Apions deutlich kritischer (vgl. dort, sowie Anm. 427), hier aber (= FGrHist 616 F 2) geht es darum, sein Zeugnis für den Synchronismus zwischen dem Pharao Ahmose und dem mythischen argivischen König Inachos (vgl. unten) präsentieren zu können; da kann Tatian wohl darüber hinwegsehen, dass Apion in seiner "Ägyptischen Geschichte" offenbar so viel Negatives über die Juden und ihre Geschichte sagte, dass sich Flavius Josephus zu seiner Gegendarstellung in Contra Apionem veranlasst fühlte.

Bei Eusebios (PE X 10,16 = FGrHist 616 F 2b) wird Apion ausdrücklich der Synchronismus zwischen Inachos, Ahmose und Moses zugeschrieben: A $\pi i ́ \omega v \delta \dot{\varepsilon}$ ó

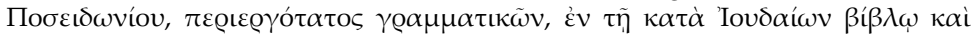

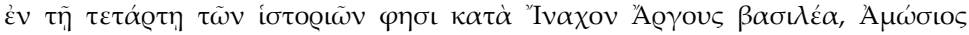

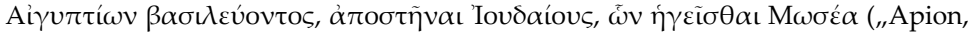
der Sohn des Poseidonios, ein unglaublich wichtigtuerischer Grammatiker, sagt in seiner Schrift, Gegen die Juden' und im vierten Buch seines Geschichtswerks, dass die Juden zur Zeit des Königs Inachos von Argos, als Ahmose über die Ägypter König war, rebelliert hätten, und Moses habe sie angeführt").

580 Die folgende Liste der mythischen Könige von Argos dürfte auf ein mythologisches Handbuch zurückgehen, wie es uns in der sogenannten Bibliotheke des Apollodor (den Pseudo-Apollodor zu nennen kein Anlass besteht) noch vorliegt. In Apollodors Bibliotheke ist das zweite Buch dem Inachos und seinen Nachfahren gewidmet, wobei sich freilich auch einige deutliche Unterschiede gegenüber Tatians Liste zeigen (Apollod. Bibl. II 1-53 = II 1,1-4,6): Inachos und Phoroneus sind in § 1 behandelt, Apis in § 2, Argos (nicht Argeios) in § 2 und 3, Kriasos ebenfalls in § 3, Agenor (nicht bei Tatian) und ein zweiter Argos (der sogenannte „Panoptes“, nicht bei Tatian) in § 4, Iasos (nicht bei Tatian) in §5, dessen Tochter Io (nicht bei Tatian) in § 5-9. Bei Apollodor kommen dann Phorbas, Triopas, Krotopos und Sthenelaos nicht vor; stattdessen geht es nach Io und ihrem Übergang nach Ägypten mit Epaphos, Libye, Belos und Danaos weiter, mit dem das Geschlecht nach Argos zurückkehrt (§ 10-13); danach folgen wie bei Tatian Lynkeus, Abas, Proitos/Akrisios (§ 24), schließlich Perseus ( $\$ 35$ und 47f.), Sthenelos ( $\$ 49$ und 53), Eurystheus ( $\$ 53$ und 73). Eine Liste der argivischen Könige von Inachos bis Perseus, die der Tatians sehr nahekommt, bietet auch Pausanias II 15,5-16,3: Inachos, Phoroneus, Argos, Peirasos/Phorbas, Triopas, Iasos/Agenor, Krotopos, Sthenelas, (Gelanor) Danaos, Lynkeus, Abas, Akrisios/Proitos, Perseus. Noch eine Liste (wiederum mit Abweichungen) von Inachos bis Danaos bietet ein Scholion zu Vers 932 von Euripides' Orestes: Inachos (er wird hier als der erste Urbarmacher und Besiedler der Ebene von Argos 
eingeführt), Phoroneus, Apis, Argos (Sohn von Apis' Schwester Niobe), Kriasos, Phorbas, Triopas, Pelasgos/Iasos/Agenor/Xanthos, Io, Epaphos, Libye, Belos, Danaos.

Die meisten Übereinstimmungen mit Tatians Liste (gerade für die erste Hälfte) bietet der im 1. Jh. v. Chr. tätige Geschichtsschreiber Kastor von Rhodos (FGrHist 250), dessen Präsentation der mythischen argivischen Könige noch in der armenischen Fassung von Eusebios' Chronik erhalten ist (FGrHist 250 F 3). Hier finden wir die Reihenfolge Inachos - Phoroneus - Apis - Argos - Kriasos - Phorbas - Triopas Krotopas [sic] - Sthenelos [sic] - Danaos - Linkeus [sic] - Abas - Proitos - Akrisios - Euristheus [sic] - Atreus und Thiestes [sic] - Agamemnon. Die einzige größere Störung ist hier der direkte Übergang von Akrisios zu seinem Urenkel Eurystheus; wurde hier ein Ausfall durch das nochmalige Auftauchen des Namens Sthenelaos verursacht?

Insgesamt wirkt die bei Tatian präsentierte Liste glatter, als sie eigentlich ist: Thre 20 Namen sollen die dann erwähnten 20 Generationen suggerieren, bei genauerem Hinsehen aber kommen die nicht zustande, denn sowohl Proitos und Akrisios als auch Atreus und Thyestes sind Brüderpaare, gehören also der gleichen Generation an. Ein gewisser Ausgleich wird dadurch geboten, dass Perseus nicht der Sohn, sondern der Enkel des Akrisios (von dessen Tochter Danae) ist, wodurch wieder eine Generation hinzukommt, so dass wir auf 19 (aber immer noch nicht 20) Generationen kommen. Tatian scheint also eine ,Komplexitätsreduktion' vorgenommen $\mathrm{zu}$ haben, um seinen Beweis überzeugender erscheinen zu lassen. Argeios heißt in den anderen Listen regelmäßig (vgl. Anm. 580) Argos.

582 Dieser zweite Sthenelaos heißt in den anderen Listen regelmäßig (vgl. Anm. 580) Sthenelos.

583 Vgl. oben 31,1 (und 36,1).

584 Vgl. dazu unten 39,5.

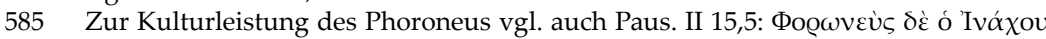

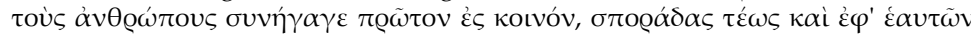

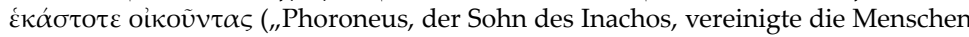
zum ersten Mal zu einer Gemeinschaft, während sie bis dahin verstreut und jeweils für sich lebten“). In dem im 6. Jh. entstandenen Epos Phoronis (Fr. 1 Bernabé = Fr. 1 DAviES = Fr. 1 WEST) und bei dem Mythographen Akusilaos von Argos (FGrHist 2 F 23a) war Phoroneus noch der erste Mensch überhaupt, was Platon im Timaios (22a) übernommen hat.

586 Die Gleichsetzung von vierhundert Jahren mit zwanzig Generationen (vgl. oben 38,3 ) ergibt eine Ansetzung von zwanzig Jahren pro Generation; damit sind diese Generationen sehr kurz angesetzt, wenn man z.B. die Generationenrechnung bei Hdt. II 142,2 vergleicht, wo drei Generationen genau einhundert Jahre ausmachen (nach dieser Rechnung hätte man für die vierhundert Jahre zwischen Inachos und Trojas Zerstörung nur zwölf Generationen gebraucht).

In $P E$ X 9,8-10 wird übrigens ein anderer Synchronismus, der des Moses mit dem attischen König Kekrops, verfochten (in 9,11 gibt Eusebios als Quelle dafür die von ihm erarbeiteten Xoovıкoì Kavóves an). Der in PE X 10,9 zitierte Julius Africanus (vgl. unten Anm. 589) wiederum situiert Moses in die Zeit des attischen Königs Ogygos, d.h. deutlich vor Kekrops (ebenso in 10,11 und 10,21); der in PE X 10,15 von Africanus zitierte Polemon dagegen platziert Moses in die Zeit des dritten argivischen Königs Apis.

587 Die attischen Könige haben in Apollodors Bibliotheke einen eigenen Abschnitt (III 177-218 = III 14,1-16,2, wo das Buch in der Darstellung des Theseus abbricht; doch bietet eine Epitome noch eine Ergänzung).

Wieder lohnt es sich, hier die attische Königsliste zu vergleichen, die Kastor von Rhodos (vgl. oben Anm. 580) präsentierte und die sich ebenfalls in der armenischen 
Version von Eusebios' Chronik erhalten hat (FGrHist $250 \mathrm{~F}$ 4): Hier finden wir die Reihenfolge Ogigos [sic] - 190 Jahre ohne Königtum (nach der Überflutung Attikas, vgl. unten Anm. 589) - Kekrops „Diphyes“ (zum Beinamen vgl. unten Anm. 591) - Kranaos - Amphiktion [sic] - Erichthonios - Pandion I. - Erechtheus - Kekrops II. - Pandion II. - Egeus [sic] - Theseus - Menestheus. Der bei Tatian erwähnte Aktaios ist hier nicht zu finden; er wurde offenbar schon seit dem 4. Jh. v. Chr. als mythischer attischer Urkönig noch vor Kekrops diskutiert (vgl. Marmor Parium, FGrHist 239 A 1; Strab. IX 1,18, 397 C, 3f. RADT), aber von Philochoros zurückgewiesen (FGrHist 328 F 92a).

588 Laut Trelenberg 2012, 185 Anm. 409 ist das Folgende, nämlich „der geschichtliche Abriss der wichtigsten Ereignisse von der Zeit des Phoroneus bis auf Agamemnon", "wörtlich von Clemens Alexandrinus übernommen worden“. Dies ist nicht völlig richtig, denn es gibt bei Clemens auch textliche Überschüsse, die eher vermuten lassen, dass er und Tatian hier die gleiche Quelle benutzt haben; vgl. oben Einführung S. 21.

589 Ogygos war ursprünglich eine Figur der böotischen Urgeschichte und wurde offenbar erst sekundär in die attische integriert, um diese genauso alt zu machen wie die böotische (denn laut Clem. Alex. Strom. I 102,2, der hier auf die nicht erhaltenen Chronoi des Dionys von Halikarnass zurückgeht, begann die attische Königslinie mit Kekrops erst vier Generationen später als die argivische); vgl. E. WöRNER, "Ogygos I", in: W.H. Roscher, Ausführliches Lexikon der griechischen und römischen Mythologie, Band II 1 (Leipzig 1902) 684f. So kennt Pausanias I 38,7 eine Genealogie, die Ogygos zum Vater des Eleusis macht, der dem gleichnamigen Ort in Attika seinen Namen gab; bei Eusebios, PE X 10,10 ist Ogygos sogar Gründer und König von Eleusis, in X 10,7 ist Ogygos attischer Autochthone, und hier wird auch die große Flut erwähnt, die zu seiner und des Phoroneus Zeit Attika überschwemmte; beide Eusebios-Partien sind Teil eines Auszugs aus dem dritten Buch der Chronographiai des ersten christlichen Chronographen Julius Africanus (der freilich etwas jünger als Tatian ist). Diese sogenannte „ogygische Flut" , die noch vor der deukalionischen stattgefunden haben soll, lässt sich in der griechischen Literatur nicht vor dem im 1. Jh. v. Chr. schreibenden Kastor von Rhodos (FGrHist 250 F 1, S. 1132,7 Jaсову; F 4. 9; vgl. auch oben Anm. 580) belegen (vgl. K. SснӧPsdau, Platon. Nomoi, Bd. I [Göttingen 1994] 359).

590 Zu Aktaios vgl. auch oben Anm. 587. Pausanias (I 2,6) präsentiert ihn als unmittelbaren Vorgänger des Kekrops, der seine Tochter heiratete.

591 Nachdem Aktaios mit Phorbas (dem sechsten in Tatians argivischer Königsreihe) synchronisiert wurde, ist es nur folgerichtig, dass Aktaios' Nachfolger Kekrops (vgl. die vorangehende Anm.) - der wie bei Kastor von Rhodos (vgl. oben Anm. 589) mit

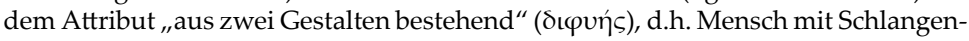
unterleib (was seine Autochthonie $=$ Erdgeborenheit vor Augen führt) bezeichnet wird - mit Phorbas' Nachfolger Triopas synchronisiert wird. Die bisher von Tatian noch nicht erwähnte Io (die bei Ovid Tochter des Inachos ist) wird in den anderen argivischen Königslisten (s. oben Anm. 580) in der Regel als Tochter des Iasos, eines Sohnes des Triopas eingeführt, was einigermaßen auch zu unserem Kontext passt. Prometheus, Epimetheus und Atlas sind alle Söhne des Titanen Iapetos (vgl. bereits Hes. Theog. 509-511).

592 Wieder eine Generation später wird hier Krotopos, der Nachfolger des Triopas, mit Deukalion, dem Sohn des Prometheus (vgl. Apoll. Rhod. Arg. III 1086f.) synchronisiert.

593 Amphiktyon ist der übernächste attische König nach Kekrops (vgl. die Liste oben in Anm. 587), und Sthenelaos der übernächste König nach Triopas, der mit Kekrops synchronisiert worden war. Auf Sthenelaos folgt Danaos, der mit seinen Töchtern 
(den Danaiden) aus Ägypten nach Argos zurückkehrt (was in Aischylos' Schutzflehenden dargestellt ist).

594 Von Dardanos war bereits in 36,1 die Rede (s. oben Anm. 561), wo er als erheblich jünger als Moses dargestellt war; dazu passt gut, dass der gleichzeitige Danaos bereits Nr. 10 auf der argivischen Königsliste ist (deren Nr. 1, Inachos, mit Moses synchronisiert war).

595 Der Raub der Kore = Persephone durch ihren Onkel, den Unterweltsherrscher Hades, die mittelbar darauf zurückgehende Gründung des Heiligtums von Eleusis (weil die nach ihrer Tochter Persephone suchende Demeter bei dieser Suche nach Eleusis gelangt) und das Wirken des attischen Heros Triptolemos, den Demeter die Gabe des Getreides in der Welt verbreiten lässt, sind wichtige Ereignisse in der nächsten Generation, die hier implizit in die Zeit des attischen Königs Erichthonios datiert werden (da Lynkeus der nächste argivische König nach dem zuletzt erwähnten Danaos ist und Erichthonios der nächste attische König nach dem zuletzt erwähnten Amphiktyon).

596 Zu Kadmos vgl. oben 39,2. Bei dem Hinweis auf die Herrschaft des berühmten Königs Minos in Kreta knirscht die mythische Chronologie freilich ziemlich stark, weil Minos' Herrschaft sonst gleichzeitig mit der des athenischen Königs Aigeus (dessen Sohn Theseus ja zu Minos fährt, um den Minotauros zu bezwingen) angesetzt wird, von dem uns jedoch in der bei Tatian anzusetzenden Chronologie (mit dem zweiten Kekrops und dem zweiten Pandion) nach Erichthonios noch vier Generationen trennen.

597 Proitos ist der übernächste argivische König nach dem zuletzt genannten Lynkeus und passt daher wieder gut zu der Zeit des erwähnten Krieges der Athener gegen den Thrakerkönig Eumolpos, den der athenische König Erechtheus, übernächster Amtsinhaber nach dem zuletzt genannten Erichthonios, führte.

598 In Argos ist (jedenfalls in Tatians Darstellung in 39,1; vgl. dazu oben Anm. 580) Akrisios und in Athen der zweite Kekrops der jeweils nächste König. Die „Ankunft des Ion" könnte hier gewisse Probleme schaffen, denn Ion ist der (uneheliche, weil von Apollon gezeugte) Sohn der Erechtheus-Tochter Kreusa, als deren Ehemann der aus dem thessalischen Iolkos stammende Xuthos in Athen regiert. Dies ist jedenfalls die Konstellation im Stück Ion des Euripides, das gewissermaßen die "Ankunft des Ion in Athen" zum Thema hat und innerhalb deren für einen zweiten Kekrops (der wie der zweite Pandion erst nach Euripides in die attische Königsliste eingeschoben wurde) eigentlich kein Platz ist.

599 Bemerkenswerterweise ist auch in der attischen Königsliste des Kastor von Rhodos (vgl. oben Anm. 587) der zweite Kekrops mit Dionysos synchronisiert, während andere Synchronismen in Kastors Liste mit solchen bei Tatian nicht übereinstimmen (auch dazu oben Anm. 580).

600 Zu Musaios vgl. unten Anm. 610 und 611.

601 Von der Zeit des Perseus überspringt Tatian vier Generationen bis zur Zeit des Agamemnon, um zum Schluss seiner Synchronisierung der argivischen und der attischen Mythengeschichte zu kommen.

602 Während in der Eusebios-Überlieferung nur $\pi$ ó $\lambda \varepsilon \omega v$ steht, findet sich in den TatianHandschriften an dieser Stelle ein erweiterter, aber zum Teil auch unsinniger Text (vielleicht die Folge einer hier unleserlichen Vorlage, die verschieden entziffert wur-

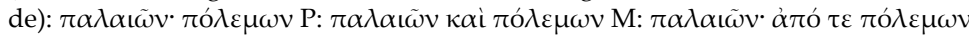
V. Von Oтto hat deswegen $\pi$ ó $\lambda \varepsilon \omega \nu, \pi o ́ \lambda \varepsilon \mu \omega \nu$ konjiziert, und MARCovich und TRELENBERG haben diese Konjektur übernommen. Aber von Kriegen (außer dem Trojanischen), im Vergleich zu denen Moses älter sein soll, war nicht die Rede; deshalb scheint hier die Eusebios-Überlieferung das Richtige wiederzugeben.

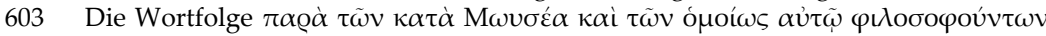
erweckt den Eindruck einer Tautologie (,,von denen, die gemäß Moses und ähnlich 
wie er philosophierten"; TrelenberG, wie bereits KuKUlA, versteht $\pi \alpha \varrho \dot{\alpha} \tau \tilde{\omega} \nu \kappa \alpha \tau \dot{\alpha}$ M $\omega v \sigma \varepsilon \dot{\alpha} \alpha$ als „aus den Büchern des Moses“, aber da von diesen bisher nicht die Rede war, müssten sie expliziter bezeichnet sein) und hat daher MArCovich zu einem drastischen Eingriff ( $\pi \alpha \varrho \grave{\alpha} \tau o \tilde{v} \kappa \alpha \tau \dot{\alpha} \mathrm{M} \omega \sigma \varepsilon \dot{\epsilon} \omega \varsigma$ ) bewogen. Die hier vorgelegte Übersetzung („,von Moses und denen ..., die ähnlich wie er philosophierten“; ähnlich

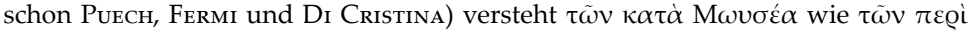

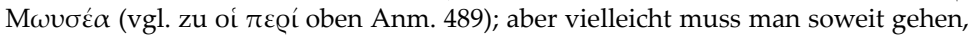
hier den Text entsprechend zu ändern.

604 Alle modernen Editionen folgen hier der Eusebios-Überlieferung, die einen Text-

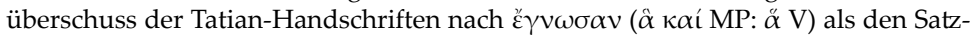
Duktus störend getilgt haben; doch könnte dieser Überschuss anzeigen, dass noch vor der Zeit des Eusebios aus Tatians Satz etwas ausgefallen ist, womit das in den Tatian-Handschriften zu findende $\alpha \hat{~}(\kappa \alpha i ́)$ noch einen Sinn ergab (vgl. NesseLRATH 2005, 262). Was das gewesen sein könnte, lässt sich vielleicht noch aus einem Passus des Clemens von Alexandria eruieren, der mit unserer Tatian-Stelle auf-

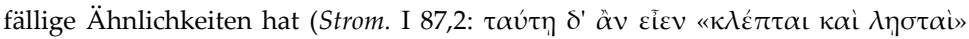

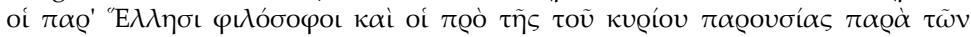

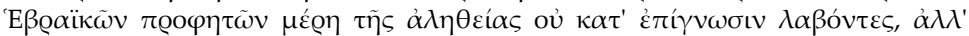

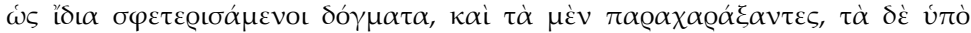

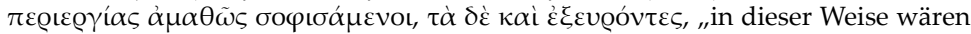
die Philosophen bei den Griechen ,Diebe und Räuber', wie auch diejenigen, die vor der Erscheinung des Herrn von den jüdischen Propheten Teile der Wahrheit nicht in echter Anerkennung übernommen, sondern sich angeeignet haben, als wären es ihre eigenen Erkenntnisse, und die das eine verfälschten, das andere aufgrund ihrer Neugier in unverständiger Weise spitzfindig verdrehten und manches auch [hinzu]erfanden“"). In Clemens' Text erwecken die Elemente oủ $\kappa \alpha \tau^{\prime} \dot{\varepsilon} \pi i ́ \gamma v \omega \sigma \iota v$,

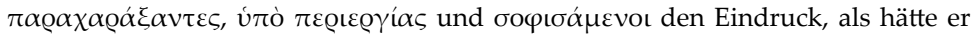
unsere Tatian-Stelle vor Augen gehabt (ähnlich Trelenberg 2012, 187 Anm. 414, ohne daraus jedoch Schlüsse für den Text zu ziehen), und vielleicht gilt dies auch

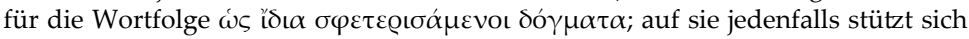

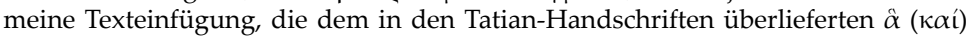
wieder einen syntaktischen Sinn gibt.

605 Der jetzt folgende Katalog hat eine Reihe von Namen gemeinsam mit der $\Sigma v v \alpha \gamma \omega \gamma \eta \dot{\eta}$

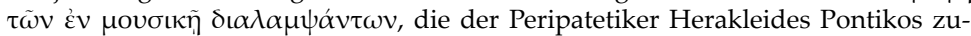
sammengestellt hat (Fr. 157 WerruI): Amphion, Linos, Philammon, Thamyris, Demodokos, Phemios.

606 Als Schriftsteller ist der frühe thebanische Sänger und Musiker Linos (zu seiner Datierung äußert sich Tatian genauer in Or. 41,2) aus folgenden Quellen bekannt: Diodor III 67,4 (= Dionysios Skytobrachion FGrHist 32 F 8) schreibt ihm als Werke

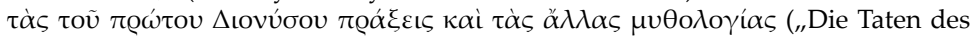
ersten Dionysos und die übrigen mythischen Geschichten“) zu, Diogenes Laertios

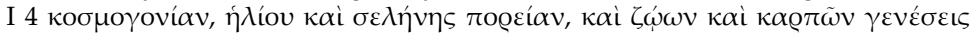
(„Die Entstehung des Kosmos, Der Lauf von Sonne und Mond, und Die Entstehung von Tieren und Pflanzen“). Vgl. auch Paus. VIII 18,1, der jedoch diese Werke als "Fälschungen“ ( $\kappa i ́ \beta \delta \eta \lambda \alpha$ ) bezeichnet (auch Paus. IX 29,9 wird die Existenz solcher Gedichte bestritten). Clemens von Alexandria rechnet Orpheus, Linos und Musaios neben Homer und Hesiod zu den Dichtern, die vieles Theologische (was sie von den

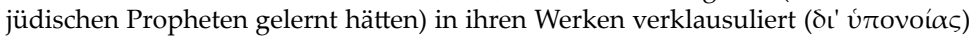
wiedergäben (Strom. V 22,1). (Ps.-Plutarch, De musica 1132A = Herakleides Pontikos, Fr. 157 WehrLi schreibt einem Linos aus Euboia Oońvous, „Trauergesänge“, zu; laut Herakleides Pontikos, Fr. 160 WehrLi gab es drei verschiedene Linoi.) Laut Diodor III 67,2 war Linos auch der Lehrer des Orpheus (so auch im Suda-Artikel zu 
Orpheus, o 654) und des Thamyras/Thamyris; dagegen ist bei Nikomachos, Math. Exc. 1 Orpheus der Lehrer des Linos und Thamyris.

607 Laut Herakleides Pontikos, Fr. 157 Wehrli (vgl. oben Anm. 605) soll Philammon

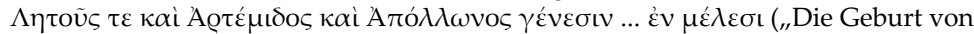
Leto, Artemis und Apollon ... in Liedern") gedichtet haben. Zu Philammon und seinem Sohn Thamyris (vgl. die folgende Anm.) vgl. auch die 7. narratio des Mythographen Konon, jetzt bei BROwn 2002, 88-92.

608 Laut Herakleides Pontikos, Fr. 157 WeHrLi soll Thamyris eine Titanomachie (Tı $\alpha^{\prime}-$

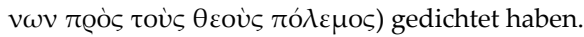

609 Amphion gehört mythenchronologisch der Großvätergeneration der Trojakämpfer an (was unten in 41,4 auch explizit gesagt wird); seine größte musische Leistung war die Erbauung von Thebens Stadtmauern, indem er die Steine allein durch sein wunderbares Leierspiel bewegte (vgl. Apoll. Rhod. Arg. I 740f.). Titel von Werken, die er verfasst hätte, sind (im Gegensatz zu den übrigen musischen Künstlern hier auf Tatians Liste) nicht überliefert.

610 Den Orpheus nennt Diog. Laert. I 5 erst nach Linos und Musaios. Zu den zahlreichen Werken, die Orpheus zugeschrieben wurden, vgl. seinen Suda-Artikel (o 654), ferner Philochoros, FGrHist 328 F 207. Als prominenter Teilnehmer der Argonautenfahrt gehört Orpheus der Generation vor dem Trojanischen Krieg an.

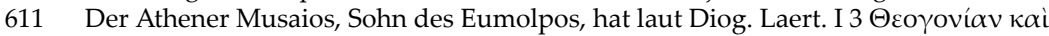
$\Sigma$ Qरĩo $\alpha v$ (,Entstehung der Götter“ und „Kugel“) gedichtet.

612 Demodokos als Sänger der Phäaken, zu denen Odysseus auf seinen Irrfahrten verschlagen wird, ist eigentlich eine fiktionale Gestalt im achten Buch der Odyssee; auch er wird jedoch im Katalog des Herakleides Pontikos (vgl. oben Anm. 605) zu „Demodokos von Kerkyra“ (bereits im 5. Jh.v. Chr. wurde die Phäaken-Insel Scheria mit Kerkyra gleichgesetzt) historisiert, und ihm werden als reale Werke eine 'I $\lambda$ íov

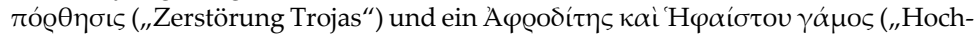
zeit der Aphrodite und des Hephaistos“) zugeschrieben, also Themen, über die er gerade im achten Buch der Odyssee singt.

613 Auch Phemios, den in der Odyssee auftretenden Sänger am Hof des Odysseus, hat Herakleides Pontikos (vgl. oben Anm. 605) als „Phemios von Ithaka“ historisiert

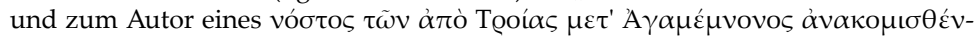
$\tau \omega \nu$ („Heimkehr derjenigen, die von Troja mit Agamemnon zurückkehrten“) gemacht.

614 Mit Tatians lapidarem Hinweis auf „die Sibylle“ sind wahrscheinlich die Sibyllinischen Orakel gemeint, eine Sammlung von hexametrischen Orakeltexten, deren erste Teile im 2. Jh. v. Chr. in jüdischem Milieu entstanden und in den folgenden Jahrhunderten um weitere Stücke (nun auch mit deutlich christlichem Tenor) erweitert wurden (vgl. H. MerkeL, Sibyllinen. Jüdische Schriften aus hellenistisch-römischer Zeit V/8 [Gütersloh 1998] 1069f.; J. L. Lightғoот, The Sibylline Oracles. With Introduction, Translation, and Commentary on the First and Second Books [Oxford 2007] 23. 219-253; O. Wassmuth, Sibyllinische Orakel 1-2. Studien und Kommentar [Leiden / Boston 2011] 14-16). Die erste Sibylle soll vom Musenberg Helikon gekommen und sich auf einem Felsen im Heiligtum von Delphi niedergelassen haben, um dort zu weissagen (Plut. Pyth. or. 9, 398C); Pausanias (X 12,1f.) spricht sogar von zwei in Delphi tätigen Sibyllen, einer älteren, Tochter des Zeus und der Poseidon-Tochter Lamia, und einer jüngeren namens Herophile, die aber auch noch vor dem Trojanischen Krieg gelebt und den Untergang Trojas vorausgesagt haben soll. Sie soll ferner einen Hymnos auf Apollon verfasst haben, so dass Tatian sie hier zu Recht unter "Autoren, die älter sind als Homer" aufgenommen hätte.

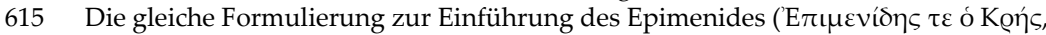

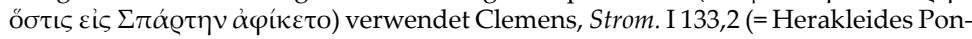
tikos, Fr. 90 WeHrLI). - Warum Epimenides in einer Reihe von Autoren erscheint, 
die als „älter als Homer“ eingeführt werden, ist nicht klar, denn die Biographie, die ihm bei Diogenes Laertios gewidmet ist (I 109-112, mit einem Katalog seiner Werke in 111f.), setzt ihn in die Zeit Solons, also ins frühe 6. Jh. v. Chr., und in Platons Nomoi (I 642d) wird er sogar ans Ende des 6. Jh.s datiert. Zu Epimenides' Kommen nach Sparta vermerkt Pausanias (II 21,3 = FGrHist 457 T 5e), dass er dorthin als Kriegsgefangener gelangte und dann von den Spartanern getötet wurde, als er ihnen düstere Prophezeiungen gab.

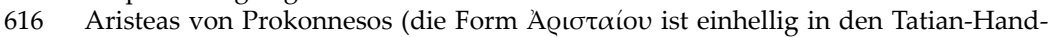
schriften und bei Eusebios überliefert und beruht auf einer Verwechslung der lautlich gleich gesprochenen Vokale $\varepsilon$ und $\alpha \mathrm{t}$ ), ist ein weiterer Autor, der in diese Liste der „Autoren vor Homer“ nicht passt, denn nach dem Bericht Herodots (IV 113-116) über ihn gehört er ins frühe 7. Jh. v. Chr. Inhalte seiner Arimaspeia referiert noch Pausanias (I 24,6; V 7,9).

617 Der Kentaure Asbolos erscheint zum ersten Mal in der griechischen Literatur in dem unter Hesiods Namen überlieferten ",Schild des Herakles“, wo er unter den Kentauren genannt wird, die am Kampf der Kentauren gegen die Lapithen teilnehmen (vgl.

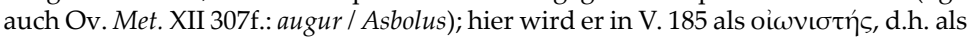
Deuter der Zukunft aus Vogelflug, eingeführt. Dass er von "tiefschwarzer“ Haut-

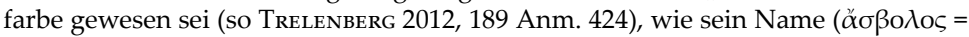
Ruß) nahelegen könnte, ist nirgends in der griechischen Literatur belegt (dagegen wird in Ov. Met. III 218 ein Asbolos "mit schwarzen Zotteln“, villis ... atris, unter den Hunden des Aktaion eingeführt).

618 Der bereits bei Herodot erwähnte Bakis soll zum Teil genaue Voraussagen zum Perserkrieg von 480 v. Chr., gemacht haben (Hdt. VIII 96,2; IX 43,1); auch er aber ist kein "Autor vor Homer".

619 Der einzige in der griechischen Literatur belegte Drymon ist ein Pythagoreer aus Kaulonia (genannt bei Iamblich, VP 267), der wiederum nicht in eine Liste von "Autoren vor Homer" passt. Vielleicht ist der Name aber auch entstellt, wie noch manche andere in dieser Liste (so steht statt Bákıঠos [coni. Schwartz] in den

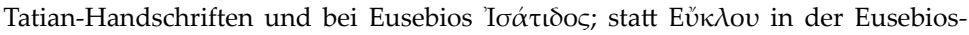

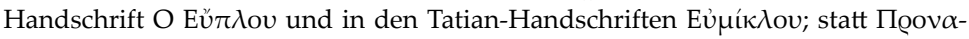

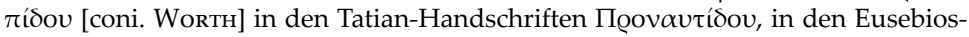

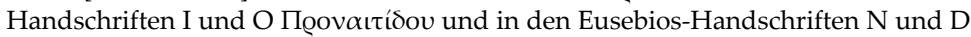

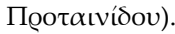

620 Der Orakelverkünder Euklus/-kloos aus Zypern passt wieder in die Reihe der „Autoren vor Homer", denn er soll Homers Geburt vorhergesagt haben (Paus. X 24,3, wo noch die entsprechenden Verse des Eukloos zitiert sind).

621 Ein Horos von Samos scheint sonst nirgends belegt zu sein.

622 Den Pronapides nennt Diodor III 67,5 (= Dionysios Skytobrachion FGrHist 32 F 8) als Lehrer Homers, womit er natürlich auch älter als Homer ist.

623 In den nächsten Sätzen werden von den in 41,1 Genannten Linos, Orpheus, Musaios, Amphion, Demodokos, Phemios, Thamyris und Philammon zeitlich näher bestimmt. Dies ist aber nur der kleinere Teil der Genannten; bei manchen anderen auf der Liste ließe sich ein solcher Nachweis gar nicht führen (vgl. oben zu Epimenides, Aristeas, Bakis). Wahrscheinlich ist es Tatians Absicht, die explizite Beweisführung auch für die nicht Genannten wirken zu lassen.

624 Der Herakles-Sohn Tlepolemos wird im Schiffskatalog der Ilias als Führer des griechischen Truppenkontingents aus Rhodos vorgestellt (Hom. Il. II 653-670); im 5. Buch unterliegt er im Kampf dem Lykierfürsten Sarpedon (V 628-669).

625 Schwartz, Marcovich und Trelenberg übernehmen aus der Eusebios-Überliefe-

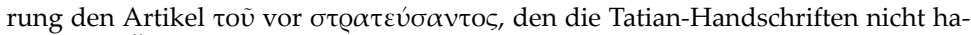
ben; diese Übernahme erscheint jedoch unnötig, da im nächsten Satz auch die Parti- 


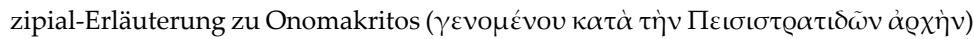
ohne einen solchen Artikel eingeführt ist.

Laut Trelenberg 2012, 189 Anm. 428 wird „die [von Tatian präsentierte] Fixierung der Lebenszeit des Herakles mittels des Auftretens seines Sohnes im Trojanischen Krieg ... von Clemens (Strom. 1,104,3) reproduziert"; er übersieht dabei, dass es bei Clemens eigentlich um die Fixierung der Lebenszeit des Theseus mithilfe des Herakles geht, während Tatian Theseus aus seiner Beweisführung eliminiert hat (vgl. oben Einführung S. 22).

626 Dass Onomakritos der wahre Autor von dem Orpheus zugeschriebenen Werken ge-

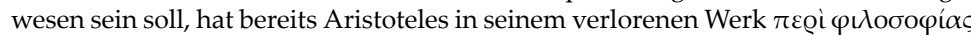
(Fr. 7 Rose $=$ Joh. Philop. in Arist. de an. 186,24-26 HAyducK) festgestellt. Vgl. auch

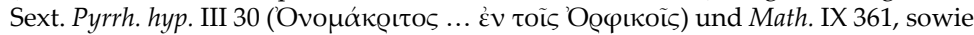
den Suda-Artikel zu Orpheus (o 654), der dem Onomakritos die unter Orpheus'

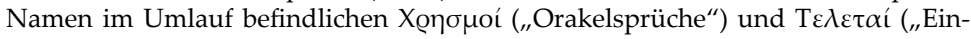
weihungen“) zuweist.

$627 \mathrm{Zu}$ Demodokos und Phemios vgl. oben Anm. 612 und 613.

$628 \mathrm{Zu}$ Thamyris und Philammon vgl. oben Anm. 607f.

629 An dieser Stelle hat Wilamowitz eine Lücke vermutet und versuchsweise mit

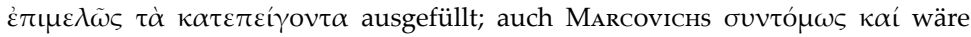

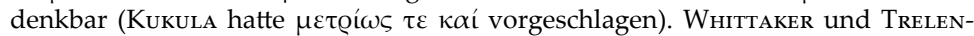
BERG versuchen, ohne die Annahme einer Lücke durchzukommen; aber $\sigma \varphi$ ódo $\alpha$ $\mu \varepsilon \tau \dot{\alpha} \pi \dot{\alpha} \sigma \eta \varsigma$ v́ $\mu \tilde{\imath} v \dot{\alpha} \kappa \varrho \iota \beta \varepsilon \dot{\alpha} \alpha \varsigma$ ist eine im Griechischen kaum denkbare Fügung (es ist wohl kein Zufall, dass die Eusebios-Handschriften N und D diese Wortfolge einfach durch ein glattes $\alpha \dot{\alpha} \kappa \iota) \tilde{\omega} \varsigma$ ersetzt haben).

630 „Die als weise gelten“ sind zunächst Gesetzgeber: der Kreter Minos (zu ihm vgl. Plat. leg. I 624a; 630d; 632d), der Spartaner Lykurg, die Athener Drakon und Solon; nur Pythagoras fällt etwas aus der Reihe heraus. Zu diesen Gesetzgebern und ihren Zeiten vgl. auch Clem. Alex. Strom. I 79,4-80,1.

Zu Minos als Gesetzgeber vgl. Paus. III 2,4.

632 Zur Synchronisierung des Minos mit dem argivischen König Lynkeus vgl. oben 39,5 und Anm. 596.

$633 \mathrm{Zu}$ den schon in der Antike recht unterschiedlichen Datierungen des Lykurg gibt Plutarch zu Beginn seiner Lykurg-Vita eine hilfreiche Übersicht (Lyc. 1,1-3): Die hellenistischen Gelehrten Eratosthenes von Kyrene und Apollodor von Athen hielten

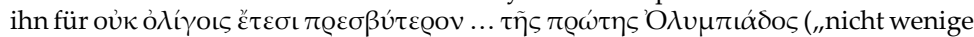
Jahre älter als die erste Olympiade"). Vgl. auch Strabon X 4,18 (=Ephoros FGrHist 70 F 149,18; sechste Generation nach Prokles). Pausanias III 2,4 setzt Lykurg in die Zeit des Agesilaos I., des sechsten Königs der Agiaden (frühes 9. Jh. v. Chr.) und damit etwa in die gleiche Zeit wie Tatian; dazu stimmt auch, dass Plut. Lyc. 1,1 und Paus. V 4,5 die Olympischen Spiele von Lykurgos und Iphitos begründen lassen, was laut Aristodemos von Elis 28 Olympiaden (= 112 Jahre) vor der ersten gezählten Olympiade (776 v. Chr.) geschah.

634 Vgl. oben $31,5$.

635 Thales ist nicht unbedingt älter als Solon, aber dieser wurde bereits unter den Gesetzgebern abgehandelt.

636 Zur Bedeutung der geographischen Angabe „im Land der Assyrer“ vgl. oben Einführung, S. 4-5. 

C. Essays 



\title{
Tatians Oratio ad Graecos und der Diskurs über ,Religion' in der frühen Kaiserzeit
}

\author{
Ferdinand R. Prostmeier
}

\section{Antiochia am Orontes und sein religiöser Kosmos}

Für die Profilierung von Tatians Oratio ad Graecos im kaiserzeitlichen Religionsdiskurs sind vor allem Zeit und Ort ihrer Abfassung relevant. ${ }^{1}$ In der Frühchristentumsforschung ist es zwar fast Konsens, dass die Oratio ad Graecos ihre Endgestalt nicht lange nach $172 \mathrm{n}$. Chr. erhalten hat. ${ }^{2}$ In der Diskussion steht hingegen der textgenerative Prozess selbst, insbesondere ob „Versatzstücke sogar aus Tatians vorchristlicher Periode“3 Verwendung gefunden haben, ob der Syrer während der Erarbeitungsphase andere Werke begonnen oder abgeschlossen hat, und vor allem das literarische Verhältnis der Oratio ad Graecos zu Justins Euvre. Bezüglich des Abfassungsortes wird weithin Harnack gefolgt, dass die Oratio ad Graecos „mit einem deutlichen Abstand von der Hauptstadt berichtet" ${ }^{4}{ }^{4}$ Unter den schon von Harnack erwogenen Abfassungsorten "Griechenland, Edessa, insbesondere aber Antiochien “5 dürfte letzterer die größte Wahrscheinlichkeit für sich haben.

Eine Abfassung oder Endredaktion der Oratio ad Graecos nach 172 n. Chr. in Antiochia am Orontes bringen Tatian und sein Euvre $^{6}$ in zeit-

\footnotetext{
${ }^{1}$ Die Prolegomena zu Tatians Oratio ad Graecos sind in der Einführung von H.-G. NEsSELRATH besprochen; vgl. ferner die einleitungswissenschaftlichen Abschnitte in der monographischen Edition und Übersetzung durch TreLENBERg 2012, 1-80. 195-240.

${ }_{2}^{2}$ Abfassungszeit und Entstehungsort der Oratio ad Graecos sind eng mit der Frage nach der literarischen Integrität des Werks sowie der Anwesenheit Tatians in Rom und seinem Verhältnis zu Justin verflochten. Zur Forschungsgeschichte vgl. die Einführung von NesSELRATH in diesem Band, S. 14-17 sowie den Forschungsüberblick bei TrelenBERg 2012, 8-15; zur Fertigstellung der Endgestalt der Oratio ad Graecos bald nach 172 n. Chr. vgl. ebd. 15.

${ }^{3}$ TRELENBERg 2012, 15.

${ }^{4}$ Trelenberg 2012, 15 .

${ }^{5}$ Trelenberg 2012, 15 .

${ }^{6}$ Tatian scheint als theologischer Schriftsteller überaus produktiv gewesen zu sein. Ne-

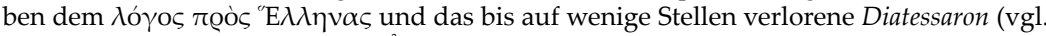
P. BRUns, „Diatessaron“, LACL [32002] 193f.; LANGe 2008) sind die Titel von vier weite-

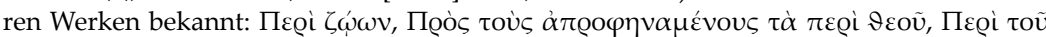

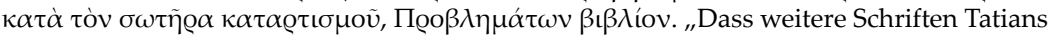


liche und räumliche Nähe zu Theophilos von Antiochia, der zwischen 180-182 sein Spätwerk, die drei Bücher An Autolykos, schreibt. ${ }^{7}$ Ebenso wie in Tatians Oratio ad Graecos lassen sich auch in der Trilogie des Theophilos beachtliche Berührungen mit Justins Schriften ausfindig machen. ${ }^{8}$ Allerdings handelt es sich dabei um bekannte Anspielungen und Verweise oder es werden Topoi verwendet, die zumal bei den frühchristlichen Apologeten nicht selten begegnen, z.B. die Betonung der Bedürfnislosigkeit Gottes (Theophilos, Autol. II 10). Weder diese Berührungen noch die Verwendung bestimmter, im Religionsdiskurs usuell aufgerufener Werke aus der griechisch-römischen Tradition ${ }^{9}$ oder aus der biblischen und der frühchristlichen Literatur sind beweiskräftig für eine direkte literarische Abhängigkeit. Vielmehr verweisen der favorisierte Abfassungsort von Tatians Oratio ad Graecos und möglicherweise auch seiner anderen Schriften, zuvorderst seines Diatessaron, ${ }^{10}$ auf ein geistig-soziales Milieu von gebildeten und darum an philosophischen und theologischen Sujets interessier-

im Umlauf waren, deren Titel wir nicht kennen, ist sehr wahrscheinlich“ (Trelenberg 2012, 3f.).

${ }^{7}$ Die drei Bücher An Autolykos sind das einzige Werk des Theophilos von Antiochia, das

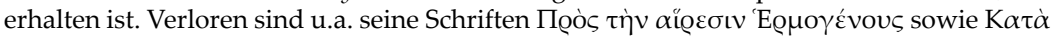

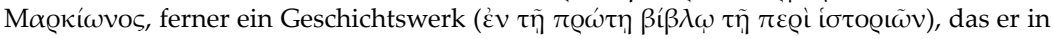
Autol. II 28; 23; 31 und III 19 erwähnt, sowie Kommentare zu Proverbien. Einen angeblichen Evangelienkommentar (vgl. von Отто 1851, 278-324) des Theophilos (К $\alpha \tau \eta \chi \eta \tau \iota \kappa \dot{\alpha}$ $\beta(\beta \lambda i ́ \alpha)$ hat A. Harnack, Die Evangelien des Matthaeus und des Marcus aus dem Codex Purpureus Rossanensis. Der angebliche Evangeliencommentar des Theophilus von Antiochien. TU 1,4 (Leipzig 1883) als Fälschung erwiesen. Die Trilogie ist wahrscheinlich kurz nach dem Tode von Marc Aurel (161-180 n. Chr.) verfasst worden; am häufigsten wird die Zeit 180-182 n. Chr. genannt. Neben der Chronologie in Autol. III 16-29, die bis zum „Tod des Kaisers Verus" reicht, ist für den termininus post quem auf die Personalnotiz in Autol. III 27,3b über

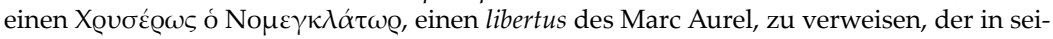
nen ảv $\alpha \gamma \varrho \alpha \varphi \alpha i ́$ die Geschichte Roms ab urbe condita bis zum Tod Marc Aurels verzeichnet habe.

${ }^{8}$ Vgl. die Synopse von 34 Textsequenzen mit auffälligen Berührungen zwischen den drei erhaltenen Werken Justins und Tatians Oratio bei TreLEnberg 2012, 196-203. Für ihn steht fest, dass Tatian die Werke Justins kannte. Allerdings scheint fraglich, ob mit TRELENBERG aus der bloßen Kenntnis von Justins Schriften und der Wiedergabe von Aussagen Justins, die weder in den Apologien noch im Dialog bezeugt sind, auf ein Lehrer-SchülerVerhältnis zwischen Justin und Tatian geschlossen werden darf. Ist die berühmte Bezeich-

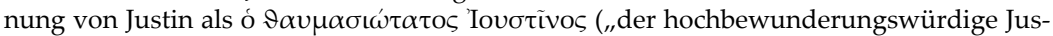
tin“) in Tatian, Or. 18,6 Beleg dafür, dass sich um Justin ein Kreis von Hörern gebildet hat, der strukturell und der Intention nach nicht nur mit jenen Lehr- und Lernzirkel zu vergleichen ist, für die der aus dem Feld philosophischer Schulen entlehnte Begriff disciplina zutreffend scheint, sondern dass Justins Schule ein contubernium war, eine Lern- und Lebensgemeinschaft? Die Personalnotiz in Or. 18,6 könnte allerdings auch nur Respekt für den Märtyrer Justin signalisieren.

${ }^{9}$ Näheres vgl. Krause 1958, 131-142; zu den Zitaten und Anklängen an die pagane Literatur in der Trilogie sowie planvollen Verteilung vgl. Prostmeier 2013.

${ }^{10}$ Vgl. ZaHN 1881; Lange 2008. 
ten Heiden und Christen. ${ }^{11}$ Diesen ambitionierten Diskurs über religiöses Wissen hat man sich in verschiedenen Aktionsräumen vorzustellen: Neben der convivialen Szenerie ${ }^{12}$ sind Sozialformen in Betracht zu ziehen, die als disciplina klassifiziert werden konnten sowie jene Sektoren der religiösen Inszenierung im öffentlichen Raum, in denen sich Einzelgestalten und disciplinae ebenso wie soziale Formen von Religion, die den Status einer secta hatten, präsentierten und für sich warben. ${ }^{13}$ In der frühen Kaiserzeit sind dieser religiöse Kosmos und der Religionsdiskurs unter Gebildeten geradezu Signum der Urbanität einer mondänen Metropole wie Antiochia am Orontes. ${ }^{14}$

Neben dem offiziellen „Reichskult “15 bot diese drittgrößte Stadt im Imperium Romanum Raum für alte wie neue Kulte und Religionen. Das Diasporajudentum wird ein Eckpfeiler im religiösen Kosmos der Stadt und seines Umlandes gewesen sein. ${ }^{16}$ Wie sehr das urbane westsyrische Judentum in der Zeit von Tatian und Theophilos aus dem Erbe des weltläufi-

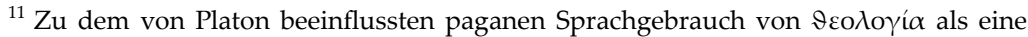
"philosophisch verantwortbare Aussage über Götter" (rep. II 379a) und die Bezeichnung

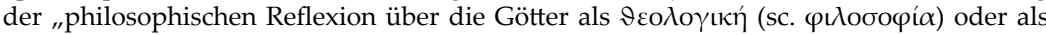
das $\vartheta \varepsilon$ oגoүıкóv“ vgl. Ch. Markschies, „Hohe Theologie und schlichte Frömmigkeit? Einige Beobachtungen zum Verhältnis von Theologie und Frömmigkeit in der Antike“, in: Grieser / Merkt 2009, [456-471] 460f.; Markschies 2007, 15-31.

${ }^{12}$ Vgl. U. EgelhaAf-Gaiser, „Blütenlese fürs Bankett. Die Organisation und Präsentation religiösen Wissens in den Deipnosophisten des Athenaios", in: Ch. Frateantonio / H. Krasser (Hg.), Religion und Bildung. Medien und Funktionen religiösen Wissens in der Kaiserzeit. Potsdamer Altertumswissenschaftliche Beiträge 30 (Stuttgart 2010) 111-132.

${ }^{13}$ Die dritte christliche Generation ruft diese Räume in ihrer literarischen Produktion gezielt auf. Zu den ältesten Zeugnissen kann die Episode von der Begegnung des Paulus mit dem Statthalter Sergius Paulus gerechnet werden (Apg 13,4-12), sodann die Areopagrede (Apg 17,16-34) sowie der Bericht über den Tumult im Theater von Ephesos (Apg 19,23-40). Zur Areopagrede vgl. Prostmeier 2013, 127-162 und zu kaiserzeitlichen Konzeptualisierungen von Religion (sacra publica, sacra privata, peregrina sacra, disciplina, secta, collegia) und den Schwierigkeiten, religiöse Deviation wirksam und für die Gesellschaft funktional zu normieren vgl. J. RüPKE, Die Religion der Römer. Eine Einführung (München 2001); ders., Aberglauben oder Individualität? Religiöse Abweichung im römischen Reich (Tübingen 2011) 77-152.

${ }^{14}$ Näheres vgl. A. J. Festugière, Antioche païenne et Chrétienne. Libanius, Chrysostome et les moines de Syrie. BEFAR 194 (Paris 1959); G. Downey, A History of Antioch in Syria. From Seleucus to the Arab Conquest (Princeton 1961); ders., "The Size of the Population of Antioch“, TPAPA 89 (1958) 84-91; F. KolB, „,Antiochia in der frühen Kaiserzeit", in: H. CANCIK u.a. (Hg.), Geschichte - Tradition - Reflexion. FS Martin Hengel, Bd. 2 (Tübingen 1996) 97-118; Kondoleon 2001; J. H. W. G. LiebesChueTz, Antioch. City and imperial administration in the later Roman empire (Oxford 1972); J. HAHN, ,,, Die Tempel sind die Augen der Städte' - Religiöse Landschaft und Christianisierung in Nordsyrien", in: ders. (Hg.), Religiöse Landschaften. AOAT 301 (Münster 2002).

${ }^{15}$ Zum Problem vgl. J. RüPKE, „,Wie veränderte ein Reich Religion - und wie die Religion ein Reich? Bilanz und Perspektiven der Frage nach der ,Reichsreligion'“, in: H. CANCIK / J. Rüрке (Hg.), Die Religion des Imperium Romanum. Koine und Konfrontation (Tübingen 2009) 5-18; ders., „Religiöser Pluralismus und das Römische Reich“, in: ebd., 331-354.

${ }^{16} \mathrm{Vgl}$. dazu auch den Hinweis bei Nesselrath, „, dass Tatian mit seinem Altersbeweis in jüdischer Tradition steht" (S. 179, Anm. 562 zu Or. 36,2).
} 
gen, hellenistischen Judentums lebt oder von frührabbinischer Glaubensund Lebenspraxis profiliert ist, ob und welche Kontakte zu christlichen Gemeinden bestanden, wäre eigens zu prüfen. ${ }^{17}$ Vier Beobachtungen weisen darauf hin, dass Juden und Christen in Antiochia schon geraume Zeit getrennte Wege gingen:

1. Im Matthäusevangelium ${ }^{18}$ scheint nicht nur eine facettenreiche Konfliktgeschichte mit der Religion durch, aus der das Christentum stammt, sondern es wird auch das ernste Bestreben erkennbar, all jene Christen in der Gemeinde zu halten, deren religiöse Wurzeln im Judentum liegen. Hierzu gehört die Modifikation des Verständnisses ererbter jüdischer Frömmigkeitsformen wie Almosen, Fasten und Gebet, ${ }^{19}$ so dass es auch jüdischen Gemeindemitgliedern möglich war, im Eigenleben der Gemeinde das Evangelium zu bezeugen. Die Rückprojektion der Konflikte in die Zeit des irdischen Jesus statten dieses Glaubensprofil und Glaubensleben mit der Autorität der ,Norm am Anfang' aus. Zu diesen Markierungen christlicher Identität gehört ebenso die Distanzierung gegenüber der Synagoge ${ }^{20}$ und die Rede gegen die Pharisäer und Schriftgelehrten in Mt 23,1-36, die für diese Repräsentanten jüdischer Rechtgläubigkeit nur noch Weherufe übrig hat.

2. Anfang des zweiten Jahrhunderts schreibt die Didache ${ }^{21}$ mit großer Wahrscheinlichkeit für Gemeinden in der Region um die syrische Metropole am Orontes ethische Standards und disziplinäre Regeln fest. Skopos der Instruktionen dieser ältesten Kirchenordnung ist die klare Scheidung

\footnotetext{
${ }^{17}$ Vgl. H. J. W. Drijvers, „Syrian Christianity and Judaism“, in: ders. (Hg.), History and Religion in Late Antique Syria. CStS 464 (Great Yarmouth / Norfolk 1994) 124-146; RoBINson 2009.

${ }^{18} \mathrm{Zu}$ den Abfassungsverhältnissen vgl. U. Luz, Das Evangelium nach Matthäus (Mt 1-7). EKK I/1 (Düsseldorf / Zürich ${ }^{5}$ 2002) [100-105] 102f.: „Das Matthäusevangelium gibt seinen Entstehungsort nicht preis. Sicher war es eine größere syrische Stadt, in der lingua franca Griechisch war. M.E. ist Antiochien nicht die schlechteste Hypothese. Das Matthäusevangelium stammt also vielleicht aus einer (!) antiochenischen Gemeinde.“ Und: „Lange nach dem Jahre 80 wird man das Matthäusevangelium nicht ansetzen dürfen" (ebd. 104).

${ }^{19} \mathrm{Vgl}$. die aus dem Sondergut des Matthäusevangeliums stammenden Grundsätze in Mt 6,1-6.16-18 bezüglich der "neuen Gerechtigkeit“ und deren Anwendung in der aus Mk 2,18-22 rezipierten Fastenperikope in Mt 9,14-17.

${ }^{20}$ In der Exposition zur fünften, galiläischen Konfliktszene', der ,Heilung der verdorr-

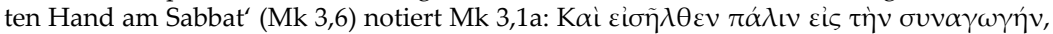
„Und er ging abermals in die Synagoge“. Das Matthäusevangelium übernimmt diese Therapiegeschichte aus Mk 3,1-6, trägt aber in die Exposition die aktuelle Konfliktlage der Gemeinde ein, indem er zwischen Gemeinde und Synagoge differenziert. In Mt 12,9 heißt

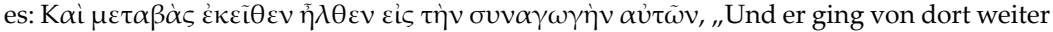
und kam in ihre Synagoge." Analog macht Mt 13,54a gegenüber Mk 6,2a eine Front auf, die den Jesus des Matthäusevangeliums von seinen Glaubensbrüdern und seiner Familie abhebt.

${ }^{21} \mathrm{Zu}$ den einleitungswissenschaftlichen Fragen vgl. Niederwimmer 1989, 78-80; J. A. Draper, „Die Didache“, in: Pratscher 2009, 17-38.
} 
zwischen Judentum und christlicher Gemeinde, die schon vor der Konversion durch unterscheidendes Handeln bezeugt werden muss. ${ }^{22}$

3. Die Ignatianen ${ }^{23}$ profilieren das Christentum u.a. damit, dass sie alles Jüdische aus dem Glaubensleben der Gemeinden eliminiert wissen wollen. ${ }^{24}$

4. Es ist auffällig, dass in der Oratio ad Graecos die jüdische Tradition weder in Gestalt eines fiktiven Gesprächspartners auftritt, wie z.B. in der Schrift An Diognet ${ }^{25}$ oder - breit ausgeführt - im Dialog mit Tryphon, noch

${ }^{22}$ Vgl. F. R. Prostmeier, „Unterscheidendes Handeln. Fasten und Taufen gemäß Did 7,4 und 8,1“, in: J. B. Bauer (Hg.), ФІ $\Lambda$ ОФРОNH $\Sigma \mathrm{I} \Sigma$. Grazer Theologische Studien 19 (Graz 1995) 55-75.

${ }^{23}$ Zumindest der literarischen Fiktion nach schreibt ein Antiochener Episkopos namens Ignatios auf seiner Deportationsreise nach Rom sieben Briefe mit Instruktionen an seinen Amtskollegen Polykarp von Smyrna (Ign. Polyk.) und an kleinasiatische Gemeinden (Ephesos, Magnesia, Tralles, Philadelphia, Smyrna) sowie an die Gemeinde im caput mundi (Ign. Röm.). - Zur komplexen neueren Ignatiosforschung vgl. R. M. HüBNER, „Thesen zur Echtheit und Datierung der sieben Briefe des Ignatius von Antiochien“, ZAC 1,1 (1997) 44-72; A. Lindemann, „Antwort auf die ,Thesen zur Echtheit und Datierung der sieben Briefe des Ignatius von Antiochien'“, ZAC 1,2 (1997) 185-194; Th. Lechner, Ignatius adversus Valentinianos? Chronologische und theologiegeschichtliche Studien zu den Briefen des Ignatius von Antiochien. SVigChr 47 (Leiden 1999); A. Brent, Ignatius of Antioch and the Second Sophistic. STAC 36 (Tübingen 2006); Roвınson 2009. Zu literarischen und historischen Grundfragen sowie den theologischen Hauptthemen des Corpus Ignatianum vgl. F. R. Prostmeier, „Ignatius von Antiochien“, LACL (2002) 346-348; H. LöHR, „Die Briefe des Ignatius von Antiochien", in: Pratscher 2009, 104-129. Strittig ist, ob das Corpus von dem bei Rufin als Episkopos von Antiochia am Orontes gelisteten Ignatios stammt und daher als echt anzusehen ist und in den Jahren 113/14 verfasst wurde, oder ob es sich um Pseudephigrapha handelt, die entweder kurz nach dem Tod Kaiser Hadrians verfasst wurden (BRENT et al.) oder bald nach 170 in Abhängigkeit von Noët von Smyrna. Sind die sieben Briefe echt, müssten sie an zwei kleinasiatischen Stationen der Deportationsreise des Antiochener Episkopos entstanden sein. Eine antivalentinianische Situierung und Stoßrichtung (HüBNER, LeCHNER) legt eine Abfassung in Smyrna in den 170er Jahren nahe. Mit dem Fokus auf die Rhetorik, die Funktionalität und Absicht der sieben Briefe rückt Rom im Kontext der ersten Phase des Quartodezimanerstreits als Abfassungsort und -zeit in den Blick (Prostmeier).

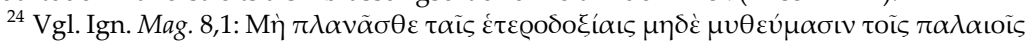

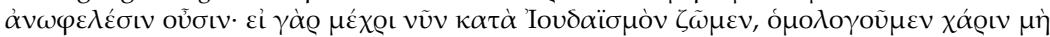

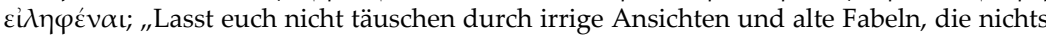
wert sind. Denn wenn wir bis heute dem Judentum entsprechend leben, so bekennen

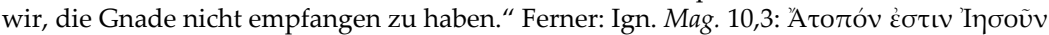

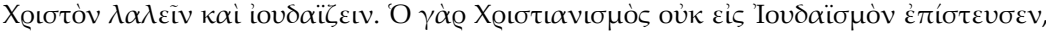

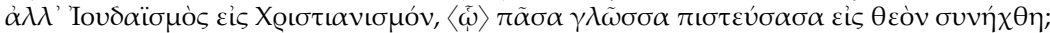
„Es ist nicht Platz, Christus Jesus zu sagen und jüdisch zu leben. Denn das Christentum ist nicht zum Glauben an das Judentum gekommen, sondern das Judentum (zum Glauben) an das Christentum, zu dem jede Zunge, die an Gott glaubte, gebracht wurde." Näheres vgl. W. R. Schoedel, Die Briefe des Ignatius von Antiochien. Ein Kommentar (München 1990) 48f. 203-205. 216.

${ }^{25}$ Vgl. Lona 2001, 141-150. 
als markierte Leerstelle, wie in der Weltchronik im dritten Buch des Theophilos von Antiochia An Autolykos. ${ }^{26}$

Außer Frage dürfte stehen, dass die Schrift und biblisch-jüdische Bildung traditionell ein Teil des religiösen Kosmos in Antiochia waren. ${ }^{27}$ Für die geistige und soziale Atmosphäre des westsyrischen Zentrums am Orontes und speziell für das Selbstverständnis der Christen in dieser Stadt und ihrem Umland dürfte vor allem die Erinnerung normierend gewesen sein, dass sich erstens in Antiochia die aus dem Judentum ,exkommunizierten' hellenistischen Jesusanhänger um Stephanus als Gemeinde etablieren konnten, dass sie zweitens nach Ausweis von Apg 11,26b in dieser Stadt zum ersten Mal in der Geschichte als unterscheidbare religiöse Gruppe wahrgenommen ${ }^{28}$ und benannt worden sind ${ }^{29}$ und dass drittens

\footnotetext{
${ }^{26}$ In der Weltchronik in Autol. III 16-29, die Theophilos mit Gen 1 beginnen lässt und bis zum Babylonischen Exil (597-539) anhand biblischer Quellen konstruiert, folgt auf die Regentschaft des Perserkönigs Kyros II., mit dem das Exil endet, sofort jene des letzten Etruskerkönig Roms, Lucius Tarquinius Superbus (III 25,5; 27,1f.). Nahtlos schließt Theophilos die Konsuln an (III 27,3) und listet danach, dem Vorbild Suetons folgend (also beginnend mit Julius Caesar), die Augusti bis Marc Aurel auf (III 27,4b-5). Weltgeschichtlich betrachtet, ist die Geschichte Israels nur eine Etappe, die mit dem Babylonischen Exil endet (III 25,3 ) und direkt in die Geschichte Roms mündet. Weder das nachexilische Judentum noch die Jesusbewegung und die Geschichte des Christentums scheinen ein weltgeschichtliches Datum zu sein. Diese Ausblendung ist ein raffinierter Schachzug in der Konstruktion der eigenen Autorität, denn nach dieser Konstruktion liegt das Christentum Rom voraus, weil das Christentum in der Schöpfung grundgelegt ist. Theophilos zufolge ist das in den ältesten Quellen, nämlich in der Genesis, nachzulesen. Daher sind das Christentum und sein gesamtes religiöses Wissen nichts Fremdes, sie sind nicht außerhalb der griechisch-römischen Geschichte und Kultur entstanden. Es ist nicht erforderlich, sie in einer Weltchronik zu erwähnen, weil sie von ihren Grundlagen her sowohl den Anfang als auch die Koordinaten der Weltgeschichte in sich tragen, deren letzte Etappe nun das Imperium Romanum mit den Konsuln und den Augusti ist. So gesehen ist die Leerstelle eine sehr gerissene Weise, die Antiquitas der christlichen Tradition in ihrer weltgeschichtlichen Bedeutung festzuschreiben. - Zur Funktion dieser Leerstelle vgl. F. R. Prostmeier, „Die Jesusüberlieferung bei Theophilos von Antiochia ,An Autolykos'“, in: M. Lang (Hg.), Ein neues Geschlecht. Entwicklung des frühchristlichen Selbstbewusstseins. FS Wilhelm Pratscher. NTOA 105 (Göttingen 2014) [179-214] 209-211.

${ }^{27}$ Näheres vgl. I. SANDwell, Religious identity in late antiquity. Greeks, Jews, and Christians in Antioch. Greek culture in the Roman world (Cambridge / New York 2007); W. A. Meeks / R. L. WiLKEN, Jews and Christians in Antioch in the first four centuries of the common era. Sources for biblical study 13 (Missoula, Mont. 1978); FeLdTKeller 1993, 84-87.

${ }^{28}$ Die neue deviante Gruppierung wurde zwar als philosophische Bewegung oder reli-

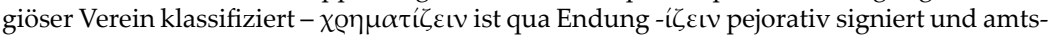

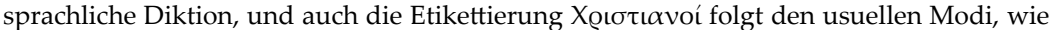
Bezeichnungen für religiöse Vereine gebildet wurden -, doch unterschied sie sich von diesen einzigartig, indem sie sich hergebrachten sozialen Formen von Religion im privaten und insbesondere im öffentlichen Raum, vor allem der sacra publica entzog. Vgl. FeLDTKELLER 1993, 93f.

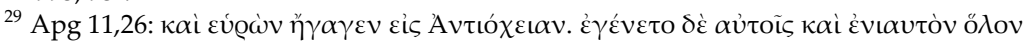

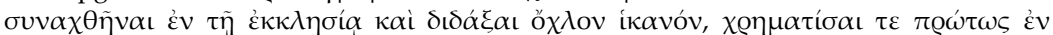

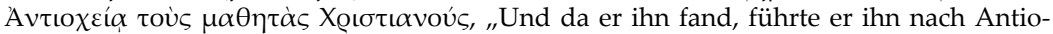


die Theologie des hellenistischen Christentums in Antiochia ihren „Brennpunkt hatte $^{\prime 30}$ und diesen erfolgreich behauptet hat (Gal 2,1-21; Apg 15).

Für die Vorgeschichte und damit für das Profil des geistig-sozialen Milieus, in dem Tatian und dann auch Theophilos auftreten werden, ist es nicht unbedeutend, dass zwischen den christlichen Anfängen und dem Ausgang des zweiten Jahrhunderts in Antiochia und seinem Umland ein sehr facettenreiches Christentum bezeugt ist. In der neutestamentlichen Forschung ist es Konsens, dass die Gemeinde hinter dem Matthäusevangelium mit größter Wahrscheinlichkeit in Antiochia zu suchen ist, ${ }^{31}$ was hinsichtlich des literarischen Verhältnisses der ersten drei Evangelien zueinander Folgen auch für die Verbreitungs- und Rezeptionsgeschichte des Markusevangeliums und der großen Spruchsammlung (Q) hat. ${ }^{32}$ Die Frühchristentumsforschung und die Liturgie- und Kirchenrechtsgeschichte lokalisieren die Gemeinden, deren liturgische Ordnung und Frömmigkeitsformen, Verfassung und ethische Standards in der ältesten Kirchenordnung, der Didache, ${ }^{33}$ mit rechtssprachlicher Diktion verbindlich und in Abgrenzung zum Judentum geregelt werden, in dem von Antiochia traditionell dominierten westsyrischen Kulturraum. In derselben Gegend scheint die Sammlung der ältesten christlichen Poesie, der Oden Salomos, ${ }^{34}$ erfolgt zu sein.

Zwar sind die materiellen Berührungen zwischen diesen frühen literarischen Zeugnissen aus dem Osten und Tatians Oratio ad Graecos sehr überschaubar. ${ }^{35}$ Diese Schriften weisen aber auf die Vielgestaltigkeit des Christentums in der syrischen Metropole und der Region hin. ${ }^{36}$ Für die zweite Hälfte des zweiten Jahrhunderts ist dieser religiöse Facettenreich-

chia. Es geschah aber, dass sie sogar ein ganzes Jahr in der Gemeinde zusammengeführt wurden und zahlreiches Volk lehrten. Und in Antiochia bezeichnete man die Jünger zuerst als Christen.“

${ }^{30}$ A. M. Ritter, ,"Antiochien“, RGG ( $\left.{ }^{4} 1998\right)$ [551-553] 552.

${ }^{31} \mathrm{Vgl}$. Anm. 14.

32 Zur Synoptikerforschung vgl. W. SchмiтнaLs, Einleitung in die ersten drei Evangelien. De-Gruyter-Lehrbuch (Berlin / New York 1985).

${ }^{33}$ Vgl. Niederwimmer 1989, 80; zu Tatian vgl. ebd. 118 Anm. 7.

${ }^{34}$ Vgl. M. LAtTKe, Oden Salomos. FC 1,19 (Freiburg u.a. 1995) 20-35. Im zweiten Jahrhundert scheint sich der Osten - Kleinasien und Syro-Palästina - als jene Region abzuzeichnen, in der die ältesten Bezeugungen der Oden vorliegen. Daher wäre es nicht unwahrscheinlich, dass sie auch im Osten entstanden sind.

${ }^{35}$ Vgl. das Stellenregister bei Trelenberg 2012, 291-305, der leider die kanonische Literatur nicht registriert hat, sowie bei МАRCOvich 1995, 83, der bedauerlicherweise nur die kanonische Literatur verzeichnet. Bei genauerem Zusehen sind die Berührungen nicht im-

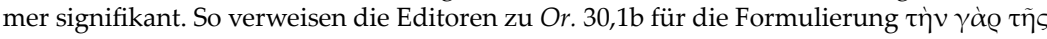

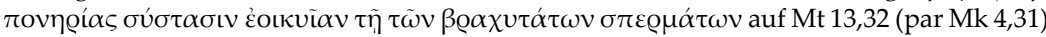

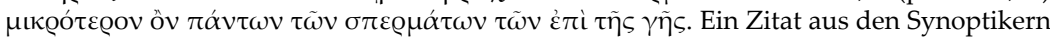
ist das kaum.

${ }^{36}$ Pluralität und Synkretismus sind Kennzeichen der Anfänge des Christentums. Das spiegelt sich wider in verschiedenen, z.T. konkurrierenden christlichen Identitäten ebenso 
tum wohl auch an Tatians Evangelienharmonie zu ermessen; denn diese belegt, dass es im religiösen Milieu, aus dem Tatian womöglich stammt und in dem er nach seiner Rückkehr aus Rom wirkte, tolerabel oder gar erstrebenswert war, die bekannten Evangelien durch ein am Johannesevangelium orientiertes Kompilat zu ergänzen oder zu ersetzen. Schließlich bezeugt die Begründung aller christlicher Propria aus der griechischen Bibel durch Theophilos, dass unter Gebildeten religiöses Wissen, das sich auf die Schrift beruft, kommunikabel war und auch als überzeugendes Argument im Diskurs über zutreffendes religiöses Wissen eingesetzt werden konnte. Anders als Theophilos, der aus der römischen Provinz Osrhoene nach Antiochia kam und dort blieb, weiß der "Assyrer ${ }^{\prime 37}$ Tatian aus seiner Zeit in Rom, dass der religiöse Kosmos und auch die christliche Pluralität noch vielgestaltiger sein können als in seiner syrischen Heimat. Bezüglich des Christentums am Tiber sind nicht nur Justin und jene frühen Zeugnisse des Christentums in den Blick zu nehmen, aus denen die catholica wird, sondern auch ein frühchristliches Milieu von dem Niveau, aus dem wohl der Hirt des Hermas ${ }^{38}$ stammt. In den Gemeinden oder an deren Rand leben Gebildete mit wachem Interesse an theologischen Kernfragen, bei denen eine nach griechischer Tradition intellektuell anschlussfähigere Erlösungsvorstellung, mit der Markion die christliche Hoffnung erschließen wollte, rasch Anklang fand. ${ }^{39}$ Tatian erwähnt Markion nicht, er schreibt auch nicht gegen ihn. Allerdings ist es kaum vorstellbar, dass er in Rom von den Vorgängen um Markion aus den 140er Jahren nicht Kenntnis erlangte. In Antiochia war man offenbar der Überzeugung, dass über das enorme Gefahrenpotential markionitischer Theologie und Soteriologie aufgeklärt werden musste. Sofern die altkirchlichen Nachrichten zutreffen, verfasste Theophilos noch vor seinem Protreptikos An Autolykos eine Streitschrift

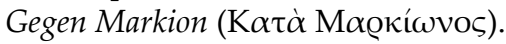

Diese wenigen Hinweise machen auf zweierlei aufmerksam: Zum einen ist das Christentum in Antiochia und seinem Umland nicht homogen, weder doxologisch noch in seinem Glaubensleben. Zum anderen ist

wie in der Vielgestaltigkeit frühchristlicher Theologien. Vgl. Мarкschies 2007, 379-383; FeldTKeLLer 1993, 120-122. 197-201; speziell zu Tatian und seiner Zeit vgl. ebd. 158f.

${ }^{37}$ Vgl. dazu die Einführung in diesem Band, oben S. 4-5.

${ }^{38}$ Vgl. Trelenberg 2012, 301, der auf Hermas, sim. 4,2; 9,1,1 verweist; ferner N. Brox, Der Hirt des Hermas. KAV 7 (Göttingen 1991) 22-25.

${ }^{39} \mathrm{Vgl}$. U. B. Schмid, Marcion und sein Apostolos. Rekonstruktion und historische Einordnung der marcionitischen Paulusbriefausgabe. ANTT 25 (Münster 1995); G. MAY (Hg.), Marcion und seine kirchengeschichtliche Wirkung. Vorträge der Internationalen Fachkonferenz zu Marcion, gehalten vom 15.-18. August 2001 in Mainz. TU 150 (Berlin / New York 2002); H. C. BrennecKE, „Marcion - oder das philosophische Gottesbild in der Spannung zwischen Orthodoxie und Häresie“, in: J. Dummer / M. Vielberg (Hg.), Leitbilder im Spannungsfeld von Orthodoxie und Heterodoxie. Altertumswissenschaftliches Kolloquium 19 (Stuttgart 2008) 11-28; B. Aland, Was ist Gnosis? Studien zum frühen Christentum, zu Marcion und zur kaiserzeitlichen Philosophie. WUNT 239 (Tübingen 2009). 
das religiöse Wissen unter Gebildeten über das Christentum nicht allein aus den Themen, Zitaten und Anspielungen in Tatians Oratio ad Graecos oder der Trilogie des Theophilos zu ersehen. In der zweiten Hälfte des zweiten Jahrhunderts war das Christentum in den Metropolen am $\mathrm{Ma}$ re nostrum keine neue Erscheinung. Art und Breite der Einwände gegen das Christentum, wie sie Kelsos im Namen der Tradition erhebt, oder das politisch-moralische Verdikt superstitio, mit dem ein halbes Jahrhundert früher Plinius d. J. in seinem Konsultationsbrief an Kaiser Trajan sein Vorgehen gegen kleinasiatische Christen begründet hat, weisen darauf hin, dass den literarisch inszenierten Auseinandersetzungen über zutreffendes religiöses Wissen und den Wert christlicher Propria eine Konfliktgeschichte vorausgeht, welche die Koordinaten des geistig-sozialen Milieus mitbestimmt, in dem die frühchristlichen Apologeten das Evangelium aktiv mit der sie umgebenden Kultur ins Gespräch bringen wollen. Die Auseinandersetzung der klassisch gebildeten Avantgarde unter den frühchristlichen Theologen ${ }^{40}$ mit der griechisch-römischen Kulturwelt oder arrivierten Vertretern dieser Tradition ${ }^{41}$ über traditionelle Achsenthemen im Diskurs über Religion ${ }^{42}$ geschieht folglich auch vor dem Hintergrund der biblisch-christlichen Tradition sowie der Erfahrungen der Anhänger der neuen und fremden Religion aus dem Judentum, die sie in ihren angestammten Lebensräumen machen.

\footnotetext{
${ }^{40}$ Diesen Kreisen sind an erster Stelle die frühchristlichen Apologeten zuzurechnen (Justin, Athenagoras, Aristides, Meliton von Sardes, Tatian, Theophilos von Antiochia, Clemens von Alexandria, Tertullian, Minucius Felix), sodann prominente Gestalten wie Markion, Irenaeus von Lyon und Protagonisten der frühchristlichen Gnosis (z.B. Valentinos, Noët von Smyrna, Herakleon), ferner anonyme Schriften wie der zu den frühchristlichen Apologeten zählende Protreptikos An Diognet oder der gnostische Brief an Rheginus sowie Pseudepigrapha wie der Traktat des Pseudo-Justin Über die Auferstehung des Fleisches.

${ }^{41}$ Die idealtypischen Vertreter der paganen Tradition sind u.a. aus den Widmungen der Werke der frühchristlichen Apologeten zu ersehen, so kann die Schrift an Personen adressiert sein, die diese Bildungswelt vertreten und die im Werk mit einem entsprechenden Profil ausgestattet werden, z.B. Diognet, Autolykos, Octavius, oder der Verfasser wendet sich demonstrativ an Repräsentanten der nichtchristlichen Kultur- und Rechtstradition wie etwa Aristides, der seine Apologie an Kaiser Hadrian adressiert und Athenagoras, der seine Legatio an die Kaiser Marc Aurel und Commodus richtet.

${ }^{42}$ Vgl. A.-Ch. JACOBSEN, „Main Topics in Early Christian Apologetics“, in: ders. / J. ULrich / D. Brakke (Hg.), Critique and Apologetics. Jews, Christians und Pagans in Antiquity. ECCA 4 (Frankfurt/M. 2009) 85-110; R. Grant, "Conflict in Christology at Antioch“, in: Studia Patristica 18 (Berlin 1985) 141-150; O. Gross, Die Gotteslehre des Theophilos von Antiochia. Abhandlung zum Jahresbericht des städtischen Realgymnasiums zu Chemnitz für Ostern (Chemnitz 1896); J. LorTZ, „Das Christentum als Monotheismus in den Apologien des zweiten Jahrhunderts“, in: A. M. Koeniger (Hg.), Beiträge zur Geschichte des christlichen Altertums und der Byzantinischen Literatur. FS Albert Ehrhard (Bonn / Leipzig 1922) 301-327; A. Роммrich, Des Apologeten Theophilus von Antiochia Gottes- und Logoslehre. Dargestellt unter Berücksichtigung der gleichen Lehre des Athenagoras von Athen, Diss. (Leipzig 1904); ProstmeIER 2010; PANNENBERg 1959.
} 


\section{Bildungsmilieu}

Das geistig-soziale Milieu, in dem Tatian seine Oratio ad Graecos konzipiert, ist ihrer Dedikation $\pi$ @ò ${ }^{\top} \mathrm{E} \lambda \lambda \eta v \alpha \varsigma^{43}$ zufolge von griechischer Kultur durchflutet. ${ }^{44}$ Ein Signum dieses medialen und kommunikativen Kontextes sind bestimmte Themen, die man diskursiv anzugehen versucht. Das Spektrum spannt sich vom Bildungsdiskurs zur pädagogischen Funktion der Philosophie, über den weit gefächerten ethischen Diskurs zur Moralität im öffentlichen Raum, etwa über Schauspiele und Agone, ${ }^{45}$ sowie in privaten Lebensräumen, wozu der Luxusdiskurs gehört, bis hin zum religiös-kultischen Diskurs, nämlich über Gott, Welt, Mensch und Rettung (vgl. Tatian, Or. 5).

Hinter der räsonierten Behandlung dieser traditionellen und in der frühen Kaiserzeit prominenten Sujets steht die Frage, wie zutreffendes Wissen $\mathrm{zu}$ erreichen und wie Sicherheit in Bezug auf die Konstitution der Wirklichkeit zu erlangen ist. Darum sind hermeneutische Grundsätze für die theologische Wahrheitsfindung im Diskurs über Religion eingebunden. ${ }^{46}$ Nicht nur Tatian pariert die Skepsis, zutreffende formale und inhaltliche Strukturierungen im Diskurs über religiöses Wissen aufzudecken, mit dem Verweis auf die höhere Anciennität der Quelle seines religiösen Wissens und deren garantierte, unbedingte Autorität, die sie als Offenbarung besitzt. Letztlich ist dadurch die Diskursivität zugunsten der gläubigen Anerkennung aufgegeben. En passant wird hierdurch die Vielfalt sozialer Formen von Religion zum Erweis, dass sie alle im Irrtum sind. Wahrhaft Gebildeten ist dies aus der Pluralität per se evident.

Bei Tatian findet diese Evidenz Niederschlag in seinem strikten Monotheismus (Tatian, Or. 5), den er als „barbarischen“ Gegenentwurf zur religiösen Vielfalt und Diskursivität religiösen Wissens (Tatian, Or. 8-11) mit dem Ziel entwickelt, die aus griechischer Tradition ererbte Pluralität von Kultur und Religion zu überwinden, um stattdessen die geistigmoralischen Herausforderungen seiner Zeit mittels des vom göttlichen Herrscher erlassenen Gesetzes (Tatian, Or. 28f.) zu bestehen.

\footnotetext{
${ }^{43}$ Zur Vielschichtigkeit des Begriffs, über sein Zusammenspiel mit dem religiöskulturellen Begriff, Barbaren' und die geradezu programmatische, kulturkritische Verwendung des letzteren im Konnex des Altersbeweises vgl. LössL 2007.

${ }^{44}$ Vgl. Pietzner 2013; Prostmeier 2007.

${ }^{45}$ Die Reserven in Tatian, Or. 23f. gegen spectacula als amoralisch, grausam und blasphemisch sind topisch, vgl. Seneca, Ep. 7,2-7; Theophilos., Autol. III 15; Athenagoras, Leg. 35, Tertullian, Apol. 38,4; Spect. passim.

${ }^{46}$ Vgl. J. LössL, Rez. zu C. M. CHin, Grammar and Christianity in the late Roman world, JTS, N.S. 59 (2008) 792-794; ders., „Hermeneutics and doctrine of God in Tatian's Ad Graecos“, in: Studia Patristica 45 (Berlin 2010) 409-412.
} 
Mit etwas mehr Eleganz als Tatian ${ }^{47}$ und höherer Raffinesse ist diese offene und zugleich verdeckte Strategie durch Theophilos von Antiochia entfaltet worden, der aus derselben Region stammt wie Tatian und in räumlicher und zeitlicher Nähe zu ihm seine drei Bücher An Autolykos verfasst. Im Verlauf der Trilogie mutiert zum einen die Diskursivität, über die zu Beginn Konsens zu herrschen scheint, zur Propädeutik für Autolykos, den Repräsentanten der hellenisch Gebildeten und Gesinnten, und aus der anfänglichen Gleichrangigkeit der Diskurspartner wird ein Lehrer-SchülerVerhältnis. Zum anderen wird auch in der kommunikativen Emphase immer klarer, dass die Diskursivität nur vordergründig existiert. Wie für Tatian steht für alle frühchristlichen Apologeten außer Frage, dass christliche Positionen nicht zur Diskussion stehen. Ihr diskursives Ziel ist es vielmehr, in der Auseinandersetzung über die religiösen Achsenthemen eine möglichst attraktive christliche Propädeutik zu betreiben. Das geistig-soziale Ambiente ist also nicht nur durch antiquarisches Wissen aus der Tradition oder exzeptionelle Kenntnisse Einzelner profiliert, die den Diskursen Stoff liefern, sondern auch durch die Machtverteilung unter den Kompetenten.

Diesem agonalen Aspekt dienen Bildungsdemonstrationen, sei es performativ oder in literarischer Inszenierung, wie etwa die Kataloge in Tatians Oratio ad Graecos oder der versierte Aufruf und argumentative Einsatz von Zeugnissen der klassischen Literatur. Sie versprechen demjenigen Ansehen und Einfluss, der gewandt ist in griechisch-römischer Tradition und es versteht, sich als Gebildeter routiniert und doch zugleich virtuos und überzeugend zu präsentieren. Bezüglich des kaiserzeitlichen Diskurses über Religion ist damit für gebildete Christen zum einen das Spannungsverhältnis zwischen dem philosophischen Wissensvorrat aus griechischrömischer Kulturtradition und biblisch-christlichen Glaubenstraditionen vorgezeichnet. Zum anderen obliegt ihnen, im Rahmen der diskursiven Usancen überzeugend zu erklären, dass nur im Christentum die zutreffende Rede von Gott möglich ist. Dieser Wahrheitsanspruch wird ebenso für die Frage nach Herkunft, Status und Ziel des Kosmos erhoben wie auch für die Anthropologie, insbesondere für die Frage nach der persönlichen Heilszukunft. Für diese durch ihre Bildung exponierten Christen beruhen sowohl der Grund für den Eintritt in den Diskurs als auch die Grenzen der Diskursivität ${ }^{48}$ auf der vorausliegenden Glaubensentscheidung und der persönlichen Integrität. ${ }^{49}$ Beides hat Folgen nicht nur für den Status gebildeter Christen im Diskurssystem Religion, sondern auch für die literarisch-rhetorische Klassifikation und Auslegung ihrer Werke.

\footnotetext{
${ }^{47}$ Vgl. J. LössL, „Sprachlich-ästhetische Darstellung und ,Anwendung' von Gewalt in Texten frühchristlicher Apologeten - das Beispiel der Rede Tatians an die Griechen", Zeitschrift für Religionswissenschaft 20 (2012) 196-222.

${ }^{48}$ Vgl. J. LössL, Rez. zu The end of dialogue in antiquity, JTS, N.S. 60 (2009) 662-664.

${ }^{49}$ Vgl. unten S. 217 Anm. 86.
} 
Darum ist Tatians Schrift, trotz ihrer Anklänge an Schutz- und Verteidigungsschriften, weder nur Apologie noch eine konturlose Redekomposition. Vor dem Hintergrund des Bildungsmilieus sowie des inhärenten Ziels und seiner Limitierung ist die Oratio ad Graecos vielmehr eine, werbende Einführung ins Christentum', die von der Zuverlässigkeit der christlichen Lehre durch eine attraktive Präsentation überzeugen will und dies tut, indem sie vor dem Forum der Gebildeten und für Sympathisanten des Christentums versucht, alle Vorhaltungen zu entkräften und denkbaren Einwänden vorzubeugen. Die Oratio ad Graecos besitzt nicht nur „protreptische Züge“" 50 sie will vielmehr selbst ein Protreptikos sein. Dass der Syrer dabei vor kaum einer Schmähung aller Repräsentationen der heidnischen Kulturtradition zurückschreckt (vgl. Tatian, Or. 19,1-4), scheint kein hinreichendes Argument zu sein, um die Oratio ad Graecos als Schmähschrift zu klassifizieren. ${ }^{51}$ Tatian ist sich der Insuffizienz der griechischen Tradition sicher und polemisiert heftig. Die Harschheit dieser literarischen Re-

${ }^{50}$ Vgl. die ausführliche Diskussion bei Trelenserg 2012, 230-240. Gegenüber der Situierung der Oratio ad Graecos in eine Phase der ,Christenverfolgung' scheint indes eine gewisse Skepsis angezeigt. Dass Christen nicht gut gelitten sind und sogar von Pogromen betroffen sein können, ist seit der als weltweit gültig hingestellten Glaubens- und Lebenssituation der Adressaten des 1 Petr nicht überraschend. Die Christenbriefe von Plinius d. J. bestätigen aus administrativer Sicht eines gebildeten Römers kurze Zeit später die im 1 Petr theologisch gedeuteten Verhältnisse der Gemeinden am Mare nostrum. Eine Christenverfolgung hat Trajan in seinem Reskript ausgeschlossen. Die Vorwürfe müssen justiziabel sein. Solange es keine lex oder ein edictum gegen das Christentum gegeben hat, kann man kaum von einer Verfolgung der Christen sprechen. Die Lage ist zwar angespannt, nicht nur in Rom, sondern im gesamten Imperium. Aber es gibt noch keinen politischen Willen, von Rechts wegen das Christentum zu unterbinden, indem seine Anhänger mit dem Tod bedroht werden. Eigentlich sprechen die Schriften der frühchristlichen Apologeten selbst gegen eine solche Vernichtungspolitik. Wie anders soll man erklären, dass Gebildete alles daran setzen, mit besten Argumenten antichristliche Einwände und Parolen zu parieren und gleichzeitig Neumitglieder zu gewinnen, indem sie nicht nur die Vernünftigkeit und Widerspruchslosigkeit der christlichen Lehre erweisen, sondern sie als die einzig wahre Philosophie präsentieren?

${ }^{51}$ Platziert man Tatians Oratio ad Graecos auf einer Skala, die die Emphase, die aus dem jeweiligen Werk hervortritt, von einer defensiven Haltung gegenüber der hellenistischrömischen Mehrheitskultur bis hin zu einer geradezu harschen, polemisch-aggressiven Distanzierung verzeichnet, dann ließen sich an dem einen Ende z.B. Philon von Alexandria mit seiner Schrift Legatio ad Gaium und Flavius Josephus mit Contra Apionem auflisten, auf der gegenüberliegenden Position könnten Tatian und Hermias eingetragen werden. Daraus scheint indes keine literarische Einordnung ableitbar. Vielmehr scheint die aggressive ,Stimmung' gegen die Philosophen - auf kaiserlichen Lehrstühlen - (Tatian, Or. 2,1-3,10; 19,1-4; 25,1-27,9) oder auch die Häme, die über Mantiker u.ä. gegossen wird (Tatian, Or. 16,7-17,1; 19,5-9), zum einen situationsbedingt zu sein, zum anderen auch der Persönlichkeit des Verfassers geschuldet. Die Konstante ist indes das gebildete Milieu. Denn die Reserven gegenüber Weissagungsglauben vertrauen ebenso wie die kaiserzeitliche Mythenkritik auf den Konsens unter Gebildeten. Der Grad des polemisch-aggressiven Tons ist weniger ein Kriterium für die literarische Form des Werks (vgl. dazu Trelenberg 2012, 79; Pilhofer 1990, 253f.) als vielmehr ein Indikator für die Funktion der jeweiligen Passage im Blick auf die Argumentationsziele des gesamten Werks. 
de gegenüber einer konstruierten Gegnerschaft will nicht nur polarisieren, sondern korrespondiert mit einem nachdrücklichen Interesse an der eigenen Gruppe, der in Abgrenzung zur griechischen Kultur die christlichen Propria in Erinnerung gebracht und durch die Verschärfung im Ton klarere Konturen verliehen werden. ${ }^{52}$ Die Reduzierung auf das Signifikante scheint ein strukturelles Merkmal propädeutischer und protreptischer Schriften zu sein. Aus dieser Perspektive unterscheidet sich die Oratio ad Graecos in der Trennschärfe von protreptischen Schriften frühchristlicher Apologeten, nicht indes durch ihre literarische Form, Disposition und Themenwahl. ${ }^{53}$

Die axiomatisch akzeptierten Werte in den soziokulturellen Räumen selbst, in denen der Diskurs über Religion geführt wird, seine gültigen Formen, Verteilungen und Usancen beruhen auf einem Konzept der Klassik, das in der hellenistisch-römischen Bildung die verbindlichen Konstituenten für eine kulturelle Koine der mediterranen Gesellschaften findet. Daher geraten Einwände gegen den Anspruch dieser Bildungstradition auf zutreffende und verbindliche Welt- und Existenzerhellung oder Kritik an Erscheinungsformen dieser Leitkultur der frühen Kaiserzeit unversehens in den Rang eines Angriffs auf die ideellen Grundlagen des Gemeinwesens und seiner Einrichtungen. Der Skopos der Einwände gegen das Christentum scheint zu sein, dass in der Kritik der Gebildeten und durch den Lebenswandel der Christen eine Distanzierung zu den kulturellen Usancen und Wertstellungen der Majoritätsgesellschaft evident wird, die nicht toleriert werden darf, weil sie die Einheit, Stabilität und Kontinuität der staatlichen Ordnung und der angestammten Lebensräume zur Disposition stellen.

Wie die Einwände gegen das Christentum nicht erst in der Mitte des zweiten Jahrhunderts aufkommen, so gibt es auch soziale Entwicklungen und thematische Vorbereitungen, die zu jenen Auseinandersetzungen zwischen Christen und Heiden hinführen, die zunehmend schärfer und grundsätzlicher geführt werden. Entsprechend bildet sich das geistigsoziale Milieu, in dem auch Tatian auftritt, nicht unvermittelt erst unter der für die griechische Kulturtradition aufgeschlossenen Politik Hadrians und seiner beiden Nachfolger heraus. Die Konturen der Vorgänge sowie die Konstanten, woran sich die Perspektiven und Deutungen ausrichten, sind vielmehr schon am Ende des ersten Jahrhunderts erkennbar, als das Christentum in der heidnischen Majoritätsgesellschaft als etwas Fremdes identifiziert und die Gläubigen in Stigmatisierungsprozesse involviert

\footnotetext{
${ }^{52}$ Näheres vgl. Lössı 2010.

${ }^{53}$ Vgl. Lona 2001, 27-34; Th. Lechner, „Süße Lust des Logos. Die Vorrede zum Protreptikos des Clemens von Alexandria und die prolaliai der Zweiten Sophistik“", in: Рrostmeier / Lona 2010, 149-205. Zur literarischen Form von Tatians Oratio ad Graecos vgl. auch die Einführung zu diesem Band durch Nesselrath, oben S. 17-19.
} 
wurden. Beides nötigte die Gemeinden, Abwehr- und Verteidigungsstrategien zu entfalten. ${ }^{54}$ Vor allem mussten überzeugende Plausibilisierungen für die zunehmend prekären Glaubens- und Lebensumstände entwickelt und den Gläubigen Wege aufgezeigt werden, um in der Marginalität bestehen und in den verschiedenen Lebensräumen produktiv damit umgehen zu können. Diesem Ziel dient eine Palette von Strategien und Deutungen des geschichtlichen Ergehens sowie deren Einordnung in religiöse Hoffnungshorizonte, aber auch die Affirmation gesellschaftlicher und politisch forcierter Leitwerte wie Eintracht und Frieden. Die Einheit, Stabilität und Kontinuität der Gemeinden avancieren zum ekklesialen Leitwert und fungieren als Regulative in den Gemeinden und in der christlichen Oikumene. Parallel zu diesen primär defensiven, auf den Bestand der Gemeinden bedachten Stimmen öffnete sich das Christentum der hellenistischrömischen Kultur und trat ihr als Ganzes gegenüber. Signifikant hierfür sind erstens die Themen, anhand derer das Evangelium unter den geistigen Konditionen des kaiserzeitlichen Diskurssystems Religion zur Sprache gebracht wird, sowie zweitens das erstrebte Niveau der Auseinandersetzung, das sich in den Formen und Prinzipien der Darlegungen Ausdruck verschafft.

Die Träger dieser am Ausgang des ersten Jahrhunderts einsetzenden und in der Mitte des zweiten Jahrhunderts auf breiter Front geführten Selbstrepräsentation im Raum der hellenistisch-römischen Kulturwelt sowie der Auseinandersetzung mit deren Wertvorstellungen sind christliche Theologen, die mindestens darin übereinkommen, dass sie in der griechisch-römischen Bildungstradition geschult sind (Tatian, Or. 35) und diese Kompetenz für ihr theologisches und schriftstellerisches Schaffen fruchtbar machen. Von der Mitte des zweiten Jahrhunderts an bis zum Anfang des dritten Jahrhunderts sind die frühchristlichen Apologeten die Exponenten dieser Auseinandersetzung unter Gebildeten über Religion. Allerdings waren sie nicht die einzigen christlichen Intellektuellen im kaiserzeitlichen Religionsdiskurs. ${ }^{55}$ Zur theologischen Avantgarde des Frühchristentums sind auch Markion sowie die verschiedenen Gruppierungen der frühchristlichen Gnosis zu rechnen. Eine Hauptschwierigkeit hierbei ist, dass die Grenzen zwischen christlichem Binnen- und Außenbereich fließend waren. Für Gebildete, die in griechischer Denktradition die klare Trennung des Kosmos von der göttlichen Sphäre als Axiom aufgeklärter Welterschließung festhielten, konnte Markions dogmatische Scheidung zwischen Schöpfer und Erlöser vernünftiger erscheinen und anschlussfä-

\footnotetext{
${ }^{54}$ Näheres vgl. R. Feldmeier, Die Christen als Fremde. Die Metapher der Fremde in der antiken Welt, im Urchristentum und im 1. Petrusbrief. WUNT 64 (Tübingen 1992).

${ }^{55} \mathrm{Zu}$ kaiserzeitlichen ,Elitenkonstruktionen' und Identitätskonzepten vgl. K. EsHLEmanN, The Social World of Intellectuals in the Roman Empire. Sophists, Philosophers, and Christians (Cambridge u.a. 2012) und Pietzner 2013.
} 
higer sein als die biblische Schöpfungsvorstellung oder die für aufgeklärte Zeitgenossen noch befremdlicher und völlig widersinnig erscheinende Rede von der Inkarnation des Logos und der Auferstehung des Fleisches, welche die catholica als Glaubenswahrheit verkündete. Markions dazu passende Auswahl autoritativer Schriften aus der breiten biblisch-christlichen Überlieferung sowie seine publizistische Arbeit schienen daher nur folgerichtig. Die Anschlussfähigkeit von Markions Konzeption bei Intellektuellen sowie der Zulauf, den sein theologischer Entwurf auslöste, stürzte die römischen Gemeinden und bald schon die christliche Oikumene in eine fundamentale Zerreißprobe, die im Ausschluss der markionitischen Theologie eskalierte.

Dieser Vorgang aus der Mitte des zweiten Jahrhunderts in Rom zeigt, dass das geistig-soziale Milieu, in dem die frühchristlichen Apologeten zu verorten sind, vernetzt und in verschiedenen Aktionsräumen realisiert ist. Herkunft und Wirkungsfeld dieser theologischen Avantgarde weisen darauf hin, dass dieses Milieu dort zu finden ist, wo hellenistisch-römische Bildungstradition das kulturelle Leben bestimmt. Der soziale und geistige Kontext von Tatians Oratio ad Graecos ist daher der in der genannten Vernetzung und mit dem genannten Facettenreichtum profilierte Diskurs unter Gebildeten über religiös-kultische Themen, und zwar in dem Bestreben, in der räsonierten Behandlung religiöser Sujets christliche Positionen überzeugend zu vertreten und für sie zu werben. Die Aktionsräume - in der Öffentlichkeit oder im Privaten -, in denen dieser Diskurs stattfindet, sind vielleicht doch weniger durch die Front zwischen heidnischer und christlicher Tradition bestimmt; sie zeichnen sich vielmehr durch die Wahl und Hierarchie der Sujets aus sowie durch Form und Niveau, wie die Themen behandelt werden.

\section{Vorgänge - Konfliktdisposition - Wissbegier}

Die Genese des geistig-sozialen Milieus, in dem im zweiten Jahrhundert von Gebildeten religiöse Themen von Rang besprochen werden, ist von einer Vielzahl von Faktoren abhängig oder doch gefördert und gelenkt worden. Drei Faktoren scheinen die sozialen Umwälzungsprozesse ${ }^{56}$ der frühen Kaiserzeit wesentlich bestimmt zu haben: 1. das geistige, politische und auch pädagogische Konzept der Klassik, wie es in der ,Zweiten Sophistik $^{57}$ zur Blüte kam und wozu die Förderung griechischer Kulturtra-

\footnotetext{
${ }^{56}$ Näheres vgl. CHRist 2009, 431-433.

${ }^{57}$ Näheres vgl. Th. Whitmarsh, Second Sophistic. Greek and Rome. New Surveys in the Classics 35 (Oxford u.a. 2005); G. Anderson, „,The pepaideumenos in Action. Sophists and their Outlook in the Early Empire", in: ANRW II.33.1 (Berlin / New York 1989) 79-208; ders., The Second Sophistic. A Cultural Phenomenon in the Roman Empire (London / New York 1993); M. W. Gleason, Making Men. Sophists and Self-Presentation in Ancient Rome (Princeton 1995);
} 
dition durch Hadrian und seine Nachfolger nicht unerheblich beitrug; 2 . die Neuformierung der alten Eliten, die den Verlust ihres politischen Einflusses, den sie in der Republik vererbten, durch öffentliches Ansehen und Meinungsführerschaft zu kompensieren versuchten; 3. das dazu komplementäre Prestigestreben der seit Augustus zunehmenden Zahl von reichen Gewerbetreibenden, ${ }^{58}$ Händlern und Freigelassenen, ${ }^{59}$ denen trotz ökonomischer und finanzieller Potenz von zum Teil märchenhaften Ausmaßen sowohl politische Partizipationsmöglichkeiten als auch gesellschaftlicher Aufstieg und Prestige schon deshalb kaum in Aussicht standen, weil sie von den von alters her durch Abstammung (gens) und Bildung konstituierten Eliten, den Senatoren und Rittern bzw. Dekurionen, Ausgrenzung und Ablehnung erfuhren. ${ }^{60}$

Im Folgenden stehen indes weder die Umstände, die diese Vorgänge initiierten, im Fokus noch, was sie im Detail bewirkten und welche Faktoren dominant waren, in welchen Lebensräumen dieses Milieu etabliert war und wer die Protagonisten waren. Das Augenmerk gilt allein Zeugnissen, aus denen - wenn auch nur exemplarisch - zu ersehen sein könnte, wie sich das Frühchristentum in diesem sich herausbildenden geistig-sozialen Milieu der hellenistisch-römisch Gebildeten positionierte, wie die Christen von diesen Bildungseliten wahrgenommen und beurteilt wurden und wie und womit sich gebildete Christen in diesem Milieu einfanden.

Seitens der Frühchristen dürfte eine der fundamentalen Voraussetzungen für die Öffnung gewesen sein, dass sich in den Gemeinden das Bewusstsein Bahn gebrochen hat, sich auf Dauer in der Geschichte einrichten zu müssen. Das beinhaltete die Aufgabe und Chance, das Christentum

Th. Schмiтz, Bildung und Macht. Zur sozialen und politischen Funktion der zweiten Sophistik in der griechischen Welt der Kaiserzeit. Zetemata 97 (München 1997); M. V. HubBard, Christianity in the Greco-Roman World. A Narrative Introduction (Peabody, Mass. 2010) 68-107; E. BowIE, "The Geography of the Second Sophistic. Cultural Variations", in: B. Borg (Hg.), Paideia. The World of the Second Sophistic. MSt 2 (Berlin / New York 2004) 65-83; Krasser 2007.

${ }^{58}$ Vgl. die monumentalen Grabmäler des Bäckers Eurysaces an der Porta Maggiore in Rom oder des Freigelassenen und Augustalen Publius Vesonius Phileros in Pompeji, beide wohl aus dem 1. Jh. n. Chr. Vgl. auch D’ Ambra / Métraux 2006.

${ }^{59}$ Vgl. dazu Petronius Arbiter, der in seinen Satyrica am Beispiel des Galadinners bei dem Parvenü Trimalchio die Zustände in der neuen ,feinen' Gesellschaft der zu Reichtum, nicht aber zu Bildung und Ansehen gelangten Freigelassenen parodistisch-satirisch schildert (Cena Trimalchionis) oder auch Juvenals Beschreibung des Sklaven Crispinus, dessen Gebaren geradezu nach beißendem Spott und nach Satire ruft (Satiren 1,26-29).

${ }^{60}$ Näheres vgl. Christ 2009, 368-373. 432; D'Ambra / MÉtraux 2006; D. F. Jones, The Bankers of Puteoli. Finance, Trade and Industry in the Roman World (Stroud 2006); R. KNAPP, Römer im Schatten der Geschichte. Gladiatoren, Prostituierte, Soldaten. Männer und Frauen im Römischen Reich (Stuttgart ${ }^{4} 2012$ ); H. Mouritsen, The Freedman in the Roman World (Cambridge 2011); M. Peachin (Hg.), The Oxford Handbook of Social Relations in the Roman World (New York / Oxford 2011); L. H. Petersen, The Freedman in Roman Art and Art History (Cambridge u.a. $\left.{ }^{2} 2011\right)$. 
im Rahmen der griechisch-römischen Kulturwelt und der zivilisatorischen Prämissen der mediterranen Gesellschaften zur Geltung zu bringen.

Für die Ermöglichung der Partizipation des Christentums in den Aktionsräumen der frühkaiserzeitlichen Bildungswelt dürfte der Missionserfolg in allen traditionellen und neuen sozialen Schichten wie der der liberti elementar gewesen sein, ${ }^{61}$ denen nach ihrer Konversion zum Christentum potentiell hohes Prestige innerhalb einer reichsweit präsenten Kultgemeinschaft in Aussicht stand. ${ }^{62}$ Mit der Konversion solcher sowohl ökonomisch als auch geistig führenden Personen eng verbunden war die Erschließung von Lebensräumen, für die der Generationsübergang konstitutiv ist, so dass christliche Glaubens- und Lebenspraxis im Alltag der Welt als essentieller Teil der Sozialisation und Tradition gelten mussten. Diese Funktion kam zuerst dem antiken oĩkos als der elementaren Sozial- und Wirtschaftsform der mediterranen Gesellschaften auch in der frühen Kaiserzeit zu. In diesem sozialen Gebilde avancierte christlicher Glaube und christliche Lebenspraxis zu einem Bildungsziel.

Der Missionserfolg und der doppelte Anspruch, nämlich die Aufhebung sozialer Diversivität in der baptismal vermittelten Einheit und die Universalität des Heilsangebots, das die Grenzen des Imperiums nicht nur

\footnotetext{
${ }^{61}$ Einerseits ist es nicht erstaunlich, dass die Mission rasch und bis in angesehenste Kreise hinein erfolgreich war, zumal wenn dreierlei beachtet wird: 1. Die Erstberufenen gehörten mit großer Wahrscheinlichkeit dem gehobenen Mittelstand Galiläas an. 2. Im ersten und zweiten Evangelium, vor allem aber im lukanischen Doppelwerk wird ein gehobenes, gebildetes Milieu aufgerufen. 3. Anspruch und Niveau des anonymen Verfassers, der den $1 \mathrm{Klem}$. geschaffen hat, weisen auf das Elitenmilieu der hellenistisch-römischen Bildungswelt. Andererseits ist der stringente Nachweis der Oberschichtszugehörigkeit von Christen aufgrund von Personalnotizen in frühchristlichen Schriften und anhand epigraphischer Zeugnisse aus zwei Gründen schwierig: 1. Das für die republikanische Zeit wohl noch gültige und wirksame pyramidale Gesellschaftsmodell wird in der frühen Kaiserzeit überlagert durch den Aufstieg neuer Gesellschaftsgruppen sowie den Wandel der voraugusteischen Macht- und Kompetenzverteilung. War Prestige ehedem nur durch Eingliederung in die ordines zu erreichen, so sind mit dem Aufstieg der liberti und speziell mit der ,Zweiten Sophistik' weitere Möglichkeiten gegeben, um soziales Ansehen zu generieren. 2. Ordoindikatoren weisen zwar auf die Zugehörigkeit zur lokalen oder gar reichsweiten Oberschicht hin. Weil mit den sozialen Umwälzungsprozessen verknüpft ist, dass soziales Ansehen nicht mehr exklusiv durch die ordines bemessen wird, sondern in sozialen Räumen generiert wird und gilt, also ein Interpretament ist, besitzen traditionelle Statusindikatoren nicht mehr die vormalige Prägekraft. Näheres vgl. W. EcK, „Das Eindringen des Christentums in den Senatorenstand bis zu Konstantin d. Gr.“, Chiron 1 (1971) 381-406; ders., „Die Präsenz senatorischer Familien in den Städten des Imperium Romanum bis zum späten 3. Jahrhundert", in: ders. (Hg.), Studien zur antiken Sozialgeschichte. FS Friedrich Vittinghoff. Kölner historische Abhandlung 28 (Köln u.a. 1980) 283-322; E. PLüMACHER, Identitätsverlust und Identitätsgewinn. Studien zum Verhältnis von kaiserzeitlicher Stadt und frühem Christentum. BThS 11 (Neukirchen-Vluyn 1987).

${ }^{62}$ Vgl. N. Brox, „Zur christlichen Mission in der Spätantike“, in: F. DünZL / A. Fürst / F. R. Prostmeier (Hg.), Norbert Brox. Das Frühchristentum. Schriften zur Historischen Theologie (Freiburg u.a. 2000) 337-373; Th. Lechner, ,Very sophisticated? Mission und Ausbreitung des Christentums in der Welt der Zweiten Sophistik", Millennium 8 (2011) 51-86.
} 
potentiell, sondern programmatisch sprengte, veränderten die Wahrnehmung und Beurteilung des Christentums seitens der nichtchristlichen Umwelt. In diesem Wandlungsprozess, in dem Konfrontationen nicht ausbleiben konnten, wurde es erforderlich, die christlichen Propria herauszustellen und in einer Weise zu formulieren, dass sie in der nichtchristlichen Kultur kommunikabel waren und als anschlussfähig entdeckt werden konnten, ohne dass die Wahrheit des Evangeliums dabei entglitt. Eines der ältesten Zeugnisse für diese Selbstpräsentation des Christentums im kaiserzeitlichen Religionsdiskurs ist die Areopagrede (Apg 17,16-34).

\subsection{Gott ist Schöpfer und Retter}

Der Verfasser der Apostelgeschichte integriert mittels der Areopagrede ${ }^{63}$ die Erschließung des Evangeliums unter den Konditionen des Diskurses über religiöses Wissen in die Mission des Paulus. Nach lukanischem Selbstverständnis gehört die Darlegung des christlichen Glaubens im Milieu der Gebildeten in die Anfänge des Christentums. Demnach beruhen sowohl die Auswahl und Hierarchie der theologischen Themen als auch die Form und das Niveau ihrer Präsentation auf apostolischer Tradition. Für das Profil des geistig-sozialen Milieus, in dem später Tatian und die frühchristlichen Apologeten auftreten, scheint die wechselseitige Wahrnehmung, die in dieser Redekomposition angezeigt ist, nicht unerheblich.

In der eigentlichen Paulusrede (Apg 17,22b-31) vor der intellektuellen Spitzengarnitur Athens treten erstmals in der christlichen Literatur zwei theologische Themen expressis verbis hervor, die miteinander vernetzt sind und die im narrativen Auftakt dieser Redekomposition als Kernthemen des Evangeliums anvisiert sind. Das erste und grundlegende Thema ist die Vorstellung von Gott als Schöpfer und Weltenherrscher. Der gelehrte Gesprächsgang bringt es mit sich, dass sich an diese theologische Kernaussage sogleich die Frage nach der theologischen Hermeneutik anschließt. Als Quelle und Kriterium der theologischen Wahrheit verweist der lukanische Paulus auf die Selbstoffenbarung Gottes. Vor dem Hintergrund der kaiserzeitlichen Denk- und Kulturgeschichte mit ihren Wertvorstellungen ist damit das Erkenntnisstreben der antiken Bildungswelt über religiöskultische Themen in eine völlig neue Wertekonkurrenz gestellt, denn die curiositas ist limitiert durch die Gewissheit akzeptierter Doktrin, welche die christliche Tradition als Offenbarung interpretiert (vgl. 1 Kor 15,3b-8; Gal 1,15f.; Lk 1,1-8) und die verkündet wird als Evangelium.

\footnotetext{
${ }^{63}$ Von den expositionellen Elementen dieser fiktiven Rede, den ausgesprochenen oder insinuierten Intentionen sowie von den offen oder subtil aufgerufenen Motiven und Kontexten kann hier abgesehen werden. Näheres vgl. Prostmeier 2013; dort auch Literaturhinweise bezüglich der literarischen und historischen Grundfragen zur Apg und dem lukanischen Doppelwerk.
} 
Das zweite Thema greift die Bedeutung dieser Gottesvorstellung für die Menschen auf. Gott wird hierbei als Richter und Retter vorgestellt, nämlich als der, der Tote zum Leben auferweckt, und zwar zuerst Jesus. Die beiden theologischen Kernaussagen der Areopagrede, dass Gott Schöpfer und Retter ist, ${ }^{64}$ werden durch das Ambiente, in das Lukas diese oratorische Selbstpräsentation des christlichen Wissens platziert, sowie die theologische Hermeneutik, derzufolge das Christentum über ein religiöses Wissen verfügt, das den Diskursen in der kaiserzeitlichen Philosophie in der Sache vorausliegt, mit einem absoluten Wahrheitsanspruch ausgestattet. Diese Argumentation will unter den Konditionen der antiken Bildungstradition zweierlei überzeugend einsichtig machen: 1. Das religiöse Wissen jener Kultur, die durch die Stoiker und Epikureer in ihrem zeitgenössischen Profil aufgerufen und durch die Situierung der Rede auf dem Areopag zurück bis auf ihre Ursprünge in den Blick genommen wird, ist gegenüber der biblisch-christlichen Glaubenstradition deszendent und daher defizitär. 2. Auf der Grundlage der biblischen Schöpfungstheologie ist die gesamte griechisch-römische Kulturtradition in die biblisch-christliche Offenbarungswahrheit zu integrieren. Eine zutreffende Gottesrede ist daher einzig im Raum der Kirche möglich, wobei dieser geistig-soziale Raum durch die $\pi \alpha \iota \delta \varepsilon \varepsilon^{6} \alpha^{65}$ mitstrukturiert ist.

Dem Paulusbild der lukanischen Tradition zufolge sind die Diskurspartner der Areopagrede durch ihre gemeinsame kulturelle Tradition verbunden. Dieses Milieu der Gebildeten bot dem Einzelnen nach Ausmaß und Niveau seiner Bildung Partizipations- und Entfaltungsräume, eröffnete ihm Aufstiegschancen und immer versprach es Prestigegewinn. Jenseits der Differenzen scheint dieses Milieu der Gebildeten weit über die frühchristlichen Apologeten hinaus als Topos des Wissensdiskurses über Religion Bestand zu haben. Religion ist Teil der Kultur. Hinsichtlich der Argumentationsstrategie lässt sich unschwer eine Linie über die frühchristlichen Apologeten des zweiten Jahrhunderts, Eusebios' Praeparatio evangelica und Demonstratio evangelica bis zur groß angelegten Apologie Graecarum affectionum curatio des Theodoret von Kyrrhos im fünften Jahrhundert zie-

\footnotetext{
${ }^{64}$ Tatian bindet die beiden theologischen Achsenthemen des Diskurses über religiöses Wissen, die er in Or. 6,2 nennt, an die Areopagrede zurück. Hierzu rahmt er seine Kernaussage über die Identität von Schöpfer und Retter durch zwei Anspielungen auf die Areopagrede: In Or. 6,1 greift er die Hoffnung auf „leibliche Auferstehung“ auf und nennt als topisches Beispiel für deren Bestreitung die Stoiker; im Anschluss an die Nennung der bei-

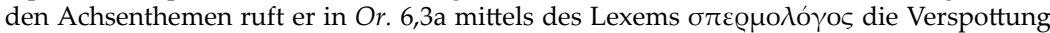
des Paulus durch die Athener ,Bildungsschickeria' auf. Sowohl die theologische Überzeugung bezüglich der Identität von Schöpfer und Retter als auch der Rang der Themen und die konkurrierenden Positionen im Religionsdiskurs sind Tradition.

${ }^{65}$ Näheres vgl. W. JAEger, Paideia, 3 Bde. (Berlin 1959); ders., Das frühe Christentum und die griechische Bildung (Berlin 1963); B. Schwenk, „Hellenistische Paideia und christliche Erziehung“, in: ColPe 1992, 141-158; P. ZANKer, Die Maske des Sokrates (München 1995).
} 
hen. ${ }^{66}$ Nach dem Zeugnis dieser Schriften, die zwischen werbender Einführung ins Christentum für Eliten und dessen Verteidigung changieren, entscheidet sich in der Behandlung der theologischen Achsenthemen, nämlich ,Gott, der Schöpfer' und ,Gott, der Retter', die Wahrheit der Rede von Gott. In diesem Diskurs erweist sich nach Überzeugung der frühchristlichen theologischen Avantgarde christliche Theologie zugleich als „wahre Philosophie" ${ }^{67}$

Für Gebildete sind daher Theologie und die theologische Hermeneutik essentielle Sujets, die per se anthropologische und ethische Fragen aufwerfen und soteriologisch-eschatologische Antworten fordern. Entsprechend ist der Diskurs über religiöses Wissen vorzüglich geeignet für Bildungsdemonstrationen. Daher nimmt es nicht wunder, dass neben der Gottesvorstellung und der theologischen Hermeneutik die ,Metapher von der Auferstehung des Fleisches ${ }^{68}$ zu einem Streitthema unter Gebildeten avanciert, das in Schriften des zweiten Jahrhunderts und selbstverständlich von Tatian und anderen frühchristlichen Apologeten traktiert wird. ${ }^{69}$ Darin mag man bestätigt sehen, dass die theologischen Achsenthemen der Areopagrede und das geistig-soziale Milieu konstant sind, auch wenn in einzelnen Schriften bestimmte Streitfragen in den Vordergrund drängen.

\subsection{Konfliktdispositionen}

Das Athener Bildungsestablishment hat dem narrativen Ausgang der Areopagrede zufolge den Skopos der beiden Achsenthemen des Evangeliums erfasst, dass die christliche Auferstehungshoffnung untrennbar ist von der Gottesvorstellung, inklusive der theologischen Hermeneutik. Nicht zuletzt wegen dieser Vernetzung grundlegender Theologumena avancierte in der Auseinandersetzung über zutreffendes religiöses Wissen die christliche Auferstehungshoffnung zum Reizthema. Repräsentanten der hellenistisch-römischen Kulturtradition wie Kelsos wiesen diese Vorstellung personaler Heilszukunft über den Tod hinaus, die mittels der Vorstellung von der Auferstehung des Fleisches eine an die biblische Schöpfungstheologie gebundene Anthropologie zur Grundlage hat, ${ }^{70}$ als zutiefst

\footnotetext{
${ }^{66}$ Vgl. F. R. Prostmeier, ",Christliche Paideia. Die Perspektive Theodorets von Kyrrhos", Römische Quartalschrift für christliche Altertumskunde und für Kirchengeschichte 100 (2005) 1-29; ders. 2001.

${ }^{67}$ Vgl. L. Honnefelder, „Christliche Theologie als ,wahre Philosophie““, in: Colpe 1992, $55-75$.

${ }^{68}$ Näheres vgl. Lona 1993, 229. 231. 256. 261. 264-270.

${ }^{69}$ Vgl. Tatian, Or. 6,2; Theophilos, Autol. I 13; II 15.26f.; Athenagoras, Leg. 36,3; Tertullian, Nat. I 19,1-3; Resurr. 1,1-3; Apol. 48,1; Adv. Marc. V 9; Minucius Felix, Octavius 34,6-12; Origenes, C. Cels. V 14; VIII 49.

${ }^{70}$ Vgl. K. WenZeL, Sakramentales Selbst. Der Mensch als Zeichen des Heils (Freiburg i.Br. u.a. 2003).
} 
töricht ab. ${ }^{71}$ Abgesehen von wenigen christlichen Stimmen, wie etwa Ps.Justin, De resurrectione carnis, der die Auferstehungshoffnung der Christen offensiv als eine neue und fremde Hoffnung charakterisiert, ist die Avantgarde der frühchristlichen Theologen bestrebt, die Vernünftigkeit der Auferstehungshoffnung unter den sprachlichen und geistigen Konditionen der hellenistisch-römischen Kulturtradition, in der sie mit ihren Hörern und Lesern stehen, einsichtig zu machen. Daher nimmt es nicht wunder, dass die allgemeine Totenauferstehung auch in den Schriften der frühchristlichen Apologeten ein herausragendes Thema bleibt, ${ }^{72}$ und zwar in der Vernetzung mit und dominiert von dem einen großen Thema, das auch die Areopagrede beherrscht: die Gottesvorstellung.

Seit den Anfängen ecken Christen mit ihrer Rede von Gott an, weil sie theologisch über Jesus sprechen. Dieser Konfliktdisposition hat Lukas in seiner Stephanusrede (Apg 7,1-51) ein literarisches Denkmal gesetzt. Die paulinische und johanneische Tradition und ebenso die synoptischen Überlieferungen bezeugen und deuten diese Separations- und Konsolidierungsvorgänge für die jeweiligen Glaubens- und Lebensumstände ihrer Gemeinden. Gemeinsam ist dieser christlichen Binnenliteratur, dass die Räume jenseits der Gemeinde als Ablehnungsfront oder unter missionarischem Gesichtspunkt in den Blick kommen. Spätestens die dritte christliche Generation sieht sich indes herausgefordert, sich aktiv mit den Reaktionen auf ihren Missionserfolg auseinanderzusetzen. Der 1. Petrusbrief ist einer der ersten Zeugen dafür, dass sich das Christentum seiner konstitutionellen Fremdheit gegenüber den Weltstrukturen bewusst zeigt und Plausibilisierungen entwirft, welche die prekäre Glaubens- und Lebenssituation mit dem Ziel theologisch ausleuchten, Christsein im Alltag der Welt zu ermöglichen. Einen späten Nachhall dieses Selbstverständnisses und dieser Strategie liest man in dem anonymen Protreptikos An Diognet, der in das zeitliche Umfeld von Tatian, Theophilos und Clemens Alexandrinus gehören wird. ${ }^{73}$ Das Verhältnis zwischen Evangelium und Kultur ist hier von einem Gebildeten, der zu schreiben verstand, zu einem Merksatz verdichtet, demzufolge dem Christentum die Fremdheit gegenüber der nichtchristlichen Umwelt eingeschrieben ist. ${ }^{74}$ Die konstitutionelle Distanz, die als Folge der Erwählung und Begnadung gedeutet wird (vgl. 1 Petr 1,1f.), prägt den gesamten Lebenswandel aller Christen bis zum Eschaton. Entgegen dem Augenschein bringt sich auch in dieser universa-

\footnotetext{
${ }^{71}$ Vgl. LoNa 2005, 288-304.

${ }^{72}$ Vgl. Justin, 1 Apol. 8,4; 19,7; 52,3; Dial. 5,4-6,2; 62,1-3; 80-82; Athenagoras, Leg. 31,3(4); Tatian, Or. 15,1; Theophilos, Autol. I 13; II 15.26f.38.

${ }^{73}$ Vgl. Lona 2001, 68f.

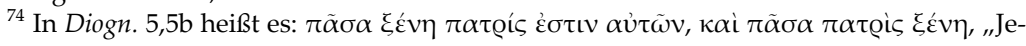
de Fremde ist ihr Heimatland, und jedes Heimatland eine Fremde.“ Vgl. Lona 2001, 151. 161-163.
} 
lisierten, die Zeit der Kirche umfassenden Entschränkung des christlichen Selbstverständnisses - im Sinne des gesetzesfreien Evangeliums, geographisch, ethnisch und sozial' (vgl. Gal 3,26-28) sowie als endzeitliche Bestandszusage an die $\dot{\varepsilon} \kappa \kappa \lambda \eta \sigma^{\prime} \alpha$ - wieder die christliche Binnenperspektive zu Gehör.

Das älteste Dokument, in dem die Außenwahrnehmung des Christentums bei Gebildeten weder nur angedeutet ${ }^{75}$ noch einzig als Kontrastfo$\mathrm{lie}^{76}$ eingesetzt ist, sondern berichtet und beurteilt wird, ist die Korrespondenz zwischen Plinius dem Jüngeren als Statthalter der Doppelprovinz Bithynien-Pontus und Kaiser Trajan. Diese Briefe aus den Jahren 110/111 bilden das Schlüsseldokument für die rechtliche Stellung der Christen vom zweiten bis zur Mitte des dritten Jahrhunderts. Das wird durch die frühchristliche Märtyrerliteratur und durch die Argumentation bei den Apologeten bestätigt, wobei zuvorderst Tertullians Replik auf die Plinius-TrajanKorrespondenz in Apol. 2,6-9 zu nennen ist. ${ }^{77}$ Plinius' Bericht über sein differenziertes Vorgehen gegen Christen bezeugt eine erfolgreiche Mission in allen Gesellschaftsschichten. Aus der imperialen Perspektive des gebildeten und von Amts wegen zuständigen Römers Plinius gefährdet die Christianisierung der Bevölkerung die öffentliche Ordnung: Zum einen verletzen die Christen durch ihr demonstratives Fernbleiben von den etablierten Kulten nicht nur das religiöse Leben im öffentlichen Raum; durch ihre reservierte Haltung gegenüber Aktionsräumen des öffentlichen Lebens wie den Schauspielen oder Wettkämpfen, in denen das Gemeinwesen seine innere Einheit bekundet, untergraben sie alle staatlichen und munizipalen Bemühungen um Frieden, Recht und Ordnung sowie um Wohlstand. Mit dem Hinweis auf den ökonomischen Schaden, den die Christen durch ihre Abkehr von allen nichtchristlichen kultischen Vollzügen anrichten, macht Plinius nicht nur auf den Ernst der Lage in seinem Verantwortungsbereich aufmerksam, sondern er deutet auch an, dass dem Christentum eine kaum zu kontrollierende Konfliktdisposition inhärent ist. ${ }^{78}$ Daraus erklärt sich sein politisch-moralisches Werturteil über die von ihm mit den Mitteln

\footnotetext{
${ }^{75}$ Vgl. die Geschichte aus dem lukanischen Sondergut von der Überstellung Jesu an Herodes Antipas (Lk 23,6-12), derzufolge der gebildete Römer Pilatus in der Behandlung Jesu durch den Tetrarchen erkannte, dass er mit Herodes Konsens hat über die kulturellen Ideale der mediterranen Gesellschaften, so dass sie „Freunde wurden“.

${ }^{76}$ Vgl. 1 Petr oder die Pastoralbriefe.

${ }^{77}$ Näheres vgl. Georges 2011, 25-30. 77-81.

${ }^{78}$ Vgl. dazu Origenes, C. Cels. I 1a; III 1-VIII 14; VIII 2a (in den Ansichten der Christen

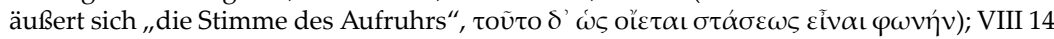

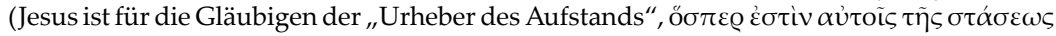

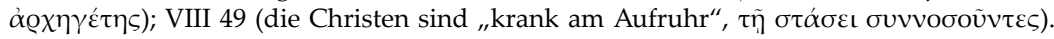
Näheres vgl. LonA 2001, 73. 179-183. 429. Für Kelsos macht die - nach seinem Urteil - defizitäre, völlig irrige und daher indiskutable Rede von Gott evident, dass das Christentum den niedersten Schichten der Gesellschaft entsprungen sein muss. Umso weniger ist indes sein Erfolg, zumal bei Gebildeten, überzeugend zu erklären; vgl. Näheres bei G. SснӧLL-
} 
gerichtlicher Wahrheitsfindung ausfindig gemachten Grundlagen für das Verhalten der ihm angezeigten Christen: superstitio. Ihre Hinrichtung befahl Plinius indes nicht superstitionis causa, sondern wegen ihrer "Hartnäckigkeit und unbeugsamen Halsstarrigkeit" ${ }^{79}$ Denn sie bestritten weder ihre Zugehörigkeit zum Christentum noch demonstrierten sie in vorgeschriebener kultischer Form ihre Loyalität zum Imperium, seinen Instanzen und Idealen. Stattdessen hielten sie an ihrer, aus der Sicht eines hochgebildeten Römers wie Plinius, völlig irrigen Gottesvorstellung fest und bekräftigten damit ihren Willen, die Einheit, Stabilität und Kontinuität des Gemeinwesens zur Disposition zu stellen.

Aus der Sicht von Gebildeten wie Plinius, ist Christentum grober Unfug; den Verantwortlichen in Staat und Gesellschaft erscheint es wegen seines Erfolgs zudem als gefährlich, weswegen Glaube und Glaubenspraxis der Christen als ethisch zutiefst verwerflich gebrandmarkt werden. Die vernunftwidrige, fremdartige Gottesvorstellung und die umfassende Konfliktdisposition scheinen die tragenden christentumskritischen Einwände zu sein, die seit Anfang des zweiten Jahrhunderts Konsens sind unter Gebildeten und Mächtigen, und die daher kultiviert werden. ${ }^{80}$

\subsection{Tradition, religiöse Wissbegier und Prestige}

Die Korrespondenz zwischen Plinius und Trajan belegt, dass das Christentum am Beginn des zweiten Jahrhunderts von öffentlichem Interesse geworden war. Mit der Ernennung von Plinius zum außerordentlichen Statthalter der Provinz Bithynien und Pontus im Jahr 111 dürfte Kaiser Trajan die Erwartung verbunden haben, dass sein legatus nicht nur gewissenhaft über die Zustände in der Doppelprovinz berichtet, sondern auch zu einer kompetenten politischen Lagebeurteilung gelangt und Maßnahmen ergreifen oder empfehlen wird, die geeignet sind, wieder geordnete Verhältnisse herzustellen. In diesen ordnungs- und wirtschaftspolitischen Kontexten erlangt das Christentum Staatsinteresse. Daher spricht Plinius in seinem Resümee, das er aus seinen richterlichen Untersuchungen des Christentums im Blick auf die Wohlfahrt des Gemeinwesens gewinnt, dass das Christentum eine "Seuche" ${ }^{\prime 81}$ (contagio) sei, sowie in der politisch-moralischen Verurteilung des Christentums als superstitio, ${ }^{82}$ vor

GEN, „Magier, Gaukler, Scharlatane. Das Christentum als Unterschichtsreligion bei Kelsos“, in: Grieser / Merkt 2009, $28-37$.

${ }^{79}$ Plinius, Ep. X 96,3; vgl. GuYot / KLein 1993, 38-43. 320-324; Косн 2013, 460-466. 521-530.

${ }^{80}$ Vgl. Krause 1958; Prostmeier 2001.

${ }^{81}$ Plinius, Ep. X 96,9.

${ }^{82}$ Plinius, Ep. X 96,8. Косн 2013, 460-466, betont zu Recht, dass mit Trajans Bescheidung des Konsularschreibens eine neue Rechtslage besteht, als nun aufgrund des nomen ipsum die Zugehörigkeit zum Christentum strafbar ist. Die wohl älteste Reaktion darauf 
allem in seiner Funktion als außerordentlicher Statthalter und damit aber auch als Repräsentant der nichtchristlichen Majoritätsgesellschaft. Unter diesem weiteren Blickwinkel wird aus dem Lagebericht des Plinius deutlich, dass Eliten, zu denen er nach Ausmaß und Niveau seiner Bildung gehört hat, mit einer milieutypischen Wissbegier auch an den Propria des Christentums interessiert sein konnten. ${ }^{83}$

liegt Косн 2013, 467-469, zufolge im 1 Petr vor. Der 1 Petr müsste also nach 112 verfasst sein; Косн zufolge „um 115 n.Chr.“ (ebd. 433). Allerdings muss die Situation, in die hinein dieses Pseudepigraphon geschrieben ist, nicht zwingend als Folge der aus der PliniusTrajan-Korrespondenz erkennbaren Rechtslage interpretiert werden. Die Lage der Christen - nicht nur in Kleinasien - ist prekär und dadurch gekennzeichnet, nicht gut gelitten zu sein, Anfeindungen und soziale Ausgrenzung durchstehen zu müssen, die mitunter in Pogrome eskalieren. Sofern diese Glaubens- und Lebensumstände, die der 1 Petr entwirft, auch vor der Anfrage des Plinius an Trajan nicht zwingend auszuschließen sind, dann ist dieses Schreiben nicht stringent mit den Christenbriefen des Plinius in Beziehung zu sehen und als Reaktion auf eine Verschärfung des rechtlichen Status von Christen im Imperium Romanum zu erklären. Vgl. dazu auch oben S. 204 Anm. 50 und F. R. ProstmeiER, Handlungsmodelle im ersten Petrusbrief. fzb 63 (Würzburg 1990) 51-72. Beachtenswert ist, dass weder in den erläuternden Anmerkungen zur Plinius-Trajan-Korrespondenz durch Guyot / KLeiN 1993, 320-324 und Косн 2013, 460-466. 521-530 das moralisch-politische Werturteil superstitio eigens bedacht wird noch die Untersuchung durch LüHRMANN 1986

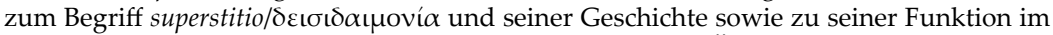
Konnex der Plinius-Trajan-Korrespondenz erwähnt ist. Eine Öffnung des Untersuchungsinteresses über die rechtlichen und rechtsgeschichtlichen Belange des Konsularschreibens und seiner kaiserlichen Bescheidung hinaus könnte auf kultur-, religions- und mentalitätsgeschichtlichen Dimensionen jener Vorgänge aufmerksam machen, mit denen Plinius, der hochgebildete Aristokrat aus Como, nun in seiner Funktion als Statthalter (17.09.110 bis zu seinem Tod in der ersten Jahreshälfte 112) konfrontiert ist, und die er in seinem Brief im Blick auf seinen besonderen Auftrag, die Doppelprovinz zu befrieden, anspricht. Ginge es nur um die rechtliche ,Rückendeckung' durch eine kaiserliche Bescheidung, ist die Mitteilung der moral-politischen Bewertung des Christentums als superstitio eher unangemessen, aber zumindest hinsichtlich seiner Funktion fragwürdig, denn nicht superstitio ist justiziabel, sondern die diesem Verdikt vorausgehenden oder auch nur absehbaren Tatbestände. Könnte es sein, dass Plinius seinen Konsens mit der Bewertung des Christentums seitens der Gebildeten als nun durch eigene Nachforschung als bestätigt signalisieren will?

${ }^{83}$ Plinius wird es zwar zuallererst als seine Amtspflicht betrachtet haben, zuverlässig über die Glaubenspraxis im Christentum und über dessen theologische Propria unterrichtet zu sein, weil es flächendeckend und in allen Schichten etabliert und schon deshalb ein ordnungspolitischer Faktor war; vgl. dazu Lührmann 1986; T. HosaKA, „Die Christenpolitik des jüngeren Plinius“, Annual of the Japanese Biblical Institute 12 (1986) o. S.; CHRIST 2009, 592-595. Gebildeten seiner couleur verhieß indes ein solcher Einblick auch exklusives religiöses Wissen. Sofern es als zuverlässiges, womöglich durch Autopsie gewonnenes Wissen über die neue und fremdartige christliche Gottesvorstellung und ebenso über das Eigenleben der Gemeinden präsentiert werden konnte, versprach es zunächst, Haltungen und Handlungen von Christen erklärbar zu machen, für die das aus griechisch-römischer Tradition gespeiste Wissen über Philosophie und Religion augenscheinlich nicht hinreichte. Vor dem Hintergrund der kaiserzeitlichen Denk- und Kulturgeschichte konnte solch exklusives Wissen über die neue Religion überdies vorzüglich dafür geeignet erscheinen, um sich im Milieu der Gebildeten durch überragenden Kenntnisreichtum eindrucksvoll in Szene zu setzen. Kenntnisse, auch und gerade über Abseitiges, Fremdes, galten in kaiserzeitlichen Bildungsmilieus, die sich wie die kulturelle Avantgarde an einem Konzept der 
Auf diese Wissbegier ${ }^{84}$ als Mittel der Statusrepräsentanz spielt wohl schon die Areopagrede mit der nicht eben freundlichen Charakterskizze der Athener ,Bildungsschickeria' an (Apg 17,21). Die frühchristlichen Apologeten rufen exakt dieses Erscheinungsbild des Gebildeten auf ${ }^{85}$ und dekonstruieren es, um den Wert dieses Bildungswissens und damit der gesamten Kulturtradition, der es entstammt, zu relativieren. Das geschieht bei Tatian, Justin, Theophilos und Minucius Felix mittels der Notizen über ihren Bildungsweg bis zu ihrer Konversion zum Christentum. ${ }^{86}$ Diese mit unterschiedlichem Grad an Raffinesse durchgeführten ethopoietischen Kompetenzkonstruktionen ${ }^{87}$ verfolgen eine Doppelstrategie: Zum einen schreiben sich die Apologeten in das Bildungsideal des kaiserzeitlichen Konzepts der Klassik ein, wozu die signifikante relecture der Tradition gehört, z.B. die Mythenkritik. ${ }^{88} \mathrm{Zu}$ dieser kulturellen Affirmation gehört

Klassik orientierten, das in der ,Zweiten Sophistik' zu einer kulturellen Leitidee gelangt ist, als äußerst erstrebenswert. Das Wissen über kuriose kultisch-rituelle Vorgänge und religiöse Vorstellungen, wie sie Lukian von Samosata zu „berichten“ weiß, etwa in Пв@i

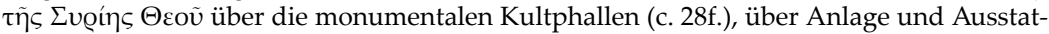
tung ihres Tempels und über das springende Kultbild Apolls, machte Eindruck; zumindest besaßen solche Schilderungen Unterhaltungswert bei Gebildeten. Näheres vgl. J. L. Lightғоот (Hg.), Lucian. On the Syrian goddess (Oxford u.a. 2003); F. Berdozzo, Götter, Mythen, Philosophen. Lukian und die paganen Göttervorstellungen seiner Zeit. Untersuchungen zur antiken Literatur und Geschichte 106 (Berlin / Boston 2011). - Kompetenz in diesen Wissenssegmenten ermöglichte also, Vorzüglichkeit nicht nur durch virtuose Verfeinerungen und ästhetische Vollendung überkommener Bildungstraditonen zu demonstrieren - etwa im literarischen Diskurs über religiöse, kultische oder ethische Sujets -, sondern zudem Unverwechselbarkeit zu kreieren. In diesem Sinn und mit dieser mimetischen Funktion war das in einer relecture der griechisch-römischen Kulturtradition konstruierte antiquarische Wissen zusammen mit der Wissbegier ein Signum des Gebildeten im zweiten Jahrhundert. Vgl. auch Krasser 2007.

${ }^{84}$ Zum Begriff und seiner differenzierten Wertung vgl. N. BROx, „Glauben und Forschen in der Alten Kirche“, in: Prostmeier 2007, 9-18.

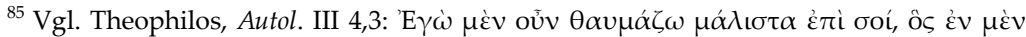

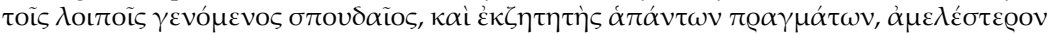

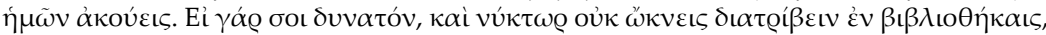
"Ich wundere mich nun am meisten über dich, dass du, der du doch sonst in den übrigen Gegenständen des Wissens ein eifriger und genauer Forscher bist, uns so wenig Interesse entgegenbringst. Denn wenn es dir nur irgend möglich ist, stöberst du unermüdlich auch zur Nachtzeit in den Bibliotheken herum."

${ }^{86}$ Vgl. Justin, 1 Apol. 25; 53,3; 2 Apol. 12,1; 13,1-2; Dial. 1-8; Tatian, Or. 29; 35; 42; Theophilos, Autol. I 2.14; Tertullian, Apol. 18,4; Minucius Felix, Octavius 1.

${ }^{87}$ Vgl. H.-M. Hagen, Ethopoiia. Zur Geschichte eines rhetorischen Begriffs (Erlangen 1966).

${ }^{88}$ Die Mythenkritik hebt mit den Vorsokratikern an; Xenophanes (vgl. 21 B 11-16 DK; 23-26) und Heraklit (vgl. 22 B 42 DK) protestierten scharf gegen die Göttervorstellung in der Dichtung. Zur Referenzgröße für die pagane Mythenkritik wird indes Platons metaphysische und psychologische Separation der Philosophie von der Dichtung, so dass dem Mythos jeder Wahrheitsanspruch entwunden ist. Die frühchristliche Mythenkritik, wie sie bei den Apologeten zuerst begegnet, verbindet - darin verwandt dem hellenistischen Judentum (vgl. Flavius Josephus, Contra Apionem 35) - die Reserven der platonischen Tradition mit dem monotheistischen Einwand aus biblisch-christlicher Tradition (vgl. 1 Kor 
auch das Bestreben, dem verbreiteten und überdauernden Vorwurf der Bildungsfeindlichkeit des Christentums, wofür fehlende Eloquenz und der Mangel an Eleganz des christlichen Schrifttums als sichere Indizien galten, ${ }^{89}$ durch den gezielten Aufruf von antiquarischem Wissen sowie einer ambitionierten literarischen Gestaltung Paroli zu bieten. Zum anderen limitieren diese Avantgardisten unter den frühchristlichen Theologen den Wahrheitswert der gesamten Kulturüberlieferung, indem sie die christliche Wissenstradition als den biographisch patentierten Konvergenzpunkt aller Erkenntnisbemühung anpreisen (vgl. Tatian, Or. 35) und dieses christliche Wissensrepertoire zeitlich und sachlich allem anderen religiösen Wissen oder - wie Tatian - sogar der gesamten griechischrömischen Kultur vorordnen. ${ }^{90}$

Theophilos setzt hierzu eine ganze Reihe von Argumenten ein. Es beginnt mit einem Paukenschlag in Autol. I 1,1 (vgl. Tatian, Or. 26,1), der die alten, seit Sokrates ${ }^{91}$ bekannten Reserven gegen Konzertredner wiederholt und mit dem Hinweis auf die Konsistenz von Wort und Tat als Wahrheitskriterium seine Ausführungen in Autol. II 2 zur theologischen Hermeneutik vorbereitet, wonach ein vom rechten Glauben an Gott getragener Lebenswandel die Voraussetzung für eine zutreffende theologische Erkenntnis bildet. ${ }^{92} \mathrm{Zu}$ dieser Destruktion des scheinbar irreversiblen Zusammenhangs von Formvollendung, Wahrheit und Moralität gehört z.B. auch die Konkordanz theologischer Epitheta in Autol. I 3 sowie die gesamte Anlage des zweiten Buches An Autolykos. Gerahmt von paganen Zeugnissen für die Achsenthemen Gott, Welt, Menschen, Rettung, deren hohe Widersprüchlichkeit (Autol. I 4f.8; III 7; vgl. Tatian, Or. 3,3) und schließlich auch geringeres Alter erwiesen werden, entnimmt Theophilos in protreptischer Absicht alle theologischen Propria des Christentums aus der biblischen Urgeschichte. Nicht nur um die Vorrangigkeit der biblisch-christlichen Tradition vor der gesamten, repräsentativ zitierten griechisch-römischen Über-

10,20; 2 Petr 1,16). Die Auswahl der Mythologeme und die Kritik stehen erkennbar in der Funktion, das überlegene Bildungsniveau des Christentums zu demonstrieren. Das zeigt sich z.B. bei Theophilos in der Platzierung der paganen Tradition in Relation zur biblischchristlichen oder auch in den unterschiedlichen Zitationseinleitungen, die die höhere Autorität der biblisch-christlichen Quellen anzeigen wollen.

${ }^{89} \mathrm{Vgl}$. Kelsos in Orig. C. Cels. III 44-55.72-78; Julian, Fr. 7 WeIs; Theodoret von Kyrrhos, Graec. aff. cur., prooem. 1.

${ }^{90}$ Näheres vgl. J. Lössl, Rez. zu L. S. Nasrallah, Christian responses to Roman art and architecture. The second-century church in the spaces of empire, JTS, N.S. 61 (2010) 771-773.

${ }^{91}$ Vgl. Platon, Theaitetos 174a4-8.

92 Ebenso wie Theophilos, Autol. I 1,1 und 2,1 ruft Tatian, Or. 26,2a.b die bei Platon, Theaitetos 174a4-8 von Sokrates wiederholte Anekdote über den leichtfertigen Spott wider die Philosophie auf und kehrt ihn gegen die Repräsentanten der philosophischen Tradition, nicht aber gegen die hellenistisch-römische Bildungskultur (vgl. Or. 26,2c). Die Pointe ist evident: Obwohl die Hellenen eine exzellente Bildungstradition besitzen, können sie daraus kein zutreffendes religiösen Wissen schöpfen. 
lieferung zu erweisen, sondern auch, um die Normativität der im Christentum evident gewordenen theologischen Wahrheit festzuschreiben, fügt der Antiochener die erste christliche Weltchronik (Theophilos, Autol. III 16-28) an, deren Argumentationsziel wohl darin zu sehen ist, zu erkennen, dass man als Gebildeter und Römer nicht anders kann als Christ zu sein, denn auf das Christentum strebt die Weltgeschichte, inklusive dem Imperium Romanum, zu. Eine vergleichbare Demontage der paganen Überlieferung scheint auch in der Oratio ad Graecos vorzuliegen. Der Erfinder(Tatian, Or. 1) und der Kunstwerkekatalog (Tatian, Or. 33,2-34,9) signalisieren gewiss Weltläufigkeit; auch der Aufruf topischer Exempla (Tatian, Or. 26,3; 27,2; 34,1), ${ }^{93}$ der Spott gegen Philosophen (Tatian, Or. 2f.) und der Abschnitt über die Astrologie (Tatian, Or. 8-10) stehen im Dienst dieser vielleicht schon usuellen Bildungsdemonstration. Womöglich bringt sich auch die Rivalität zwischen Provinzialen und dem caput mundi, zwischen dem Osten und dem Westen zu Gehör. Aber ähnlich wie die Batterie der paganen Zeugnisse bei Theophilos liefern diese Exkurse in der Oratio ad Graecos keinen Beitrag zur Wahrheitsfindung. Sie sind vielmehr degradiert zu ornamentalen Relikten einer Kultur, deren geistiges Fundament und Auffassung zu zentralen Themen im Bildungsdiskurs auf deszendenten, korrumpierten und somit irrigen Quellen beruhen. Daher nimmt es nicht wunder, dass für beide Syrer der Altersbeweis (Tatian, Or. 31.36-41; Theophilos, Autol. III 16.) eine wichtige Rolle spielt.

Ebenso wie Theophilos und andere frühchristliche Apologeten komplementiert diese Destruktion auch Tatian mit einer theologischen Hermeneutik, die mit der philosophischen Tradition, vor allem der Mythenkritik, sowie mit der biblisch-jüdischen und der christlichen Überlieferung die Möglichkeit einer direkten Gottesschau (Autol. I 2f.; Tatian, Or. 4,1f.) verwirft und stattdessen Gottes Unsichtbarkeit, Unberührbarkeit, Unbegreiflichkeit, Unaussprechbarkeit, Anfangslosigkeit und Unveränderlichkeit (Autol. I 4; Tatian, Or. 4,3; Aristides, Apol. 1,4-6) als theologischen Grundkonsens konstatiert. ${ }^{94}$ Sodann werden die Schöpfung selbst (Autol. I 4,5-6,6; Tatian, Or. 4,3c) sowie die garantierte Überlieferung (Autol. II; Tatian, Or. 5,1) als die Quellen theologischer Wahrheitsfindung definiert.

Was als konsequente Abkehr von der paganen Welt erscheint und gefordert wird, ist der Versuch, das Spannungsverhältnis von Evangelium und Kultur in drei Richtungen zu klären: 1 . Christentum beruht auf der allein zutreffenden, weil nach konsensfähigen Prinzipien gewonnenen Gotteserkenntnis und wirbt daher zu Recht für den christlichen Glauben. 2. Christentum und die griechisch-römische Tradition schließen einander nicht aus; vielmehr ist das Christentum der Raum, in dem das Wahre an die-

\footnotetext{
93 Vgl. SChubert 2014, 168.

${ }^{94}$ Vgl. Prostmeier 2010; Pannenberg 1959, 16-45.
} 
ser Tradition bewahrt und in seinem Rang erkannt wird. 3. Christen sind loyale Bewohner des Imperium Romanum (Diogn. 5,5).

\section{Achsenthemen und Protagonisten in der frühchristlichen Apologetik}

Im Zentrum der frühchristlichen Apologetik steht die Frage nach Gott. ${ }^{95}$ Es geht nicht zuerst um die Verteidigung des Christentums oder einzelner Züge an ihm, die von der antichristlichen Kritik ins Zentrum gerückt werden. Auch die Werbung für das Christentum ist nicht das erste Anliegen der frühchristlichen Apologeten, wiewohl sie ihre Leser vom Christentum überzeugen oder sie darin festigen wollen. Die prominenten ThemenEntstehung der Welt, der Mensch, seine Rettung und die Zukunft des Kosmos - scheinen der Frage nach der Gottesvorstellung sowie den Konditionen für die Möglichkeit einer zutreffenden theologischen Erkenntnis und Rede nachgeordnet. Das hat Folgen für die Selbstpräsentation des Christentums, insbesondere für die Verknüpfung christlicher Propria mit dem monotheistischen Hauptthema. Dass im kaiserzeitlichen Diskurs über Religion durchaus der Glaube an die Inkarnation des Logos in Jesus Christus bekannt war, zeigt die Polemik des Kelsos gegen den Glauben, ein gewisser Gott oder Gottessohn sei bereits auf die Erde herabgekommen. ${ }^{96}$ Seine süffisante Präsentation der aus der Sicht der griechisch-römischen Tradition einzig denkbaren Alternativen, wie diese christologische Vorstellung zu deuten ist, nämlich als grober Unfug oder als Erweis eines völlig widersinnigen Gottesbildes, macht evident, dass dieser gebildete Lehrer, der im Namen der Wahrheit der Tradition, in der er steht, protestiert, erkannt hat, dass der Skopos dieser christologischen Rede die Gottesvorstellung ist. Im christlichen Glauben an die Inkarnation des Logos wird für Kelsos wie in einem Brennglas die unüberbrückbare Fremdartigkeit der christlichen Lehre sichtbar. Das gilt analog hinsichtlich des Osterglaubens und damit auch bezüglich der christlichen Auferstehungshoffnung. ${ }^{97}$ In seiner Themenauswahl und -besprechung wird deutlich, dass etwa der Dissens in der vorausgesetzten Anthropologie dort elementar wird, wo zwei signifikante Themen christlicher Theologie tangiert sind: Gott und Rettung. Denn mit der Gottesfrage ist, neben der Hermeneutik, sogleich das Verhältnis von Gott und Welt im Blick. Diese Relation gewinnt durch die Antwort auf die Frage nach der Rettung christliches Profil. Daher nimmt es

\footnotetext{
${ }^{95}$ Vgl. Aristides, Apol. 1,1f. ; Tatian, Or. 5-7; Theophilos, Autol. I 1,2; Näheres vgl. PANNENBERG 1959. Anders bewertet Trelenberg 2012, 29-54 den Befund bei Tatian. Unter der Überschrift „Die Theologie Tatians“ handelt er fünf bzw. sechs theologische Traktate ab, ohne dass eine Priorisierung und Vernetzung erkennbar wird.

${ }^{96}$ Vgl. Lona 2005, 220-223.

${ }^{97}$ Origenes, C. Cels. IV 2 (vgl. BKV 1926, 298); vgl. Lona 2005, 288-292.
} 
vielleicht doch nicht wunder, dass beide theologische Fragen bereits in dem ältesten Dokument für die direkte Begegnung zwischen Christentum und Repräsentanten der griechisch-römischen Bildungskultur, der Areopagrede, dominieren: Gott als Schöpfer und als Retter.

Während in der Trilogie des Theophilos diese Achsenthemen allein schon dadurch hervorgehoben sind, dass Autolykos nur bei diesen beiden Fragen direkt zu Wort kommt (Autol. I 2,1.13,1), scheinen in Tatians Oratio ad Graecos deutlich mehr und voneinander abgegrenzte theologische Sachfragen traktiert zu sein: Schöpfungslehre, Logosspekulation, Pneumatologie, Dämonologie, Anthropologie und Ethik. ${ }^{98}$ Doch wird man zweierlei fragen dürfen: 1 . In welchem Verhältnis stehen diese theologischen Themen zueinander? 2. Hat Tatian die Eschatologie ausgeblendet? Letzteres scheint nicht der Fall, wie Tatian, Or. 15,2c belegt. Die Eschatologie steht in engem Konnex mit der Anthropologie. Die Auferstehungshoffnung folgt bei Tatian aus seinem Verständnis der menschlichen Leiblichkeit, das grundgelegt und gebunden bleibt an seine Schöpfungslehre. „In strenger Systematik führt der Gedankengang von der Schöpfung des Alls und des ersten Menschen über die Interpretation des Falls als Verlust der Unsterblichkeit durch die Trennung vom göttlichen Geist zu seinem Bild vom gefallenen Menschen, dem der Weg zum Heil durch die Erkenntnis der Wahrheit und die Gemeinschaft mit dem Geist eröffnet wird. In der Anthropologie zeigen sich die Grundzüge seiner eigenartigen Soteriologie. " 99 Während bei Justin die Auferstehungshoffnung in einem klaren christologischen Bezugsrahmen steht, fehlt dieser sowohl bei Theophilos als auch bei Tatian. In den Werken der beiden Syrer spielt die Christologie keine Rolle; bei Theophilos fehlt sogar jede Jesuserinnerung. ${ }^{100} \mathrm{Da}-$ für steht bei beiden die monotheistische Gottesvorstellung der biblischen Tradition im Vordergrund, und damit Gott als Schöpfer. Bei Tatian und

\footnotetext{
${ }^{98}$ Vgl. die traktatartige Kategorisierung von Tatians theologischen Aussagen bei TRELENBERG 2012, 29-54. Dogmengeschichtlich betrachtet ist es allerdings nicht nur ein Anachronismus, sondern tatsächlich nicht sachgemäß, im Rahmen der Oratio ad Graecos $\vartheta$ gós und $\lambda$ ó $\gamma$ o als die „beiden ersten trinitarischen Personen“ (ebd. 73) zu bezeichnen. Dass Tatian „statt eines Bekenntnisses zur christlichen Trinität ... eine zwar komplizierte, aber keineswegs unverständliche oder gar kryptische Pneumatologie“ (ebd.) offeriert, ,"dass sie den Trinitätsgedanken nicht zum Ausdruck bringt“ (ebd.) ist kaum verwunderlich, vielmehr typisch für diese Zeit. Das Ringen um den theologischen Status des Sohnes und des Pneumas gehört ins vierte Jahrhundert; Näheres vgl. DüNZL 2000, 30-44. 60. 361. Im Vordergrund stehen die tastenden Versuche etwa von Justin, eine Sprachregelung für eine zutreffende christliche Rede von Gott zu begründen, die den biblischen Monotheismus wahrt und zugleich gestattet, theologisch Maximales über Jesus zu sagen. Vgl. dazu N. Brox, Terminologisches zur frühchristlichen Rede von Gott. SBAW.PH 1996/1 (1996) 1-46. Aufschlussreich für die Problemlage ist Autol. I 3. Näheres vgl. Prostmeier 2010.

${ }^{99}$ Lona 1993, 123; ferner S. 124f. den Vergleich von Justins Position mit jener in Tatians Oratio ad Graecos.

${ }^{100}$ Vgl. Prostmeier 2013.
} 
Theophilos scheinen die Aussagen über den Logos und das Pneuma sowie die anthropologischen und ethischen Aussagen der Grundauskunft über das Verhältnis von Gott zur Welt bei- oder nachgeordnet. Dies fügt sich zu der vehementen Kritik an der heidnischen Kultur zugunsten der biblisch-christlichen Überlieferung, der „barbarischen“ Tradition im Sinne Tatians. ${ }^{101}$

\section{Diskurs und Konstruktion}

Die Werke der frühchristlichen Apologeten sind literarische Inszenierungen im Rahmen des kaiserzeitlichen Religionsdiskurses. Die Forschungsgeschichte zur Historizität und Ereignistreue von Justins Dialog mit Tryphon $^{102}$ sammelt wie ein Brennglas die Problematik. Der Wert der Personalund Lokalnotizen wurde durchweg nicht aus der Perspektive ihrer literarischen Funktion beurteilt, sondern in enger Abhängigkeit von ihrer historischen Verlässlichkeit. Für die Frühchristentumsgeschichte ist aber nicht nur relevant, ob Justin mit Tryphon und dessen Begleiter debattiert hat, ob Autolykos, Diognet, Octavius und Caecilius historische Personen waren, ob in den jeweiligen Werken tatsächliche Vorgänge und Diskurse bewahrt sind, ob ein Lehrer im caput mundi oder Aristides in Athen, die kaum persönlich Zugang zum Hof hatten, den Kaiser schriftlich kontaktieren konnten. Mindestens ebenso bedeutsam sind das Selbstverständnis und die Situierung, die aus den Widmungen bzw. Adressierungen hervortreten. In dieser Hinsicht scheint die kollektive Adresse von Tatians Oratio weiterführend. In Verbindung mit den Sujets, der Vorordnung der „barbarischen" Tradition vor der griechisch-römischen Kultur ist die Adressierung des gesamten Werks ad Graecos programmatisch. Der harsche Ton Tatians und seine rigorose Haltung zur paganen Kulturtradition sprechen nicht dafür, dass er einen offenen, wohltemperierten Diskurs über grundsätzliche und aktuell interessierende religiöse Fragen sucht und dabei die Hoffnung hegt, seine Polemik wäre angemessen, um Gebildete für das Christentum zu werben. Seine Leser sind jene, die in der von ihm als „barbarisch" bezeichneten Tradition stehen oder mit ihr sympathisieren. Trifft das zu, dann ist der diskursive Kontext, den Tatian mittels prominentem antiquarischen Wissen aufruft, von Anfang an eine literarische Konstruktion. Tatian weiß vom kaiserzeitlichen Diskurs über religiöses Wissen, aber er hat weder Zugang dazu noch strebt er danach, diese Auseinandersetzung tatsächlich zu führen und seine Argumente zu erproben. Weder die theologischen Inhalte noch seine Haltung gegenüber der paganen Kultur

\footnotetext{
${ }^{101}$ Näheres vgl. LössL 2007.

${ }^{102}$ Vgl. P. Bobichon (Hg.), Justin Martyr. Dialogue avec Tryphon, 2 Bde. Paradosis 47/1+2 (Fribourg 1999).
} 
sind diskursfähig, weil beides bereits zugunsten des Christentums entschieden ist.

Von hier aus stellt sich die Frage, ob die Werke der frühchristlichen Apologeten erstreben, in den kaiserzeitlichen Diskurs über zutreffendes religiöses Wissen tatsächlich einzutreten, oder ob sie diesen Diskurs nur voraussetzen, ohne sich darin positionieren zu wollen. ${ }^{103}$ Im ersten Fall müsste für die jeweilige Schrift einsichtig gemacht werden können, dass im Diskurs mit gebildeten Heiden oder Juden das Arsenal an Themen, die Argumente, rhetorischen Mittel und die Darstellungsform funktional sein konnten zur prophylaktischen oder tatsächlichen Abwehr antichristlicher Einwände oder sogar dafür, um die anvisierte Klientel zur Konversion zu motivieren. Schlagende Beweise dafür, dass gebildete Heiden die Schriften der frühchristlichen Apologeten intensiv konsultiert haben, dass die gelehrte Entkräftung antichristlicher Vorwürfe Wirkung gezeigt hat bei Gegnern oder staatlichen Instanzen, dass Gebildete aufgrund der ambitionierten Darlegungen christlicher Propria konvertiert sind, scheinen zu fehlen. Die Rezeptionsgeschichte dieser Werke und Argumentationen ${ }^{104}$ ist begrenzt und scheint exklusiv binnenchristlich zu sein. ${ }^{105} \mathrm{Im}$ zweiten Fall sind die Schriften der frühchristlichen Apologeten christliche Binnenliteratur, die zwei verwandte Ziele verfolgen, nämlich zum einen Gebildeten Argumente an die Hand zu geben, um auch mit Vernunftgründen im Christentum zu bleiben, und zum anderen für Sympathisanten, womöglich Gottesfürchtige, um das Spannungsverhältnis von Evangelium und Kultur in den genannten drei Richtungen aufzuklären.

\footnotetext{
${ }^{103}$ Vgl. F. DüNZL, Fremd in dieser Welt? Das frühe Christentum zwischen Weltdistanz und Weltverantwortung (Freiburg u.a. 2015) 215-219. 228f. 239-243.

${ }^{104}$ Vgl. Lona 2001, 27-31; Lona 2005, 67-69.

${ }^{105}$ Vgl. Fiedrowicz 2000, 47f.; Georges 2011, 48-50; Schubert 2014, 80-82.
} 



\title{
Tatians Seelenlehre im Kontext der zeitgenössischen Philosophie
}

\author{
Holger Strutwolf / Marie-Luise Lakmann
}

\section{Einleitung}

Im Falle eines Theologen, der wie Tatian über die griechischen Philosophen kaum Gutes zu sagen vermag, sondern sie in Bausch und Bogen zu verwerfen scheint, mag es zunächst müßig erscheinen, nach dem Zusammenhang seiner Seelenlehre mit zeitgenössischen philosophischen Konzepten zu fragen.

Es ist ja gerade dieser frühchristliche Theologe, der die christliche Glaubenslehre streng wie kein anderer von der griechischen Philosophie abgegrenzt hat. Er sah es eher als eine Auszeichnung jenes als Lehre der „Barbaren“ ( $\beta \alpha \dot{\varrho} \beta \alpha \varrho o \iota)^{1}$ geltenden Glaubens an, nicht mit den Ansichten der meisten Philosophen übereinzustimmen.

Tatian, der selbst in jüngeren Jahren die griechische Philosophie erlernt haben will, ${ }^{2}$ wendet sich namentlich gegen die "ganz bedeutenden“ ( $\pi \alpha ́ v v$

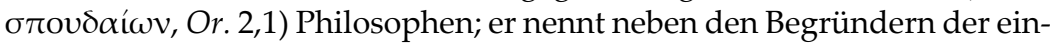
zelnen Philosophenschulen - Diogenes (der Kyniker), Aristippos (der Kyrenaiker), Platon, Aristoteles, Zenon (Stoa) und Epikur - auch die Vorsokratiker Heraklit, Empedokles, Demokrit und dessen Schüler Anaxarchos aus Abdera, den Diogenesschüler Krates und Pherekydes, den Lehrer des Pythagoras. ${ }^{3}$ Auffälligerweise fehlen konkrete Namen zeitgenössischer Philosophen, z.B. die Mittelplatoniker Plutarch von Chaironeia oder Attikos. ${ }^{4}$

Ganz allgemein polemisiert Tatian gegen die Philosophen, die durch ihre äußere Erscheinung (langer Bart, lange Haare, mangelnde Körperpflege) den Anschein erwecken wollen, ehrbare Philosophen zu sein, aber, getrieben von ihrer Sucht nach Ruhm und Luxus, nichts anderes sind als Be-

\footnotetext{
${ }^{1}$ Or. 1,$1 ; 31,1 ; 35,2.3 ; 42,1 ;$ s. auch 1,$4 ; 12,10 ; 28,3 ; 29,2 ; 30,3$.

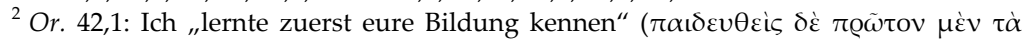

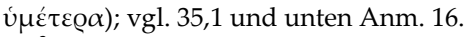

${ }^{3}$ Eine positive Ausnahme scheint Sokrates zu sein; vgl. Or. 3,3.

${ }^{4}$ Im Rahmen des Altersbeweises, den Tatian selbst in Or. 31-41 führt, ist dieses Fehlen allerdings nicht verwunderlich, da für dessen Vertreter nur die Archegeten der Philosophenschulen von Interesse sind.
} 
trüger und wie die Kyniker die Philosophie nutzen, um daraus materiellen Gewinn zu ziehen, und bei denen ein starker Widerspruch zwischen ihren Worten und ihren Taten herrscht. ${ }^{5}$

Als ein Kriterium der Unwahrheit führt Tatian die Uneinigkeit der vielen verschiedenen Philosophenschulen untereinander an, ${ }^{6}$ beispielhaft vertreten durch Platon und Epikur sowie durch Aristoteles und Demokrit $(O r .25,3)$. Dies betrifft neben kosmologischen, ethischen und anderen Fragen vor allem auch die Seelenlehre. ${ }^{7}$ Zweimal verweist er auf die Unhaltbarkeit bzw. Lächerlichkeit der Seelenwanderungslehre des Pherekydes, die Pythagoras übernommen habe; von diesem wiederum hat seiner Meinung nach Platon die Lehre von der Unsterblichkeit der Seele übernommen, der Aristoteles aber widerspricht. ${ }^{8}$ Ebenso lehnt Tatian die Lehre des Stoikers Zenon ab, nach der durch den zyklisch wiederkehrenden Zerstörungs- und Wiederentstehungsprozess, den Weltenbrand, immer wieder die gleichen Menschen wiederauferstehen und die gleichen Taten vollbringen. ${ }^{9}$ Der schillernden Vielzahl philosophischer Positionen stellt er dabei selbstbewusst die "barbarische Lehre" entgegen, die nicht von Menschen stammt, sondern von Gott durch den Geist den Menschen offenbart wurde. ${ }^{10}$ Tatian argumentiert also von vornherein von einem offenbarungstheologischen Standpunkt aus, der die Gewissheit einer von Gott stammenden Erkenntnis den menschlichen Wahrscheinlichkeitsschlüssen und Meinungen entgegensetzt. ${ }^{11}$

Aber auch wenn Tatian selbst den Dialog mit der zeitgenössischen Philosophie strikt zu verweigern scheint, kann es sinnvoll sein, sein Denken mit dem Denken seiner philosophischen Zeitgenossen oder Vorgänger ins Gespräch zu bringen und zu untersuchen, welche dem Autor vielleicht selbst unbewussten oder von ihm auch bewusst verschleierten Beziehun-

\footnotetext{
${ }^{5}$ Vgl. Or. 2,1-3,7; 19,2-4; 25,1f. Mit dieser Anklage verweist Tatian zu Recht auf ein Phänomen, das zu seiner Zeit weit verbreitet war. Die große Zahl der damals auftretenden sogenannten Scheinphilosophen war nicht nur Ziel des Spottes bei dem Satiriker Lukian (z.B. Nigrinos, Hermotimos, Symposion), sondern auch ehrbare Philosophen wie der Platoniker Tauros beklagten den Mangel an Seriosität mancher Berufskollegen (Gellius VII 10,5); vgl. M.-L. Lakmann, Der Platoniker Tauros in der Darstellung des Aulus Gellius. Philosophia Antiqua 63 (Leiden 1995) 65-68; Dörrie / Baltes 1993, 358-374.

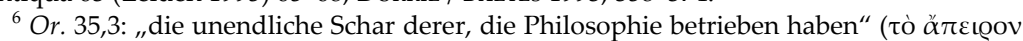

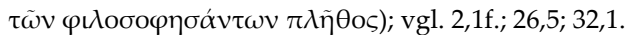

${ }^{7}$ Nemesios von Emesa beginnt seine Darstellung der verschiedenen Seelenlehren mit

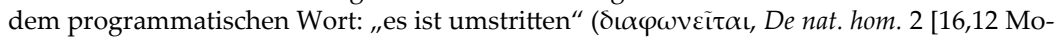
RANI]); dazu DöRRIE / BaLTES 2002/1, 164-168.

${ }^{8}$ Or. 3,$5 ; 25,3$. Tatian streift damit kurz die in der Antike geführte Diskussion, ob Platon zu Recht der pythagoreischen Tradition zugerechnet werden darf; vgl. DörRIE / BALTES 1990, 246-264 und unten Anm. 51.

${ }^{9}$ Or. 3,3; 6,1.

${ }^{10}$ Or. 29,3: „Und da meine Seele von Gott unterrichtet wurde, begriff ich ..."

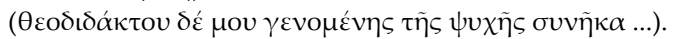

${ }^{11}$ Vgl. Or. 12,4.9; 32,1.
} 
gen sein eigenwilliges theologisches Denken trotz aller vordergründiger Gesprächsverweigerung zu jenem Anderen hat, das er als Menschenmachwerk ablehnt und als schändliche Irrlehre perhorresziert.

Zur Darstellung dieser Beziehung bietet sich besonders die Seelenlehre Tatians an, weil hier zum einen das Herz des tatianischen Welt- und Menschenbildes sichtbar werden kann, zum anderen seine direkte Auseinandersetzung mit der Philosophie, wenn auch negativ, festzustellen ist. Eine solche Darstellung kann aber nur verständlich sein, wenn man berücksichtigt, dass die Seelenvorstellung Tatians nicht von seinem theologischen Gesamtentwurf zu trennen ist. Vielmehr stellt sie die theologische Mitte seines Denkentwurfs dar, in dem die verschiedenen Fäden seiner originellen Gedanken zusammenlaufen.

\section{Wesen und Ursprung der Seele}

Zunächst steht für den christlichen Theologen Tatian von vornherein fest, dass die Seele als Geschöpf Gottes zu gelten hat und als solches grundsätzlich von ihm zu unterscheiden ist. Diese Grundunterscheidung expliziert er anhand eines differenzierten Geistbegriffs.

Gott selbst ist reiner "Geist" $(\pi v \varepsilon \tilde{v} \mu \alpha){ }_{1}^{12}$ ",unsichtbar und unberührbar"

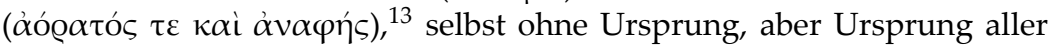
Dinge und Schöpfer der an die Materie gebundenen Geister und „Formen“ $(\sigma \chi \eta \dot{\mu} \mu \alpha \tau \alpha) .{ }^{14}$ Es ist Tatian dabei aber wichtig zu betonen, dass Gott als Geist gerade nicht, wie der stoische Gott, die Welt immanent durchwaltet, sondern der Materie prinzipiell fern bleibt. ${ }^{15}$ Die absolute Transzendenz

\footnotetext{
${ }^{12}$ Or. 4,3; vgl. Joh 4,24. Als erster bezeichnete Poseidonios Gott als Pneuma, das ohne Form ist: Fr. 101 Edelstein / Kidd = Fr. 349 Theiler.

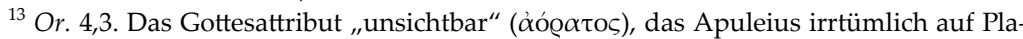
ton selbst zurückführt (De Plat. I 5,190), kommt aus der gnostischen Literatur; vgl. DörRIE / Baltes 2008, 345. Für die Unkörperlichkeit Gottes finden sich Beweise bei Alkinoos, Didasc. 10 (165,42-166,14 Whittaker / Louis); vgl. Dörrie / Baltes 2008, 340f. Für die Stoiker hingegen konnte Gott nur körperlich sein, da nur den Körpern das eigentliche Sein zukommt; vgl. Procl. Theol. Plat. 1,3 (12,11-17 SAfFrey / WesterinK).

${ }^{14}$ Or. 4,3. $\Sigma \chi \eta ́ \mu \alpha \tau \alpha$ dürfte hier für die platonische Vorstellung von den Formen stehen, die sich in der Materie ausprägen und sie zum Körper machen, wie es im Platonikerreferat bei Hippolytos, Haer. I 19,3 Marcovich dargestellt ist: Die formlose Materie nehme „For-

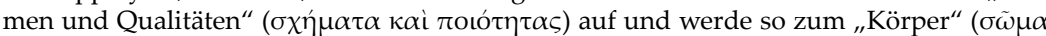
- im Gegensatz zur Stoa, nach der die Arten „,aus dem Schoß der Materie“ erwachsen; vgl. Chalc. Comm. 321 [317,6-9 WAszink]). Die parallele Formulierung in Haer. I 19,4 zeigt, dass $\sigma \chi \eta ́ \mu \alpha \tau \alpha$ gleichbedeutend mit iঠé $\alpha$ ı gebraucht wird; vgl. Plat. Tim. 50c7-51b6; Alkinoos, Didasc. 8 (162,32-35 Whittaker / Louis); Apul. de Plat. 1,5,190; 1,6,192f.

${ }^{15}$ Wenn Tatian schreibt: „Ein Geist ist Gott, aber nicht einer, der durch die Materie

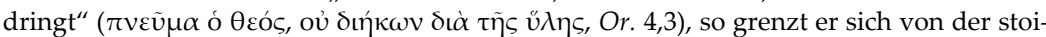
schen Philosophie ab, indem er unterstreicht, dass Gott, obwohl er als Geist bezeichnet wird, anders als der stoische Geistgott nicht die Materie durchwaltet. Für die Stoa ist der Geist, der die Welt durchwaltet, substantiell mit Gott identisch - eine Aussage, die Tatian
} 
Gottes, d.h. das vollkommene Freisein von der Materie und dem Körperlichen insgesamt, war allgemein anerkannte Lehre Platons, wie sie auch in den Doxographien dargestellt wurde. ${ }^{16}$

Um die materielle Welt zu schaffen und gleichzeitig seine Transzendenz zu wahren, hat der Gott und Vater ${ }^{17}$ den himmlischen Logos hervorgebracht, der selbst als Geist vom Geist und als Logos von der „Kraft des

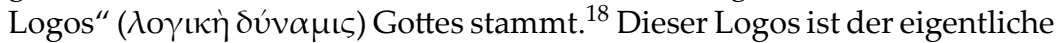
Ursprung der Welt, der zunächst die Materie hervorgebracht und danach aus ihr die Schöpfung gestaltet hat, in der wir leben. ${ }^{19} \mathrm{Er}$ ist es auch, der den Menschen in Nachahmung des Vaters als Abbild von dessen Unsterblichkeit geschaffen hat. Sind nun der Vater und sein Wort als reiner schöpferischer Geist bestimmt, so kann Tatian auch noch von einem göttlichen Geist sprechen, dessen Zuordnung zu diesen jedoch nicht unmittelbar klar gemacht wird.

Von diesem göttlichen Geist, der gerade dadurch gekennzeichnet ist, dass er die Materie nicht durchwaltet, wird ein geschöpfliches Pneuma strikt unterschieden:

„Der Geist nämlich, der die Materie durchdringt, ist geringer als der göttlichere Geist, und wie er der Seele angeglichen ist, darf er nicht auf der gleichen Stufe wie der

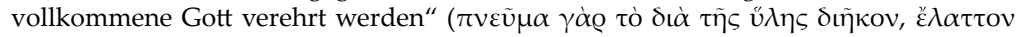

aufgrund seines transzendenten Gottesbildes ablehnen muss. Vgl. Chrysipp, SVF II 416: "der alles durchdringende Geist, von dem alles zusammengehalten und verwaltet wird" ( Pohlenz 1972, 42); Ps.-Aristot. Mund. 5 396b28f.: „die alles durchdringende Kraft“ (í $\delta \dot{\alpha}$

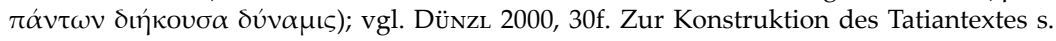
TRELENBERg 2012, 94, Anm. 50.

${ }^{16}$ Aëtios bei Stobaios I (37,4-15 Wachsmuth / Hense); Ps.-Plut. Plac. philos. 1,7 (881E LACHENAUD) - hierin liegt ein Hinweis, dass das philosophische Wissen Tatians nicht auf einem grundlegenden Studium einzelner Lehren beruht, sondern allgemeinem Wissensstandard entsprach, der in einschlägigen Lehrbüchern dargestellt wurde.

${ }^{17}$ Der Begriff „Vater“ findet sich häufig auch bei Platon: Tim. 28c 3; 37c7; 41a7; 42e6f.; Pol. $273 b 2$ u.ö.

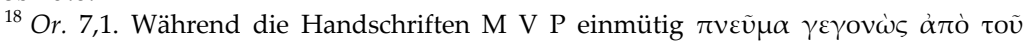

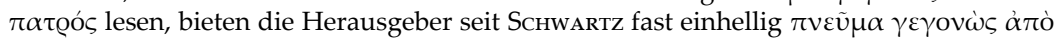

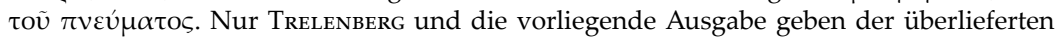
Lesart den Vorzug; vgl. DüNZL 2000, 60, Anm. 41.

${ }^{19}$ Or. 5,6: „Und wie der Logos, nachdem er im Anfang hervorgebracht worden war, selbst wiederum unsere Schöpfung durch sich selbst hervorbrachte, indem er die Mate-

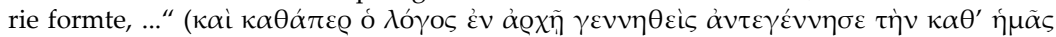

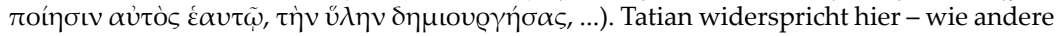
Christen auch - der aristotelischen und platonischen Lehre, dass die Materie unentstanden ist. Damit wäre sie Gott gleichrangig, was der oben postulierten Transzendenz gegenüber der Materie grundlegend widerspricht. Dass die Materie entstanden sei, lehren einige Pythagoreer und spätere Neuplatoniker; vgl. dazu DörRie / Baltes 1996, 473f. 517-523; dies. 1998, 468f. 473. 


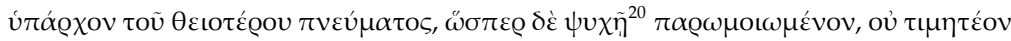
$\dot{\varepsilon} \pi^{\prime}$ ľōৎ $\left.\tau \tilde{\omega} \tau \varepsilon \lambda \varepsilon \dot{c} \omega \theta \varepsilon \tilde{\omega}, O r .4,4\right)$.

Diese grundsätzliche Dichotomie von Schöpfer und Geschöpf drückt sich also bei Tatian in der Lehre von den zwei Arten von "Geistern" $(\pi \nu \varepsilon \dot{v} \mu \alpha \tau \alpha)$ aus, von denen das eine der göttliche Geist und das andere der als Seele bezeichnete und an die Materie gebundene Geist ist: ${ }^{21}$

\begin{abstract}
„Zwei unterschiedliche Arten von Geistern kennen wir, von denen die eine ,Seele' genannt wird, die andere aber größer als die Seele ist und Gottes Bild und Gleichnis“ (סúo

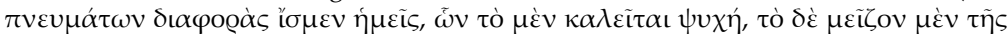

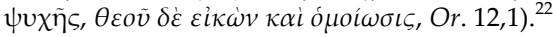

Hier wird nun interessanterweise der ,vornehmere' Geist im Rückgriff auf die biblische Schöpfungsgeschichte (Gen 1,26) als „Bild Gottes und Annäherung an ihn" bezeichnet. Es ist also deutlich in einem Zusammenhang, in dem von den Geistern allgemein geredet wird, dennoch speziell der menschliche Geist, der allein als Seele bezeichnet wird, im Blick. Die Seelenlehre ist von Anfang an anthropozentrisch entworfen, und die Lehre von den anderen geschöpflichen Geistern ist von vornherein auf die Lehre von der Menschenseele hingeordnet. Deswegen werden die anderen an die Materie gebundenen Geister auch nicht als Seelen bezeichnet, sondern nur als seelenähnlich $(\mathrm{Or} .4,4)$ angesehen. Denn es ist eindeutig klar, dass für Tatian allein der Christ, d.h. der Mensch ante lapsum, „Bild und Gleichnis Gottes" ist (Or. 15,3).

Wird nun der höhere Geist, der auch als Heiliger Geist (Or. 15,1), göttlicher Geist (Or. 13,3), himmlischer Geist (Or. 16,7), vollkommener Geist $(O r .20,2)$ oder als der Geist, der Diener des Gottes ist, der gelitten hat $\left(\right.$ Or. 13,6), ${ }^{23}$ bezeichnet wird, einerseits eindeutig als selbst göttlich qua-

\footnotetext{
${ }^{20}$ Während die Handschriften einhellig $\psi v x \tilde{\eta}$ lesen, konjiziert Marcovich mit WiLAmo-

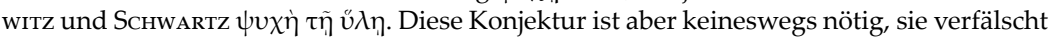
vielmehr den Sinn des Textes.

${ }^{21}$ Dass die Substanz der Seele Pneuma ist, kann als allgemein stoische Lehre angesehen werden; vgl. hierzu Diog. Laert. VII 157: „Zenon von Kition und Antipatros in ihren Werken ,Über die Seele' sowie Poseidonios (haben gelehrt), dass die Seele warmes Pneuma ( $\pi v \varepsilon \tilde{v} \mu \alpha$ ع́v $\theta \varepsilon Q \mu o v)$ sei; durch dieses sind wir lebendig und von diesem werden wir bewegt"; s. auch SVF I 136. 140. 145f.; II 773-787. Schon die Vorsokratiker haben die Seele als „Luft“ (ảń) oder Pneuma bezeichnet; vgl. Anaximenes, 13 B 2 DK; Diogenes von Apollonia, 46 A 19. 20 DK.

${ }^{22}$ Auch Marius Victorinus kennt den Gegensatz von "göttlicher / himmlischer Seele“ (anima divina / caelestis) und "materieller Seele" (anima hylica): Adv. Arium I b 62f. (97,5-26); III 1 (114,1-3 Locher). Vgl. auch Origenes, Princ. III 4,2 (267,1f. Kоетschau): Die Seele sei "gewissermaßen in der Mitte ... zwischen dem Fleisch und dem Geist" (media quaedam ... inter carnem et spiritum).

${ }^{23}$ Diese Bezeichnung des Geistes spricht eindeutig dagegen, ihn mit dem göttlichen Logos zu identifzieren, denn der Gott, der gelitten hat, dürfte doch wohl der inkarnierte Logos sein, als dessen Diener hier der Heilige Geist bezeichnet wird. Da Tatian eindeutig Vater und Logos voneinander unterscheidet und auch den Heiligen Geist vom Logos abhebt,
} 
lifiziert, ${ }^{24}$ so soll er andererseits den Menschen als Ebenbild Gottes kennzeichnen. In der Anthropologie und Seelenlehre wird also der Zusammenhang der beiden Arten des Pneuma thematisiert; denn im ursprünglichen Menschen waren nach Tatian beide vorhanden und harmonisch aufeinander bezogen, und sie sorgten dafür, dass der Mensch in der wohlgeordneten Schöpfung Gottes eine Mittelstellung einnehmen konnte, indem er einerseits mit der Materie verbunden, andererseits ihr aber auch überlegen war $($ Or. 12,1).

Diese Mittelstellung der Seele zwischen dem Intelligiblen (Gott) und der sichtbaren Welt (Materie) war eine auf Platons Darstellung der Seelenmischung ${ }^{25}$ zurückgehende Überzeugung der Platoniker. ${ }^{26}$ Vergleichbar ist u.a. die Lehre Plutarchs, wonach die Seele eine Mittelstellung einnimmt zwischen dem Nus (voũs) und dem Körper. Plutarch sieht den Nus nicht als einen Teil der Seele, so dass der Mensch als aus drei Teilen bestehend gesehen wird: Körper, Seele, Nus, ${ }^{27}$ wobei der Nus in dem Maße besser und göttlicher ist als die Seele, wie die Seele dem Körper überlegen ist. ${ }^{28}$ Ähnlich besteht auch für Marc Aurel der Mensch aus dem materiellen Leib, dem den Leib beseelenden Pneuma und dem Nus, der als das Hegemonikon den eigentlichen Wesenskern des Menschen ausmacht. ${ }^{29}$

Für Tatian allerdings besteht die Mittelposition des Menschen zwischen materieller und geistiger Welt nicht in seiner Seelennatur als solcher, sondern in der idealen Verbindung der Seele mit dem Heiligen Geist. Als materielles Naturwesen besitzt der Mensch nämlich nur einen „materiellen Geist" ( $\pi v \varepsilon \tilde{v} \mu \alpha$ v́lıкóv, Or. 12,3), der derselbe ist wie in allen anderen Geschöpfen, seien es Gestirne, Engel, Pflanzen, Gewässser, Tiere (Or. 12,8) oder auch Dämonen (Or. 12,5). Den göttlichen Geist dagegen hat der Mensch offenbar nicht mehr naturhaft, sondern von außen erhalten; denn er macht den Menschen zwar zum vollkommenen Geschöpf, ist aber nicht

kann man bei ihm eher von einem trinitarischen Ansatz der Gotteslehre ausgehen, die er aber nicht weiter expliziert.

${ }^{24} \mathrm{Vgl}$. TReLenberg 2012, $41 \mathrm{f}$.

${ }^{25}$ Plat. Tim. 35a1-b3.

${ }^{26}$ Vgl. Chalc. Comm. 29 (79,6-24 WAszink); Procl. In Plat. Tim. II (153,15-154,9 DienL); dazu DöRrie / BaLtes 2002/1, 201-217.

${ }^{27}$ Plut. De facie 28 (943Af.).

${ }^{28}$ Zum Ganzen vgl. DöRrIE / BALTEs 2002/1, 203-213. Insgesamt scheint die Dichotomie der tatianischen Seelenlehre deutliche Anklänge an die Lehre des Plutarch von der Weltseele zu haben, die vom Demiurgen aus zwei Teilen zusammengesetzt wurde: der mit der Materie verhafteten alogischen Seele als negativem Prinzip und der ordnenden Vernunft als dem göttlichen Teil; vgl. M. Baltes, "La dottrina dell'anima in Plutarco“, Elenchos 21 (2000) [245-270] 248-253 (= M. Baltes, „Plutarchs Lehre von der Seele“, in: M.-L. LakmanN (Hg.), EПINOHMATA. Kleine Schriften zur antiken Philosophie und homerischen Dichtung. Beiträge zur Altertumskunde 221 [München 2005] [77-100] 79-84).

${ }^{29}$ Marc. Aurel. 12,3,1: „Drei Teile sind es, aus denen du bestehst: das Körperliche, das

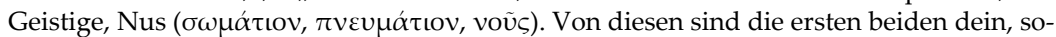
weit du für sie sorgen musst, das Dritte aber ist allein wirklich dein." 
Teil seiner natürlichen Ausstattung, sondern verlierbar, wie der Sündenfall offenbar macht. Da die menschliche Seele - wie auch die Engelwesen, die noch vor dem Menschen geschaffen worden sind - frei ist $(O r .7,2)$ und sie diese Freiheit im Anfang zum Abfall von Gott genutzt hat, hat der höhere Geist die Seele verlassen, so dass der Mensch seine Gottesebenbildlichkeit verloren hat. Er ist somit von einem „pneumatischen“ zu einem „psychischen" Wesen geworden, d.h. er hat seine Verbindung mit dem göttlichen Geist eingebüßt und ist als solcher nur noch ein psychischer Mensch und daher nicht mehr in der Lage, Gott angemessen zu erkennen. In diesem Zustand, d.h. wenn die Seele vom göttlichen Geist verlassen ist, wird er das Ziel dämonischer Versuchungen, die die Seele an die Materie fesseln und so beherrschen können. ${ }^{30}$ Tatian kann diesen Fall auch in Anlehnung an den platonischen Mythos des Phaidros ausdrücken: Da der Heilige Geist das "Gefieder" der Seele sei und diese ihn nach dem Fall verloren habe, sei sie nun an die Erde gebunden und habe den Kontakt zur überirdischen Wirklichkeit eingebüßt. ${ }^{31}$ Dass die Seele in ihrem vom Geist verlassenen Zustand ihre Mittelstellung zwischen materieller und göttlicher Wirklichkeit nicht mehr inne hat, macht Tatian auch dadurch deutlich, dass er davon sprechen kann, die Seele sei an sich Finsternis und nicht Licht (Or. $13,2)$.

Wie die Gottesebenbildlichkeit des Menschen sich zu seiner physischen Konstitution als Naturwesen verhält, hat Tatian in Or. 15,3-5 angedeutet: Zunächst lehnt er die auf Aristoteles zurückgehende Definition des Men-

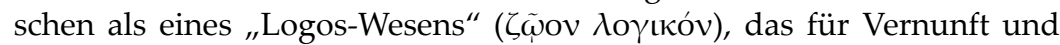
Erkenntnis zugänglich ist, ab, weil dadurch die Sonderstellung des Menschen im All nicht angemessen zum Ausdruck komme. Vielmehr lasse sich ja zeigen, dass für die Vertreter dieser Lehre auch die sogenannten verstandeslosen Wesen Anteil an Vernunft und Erkenntnis hätten. ${ }^{32}$ Einer solchen philosophischen Definition des Menschen stellt der christliche Denker dann dessen Gottesebenbildlichkeit entgegen, die den Menschen angemessener bestimme, da sie ausschließlich auf diesen zutreffe. Die Gottesebenbildlichkeit wird nun aber nicht als neutrale und allgemein anthropologische und naturhafte Eigenschaft verstanden, die dem Menschen in

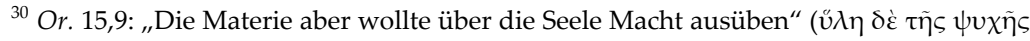

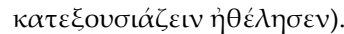

${ }^{31}$ Or. 20,2; vgl. Plat. Phaidr. 246a6-248e3.

${ }^{32}$ Hiermit greift Tatian interessanterweise inhaltlich eine Passage auf, die sich auch bei Sext. Emp. Pyrrh. hyp. II 26 niedergeschlagen zu haben scheint: „Andere aber sagen, der Mensch sei ein vernunftbegabtes und sterbliches Lebewesen, fähig zur Aufnahme von Ver-

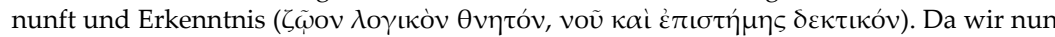
in dem ersten Argument für die Urteilsenthaltung gezeigt haben, dass es keine unvernünftigen Lebewesen gibt, sondern alle sowohl des Verstandes als auch der Erkenntnis fähig sind, jedenfalls nach ihren eigenen Aussagen, so wissen wir nicht, was sie damit überhaupt sagen wollen“; vgl. auch II 211 und Math. VII 269.
} 
jedem Falle zukomme, sondern als eine normative und streng auf das Gottesverhältnis des Menschen bezogene Größe: Nicht der Mensch, der sich wie ein Tier verhält, ist Gottes Abbild und Gleichnis, sondern nur derjenige, der sich über sein Menschsein hinaus erhoben hat und auf Gott hin ausgerichtet lebt. ${ }^{33}$

Damit definiert Tatian die Gottesebenbildlichkeit eindeutig relational und nicht physisch bzw. substanzhaft ontologisch. Für ihn ist die Sonderstellung des Menschen durch sein faktisches Verhalten bestimmt, nicht durch eine festgelegte Naturanlage. Dies verdeutlicht er noch einmal besonders, wenn er anschließend darlegen will, „,welcher Art und was das

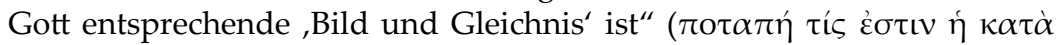

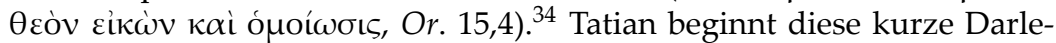
gung mit der Unterscheidung von Vergleichbarkeit und Unvergleichbarkeit: „Das, was unvergleichbar ist, ist nichts anderes als das Seiende selbst,

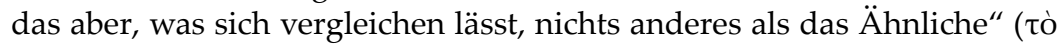

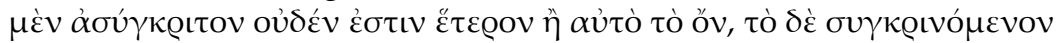

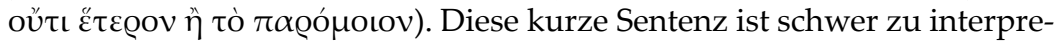
tieren: Ist sie eine allgemeine Aussage über das Seiende, oder ist mit dem Seienden a priori Gott selbst gemeint? ${ }^{35}$ Der Text lässt wegen seiner Kürze eine eindeutige Antwort nicht zu. Deutlich ist jedenfalls, dass in diesem Satz davon die Rede ist, dass nur das Ähnliche an den Dingen und nicht das Seiende verglichen werden kann. Nun sind aber Gott und der Mensch einander zunächst in ihrem Sein sehr unähnlich: Der vollkommene Gott

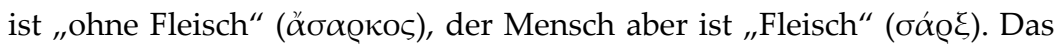
Fleisch steht in enger Zusammengehörigkeit mit der Seele, da das „Band

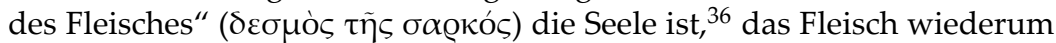

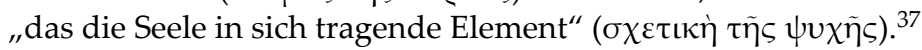

Interessanterweise identifiziert Tatian weder diese anthropologische Zusammensetzung noch die Seele allein direkt mit der Gottesebenbild-

\footnotetext{
${ }^{33}$ Dass der Mensch als Seele zwischen Gott und Tier steht und sich zwischen den entsprechenden Lebensweisen zu entscheiden hat, ist ebenfalls stoisches Allgemeingut; vgl. Pohlenz 1978, 288f.; ders. 1972, 114 mit den Belegen.

${ }^{34}$ Tatian verweist in diesem Zusammenhang auf eine eigene Schrift „,̈̈ber Tiere“, in der er sich über die hier angesprochenen Probleme extensiver geäußert haben will. Eine solche Abhandlung, die sich nicht erhalten hat, kann aber als ein Indiz dafür gelten, dass sich unser Autor nicht nur im Vorübergehen über dieses wissenschaftliche Thema geäußert hat, sondern auch über tiefere und ausgearbeitetere Lehren zum Verhältnis von Mensch und Tier verfügt, als er sie in seiner Oratio anzureißen vermag.

${ }^{35}$ Tò őv („,das Seiende“) war nach Platon (Tim. 27d6) das höchste Prinzip, nach Ex 3,14 spricht Gott von sich als ó öv („,der Seiende“). Vgl. Elze 1960, 66.

${ }^{36}$ Die Seele als Band des Körpers findet sich oftmals bei den (Mittel-)Platonikern; vgl. z.B. Alkinoos, Didasc.14 (170,4-9 WhitTAKer / Louis) über die Weltseele als Band des Kosmos; vgl. DörRIe / BaLtes 1996, 322; dies. 2002/1, 147. 302.

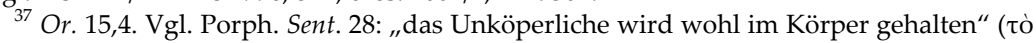

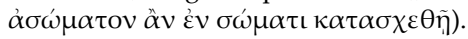


lichkeit, sondern eine bestimmte Haltung dieses Leib-Seele-Gebildes wird als Voraussetzung für die Einwohnung des göttlichen Geistes beschrieben: Wenn diese Zusammensetzung aus Fleisch und Seele sich so verhält, dass es als Gottes Tempel geeignet erscheint, dann werde Gott durch seinen Gesandten, den Geist, darin wohnen; wenn der Mensch allerdings keine solche Wohnung darstellt, dann sei er den Tieren nicht wesentlich überlegen, sondern führe ein ähnliches Leben wie diese und sei daher auch kein Gleichnis Gottes. Die Gottebenbildlichkeit ist also keine Eigenschaft des Menschen als solchen, sondern wird zum einen durch seine Ausrichtung auf Gott, ${ }^{38}$ zum anderen durch die Einwohnung des Heiligen Geistes in ihm bestimmt, die durch diese Ausrichtung ermöglicht wird. ${ }^{39}$

Diese Doppelung von menschlicher Prädisposition zur Aufnahme des Heiligen Geistes, der sich von den sündigen Menschen trennt, auf der einen Seite und der dann gewährten Wiedervereinigung des Menschen mit diesem Geist auf der anderen Seite ist für die Vorstellung von der Gottesebenbildlichkeit bei Tatian offenbar charakteristisch. Daher legt er in diesem Zusammenhang großen Wert auf die Feststellung, dass die Seele nicht nur vor dem Sündenfall frei war, sondern es auch danach in gewissem Umfange geblieben ist. Denn daran hängt für ihn die Zurechnungsfähigkeit und damit auch die Schuldfähigkeit des Menschen, wenn er sich der Sünde hingibt $(O r .7,2)$. So betont Tatian, dass der Mensch, da er sich aus freien Stücken von Gott abgewandt und den bösen Mächten unterworfen hat, auch die Möglichkeit besitzt, wieder zu seinem ursprünglichen Zustand zurückzustreben (Or. 11,4; 20,2-4). Zum anderen kann allein die Freiheit

\footnotetext{
${ }^{38}$ Die "Angleichung an Gott" (ó $\mu$ oí $\left.\omega \sigma \iota \varsigma, \theta \varepsilon \tilde{\omega}\right)$ war ein wesentliches Ziel platonischer Ethik: Nach Areios Didymos (bei Stobaios II [49,8f. Wachsmuth / Hense]) hat schon Pythagoras diese Lehre begründet. Platon sagt an der zentralen Stelle im Theaitetos (176b1f.),

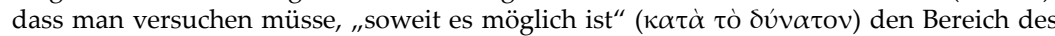
Sterblichen und Schlechten zu verlassen und nach oben, d.h. zu den Göttern zu fliehen,

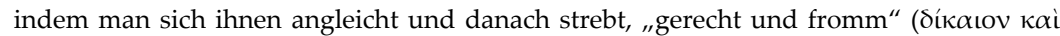
ő $\theta \varepsilon \tilde{\omega}$ eine der Definitionen der Philosophie. Vgl. Dörrie / Baltes 1996, Nr. 102 mit Kommentar; H. Merki, OMOI $\Omega \Sigma I \Sigma \Theta E \Omega$. Von der platonischen Angleichung an Gott zur Gottähnlichkeit bei Gregor von Nyssa. Paradosis. Beiträge zur altchristlichen Literatur und Theologie 7 (Freiburg [Schweiz] 1952) 1-7.

${ }^{39}$ Vergleichbar, aber zugleich deutlich anders akzentuiert, ist vor allem Philon von Alexandria, der den oberen Teil der Seele, den er Vernunft nennt (Opif. 66; 69), als das Abbild Gottes bezeichnet. Diesen Teil, der für ihn die „Seele der Seele“ ist, nennt er oftmals göttlich oder gottähnlich oder auch „Gott auf Erden“ (ebd. 66). Und für diese Seele, die „von

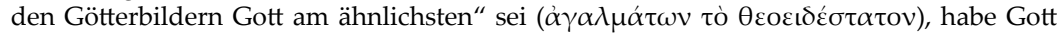
die menschengestaltige Figur als Haus oder heiligen Tempel geschaffen (ebd. 137). Vgl. D. T. Runia, Philo of Alexandria and the Timaeus of Plato. Philosophia Antiqua 44 (Leiden 1986) 331-340; H. MERKI, ,"Ebenbildlichkeit“, RAC 4 (1959) [458-479] 463. Während bei Philon die höhere Seele im Leib als Tempel wohnend dargestellt wird, wohnt bei Tatian der göttliche Geist in der auf Gott ausgerichteten leib-seelischen Einheit des geretteten Menschen.
} 
der Seele und der anderen materiellen Geistwesen den sündigen Zustand des Menschen in der gegenwärtigen Welt erklären, ohne Gott selbst dafür verantwortlich machen zu müssen (Theodizee).

So ergibt sich für das Denken Tatians die Aporie, dass er auf der einen Seite an der Freiheit des Menschen festhalten möchte, auf der anderen Seite aber lehrt, dass die menschliche Seele als solche nicht Licht, sondern Finsternis ist. Diese pessimistische Anthropologie, die sicher der christlichen Erlösungsvorstellung ${ }^{40}$ geschuldet ist, lässt eigentlich nicht $\mathrm{zu}$, dass der Mensch von sich aus von der Finsternis zum Licht strebt. Daher kann Tatian seinen strengen Dualismus in der Pneumalehre nicht wirklich durchhalten, sondern muss einen Rest von höherer Geistigkeit auch im gefallenen Menschen postulieren. Er tut dies, indem er die äußerst wirkungsvolle Lehre von einem „Funken“ oder Überbleibsel der ursprünglichen Gottes-

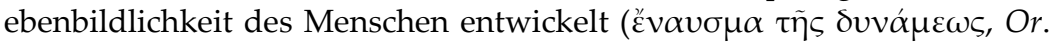
13,4).

In dieser Formulierung könnte man eine Analogie zu dem logos spermatikos der stoischen Lehre erblicken, ${ }^{41}$ nach der der die Welt durchwaltende Logos keimhaft in allen vernunfthaften Lebewesen vorhanden ist und sie befähigt, die Tugend zu erlangen. ${ }^{42}$ Allerdings ist auch diese Vorstellung bei Tatian eigentümlich gebrochen. Denn die Lehre vom Rest einer göttlichen Kraft im Menschen wird bei ihm gerade nicht dazu genutzt, um die Möglichkeit der Wahrheitserkenntnis des Menschen zu begründen, sondern dient dazu, den menschlichen Irrtum verständlich zu machen: Der Funken göttlicher Kraft befähigt den Menschen zwar, nach dem Göttlichen zu suchen, führt aber, weil der Mensch die Verbindung mit dem Geist verloren hat, gerade dazu, dass der Mensch, von den Dämonen getäuscht, die Erkenntnis des wahren Gottes verfehlt und der Verehrung der falschen Götter verfällt (Or. 13,4).

Der tiefere Grund für den Dualismus im Pneumabegriff des Tatian wird in seiner Polemik gegen Zenon als Archegeten der Stoa deutlich sichtbar: Zenon wird nicht nur wegen seiner Lehre von der ewigen Wiederkehr aller Dinge und Personen im ewigen Kreislauf der Welten des Öfteren angegrif-

\footnotetext{
${ }^{40}$ Vgl. H. Strutwolf, ,',Novitas Evangelii'. Die Grundfrage der christlichen Gnosis und die Funktion der gnostischen Systeme", in: U. Irrgang / W. Baum (Hg.), Die Wahrheit meiner Gewissheit suchen. Theologie vor dem Forum der Wirklichkeit (Würzburg 2012) 487-511.

${ }^{41}$ So verwendet Clem. Alex. Paed. II 1,18,1 diesen Begriff, um damit die wahre Lehre Platons, die er von der hebräischen Philosophie übernommen habe, zu erklären. In Protr.

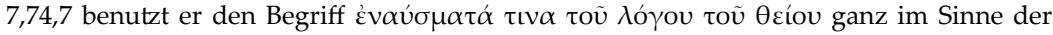
stoischen logoi spermatikoi.

${ }^{42}$ Siehe SVF I 102; II 780. 986. 1029; PoHLEnz 1978, 78f. 123; ders. 1972, 71. Es erinnert aber auch an die Lehre Platons, der in Leges (906a8-b3) sagt, dass der Mensch gerettet werde

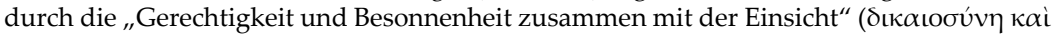

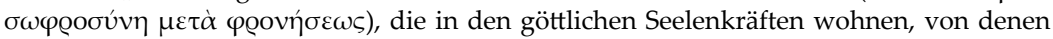
aber auch ein kleiner Teil noch in uns gesehen werden kann.
} 
fen, ${ }^{43}$ sondern auch gerade wegen seiner Pneumalehre, die nach Tatian dazu führt, dass laut Zenon Gott „,als ein Schöpfer des Schlechten“ befunden werden wird, ,da er in Kloaken, Würmern und Unholden seine Wohnstatt nimmt" $(O r .3,3)$. Damit wendet sich Tatian ausdrücklich gegen den stoischen Monismus, nach dem das Pneuma mit dem Weltgeist (als Pneuma und Feuer aufgefasst) gleichen Wesens ist und die Welt von der höchsten bis zur niedrigsten Stufe durchwaltet. ${ }^{44}$

Interessanterweise hat schon Poseidonios den eigentlich monolithischen Pneumabegriff der Stoa platonisierend aufgebrochen, indem er einen oberen Seelenteil von einem niederen unterschieden und beide fast dualistisch einander gegenübergestellt hat. ${ }^{45}$ So kann er davon sprechen, „der Mensch solle seinem oberen Seelenteil folgen, der göttlich ist und glei-

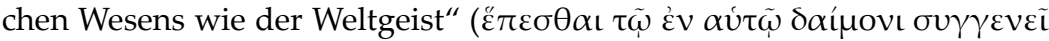

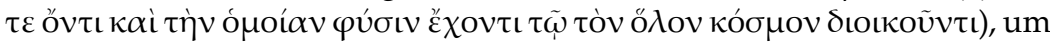
gut zu leben, während er, wenn er dem niederen Seelenteil folgt, seinem

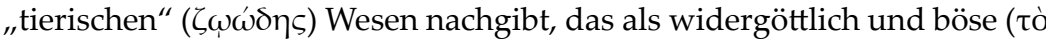

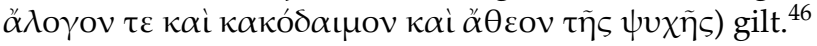

Dieser platonisch-stoische Pneumabegriff wird nun bei Tatian augenscheinlich nochmals unter Einfluss der strengen Unterscheidung von Schöpfer und Geschöpf weiter dualisiert.

Es ist sicher kein Zufall, dass die Lehre von den zwei Pneumata ihre nächste Entsprechung im Werk Philons von Alexandria hat, der selbst von Poseidonios beeinflusst ist. In seiner Allegorese von Gen 2,777 ringt Philon mit dem anthropomorphen Bild von der Schöpfung des Menschen durch Gott. Da bei ihm Gott selbst keinen direkten Kontakt mit der Materie haben kann, sieht er sich genötigt, den aus Lehm geschaffenen Menschen nicht für den materiell-leiblichen Menschen zu halten, sondern zu betonen, dass der aus Lehm geschaffene Mensch, in den Gott seinen Lebensgeist einhaucht, mit dem menschlichen Nus gleichzusetzen ist, der dazu bestimmt ist, in einen Leib einzugehen, aber noch nicht in einen solchen eingetre-

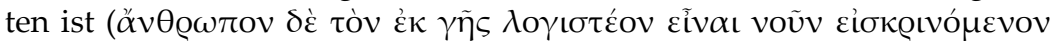

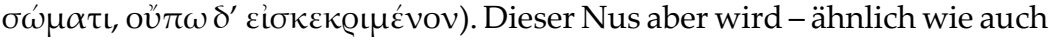

\footnotetext{
${ }^{43}$ Siehe oben, S. 226.

${ }^{44}$ Stobaios I (37,23-38,3 Wachsmuth / Hense); vgl. Pohlenz 1978, $229 f$.

${ }^{45}$ Poseidonios bei Tertullian, De an. 14 = Fr. 147 Edelstein / Kidd = Fr. 396 Theiler. Vgl. F. Rüsche, Das Seelenpneuma. Seine Entwicklung von der Hauchseele zur Geistseele. Ein Beitrag zur Geschichte der antiken Pneumalehre. Studien zur Geschichte und Kultur des Altertums 18,3 (New York 1933; Nachdr. Paderborn 1968) 18.

${ }^{46}$ Poseidonios bei Galen, Plac. Hipp. Plat. V 6 (326,19-27 de LACY) = Fr. 187,3-13 EdeLSTEIN / KIDD = Fr. $417(448,15-449,9)$ THEILER.

47 „Und Gott formte den Menschen, indem er Erde von dem Boden nahm, und blies in sein Gesicht den Lebensatem, und es wurde der Mensch zu einem lebendigen Wesen"

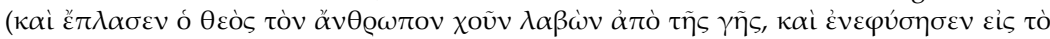

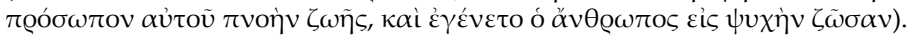




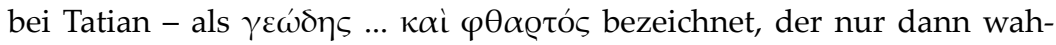
res Leben erlangt, wenn er mit dem göttlichen Geist verbunden wird. Erst durch die Einhauchung des göttlichen Geistes wird der menschliche Nus

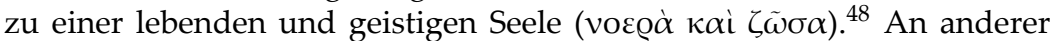
Stelle bezeichnet Philon diesen menschlichen Nus auch als $\pi v \varepsilon \tilde{v} \mu \alpha,{ }^{49}$ wodurch die Nähe Tatians zur philonischen Geistvorstellung noch deutlicher werden kann.

\section{Die Unsterblichkeit der Seele}

In ausdrücklichem Gegensatz zur platonischen Tradition (Or. 3,5; 25,3f.)

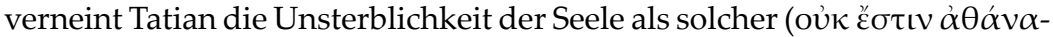

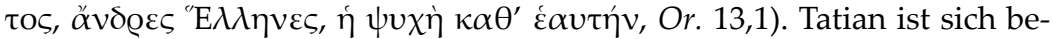
wusst, dass diese Lehre von Platon verfochten worden ist, ${ }^{50}$ wobei er von Pythagoras abhängig sein soll, ${ }^{51}$ während Aristoteles sie ausdrücklich abgelehnt habe. ${ }^{52}$

Für Aristoteles ist die Seele als die Form des Körpers oder als seine Entelechie nicht von diesem abzutrennen und daher mit dem Körper sterblich. Allein das höchste Seelenvermögen, d.h. der Geist, der „von außen“ in die Seele hineingekommen ist, ${ }^{53}$ ist unsterblich, aber er ist nicht mit der

\footnotetext{
${ }^{48}$ Philo, Leg. alleg. I 32.

${ }^{49}$ Philo, Gig. 23-28; vgl. H. Leisegang, Der heilige Geist. Das Wesen und Werden der mystisch-intuitiven Erkenntnis in der Philosophie und Religion der Griechen. I 1: Die vorchristlichen Anschauungen und Lehren vom ПNEYMA und der mystisch-intuitiven Erkenntnis (Leipzig 1919) 22f. Hier wird der Geist, der von Moses auf die Siebzig übergeht, eindeutig als göttlicher Geist vom individuellen Geist des Moses unterschieden. Wir haben es hier also mit einer Vorstellung vom endlichen menschlichen Geist zu tun, der vom göttlichen Geist inspiriert werden muss, um zur heilvollen Erkenntnis Gottes zu gelangen.

${ }^{50}$ Platon vertritt diese Lehre vor allem im Phaidon und im Phaidros (vgl. Phaidr. 245c5:

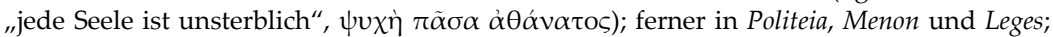
dazu Dörrie / Baltes 2002/1, 406f. 419.

${ }^{51}$ Or. 3,5. Die Vorstellung von der Abhängigkeit Platons von Pythagoras ist schon im antiken Platonismus verbreitet und auch von den christlichen Schriftstellern breit rezipiert worden.

Die Lehre von der Unsterblichkeit der Seele wurde auch dem Pythagorasschüler Pherekydes zugeschrieben (vgl. Or. 25,3; Cicero, Tusc. I 38f. [zitiert bei Trelenberg 2012, 92, Anm. 39]; ferner Hippolytos, Haer. VI 21,1 Marcovich), von anderen auch auf Empedokles zurückgeführt (Tertullian, De an. 54,1). Vgl. oben Anm. 8 und Dörrie / Baltes 2002/1, 151. 406f. Nach Iust. Mart. 1 Apol. 44,8f. ist diese Lehre eine Entfaltung von Denkanstößen, die auf Moses zurückgehen.

${ }^{52}$ Or. 25,3. Dass Aristoteles die Unsterblichkeit der Seele abgelehnt habe, ist - auch unter christlichen Autoren - doxographisches Allgemeingut; vgl. Hippolytos, Haer. I 20,4.6 Marcovich; Greg. Nyss. De an. et resurr. 8,2 (PG 46,52A).

${ }^{53} \mathrm{Vgl}$. Aristot. Gen. an. II 3,736b27-29: „Es bleibt daher nur, dass allein der Geist von außen hineinkommt und er allein göttlich ist; denn die körperliche Wirksamkeit hat keine

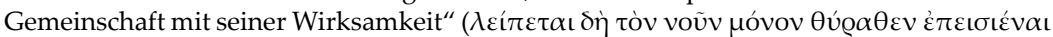

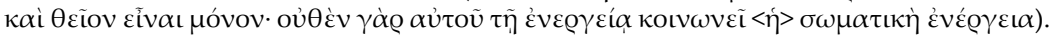


individuellen Person identisch, sondern überpersönlich. Daher kann bei Aristoteles nicht von der Unsterblichkeit des Individuums die Rede sein. Obgleich Tatian eine ebenso starke Verbundenheit der Seele mit dem Leib voraussetzt, so dass mit dem Tod des Leibes auch die Seele sich auflösen muss, ist dagegen für ihn der Geist auch postmortal in der Lage, die Seele erneut zu beleben und auch den Leib aufzuerwecken, so dass die im Tode untergegangene leib-seelisch-pneumatische Einheit für ewig wiederhergestellt wird.

Die Seele ist für Tatian also an und für sich betrachtet sterblich, vermag aber auch "die Unsterblichkeit zu erlangen“ ( $\alpha \pi \alpha \theta \alpha v \alpha \tau i \zeta \zeta \sigma \theta \alpha$ l, Or. $25,4)^{54}$ bzw. dem Sterben zu entgehen. ${ }^{55}$ Das Schicksal der Seele entscheidet sich dabei aufgrund ihres Verhaltens, d.h. in Folge ihrer Entscheidung für oder gegen die Wahrheit, die für Tatian mit der christlichen Botschaft identisch ist: ${ }^{56}$ Sie stirbt und löst sich zusammen mit dem Körper auf, wenn sie die Wahrheit nicht erkennt, oder sie stirbt nicht, wenn sie diese Wahrheit annimmt. Allerdings bedeutet der Tod der unwissenden Seele nicht zugleich, dass sie sich für alle Zeit ins Nichts verflüchtigt, wie auch andererseits das ewige Leben der erkennenden Seele keineswegs deren „physische Unsterblichkeit" bedeutet: Auch die den Tod der Unwissenheit sterbende und sich dadurch auflösende Seele wird nämlich nach Tatian Anteil an der Auferstehung haben, um im Endgericht bestraft und der ewigen Verdammnis überantwortet zu werden. ${ }^{57}$ Dagegen stirbt die Seele nicht, wenn sie die Erkenntnis erlangt hat, auch wenn sie sich zeitweilig auflösen wird $($ Or. 13,1).

Hier wird deutlich, dass Tatian mit einer terminologischen Unterscheidung von "Sterben“ und „Auflösung“ operiert: ${ }^{58}$ Es lässt sich nämlich beobachten, dass Tatian von der Auflösung und vom Tod der unwissenden Seele spricht, während er eindeutig herausstellt, dass die wissende Seele sich zwar auflöst, aber nicht stirbt. Während also jede Seele sich auflösen muss, müssen nicht alle Seelen sterben. Der Begriff des Sterbens scheint also bei Tatian auf den geistigen Tod der Seele beschränkt zu sein, weil ja

\footnotetext{
${ }^{54} \mathrm{Zu}$ diesem Begriff vgl. z.B. Philo, Conf. ling. 149.

${ }^{55}$ Or. 13,1: ,... sondern sterblich; doch ist die gleiche in der Lage, auch nicht zu sterben"

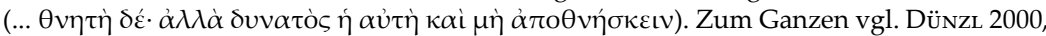
$242 \mathrm{f}$.

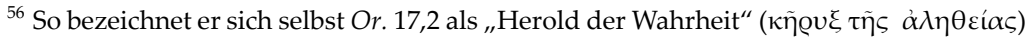
und sagt Or. 19,2, dass Justin die Wahrheit verkündigt habe.

${ }^{57}$ Wie Or. 6,1 zeigen kann, besteht für Tatian - wie für die meisten anderen Apologeten - die Notwendigkeit der allgemeinen Auferstehung hauptsächlich im Zusammenhang mit

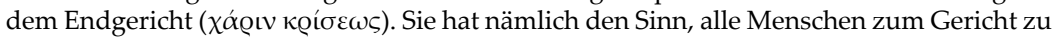
versammeln.

${ }^{58}$ Trelenberg 2012, 121, Anm. 158 spricht davon, dass Tatian den „irdischen und den geistlichen Tod" unterscheide.
} 
gerade die Möglichkeit bestehen soll, dass die gläubigen Seelen dem Todesschicksal entgehen. ${ }^{59}$

Die Leugnung der naturhaften Unsterblichkeit der Seele ist bei Tatian die logische Konsequenz seines dualistischen Pneumabegriffs, in den bei ihm die Seelenlehre eingebunden ist. Hat die Seele nämlich nichts Göttliches an sich, sondern ist, sofern sie für sich selbst und getrennt vom göttlichen Geist betrachtet wird, Finsternis und gerade nicht Licht, ${ }^{60}$ so kommt ihr auch die Unsterblichkeit nicht als wesensmäßige Eigenschaft, sondern nur in ihrer Verbindung mit dem göttlichen Licht zu, das in Anlehnung an das Johannesevangelium ${ }^{61}$ mit dem göttlichen Logos gleichgesetzt werden kann. ${ }^{62}$ Daher kann Tatian in diesem Zusammenhang davon sprechen, dass der Geist die Seele rettet und nicht umgekehrt. ${ }^{63}$ Die Seele bedarf also der Rettung, d.h. einer ihr von außen zukommenden Hilfe, um an der Unsterblichkeit teilzuhaben. Dies drückt Tatian an anderer Stelle auch so aus, dass er den Heiligen Geist als die Kraft bezeichnet, die den Seelen Unsterblichkeit verleiht. ${ }^{64}$ Daher gilt ihm der Mensch als ein „Abbild der

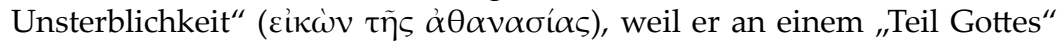
( $\theta \varepsilon$ cỗ $\mu$ oĩ $\alpha)$, seiner „Unvergänglichkeit“ ( $\alpha \varphi \theta \alpha \varrho \sigma i ́ \alpha)$, Anteil bekommen und dadurch auch die Unsterblichkeit erlangt hat $(O r .7,1) .{ }^{65}$ Diese Geist-

\footnotetext{
${ }^{59}$ Diese Deutung vertritt schon Kukula 1913, 41, Anm. 2 gegen Puech 1903, 70f. Dies erinnert nicht zufällig an die johanneische Vorstellung: „Wer an mich glaubt, wird leben, auch wenn er stirbt, und jeder, der lebt und an mich glaubt, wird in Ewigkeit nicht sterben"

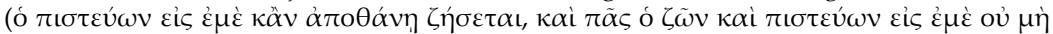

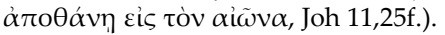

${ }^{60}$ Or. 13,2: „An und für sich nämlich ist sie Dunkelheit, und nichts in ihr ist Leuchtendes"

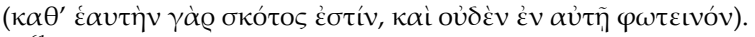

${ }^{61}$ Joh 1,5: „Und das Licht leuchtet in der Finsternis, und die Finsternis hat es nicht er-

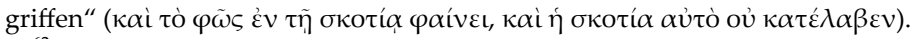

${ }^{62}$ Or. 13,2. Trelenberg 2012, 121, Anm. 159 weist zwar auf die Debatte zwischen T. BAARDA (,John 1,5 in the Oration and Diatessaron of Tatian. Concerning the Reading KATA $\Lambda$ AMBANEI“ , VigChr 47 [1993] 209-225) und J. MoINGT („La réception du prologue de Jean au Ile siècle", Recherches de science religieuse 83 [1995] 262f.) hin, nimmt aber inhaltlich dazu nicht Stellung. Während BAARDA davon ausgeht, dass Tatian hier bewusst auf Joh 1,5 zurückgreift und auch eine bewusste Textänderung vornimmt ( $\alpha \alpha \tau \alpha \lambda \alpha \mu \beta \alpha ́ v \varepsilon \iota$

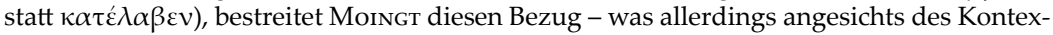
tes kaum begründet ist. Denn wenn Tatian hier das Licht, das in die Finsternis scheint, mit dem $\lambda$ ó $\gamma$ os gleichsetzt, dann ist die Nähe zur Aussage des Johannesprologs inhaltlich wie auch sprachlich so groß, dass von einer bewussten und für den Leser auch wahrnehmbaren Anspielung auf den johanneischen Kontext ausgegangen werden muss.

${ }^{63}$ Or. 13,2: „Denn die Seele rettet nicht selbst den Geist, sondern wird von ihm gerettet"

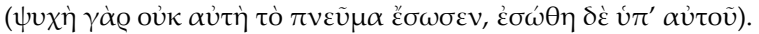

${ }^{64}$ Or. 16,4. Gesner, gefolgt von TreLenberg, emendiert den offenbar lakunösen Text der

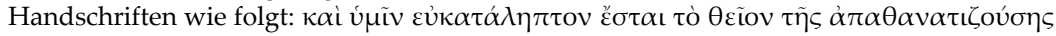

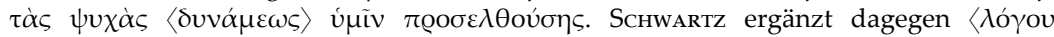
$\delta v v \alpha ́ \mu \varepsilon \omega \varsigma\rangle$, Marcovich $\langle\theta \varepsilon$ oṽ $\delta v v \alpha ́ \mu \varepsilon \omega \varsigma\rangle$. Was genau in der postulierten Lücke gestanden hat, lässt sich nicht mehr mit Sicherheit sagen, deutlich ist aber, dass von dem Heiligen Geist als der die Unsterblichkeit verleihenden Wesenheit die Rede ist.
}

${ }^{65} \mathrm{Vgl}$. Weish 2,23. 
teilhabe ist hier aber deutlich mit dem Einbrechen des göttlichen Logos in die Welt der Finsternis verbunden, als deren Teil auch die menschliche Seele in ihrem postlapsarischen Zustand aufgefasst wird (Or. 13,2), und somit ganz johanneisch verstanden.

Mag diese Vorstellung zunächst als strenger Dualismus erscheinen, so betont der Text gleich darauf erneut die Mittelstellung der menschlichen Seele zwischen Geist und Materie: Die Seele hat zwar, wenn sie vom Geist getrennt ist, ein Streben zur Materie und wird, wenn sie diesem Streben nachgibt, mit dem Fleisch sterben. Sie kann aber auch, wenn sie Gemeinschaft mit dem Heiligen Geist besitzt, nach oben aufsteigen und so das Leben gewinnen. Hierbei wird zwar wieder deutlich der Gegensatz von Seele und Geist betont, indem unterstrichen wird, die Seele stamme von unten, der Geist dagegen habe seine Wohnstatt oben (Or. 13,3), aber es ist zugleich deutlich, dass der Seele beide Seinsweisen offenstehen. Denn einerseits war die Seele vor dem Sündenfall mit dem Geist verbunden, wurde von ihm geleitet und hatte Anteil am göttlichen Sein (Or. 12,1; 13,3), andererseits hat die Seele diese Verbindung mit dem Göttlichen aus ei-

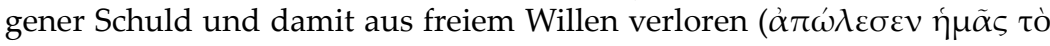
$\alpha$ $v \dot{\tau \varepsilon \xi o u ́ \sigma ı v, ~ O r . ~ 11,4) ~ u n d ~ k a n n ~ d a h e r, ~ s o ~ T a t i a n, ~ a u c h ~ w i e d e r ~ d u r c h ~ e i n e ~}$ Willensentscheidung in den ursprünglichen Zustand zurückstreben ${ }^{66}$

Da der Geist nur bei denen wieder einkehrt, die gerecht leben, und sich dann mit deren Seele verbindet (Or. 13,5), ist somit die freie Entscheidung des Menschen für das gute Leben eine Voraussetzung für den Geistempfang, der zur Erlösung führt. Man kann also bei Tatian eine auch sonst in der altkirchlichen Geistlehre nicht zu verleugnende synergistische Tendenz sehen. ${ }^{67}$ Die Seelen jedenfalls, die der Weisheit folgten, zogen dadurch dann auch den Geist an sich. Dieser Geist wird dabei interessanterweise als einer bezeichnet, der mit den Gläubigen irgendwie verwandt ist ( der Seele scheint nun einerseits der strengen, fast dualistischen Entgegensetzung von höherem Geist und menschlicher Seele zu widersprechen, wird aber andererseits noch dadurch unterstrichen, dass Tatian die Verbindung von Seele und Geist als eine ,Paargenossenschaft' ( $\sigma v \zeta v \gamma^{\prime} \alpha$, Or. 13,3; 15,1) bezeichnen kann, ${ }^{68}$ ein Begriff, der aus der gnostischen Vorstellungswelt u.a. der Valentinianer bekannt ist. Im Valentinianismus bezeichnet der Begriff einerseits die Paargenossenschaft der Äonen im Pleroma, die

\footnotetext{
${ }^{66}$ Or. 11,4: „Die Schlechtigkeit haben gerade wir ans Licht gebracht; die aber, die sie

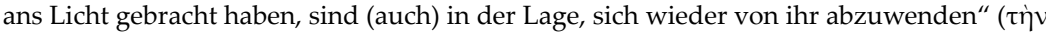

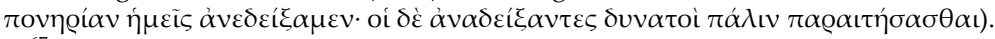

${ }^{67}$ Man vergleiche die ähnlichen Ausführungen des Origenes, Princ. I 3,5 (56,15-18 KовтsCHAU), der ebenfalls davon spricht, dass der Heilige Geist nur bei denen einkehrt, die sich schon bekehrt und gebessert haben.

${ }^{68}$ Vgl. DüNZL 2000, 289f.
} 
jeweils eine mann-weibliche Einheit bilden, die ihre Vollkommenheit ausmacht. ${ }^{69}$ Zugleich kann er auch die Beziehung des pneumatischen Samens $\mathrm{zu}$ seinem ebenfalls pneumatischen engelhaften Gegenstück bezeichnen, mit dem sich die Pneumatiker im Endheil vereinigen müssen, um ins Pleroma eingehen zu können. ${ }^{70}$ Bei Tatian bezeichnet dieser Begriff die in der Schöpfung fundierte und in der Eschatologie wiederhergestellte Verbindung von geschöpflichem und göttlichem Geist.

Dass für Tatian die Unsterblichkeit der Seele eine dieser an und für sich nicht zukommende, sondern nur in der Verbindung mit dem göttlichen Geist verliehene Eigenschaft ist, zeigt sich auch in Or. 16,1f.: Als Argument gegen die Ansicht, die Dämonen seien die Seelen der Verstorbenen, ${ }^{71}$ fragt er:

„Denn wie könnten sie tätig werden auch nach dem Tod? Es sei denn, dass als Lebender der Mensch unverständig und kraftlos wäre, man dann aber annähme, dass er, wenn er zum Leichnam geworden ist, Anteil an größerer Tatkraft erhielte. Aber zum einen ist dies nicht so - wie ich in anderen Darlegungen gezeigt habe -, und zum anderen fällt es schwer zu glauben, dass die unsterbliche Seele von den Gliedern des Körpers gehemmt sein und erst dann vernünftiger werden soll, wenn sie sich von ihm trennt."

In dieser Argumentation wird die sich durchsetzende Axiomatik der Psychologie des christlichen Autors deutlich. Für ihn ist offenbar von vornherein evident, dass Leib und menschliche Seele eine untrennbare, lebensnotwendige Einheit bilden, so dass eine Trennung der Seele vom Leib sie ihrer Möglichkeit zum Handeln berauben würde. So betont Tatian an anderer Stelle, dass der Mensch eine leib-seelische Einheit ist, so dass einerseits der Leib nicht ohne die Seele lebensfähig ist, andererseits aber auch die Seele ohne den Leib nicht in Erscheinung treten kann (Or. 15,2.6f.).

Daher ist für ihn die Verbindung der Seele mit dem Leib gegen platonische und auch stoische Vorstellungen keineswegs mit einer Kraftminderung oder Hemmung der Seele durch den Leib verbunden, ${ }^{72}$ sondern gibt ihr erst die Lebens- und Handlungsmöglichkeiten. Wenn Tatian im zweiten Teil dieser Aussage dann die schwer zu glaubende Ansicht anführt, die unsterbliche Seele werde durch die Verbindung mit den Körperglie-

\footnotetext{
${ }^{69}$ Vgl. Clem. Alex. Exc. Theod. 32,1 (117,14f. Stählin / Früchtel / Treu).

${ }^{70}$ Vgl. Clem. Alex. Exc. Theod. 64 (128,15-19 StäHLiN / Früchtel / Treu), wo das eschatologische Heil der mit ihren pneumatischen Engeln verbundenen Pneumatiker als die „ewigen Hochzeiten der Syzygien“ bezeichnet wird. Vgl. hierzu auch Strutwolf 1993, 183.

${ }^{71}$ So z.B. bei Apul. De deo Socr. 15,152-154.

${ }^{72}$ Die Platoniker sahen die Verbindung der Seele mit dem Körper überwiegend als einen Abstieg oder Fall bzw. Strafe an und werteten den Einfluss des materiellen Körpers auf die Seele als grundweg negativ; vgl. z.B. Alkinoos, Didasc. 25 (177,26-30 WhitTaKer / Louis); weitere Verweise bei Dörrie / BaLtes 2002/2, 404f. Interessanterweise gibt es seit Platon

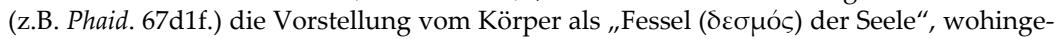

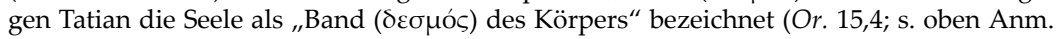
36). Auch die Stoa vertrat trotz ihres grundsätzlichen ,Materialismus' die Vorstellung, dass der irdische Leib die Seele behindere: vgl. bes. Poseidonios nach Cic. Div. I 110.
} 
dern gehemmt und komme erst durch die Trennung vom Leib wieder voll zu ihren Kräften, ${ }^{73}$ dann will er damit eine Konsequenz aus der gegnerischen Lehre ziehen, durch die deren Unsterblichkeitsglauben widerlegt wird: Wenn die Seele wirklich unsterblich und damit göttlich wäre, dann wäre es undenkbar, dass eine solche Seele so schwach sein sollte, dass der Körper sie schwächen und der Vernunft berauben könnte. ${ }^{74}$ In dieser Passage wird auf alle Fälle die Ansicht Tatians selbst deutlich, dass der Leib und seine Organe als solche die Seele nicht behindern und in ihrer Erkenntniskraft schmälern, sondern dies geschieht durch das Wirken der Sünde und der Dämonen (Or. 16,3).

Die wesentliche und untrennbare Zusammengehörigkeit von Seele und Leib drückt sich auch in der Ablehnung der pythagoreisch-platonischen Vorstellung von der Seelenwanderung aus, deren Grundlage und Ermöglichungsgrund, die Lehre von der Präexistenz einer unsterblichen und aus himmlischem Bereich herabgestiegenen Seele, Tatian ausdrücklich zurückweist: Für ihn stammt die Seele als innermaterielles Bewegungs- und Lebensprinzip von unten und keineswegs von oben. Da sie "von unten her

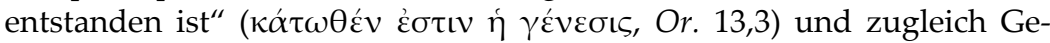
schöpf des göttlichen Logos ist, ist eine überweltliche Präexistenz der Seele ausgeschlossen. Die Seele ist vielmehr vom göttlichen Logos zusammen mit der Materie geformt worden, wie folgender Passus nahelegt:

\begin{abstract}
„Wie ich nämlich nicht war, bevor ich wurde, und daher (auch) nicht erkannte, wer ich war, sondern nur im Bestand der fleischlichen Materie vorhanden war, nachdem ich aber - der ich nicht von altersher bin - geworden bin, erst durch mein Werden den Glauben an meine Existenz habe, auf die gleiche Weise werde ich, nachdem ich geworden und durch den Tod nicht mehr bin und man mich dann auch erneut nicht mehr sieht, wiederum sein, wie ich, nicht von altersher entstanden, dann erst hervorgebracht wurde." (Or. 6,3)
\end{abstract}

Die Seele ist nicht einheitlich, sondern ,aus verschiedenen Teilen zusam-

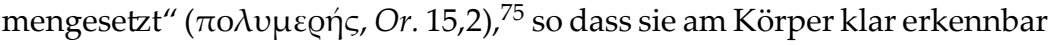
ist. Als solche, auf die verschiedenen Körperteile verteilte Seele ist sie auch nicht vom Körper abzutrennen (Or. 15,2). Diese enge Verbindung und Zusammengehörigkeit von Seele und Leib zeigt sich bei Tatian denn auch

\footnotetext{
${ }^{73}$ Die „Trennung der Seele vom Körper“ war den Platonikern nicht nur eine Definition des Sterbens, sondern gleichsam auch eine Definition und ein wesentliches Ziel der Philosophie. Es galt, die Seele von den negativen Einflüssen des Körpers zu befreien und wieder zu sich selbst zu führen - ähnlich der „Angleichung an Gott“; vgl. Dörrie / BaLtes 1996, 255.

74 Ähnlich argumentiert auch Tertullian, De an. 54 mit der von Platon angesetzten hohen Würde der Seele, die ein Vergessen auf Grund der Verbindung mit dem Körper eigentlich unmöglich machen sollte.

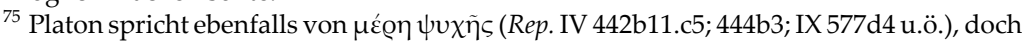
bezieht er dies auf die drei bekannten Seelenteile. Diese bilden zusammen wiederum eine Einheit. Andere, vor allem Aristoteles und die Stoiker, sprachen dagegen lieber von den

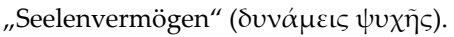


in seiner genuin jüdisch-christlichen Auferstehungshoffnung: Sowohl die Seele als auch der Leib erlangen im Endheil die Unsterblichkeit. Damit wird zum einen die christliche Vorstellung von der Auferstehung des Leibes gegen die platonische Lehre von der leiblosen Postexistenz der Seele verfochten, ${ }^{76}$ zum anderen auch die Seele durch ihre an und für sich bestehende Vergänglichkeit prinzipiell auf dieselbe Ebene wie der materielle Leib gestellt (Or. 25,4).

Die Unsterblichkeit der Vernunftseele ist Konsens in der platonischen Tradition. Ausgehend von Platon, Tim. 41c6-d3, wonach der Gott zur Erschaffung der Lebewesen den unsterblichen, göttlichen Teil beigibt, ${ }^{77}$ mit dem die jungen Götter den sterblichen Anteil verbinden sollen, war es überwiegende Meinung bei den mittelplatonischen Interpreten, dass damit der obere, vernünftige und der untere, unvernünftige Seelenteil gemeint seien. ${ }^{78}$ Hippolytos behauptet nun in seinem aus Doxographien geschöpften Bericht über die verschiedenen philosophischen Lehrmeinungen, dass es unter den Platonikern einen Dissens über die Unsterblichkeit der Seele gäbe: Während die einen sie als ungeworden und unsterblich, andere dagegen als geworden, aber durch den Willen Gottes als unsterblich ansähen, würden wiederum andere Platoniker sie als geworden und vergänglich bezeichnen. Letztere sollen sich für ihre Sondermeinung auf Tim. 41d4f. berufen haben, wonach die Seele aus dem Mischkrug stamme und daher geworden sei; und da alles, was geworden ist, auch vergänglich sei, ${ }^{79}$ müsse sie notwendigerweise auch wieder vergehen. ${ }^{80}$ Eine solche Ansicht lässt sich jedoch im genuin platonischen Kontext nicht nachweisen; ${ }^{81}$ die Platoniker lehren nach unseren Zeugnissen einmütig die Unsterblichkeit der vernünftigen Seele. ${ }^{82}$ Es gibt aber platonisierende gnostische Vorstellungskomplexe, die dieser Vorstellung, die Seele sei sterblich, entsprechen. ${ }^{83}$ Besonders nahe liegt hier die valentinianische Seelenlehre: Für einige Valentinianer war die Seele zwischen Materie und Geist gestellt: Während der Geist unsterblich und unvergänglich ist und die Materie nicht gerettet werden kann, „hat das Seelische (im Menschen) den freien Willen“ (

\footnotetext{
${ }^{76}$ Der Tod wurde ja gerade als die Trennung der Seele von dem Körper definiert; s. oben Anm. 73.

${ }^{77}$ Vgl. Or. 7,1: Der Mensch besitzt durch einen Anteil am Wesen Gottes die Unsterblichkeit.

${ }^{78}$ Attikos und Albinos bei Procl. In Plat. Tim. III 234,8-18 DieHL. Der obere Teil, der mit dem Nus gleichgesetzt wird, ist es auch, der sich den Göttern angleicht (ebd.) - vgl. Or. 7,1.

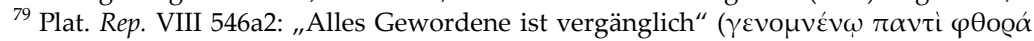

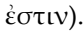

${ }^{80}$ Hippolytos, Haer. I 19,10 Marcovich.

${ }^{81}$ Vgl. Dörrie / Baltes 2002/1, 419, Anm. 74.

${ }^{82}$ Einen Dissens gab es lediglich hinsichtlich der Unsterblichkeit bzw. Sterblichkeit der unvernünftigen Seele; vgl. Dörrie / BALtes 2002/1, 406-437; 2002/2, 402.

${ }^{83}$ Vgl. Strutwolf 1993, 113.
} 
sterblich, wenn sie sich aber dem Geist angleicht, wird sie durch den Geist gerettet; wenn sie sich der Materie angleicht, wird sie mit ihr zugrunde gehen. ${ }^{84}$

Die Ansicht, dass die Seele an und für sich nicht unsterblich ist, teilt Tatian offenbar auch mit seinem Lehrer Justin. ${ }^{85}$ Dieser hat in seinem Dialog mit dem Juden Tryphon die Bestreitung der platonischen Lehre von der Unsterblichkeit jenem weisen alten Mann in den Mund gelegt, dem er selbst seine Bekehrung zum Christentum verdanken will: Der Alte argumentiert hier mit dem - auch von einigen Platonikern angenommenen ${ }^{86}$ - Gewordensein der Welt, die keine ewige und gottgleiche Existenz der Seelen zulasse, ${ }^{87}$ und der Justin des Dialogs lässt sich von dieser Argumentation bereitwillig überzeugen. ${ }^{88}$ Allerdings bedeutet das keineswegs, dass auch alle Seelen tatsächlich sterben werden, sondern vielmehr für das Gericht Gottes aufbewahrt werden und durch den Willen Gottes entweder als gute Seelen nicht mehr sterben werden oder als böse Seelen solange existieren werden, wie Gott es zu ihrer Bestrafung für richtig hält und will. ${ }^{89}$ Justin bringt diese Ansicht von der von Gottes Willen und nicht von der Natur der Seele abhängigen Fortexistenz der Seelen ganz bewusst und explizit mit Platon, Tim. 41a7-b6 in Verbindung, wenn er die von seinem Gegen-

\footnotetext{
${ }^{84}$ Vgl. Clem. Alex. Exc. Theod. 56,3 (125,18f. StÄHLIn / Früchtel / Treu); ferner Iren. Adv. haer. I 5,1; s. auch Hippolytos, Haer. X 13,3 Marcovich: Christus ist gekommen, um den Geist zu retten, der im „,inneren Menschen“, der mit der Seele des Menschen gleichgesetzt ist (vgl. VI 34,5), wohnt; der innere Mensch wiederum wird durch den in ihm wohnenden Geist gerettet. Wie bei Tatian ist es hier der Geist, der die an und für sich sterbliche Seele rettet. Nur ist der Geist dabei als pneumatischer Samen des Gnostikers verstanden und nicht mit dem Heiligen Geist identifiziert.

${ }^{85}$ Zur Frage der Schülerschaft Tatians bei Justin, die zuerst von Irenäus, Adv. haer. I 26,1, dann in deutlicher Abhängigkeit von ihm auch von Eusebios, HE IV 16,7 und Hieronymus, Vir. ill. 29 behauptet wird, vgl. die Diskussionen bei TreLenBerg 2012, 195-203. Allerdings besteht kein wirklich überzeugender Grund für die Bestreitung dieser doch recht gut bezeugten Schülerschaft. Vgl. auch Neymeyr 1989, 24. 183f.

${ }^{86}$ Wie schon Aristoteles (Cael. A 10 279b-280a34) verstehen vor allem die beiden Platoniker Attikos und Plutarch die Aussagen Platons im Timaios (28b2-c2) im eigentlichen Wortsinne und lehren die reale Gewordenheit der Welt; z.B. Plut. De an. procr. 5 (1014A-C); Quaest. Plat. 8,4 (1007Cf.); Attikos, Fr. 19. 25 des Places; vgl. Dörrie / Baltes 1998, 374-425. 523-527 mit weiteren Verweisen. Auch Iust. Mart. Dial. 5,1 weiß von dieser Lehrdifferenz innerhalb des Platonismus, dem er sich zum (fiktiven) Zeitpunkt des Gesprächs zugehörig fühlt, und plädiert hier für das platonische Minderheitsvotum im Sinne eines realen Anfangs der geschaffenen Welt.

${ }^{87}$ Andererseits diente einigen Platonikern die Ewigkeit der Seele als Argument für das Ungewordensein der Welt; vgl. z.B. Alkinoos, Didasc. 14 (169,32-35 WhitTaKer / Louis).

${ }^{88}$ Iust. Mart. Dial. 5,1f. Wenn er 1 Apol. 18,1-6 vom Weiterleben der Seelen nach dem Tod spricht, so ist damit ebenfalls nicht die Unsterblichkeit der Seele gemeint, sondern die durch den göttlichen Willen mögliche Weiterexistenz der an und für sich sterblichen Seele - wie auch die Begründung vom Weiterleben der Seele in Parallelität zu der durch den göttlichen allmächtigen Willen bewirkten Auferstehung des Leibes zeigen kann.

${ }^{89}$ Iust. Mart. Dial. 5,3.
} 
über ins Spiel gebrachte vom göttlichen Willen abhängige „Unsterblichkeit der Seele" mit der Vorstellung Platons vergleicht, nach der die Welt zwar als gewordene an und für sich vergänglich sei, aber auf Grund des göttlichen Willens keinen Anteil am Todeslos haben wird. ${ }^{90}$ Interessanterweise gilt auch für den Dialog mit dem Juden Tryphon, dass das lebensspendende Element für die Seele der Geist ist: So wie der Leib, wenn er von der Seele verlassen werde, stirbt, so sterbe auch die Seele, wenn sie vom "lebensspendenden Geist" verlassen wird. ${ }^{91}$

\section{Fazit}

Tatians Seelenlehre ist zwar durch und durch vom jüdisch-christlichen Schöpfungsgedanken und damit der theologischen Differenz von Gott und Kreatur bestimmt und als solche kritisch gegenüber philosophischen Konzepten eingestellt, die diese Differenz zu verwischen drohen, aber dieser ,unphilosophische' Gedanke prägt sich dennoch auch mithilfe philosophischen Materials aus. So lässt sich durchaus eine gewisse Nähe seiner Vorstellungen zu bestimmten, auf Poseidonios zurückgeführten stoischen und mittelplatonischen Lehrmeinungen konstatieren, die allerdings von der theologischen Differenz her gebrochen werden. So erscheint dann das, was im Rahmen der zeitgenössischen Philosophie als Einheit gesehen wird, bei Tatian in eine Dualität aufgesprengt, deren einer Teil auf Seiten der menschlichen Seele, deren anderer auf Seiten des göttlichen Wesens zu stehen kommt.

Kann die stoische wie die platonische Psychologie von einer Verwandtschaft des menschlichen Geistes mit dem göttlichen sprechen und dabei in gewissem Sinne den menschlichen Nus als Teil der Gottheit ansehen, so kann auch Tatian das höhere Pneuma im Menschen als „Teil Gottes“ sehen, aber er unterscheidet es dabei streng vom menschlichen Pneuma, das sterblich und wandelbar ist. Während für die meisten Platoniker allein der niedere Seelenteil des Menschen sterblich ist, der höhere dagegen die Unsterblichkeit besitzt, ist für den christlichen Theologen Tatian die Seele als ganze sterblich. Aus philosophischer Perspektive betrachtet identifiziert Tatian also den menschlichen Geist als ganzen mit dem niederen Seelenteil der poseidonianischen und platonischen Philosophie und stellt ihm den Heiligen Geist als das göttliche Komplement gegenüber.

\footnotetext{
${ }^{90}$ Iust. Mart. Dial. 5,4. Allerdings spricht Platon an der von Justin angeführten Stelle des Timaios nicht von der Gewordenheit und Vergänglichkeit der Welt, sondern von der der gewordenen Götter, deren ewige Existenz vom göttlichen Willen abhängt. Dieses Argument ist dann von Attikos von den Göttern auch auf die Schöpfung als ganze übertragen worden.

${ }^{91}$ Iust. Mart. Dial. 6,2; vgl. Koh 12,7; 3,19f.
} 
Mag Tatian sich also dem Dialog mit der zeitgenössischen Philosophie expressis verbis verweigern, so zeigt doch seine Darstellung der Seelenlehre, wie wenig eine solche Gesprächsverweigerung faktisch möglich war. Tatians eigene Seelenvorstellung ist ohne ihre untergründige Verwurzelung im zeitgenössischen philosophischen Diskurs nicht wirklich verstehbar. 



\title{
Tatian und die antike Paideia. Ein Wanderer zwischen zwei (Bildungs-)Welten
}

\author{
Peter Gemeinhardt
}

\section{Zum Einstieg: Uneindeutigkeit als Programm?}

Tatian hat von der klassischen griechischen Bildung keine hohe Meinung. Oder: Tatian hat von der klassischen griechischen Bildung eine sehr hohe Meinung. Beide Sätze lassen sich aus der Oratio ad Graecos hinlänglich begründen. Genau darin liegt das Problem, wenn man sich Tatians Bildungsvorstellungen annähern möchte: Eine eindeutige Haltung zu Bildungsfragen - sei es kritisch, sei es affirmativ - ist von Tatian nicht zu erhalten. Vielmehr setzt er seine rhetorische Kompetenz gezielt ein, um sich von ihr (und ihren nichtchristlichen Bewunderern) zu distanzieren. Insofern muss jegliche Analyse seiner Bildungskonzeption in Rechnung stellen, dass Tatian selbst ein apologetisches oder auch protreptisches, ${ }^{1}$ jedenfalls aber nicht primär ein bildungstheoretisches Anliegen verfolgt.

Der Fragestellung nachzugehen, welche Bildung Tatian besitzt, favorisiert und kritisiert, lohnt sich dennoch. Wie gebildet Christen sein dürfen, ob sie es in gleichem Maße wie ihre nichtchristlichen Zeitgenossen sein sollen oder ob sie eine spezifisch christliche Bildung erwerben und vermitteln müssen - das war seit den Anfängen des Christentums strittig. Und zumal für die Apologeten, die auf die Vernunftgemäßheit des Glaubens und auf die Vermittelbarkeit ihrer handlungsleitenden Überzeugungen setzten, war es weit mehr als eine Nebensache, ob die hellenische Paideia das Terrain war, auf dem man sich mit (realen oder virtuellen) paganen Zeitgenossen treffen konnte. Bei Tatian ist dies eine besonders reizvolle Frage, weil er sich prima facie von dieser Paideia kategorisch absetzt und für die klassischen Philosophen nur Spott übrig hat - zugleich aber schon Zeitgenossen als Schüler des von ihm als „hochbewunderungswür-

\footnotetext{
${ }^{1}$ Dass Tatian keine Apologie, sondern einen Protrepticus verfasste, betont F. R. PRosTMEIER in seinem Beitrag zum vorliegenden Band (S. 204-205); vgl. auch die Einführung von H.-G. Nesselrath (S. 17-19). Besonders McGehee 1993 argumentierte in diese Richtung; kritisch zu einer solchen Gattungsbestimmung äußerte sich W. KINZIG, „,Überlegungen zum Sitz im Leben der Gattung Пஹò "E $\lambda \lambda \eta v \alpha \varsigma$ / Ad nationes", in: R. von HaeHLing (Hg.), Rom und das himmlische Jerusalem. Die frühen Christen zwischen Anpassung und Ablehnung (Darmstadt 2000) [152-183] 158-161, affirmativ hingegen Lössl 2007, 135. Die Diskussion über die Gattung der Oratio zeichnet TRELENBERG 2012, 230-240 nach.
} 
dig" bezeichneten Justin ${ }^{2}$ gilt, der wiederum eine ganz andere, Brücken bauende Bildungskonzeption vertrat. ${ }^{3}$ Man könnte - wiederum prima facie - sagen: Wenn Tatian tatsächlich Justins Schüler gewesen sei, habe er bei ihm nicht allzu viel gelernt. Diese Beobachtung mag aber auch den Anlass bieten, eingehender nach dem Aufreißen von Gräben und dem Bauen von Brücken durch Tatian zu schauen. Genau dies - und nur dies - soll in diesem Beitrag geschehen. ${ }^{4}$

\section{Ein weit gereister Autor: Bildungsbiographische Streiflichter}

Wenn Tatian die radikale Diastase zwischen ,barbarischer' und ,hellenischer' Bildung betont, dann tut er dies im Habitus dessen, der genau weiß, was er hinter sich lässt. Daher müssen zunächst die verstreuten Informationen zu Tatians Bildungsbiographie genannt werden, wohl wissend, dass sämtliche Hinweise, die nicht der Oratio selbst entnommen werden können, von Autoren stammen, die Tatian nicht freundlich gesinnt waren. ${ }^{5}$ Das betrifft beispielsweise die Tatian zugeschriebene extreme Askese, die ihn zum Begründer des ,Enkratismus' werden ließ, jedenfalls in der Optik des Irenaeus von Lyon, dessen knapper Bericht über Tatian viele spätere Häresiologen inspiriert hat:

„Tatian war Anhänger Justins gewesen und hatte solche Vorstellungen nie vertreten, solange er in dessen Nähe war. Nach Justins Märtyrertod fiel er von der Kirche ab. In der überheblichen Selbsteinschätzung, ein Lehrer zu sein, wurde er stolz und aufgeblasen, als ob er besser sei als die übrigen. Er gab seiner Schule eine eigene Richtung,

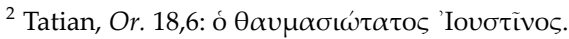

${ }^{3}$ Das wird schon daran deutlich, dass und wie Justin, 1 Apol. 2,2 an die Selbsteinschätzung der Adressaten als „Fromme und Liebhaber der Weisheit, Wächter der Gerechtig-

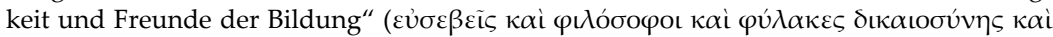

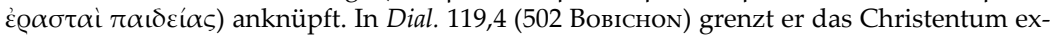
plizit von einem ,Barbarenstamm' ab: „Wir sind weder ein verachtenswertes Volk noch ein Barbarenstamm noch so etwas ähnliches wie die Völker der Karer oder Phryger" (Oủkoũv

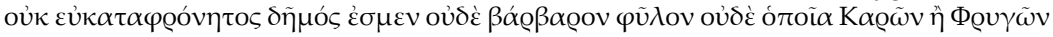
$\varepsilon \dot{\theta} \theta \vee \eta)$. Vgl. hierzu J. H. WAszinK, „Some Observations on the Appreciation of ,The Philosophy of the Barbarians' in Early Christian Literature“, in: L. J. Engels (Hg.), Mélanges offerts à Mlle Christine Mohrmann (Utrecht 1963) [41-56] 49.

${ }^{4}$ Ich führe damit Gedanken aus, die zuerst skizzenhaft in GemeInHARDT 2007, 104-108 formuliert wurden.

${ }^{5}$ Zum Folgenden vgl. Hunt 2003, 1f.; W. L. Petersen, „,Tatian the Assyrian“, in: A. MarJANEn / P. Luomanen (Hg.), A Companion to Second-Century Christian "Heretics". SVigChr 76 (Leiden / Boston 2005) 125-158; wieder in: ders., Patristic and Text-critical Studies. The Collected Essays of William L. Petersen, hg. v. J. Krans / J. Verheyden. New Testament Tools, Studies and Documents 40 (Leiden u.a. 2012) [437-469] 440-445; Pouderon 2005, 175-177; Trelenberg 2012, 1-8; R. Falkenberg, "Tatian“, in: J. Engberg / A.-Ch. Jacobsen / J. Ulrich (Hg.), In Defence of Christianity. Early Christian Apologists. ECCA 15 (Frankfurt/M. u.a. 2014) [67-79] 76-78.
} 
fabelte von bestimmten unsichtbaren Äonen, wie sie bei Valentin vorkommen, erklärte ganz ähnlich wie Marcion und Saturninus die Ehe für Schändung und Unzucht und bestritt - allerdings als eigene Idee - dem Adam das Heil. ${ }^{\text {}}{ }^{6}$

Tatian ist damit ein prominentes Beispiel für Irenaeus' Klage über selbsternannte „Lehrer" (doctores), die sich von ihrer ursprünglichen „(Splitter-) Gruppe" (haeresis) trennten, eine eigene "Lehre" (dogma) erfänden und so dazu beitrügen, dass sich die ,Häresien' zahllos vermehrten ${ }^{7}$ - und damit die Einheit der Kirche und ihrer Lehre gefährdeten. Dabei hätte Tatian (in Irenaeus' Sicht) als Schüler des rechtgläubigen Philosophen und Märtyrers Justin die besten Voraussetzungen gehabt, ein wahrer Lehrer des Evangeliums zu werden, begab sich aber in die geistige Gesellschaft bereits identifizierter ,Häretiker'. Irenaeus zeichnet also Tatian in sein Gesamtbild der Kirche im 2. Jahrhundert ein, in der ein Streit um die wahre Lehre und um ihre authentischen Vertreter tobt, sei es um kosmologische Spekulationen wie bei Valentin oder um die Legitimität der Ehe wie bei Marcion und Saturninus. Allerdings lassen sich solche Gedanken und Positionen in der Oratio nicht identifizieren, in der die religiöse Praxis gar keine Rolle spielt - der Tatian in der Tradition häufig zugeschriebene Enkratismus müsste, wenn überhaupt, in anderen Texten verbreitet worden sein. ${ }^{8}$ Die traditionelle, bis weit in die moderne Forschung hinein anerkannte häresiologische Klassifizierung hat weitreichende Konsequenzen für die Interpretation der Oratio: Die Frage nach der enkratitischen Pra$x$ is verdeckt tendenziell die auf den Intellekt konzentrierte Soteriologie der Oratio, denn Tatian propagierte, so Naomi Koltun-Fromm, eine „Erlösung durch Erkenntnis ${ }^{\prime 9}$, nicht durch Rituale, Handlungen oder Lebensformen - und schrieb gerade Bildung und Philosophie eine für das Heil maßgebliche Bedeutung zu.

Das alles spricht nicht dagegen, dass Tatian - wie Euseb berichtet - nach

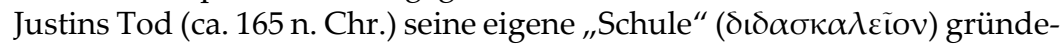

\footnotetext{
${ }^{6}$ Irenaeus von Lyon, Adv. haer. I 28,1 (FC 8/1, 324,10-18 BRox): Qui cum esset Iustini auditor, in quantum quidem apud eum erat, nihil enarravit tale; post vero illius martyrium absistens ab ecclesia et praesumptione magistri elatus et inflatus, quasi prae ceteris esset, proprium characterem doctrinae constituit, Aeonas quosdam invisibiles similiter atque hi qui a Valentino sunt velut fabulam enarrans, nuptias autem corruptelas et fornicationes similiter ut Marcion et Saturninus dicens, Adae autem saluti ex se contradictionem faciens. Übers. ebd. 325.

${ }^{7}$ Irenaeus, Adv. haer. I 28,1 (FC 8/1, 322,20-26 BRox).

${ }^{8}$ Vgl. Koltun-Fromm 2008, 5-18. Tatian wird z.B. von Euseb von Caesarea (HE IV 28; GCS Eus. II/1, 390,1 Schwartz sowie Chron. a. 2188; GCS Eus. VII, 206,13f. Helm) als Urheber des Enkratismus bezeichnet, ebenso von Epiphanius, Pan. 46,1,8 (GCS Epiph. II, 204,13f. Holl / Dummer) und Hieronymus, Comm. in Ioelem 1; Comm. in Amos 2,12 (CChr.SL 76, 172,431f.; 239,354f. Adriaen); weitere Belege bei Whittaker 1982, 82f. Zu derlei Formen (allzu) radikaler Askese im frühen Christentum vgl. P. GEMEINHARdT, „Encratism“, EBR 7 (2013) 889-892.

${ }^{9}$ So Koltun-Fromm 2008, 15: „One gains redemption through an intellectual soteriology, a soteriology discovered by reading the ancient scriptures."
} 
te und sich, ganz wie dieser, als $\delta \iota \delta \alpha \sigma \kappa \alpha \lambda$ o zu etablieren suchte. ${ }^{10}$ In der Oratio nimmt Tatian verschiedentlich die Pose des Lehrers ein (vgl. z.B. Or. 19,10). Mit Rhodon nennt Euseb zumindest eine Person, die als Schüler Tatians galt. ${ }^{11}$ Allerdings ist die pejorative Konnotation bei Irenaeus in Rechnung zu stellen, die den intensiven Diskurs über die christliche Lehre im 2. Jahrhundert vermittels der Dichotomie von ,wahr' und ,falsch' zu

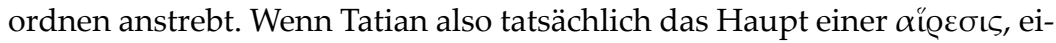
ner „Schulrichtung" (mit wohl nicht sonderlich großer Anhängerschaft), war, ist dies von Irenaeus' Anklage zu unterscheiden, er sei ein ,Häretiker' im dogmatischen Sinne gewesen, also ein Irrlehrer, der sich der falschen Schulrichtung angeschlossen habe. ${ }^{12}$ Dass eine solche Differenz von ,orthodoxer' und ,häretischer' Lehre sich in der zweiten Hälfte des 2. Jahrhunderts erst herausbildete und nicht als gegeben vorausgesetzt werden kann, ist seit langem erkannt worden. ${ }^{13}$ Man muss also Vorsicht walten lassen, um nicht in anachronistischer Weise Maßstäbe späterer Zeiten an Tatian und seine Zeitgenossen anzulegen. Vielmehr ist zu fragen, in welchen laufenden Diskursen sich Tatian mit seinen Aussagen positionieren wollte und warum es später so erschien, als sei damit die Grenze zur Häresiologie überschritten worden. Dass dabei gerade in biographischer Hinsicht nicht allzu viel Verlässliches übrig bleibt, teilt Tatian mit so gut wie

\footnotetext{
${ }^{10}$ Die Begriffe überliefert Euseb, HE IV 29,2f. (GCS Eus. II/1, 390,15f. SchwArTz) in einem Zitat des griechischen Originals von Irenaeus, Adv. haer. I 26,1. Harnack 1882, 203 Anm. 240 interpretiert $\delta เ \delta \alpha \sigma \kappa \alpha \lambda \varepsilon \tilde{\imath}$ ov als „Lehre“ (mit der lateinischen Übersetzung des Irenaeus: doctrina) und findet hierfür bei TRelenberg 2012, 2 Anm. 8 Zustimmung, was freilich nur dann einleuchtet, wenn man unter einer ,Schule' ein festes organisatorisches Gebilde versteht - Justins und auch Tatians ,Schulen' bestanden hingegen vermutlich nur durch den (lockeren) personalen Zusammenhalt von Schülern und Lehrer (vgl. Georges 2012, 81 sowie bereits Neymeyr 1989, 194f., McGehee 1993, 154-158 und B. Pouderon, „Réflexions sur la formation d'une élite intellectuelle chrétienne au IIe siècle: les ,écoles' d'Athènes, de Rome et d'Alexandrie", in: Pouderon / Doré 1998, [237-269] 241. 261).

${ }^{11}$ Euseb, HE V 13,1 (GCS Eus. II/1, 454,15f. Schwartz): $\mu \alpha \theta \eta \tau \varepsilon v \theta \varepsilon \dot{~}$

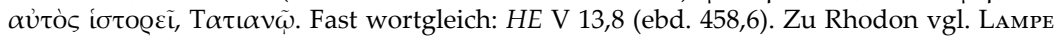
1987, 250f.; NEYMEYR 1989, 35f. 186.

${ }^{12}$ Markschies 2007, 93 sieht in den Lehrdifferenzen zwischen Justin und Tatian einen Ausdruck des vom paganen philosophischen Schulbetrieb übernommenen Pluralismus der Lehrmeinungen, insofern „,eine streng normierte Traditionsweitergabe und institutionelle Ausgestaltung von Meinungen, wie sie die christliche Kirche dann in Gestalt von Kanon und regula fidei intendierte, weitgehend außerhalb des Blickfeldes von philosophischen Schulen lag". Wenn freilich die Beobachtung von HaNig 1999, 49 stimmt, dass Tatian in der Logoslehre „,in der Nähe jener Position zu stehen scheint, die von Justin abgelehnt wird", wäre die Angelegenheit etwas weniger harmlos. Dies kann hier nicht näher diskutiert werden.

${ }^{13}$ Klassisch: Bauer 1964; vgl. jetzt die Darstellung und Kritik seiner Thesen bei MarKschies 2007, 339-369 und ihre Substituierung durch ein Modell von "pluraler Identität"; vgl. hierzu allerdings wiederum die kritischen Bemerkungen von E. MüHLEnBERG, Göttingische Gelehrte Anzeigen 262 (2010) 230-247, bes. 245-247.
} 
allen christlichen Autoren, zumal mit den ,Häretikern', der vorkonstantinischen Zeit.

Syrer von Herkunft, empfing Tatian - dies ist unstrittig - eine fundierte grammatische und rhetorische Bildung. ${ }^{14}$ Nach Eusebs Bericht erteilte er eine Zeitlang "in den griechischen Wissenschaften Unterricht"

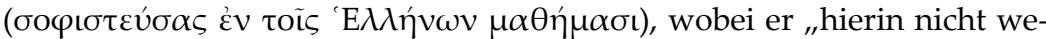
nig Ruhm erntete, auch zahlreiche wissenschaftliche Denkmäler hinter-

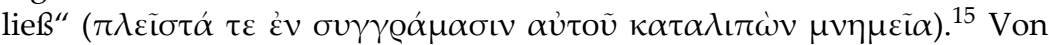
diesen Schriften aus der Zeit vor seiner Konversion ist freilich nichts erhalten. Tatian selbst ist daran gelegen, sich als in der antiken Paideia versiert darzustellen:

„Ich habe (selbst) ein großes Stück Erde bereist und zum einen eure sophistischen Künste gelehrt, ${ }^{16}$ bin zum anderen aber auch vielen (anderen) Künsten und Vorstellungen begegnet und habe mich zuletzt auch in der Stadt der Römer aufgehalten. ${ }^{\text {17 }}$

Zweierlei ist hieraus über Tatians Bildung zu entnehmen: Einerseits lässt er, durchaus unbescheiden, erkennen, wie gewandt er sich im griechischen Bildungskosmos bewegt - wieviel er davon materialiter parat hatte, ist eine andere Frage: „Tatian fügt sich bestens in das Bild ein, das wir von der Rhetorik des 1./2. Jh.s n. Chr. besitzen - als einer Prunkberedsamkeit, die eine imponierende Breite von Bildungselementen auffährt, aber an der Oberfläche bleibt. ${ }^{18}$ Die Oratio enthält zahlreiche Listen von Erfindungen (Kap. 1), Philosophen (Kap. 2-3), Göttern (Kap. 8) oder Statuen (Kap. 33-34); dass Tatian all dies durch Autopsie oder eigene Lektüre kennen gelernt hatte, ist mit Recht bezweifelt worden, vielmehr scheint er sich durchaus virtuos bereits existierender literarischer Kataloge bedient zu haben. ${ }^{19}$ Deutlich wird andererseits Tatians Selbstdarstellung, die Nähe und Distanz glei-

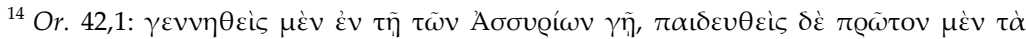
v́ $\mu \varepsilon ́ \tau \varepsilon \rho \alpha$ (,geboren wurde ich im Land der Assyrer und lernte zuerst eure Bildung kennen“). Das „Eure“ ist, für sich genommen, inhaltlich unbestimmt, aus dem Kontext der Oratio und insbesondere aus den sogleich zitierten Stellen geht aber zweifelsfrei hervor, dass es sich um die hellenische Paideia handeln muss. Die in der Oratio zu identifizierenden Elemente grammatisch-rhetorischer Bildung listet Lampe 1987, 363f. auf.

${ }^{15}$ So Euseb, HE IV 16,7 (GCS Eus. II/1, 358,2-5 Schwartz); Übers. Ph. Haeuser, 216.

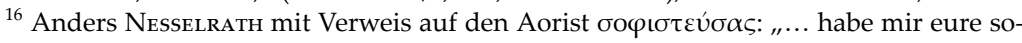
phistischen Künste erworben“; ähnlich TreLENBERG 2012, 179: „.... habe ich eure Sophistik

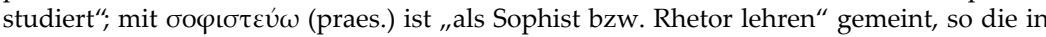
LSJ s. v. aufgeführten Belege (vgl. insbesondere Aristoteles, Soph. el. 165a28 sowie Plutarch, Caesar 3,1; Lucullus 22,7; Quaest. Conv. VIII 3,2 720E11). Die oben gegebenen Hinweise auf Tatians Lehrtätigkeit machen m.E. die letztere Deutung wahrscheinlich.

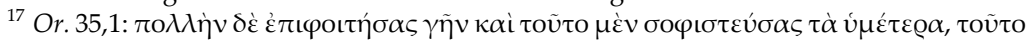

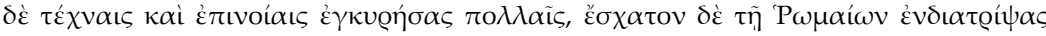

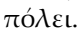

${ }^{18}$ LAmpe 1987, 247.

${ }^{19}$ Nach TreLEnberg 2012, 78 ist Tatian ,"gerade in dieser Hinsicht (sc. der Kulturkritik am Griechentum) weniger ein origineller Denker als ein Sammler von ihm geeignet erscheinenden Informationen".
} 
chermaßen markiert: In der Einleitungspassage der Oratio distanziert sich Tatian plakativ von "eurer ,Weisheit ' ... auch wenn ich in ihr eine recht respektable Figur machte ${ }^{\prime 2}{ }^{20}$ Tatian weiß also, was er hinter sich lässt. Der Anspruch, zu den hellenisch Gebildeten zu gehören, ist gleichwohl unbestreitbar; allerdings handelt es sich hier nicht - wie bei Justin - um an philosophischen Lehrtraditionen orientierte, sondern vielmehr um rhetorische, ,formale' Gelehrsamkeit, die auch die Rezeption der antiken Rhetorikkritik einschließt. ${ }^{21}$

Tatian stellt sich selbst als einen Suchenden dar, wiederum in gewisser Analogie zu Justin (s.u.), aber nicht nur als nach Bildung, sondern auch nach der rechten religiösen Praxis Suchenden, weshalb er sich seiner eigenen Aussage zufolge sogar in Mysterienkulte initiieren ließ. ${ }^{22}$ Dem Zusammenhang nach erscheint dies nicht als Selbsthingabe an einen geheimnisvollen Kult, sondern eher als Teil der Bestandsaufnahme religiöser Affiliationen unter Griechen und Römern, die den Syrer von Herkunft intellektuell faszinierten und ihn als ",travelled polymath“ auswiesen. ${ }^{23}$ Dann aber erlebte er eine tiefgreifende Konversion religiöser und kultureller Natur:

„Deshalb habe ich sowohl der Prahlerei der Römer als auch der kalten Klügelei der Athener - Meinungen ohne sinnvollen Zusammenhang - Lebewohl gesagt und mich einer Philosophie zugewandt, die ihr für ,barbarisch' haltet. ${ }^{\text {"24 }}$

Wir kommen auf den Zusammenhang dieser biographischen Notiz noch zu sprechen. Hier sei nur festgehalten, dass die Abgrenzung von Römern und Griechen - die übrigens nur an dieser Stelle gesondert genannt werden - nicht nur thetisch behauptet, sondern auch lebensgeschichtlich untermauert wird. Der ,Barbar' steht über den (Bildungs-)Dingen, jedenfalls soweit, dass seine Suchbewegung ihn zu einer kritischeren Haltung führt,

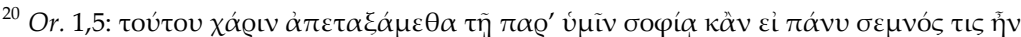

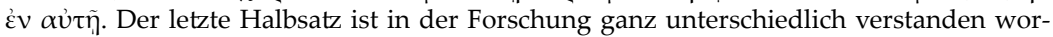
den (vgl. die Anm. z. St.), nämlich entweder (wie oben) als Selbstaussage Tatians in der 1. Person oder, so zuletzt Trelenberg 2012, „, auch wenn vielleicht sich manch einer (3. Ps.!) durchaus achtbar in ihr zeigte"(87). Letzteres konnte dann wiederum als verkappte Selbstbeschreibung verstanden werden, so LAMPe 1987, 248; Fојтік 2009, 23f. u.a. Doch präsentiert sich Tatian mehrfach explizit als hellenisch Gebildeter, so dass m.E. nicht ersichtlich ist, wozu es einer zusätzlichen anonymen Selbstbeschreibung bedurft hätte (so auch TRELENBERg 2012, 56 mit Anm. 307). Kukula 1913, 197 Anm. 1 übersetzt „mancher (von uns)“ und sieht hierin eine Anspielung auf Justin, doch passt die o.g. Interpretation NesselrathS besser zu anderen Selbstaussagen Tatians, insbesondere zu der bereits zitierten Passage Or. 35,1 .

${ }^{21}$ Vgl. Lampe 1987, 248-250.

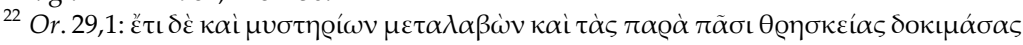

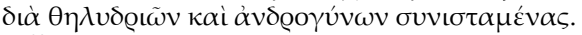

${ }^{23}$ WhitTAKER 1975, 59.

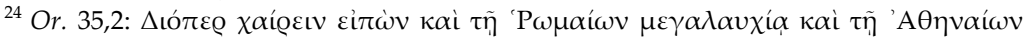

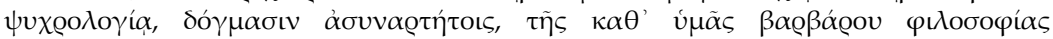

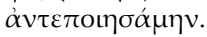


als sie die Inhaber der Paideia besitzen, und ihm die Möglichkeit offen lässt, sich der wahren, eben ,barbarischen' Weisheit zu verschreiben, wie es Tatian ohne einen Anflug von Bescheidenheit für sich in Anspruch nimmt: „Gemäß der Nachahmung des Logos wurde ich wiedergeboren und zur Wahrnehmung des Wahren geschaffen. “25

Die Oratio macht also einerseits deutlich, dass Tatian tatsächlich hellenische Bildung genossen hatte (und sie auch einzusetzen verstand). Andererseits trifft aber auch zu, was Naomi Koltun-Fromm lapidar formuliert hat: „Tatian puts himself forward as a model convert.“26 Tatians Bildungsbiographie dient seinem apologetischen und protreptischen Anliegen wie alle anderen (auto-)biographischen Darstellungen aus frühchristlicher Zeit, sei es Justins Tour d'Horizon durch die zeitgenössische Philosophie, die Lobrede auf Origenes durch Gregor Thaumaturgos oder auch der Bildungsroman, den die Pseudo-Clementinen überliefern; ${ }^{27}$ und $m u$ tatis mutandis gilt dies auch noch für Augustins Confessiones. So spannend es wäre, genauer zu wissen, welchen Unterricht Tatian selbst genossen und welchen er später erteilt hatte - die Quellen lassen uns diesbezüglich im Stich. Wie Tatian die ihm und seinen Adressaten zu Gebote stehende Bildung charakterisiert und wie er sie einsetzt und sich zugleich von ihr distanziert - all das kann freilich gefragt und auch beantwortet werden, und eben dem wenden wir uns im Folgenden zu.

\section{Tatians Auseinandersetzung mit dem hellenischen Bildungsideal}

Bildungsostentation und -kritik sind bei Tatian eng miteinander verbunden. Er schreibt für ein hellenisch gebildetes Publikum, bei dem er Schulbildung und Grundkenntnisse der Philosophie voraussetzen kann und dem er sich als ebenbürtig und zugleich als überlegen präsentieren möchte. Die Oratio ist daher von starken Dualen geprägt: Den ,Hellenen' stehen die ,Barbaren' gegenüber, die selbst ,Philosophen' sind und dem richtigen Erkenntnisweg folgen, nämlich „die Inhalte einer göttlicheren Offenbarung“. ${ }^{28}$ Tatian selbst sieht sich als ,Barbarenphilosoph': „,[Ich] lernte zu-

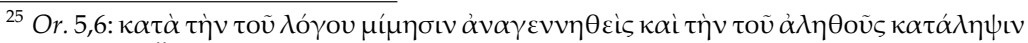

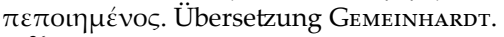

${ }^{26}$ Koltun-Fromm 2008, 4.

${ }^{27} \mathrm{Zu}$ diesen biographischen Abrissen, ihren Gemeinsamkeiten und Differenzen vgl. P. Gemeinhardt, „In Search of Christian Paideia. Education and Conversion in Early Christian Biography“, in: Gemeinhardt / Georges 2012, 88-98. Zum Verhältnis von Justins und Tatians Konversionsberichten vgl. auch Hanig 1999, 34-37; Hunt 2003, 56-58.

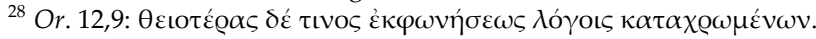


erst eure Bildung kennen, danach aber die, die zu verkünden ich mich jetzt anheischig mache ${ }^{\text {" }}{ }^{29}$

Nun ist das deutsche Wort ,Bildung' nicht unmittelbar deckungsgleich mit dem antiken Begriff und Konzept $\pi \alpha$ เ $\delta \varepsilon \alpha$. Tatian greift, wie noch auszuführen sein wird, auf viele Bereiche von Bildung, Wissen und Kultur zu, legt aber offensichtlich kein systematisches Konzept einer $\dot{\varepsilon} \gamma \kappa u ́ \kappa \lambda \iota \varsigma$

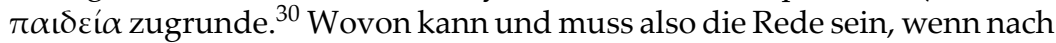
Bildungsvorstellungen bei Tatian gefragt wird? Dass es hierauf keine einfache Antwort gibt, wird deutlich, wenn man kursorisch die Wiederga-

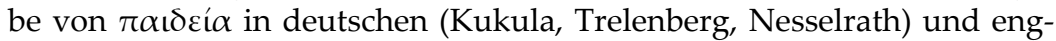
lischen (Whittaker) Übersetzungen und die damit verbundenen inhaltlichen Implikationen betrachtet. Die zehn Stellen in der Oratio, an denen das Wortfeld $\pi \alpha \iota \delta$ - vorkommt, seien im Folgenden kurz analysiert:

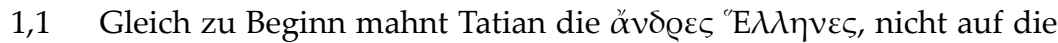
,Barbaren' herabzuschauen, hätten sie doch von diesen alles Wesentliche übernommen, unter anderem (als letztes Glied einer achtteiligen Reihe, die neben religiös-kultischen Praktiken wie Traumdeutung und Opferschau auch Astronomie, Magie und Geometrie be-

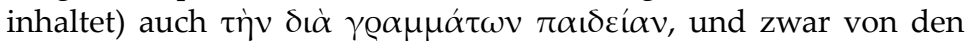
Phöniziern. Nach Kukula und Trelenberg ist die „Buchstabenkunde“ bzw. "-lehre“ gemeint, nach Nesselrath die „Erziehung durch Schrift" ${ }^{31}$ Obwohl im gleichen Atemzug andere, später, enzyklopädische' Fächer (Astronomie und Geometrie) genannt werden, ist wohl weniger an die Grammatik im Sinne der Kunst der Dichterexegese zu denken als an die basale Ausstattung der Menschheit mit Schriftzeichen: Kadmos, Sohn von König Agenor von Sidon und Herrscher von Theben, der hier nur im Hintergrund steht, ${ }^{32}$ wird später noch einmal explizit genannt als derjenige, der den Griechen

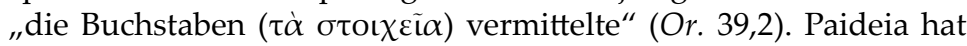
hiernach mit Schrift zu tun und ist insofern die Basis dessen, was

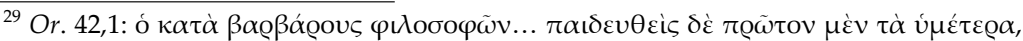

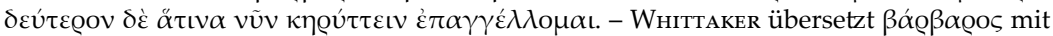

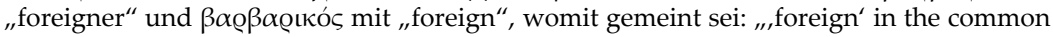
sense of non-Greek and therefore uneducated, not necessarily barbarous" (WHitTAKER 1982, 3 Anm. a zu Or. 1,1). In der Sache trifft dies zweifellos zu, blendet aber den pejorativen Unterton von ,barbarisch' aus und trägt zudem der durchaus differenzierten Verwendung von Bildungsbegriffen durch Tatian (s.u.) nicht hinreichend Rechnung.

${ }^{30}$ Zur Entwicklung dieses Konzepts vgl. I. НАDot, Arts libéraux et philosophie dans la pensée antique. Contribution à l'histoire de l'éducation et de la culture dans l'Antiquité. Textes et Traditions 11 (Paris [1984] ${ }^{2} 2005$ ).

${ }^{31}$ Beide Vorschläge verbindet WHITTAKER 1982: „,education through the letters of the alphabet".

${ }^{32}$ So Trelenderg 2012, 85 Anm. 6.
} 
im Folgenden genannt wird (Dichtkunst, Kalender und Historiographie, Epistolographie; Or. 1,2).

12,10 Tatian argumentiert, da die Griechen den Skythen Anacharsis, einen Zeitgenossen Solons, als Weisen betrachtet und von ihm manche Erfindungen rezipiert hätten, ${ }^{33}$ sollten sie sich nicht sträuben, nun auch von denjenigen, die einer „barbarischen Satzung“ ( $\beta \alpha \varrho \beta \alpha \varrho \iota \kappa \eta$

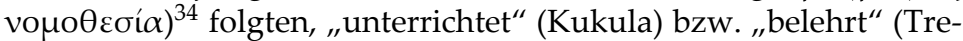
lenberg) zu werden oder sich von diesen „Bildung vermitteln“ $\mathrm{zu}$ lassen (Nesselrath). $\pi \alpha \iota \delta \varepsilon v \varepsilon \varepsilon \sigma \alpha$ เ bezeichnet hier den Prozess der Vermittlung von etwas, was dann auch spezifiziert wird: Während herkömmliche divinatorische Praktiken Werke der Dämonen seien, stehen „die Gegenstände unserer Paideia“ (Nesselrath) bzw. „der Inhalt unserer Lehre“ (Trelenberg) bzw. „Wissenschaft” (Kukula) „höher als die Erfassungskraft dieser Welt". $\pi \alpha$ เ $\delta \varepsilon i ́ \alpha$ hat es also mit Kontakt zu Übernatürlichem zu tun und erfordert einen auf Göttliches bezogenen Lerneifer. Dieser kann nur durch Tatians eigene Botschaft befriedigt werden, „da wir dies aber nicht (einfach) mit der Zunge behaupten oder aufgrund von Wahrscheinlichkeiten oder gedanklichen Schlüssen und sophistischer Kombinatorik, sondern weil wir uns auf die Inhalte einer göttlicheren Offenbarung berufen" (Or. 12,9). Diese Rhetorikkritik gehört spiegelbildlich zu Tatians Sicht der christlichen $\pi \alpha$ เ $\delta \varepsilon i ́ \alpha$ als einer Lehre, die zur Erkenntnis des Göttlichen anleitet und nicht menschlichen, sondern göttlichen Ursprungs ist: Wer ihr folgt, gibt sich eben der „barbarischen Gesetzgebung" hin, während diejenigen, die auf attische Redeweisen, Kettenschlüsse und Syllogismen Wert legen, ,seine eigenen Lehren

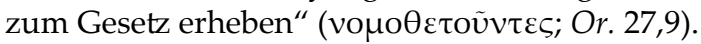

22,3 Weniger spezifisch im Blick auf unsere Fragestellung ist die Erwähnung eines $\pi \alpha \iota \delta \varepsilon v \tau \eta ́ \varsigma$ innerhalb einer langen Reihe der im Thea-

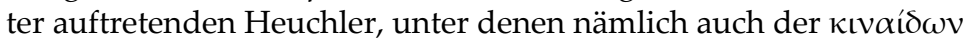
$\tau \alpha \iota \delta \varepsilon v \tau \eta ́ \varsigma$, der „Lehrmeister für Lustknaben“ (Kukula), seinen Platz hat. Hingegen wird an der nächsten Stelle erneut die Beobachtung, dass Bildung mit Religion zu tun hat, bestätigt:

25,5 Die Griechen, die „diejenigen, die dem Logos Gottes folgen“, hassen und ihnen "Menschenfresserei“ zuschreiben, ${ }^{35}$ haben ihrerseits kein Problem mit Göttern, die Menschen, ja sogar ihre eigenen Kin-

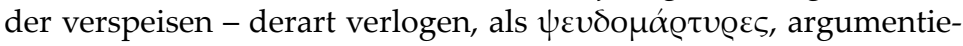

\footnotetext{
${ }^{33}$ Vgl. Trelenberg 2012, 118f. Anm. 152 mit Belegen.

${ }^{34}$ KuKula 1913 ad loc. übersetzt „Jünger einer barbarischen Religionslehre“ - von Religion ist aber explizit gar nicht die Rede.

${ }^{35}$ Zum Vorwurf der Thyesteischen Mahlzeiten ( $\dot{\alpha} v \theta \varrho \omega \tau о \varphi \alpha \gamma$ í $\alpha$ ) gegenüber dem frühen Christentum vgl. Trelenberg 2012, 152 Anm. 276 mit Belegen.
} 
ren nun gerade oi $\pi \varepsilon \pi \alpha \mathrm{t} \delta \varepsilon v \mu \varepsilon ́ v o !^{36}$ Dieser Vorwurf hat darin seine Pointe, dass es sich bei den Mythen von Tantalos, Kronos und Zeus nicht nur um Literatur handelt, sondern nach Tatians Auffassung (und der seiner christlichen Zeitgenossen) um religiös ernst zu nehmende Texte, die mit der Anklage des Kannibalismus gegen die Christen auf eine Stufe zu stellen sind. An anderer Stelle lehnt Tatian die Entschärfung solcher Mythen durch Allegorese kategorisch ab: „Allegorisiert nicht eure Mythen und auch nicht eure Götter; wenn ihr nämlich dies zu tun unternehmt, dann ist ,Göttlichkeit'(sc. der Götter), wie ihr sie versteht, aufgehoben, und zwar sowohl von uns als auch von euch selbst. " ${ }^{37}$ Tatian greift hier ein Argument auf, das die Diskussion über das Verhältnis des antiken Christentums zur paganen Bildung weit über die Apologetik hinaus prägen wird: Die in der griechischen Philosophie geübte Kritik an mythologischen Stoffen und ihren anthropomorphen Götterbildern (allen voran Homers Dichtung) verträgt sich nicht mit dem Vorwurf an die Christen, diesen Göttern nicht zu opfern. Dass die alten Götter ohnehin nur Dämonen sind, ist die christliche Innensicht. ${ }^{38}$ Wenn nun aber die Hellenen selbst ihre Götter auf dem Weg der Allegorese zu bloßen Gestalten der Literatur depotenzieren, dann fällt die apologetische Strategie in sich zusammen, den Gott der Christen als einzigen und besseren Gott zu erweisen. ${ }^{39}$ Daher dürfen aus Tatians Perspektive die Gebildeten - in seiner Optik eher: ,Eingebildeten' - die Mythen nicht als Stoff des Schulunterrichts abtun, sondern sollen sie als Texte (natürlich falscher) religiöser Bildung ernst nehmen.

27,1 In einem ähnlichen Kontext wird ein weiteres Mal $\pi \alpha \iota \delta \varepsilon i ́ \alpha$ thematisiert: Tatian beklagt die Vielfalt und Inkohärenz philosophischer Lehren; schon zu Beginn der Oratio hatte er festgestellt, dass die Widersprüchlichkeit der Meinungen und die Eitelkeit ihrer Vertreter diese statt zu „Liebhabern der Weisheit“ (

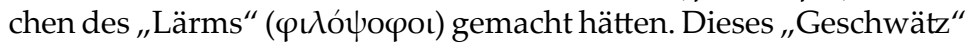
( $\varphi \lambda v \alpha \varrho i ́ \alpha)$ gehe auf die $\gamma \varrho \alpha \mu \mu \alpha \tau \iota \kappa o{ }^{40}$ zurück (Or. 26,5), deren Aufgabe es war, Texte zum Zweck der Interpretation kunstgerecht aus-

\footnotetext{
${ }^{36}$ Vgl. hierzu Fojtik 2009, 26.

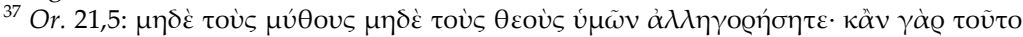

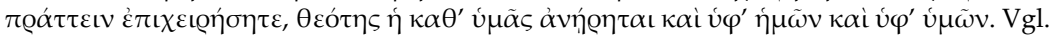
hierzu auch Ch. Gers-Uphaus, "Rhetorik des Monotheismus in der Oratio ad Graecos Tatians", in: A. Fürst / L. Ahmed / Ch. Gers-Uphaus / S. Klug (Hg.), Monotheistische Denkfiguren in der Spätantike. STAC 81 (Tübingen 2013) [83-93] 87f.

${ }^{38} \mathrm{Vgl}$. hierzu den Beitrag von A. TімотіN in diesem Band, S. 274-278.

39 Trelenberg 2012, 61f.

40 Zu unpräzise: „Schulmeister“ (Kukula 1913, Trelenberg 2012).
} 
einanderzunehmen und deren Teile zu benennen. ${ }^{41}$ Genau so hätten auch die Philosophen "die Wahrheit aufgeteilt" und den Teilen der (göttlichen!) Wahrheit "Namen zugewiesen“ (ebd.). Aber die Grammatiker hätten darüber hinaus einen regelrechten „Krieg der Buchstaben" angezettelt und bestimmte Dialekte, in erster Linie den attischen, als vorbildlich definiert (Or. 26,8). Dies, so Tatian, sei gegenüber allen Nicht-Athenern unfair und offensichtlich willkürlich, aber es entspreche präzise dem Verhalten der Griechen gegenüber den Christen: Die Einigkeit der zeitgenössischen Philosophenschulen bestehe nur darin, dass sie die Christen, die wiederum untereinander einig seien, bekämpften. ${ }^{42}$ Tatian wandelt diese Kritik aber in ein Argument um: Warum sei es nicht auch den Christen erlaubt, diejenigen „Lehren“ (ઠó $\gamma \mu \alpha \tau \alpha)$ zu wählen, die ihnen zusagten, wenn doch für die Griechen ebenso nur eine "Bildung“ (Nesselrath), „Unterweisung“ (Kukula) oder "Lehre“ (Trelenberg) bzw. „education“ (Whittaker) von mehreren möglichen, nämlich die der Grammatiker, als maßgeblich akzeptiert werde? Tatian stellt also das stilistische, in der Schule den heranwachsenden Hellenen vermittelte und für deren soziale und politische Karriere ausschlaggebende Ideal seiner Zeit zur Disposition. Mit $\pi \alpha \iota \delta \varepsilon i ́ \alpha$ dürfte dabei eher der Gesamtkomplex der klassischen Bildung gemeint sein, weniger die Art und Weise der Unterweisung oder (nur) der Schulunterricht. Der Vorstellung, dass es nur eine $\pi \alpha \iota \delta \varepsilon i ́ \alpha$ gebe, wird widersprochen, indem Tatian die Möglichkeit unterschiedlicher Arten von Bildung suggeriert, zwischen denen mit Gründen gewählt werden

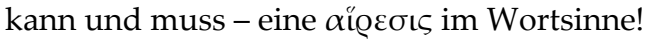

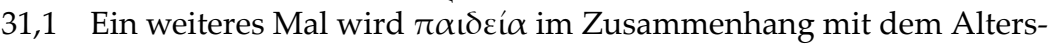
beweis erwähnt, also mit einem weit verbreiteten Topos der Apologetik. ${ }^{43}$ Verglichen werden Homer und Mose, die beide in ihren Traditionen hervorstechen - jener als der älteste unter den „Dichtern und Geschichtsschreibern“, dieser als „Archeget jeglicher Weisheit der ,Barbaren““. Tatian kündigt an, aufzuzeigen, „dass unsere Lehren nicht nur über die Paideia der Griechen, sondern auch über die Erfindung der Schrift hinaufreichen." Wenn in Or. 1,1 mit

\footnotetext{
${ }^{41} \mathrm{Zu}$ den Grammatikern der Spätantike vgl. R. A. KAster, Guardians of Language. The Grammarian and Society in Late Antiquity. The Transformation of the Classical Heritage 11 (Berkeley 1988).

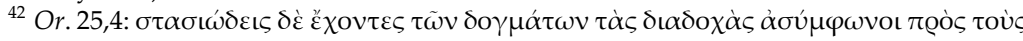

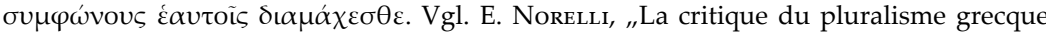
dans le Discours aux Grecs de Tatien“, in: Pouderon / Doré 1998, [81-120] 93; Fojtik 2009, $27-31$.

${ }^{43}$ Grundlegend dazu Pilhofer 1990. Tatian sei hierbei, so Clemens von Alexandria (Strom. I 101,2; GCS Clem. Alex. II, 64,22f. StäHLin / Früchtel / Treu) besonders „sorgfältig“" ( $\alpha \kappa \varrho \iota \tilde{\omega} \varsigma)$ vorgegangen.
} 
$\tau \dot{\alpha} \gamma \varrho \alpha ́ \alpha \mu \alpha \tau \alpha$,die Buchstaben“, nicht die Literatur gemeint waren, dürfte dies auch hier der Fall sein; und das ist auch insofern einleuchtend, als die literarische Kultur ja Inbegriff der Paideia ist und ihr nicht vorausliegen kann. Obwohl gesagt wird, dass Homer der erste der Poeten und Historiker ist, was klar auf grammatische und rhetorische Bildung als Thema hindeutet, übersetzen Kukula, Trelenberg und Whittaker "Kultur" bzw. „culture“. Das erscheint zu unspezifisch, insofern Tatian aus der Philosophie der Christen und der von Mose begründeten „Weisheit der Barbaren“ einen Rahmen konstruiert, in den sich die Einführung der Buchstaben und die Entstehung der hellenischen Paideia einfügen. Bildung ist hiernach ein Teil der Philosophie, aber nicht das Ganze, und sie hat mit Schrift zu tun, jedoch ist die wahre Weisheit nicht konstitutiv an Schrift und damit an die Vermittlung literarischer Kompetenz durch menschliche Lehrer, also an den üblichen Schulbetrieb, gekoppelt: Gerade zuvor hat sich Tatian als jemand zu erkennen gegeben, dessen See-

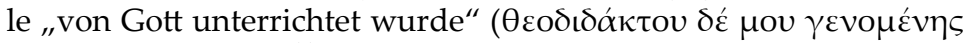
$\tau \tilde{\eta} \varsigma \psi v \chi \tilde{\eta} \varsigma$, Or. 29,3) ${ }^{44}$, d.h. konkret: durch „Schriften von Barbaren" (Or. 29,2). Obwohl also natürlich auch die Christen mit Schriften umgehen, liegt doch deren Bedeutung nicht in den von Menschen gemachten Texten selbst - hier ist die Begrenztheit der E $\lambda \lambda \eta \dot{v \omega \nu}$ $\pi \alpha \iota \delta \varepsilon i ́ \alpha$ klar zu erkennen -, sondern diesen voraus.

34,1 Die oben (Or. 25,5) erwähnte Anklage des Kannibalismus greift Tatian im Zuge seines Statuenkatalogs auf und münzt sie auf die Gebildeten: In Agrigent halte man das Bildnis des Tyrannen Phalaris in Ehren, der Säuglinge verspeist habe. ${ }^{45}$ Das Volk von Agrigent erschauere vor seinem Gesicht, während gerade die, „denen an Bildung liegt“ (Nesselrath), die „Bildungsbeflissenen“ (Trelenberg), ${ }^{46}$ sich daran begeistern. Die hellenische Paideia erscheint also als ethisch indifferent, ja als unfähig, Menschen zu einer normalen Empfindung wie der Abscheu vor einem Kinder mordenden Tyrannen zu bewegen. ${ }^{47}$ Wer sich auf eine Paideia verlässt, die nicht die wahre (barbarische) Weisheit zur Grundlage hat, geht also in dra-

\footnotetext{
${ }^{44}$ Dieser Begriff hat in der christlichen Tradition dadurch besondere Prominenz erlangt, dass in Athanasius' Vita Antonii $(66,2)$ der Einsiedler Antonius als "Theodidakt" (und Verweigerer formaler Schulbildung, ebd. 1,2) beschrieben wird; er ist bereits in 1 Thess 4,9 und Barn. 21,6 belegt und wird auch von anderen Autoren in Tatians zeitlichem Umfeld verwendet: Theophilus von Antiochien, Autol. II 9; Athenagoras, Leg. 11,1; Clemens von Alexandria, Strom. VI 166,4 (GCS Clem. Alex. II, 517,27-29 StÄhlin / Früchtel / Treu).

${ }^{45}$ Belege bei Trelenberg 2012, 175 Anm. 368; vgl. auch oben den Kommentar ad loc.

${ }^{46}$ WhitTAKer 1982: „devotees of culture“.

${ }^{47}$ Obwohl Tatian mit Belegen aus dem Neuen Testament bekanntlich zurückhaltend ist, wäre doch zu überlegen, ob christliche Leser der Oratio sich hier an Herodes (Mt 2,16) erinnert gefühlt haben mögen.
} 
matischer Weise in die Irre - wie Tatian mit dem gesamten Statuenkatalog zu beweisen sucht.

35,3 Dem stellt Tatian einige Absätze weiter „unsere Paideia“ (向 $\left.\pi \alpha \mathrm{t} \delta \varepsilon^{\prime} \alpha\right)$ gegenüber, die man nicht auf „Belehrung“ (Trelenberg) oder „Unterricht" (Kukula) reduzieren oder als "culture“ (Whittaker) entdifferenzieren sollte: Den ,Gebildeten', die für sich in Anspruch nehmen, sich im literarischen, sozialen und kulturellen Kosmos der Antike zu Hause zu fühlen, empfiehlt Tatian mit der ihm eigenen Unverblümtheit, sich für eine andere Belehrung zu öffnen und diese nicht nur deshalb abzuweisen, weil sie prima facie mit der Tradition und den anerkannten Philosophen breche (ebd.). In dem, worauf es ankommt, sind sie ja "ungelehrt" ( $\dot{\alpha} \mu \alpha \theta \varepsilon \tilde{\iota} \varsigma$, Or. 35,4) und sitzen gewissermaßen in demselben Boot, dem Tatian, ihr einstiger

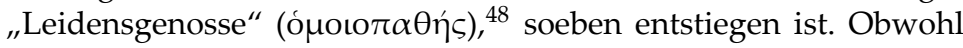
Tatian bereits zuvor ausführlich die Anciennität der „barbarischen Philosophie" begründet hat, ${ }^{49}$ findet er sogar noch ein Argument, weshalb man sich auch einer Neuheit nicht verweigern solle: Kein Geringerer als Solon habe bekannt, "dass man auch im Alter noch ständig alles Mögliche (hinzu)lernt ${ }^{\text {" }}{ }^{50}$ Für die apologetische Tradition ist ein solches Eingeständnis, eine Innovation zu lehren, keineswegs selbstverständlich. ${ }^{51}$

42,1 Ein letztes Mal wird das Wortfeld $\pi \alpha \iota \delta$ - ganz am Ende der Oratio aufgerufen, wo Tatian nochmals bekundet, dass er zuerst in der griechischen Bildung, dann in der der Christen unterwiesen worden sei $(\pi \alpha \iota \delta \varepsilon v \theta \varepsilon i \varsigma)$. Nicht zufällig wird am Ende noch einmal sehr deutlich das eigene ,Gebildet-Sein' akzentuiert, nachdem zuvor $\pi \alpha$ เ $\delta \varepsilon i ́ \alpha$ in derselben Ambivalenz verwendet worden war, wie sie die ganze Oratio prägt: als ,Ver-' oder ,Einbildung' der Hellenen einerseits, als wahre (christliche respektive barbarische) Bildung andererseits.

Zugespitzt lässt sich sagen, dass Tatian das Konzept einer christlichen Paideia propagiert, die er auch als solche benennt: „Damit aber steht er unter

\footnotetext{
${ }^{48}$ Vgl. Justin, 2 Apol. 1,1.

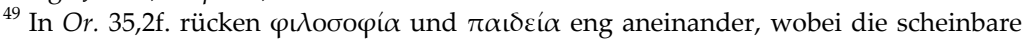
Synonymität eher in der wenig differenzierten Rede von „Philosophie“ bei Tatian begründet ist.

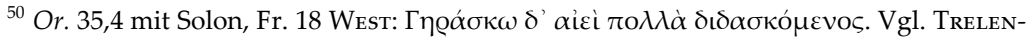
BERG 2012, 179.

${ }^{51}$ Das wohl berühmteste Postulat eines „lebenslangen Lernens“ in christlichen Texten der Spätantike ist das Bekenntnis der Stadt Rom in Ambrosius' Erwiderung auf die dritte Relatio des Symmachus (Ep. 73[18],7): Non erubesco cum toto orbe longaeva converti. Verum certe est quia nulla aetas ad perdiscendum sera est. Erubescat senectus quae emendare se non potest, ,IIch schäme mich trotz meines hohen Alters nicht, mich mit dem ganzen Erdkreis zu bekehren. Es ist eine unumstößliche Wahrheit, dass man niemals zu alt ist, um zu lernen. Schämen sollte sich das Alter, welches sich nicht mehr bessern kann“.
} 
den frühen Apologeten völlig allein. ${ }^{52}$ Materialiter läuft dies (wie auch bei anderen Apologeten jener Zeit) auf eine christliche Rezeption der antiken Philosophie hinaus. ${ }^{53}$ Formaliter richtet sich Tatians Kritik gegen die Bildung, die das Schulsystem der Antike vermittelte, ${ }^{54}$ d.h. gegen die von der grammatischen Analyse und der rhetorischen Aufbereitung eines Kanons von klassischen Schultexten geprägten Einweisung in den hellenischen kulturellen Kosmos. Schon im ersten Kapitel der Oratio distanziert sich Tatian von „,eurer Weisheit":

„Wie nämlich der Komödiendichter sagt, sind das ,Nachlesetrauben und Geschwätz und Schwalbenzwitscherschulen und Verderber der Kunst'; und es strapazieren ihre Stimmröhre, die nach dieser (Weisheit) trachten, und geben nur Rabengekrächze von sich. Denn die Redekunst habt ihr entwickelt, um Unrecht zu tun und andere anzuschwärzen; gegen Geld verkauft ihr die Freiheit eurer Worte und stellt oft das, was jetzt gerecht ist, ein anderes Mal als nicht gut hin; die Dichtkunst aber (habt ihr entwickelt), um Kämpfe und Liebschaften von Göttern und Verderbnis der Seele darzustellen. “55

Dies ist ein schönes Beispiel dafür, wie Tatian die Griechen „mit ihren eigenen Waffen" schlagen will (vgl. Or. 31,2), indem er sich von Aristophanes (Ran. 92f.) Stichworte für seine beißende Kritik an der Rhetorik geben lässt. Gleiches gilt für den Verweis auf den ,, unmäßig Worte machenden' Thersites" (Or. 27,6), womit Homer (Il. II 212) zitiert wird. ${ }^{56}$ Natürlich geht es Tatian dabei, wie erwähnt, um Bildungsostentation: Er will und muss zeigen, dass er weiß, was er verwirft. ${ }^{57}$ Es geht aber auch - durchaus mit der-

${ }^{52}$ Elze 1960, 21. - Hingegen wird die biblische (insbesondere in der Septuaginta zu findende) Rede von $\pi \alpha$ เ $\delta \varepsilon i ́ \alpha$ nicht aufgegriffen, anders als im 1. Clemensbrief, wo der Begriff zumeist im Sinne von „Züchtigung“ verstanden wird (vgl. 1 Clem. 56,2: $\alpha \dot{v} \alpha \lambda \alpha ́ \beta \omega \mu \varepsilon v$

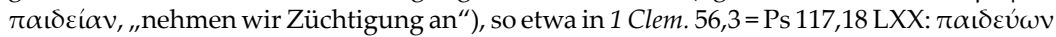

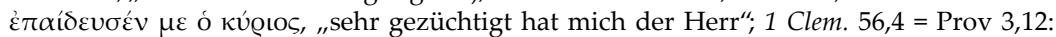

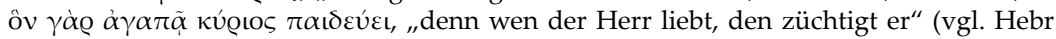

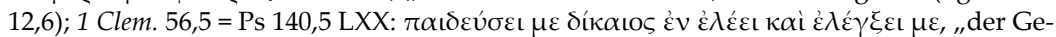
rechte wird mich mit Erbarmen züchtigen und mich tadeln“. Aber auch im Sinn von „Er-

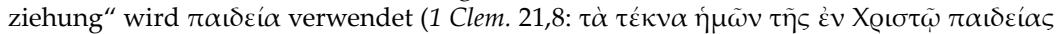
$\mu \varepsilon \tau \alpha \lambda \alpha \mu \beta \alpha \nu \varepsilon \dot{\tau} \omega \sigma \alpha v$, "unsere Kinder sollen der Erziehung in Christus teilhaftig werden“). Vgl. Gemeinhardt 2007, $7 \mathrm{f}$.

${ }^{53}$ Vgl. hierzu den Beitrag von F. R. Prostmeier in diesem Band, S. 207-222.

${ }^{54}$ Vgl. grundlegend K. Vössing, ,Die Geschichte der römischen Schule - ein Abriß vor dem Hintergrund der neueren Forschung“, Gymnasium 110 (2003) 455-497 sowie GemeinHARDT 2007, 27-61.

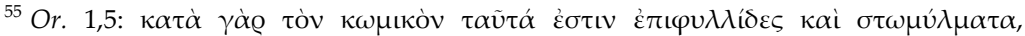

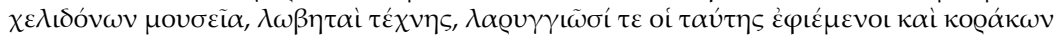

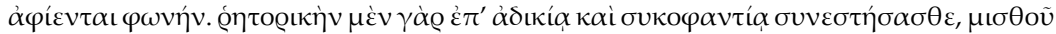

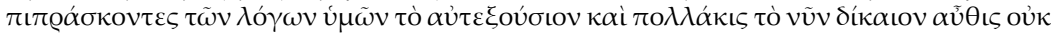

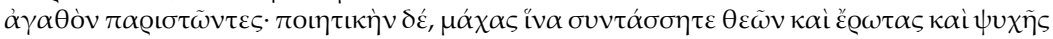

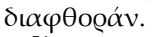

${ }^{56}$ Hierzu Freund 2006, 111. Zu Thersites' Geschwätzigkeit (und Hässlichkeit!) vgl. auch Or. 32,6 .

${ }^{57}$ Über diese apologetische Technik Tatians besteht Konsens; vgl. pars pro toto G. DoRIVAL, „L'apologétique chrétienne et la culture grecque“, in: Pouderon / Doré 1998, [423-465] 
selben Stoßrichtung wie bei zeitgenössischen paganen Kritikern - um die ethische Irrelevanz des Bildungsstoffes und der Institutionen seiner Vermittlung:

„Ihr habt wunderbare Hör-Säle, die alles verkünden, was nachts auf schändliche Weise praktiziert wird, und die Zuhörer mit der lauten Darbietung schändlicher Reden erfreuen. Wunderbar sind auch eure Dichter, Lügenerzähler und Leute, die mit Hilfe stilistischen Putzes die Zuhörenden hinters Licht führen. “58

Die Rhetoren und Dichter disqualifizieren sich also bereits durch den Inhalt ihrer Rede: Gepriesen wird unanständiges Verhalten, gefeiert werden die „(Er-)Dichter lügenhafter Geschichten“ ( $\psi \varepsilon v \delta о \lambda o ́ \gamma o \iota)$, die sich dreist

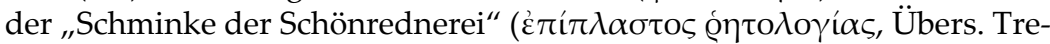
lenberg) bedienen, „um die Wahrheit wie einen Mythos zu verfälschen“ $(O r .40,2)$ - also in unangemessener Weise vom Göttlichen zu reden. ${ }^{59}$ Eine „Lizenz zum Lügen“, die Augustin - im Gefolge Ciceros - den Dichtern konzedierte, ${ }^{60}$ liegt außerhalb von Tatians Denkhorizont. Rhetoren und Grammatiker als Vertreter des antiken Bildungssystems sind in seiner Sicht vielmehr dadurch belastet, dass sie es per definitionem mit Göttlichem zu tun haben, diesem aber nicht gerecht werden. ${ }^{61}$ Ihnen fehlt die Einsicht, dass Bildung über schöne Sprache hinaus eine ethische, lebenspraktische Dimension hat:

„Und deswegen seid ihr alle nichts, da ihr euch zwar Argumentationen aneignet, aber miteinander redet wie ein Blinder mit einem Tauben. Warum verfügt ihr über Werkzeuge zum Bauen, versteht dies aber nicht zu tun? Warum kümmert ihr euch so sehr um Worte und seid von den Taten weit entfernt? ${ }^{\mu 62}$

463: „Le pourfendeur de l'hellénisme, Tatien, se révèle comme un rhéteur raffiné“; dazu auch Elze 1960, 20; WhitTaker 1975, 57; Freund 2006, 100.

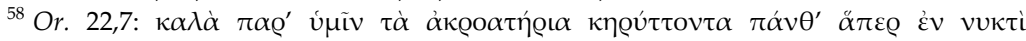

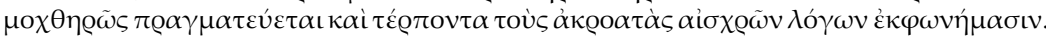

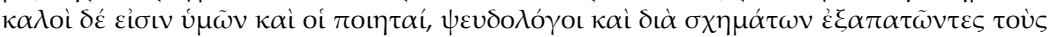

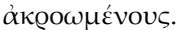

${ }^{59}$ Zur Mythenkritik antiker christlicher Autoren und zur Inanspruchnahme mythischer Denkstrukturen für ihre eigenen Zwecke vgl. P. Gemeinhardt, „,Nicht Mutige, sondern Flüchtlinge bedürfen des Mythos'. Distanzierungen und Annäherungen an den Mythos im spätantiken Christentum“, in: A. Zgoll / R. G. Kratz (Hg.), Arbeit am Mythos. Leistung und Grenze des Mythos in Antike und Gegenwart (Tübingen 2013) 249-271.

${ }^{60}$ Augustin, Soliloq. II 11,19,2; Ord. II 14,40; vgl. auch Laktanz, Epit. 11,1; dazu GemeinHARDT 2007, 412f.

${ }^{61}$ Vgl. zur Bedeutung der Dichtung Freund 2006, 99: „Dichterzitate sind Berührungspunkte zwischen der paganen Kultur, repräsentiert durch einen poetisch-literarischen Text, und dem Christentum, das Tatian vertritt. In jedem einzelnen Zitat vollzieht sich gewissermaßen in nuce die Auseinandersetzung zwischen Antike und Christentum." $\mathrm{Zu}$ Tatians Sicht der Grammatiker s. auch K. O. SAndnes, The Challenge of Homer. School, Pagan Poets and Early Christianity. LNTS 400 (London u.a. 2009) 89f.

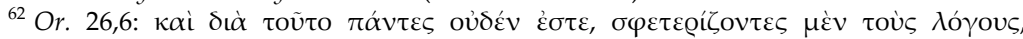

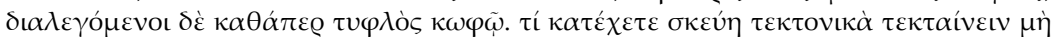

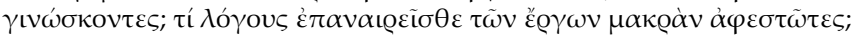


Tatian steigert sich zu schärfsten Invektiven: Die Griechen seien „in Worten großmäulig, im Erkennen schwachsinnig "63 - so die Übersetzung von Kukula, während sich neuere Ausgaben einer etwas weniger brachialen, in der Sache aber ebenso deutlichen Diktion befleißigen. ${ }^{64}$ Die Diskrepanz zwischen Sprache und Sache, zwischen Reden und Tun entwertet nach Tatian (und auch nach anderen antiken, nicht nur christlichen Autoren) den Unterricht, den sie selbst genossen haben, und das hellenische Selbstbewusstsein, das sich auf das dabei erworbene kulturelle Kapital gründet. Genau anders herum steht es mit den christlichen Schriften, deren Lektüre zu Tatians Konversion geführt hatte:

„Und ich gelangte dazu, ihnen Glauben zu schenken wegen ihrer unaffektierten Ausdrucksweise, des Unverstellten ihrer Sprecher, der guten Erfassung der Schöpfung des Alls, der Vorausschau auf das Zukünftige, des Außerordentlichen ihrer Anordnungen und des Prinzips, dass es einen Herrscher über das All gibt. “65

Diese biographische Notiz - die mit der fehlenden sprachlichen Eleganz der biblischen Schriften ein Hauptthema der Apologetik anschlägt, das wiederum bis zu Augustin zu verfolgen ist ${ }^{66}$ - bildet zugleich die Grundlage für eine Legitimation des Sachverhalts, dass in den christlichen Gemeinden Menschen anwesend sind und mitreden, die jeglicher formalen Bildung

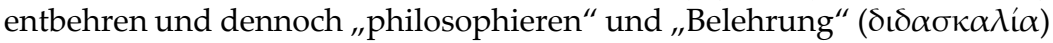
empfangen (Or. 32,2; vgl. 33,1). Die christliche Gemeinde erscheint als eine Art Schule, und in dieser partizipieren Personen aller Lebensalter und beiderlei Geschlechts an der christlichen „Philosophie“, also auch solche Personen, die im öffentlichen Leben der hellenistischen Polis mangels Bildung keine Rolle spielten. ${ }^{67}$ Tatian hält dagegen:

„Alle, die philosophieren wollen, [sind willkommen] bei uns, ${ }^{68}$ die wir nicht das beurteilen, was man sehen kann, und auch nicht, die zu uns kommen, nach ihrer äußeren

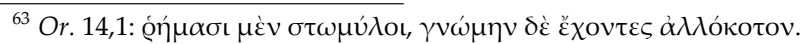

${ }^{64}$ Trelenberg 2012, 123: „mit Phrasen geschwätzig, mit einer sonderbaren Erkenntnis versehen“; Nesselrath: „mit Worten sehr gewandt, aber von einer seltsamen Urteilsart.“

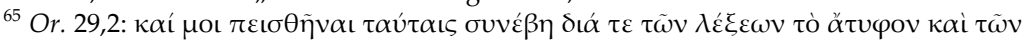

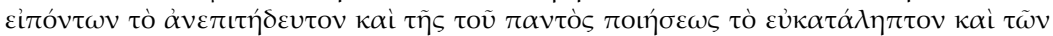

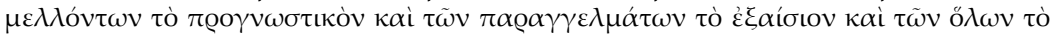

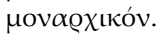

${ }^{66}$ Fiedrowicz 2001, 277f. Vgl. dazu auch Karadimas 2003, 32.

${ }^{67}$ Ebenso Justin, 1 Apol. 60,10f.

${ }^{68}$ Ergänzung und Übersetzung von P. Gemeinhardt. Schwartz konjizierte oî, wo die

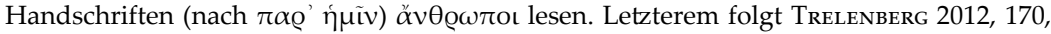
der die davor festzustellende Lücke mit der Konjektur von Мarcovich 1995 ( $\varphi$ íloı) füllt und übersetzt: "Alle, die philosophieren wollen, sind bei uns gerne gesehene Menschen." Mit Schwartz' Text (aber ohne die von ihm konjizierte Lücke) übersetzt WhitTaKer 1982: "All who wish to philosophize are at home with us." Vgl. oben auch Anm. 504 zur Übersetzung.
} 
Erscheinung bewerten; wir sind nämlich der wohldurchdachten Meinung, dass ein solider Verstand bei allen sein kann, auch wenn sie körperlich schwach sind. “69

Man könnte hier 1 Sam 16,7 („Ein Mensch sieht, was vor Augen ist; der Herr aber sieht das Herz an") anklingen hören, sollte aber wohl aus der Logik von Tatians Argumentation heraus die Schlussfolgerung ziehen, dass eben nicht körperliche Vorzüge, finanzielle Situiertheit und formale Bildung den Philosophen ausmachen, sondern die Geisteskraft, die grundsätzlich allen Menschen zu eigen ist, die sich aber auf den ihr gemäßen Gegenstand richten muss. Das ist gewiss nicht die Bildung, die man auf dem Markt kaufen kann, wo Grammatiker und Rhetoren ihren Unterricht gegen Geld in Ladenlokalen erteilten. Dass sich manche Philosophen von Kaisern aushalten ließen, spießt Tatian gnadenlos auf: Sie erhielten das Geld wohl deshalb, „, damit sie nicht einmal ihren herabwallenden Bart umsonst haben “ ${ }^{70}$ Die Christen bezahlen hingegen nicht für die ihnen „theodidaktisch“ vermittelte Bildung, "denn die von Gott kommenden Gaben übertreffen die Vergeltung eines innerweltlichen Geschenks" (Or. 32,2).

Mit aller Vorsicht kann man hier das Bild einer christlichen Philosophenschule, das oben schon angedeutet wurde, Gestalt annehmen sehen: Menschen versammeln sich mehr oder weniger spontan um einen Lehrer, der sie in den Genuss seiner Unterweisung kommen lässt, die in Wissen über Gott und die Welt, aber auch in der Anleitung zur „Askese“ (vgl. Or. 19,1), also zu einer der geistigen Erkenntnis entsprechenden Lebenspraxis, besteht. Tatian steht als Lehrer im Mittelpunkt seiner Schule - und in Konkurrenz mit anderen freien Philosophen auf dem Forum in Rom oder andernorts. Wenn das so ist, gewinnt die Frage nach dem Sitz im Leben der Oratio noch einmal neue Brisanz: Handelt es sich doch um eine rhetorisch zwar teils brachiale, aber präzise durchkomponierte Schrift, die so die These von Dimitrios Karadimas - einzelne Stücke beinhalte, die ursprünglich separat vorgetragen worden seien. Anders als die relativ umfangreiche Oratio selbst seien solche kürzeren Passagen als Lehrvorträge vorstellbar, in denen Tatian seine Gedanken Stück für Stück entwickelt habe, bevor er sie in einen zusammenhängenden Text integriert habe. ${ }^{71}$ Der Praxis des kaiserzeitlichen philosophischen Unterrichts, an dem auch die

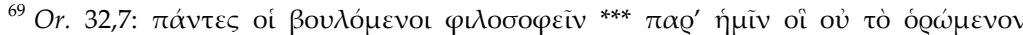

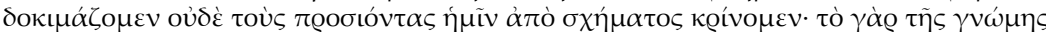

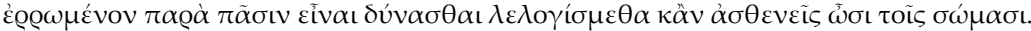

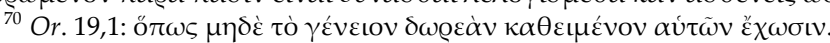

${ }^{71}$ Nach Karadimas 2003, 14. 18f. 24 lassen sich Kap. 8-11 (eine Rede über die

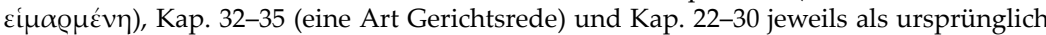
eigenständige Redeeinheiten erweisen, wobei letztere (,,a separate, self-reliant epideictic speech“) das älteste Textstück sei. Man muss dieser Aufteilung nicht in jeder Hinsicht folgen, um doch jedenfalls der Grundthese etwas abgewinnen zu können.
} 
christlichen Apologeten partizipierten, ${ }^{72}$ würde dies gut entsprechen. Man müsste dann allerdings die eben skizzierte Selbstdarstellung einer auch für bildungsferne Schichten offenen Institution kritisch hinterfragen: Vorträge für Anfänger oder Hobbyphilosophen bildeten sicher nicht die Basis der Oratio. Und es wäre genauer zu fragen, ob Karadimas' Schlussfolgerung stimmt, dass nicht nur die Form, sondern auch der Inhalt der Oratio sich der rhetorischen Bildung ihres Autors verdankt - eine Frage, die freilich die Begrenzung dieses Beitrags auf Tatians Bildungsvorstellungen sprengen würde. ${ }^{73}$

\section{Fazit: Ein Wanderer zwischen den (Bildungs-)Welten}

Das Wegweisende, ja Aufregende an Tatians Bildungskonzeption liegt darin, dass Paideia nicht nur - wie bei seinem Lehrer Justin - als Verbindung zwischen Christen und Heiden in Anspruch genommen wird. Vielmehr unterscheidet Tatian die beiden Bildungskonzepte strikt voneinander und präsentiert eine andere Verhältnisbestimmung als Justin: Hatte dieser (wie die meisten Apologeten) die christliche ,Philosophie' als Bestandteil, ja Kern des griechischen Bildungskosmos zu erweisen versucht, so dass die Griechen gerade im Christentum das Ziel ihrer eigenen philosophischen Suche erblicken sollten, so forderte Tatian die Hellenen zur Rückkehr zur ,barbarischen Bildung' auf, der sie doch alles verdankten, was bei ihnen wertgeschätzt werde. Er fordert also nicht nur ein, dass die Christen einen Platz im kulturellen Kosmos der Kaiserzeit haben dürfen, vielmehr postuliert er geradezu die Existenz unterschiedlicher $\pi \alpha \iota \delta \varepsilon \tilde{\alpha} \alpha \mathrm{t}$ : Die Christen sollen in der Welt der Antike leben dürfen, auch wenn sie nicht als ,Hellenen', sondern als ,Barbaren' mit ihrer eigenen Bildung dort auftreten. Das kann

\footnotetext{
${ }^{72}$ Dies ist besonders deutlich im Fall von Justins Schule in Rom; vgl. Georges 2012, 76-80; skeptischer äußert sich allerdings J. ULRICH, „What Do We Know About Justin's ,School' in Rome?“, in: Gemeinhardt / Georges 2012, [62-74] 70-73.

${ }^{73}$ Vgl. die zusammenfassenden Bemerkungen in Karadimas 2003, 38: „It seems that Tatian was unable to associate with $\lambda$ ó $\gamma 0 \varsigma$, not even with the Logos of God, properties which were alien to his deeply rhetorical conception of $\lambda$ ó $\%$ os. This means that the nature of a rhetorically educated man, moulded by his discipline, received all the doctrines of the new faith, but then revised and reworded those related to the main rhetorical concept of $\lambda$ ó $\gamma \mathrm{os}$. It is not easy to determine whether this process took place consciously or unconsciously in Tatian, but the result remains the same: his rhetoric is not only a means used to explain, defend, and spread efficiently the new faith, or even to attack its opponents, it also participates essentially in the formation and final formulation of a number of doctrines of his faith. What appears to be unique for Tatian is that he presents a theological system which he calls 'philosophy', but which seems to be essentially influenced by rhetoric." Zustimmend äußert sich Trelenberg 2012, 236: Die Oratio bestehe aus vielen "Syntagmata" und habe "gleichsam einen Portfolio-Charakter", entbehre aber ",als Gesamtprodukt eines einheitlichen, in sich kohärenten und systematisch strukturierten Lehrinhalts." Lehrvorträge als Teil- oder Basistexte der Oratio erwog auch schon Neymeyr 1989, $193 f$.
} 
natürlich nur ein Zwischenzustand sein; es wäre vermessen, gerade den polemisch argumentierenden Tatian zu einem frühen Beispiel religiöser Toleranz verklären zu wollen. Es ist gerade umgekehrt: Mehr als manch anderer Apologet nimmt Tatian das Konkurrenzverhältnis des Christentums zu seiner Umwelt bewusst und offensiv in den Blick und postuliert eine eigene Bildung - die materialiter wiederum viel von dem enthält, was philosophisch seinerzeit en vogue war, wie die Beiträge zur Seelenlehre und zu den Dämonen im vorliegenden Band zeigen.

Der Begriff „Bildung“ ( $\pi \alpha \iota \delta \varepsilon i ́ \alpha)$ birgt für Tatian eine Ambivalenz zwischen hellenischer "Verbildetheit" und dem, was allen Menschen von Gott zugedacht, aber nur von den Barbaren angemessen rezipiert wurde. Dem

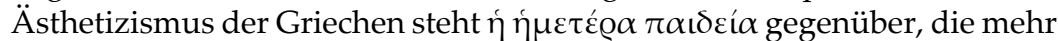
sei „als die Ausgeburten eines irdischen Verstandes“ (Kukula). Von den Jüngern dieser „barbarischen Satzung“ sollten die Hellenen sich unterweisen lassen (Or. 12,10). Kritisch wird $\pi \alpha \iota \delta \varepsilon i ́ \alpha$ im Sinne von „Unterweisung" in Verbindung mit den $\gamma \varrho \alpha \mu \mu \alpha \tau \iota \kappa o$ gebraucht; für Tatian spezifisch ist hingegen die Verwendung als Inbegriff eines religionskulturellen Konzepts, das in (mindestens) zwei kontradiktorisch zueinander stehenden Varianten existiert, von denen eine - nämlich die ,barbarische' - nach allen Regeln der apologetischen Kunst als prioritär erwiesen wird. Anders als bei Justin ist dies aber allenfalls eine Zukunftsperspektive, die eine Konversion der ,Heiden' voraussetzt. Der Oratio ad Graecos liegt die Leitdifferenz von Bildung und Verbildetheit zu Grunde: oí "E $\lambda \lambda \eta v \varepsilon \varsigma$ sind nicht die Griechen im ethnischen Sinne, sondern diejenigen Bewohner des Imperium Romanum, die sich über Bildung im Sinne eines bestimmten kulturellen Codes definieren. ${ }^{74}$ Dieser Code umfasst nicht nur einen sprachlichen Attizismus, dem der ,Assyrer' Tatian kritisch begegnet; er umfasst auch eine religiöse Komponente, insofern die Fähigkeiten zur Analyse, Komposition und Deklamation von Texten an Schriften erlernt wurden, die von Göttern handeln. ${ }^{75}$ Für christliche Autoren geht es hierbei nicht lediglich um Literatur, sondern eben um Religion. Tatians Bildungsvorstellung reflektiert diesen Konvergenzprozess von Religion und Bildung bzw. Philosophie, der für die Kaiserzeit kennzeichnend war und weitreichende Auswirkungen auf die Spätantike haben sollte. Und eine klassische apologetische Strategie bestand in der Behauptung, das Christentum habe sein Wirklichkeitsverständnis unabhängig von der Entstehung der hellenischen Paideia empfangen und vermöge dieser zur wahren Erkenntnis von Gott und Welt zu verhelfen, wobei Tatian diese Behauptung in ebenso konfrontativer wie kreativer Weise zur Sprache brachte wie sonst allenfalls

\footnotetext{
${ }^{74}$ Vgl. ELze 1960, 25.

${ }^{75}$ Den Zusammenhang zwischen Bildung und Religion in der Oratio betont auch LössL 2007, 148-151.
} 
noch Tertullian. ${ }^{76}$ Inwieweit sich seine Adressaten - seien es Nichtchristen oder Christen - davon überzeugen ließen, eine christliche $\pi \alpha \mathrm{t} \delta \varepsilon i ́ \alpha$ zu erwerben, die zugleich eine ,barbarische' war, muss mangels Quellen offen bleiben. Und ebenso offen bleiben muss die Frage, ob nicht vielleicht als Reaktion auf Tatians Oratio ad Graecos „, sich ein unsterbliches Gelächter erhob unter den seligen Göttern. ${ }^{" 77}$

\footnotetext{
${ }^{76} \mathrm{Zu}$ Tertullians Kritik und Rezeption der antiken paganen Bildung vgl. GemeINHARDT 2007, 64-81. Es ist daher nicht zutreffend, dass „der Bruch Tatians und Tertullians mit der orthodoxen Kirche geradezu als ein Symbol für die Sackgassen angesehen werden (könne), in die man mit einer allzu starren Haltung zur heidnischen Paideia gelangt war" (R. KLEIN, „Christlicher Glaube und heidnische Bildung. Zum sozialen Hintergrund eines innerchristlichen Problems in den ersten Jahrhunderten“, Laverna 1 [1990] [50-100] 61f.). Wie oben angedeutet, hat bei Tatian sein Bildungsverständnis nichts mit dem ihm später zugeschriebenen Enkratismus zu tun. Von einem ,Bruch' sprechen nur seine Kritiker!

${ }^{77}$ Homer, Il. I 599; Od. VIII 326; zit. bei Tatian, Or. 8,1; kritisch aufgespießt schon von Platon, Rep. III 388e-389a. Vgl. Freund 2006, 101.
} 


\title{
Gott und die Dämonen bei Tatian*
}

\author{
Andrei Timotin
}

Tatians Theologie und seine Dämonologie gehören zum geistigen Kontext der Apologetik des zweiten Jahrhunderts und bezeugen dabei ihren Dia$\log$ mit der jüdischen und der griechischen (vor allem der stoischen und der mittelplatonischen) Tradition. Gleich anderen Apologeten nahm auch Tatian am Bildungsprozess einer christlichen Theologie in ihrer Auseinandersetzung mit der zeitgenössischen Philosophie teil. Tatians Figur ist in diesem Zusammenhang vor allem durch die zentrale Stellung charakterisiert, die die Dämonologie in seiner Theologie und Anthropologie einnimmt. Sowohl auf griechische als auch auf jüdische Überlieferungen sich stützend versucht er mittels seiner Dämonologie die Stelle des Menschen in der Welt und im Verhältnis zu Gott zu definieren.

\section{Tatians Theologie}

Tatians Theologie hat keinen systematischen Charakter. ${ }^{1}$ Sie hat allerdings vieles gemeinsam mit der Theologie anderer Apologeten des 2. Jahrhunderts (vor allem mit jener Justins), zeigt aber trotz dessen auch etliche Besonderheiten. ${ }^{2}$ Unter den gemeinsamen Zügen könnte man den gut ausgeprägten Monotheismus, den doppelten Gottesbegriff - Gott als transzendentes Sein und als Schöpfer der Welt - sowie auch den auffälligen Mangel an Hinweisen auf die historische Figur Jesus Christus erwähnen (in letzterer Hinsicht sind wohl Justin und Tertullian die bemerkenswertesten Ausnahmen). ${ }^{3}$ Was die charakteristischen Züge von Tatians Theologie angeht, so sind die beachtlichsten darunter seine Logoslehre und seine Pneumatologie, beide mit einem auffallenden anti-stoischen Charakter.

\footnotetext{
${ }^{*}$ Der vorliegende Text wurde aus dem Englischen von Christian Ferencz-Flatz übersetzt, dem ich hiermit danke.

${ }^{1}$ Zu Tatians Theologie s. vor allem Elze 1960. Für neuere Ausführungen dazu vgl. Whiтtaker 1982, xv-xvii; Hunt 2003, 125-130; Pouderon 2005, 186-189; Trelenberg 2012, 29-44.

${ }^{2}$ Zu Tatian im Kontext der christlichen Apologetik des 2. Jahrhunderts, vgl. den Beitrag von F. R. Prostmeier in diesem Band, S. 207-222.

${ }^{3}$ Vgl. hierzu TRELEnBerg 2012, 219-224.
} 


\subsection{Die Gotteslehre}

In Tatians Theologie ist die Transzendenz Gottes absolut. Gott wird vor-

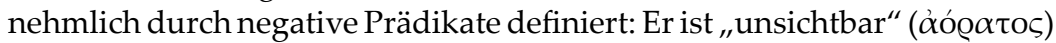

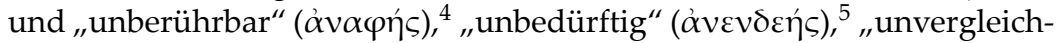

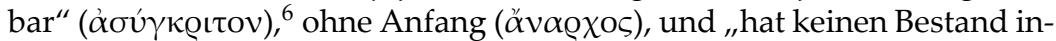
nerhalb der Zeit". ${ }^{7}$ Jedoch wird diese apophatische Theologie von einer ganzen Reihe positiver Prädikate aufgewogen: Er ist "Anfang von Allem“

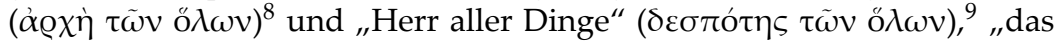

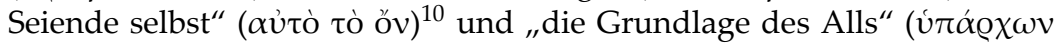

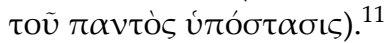

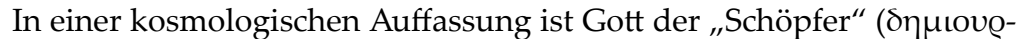
$\gamma$ ós) aller Dinge. ${ }^{12}$ Die Schöpfung wird von Tatian als ein zweistufiger Pro-

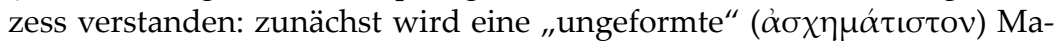
terie geschaffen; dann entsteht der Kosmos durch die „Differenzierung"

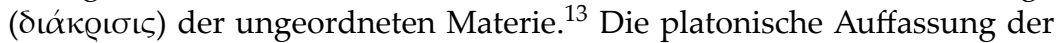
Schöpfung als Organisierung einer präexistenten Materie hat zweifellos Tatians Kosmologie beeinflusst, wenn auch in einem kleineren Ausmaß als jene Justins. ${ }^{14}$

In Betreff seiner Natur wird Gott als Geist bestimmt ( $\pi v \varepsilon \tilde{v} \mu \alpha$ ó $\theta \varepsilon \delta$ ćs), ${ }^{15}$ was freilich an Joh 4,24, aber auch an die stoische Theologie erinnert. ${ }^{16}$ Ein Ausdruck wie $\pi v \varepsilon \tilde{v} \mu \alpha$ ó $\theta \varepsilon$ có $\zeta$ hätte in der Tat leicht als ein Hinweis auf eine allgemein bekannte stoische Lehre, wie das etwa bei Kelsos der Fall war, gelesen werden können. ${ }^{17}$ Daher betont Tatian die Unterscheidung zwischen dem Gott-Pneuma, dem „Schöpfer der materiellen Geister und der

\footnotetext{
${ }^{4}$ Tatian, Or. 4,3.

${ }^{5}$ Or. 4,5; vgl. Ps. 49(50),12; Apg 17,25; Justin, 1 Apol. 10,1; 13,1; Dial. 22,1; 23,2; Athenagoras, Leg. 13,2; 16,1; 29,2; Theophilos, Autol. II 10.

${ }^{6}$ Tatian, Or. 15, 3; vgl. Philon, De mut. nom. 3; Leg. alleg. I 2.

${ }^{7}$ Tatian, Or. 4,3; vgl. Platon, Tim. 29a; Tertullian, C. Marc. I 8,3; Dörrie / Baltes 2008, 321.

${ }^{8}$ Tatian, Or. 4,3; vgl. Philon, Decal. 52; Plant. 77,93; Clemens, Strom. IV 162,5; Justin, Dial. 5,6; Theophilos, Autol. I 4.

${ }^{9}$ Tatian, Or. 5,1; vgl. Ps.-Arist. De mundo 398a22. S. auch Hanig1999, 64-69.

${ }^{10}$ Tatian, Or. 15,4; vgl. Platon, Symp. 211a; Tim. 34a; 37a; Dörrie / Baltes 2008, 321.

${ }^{11}$ Tatian, Or. 5,1; vgl. Corpus Hermeticum VIII 5; X 2; Tertullian, Adv. Prax. 5; Iren. Adv. haer. I $1,1$.

${ }^{12}$ Tatian, Or. 5,7; vgl. Platon, Tim. 29a; Dörrie / Baltes 2008, 322.

${ }^{13}$ Tatian, Or. 12,2; vgl. auch 5,5.

${ }^{14}$ Vgl. Justin, 1 Apol. 10,2; 59,1-6; 67,8; 2 Apol. 6. Der Einfluss des Timaios auf Justin wurde untersucht von Рғӓттіsch 1910, 93-103. Zur Kosmologie der Apologeten des 2. Jahrhunderts vgl. F. Снарот, „Les apologistes grecs et la création du monde. À propos d'Aristide, Apologie, 4,1 et 15,1“, in: Pouderon / Doré 1998, 199-218.

${ }^{15}$ Tatian, Or. 4,3; vgl. auch Hauschild / Drecoll 2004, 243.

${ }^{16}$ Vgl. SVF II 1009 (= Aët. Plac. I 6); II 1027 (= Aët. Plac. I 7,33).

${ }^{17}$ Origenes, C. Cels. II 71.
} 
in der Materie zu findenden Formen “, 18 und dem Pneuma, „, das die Ma-

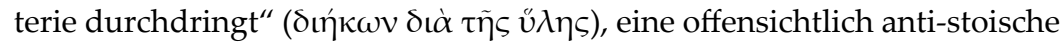
Andeutung. ${ }^{19}$

\subsection{Die Logoslehre}

Tatians Logoslehre weist viele Ähnlichkeiten mit jener Justins auf ${ }^{20}$ und muss dabei im Zusammenhang der frühchristlichen Logostheologie verstanden werden, die sich auf Joh 1,1-3 gründet und von der hellenistischen (der jüdischen, stoischen und hermetischen) Logosspekulation ${ }^{21}$ durchtränkt wurde. In diesem Zusammenhang bezeugt aber Tatians Logoslehre dennoch einige spezifische Merkmale (und zwar vor allem einen ausgeprägten Subordinationismus), die sich im Allgemeinen auf sein Bestreben gründen, ein dualistisches Verständnis der Gottheit zu vermeiden. Diese Tendenz ist beispielsweise in seiner Unterscheidung zweier Arten von

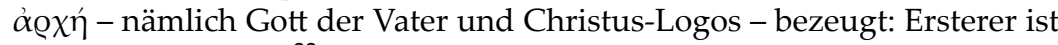

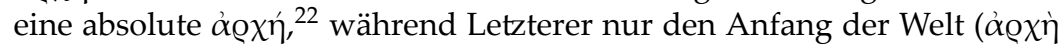

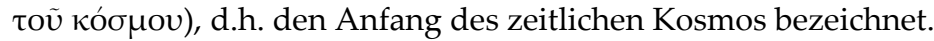

Diese anti-dualistische Tendenz könnte zugleich auch Tatians Gebrauch zweier verwandter Begriffe erklären, die eine zentrale Stelle in seiner Lo-

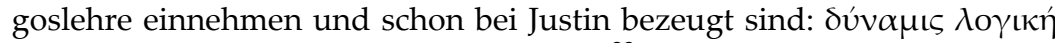

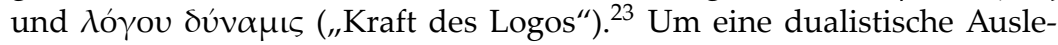
gung des Logos zu vermeiden, bemüht sich Tatian zu unterstreichen, dass

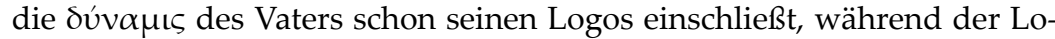
gos immanent (und d.h. in Potenz) im Vater beschlossen ist. ${ }^{24}$ Somit ist die

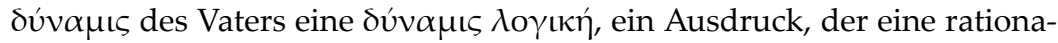
le Substanz bezeichnet, die dem Vater und dem Sohn gemeinsam ist. Auf einer zweiten Stufe wird der immanente Logos vom Vater gezeitigt als eine von ihm unterschiedene Hypostasis: „der himmlische Logos nämlich,

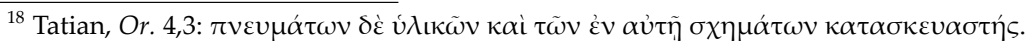
Diese Formulierung ist ein anti-stoischer Hinweis; vgl. SVF II 449 (= Plut. De Stoic. repugn. 43, 1054A). Dazu DünzL 2000, 30f.

${ }^{19}$ Vgl. SVF II 416 (= Gal. Intr. s. medicus 9, XIV 698 KüHN); II 1021 (= Diog. Laert. VII 147). Eine ähnliche Unterscheidung zwischen Gott und dem kosmischen Pneuma kann bei Theophilos gefunden werden, Autol. II 13; I 7; vgl. Athenagoras, Leg. 24bis.

${ }^{20}$ Zu Tatians Logoslehre vgl. Elze 1960, 70-83; Trelenberg 2012, 34-40. Zu Justins Logoslehre (vgl. Justin, Dial. 61,1;62,4) und ihrem Verhältnis zu jener Tatians s. HaNig 1999.

${ }^{21} \mathrm{Vgl}$. L. AвramowsкI, „Der Logos in der altchristlichen Theologie“, in: C. Colpe / L. Honnefelder / M. Lutz-Bachmann (Hg.), Spätantike und Christentum. Beiträge zur Religionsund Geistesgeschichte der griechisch-römischen Kultur und Zivilisation der Kaiserzeit (Berlin 1992) 189-201; M. J. EDwARDS, ,Justin's Logos and the Word of God“, JECS 3 (1995) 261-280; ders., "Clement of Alexandria and His Doctrine of the Logos“, VigChr 54 (2000) 159-177.

${ }^{22}$ Tatian, Or. 5,1.

${ }^{23}$ Tatian, Or. 5,1 (vgl. 7,1); Ps.-Arist. De mundo 398b6.19. S. auch VerbeKe 1945, 140.

${ }^{24}$ Tatian, Or. 5,1.
} 
der Geist vom Vater her geworden ist und Logos aus der Kraft des Logos"

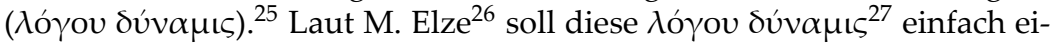

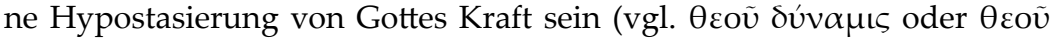
бoфí $\alpha$ in 1 Kor 1,24), und damit bloß ein anderer Titel für Christus. Hingegen stimme ich $\mathrm{S}$. Di Cristina ${ }^{28} \mathrm{zu}$, der gezeigt hat, dass die Ausdrücke

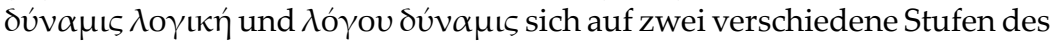
Logos beziehen - vor und nach seiner Verzeitlichung -, sowie es schon der

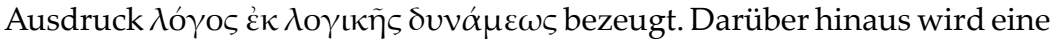

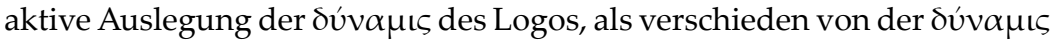
$\lambda о \gamma \iota \kappa \dot{~ d e s ~ V a t e r s, ~ a u c h ~ v o n ~ d e r ~ A n w e s e n h e i t ~ e i n e s ~ s p e z i f i s c h e n, ~ v o n ~ d e m ~}$ Pneuma des Vaters unterschiedenen Pneumas des Logos in Tatians Theologie unterstützt. ${ }^{29}$ So entspricht einem anderen Logos (nämlich dem - an-

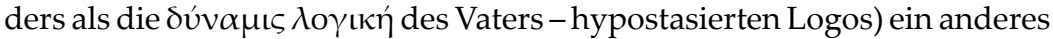
Pneuma und eine andere $\delta \dot{v} \alpha \alpha \mu \varsigma^{30}$

Eine andere Tendenz Tatians betrifft die anti-deterministische Betrachtung der Entstehung des Logos: „Durch den Willen“ Gottes springt der

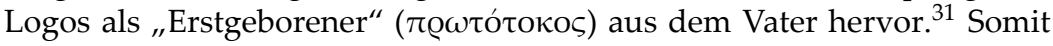
wird die Entstehung des Logos als ein freier Akt Gottes dargestellt, der implizit einem deterministischen Verständnis dieses Prozesses als Produkt einer immanenten Notwendigkeit entgegengesetzt wird. ${ }^{32}$ Laut Tatian ist

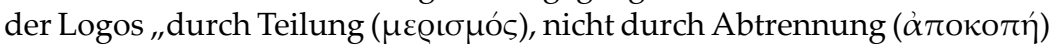
entstanden; denn das Abgetrennte ist vom Ersten geschieden, das Geteilte aber erfährt (nur) eine ,hauswirtschaftliche' Funktionsteilung und verursacht bei dem, von dem es genommen ist, keinen Mangel“. ${ }^{33}$ Damit weigert sich Tatian eine $\dot{\alpha} \pi$ коктү் Gottes anzunehmen; indessen akzeptiert

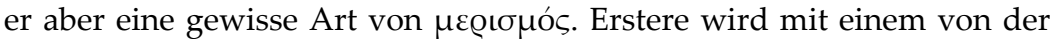
„Trennung" ( $\chi \omega \varrho i \zeta \zeta \varepsilon เ v)$ verursachten Substanzverlust, Letzteres mit einer

${ }^{25}$ Tatian, Or. 7,1.

${ }^{26}$ Elze 1960, 74.

${ }^{27}$ Vgl. Justin, 1 Apol. 14,5; 23,2; 32,9; 60,5; 2 Apol. 10,8; Dial. 61,1.3; 105,1. Zum rhetorischen Hintergrund dieses Ausdrucks und zu seinem Gebrauch bei Tatian s. Lösss 2010.

${ }^{28}$ Di CRistina 1977, 497-499.

${ }^{29}$ In dieser Hinsicht bezeugt Tatians Theologie eine Reihe von Ähnlichkeiten mit jener des Athenagoras (vgl. Leg. 16,17; 10,11), wie dies aufgezeigt wurde von Di CRIsTinA 1977, 499 Anm. 41.

${ }^{30}$ Die Lehre von den zwei Logoi (dem immanenten und dem hypostasierten Logos) an-

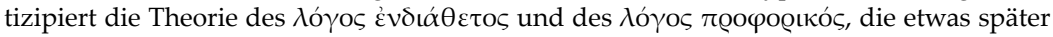
von Theophilos von Antiochia ausgearbeitet wurde; vgl. Pouderon 2005, $186 f$.

${ }^{31}$ Tatian, Or. 5,2; vgl. Kol 1,15. Dazu Hanig 1999, 43-49.

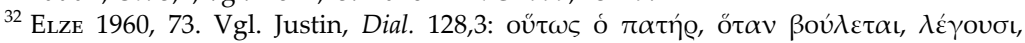

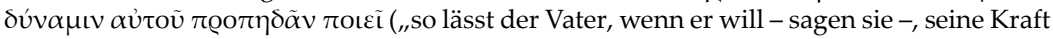
hervorspringen"). Sowohl Justin als auch Tatian gebrauchen den Ausdruck $\pi \varrho 0 \pi \eta \delta \tilde{\alpha} v$; in derselben Hinsicht benutzt Tatian auch $\chi \omega \varrho \varepsilon \tilde{\imath} v$ sowie, allgemeiner, $\gamma$ '́ $\gamma v \varepsilon \sigma \theta \alpha$ เ oder тео $\beta \alpha \alpha \lambda \varepsilon เ v$.

${ }^{33}$ Tatian, Or. 5,3. 
freiwilligen "Zuteilung" (оікоvоนí $\alpha$ ) von Seiten des Vaters an den Logos verbunden. Die Wendung, die vermutlich aus dem platonischen Wortschatz inspiriert ist, ${ }^{34}$ ist eher ungewöhnlich im Zusammenhang des frühen Christentums, wo Gegenteiliges etwa bei Clemens von Alexandria, bei Tertullian und Justin wohl bezeugt ist. ${ }^{35}$

Tatian scheint dabei dem Erbe Justins mit Bezug auf die materiellen Analogien in der Betrachtung der Entstehung des Logos treu geblieben zu sein, da er diese sowohl mit der Ausstrahlung des Lichts aus einer Fackel als auch mit der Ausbreitung der gesprochenen Rede vergleicht. ${ }^{36}$ Letzteres ist auch bei Philon bezeugt, ${ }^{37}$ doch das Zusammentreffen beider Analogien bei Justin legt die Vermutung nahe, dass Tatian sie eher von Justin als direkt von Philon übernommen hat. ${ }^{38}$

In Tatians Theologie hat der Logos hauptsächlich eine kosmologische Funktion. Auf der zweiten Stufe der Schöpfung „ordnet“ (

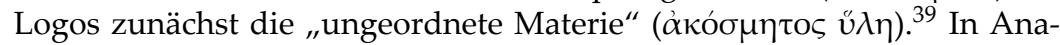

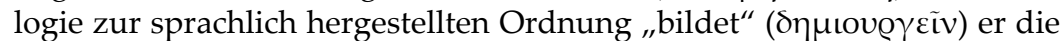
Materie als Vertreter des Vaters, des Schöpfers aller Dinge. ${ }^{40}$ Dazu behauptet Tatian ausdrücklich in seiner gewöhnlichen anti-dualistischen Weise, dass die Materie von Gott geschaffen wurde und dass sie weder $\alpha$ v $v \alpha \varrho \chi 0 \varsigma^{41}$

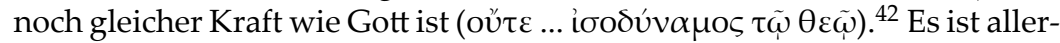

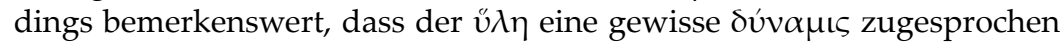
wird.

Der Logos ist also der Schöpfer des Menschen wie auch der Engel. Letz-

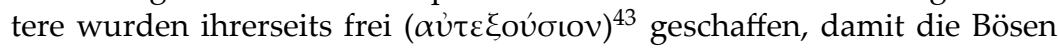
gestraft werden könnten und die Guten gelobt. ${ }^{4}$ In offensichtlich antideterministischer Weise behauptet Tatian mit Bezug auf die göttliche Vor-

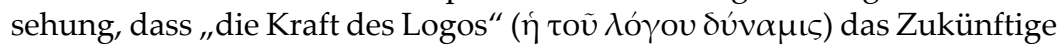

\footnotetext{
${ }^{34}$ Vgl. Alkinoos, Didasc. 154,6 WhitTaker; Plotin, Enn. IV 9,5; III 3,7.

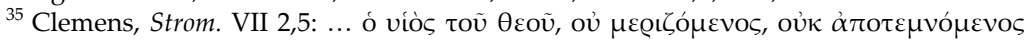
(„,der Sohn Gottes, der nicht geteilt, nicht abgeschnitten wird“); Tertullian, Adv. Prax. 9,1: non tamen diuersitate alium Filium a Patre, sed distributione, nec diuisione alium, sed distinctione („den Sohn, nicht anders vom Vater durch Verschiedenheit, sondern durch Aufgliederung, und nicht anders durch Teilung, sondern durch Unterscheidung“). Justin (Dial. 128,4) unterscheidet seinerseits nicht zwischen den beiden Termini.

${ }^{36}$ Tatian, Or. 5,2.

${ }^{37}$ Philon, Gig. 24; vgl. Athenagoras, Leg. 10; 24.

${ }^{38}$ Justin, Dial. 61,1; vgl. Elze 1960, 76. Zu diesen Analogien, vgl. auch Hanig 1999, 51-57.

${ }^{39}$ Tatian, Or. 5,5.

${ }^{40}$ Tatian, Or. 5,6.

${ }^{41}$ Vgl. Alkinoos, Didasc. 163,11 Whittaker; Apuleius, De Plat. I 5; Aëtius, Plac. I 3,21; Hippolytos, Refut. I 19,1.

${ }_{42}$ Tatian, Or. 5,7; vgl. Theophilos, Autol. II 4.

${ }^{43}$ Tatian, Or. 7,2; vgl. Justin, 2 Apol. 7,5; Athenagoras, Leg. 24,4f. S. auch Van Der NAt 1976, $721 f$.

${ }^{44}$ Vgl. Mt 19,17; Mk 10,18; Lk 18,19.
} 
kennt „,nicht in Hinsicht auf ein (unabänderliches) Schicksal, sondern aufgrund des freien Willens der eine Entscheidung treffenden Menschen“. ${ }^{45}$

\subsection{Die Pneumatologie}

Tatians Theologie ist nicht eigentlich trinitarisch, sondern eher dyadisch. Im Gegensatz zu Justin versteht Tatian das Pneuma nicht als ein von der Hypostasis unterschiedenes. ${ }^{46}$ Das Pneuma ist die Substanz des Vaters

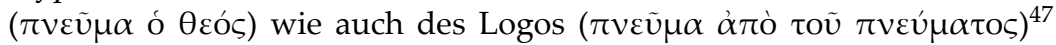
und somit ein Prinzip der Einheit Gottes, aber nicht eine von ihm verschiedene Person. ${ }^{48}$ Tatsächlich ist Tatian vielmehr damit beschäftigt, zwischen zwei Arten von Pneuma, Gottes Pneuma und einem untergeordneten, stofflichen Pneuma, zu unterscheiden: „Der Geist nämlich, der die Materie durchdringt, ist geringer als der göttlichere Geist. ${ }^{\prime 49}$ Hiermit unterstreicht Tatian wiederum die Unterscheidung zwischen dem christlichen Pneumabegriff und dem stoischen, obzwar das stoische Pneuma eine göttliche Dimension hat, die in Tatians $\pi v \varepsilon \tilde{v} \mu \alpha$ úlıкóv gänzlich fehlt. ${ }^{50}$

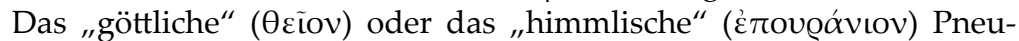
ma, ${ }^{51}$ auch als "Gottes Bild und Gleichnis "52 benannt, ist "größer als die Seele" ( $\mu \varepsilon \tilde{i} \zeta$ ov $\tau \tilde{\eta} \varsigma \psi v \chi \tilde{\eta} \varsigma$ ) und wird somit einer anderen Art von Pneuma gegenübergestellt, die als „Seele ${ }^{\text {“53 }}$ bezeichnet wird. Das Pneuma, das wie die Seele ist, kann nichts anderes sein als das Pneuma, das ,"die Materie durchdringt ${ }^{\prime \prime},{ }^{54}$ das im gesamten Weltall durchstreut ist: „,Es gibt also Geist in den Sternen, Geist in den Engeln, Geist in den Pflanzen und Gewässern, Geist in den Menschen, Geist in den Tieren; obwohl er aber ein und derselbe ist, trägt er doch Unterschiede in sich. “55 Diese Gleichstellung des v́גıкóv $\pi v \varepsilon \tilde{v} \mu \alpha$ mit der Seele ist keineswegs überraschend, da für Tatian die menschliche Seele ein hylisches Pneuma ist, sterblich und (Gottes) un-

\footnotetext{
${ }^{45}$ Tatian, Or. 7,3.

${ }^{46}$ Zum Pneumabegriff in der frühchristlichen Literatur, vgl. Verbeke 1945, 387-510; Dünzl 2000; Hauschild / Drecoll 2004.

${ }^{47}$ Tatian, Or. 4,$1 ; 7,1$.

${ }^{48}$ Zu Tatians Pneumatologie s. VerbeKe 1945, 411f. und 416-420; M. SPAnNeut, Le stoïcisme des Pères de l'Église de Clément de Rome à Clément d'Alexandrie. Patristica Sorbonensia 1 (Paris 1957) 335-337; Elze 1960, 83-88; Hauschild / Drecoll 2004, 244-246; Trelenberg 2012, 41-44.

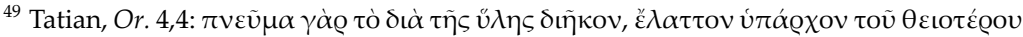

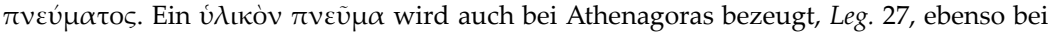
Tertullian, C. Marc. II 8 (spiritus materialis).

${ }^{50}$ Vgl. z.B. SVF II 634; 644; 1021 (= Diog. Laert. VII 138f.147).

${ }^{51}$ Tatian, Or. 13,2; 16,3.

52 Tatian, Or. 12,1.

${ }^{53}$ Tatian, Or. 12,1.

${ }^{54}$ Tatian, Or. 4,4 .

${ }^{55}$ Tatian, Or. 12,8; vgl. z.B. SVF II 634 (= Diog. Laert. VII 138).
} 
kundig - „, an und für sich nämlich ist sie Dunkelheit“56 -, außer wenn sie sich vom göttlichen Pneuma führen lässt wie von einem Schutzengel und somit Kunde von Gott erhält und unsterblich wird. ${ }^{57}$ Diese gesamte Reihe von Gegenüberstellungen zwischen den zwei Arten von Pneuma könnte folgenderweise dargestellt werden:

\begin{tabular}{|c|c|}
\hline$\theta \varepsilon \tilde{\iota} O \nu \pi \nu \varepsilon \tilde{v} \mu \alpha$ & $\dot{v} \lambda \iota \kappa o ̀ v \pi v \varepsilon \tilde{v} \mu \alpha$ \\
\hline 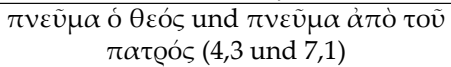 & 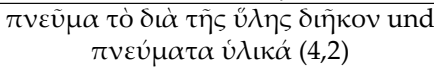 \\
\hline 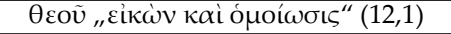 & $\psi v \times \eta ́(12,1)$ \\
\hline
\end{tabular}

Eine ähnliche Opposition scheint von Tatian auch mit Bezug auf die Begriffe $\lambda$ ó $о \varsigma$ und $\delta u ́ v \alpha \mu \iota \varsigma$ aufgestellt zu werden. Er unterscheidet dabei in

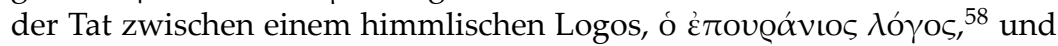

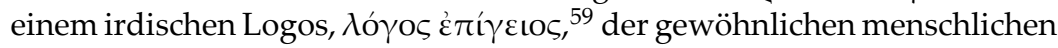

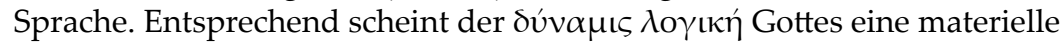

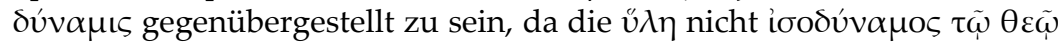
ist. Diese gesamte Reihe analogischer Paare könnte mit Hilfe des folgenden Diagramms zusammengefasst werden:

\begin{tabular}{|c|c|c|}
\hline & Göttlich & Hylisch \\
\hline 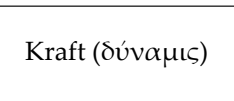 & 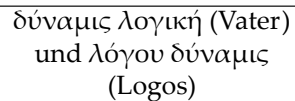 & 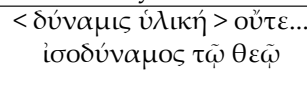 \\
\hline 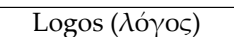 & غ̇ंTov@óv & 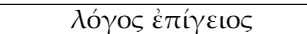 \\
\hline Pneuma $(\pi \nu \varepsilon \tilde{v} \mu \alpha)$ & 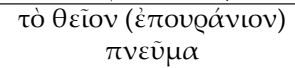 & v́lıкòv $\pi v \varepsilon \tilde{v} \mu \alpha$ \\
\hline
\end{tabular}

Zusammenfassend können wir sagen, dass Tatians theologisches Hauptanliegen daraufhin geht, die Transzendenz und die Unveränderlichkeit Gottes dadurch zu erhalten, dass er seinen Einfluss auf die Welt seiner

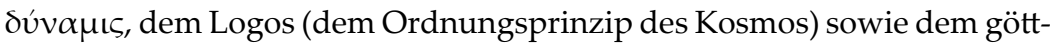
lichen Geist überlässt, was allerdings eine allgemeine Tendenz der mittelplatonischen Theologie darstellt. ${ }^{60}$ Dabei werden aber die Verhältnis-

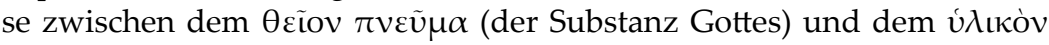
$\pi v \varepsilon \tilde{v} \mu \alpha$ (einer Schöpfung Gottes), wie auch zwischen der göttlichen und der hylischen $\delta u ́ v \alpha \mu \iota \varsigma$ nicht wirklich geklärt.

\footnotetext{
${ }^{56}$ Tatian, Or. 13,2.

${ }^{57}$ Tatian, Or. 13,3-6; vgl. hierzu den Beitrag von H. Strutwolf und M.-L. LaKmanN in diesem Band, S. 238-240.

${ }^{58}$ Tatian, Or. 7,1; vgl. 2 Clem. 9,5; Clemens, Paed. I 43,3; Theophilos, Autol. II 10.

${ }^{59}$ Tatian, Or. 33,2.

${ }^{60}$ Vgl. Ps.-Arist. De mundo 398a; Philon, Somn. I 140-143; Spec. leg. I 329; De mut. nom. 27f.; 120f.; Ps.-Plutarch, De fato 9 (572F-573A); Alkinoos, Didasc. 171,15-26 WhitTaKer; Apuleius, De Plat. I 12,205f.
} 


\section{Tatians Dämonologie}

Tatians Dämonologie ist wahrscheinlich eine der komplexesten im gesamten Zusammenhang des frühen Christentums. ${ }^{61}$ Als eine originelle Synthesis von jüdischen und mittelplatonischen Traditionen ${ }^{62}$ weist sie eine bemerkenswerte Kohärenz auf und ist dabei durchwegs in Tatians Theologie integriert. Tatian beschäftigt sich mit dem Ursprung, der Natur und den Tätigkeiten der Dämonen hauptsächlich mit Bezug auf ihren Einfluss auf die Menschen.

\subsection{Der Ursprung der Dämonen}

Für Tatian wie auch für andere frühchristliche Theologen sind die Dämonen gefallene Engel. ${ }^{63}$ Diese Auffassung hat ihre Wurzeln im hellenistischen Judentum, wo wenigstens zwei verschiedene Traditionen bezüglich des Engelfalls bezeugt sind: einerseits sollen sie wegen ihres Aufstands gegen Gott (d.h. wegen ihres Versuchs, sich Gott anzugleichen) aus dem Himmel vertrieben worden sein (2 Henoch 29, mit einem Echo in Lk 10,18), andererseits sollen sie Gottes Gebot übertreten haben, um daraufhin zur Erde zu fallen und sich mit den Töchtern der Menschen zu vereinigen (Henoch 6 im Zusammenhang mit Gen 6,1-4, ebenfalls mit einem Echo in Jud 6). ${ }^{64}$ Tatian folgt der ersteren Tradition, ${ }^{65}$ während die zweite von Justin, Athenagoras und Tertullian aufgenommen wird. ${ }^{66}$ Somit sind laut Tatian die Menschen und die Engel dem erstgeborenen Engel, der klüger als alle anderen

\footnotetext{
${ }^{61} \mathrm{Zu}$ Tatians Dämonologie vgl. F. Andres, Die Engellehre der griechischen Apologeten des zweiten Jahrhunderts und ihr Verhältnis zur griechisch-römischen Dämonologie. Forschungen zur christlichen Literatur- und Dogmengeschichte (Paderborn 1914) 43-65; TLASCAL 1956, 176-219; Wey 1957, 61-91; Elze 1960, 100-103; Trelenberg 2012, 45-49. Zur frühchristlichen Dämonologie vgl. Tlascal 1956; Wey 1957; Monaci Castagno 1995; Lange 2003, 463-609.

${ }^{62}$ Zur mittelplatonischen Dämonologie vgl. P. Doninı, „Nozioni di daimon e di intermediario nella filosofia tra il I e il II secolo D.C.“, in: E. Corsins u.a. (Hg.), L'autunno del diavolo. Diabolos, Dialogos, Daimon, I (Milano 1990) 37-50; ders., "Sokrates und sein Dämon im Platonismus des 1. und 2. Jahrhunderts n. Chr.", in: Baltes 2004, 142-161; C. MoresChiNI, "Il demone nella cultura pagana dell'età imperiale“, in: Pricoco 1995, 75-110; Dillon 2004; TiмотіN 2012.

${ }^{63}$ Vgl. Clemens, Paed. III 3-15; Athenagoras, Leg. 24f.; Irenaeus, Demonstr. 11-16.

${ }^{64}$ Eine wiederum andere Tradition ist im Leben von Adam und Eva (Lateinische Version) 15 erhalten, wonach der Fall der Engel von ihrer Verweigerung verursacht worden sein soll, Adam anzubeten.

${ }^{65}$ Tatian, Or. 7,2-5.

${ }^{66}$ Justin, 2 Apol. 5,3; Athenagoras, Leg. 24f.; Tertullian, Apol. 22,3; Cult. fem. I 2,1; vgl. Philon, Gig. 6. Laut Justin und Tertullian sind die Dämonen aus der Vereinigung der Engel mit den Töchtern der Menschen geboren, während sie laut Athenagoras die Seelen der durch diese Vereinigung geborenen Giganten darstellen (was ein Versuch ist, Gen 3,1-4 mit Gen 6,1-3 in Einklang zu bringen). S. dazu Van Den NAt 1976, 724-726.
} 
war, nachgefolgt und haben diesen als Gott ausgerufen. ${ }^{67}$ Dafür hat „die

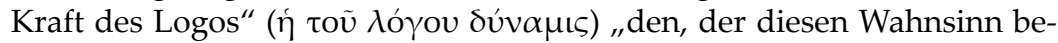
gonnen hatte, und seine Gefolgsleute aus seiner Gegenwart “68 verbannt. Als das göttliche Pneuma von ihm abschied, wurde der Mensch sterblich,

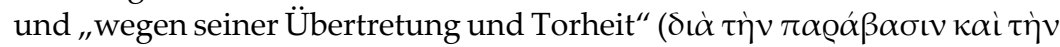
$\not \check{\gamma} \gamma v \cos \alpha v)$, wurden der erstgeborene Engel und seine Nachfolger durch ihre eigene Willensfreiheit zu Dämonen.

Diese Dämonen sind nichts anderes als traditionelle heidnische Götter, ${ }^{69}$ eine gewöhnliche Auffassung nicht nur für das frühe Christentum, ${ }^{70}$ sondern auch für den Mittelplatonismus und die Stoa, ${ }^{71}$ obgleich die philosophischen $\delta \alpha i ́ \mu o v \varepsilon \varsigma$ sehr wenig gemeinsam haben mit ihren neutestamentarischen Homonymen.

\subsection{Die Konstitution der Dämonen}

Die Dämonen, d.h. die heidnischen Götter, sind $\pi v \varepsilon v ́ \mu \alpha \tau \alpha \hat{v} \lambda \iota \kappa \alpha ́$ (sie haben einen hylischen Geist), sie sind Teil dieses in der Materie, in den Pflanzen, den Tieren oder den Menschen ausgebreiteten Pneumas, eine Auffassung die auch von Athenagoras und Tertullian geteilt wird. ${ }^{72}$ Sie sind sterblich wie die menschliche Seele, auch wenn sie „nicht leicht“ "sterben, ${ }^{73}$ da sie kein Fleisch haben. Obwohl sie dieselbe pneumatische Konstitution wie die Menschen haben, behauptet Tatian ausdrücklich, dass die Dämonen, die über den Menschen herrschen, nicht Seelen von Menschen sind, da die menschliche Seele nach dem Tod keineswegs klüger werden könnte. $^{74}$

\footnotetext{
${ }^{67}$ Tatian, Or. 7,4. Zu den philologischen Problemen dieser Passage s. Nesselrath 2005, 248-250. Vgl. Justin, 1 Apol. 28; Athenagoras, Leg. 24,2; 25,3; Clemens, Strom. VI 155,1; Origenes, C. Cels. III 37; Porphyrios, Abst. II 42,2.

${ }^{68}$ Tatian, Or. 7,4.

${ }^{69}$ Tatian, Or. 8,2 (vgl. 12,6).

${ }^{70}$ Vgl. 1 Kor 10,14-22; Justin, 1 Apol. 5,2 (die Menschen begannen, Dämonen als Götter zu verehren, gemäß dem Namen, den jeder von ihnen sich gab); 2 Apol. 5 (die Dichter haben die Taten der Dämonen den Göttern zugeschrieben); Athenagoras, Leg. 26,1; Clemens, Protr. II 40,1. S. auch Monaci Castagno 1995, 116; P. Lampe, „,Die dämonologischen Implikationen von 1 Korinther 8 und 10 vor dem Hintergrund paganer Zeugnisse“, in: LANGE 2003, [584-599] 587f.

${ }^{71}$ Vgl. Xenokrates, Fr. 24-25 Heinze = 227-230 Isnardi Parente; Plutarch, De def. or. 15 (417E); De Is. 25 (360D-F); SVF II 1103 (= Plut. De Is. 360D); II 1104 (= Plut. De def. or. 419A); II 1178 (= Plut. De Stoic. repugn. 1051C-D); Maximos von Tyros, Or. 8,1-6; 9,7. S. Tiмotin 2012, 163-208.

${ }_{72}$ Athenagoras, Leg. 27; Tertullian, C. Marc. II 8; vgl. Porphyrios, Abst. II 42.

${ }^{73}$ Tatian, Or. 14,3; vgl. Justin, 1 Apol. 28. Die Idee der Sterblichkeit der Dämonen ist zwar kein Gemeinplatz, kann aber dennoch gut in der mittleren und neuplatonischen Tradition bezeugt werden, vgl. Plutarch, De def. or. 16 (418F); 17 (419 A-D); Apuleius, De Plat. I 12,205f.; Porphyrios, Abst. II 39.

${ }^{74}$ Tatian, Or. 16,1. Dies ist wahrscheinlich eine anti-stoische Anspielung (vgl. SVF II 812 [= Sextus, Math. IX 71]; II 810 [= Aëtius IV 7,3]), aber der Gedanke, dass die menschliche
} 
Die „Verfassung“ ( $\sigma u ́ \mu \tau \eta \xi \xi \varsigma)$ ihres Pneumas ist ähnlich jener des Feuers und der Luft. ${ }^{75}$ Ihre unsichtbaren Leiber können nur von jenen gesehen werden, die das $\pi v \varepsilon \tilde{v} \mu \alpha \theta \varepsilon \delta \tilde{v}$ besitzen, während die anderen - d.h. die

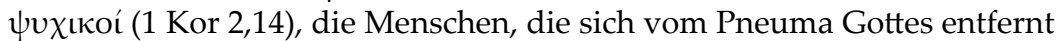
haben und somit nur eine ,psychische' Natur haben ${ }^{76}$ - es nicht können. Indessen gibt Tatian an einer anderen Stelle dennoch zu, dass Dämonen zuweilen doch auch von den $\psi v \chi$ «кó́ gesehen werden können, nämlich wenn sie sich den Menschen zeigen, um ihnen zu suggerieren, sie anzubeten. ${ }^{77}$ Die Auslegung der Theophanien der heidnischen Götter als ,daimonische ${ }^{\prime}$ Epiphanien war nicht ungewöhnlich im Mittelplatonismus, ${ }^{78}$ und es ist sehr wahrscheinlich, dass Tatian gerade diesen philosophischen Topos hier im Sinn hat. Andererseits sind aber die Götter der griechischen Mythologie von Tatian mit den Dämonen in einem Zusammenhang identifiziert, wo es gerade um ihren täuschenden Charakter geht, d.h. um ihre Tendenz, die Menschen dazu anzuregen, ihr schlechtes Verhalten nachzuahmen. ${ }^{79}$

Ein anderer Widerspruch der Oratio betrifft die Fähigkeit der Dämonen, ihre eigene conditio zu übersteigen. Zum einen behauptet Tatian, dass „das Wesen der Dämonen keinen Ort für Buße und Umkehr“ kennt (vgl. Hebr 12,17), und dass sie nur "Austrahlungen von Materie und Schlechtigkeit" sind. ${ }^{80}$ Zum anderen muss er aber zugeben, dass „einige von ihnen sich zwar zum Reineren hin[wandten], die anderen aber [...] sich das Minderwertige der Materie" aussuchen, was wahrscheinlich auf die internen Hierarchie in der Konstitution der Dämonen gemäß den verschiedenen Stufen der Materie geht. ${ }^{81}$

Seele nach ihrem Tod zu einem Dämon werden könne, ist ebenfalls im Mittelplatonismus gut belegt; vgl. Philon, Gig. 13f.; Somn. I 139f.; Plutarch, De def. or. 10 (415 B); Maximos von Tyros, Or. 9,5d.

${ }^{75}$ Tatian, Or. 15,6. Ohne besondere dämonologische Konsequenzen wurde die

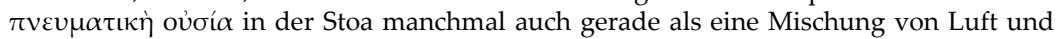
Feuer beschrieben; vgl. SVF II 439 (= Galenus, Пвœі $\pi \lambda \hat{n} \theta$ ous 3, VII,525 KüHN); II 442 (= Alex. Aphrod. De mixt. 224,14 Bruns). Andererseits ist die Verortung der Dämonen in der Luft ein Topos sowohl für die platonische wie auch für die stoische Tradition; vgl. Ps.Platon, Epin. 984d-e; Xenokrates, Fr. 15 Heinze = 213 Isnardi Parente; SVF II 773, 785 etc.

${ }^{76}$ Tatian, Or. 15,6; vgl. Tertullian, De an. 8,5. Zum unsichtbaren Leib der Dämonen in der früchristlichen Literatur vgl. G. A. SмIтH, „How thin is a Demon?“, JECS 16 (2008) 479-512.

${ }^{77}$ Tatian, Or. 16,5. Diese Vorstellung ist sowohl im hellenistischen Judentum (1 Henoch 19,$1 ; 8,2$ ) als auch im Neuplatonismus bezeugt; vgl. Porphyrios, Abst. II 40, 2; Iamblich, De myst. III 31,176,2; Orac. Chald. fr. 135. Vgl. auch Ps.-Clemens, Hom. IX 13,2.

${ }^{78}$ Vgl. z.B. Maximos von Tyros, Or. 9,7b-c; 15,7. S. auch Porphyrios, De phil. ex orac. haur. II 128f. (= Eusebios, PE V 5,8f.); Abst. II 42,1. Zur Sichtbarkeit der Dämonen, vgl. Ps.-Platon, Epin. 984b; Apuleius, De deo Socr. 20,167 (= Arist. Fr. 193 RosE); Porphyrios, V. Plot. 10.

${ }^{79}$ Tatian, Or. 8,2f.

${ }^{80}$ Tatian, Or. 15,8 .

${ }^{81}$ Tatian, Or. 12,5; vgl. dazu Tlascal 1956, 190-194. 
Das Hauptziel der Dämonen besteht darin, die Menschen von der Verehrung Gottes abzulenken - ein Gedanke, den auch Justin hervorhebt ${ }^{82}$ - um somit ihre Verbindung mit dem göttlichen Geist zu verhindern und letztendlich ihnen ihre Unsterblichkeit zu versagen. ${ }^{83}$ Die Menschen werden von den Dämonen „durch Unwissenheit und falsche Vorstellungen“84 getäuscht, was auf die trügerischen Epiphanien der Dämonen, d.h. der heidnischen Götter hinweist. Die Unwissenheit der Menschen beruht hauptsächlich auf ihrer Neigung zur Materie, da laut Tatian die Dämonen die Menschen dann irreleiten, wenn sie „schon nach unten geneigt [sind] “. ${ }^{85}$ Somit hätten die Dämonen keine Kraft über die Gedanken der Menschen, wenn diese sich nicht selbst von ihnen beeinflussen ließen, um so von Gott abgelenkt zu werden und sich der Materie zuzuwenden, ein Gedanke, den man allerdings auch bei Plotin findet. ${ }^{86}$ Demnach ist, nach Tatian, die Geneigtheit des Menschen zur Materie daran schuld, dass er unter das Joch der Dämonen fällt (da letztere an sich selbst kraftlos sind) und nicht umgekehrt. So ist die ă $\gamma$ vot $\alpha$ $\theta \varepsilon$ ov des Menschen (und damit auch seine Geneigtheit zur Materie) die einzige Ursache seiner Sterblichkeit; die Dämonen sind nur das nebensächliche Instrument (man könnte sogar sagen: der äußerliche Ausdruck) seiner intellektuellen und geistigen Schwäche.

Es ist bemerkenswert zu sehen, wie Tatian in einer äußerst originellen Weise diese Auffassung einer bloß scheinbaren Kraft der Dämonen (über die Menschen) mit dem Bild der Dämonen als Herrscher der Städte zusammenstellt: "Ihr (scil. die Griechen) habt mehr die ,Vielherrschaft"

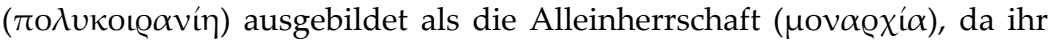
den Dämonen zu folgen pflegt, als seien sie mächtig“ (vgl. Mt 12,29). ${ }^{87}$ An dieser Stelle führt Tatian eine politische Begründung des Monotheismus an, indem er der griechischen Polyarchie und dem Polytheismus, d.h. der Dämonenverehrung, die römische Monarchie und den christlichen Monotheismus entgegensetzt. Die Zusammenstellung von Dämonen und Herrschern ist dabei besonders bemerkenswert, da sie die Verknüpfung des biblischen Themas der Engel der Nationen (Dtn 32,8; vgl. Dan 10,13-21; Jes 24,1f.) einerseits mit der griechischen Vorstellung der Dä-

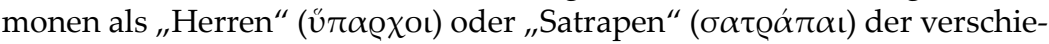
denen Regionen der Erde andererseits bezeugt, eine Vorstellung die von der pseudo-aristotelischen Schrift De mundo 398a18-23 ausgeht (aber letzt-

\footnotetext{
${ }^{82}$ Justin, 1 Apol. 58. Wie in der Gen ist der Dämon der „Verführer“, der versucht, die Menschen in die Sünde zu führen (1 Joh 3,8; 1 Kor 7,5) und sie mit Gott in Widerstreit zu stellen (Apg 5,3f.; vgl. 1 Thess 3,5).

${ }^{83}$ Tatian, Or. 16,3.

${ }^{84}$ Tatian, Or. $14,2$.

${ }^{85}$ Tatian, Or. 16,3.

${ }^{86}$ Plotin, Enn. III 5,7,30-39.

${ }^{87}$ Tatian, Or. 14,1.
} 
lich auf Platon, Leg. IV 713c-d und Kritias 109b-c, zurückgeführt werden kann) und im Mittelplatonismus ausgebildet wurde. ${ }^{88}$ Diese Vorstellung wurde in der frühchristlichen Theologie aus dem Mittelplatonismus (und vornehmlich von Philon, wenn nicht direkt aus De mundo $)^{89}$ geerbt, wobei Tatian hier keineswegs eine Ausnahme ist.

\subsection{Die Tätigkeiten der Dämonen}

Tatian ist dagegen viel origineller in der Darstellung der (bösen) Tätigkeiten der Dämonen. Im Gegensatz zu Justin, Athenagoras und Clemens von Alexandria ${ }^{90}$ zeigt er wenig Interesse an der Erklärung der traditionellen Opferriten als Formen des Dämonenkults. ${ }^{91}$ Laut Tatian unterstehen die Menschen den Dämonen vornehmlich durch die Praktiken der Astrologie, der Mantik, der Zauberei und der „Heilkunde“ $(\varphi \alpha \varrho \mu \alpha \kappa \varepsilon i ́ \alpha) .{ }^{92}$

\subsubsection{Die Astrologie}

„Da sie (scil. die Dämonen) ihnen (scil. den Menschen) nämlich einen Plan mit der Stellung der Sterne zeigten - wie die, die mit Würfeln spielen -, führten sie die Heimarmene ein, eine außerordentlich ungerechte Macht. "93 Laut Tatian sind die Dämonen also als Ursprung der Astrologie zu betrachten, mittels welcher sie den Glauben ans Schicksal stärken und den Menschen von Gott ablenken. Im Rahmen seiner allgemeineren Auseinandersetzung mit dem stoischen Determinismus führt Tatian somit eine anti-astrologische Polemik durch, indem er ein dämonologisches Argument in einer bemerkenswerten Weise bemüht. ${ }^{94}$ Zunächst ist dabei wichtig festzustellen, dass Tatian im Zusammenhang dieser Polemik den

\footnotetext{
${ }^{88}$ Philon, Somn. I 140; Maximos von Tyros, Or. 11,12d; Origenes, C. Cels. VIII 35,2-7. Vgl. TімотіN 2012, 110-112. 128-132.

${ }^{89}$ Vgl. Clemens, Strom. VI 157,5; VII 6,4; Athenagoras, Leg. 24; Cicero, Nat. II $164 \mathrm{f}$.

${ }^{90}$ Justin, 2 Apol. 5; Athenagoras, Leg. 26; Clemens, Protr. II 41,3.

${ }^{91}$ Dennoch kann man bei Tatian (Or. 29) den auch von Justin und Pseudo-Clemens angeführten Gedanken geäußert finden, die Götter/Dämonen würden am Blut der ihnen gebrachten Opfer Gefallen finden.

92 Tatian, Or. 8f., 12 und 14-19. Für andere Listen der opera diaboli vgl. J. H. WAszinK, „Pompa diaboli“, VigChr 1 (1947) [13-47] 35. Zauber und Astrologie sind schon in der jüdischen Apokalyptik stark verbunden, ein Gedanke, der nicht nur bei Tatian, sondern auch bei Justin (1 Apol. 14,1; 2 Apol. 5,4) und bei Tertullian (Apol. 35,12; Cult. fem. I 2,1; II 10,3) ein Echo findet; vgl. VAN DER NAT 1976, 748f.

${ }^{93}$ Tatian, Or. 8,1; vgl. ebd. 9,2; Tertullian, Cult. fem. I 2,1 (die Engel haben den Menschen die Astrologie beigebracht); Idol. 9; Justin, 2 Apol. 7 (die Verbindung zwischen den Dämonen und dem stoischen Determinismus).

${ }^{94}$ Zur Ablehnung der Horoskop-Anbetung seitens der Christen s. Gundel 1992, 32. Dabei wurden aber, wie Gundel hervorhebt, die Figuren des Horoskops gelegentlich auch mit den 12 Aposteln, den 12 Patriarchen und den 12 Engeln des Paradieses identifiziert. Zur ambivalenten Haltung gegenüber der Astrologie im frühen Christentum s. BARTON
} 
Einfluss des Horoskops und der Planeten auf das Leben der Menschen keineswegs leugnet, wie es eine allgemein verbreitete Meinung zu seiner Zeit war; indessen schreibt er diese bloß einer dämonischen Ablenkung zu. Die Dämonen haben das von den Sternen geleitete Schicksal eingerichtet, und somit den Zugang des Menschen zum Himmel gesperrt, damit sie selbst verehrt würden, als ob sie im Himmel hausten. ${ }^{95}$ Die zwei miteinander verwandten Vorstellungen, die ihre Wurzel im hellenistischen Judentum haben (jene von den Dämonen als Usurpatoren Gottes und als Betrüger der Menschen, welche sie geflissentlich von Gott ablenken), besetzen eine zentrale Stelle in Tatians Dämonologie sowie auch in seiner anti-astrologischen Polemik.

Dabei muss zugleich festgestellt werden, dass das enge Verhältnis zwischen dem $\delta \alpha i ́ \mu \omega v$ und dem menschlichen Schicksal sonst in der altgriechischen Dichtung gut bezeugt ist und - sogar bedeutender - die mittelplatonische Tradition beeinflusst hat, die den $\delta \alpha i ́ \mu \omega v$ zu einer Figur der individuellen Vorsehung umgedeutet hat. ${ }^{96}$ Zugleich konnte die Zusammenstellung der Horoskopfiguren mit den traditionellen Göttern in der hellenistischen Astrologie, ${ }^{97}$ zusammen mit der allgemein herrschenden mittelplatonischen und frühchristlichen ,Daimonisierung' des griechischen Pantheons, konsequenterweise zu einer Dämonisierung des Horoskops führen. ${ }^{98}$ Diese Tendenz ist vermutlich durch die angelologischen Spekulationen des hellenistischen Judentums geschärft worden, die etwa in dem Gedanken ihren Ausdruck finden, die Bahnen der Sterne, aber auch die Jahreszeiten und die Monate seien von den Engeln geleitet und die Drehbewegungen der Himmel würden gemäß der Anzahl der Engel erfolgen. ${ }^{99}$

Man könnte somit meinen, dass Tatian die Dämonen als Herren der himmlischen Bewegungen betrachte, ein Gedanke, den auch die (groteske) Vorstellung unterstützt, die Götter/Dämonen fänden Gefallen daran, das Spiel der planetengelenkten menschlichen Leben $\mathrm{zu}$ beobachten. ${ }^{100}$ Dennoch erklärt Tatian in einer etwas konfusen Weise, dass die heidnischen Götter, die eigentlich Dämonen sind, ihrerseits samt ihrem Fürsten

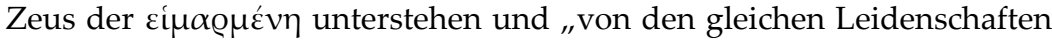

1994, 71-77; B. Вакноuche, L'astrologie à Rome. Bibliothèque d'études classiques 29 (Louvain 2002) $111 \mathrm{f}$.

${ }^{95}$ Tatian, Or. 9,1.

${ }^{96}$ Vgl. Timotin 2012, 85-161.

${ }^{97}$ Vgl. z.B. Plutarch, De Is. 48. S. dazu Bouché-Leclerce 1899, 132-148; Gundel 1992, 30f., auch zur Anbetung der als Talismane und Amulette gebrauchten Figuren des Horoskops.

${ }^{98}$ Vgl. Bouché-Leclerce 1899, 220; Bidez / Cumont 1938, I $177 f$.

991 Henoch 82,6-12; 83,2; vgl. Offb 1,20. Clemens von Alexandria (Ecl. proph. 55,1, 152.14-15 StÄHLIN-Früchtel) spricht auch davon, dass die Sterne die Herrschaft über die Welt mit den von Gott bestellten Engeln teilen, was eine astrologische Adaptierung des Themas der Engel der Nationen darstellt. S. auch Bouché-Leclerce 1899, 623; Bidez / CuMONT 1938, I 187.

${ }^{100}$ Tatian, Or. 9,2. 


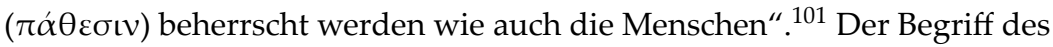

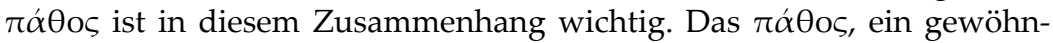
liches Attribut der Dämonen im Mittelplatonismus ${ }^{102}$ (wo zwischen den

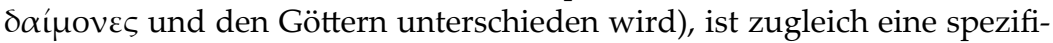

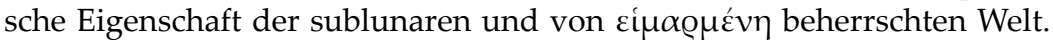

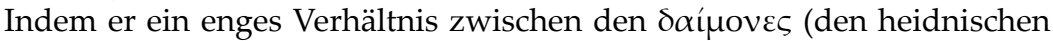

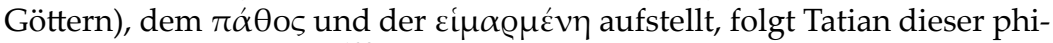
losophischen Tradition. ${ }^{103}$ Der Gedanke eines unerbittlichen, auf den Einfluss der Dämonen zurückgeführten Schicksals ist in der Oratio auch im

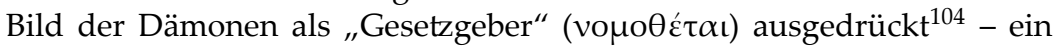
Bild, das platonischen Vorstellungen verwandt ist (vgl. Leg. IV 713d-e), aber auch Wurzeln in der altgriechischen Religion hat (die $\delta \alpha i ́ \mu o v \varepsilon \varsigma$ als

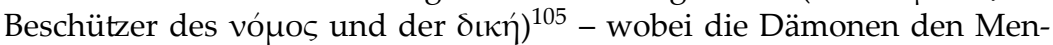
schen "Gesetze des Todes" gegeben haben sollen. ${ }^{106}$

Laut Tatian sind die Christen von diesem dämonischen Verhängnis nicht betroffen; sie „stehen höher als die Heimarmene“;107 "anstelle der herumirrenden Planeten-Dämonen $(\pi \lambda \alpha v \eta \tau \tilde{\omega} v \delta \alpha \iota \mu o ́ v \omega v)^{\prime \prime}$ - die Planeten sind (sichtbare) Götter und somit, für Tatian, Dämonen im neutestamentlichen Sinn -, haben sie „,... einen Herrn, der nicht irrt, kennengelernt ${ }^{\prime \prime}{ }^{108}$ Als ein Gegenmittel zum negativen Einfluss der Astrologie und der heidnischen Götter, die damit verbunden werden, betrachtet Tatian die Verehrung des wahren (und einzigen) Gottes. Dieser Gedanke war nicht ungewöhnlich für seine Zeitgenossen. Er wurde geteilt sowohl von einigen der Gnostiker, wie Theodotos, als auch von einigen Neuplatonikern, wie Plotin. ${ }^{109}$ Laut Theodotos ist etwa die $\varepsilon \dot{\mu} \mu \alpha \varrho \mu \varepsilon ́ v \eta$ der Ausdruck der (gegenläufigen) Tätigkeiten der Dämonen, wobei diese mittels des Horoskops und der Planeten darüber herrschen. ${ }^{110}$ Jeder Planet beherrscht als solcher die Wesen, die während seiner Aszendenz geboren wurden: Einige

\footnotetext{
101 Tatian, Or. 8,2.

102 Vgl. Xenokrates, Fr. 23 Heinze = 222 Isnardi Parente; Maximos von Tyros, Or. 9,4; Apuleius, De deo Socr. XIII 147f.; Origenes, C. Cels. VIII 35; Calcidius, In Tim. 131. S. Tiмotin 2012, 122-125.

${ }^{103}$ Eher am heidnischen Kultus als an der Astrologie interessiert, stellt Justin (2 Apol. 5)

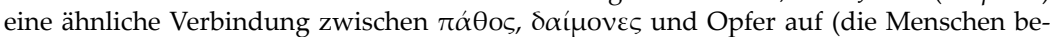
gannen die Dämonen durch Opfer und Libationen zu verehren, da sie von ihren Leidenschaften beherrscht waren).

104 Tatian, Or. 9,3.

${ }^{105}$ Vgl. Tімотіn 2012, 26. 73. 81.

106 Tatian, Or. 15,9; vgl. 9,3.

107 Tatian, Or. 9,3.

${ }^{108}$ Tatian, Or. 9,3.

${ }^{109}$ S. A. TiмотıN, „Le traité 52 (II, 3) de Plotin. Critique de l'astrologie et polémique antignostique", in: Plotin et les Gnostiques. Colloque en hommage à Pierre Hadot (EPHE-Université Paris Ouest Nanterre, 8-9 December 2011) (Paris, im Druck).

${ }^{110}$ Clemens, Excerpta ex Theodoto 69-70 SAIGNARD.
} 
sind uns günstig, andere nicht. Laut dem Marsanes - einem der Sethianischen Bewegung zugehörigen gnostischen Traktat aus dem späten dritten (oder frühen vierten) Jahrhundert, der wahrscheinlich in Alexandria abgefasst wurde - sind die Sterne und die Planeten auch von Engeln beherrscht, die mit den Figuren des Horoskops verknüpft werden. ${ }^{111}$ Für Theodotos, wie auch in der hermetischen Tradition, ${ }^{112}$ ist nur die Gnosis (die gnostische Taufe) fähig, uns vom Schicksal zu befreien. ${ }^{113}$

Wie Theodotos und Tatian räumt Plotin der Astrologie eine gewisse Wirksamkeit ein (der Kosmos wird als ein Lebewesen betrachtet, dessen Teile gegenseitig voneinander abhängen), obzwar sich diese bloß auf die materielle Welt beschränkt; insofern sich die Seele aber zum Göttlichen (zum Bereich des Intelligiblen) hinwenden kann, ist sie durchaus frei von allen astrologischen Einflüssen. ${ }^{114}$ Der Einfluss der Sterne betrifft nur den Leib und die unteren Stufen der Seele; wenn die Seele diesen Teilen unterliegt, ist sie unerbittlich an das Schicksal gebunden; wenn sie aber dem intelligiblen Sein zugewendet bleibt, ist die Seele absolut frei von jedem himmlischen Einfluss, der ihre oberste Stufe nicht berühren kann. Ähnlich wie Theodotos und Tatian ist also auch Plotin (wahrscheinlich nicht ohne einen gewissen polemischen Hintergedanken) bestrebt, ein geistiges (obzwar weniger religiöses) Gegenmittel zum astrologischen Determinismus bereitzustellen.

\subsubsection{Die Mantik}

Die Zurückweisung der Mantik ( $\mu \alpha v \tau \iota \kappa \eta ́)$ ist bei Tatian ${ }^{115}$ eine direkte Konsequenz seiner Dämonisierung des griechischen Pantheons. Zunächst ist die Mantik verachtenswert, da sie bloß dazu nützt, weltliche Vorteile zu erlangen (im Krieg, in der Liebe oder bei der Heilung von Krankheiten), und dabei mit weltlichen und vulgären Mitteln arbeitet (Tiere, Vögel usw.). Aber diese Züge sind bloß das Resultat ihres dämonischen Charakters, ${ }^{116}$ der implizit auf ihre Verbindung mit den menschlichen Leidenschaften zurückgeführt wird. ${ }^{117}$

\footnotetext{
${ }^{111}$ Marsanes 25,1-14 (W.-P. Funk / P.-H. Poirier / J. O. Turner [Hg.], Marsanès (NH X). Bibliothèque copte de Nag Hammadi [Québec / Louvain 2000] 287, und für die Kommentare, 414).

${ }^{112}$ Vgl. z.B. Corpus Hermeticum XVI 15.

${ }^{113}$ Clemens, Excerpta ex Theodoto 76-78 SaIgnard. Für andere ähnliche gnostische Belege s. BARTON 1994, 73f.

${ }^{114}$ Plotin, Enn. II 9,7-9. Zu Plotins Kritik der Astrologie s. J. M. Dillon, „Plotinus on whether the Stars are Causes“, in: R. Gyselen (Hg.), La Science des cieux. Sages, mages, astrologues. Res Orientales 12 (Bures-sur-Yvette 1999) 87-92.

115 Tatian, Or. 19,6-8.

116 Tatian, Or. 19,5.

117 Tatian, Or. 19,9.
} 
Diese Kritik ist freilich nicht originell. Zur Zeit Tatians wurde die Wirksamkeit der Orakel im Mittelplatonismus gewöhnlich durch den Eingriff

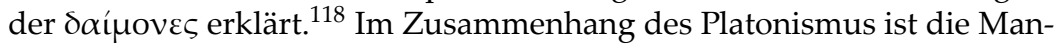
tik ohnehin traditionsgemäß ein Tätigkeitsbereich der $\delta \alpha i ́ \mu o v \varepsilon \varsigma$, so wie dies an einer grundlegenden Stelle bei Platon, Symp. 202d-e, dargestellt ist. Somit wird - gemäß einer von Kleombrotos in Plutarch, De def. or. 10-23 angeführten Lehre - die Wirksamkeit des delphischen Orakels und das Verstummen einiger Orakelstätten nicht durch einen direkten Eingriff der

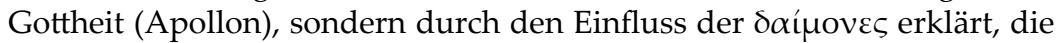
als Zwischenwesen zwischen den Göttern und den Menschen angesehen werden. Diese unterliegen ihrerseits den Leidenschaften, dem Wandel und dem Tod, was auch das Aussterben einiger Orakel oder die Schwächung ihrer Wirksamkeit erklärt. Immerhin war aber diese ,Daimonisierung' (im platonischen Sinn) der griechischen Orakel nicht eigentlich eine Kritik an der Mantik, die vielmehr als eine traditionelle und ansehnliche Institution in der griechischen Welt galt, sondern einfach ein Versuch, sie der platonischen Theologie anzupassen.

Darüber hinaus war ein anderer Punkt der Tatian'schen Kritik an der Mantik - nämlich die Behauptung, die Inspiration der Propheten habe ihrerseits materielle Ursachen ${ }^{119}$ - ein Gemeinplatz der Stoa, ${ }^{120}$ obgleich dies keineswegs als eine Entehrung oder als eine Bezweiflung ihres göttlichen Charakters gemeint war, da im Gegenteil, wie Plutarch versucht hat zu zeigen (in der quasi-stoischen Rede des Lamprias in De defectu oraculorum), die Erklärung des Orakels durch ein stoffliches Pneuma ${ }^{121}$ nicht unvereinbar ist mit ihrem göttlichen Charakter, da das stoische stoffliche Pneuma, im Gegensatz zu jenem Tatians, doch noch eine göttliche Dimension behält.

Immerhin war die ,Daimonisierung' (im platonischen Sinn) etlicher traditioneller religiöser Institutionen - wie der Mantik, der Initiationsriten oder der Opfer - Teil einer theologischen Auslegung der griechischen Religion, die dazu neigte, diese religiösen Praktiken einem geistlicheren und innerlicheren Kultus entgegenzusetzen, der einem theologischen Ansatz zur Religion näher stand. Plutarch eröffnet diese Tendenz, die hauptsächlich im zweiten und dritten Jahrhundert durch Platoniker wie Maximos von Tyros, Apuleius und Porphyrios ${ }^{122}$ belegt wird. Porphyrios unterscheidet mit jenem außergewöhnlichen Sinn für Unterschiede und Hier-

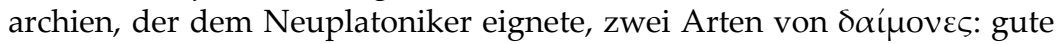

\footnotetext{
118 Plutarch, De def. or. 13 (417A); 15 (418C-D); Apuleius, De deo Socr. VI 133-136; Maximos von Tyros, Or. 8,1-3; Porphyrios, Abst. II 41,3; II 53.

119 Tatian, Or. 19,3; vgl. Origenes, C. Cels. III 25; Johannes Chrysostomos, In ep. 1 Cor. Hom. XXIX 1, PG 61, 242.

${ }^{120}$ Vgl. Cicero, Div. I 19,37; I 50,115.

${ }^{121}$ Plutarch, De def. or. 39f. Zu dieser Lehre und ihren stoischen Entsprechungen s. VerBEKE 1945, 260-287.

${ }^{122}$ Vgl. Tiмотіn 2012, 201-215.
} 


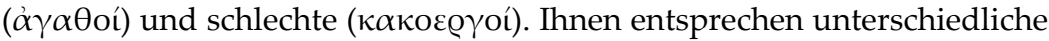
religiöse Praktiken. ${ }^{123}$ Etliche der unteren, schlichteren Riten (wie etwa die menschlichen Opfer) wurden der zweiten Kategorie zugerechnet, was eine allgemeine dämonische (im neutestamentlichen Sinn) Auslegung der griechischen Religion förderte. Obwohl Porphyrios im Allgemeinen die Weissagung den guten $\delta \alpha i ́ \mu o v \varepsilon \varsigma^{124}$ zuschreibt, hat Eusebios von Caesarea diese Stelle im Gegenteil als Beleg gebraucht, um zu beweisen, dass die griechische Wahrsagung ein Werk böser Dämonen ist. ${ }^{125}$ Wie dem auch sei, war die christliche Kritik an der griechischen Mantik als einem Werk der Dämonen im zweiten und im dritten Jahrhundert schon gut etabliert, ${ }^{126}$ als Tatian sie als einer der ersten äußerte.

\subsubsection{Die Magie}

Im 17. Kapitel seiner Oratio erwähnt Tatian in polemischer Absicht zwei Traktate, die Demokrit bzw. Ostanes zugeschrieben werden. ${ }^{127}$ Der eigentliche Verfasser der letzteren Schrift war ein gewisser Bolos aus Mendes, der im dritten Jahrhundert v. Chr in Ägypten lebte und einen Traktat Пzœi $\sigma v \mu \tau \alpha \theta \varepsilon \iota \tilde{\omega} \nu \kappa \alpha \dot{\imath} \alpha \dot{v} \tau \iota \tau \alpha \theta \varepsilon \iota \tilde{\omega} \nu$ schrieb. Dieser gründet auf der Lehre, dass ,sympathetische' Mittel, d.h. Heilmittel und Amulette, sowohl um zu heilen als auch um zu zerstören gebraucht werden können. ${ }^{128}$ Entgegen dieser Lehre behauptet Tatian, dass ein „Leiden“ ( $\pi \alpha ́ \theta 0 \varsigma)$ nicht durch „Antipathie“ entfernt werden könne; somit ist jedes Amulett nutzlos: „Der, der verrückt ist, wird nicht durch Anhängsel am Lederriemen geheilt. “129 Da-

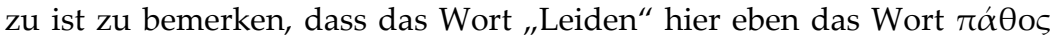
übersetzt, und wir haben schon früher gesehen, wie wichtig dieser Termi-

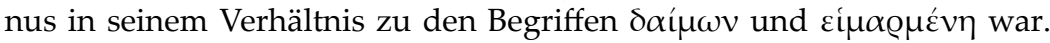
Demnach ist es keineswegs überraschend, dass die sympathetische Magie sowohl mit den Dämonen als auch mit den Leidenschaften verknüpft wird: „Dämonen-Heimsuchungen gibt es, und der Kranke, der seine Liebe Beteuernde, der Hassende und der, der sich rächen will, nehmen diese Wesen

\footnotetext{
${ }^{123}$ Porphyrios, Abst. II 38; II 54-57; II 58,2.

${ }^{124}$ Porphyrios, Abst. II 41,3. Dieser Gedanke wird von Iamblich scharf abgewiesen, De myst. III 7,114,6-9.

${ }^{125}$ Eusebios, PE IV 19,3. Proklos (In Remp. I 41,22-25) wird gerade diese Auslegung behalten, gemäß welcher die Dämonen die Stelle der Götter usurpieren, indem sie an ihrer Stelle den Menschen Orakel geben.

${ }^{126}$ Vgl. Athenagoras, Leg. 26,3f.; 23,2; Tertullian, Apol. 22,10; Minucius Felix, Oct. 27,1; Ps.-Clemens, Hom. IX 16f.; Origenes, C. Cels. IV 92.

${ }^{127}$ Tatian, Or. 17,1. Zu dem Ostanes zugeschriebenen Buch (oder Büchern) s. BidezZ / CuMONT 1938, I 167-174; II 295.

${ }^{128}$ Vgl. Waszink 1954; J. Letrouit, „Bolos de Mendès“, DPhA II (1994) $133 f$.

${ }^{129}$ Tatian, Or. 17,3. Zu dieser Stelle, die wahrscheinlich aus Bolos von Mendes übernommen wurde, vgl. die Ausführungen von Bidez / Cumont 1938, I 189.
} 
als Beistand. “130 Die Heilmittel und die Amulette selbst haben an sich gar keinen Wert und rufen keine Wirkung hervor ${ }^{131}$ (deshalb ist es sinnlos zu

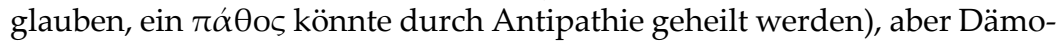
nen benutzen sie so wie sie auch die Sterne benutzen, um die Schicksale der Menschen zu beherrschen (indem sie in beiden Fällen die Sympatheia gebrauchen, welche die Teile des Kosmos aneinander bindet). ${ }^{132}$ Insofern die Menschen zu diesen Mitteln greifen (und von den Leidenschaften bewegt werden, die diese angeblich heilen), nehmen sie die Dienste der Dämonen hin und werden somit von ihnen geführt.

Zum Ursprung dieser Auffassung ist wichtig festzuhalten, dass neben

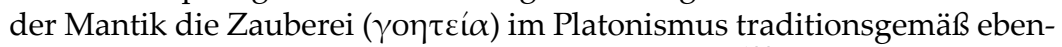
falls als ein Bereich der $\delta \alpha$ í $\mu$ ov $\varsigma$ betrachtet wurde. ${ }^{133}$ Insofern sie als solche auf einer gewissen Form der Überzeugungskunst ( $\pi \varepsilon i \theta \varepsilon \varepsilon v)$ beruht,

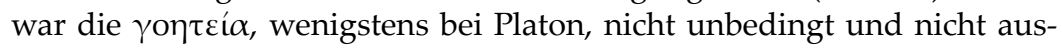
schließlich in einer negativen Weise aufgefasst. Obwohl sie in den Leges

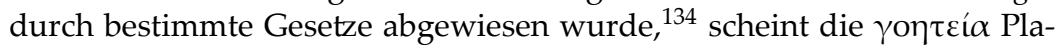
tons doch auch eine nützlichere und glaubwürdigere Seite aufzuweisen, insofern sie mit der Dichtung, der Liebe und der Philosophie verwandt ist. Im Symposion und im Menon wird Sokrates zweimal als $\gamma$ ó $\varsigma^{135}$ bezeichnet, während seine Maieutik mit der Inkantation verglichen wird. ${ }^{136}$ Als ein ,guter Zauberer' gebraucht Sokrates eine richtige Form der Überzeugungskunst, indem er wahre Reden herstellt, ${ }_{137}$ im Unterschied zu den Sophisten, die als ,schlechte Zauberer' dargestellt werden und einen schlechten Gebrauch von der Magie des Logos machen.

Dagegen sollte aber die platonische Tradition dieses Erbe nicht aufneh-

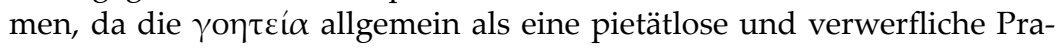
xis betrachtet wurde, gemäß einer Auffassung, die jener Tatians durchaus

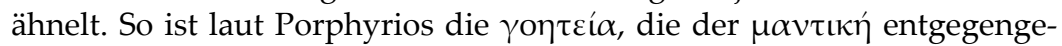

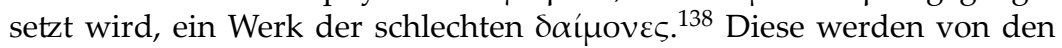
Zauberern verehrt ${ }^{139}$ und sollen angeblich die Unwissenden dazu antreiben, „böse Tränke und Liebesamulette“ zu gebrauchen, eine Auffassung,

\footnotetext{
${ }^{130}$ Tatian, Or. 17,3.

131 Tatian, Or. 17,4: „in ähnlicher Weise sind auch die vielfältigen Anwendungen von

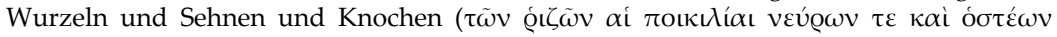
$\tau \alpha \varrho \alpha \lambda \eta ́ \psi \varepsilon \iota \varsigma)$ nicht an und für sich irgendwie wirkmächtig, sondern sie sind die Instru-

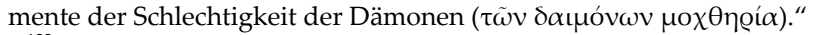

${ }^{132}$ Vgl. Tertullian, Cult. femin. I 2,1; II 10,3; Apol. 35,12.

133 Vgl. z.B. Platon, Symp. 202e.

134 Platon, Leg. XI 932a-d.

135 Platon, Symp. 219e; Men. 80a.

136 Platon, Charm. 157a.

${ }^{137}$ Vgl. Platon, Symp. 215b-e.

138 Porphyrios, Abst. II 41,3.

139 Porphyrios, Abst. II 41,5.
} 
die bedeutende Parallelen im griechischen Judentum hat. Laut 1 Henoch sollen die Dämonen die Menschen Zauber gelehrt haben, um wie Götter verehrt zu werden, ${ }^{140}$ zwei Gedanken - nämlich: die Dämonen als Lehrer der Zauberpraktiken und als Betrüger der Menschen -, die auch bei Tatian stark verbunden sind. Es ist in der Tat wahrscheinlich, dass Tatian hier zwei Erbschaften miteinander verknüpft, die schon zu seiner Zeit zusammengebracht wurden.

\subsubsection{Die Heilkunde}

Die Bestimmung der Heilkunde ( $\varphi \alpha \varrho \mu \alpha \kappa \varepsilon i ́ \alpha)$ als ein Mittel der Dämonen ist sogar in der christlichen Überlieferung äußerst ungewöhnlich. Indessen behauptet Tatian, dass die $\varphi \alpha \varrho \mu \alpha \kappa \varepsilon i ́ \alpha$ sich in allen ihren Formen auf den Einfluss der Dämonen gründet. ${ }^{141}$ Somit werden $\tau \dot{\alpha} i \omega \dot{\mu} \mu v \alpha$ und $\tau \dot{\alpha}$

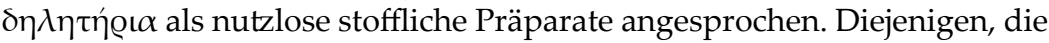

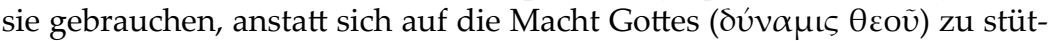
zen, setzen ihr Vertrauen in die Materie und werden so zu Opfern der dämonischen Tätigkeiten. ${ }^{142}$

Anscheinend macht Tatian dabei gar keinen Unterschied zwischen Magie und Heilkunde, indem er auch letztere als eine Zusammenstellung von materiellen Elementen erklärt, die die Dämonen gebrauchen, um die Menschen zu täuschen. Indessen scheint dem doch nicht ganz so zu sein. Im Gegensatz zur Zauberei war die Heilkunde in Griechenland wie überall in der antiken Welt ein Attribut der heilenden Götter. Somit bedeutet die Bestreitung der Heilkunde nichts anderes als die Leugnung jener Kraft, die den heilenden Göttern zugesprochen wurde. Deshalb ist Tatian nicht an der Arzneikunde selbst interessiert, sondern an der göttlichen Kraft, die dahinter angenommen wurde: „Nicht wirklich heilen können die Dämonen, sondern sie machen durch Trickserei die Menschen zu ihren Gefangenen. " ${ }^{143}$ Dabei verursachen sie selbst jene Krankheiten und spiegeln den Menschen durch Träume vor, sie könnten diese heilen. ${ }^{144}$ Wie Räuber nehmen sie die Menschen als Gefangene und befreien sie nur gegen Zahlung.

Offensichtlich bezieht sich Tatian hier auf jene göttlichen Heilungen, in denen „die angeblichen Götter“ ihre Patienten besuchen; „,sodann betreiben sie durch Träume die Erzeugung einer Reputation für sich selbst, ${ }^{145}$ befehlen denen, die sich in solchem Zustand befinden, öffentlich aufzutre-

\footnotetext{
${ }^{140} 1$ Henoch 8,3 .

${ }^{141}$ Tatian, Or. 18,1.

${ }^{142}$ Tatian, Or. 18,1.

${ }^{143}$ Tatian, Or. $18,5$.

${ }^{144}$ Tatian, Or. 18,6; vgl. Tertullian, Apol. 22,4; De an. 46,12. Eine andere Erklärung der göttlichen/dämonischen Heilung kann gefunden werden bei Ps.-Clemens, Hom. IX 14 (hier kennen die Dämonen wirklich die richtigen Heilmittel).

${ }^{145}$ Derselbe Gedanke wird auch von Justin geäußert, 1 Apol. 14,1.
} 
ten " ${ }^{146}$ was höchst wahrscheinlich einen Hinweis auf jene Art von Lobreden darstellt, wie Aelius Aristides sie verfasste. Da die Theophanien der heidnischen Götter zu Tatians Zeit gewöhnlich als Epiphanien der Dämonen (im mittelplatonischen Sinn) ausgelegt wurden, ${ }^{147}$ war es Tatian keineswegs schwer, die nächtlichen Theophanien der heilenden Götter (z.B. Asklepios) mit den dämonischen Erscheinungen ${ }^{148}$ und ihre göttliche ärztliche Kunst mit einer illusorischen dämonischen Tätigkeit, die die Menschen bloß von der wahren Ursache ihrer Heilung ablenkt, gleichzusetzen.

\section{Schluss}

Tatians in der Oratio dargelegte Theologie ist vornehmlich bemerkenswert (obzwar nicht außergewöhnlich im Zusammenhang des frühen Christentums) wegen der gänzlichen Abwesenheit einer Christologie und der fast ausschließlich kosmologischen Funktion, die dem Logos zugesprochen wird, der hier in einer platonischen Perspektive hauptsächlich als organisierendes Prinzip des Kosmos betrachtet wird. Der Logos und das göttliche Pneuma drücken die Anwesenheit eines transzendenten und unveränderlichen Gottes in der sublunaren Welt aus, eine Auffassung, die Tatian durchaus mit der mittelplatonischen Theologie teilt. Darüber hinaus spielt das göttliche Pneuma auch in der Heilsgeschichte eine wichtige Rolle, im Zusammenhang mit der Funktion, die hier den Dämonen zugeschrieben wird, da das Ziel der Dämonen gerade darin besteht, die Menschen daran zu hindern, sich wieder mit dem $\theta \varepsilon \tilde{\imath} о v \pi v \varepsilon \tilde{v} \mu \alpha$ zu vereinigen und so der Unsterblichkeit habhaft zu werden. Das wesentliche Merkmal der Dämonen ist ihre Tendenz, die Position Gottes zu usurpieren, um an seiner Stelle verehrt zu werden, ein Merkmal, das durch ihre aus dem Mittelplatonismus (entstellt) übernommene Identifikation mit den heidnischen Göttern geschärft wird. Diese Tendenz erweist sich laut der Oratio in verschiedenen Bereichen, wie etwa Astrologie, Mantik und Heilkunde, die freilich obzwar gewöhnlich ohne negative Konnotationen - auch für die mittelplatonischen $\delta \alpha i ́ \mu o v \varepsilon \varsigma$ bevorzugte Bereiche waren. Somit kann man sagen, dass Tatian wissentlich wesentliche Züge der mittelplatonischen Dämonologie aufgenommen und modifiziert hat, um sie in einer scharfen (und in vielen Hinsichten paradoxalen) Kritik an dem griechischen Polytheismus und allgemeiner an der griechischen $\pi \alpha \iota \delta \varepsilon i ́ \alpha$ einzusetzen. ${ }^{149}$

\footnotetext{
${ }^{146}$ Tatian, Or. 18,6 .

${ }^{147}$ S. oben Anm. 78.

${ }^{148}$ Eine eindrucksvolle Parallele dazu ist bei Porphyrios zu finden (Abst. II 42,1). Laut Por-

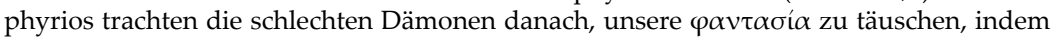
sie uns vorspiegeln, die Götter würden sich uns in (nächtlichen) Theophanien offenbaren. Vgl. Ps.-Clemens, Hom. IX 14,2f.; IX 15,1; Justin, 1 Apol. 14,1; Athenagoras, Leg. 25.

${ }^{149}$ Vgl. dazu den Beitrag von P. Gemeinhardt in diesem Band, S. 253-264.
} 


\title{
Spuren Tatians und seiner Oratio ad Graecos in der christlichen Literatur der Spätantike
}

\author{
Adolf Martin Ritter
}

\section{Vorbemerkungen}

Wenn im Folgenden von ,Einfluss' die Rede ist, dann womöglich in einem anderen, weiteren Sinne, als das Leserinnen und Leser in ihrer Mehrheit erwarten mögen. Verstanden wird darunter nämlich jede Art von Reaktion auf ein Ereignis oder menschliches Tun und Lassen. In diesem Fall steht Tatians Wirken im Fokus, soweit es sich in seinem erhaltenen oder doch wenigstens in gewissem Umfang rekonstruierbaren Schrifttum, aber nicht ausschließlich darin, niedergeschlagen hat. Der Schwerpunkt der folgenden Darstellung liegt allerdings, wie in diesem Band nicht anders zu erwarten, auf den Spuren, die die Oratio ad Graecos als das einzige uns vollständig erhaltene Werk Tatians in der theologischen Literatur der Spätantike hinterließ.

Wäre es anders und ginge es lediglich um die eindeutig nachzuweisende, unmittelbare und prägende Wirkung, die unser Autor auf Zeitgenossen oder Nachgeborene ausübte, so wäre das mir gestellte Thema rasch abgehandelt. Denn von einem derartigen Einfluss Tatians lässt sich allenfalls bei dem Kleinasiaten Rhodon sprechen, der, wie der Kirchenhistoriker Euseb von Caesarea (gestorben um 340) zu berichten weiß, von sich selbst sagte, er sei „in Rom bei Tatian in die Schule gegangen“ ( $\mu \alpha \theta \eta \tau \varepsilon v \theta \varepsilon i \varsigma$ غ̇ $\pi i$

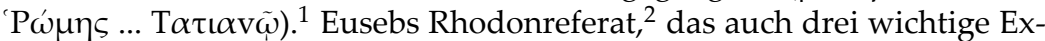
zerpte aus einer gegen den ,Ketzer' Markion (aus Sinope?) ${ }^{3}$ gerichteten Schrift des Tatianschülers einschließt, umschreibt bis zur Stunde unser gesamtes Wissen um den Betreffenden; wir werden deshalb auf dieses Referat später zurückkommen müssen.

Allerdings führt auch Clemens von Alexandria, an einer vieldiskutierten Stelle seiner Teppiche ( $\Sigma \tau \varrho \omega \mu \alpha \tau \varepsilon \tilde{\iota} \varsigma)$, unter denjenigen, bei denen

\footnotetext{
${ }^{1}$ Euseb, HE V 13,8.

${ }^{2}$ HE V 13,1-9.

${ }^{3}$ Nach seinem Ausschluss aus der römischen Christengemeinde im Juli 144 - es ist dies das einzig feststehende Datum aus seiner Biographie - wurde er zum Begründer einer Gegenkirche, die sich rasch ausbreitete und bis weit in die Zeit der Reichskirche hinein neben der catholica existierte.
} 
er auf seiner Bildungsreise Station machte und die speziell seine Lehrmeister im christlichen Glauben waren, „einen (Orientalen) aus dem Assyrerland" auf; ${ }^{4}$ und es gibt nicht wenige Forscher, die dabei an Tatian dachten und denken, welcher nach eigenem Bekunden aus eben dieser (nordmesopotamisch-syrischen) Region stammte. ${ }^{5}$ Allein, selbst wenn die genannte Identifizierung zutreffen sollte, so ist doch jedem Wissenden klar, dass, unerachtet allerlei im Werk des Clemens verstreuter positiver Urteile über Tatian, dessen Einfluss auf den Alexandriner nur begrenzt gewesen sein kann. Dennoch wird die Beschäftigung mit den clementinischen Tatiantestimonia, ihrer Anzahl wie der Fülle ihrer Aspekte wegen, einen breiteren Raum in unserer Darstellung einnehmen.

Eine letzte Vorbemerkung: wegen der - nicht allein unsere Tatianschrift betreffenden - Datierungsprobleme, ${ }^{6}$ von denen noch zu sprechen sein wird, ist es nicht in jedem Fall ohne weiteres auszumachen, ob ein bestimmtes Quellenzeugnis eine Reaktion auf Tatian darstellt oder ob die ,Beeinflussung' nicht vielmehr in umgekehrter Richtung erfolgt sein müsste. In all diesen Fällen ist also über Vermutungen nur schwer hinauszugelangen.

\section{Spuren Tatians in antiken Geschichtsquellen - ein Überblick}

Die weitaus zahlreichsten Spuren hat Tatian in antiken (und mittelalterlichen) Quellen mit seiner Evangelienharmonie, dem Diatessaron $(\Delta \mathrm{i} \alpha$ $\tau \varepsilon \sigma \sigma \alpha ́(\omega v)$, hinterlassen, ${ }^{7}$ über das wir, nach bisherigem Kenntnisstand, erstmals durch Euseb unterrichtet werden. ${ }^{8}$ Bedenkt man, in wie vielen Sprachen und Ländern, von England bis China, dieses Werk einstmals verbreitet war und über wie viele Jahrhunderte sich seine Bezeugungen erstrecken, so ist es schon berechtigt, es als "Tatians namhaftestes und dauerhaftestes Erbe" zu bezeichnen. ${ }^{9}$

\footnotetext{
${ }^{4}$ Clem. Alex. Strom. I 1,11,2 (8 StÄHLIN / FrüChTEL); vgl. zur Diskussion die bei Petersen 1994, 43 Anm. 26 versammelten Stimmen. Petersen selbst äußert sich über die angebliche Tatianschülerschaft des Clemens skeptisch, doch die von ihm genannten Gründe erscheinen mir als fragwürdig.

${ }^{5}$ Or. 42,1; vgl. zur Diskussion o. Einführung, S. 4-5.

${ }^{6}$ S.o. Einführung, S. 14-17.

${ }^{7}$ Vgl. dazu Petersen 1994 mit weiterer Literatur.

${ }^{8}$ HE IV 29,6. Wie Eusebs reichlich vage Ausdrucksweise: „Tatian verfasste irgend so et-

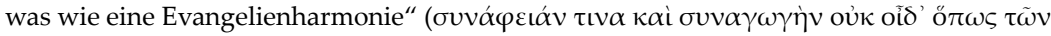
$\varepsilon \dot{v} \alpha \gamma \gamma \varepsilon \lambda \hat{i} \omega v$ $v v v \theta \varepsilon i ́())$ zeigt, hat er schwerlich ein Exemplar dieser ,Komposition' in Händen gehabt, sondern nur davon gehört; anders sein (anonymer) Übersetzer ins Syrische, wohl noch aus dem 4. Jh.; s. dazu die einschlägigen Texte und Diskussionen bei Petersen 1994, 35-37.

${ }^{9}$ Petersen 1994, 1.
} 
Wir jedoch haben keinen Anlass, uns an dieser Stelle näher damit zu befassen. Nur eine Frage sollte im Vorübergehen angesprochen werden: wie man sich eigentlich den Zusammenhang zwischen den beiden Hauptwerken Tatians, dem Diatessaron und Ad Graecos, vorzustellen habe. M. Elze zufolge, dem die bislang eingehendste Studie zu Tatians Theologie auf der Grundlage von Ad Graecos zu verdanken ist, musste der "Assyrer" einfach „im Zuge seiner Grundkonzeption ein übereinstimmendes, einheitliches Evangelienbuch herstellen", wenn anders es richtig ist, dass sich ihm - so Elzes Deutung - die „wahre Philosophie“ (d.h. das Christentum, ein Ausdruck, der in der fraglichen Schrift freilich nie benutzt wird!) als durch drei Grundzüge gekennzeichnet darstellt, nämlich ihren göttlichen Ursprung, ihr Alter und ihre Einheit(lichkeit). ${ }^{10}$ Daran ist sicherlich viel Bedenkenswertes; doch wird es so gut wie sicher noch weitere Antriebe zur Abfassung des Werkes ${ }^{11}$ gegeben haben, nicht zuletzt die heidnische (und jüdische) Kritik an den Widersprüchen zwischen den Evangelien, ${ }^{12}$ wie sie annähernd zur selben Zeit der mittelplatonische Philosoph Kelsos in seiner

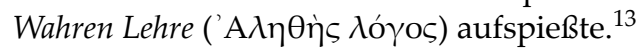

Rätselhaft ist auf den ersten Blick, warum die Rezeptionsgeschichte des Diatessaron und unserer Rede an die Griechen zwischen den ,westlichen' (gemeint: den griechisch-lateinischen im Unterschied zu den orientalischen) Kirchen und den Nationalkirchen des Orients so unterschiedlich verlief. Es beginnt schon mit dem Namen des Autors. Während dieser bereits von Irenäus (gestorben um 200), allerdings als ,Häretiker', namentlich genannt wird, ${ }^{14}$ taucht sein Name in einer orientalischen (diesmal syrischen) Originalquelle (wohlbemerkt: nicht in Übersetzungen ,westlicher' Quellen, wie Irenäus oder Euseb, in orientalische Sprachen) zum ersten Mal Ende des 8. Jh.s im Scholienbuch (Liber scholiorum) des Theodor bar Koni (791) auf, und zwar als der des „Griechen Tatian“!15 Und während im Westen, wie wir sehen werden, die Rede an die Griechen fürs erste in hohem Ansehen stand, wird das Diatessaron erstmals bei Euseb erwähnt (s.o.), aber so, dass man den Eindruck gewinnt, dieser habe keine unmittelbare Kenntnis davon besessen. Und als Bischof Viktor von Capua Mitte des 6. Jh.s in Italien

\footnotetext{
${ }^{10}$ ELze 1960, 126 im Vergleich mit 13. 34 u.ö.

${ }^{11}$ Bei dem Tatian übrigens bereits mindestens einen Vorgänger gehabt haben dürfte, nämlich seinen eigenen Lehrer Justin; vgl. Petersen 1994, 27-29.

${ }^{12} \mathrm{Vgl}$. dazu noch immer H. MERKEL, Widersprüche zwischen den Evangelien. Ihre polemische und apologetische Behandlung in der Alten Kirche bis zu Augustin. WUNT 13 (Tübingen 1971).

${ }^{13} \mathrm{Zu}$ diesem wie zu weiteren möglichen Faktoren s. die Diskussion bei Petersen 1994, 74-76. Dass auch Ad Graecos sich als implizite Erwiderung auf Kelsos verstehen ließe, versuchte Droge 1989, 97-101, plausibel zu machen. Die kaum zu entscheidende Frage ist allerdings, ob das alles aus chronologischen Gründen überhaupt möglich ist! Denn die Datierung des Kelsoswerkes (177-180?) ist nicht minder umstritten als die von Ad Graecos.

${ }^{14}$ Adv. haer. I 28,1; zit. bei Euseb, HE IV 29,2,3.

${ }^{15}$ Zitiert und kommentiert bei Petersen 1994, 51f.; Elze 1960, 122.
} 
auf ein Exemplar dieser Evangelienharmonie, ohne Verfassernamen und Titel, stieß, bedurfte es eingehender Recherchen, um beide Angaben zu ermitteln. ${ }^{16}$ Das spricht doch wohl dafür, dass Tatian und sein Diatessaron mittlerweile im Westen unbekannt waren.

Im Orient aber war es genau umgekehrt, zumindest was das Diatessaron betrifft. Denn dieses stand seit Ende des 2. Jh.s als Standardevangelium der syrischen Kirche in anscheinend unhinterfragtem Ansehen. Der Grund der Differenz könnte in der Tat der gewesen sein, dass das theologische Gedankengut, das Tatian nach seiner Trennung von der römischen Gemeinde (s.u.) in den heimischen Orient mitbrachte, dort dermaßen ins allgemeine christliche Bewusstsein eingegangen sein muss, dass der Name des Übermittlers um so eher vergessen werden durfte. ${ }^{17}$ Genau so gut ist freilich denkbar, dass man diesen, der zunehmenden Kritik des,Westens ${ }^{\prime}$ an diversen ,Irrlehren' des ,Assyrers' wegen, lieber für sich behielt.

Die Rede an die Griechen aber erfuhr dort anfänglich höchstes Lob. Euseb spricht gewiss für viele, westliche' Zeitgenossen und Vorgänger, wenn er schreibt:

\begin{abstract}
„(Der Mann) hinterließ eine Menge an Schriften, unter denen den größten Ruhm bei vielen seine Schrift An die Griechen genießt. Darin greift er auf längst vergangene Zei-

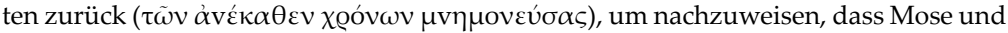
die Propheten der Hebräer älter sind als sämtliche berühmten Männer der Hellenen. Tatsächlich hat es den Anschein, als sei diese Schrift das schönste und nützlichste von allen Werken Tatians. ${ }^{\text {“18 }}$
\end{abstract}

Die "Menge an Schriften", von der hier die Rede ist, abgesehen von der einen, hochgelobten (und dem Diatessaron, von dem Euseb immerhin hat läuten hören), muss in Teilen zumindest noch Eusebs Lebzeiten überdauert haben. Denn sonst wäre so manches Echo, das an dem bis heute erhaltenen Werk des ,Assyrers' keinen erkennbaren Anhalt besitzt, nur schwer zu erklären. Tatian kommt in unserer Rede an die Griechen selbst auf weiteres Schrifttum zu sprechen; so in Kap. 15 auf eine Abhandlung „Über

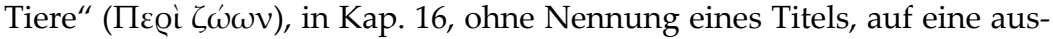
führlichere Beschäftigung mit der Frage, ob etwa der Mensch zu Lebzeiten geist- und kraftlos, als Toter hingegen von größerer Aktivität und Kraft sei, und damit auch über die Beziehung zwischen Dämonen, die den Menschen gebieten, sowie deren Seelen, endlich in Kap. 40 auf einen geplanten Traktat mit dem (kryptischen) Titel „An diejenigen, die (ihre) Ideen über

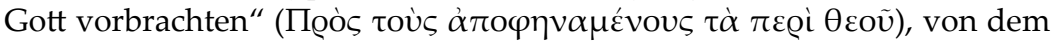
jedoch nicht feststeht, ob er dies Projekt je auszuführen vermochte. Da es sich in allen diesen Fällen, nur' um Weiterungen dessen handelte, was auch

\footnotetext{
${ }^{16}$ S. die Quellenangabe (Vorwort zum Codex Fuldensis) und Diskussion bei Petersen 1994, 45-51.

${ }^{17}$ Euze 1960, 121.

${ }^{18}$ HE IV 29,7 (392 Schwartz / MommSen).
} 
in Ad Graecos mindestens angedacht und -gedeutet wurde, lässt sich nicht entscheiden, worauf sich ein mögliches Echo des näheren bezieht; es muss damit offen bleiben, ob die betreffende Schrift zu der Zeit, aus der uns eine Reaktion auf eine bestimmte von Tatian behandelte Problematik vorzuliegen scheint, noch zugänglich war oder nicht.

Anders liegen die Dinge bei einem Buch, betitelt Probleme (dem Пळo $\beta \lambda \eta$ -

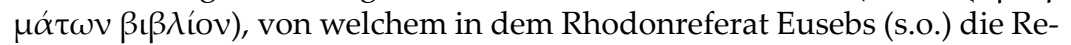
de ist. Es heißt dort:

„Da Tatian es auf sich nahm, darin die unsicheren und dunklen Stellen in den göttlichen

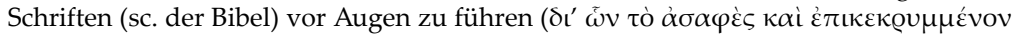

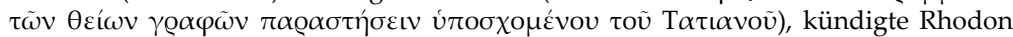
an, ${ }^{19}$ in einer eigenen Schrift Lösungen zu dessen Problemen zu bieten. ${ }^{\prime 20}$

$\mathrm{Ob}$ dieser Plan allerdings ausgeführt werden konnte, ist gleichfalls nicht bekannt. Klar ist hingegen, dass uns das Zeugnis des Tatianschülers über das hinausführt, was wir sowohl aus Ad Graecos als auch aus dem Diatessaron wissen können!

Das Gleiche gilt wohl (in der Hauptsache zumindest) von dem in patristischer Literatur vielstimmig erhobenen Vorwurf, Tatian habe in seinen Schriften Irrlehren vertreten. Das älteste Zeugnis dieser Art ist in dem umfangreichen antihäretischen Werk des Irenäus von Lyon (gest. wohl um 200), meist abgekürzt Wider die Häresien (Adversus haereses) zitiert, enthalten, in einer Passage, die, weil Euseb sie in seine Kirchengeschichte aufgenommen hat, ${ }^{21}$ auch im griechischen Original überliefert ist. Es heißt dort: ${ }^{22}$

„Von Satornin ${ }^{23}$ und Markion ${ }^{24}$ ausgehend, propagierten ( $\left.\dot{\varepsilon} \kappa \eta ́ \varrho v \xi \alpha \nu\right)$ die sog. Enkratiten $^{25}$ die Ehelosigkeit; sie verwarfen damit Gottes ursprüngliche Ordnung (

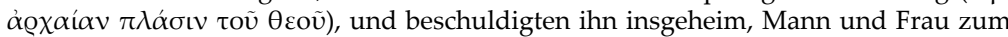
Zweck der Erzeugung des Menschengeschlechts (wörtl. von Menschen) erschaffen zu haben. Sie führten die Enthaltung von ,tierischer Nahrung' (wörtl.: von Beseeltem), wie es bei ihnen heißt, ein und erwiesen sich dadurch als undankbar gegenüber dem Allschöpfer Gott. Auch leugneten sie die Erlösung des Protoplasten (Ersterschaffenen,

\footnotetext{
${ }^{19}$ In einer an einen Kallistion gerichteten Schrift, aus der Euseb zuvor drei längere Exzerpte bot.

${ }^{20}$ Euseb, HE V 13,8.

${ }^{21}$ HE IV 29,2,3.

${ }^{22}$ Adv. haer. I 28,1.

${ }^{23}$ Satornin oder Satornil, frühchristlicher ,Gnostiker' (?), der bereits von Justin (Dial. 35) bekämpft wird.

${ }^{24}$ S.o. Anm. 3.

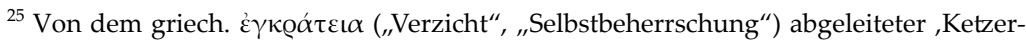
name', der zum Ausdruck bringen will, dass Vegetarismus und Eheverzicht (bzw. Verzicht auf Geschlechtsverkehr in der Ehe), sofern sie allen (wahrhaften) Christen abverlangt werden, als mit dem christlichen Schöpfungsglauben unvereinbar zu gelten haben.
} 
Adams) ${ }^{26}$ Solches (Denken) ist jetzt bei ihnen auszumachen; und es ist ein gewisser Tatian, der diese Blasphemie (Gotteslästerung) einführte. Ursprünglich ein Schüler (Hörer) Justins, hat er dergleichen nicht von sich gegeben, solange er mit diesem Umgang hatte. Doch nach dessen Martyrium (Blutzeugnis) fiel er von der Kirche ab ( $\dot{\alpha} \pi$ oot $\dot{\alpha} \varsigma$

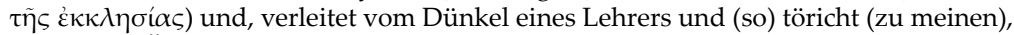
er sei allen Übrigen überlegen, begründete er eine eigene Schule (bzw. einen eigenen Lehrtyp), indem er von gewissen unsichtbaren Äonen - ähnlich wie die Valentinianer ${ }^{27}$ - faselte und, wie Markion und Satornin, die Ehe öffentlich zum Verderben und zur Unzucht erklärte. Was er gegen die Erlösung Adams einzuwenden hatte, war allerdings

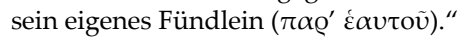

Aus dieser Quelle ist, ob direkt oder auf Umwegen, das Meiste geschöpft, was in patristischer Literatur über Tatian und die von ihm vertretenen Irrlehren zu lesen steht; ${ }^{28}$ das Meiste, wohlbemerkt, aber nicht alles. So folgt der ,Schüler' Hippolyt von Rom (gestorben 235), Verfasser einer Widerlegung sämtlicher Häresien (Refutatio omnium haeresium), in seiner Beurteilung Tatians $^{29}$ unverkennbar des Irenäus Spuren, so dass sie hier nicht eigens zur Sprache kommen muss. Allein, sollte er, wie vielfach angenommen, auch der Verfasser der von Euseb erwähnten Schrift gegen die Häresien des Artemon ${ }^{30}$ und diese wiederum mit einer anderen, von Theodoret von Cyrus (ca. 393 - ca. 466) erwähnten Schrift, betitelt Das kleine Labyrinth, ${ }^{31}$ identisch sein, so wäre damit bewiesen, dass er von Irenäus unabhängige, aber wohl auch über Ad Graecos und das Diatessaron hinausführende Tatiankenntnis besaß. Wird Tatian doch darin, zusammen mit seinem Lehrer Justin, ferner Miltiades (natürlich dem "großkirchlichen" Autor und Träger dieses Namens), „Clemens [wohl dem Alexandriner] und vielen anderen", in die Front derer eingereiht, an deren Orthodoxie nicht zu zweifeln ist, sondern „,bei denen allen die Gottheit Christi gelehrt wird“ ( $\dot{\varepsilon} v$ oĩ $\varsigma$

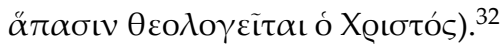

Ähnlich steht es mit Clemens selbst. Auch sein Wissen ist offensichtlich nicht ausschließlich aus Irenäus gewonnen, wenn er zu berichten weiß, ${ }^{33}$ Tatian habe in seiner Schrift „Über die Vollkommenheit nach den Worten

\footnotetext{
${ }^{26}$ Hippolyt, der im Übrigen ganz von Irenäus abhängig ist, weiß auch den Grund für Adams Unerlöstheit in den Augen Tatians zu nennen: Er war zum „Anführer des Unge-

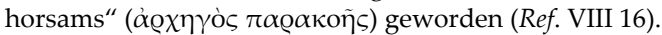

${ }^{27}$ (Zum Teil recht selbständige) Anhänger des neben Basilides wohl bedeutendsten christlichen Gnostikers, Valentinos, der in der Mitte des 2. Jh.s unangefochten in Rom lehrte.

${ }^{28}$ Vgl. zu den wichtigsten patristischen Zeugnissen TreLEnberg 2012, 204-224, bes. 206-208.

${ }^{29}$ Ref. VIII 4,16; X 18.

${ }^{30}$ Euseb, HE V 28,1.

${ }^{31}$ Theodor. Cyr. Haer. fab. comp. 2,5.

${ }^{32}$ Dass diese Charakterisierung nicht so leicht zumal mit der Oratio ad Graecos in Einklang zu bringen ist, lässt sich bei Elze 1960, 70-83 (Logoslehre) und Trelenberg 2012, 219-224 („,Warum fehlt der Name Christi?“) nachlesen.

${ }^{33}$ Clem. Alex. Strom. III 12,81.
} 


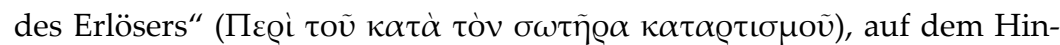
tergrund einer recht gewaltsamen Exegese von 1 Kor 7,5, die ,Erfindung' der Ehe auf das Konto des Teufels gehen lassen; Begründung: die sexuelle Vereinigung führe, selbst in der Ehe, notwendigerweise ins „Verderben“ ( $\varphi$ Өo@ó), und ein jeder Geschlechtsakt störe nicht allein beim Beten, sondern mache es regelrecht zunichte. ${ }^{34}$ Ebenso sicher aber scheint mir zu sein, dass die hier inkriminierte Lehre an den beiden Hauptwerken Tatians, besonders an der Rede an die Griechen, keinen wirklichen Anhalt hat, genau so wenig wie das, was Clemens "dem Syrer“ im unmittelbaren Anschluss an die genannte Stelle nachsagt: er unterscheide "nicht wie wir" zwischen dem „,alten“ und dem „neuen Mann“ (vgl. 1 Kor 7); wohl sei es richtig, den „alten“ mit dem „Gesetz" und den „,neuen“ mit dem Evangelium zu identifizieren, grundfalsch dagegen, das "Gesetz" wie jener aufzulösen und es einem "anderen Gott“ zuzuschreiben (oủ $\chi \tilde{\eta}$ ßoú $\lambda \varepsilon \tau \alpha$ เ

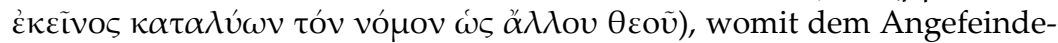
ten ein solenner Dualismus, eine Zwei-Götter-Lehre im Sinne Markions, unterstellt wird. ${ }^{35}$ An einer weiteren wichtigen Stelle, diesmal in den (wohl als Materialsammlung angelegten) Ausgewählten Prophetenstellen (Eclogae prophetarum), ist von einer für Clemens abwegigen Interpretation des Fiat lux („Es werde Licht") der ersten Schöpfungsgeschichte vom Anfang der Bibel (Gen 1,3) die Rede, ${ }^{36}$ einer Interpretation, die weder an der Oratio ad Graecos einen eindeutigen Anhalt hat, noch Bestandteil des Diatessaron gewesen sein kann. Gleichwohl dient sie Clemens als weiterer Beweis dafür, dass Tatian, ähnlich wie Markion, einen Widerstreit in Gott hineingetragen habe; ich halte es allerdings für denkbar, wenn nicht gar wahrscheinlich, dass der Alexandriner hier einem Missverständnis erlegen ist.

Tertullian, der - nach Ausweis verschiedener Textvergleiche ${ }^{37}$ - Tatians Oratio ad Graecos aus eigener Anschauung gekannt haben muss, wiederholt nichtsdestotrotz in seinem Traktat Über das Fasten (De ieiunio) ${ }^{38}$ die irenäischen Häresievorwürfe (Nähe zu Markion, Insistieren auf allgemeiner Nahrungsaskese unter Christen, die - eben weil von allen verlangt als Verachtung der Schöpfungswerke Gottes anzusehen sei); besonders so-

\footnotetext{
${ }^{34}$ Nicht allein an der zitierten Stelle in Adv. haer., sondern auch den beiden anderen, an denen Tatians Name fällt (I 26,1; III 23,8), hat diese Information keinen Anhalt.

${ }^{35}$ Darin, dass Tatian eine dualistische Gotteslehre fernlag, dürfte Eıze 1960, 70-83, gegen Petersen 1994, 77f., Recht zu geben sein; wohl aber gibt er sich in der Oratio als Inferiorist zu erkennen, da er den göttlichen Logos dem transzendenten Gott eindeutig untergeordnet sein lässt (vgl. Elze 1960, 76-79 und die dort besprochenen Tatiantexte).

${ }^{36}$ Clem. Alex. Eclog. proph. 38; ähnlich, wohl in Abhängigkeit von seinem alexandrinischen Vorgänger, Origenes, De orat. 24.

${ }^{37}$ S. Elze 1960, 117 Anm. 1; er nimmt an, dass Apol. 46,10.15 und 48, 9 die Kenntnis von Ad Graecos 2 und 6 voraussetzen.

${ }^{38}$ Tert. Ieiun. 15,1.
} 
weit es die angebliche Nähe zu Markion betrifft, können sie sich auf diesen Tatiantext sicherlich nicht stützen.

Auch der Kirchenhistoriker Euseb teilt, bei aller Begeisterung über Tatians Griechenrede, die Bedenken gegen dessen ,Rechtgläubigkeit'. Nicht umsonst hat er die entsprechende Passage aus Irenäus, Adv. haer., in seine Kirchengeschichte aufgenommen (s.o.). Über diese hinausgehend, dafür unter Berufung auf ein (uns nicht erhaltenes,) „im höchsten Maße zur Umkehr", um nicht zu sagen: zur Denkbuße „dienendes Buch“

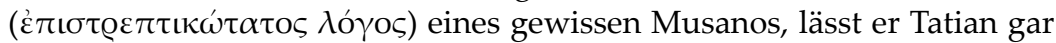
zum „Urheber der" ebionitischen „Verwirrung“ avancieren. ${ }^{39}$ Schließlich, so ist ihm zu Ohren gekommen ( $\varphi \alpha \sigma i$ ), habe sich dieser erkühnt, zur Verbesserung der Ausdrucksweise einige paulinische Wendungen $\mathrm{zu}$ „,übersetzen" ( $\mu \varepsilon \tau \alpha \varphi \varrho \alpha ́ \sigma \alpha \iota) .{ }^{40}$

Damit ist das Arsenal an Häresievorwürfen gegen Tatian in der altchristlichen Tradition im Wesentlichen erschöpft, und wir können mit J. Trelenberg zusammenfassend feststellen:

\begin{abstract}
„Mit einer hohen Wahrscheinlichkeit hat Tatian in seinen Schriften häretische Lehren vertreten. Das vielfache Zeugnis der Kirchenväter kann nicht ignoriert werden, zumal sich darunter frühe und voneinander unabhängige Nachrichten befinden. Die Tatsache, dass die Mehrheit der Werke Tatians heute verschollen ist, dass sich andererseits die Häresievorwürfe nicht vollständig, sogar nur zu einem geringen Teil aus der oratio ableiten lassen, zwingt zu dem Schluss, dass den spätantiken Zeitgenossen weitere Schriften Tatians, deren Inhalt wir nicht genau kennen, vorgelegen haben müssen. Das in der Vergangenheit praktizierte Verfahren, Tatian vom Verdacht der Häresie freizusprechen, weil sich die Kritik der Kirchenväte $\tau$ in der oratio nicht ausreichend verifizieren lasse, muss als verfehlt gelten. ${ }^{41}$
\end{abstract}

\title{
3. Zum Problem der Nachwirkung Tatians am Leitfaden von Hauptthemen seiner Oratio ad Graecos
}

\subsection{Der göttliche Ursprung und Charakter des Christentums}

Wie erwähnt, ist Tatians Bild vom Christentum oder, mit seinen Worten zu reden, von der „,wahren Philosophie“, so wie es in seiner Griechenrede ent-

\footnotetext{
${ }^{39}$ HE IV 28 im Vergleich mit 21.

${ }^{40} H E$ IV 29,6. Ob das in irgend einem Zusammenhang damit steht, eventuell daraus fortgesponnen ist, was Clemens Alexandrinus über Tatians gewaltsamen Umgang mit 1 Kor 7 anzumerken hatte (s. oben Anm. 33)? Bei Hieronymus jedenfalls (ca. 347-419), der Eusebs Kirchengeschichte natürlich bestens kannte, wird daraus, Tatian - über den er, genau so wie sein Zeitgenosse, der ,Ketzerhammer' Epiphanios von Salamis (Panar. haer. 46f.) nur Negatives zu berichten hat - habe gleich Markion und anderen Häretikern „einige Paulinen nicht anerkannt" (nonnullas Pauli epistolas repudiavit): Hieron. In ep. ad Tit. praef.

${ }^{41}$ Trelenberg 2012, [204-219 (zur Frage: „War Tatian ein Gnostiker?“)] 218. Die berechtigte Kritik richtet sich nicht zuletzt gegen Elze 1960, Kap. 6.
} 
worfen wird, nach M. Elzes Deutung durch drei Grundzüge gekennzeichnet: göttlichen Ursprung, Alter und Einheit(lichkeit). ${ }^{42}$ Um mit dem Ersteren zu beginnen, so ist vom göttlichen Charakter "unserer“ (der "Barba-

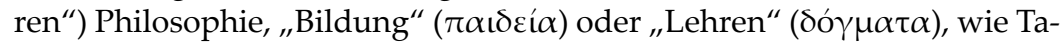
tian promiscue, ohne erkennbaren Unterschied, und im Kontrast zu denen der "Griechen", zu sagen pflegt, in der Tat mehrfach in unserem Text die Rede. Es zeichnet danach den Christen bzw. den „wahren Philosophen“ aus, dass er, anders als etwa Heraklit, nicht sein eigener Lehrer, sondern „,von Gott gelehrt" $(\theta \varepsilon \mathrm{o}-$, nicht $\alpha \dot{\tau} \tau o \delta i ́ \delta \alpha \kappa \tau o \varsigma)$ ist, ${ }^{43}$ was er äußert, ist nicht einfach so dahingesagt oder aus Wahrscheinlichkeitserwägungen und sophistischen Schlüssen gewonnen, sondern erfolgt unter Berufung auf eine gewisse höhere göttliche Offenbarung und ist mithin auch allem weltlichen Begreifen überlegen. ${ }^{44}$ Denn der Bau der Welt, aus der ihr Schöpfer sich sehr wohl zu erkennen gibt, ${ }^{45}$ ist schön, nicht aber der Lebenswandel aller derer, die sie bewohnen, so dass man auch, wie bei einem Volksfest, Leute um Beifall buhlen sieht, die von Gott nichts wissen. ${ }^{46}$ Sie (die Christen) haben von dem, was sie nicht wissen, durch ihre Propheten Kenntnis, ${ }^{47}$ Schriften zudem, die sich im Vergleich mit den Lehren der Griechen und ihrem ziellosen Dahinirren als göttlicher erweisen. ${ }^{48}$ Endlich folgen sie dem Logos Gottes, während die anderen danach suchen, was Gott ist, aber nicht wissen, was sich in ihnen selbst verbirgt. ${ }^{49}$

Inwieweit Tatian damit nachgewirkt hat, ist nicht leicht auszumachen. Denn das sind, zumal in apologetischer Literatur, verbreitete Gedanken. Tertullian z.B. kann es auf den für ihn typischen knappen Ausdruck bringen und sagen, wer von Gott reden wolle, der müsse von Gott selbst unterrichtet sein; er werde seinen Glauben daher „nicht auf fremdem, sondern eigenem Grund erbauen " ${ }^{50}$ Und bei Clemens von Alexandria heißt es, auf den gewaltigen Unterschied abhebend zwischen dem Reden oder Mutmaßen über die Wahrheit und der Weise, wie sie sich selbst auslege: „Wir sind ,von Gott gelehrt' (vgl. 1 Thess 4,9) und werden vom Sohne Gottes, von dem, der sagte: ,Ich bin der Weg, die Wahrheit und das Leben ...' (Joh 14,6), in wahrhaft heiligem Wissen unterrichtet. ${ }^{\text {"51 }}$

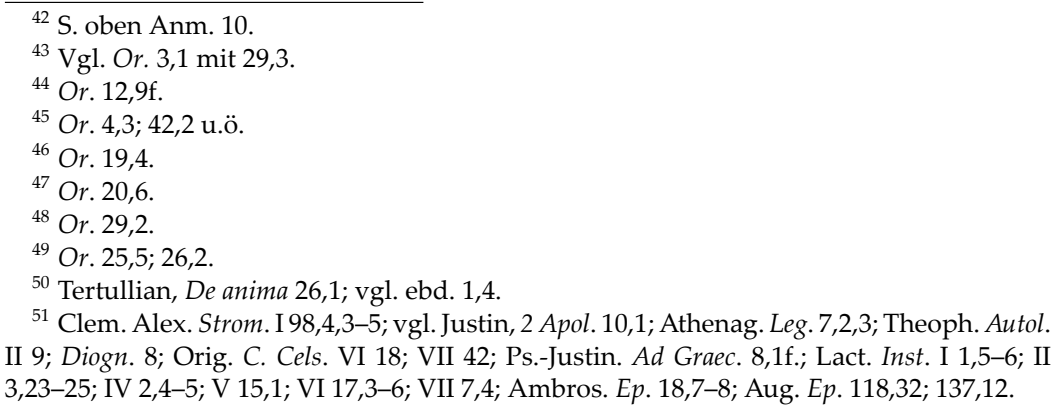


Bei solcher Begründung christlichen Selbstverständnisses konnte man sich durchaus auf Ansätze griechischen Denkens berufen und diese apologetisch-offenbarungstheologisch auswerten. ${ }^{52}$ Doch sich darauf einzulassen, passte zwar etwa in das Konzept Justins, aber absolut nicht in dasjenige seines Schülers Tatian, zumindest nicht des Tatians der Griechenrede, wie wir sehen werden.

\subsection{Altersbeweis für das Christentum}

Schule gemacht hat Tatian dagegen mit seinem Altersbeweis für das Christentum, ${ }^{53}$ welcher geradezu begeisterte Aufnahme fand.$^{54}$ Genauer gesagt, ging es um den Nachweis, „dass unsere Philosophie älter ist" als sämtliche Errungenschaften der Griechen. Maßgeblich durchgeführt wird der

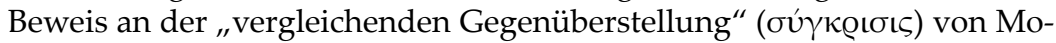
se und Homer als dem „,ältesten unter den Dichtern und Geschichtsschreibern“ der Griechen, während Mose der Ruhm zukommt, "Archeget jeglicher Weisheit der Barbaren“ zu sein! $!^{55}$ Obwohl der Altersbeweis an sich viel älter ist ${ }^{56}$ und die christliche Theologie hier direkt an die des hellenistischen Judentums anknüpfen konnte, ${ }^{57}$ zeichnet es die Weise, wie er überaus „sorgfältig“ ( $\dot{\alpha} \kappa \curlywedge \iota \tilde{\omega} \varsigma)$, findet der Alexandriner Clemens ${ }^{58}$ - von Tatian geführt wird, aus, dass er als erster christlicher Autor den Beweis "methodisch anzugehen versucht", 59 indem er Mose und Homer zu den jeweils Maßgebenden (den ő○oı) erklärt und sie „,ausdrücklich zur Grundlage seiner Argumentation macht"; 60 ja, Mose sei nicht nur älter als die „literarische Bildung“ ( $\pi \alpha \iota \delta \varepsilon i ́ \alpha)$ der Griechen, sondern sogar älter als die Er-

\footnotetext{
${ }^{52}$ Vgl. Fiedrowicz 2000, 297-300; A. M. Ritter, „Antikes Christentum und platonische Philosophie“, in: Ritter / Andresen 2011, 111-116.

${ }^{53}$ Durchgeführt in Kap. 31 und 36-41; vgl. dazu vor allem PiLhofer 1990.

${ }^{54}$ Diese Begeisterung findet auch darin ihren Ausdruck, dass manche (jüngeren) Codi-

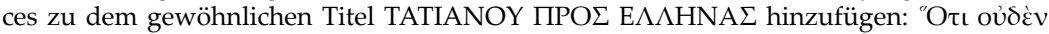

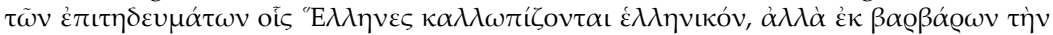

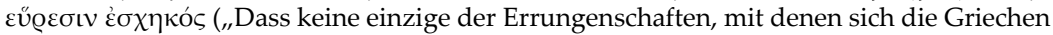
brüsten, griechischer Herkunft ist, sondern die Erfindung einer jeden den Barbaren zu verdanken ist"), ",offenbar doch in der Annahme, damit einen wichtigen, vielleicht sogar den wichtigsten Gesichtspunkt der Schrift wiederzugeben“ (Pilhofer 1990, 254). Die Information fehlt in den neueren Textausgaben (einschließlich der von SchwarTz), findet sich hingegen in der von Otтos (zit. ebd., Anm. 5).

${ }^{55}$ Or. 31,1.

${ }^{56}$ Dieser Altersbeweis ist bereits in der klassischen griechischen Literatur grundgelegt und findet auch im apologetischen Altersbeweis in der römischen Literatur von den frühen Annalisten bis zu Cicero eine zeitgenössische Parallele; vgl. dazu bes. Pilhofer 1990, Kap. 1 und 2.

${ }^{57}$ Pilhofer 1990, Kap. 3.

${ }^{58}$ Clem. Alex. Strom. I 101,1f.

${ }^{59}$ Pilhofer 1990, 254.

${ }^{60}$ Pilhofer 1990, 255.
} 
findung des griechischen Alphabets. ${ }^{61}$ Erinnert dies Letztere an den jüdischen Historiker Josephus, ${ }^{62}$ so auch die Beteuerung, als Zeugen für seine These "nicht unsere eigenen Leute“ heranzuziehen, sondern ausschließlich "Stützen" (ßoךӨoó) der Griechen aufzubieten. ${ }^{63}$ Doch selbst im Vergleich mit Josephus ist Tatians Methode alles andere als ,primitiv' zu nennen; ${ }^{64}$ argumentiert er doch, nach den Maßstäben der Zeit, ausgesprochen ,wissenschaftlich', nämlich auf der Grundlage der Chronologie, unter Auswertung der gesamten verfügbaren Literatur; und er kommt z.B. zu dem wahrscheinlich allerdings bereits übernommenen - Ergebnis, dass die von Homer beschriebene Eroberung Ilions im 18. Jahr des 20. argivischen Königs stattfand. ${ }^{65}$ Ohne Übertreibung lässt sich mithin sagen, dass sich seine Argumentation ,, auf der Höhe der Zeit" befand ${ }^{66}$ und verdientermaßen innerhalb der christlichen Apologetik auf eine wesentlich größere Akzeptanz traf als etwa die des Josephus. ${ }^{67}$ - Doch warum ist der Altersbeweis, nicht nur für Tatian, so wichtig?

Wohl seit jeher leuchtete dem antiken Menschen, ob ,Heide', Jude oder Christ, ein, dass „dem Älteren im Vergleich mit dem Jüngeren, Neueren

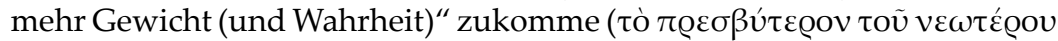

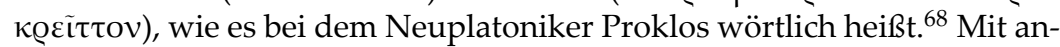
deren, des Mittelplatonikers Kelsos, Worten gesagt, ist der „wahre Logos“ zugleich der ,alte“, uranfängliche und umgekehrt. ${ }^{69}$ Oder mit dem Christen Tertullian zu reden: „Älter als alles ist die Wahrheit" (antiquior omnibus veritas) ${ }^{70}$ Erstmals, in dorischer Fassung, bei Timaios von Lokroi, der Titelfigur in Platons gleichnamigem Dialog, belegt, ${ }^{71}$ liegt das Prinzip TO

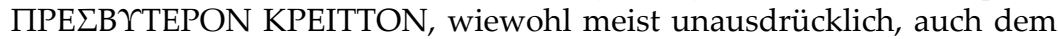

${ }^{61}$ Or. 31,1. D.h. Homer ist für Tatian lediglich der älteste Dichter und Geschichtsschreiber; im Übrigen rechnet dieser durchaus mit älteren Schriftstellern als Homer, wie Kap. 41 zeigt (Pilhofer 1990, 255 Anm. 10).

${ }^{62}$ Joseph. C. Ap. I 11; vgl. dazu Pilhofer 1990, 196.

${ }^{63}$ Or. 31,2 mit Joseph. C. Ap., wo durchgängig mit ,unverdächtigen', nichtjüdischen Zeugnissen gearbeitet wird.

${ }^{64}$ Gegen H. Conzelmann, Heiden - Juden-Christen. Auseinandersetzungen in der Literatur der hellenistisch-römischen Zeit. BHTh 62 (Tübingen 1961) 291.

${ }^{65}$ Or. 39,1; vgl. dazu oben den Kommentar zur Stelle, S. 182-183 Anm. 580.

66 So Droge 1989, 96; Pilhofer 1990, 259 f.

${ }^{67}$ Vgl. Theophil. Autol. II 30; III 16.20; Tertull. Apol. 19; Ps.-Just. Coh. 9,1; Clem. Alex. Strom. I 79f.; 87,lf.; 101-104; 114; 117; 122; 129-131; 165,2f.; Julius Africanus, Chronographiae, F34,38; T48a,5; T48b,3 (GCS NF 15, WallrafF); Euseb, PE X I 1,1-35 (mit dem Exzerpt der Kap. 31; 36-42!); Euseb / Hieronymus, Chron. $66 \alpha-67 \alpha$ Helm / Treu.

${ }^{68}$ So wörtlich bei Proclus, In Platonis Timaeum commentaria II 114,11f. Diels.

${ }^{69}$ Vgl. Origenes, C. Cels. VII 45, und dazu H. Dörrie, Die platonische Theologie des Kelsos in ihrer Auseinandersetzung mit der christlichen Theologie. NAG 1967, 2 (Göttingen 1967).

70 Tert. Apol. 47,1 (nach der Vulgata-Rezension); vgl. Justin, 1 Apol. 23,1.

${ }^{71}$ S. Pilhofer 1990, 18. 
Altersbeweis zugrunde, in dessen geschichtlicher Ausarbeitung der ,Assyrer', wie gesehen, eine hervorgehobene Rolle spielt. ${ }^{72}$

\subsection{Die Einheit des Christentums als Problem}

Neben und nach dem göttlichen Ursprung und dem Alter ist, nach M. Elzes Deutung, ein weiterer Grundzug des von Tatian entworfenen Bildes vom Christentum als der "wahren Philosophie“ ihre Einheit und Unteilbarkeit im Kontrast zur Verwirrung der „Hellenen“. Diesen wirft er vor, die "Weisheit zerteilt" und sich so „von der wahren Weisheit" selbst "abgeschnitten" zu haben. Damit, dass sie deren Einzelteile nach Menschen (z.B. Platon oder Aristoteles) benannt haben, offenbaren sie, dass sie Gott nicht kennen. Und weil das so ist, führen sie Krieg gegen sich selbst und verdammen sich gegenseitig. ${ }^{73}$ Auf diese Weise geht es für ihn „um ein klares und kompromissloses Entweder - Oder. Wahrheit drückt sich in Einheit aus. Wo diese nicht zu finden ist, herrscht Irrtum. Einen Teilbesitz der Wahrheit gibt es nicht. ${ }^{\prime \prime 4}$

Freilich bringt sich Tatian damit in große Schwierigkeiten, sowohl im Blick auf die biblische Tradition wie auf die Realität, in der sich das Christentum zu seiner Zeit befindet. Mit der biblischen Tradition ist nur mühsam vereinbar, dass sein Gottesbegriff, ${ }^{75}$ de facto - ähnlich dem des zeitgenössischen Platonismus - ,methodisch' durch Rückschluss aus dem Vorhandenen auf eine einzige göttliche Ursache gewonnen, ${ }^{76}$ in seiner nahezu exklusiven Betonung der göttlichen Transzendenz zwar dem Einheitspostulat in vollkommener Weise entspricht. Aber diese Kongruenz hat einen hohen Preis. Sie wird nämlich erkauft mit konsequenter Ausblendung der geschichtlich-heilsgeschichtlichen Perspektive. Die darin einbezogene Logoslehre mit ihrer strikten Unterordnung des göttlichen Logos unter den transzendenten Gott weist durchaus biblische Anspielungen (bes. auf Gen 1; Weish 8,21-9,4; Joh 1,1-5) auf; doch das für das Christentum (mindestens sehr bald) zentrale Zeugnis von der ,Fleischwerdung' des Logos-Wortes (Joh 1,14) hat darin keinen Niederschlag gefunden.

Auch die kirchliche Realität zu seiner Zeit bleibt total ausgeblendet, wenn es etwa heißt, „,bei uns“, den Christen, gebe es kein Verlangen nach

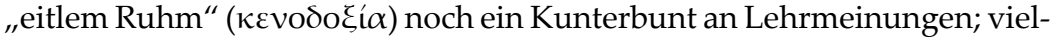

${ }^{72}$ Vgl. bei Tatian bes. Or. 29,2; 40,1.

${ }^{73}$ Or. 26,5.

${ }^{74}$ Elze 1960, 37.

${ }^{75}$ Vgl. bes. Or. 4,3f.; 5 .

${ }^{76}$ Vgl. dazu besonders PAnnenberg 1967, 296-346; A. M. RitTer, „Ulrich Wickert, Wolfhart Pannenberg und das Problem der ,Hellenisierung des Christentums'“, in: D. WYrwA, Die Weltlichkeit des Glaubens in der Alten Kirche. FS Ulrich Wickert. BZNW 1985 (Berlin / New York 1997) 308-318; Nachdr. in: A. M. RITTER, Vom Glauben der Christen und seiner Bewährung in Denken und Handeln (Mandelbachtal / Cambridge 2003) 55-65. 
mehr gehorchten alle den göttlichen Geboten, folgten dem Gesetz des unsterblichen Vaters und wiesen von sich, was sich einzig menschlichem Meinen (menschlicher $\delta o ́ \xi \alpha$ ) verdanke. Und dieser Übereinstimmung in der Wahrheit entspreche auch die Allgemeinheit ihrer Erkenntnis; alle, die

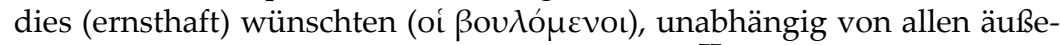
ren Voraussetzungen, "philosophieren bei uns “. ${ }^{77}$

Kein Wunder, dass derartige Abstraktionen im antiken Christentum, soweit zu sehen, kaum auf Gegenliebe stießen. Tertullian, der die Lage realistischer wahrgenommen zu haben scheint als der Verfasser von Ad Graecos, ,löste' das Problem, wie sich die ,Einheit', die auch ihm äußerst wichtig war, mit der real existierenden Vielzahl von Christentümern in seiner Zeit vereinbaren lasse, so, dass er den ,Altersbeweis' (zumal in seiner Schrift Über die Prozesseinrede der Häretiker [De praescriptione haereticorum]) als Instrument im Kampf gegen die ,Häresie' einsetzte, mit dem Ergebnis, dass die Einheit der Ausgang, das Ursprüngliche gewesen sei, ${ }^{78}$ nicht die Vielheit, die ,Rechtgläubigkeit', nicht die ,Ketzerei', womit er, wie W. Bauer ${ }^{79}$ gezeigt hat, Schule machen sollte.

\subsection{Christentum als „Barbarenphilosophie“}

Sehr prononciert und bewusst positioniert sich Tatian, von Beginn seiner Oratio ad Graecos an, in der Welt der "Barbaren“, in scharfem Gegensatz zu der der Griechen. ${ }^{80}$ Er spricht von der „barbarischen Weisheit“ als „unserer Philosophie", 81 von der "Barbarenphilosophie", wie sie die "hellenischen" Gegner nennen, ${ }^{82}$ von den seit seiner Bekehrung von ihm akzep-

\footnotetext{
${ }^{77}$ Or. 32,1-3.; 32,7, nach der m. E. mindestens erwägenswerten Konjektur von Euze 1960, 15, zu Or. 32,7 (Anfang); vgl. dazu oben den Kommentar zur Stelle, S. 171 Anm. 504.

${ }^{78}$ Die Argumentation ist rein juristischer Natur, wie schon der Begriff der praescriptio aus dem römischen Zivilrecht stammt. Danach konnte die im Besitz einer strittigen Sache befindliche Partei gegen eine Klage Einspruch erheben. Hatte sie Erfolg, so erreichte sie damit, dass der Prozess gar nicht erst stattfand, wofür das Argument der Verjährung maßgeblich war. Auf die Kirche übertragen heißt das: Sie hat sich seit ihrer Gründung im Besitz der Wahrheit befunden, die nur eine einzige ist und sein kann. Von Christus ist über die Apostel in rechtmäßiger Abfolge die Lehrtradition auf die Kirche der Gegenwart übergegangen. Die Häresien sind dagegen - man prüfe das an den Bischofslisten der maßgebenden Kirchen in Ost und West nach - erst später aufgetreten. Sie können darum auch keinen Anspruch auf die Wahrheit erheben.

${ }^{79}$ Bauer 1964; vgl. dazu A. M. RitTeR, „Die große innere Krise des Christentums im 2. Jahrhundert oder Das Ringen um ,Rechtgläubigkeit und Ketzerei'“, in: RitTER / ANDRESEN 2011, 56-59, mit weiterer Literatur. Dass Tertullian Schule gemacht hat, betrifft freilich nicht die rein juristische Fassung seines Arguments, sondern die fortan traditionelle Sicht, dass der Entwicklung das Schema zugrundeliege: vom Unglauben über den Rechtglauben zum Irrglauben!

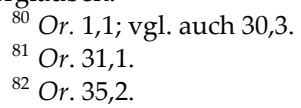


tierten „Dogmata“ als „,der Barbaren Lehren“, ${ }^{\circ 3}$ so wie schon die Schriften „,barbarisch“ waren, auf die er seine Bekehrung zurückführt, ${ }^{84}$ „,barbarisch" ist auch die Gemeinschaft, der er sich anschloss, ${ }^{85}$ samt der Lebensform, die er übernahm. ${ }^{86}$ Am Ende bezeichnet und versteht er sich

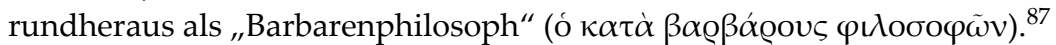

Man könnte meinen, damit machten sich einfach die Ressentiments eines ,Orientalen', der Überdruss an der griechisch-römischen Zivilisation Luft. Doch weit gefehlt. In Wahrheit schließt sich nämlich Tatian einer Traditionslinie an, die tief in der griechischen Denkwelt selbst verwurzelt ist und weit in die Vergangenheit zurückreicht. Danach erweist die Philosophie ihre Wahrheit daran, dass sie mit der unverbildeten Weisheit der Barbarenvölker übereinstimmt. Ja, man muss - so Poseidonios (ca. 135-51 v. Chr.) - zu den ältesten Völkern und Generationen zurückgehen, um das Göttliche und Wahre wiederzufinden. ${ }^{88}$

Weil es diesen breiten Traditionsstrom gab und es unmöglich ist, Tatians Vorliebe für das Barbarentum etwa mit seiner orientalischen Herkunft zu erklären, darum überrascht es auch nicht festzustellen, dass das Thema der „Barbarenphilosophie“ im Verhältnis zu der der Griechen in der patristischen Literatur weit über seine Oratio ad Graecos hinaus, mehr oder weniger intensiv, erörtert wird; am ausführlichsten und nuancenreichsten bei Clemens von Alexandria, danach bei Euseb und später bei Gregor von Nyssa (Vita Gregorii Thaumaturgi) und Johannes Chrysostomos. ${ }^{89}$

Der scharfe Gegensatz hingegen, in dem „barbarische“ und "griechische Philosophie" bei Tatian zu stehen (zu) kommen (scheinen), ist zwar nicht ganz ohne jede patristische Parallele, ${ }^{90}$ unterscheidet ihn aber radikal von seinem Lehrer Justin. Es stellt sich somit zum Schluss die Frage, wie Tatian prinzipiell - in der uns geläufigen Begrifflichkeit ausgedrückt - über das Verhältnis von Philosophie und Theologie gedacht habe. Doch ehe wir darauf eingehen, sei zuvor noch ein nicht ganz unwichtiges Einzelproblem angesprochen.

\footnotetext{
${ }^{83}$ Or. 35,3.

${ }^{84}$ Or. 29,2 .

${ }^{85}$ Or. 30,3.

${ }^{86}$ Or. 12,10 .

${ }^{87}$ Or. $42,1$.

${ }^{88}$ Vgl. dazu A. Dinle, Die Griechen und die Fremden (München 1994) 67-121; ferner Elze 1960, 24-27; Droge 1989, Kap. IV.

${ }^{89}$ Indices wie der von O. SтÄHLIN zum Werk des Clemens (GCS Clem. Alex. IV 293f., s.v $\beta \alpha \varrho \beta \alpha \varrho \iota k o ́ \varsigma$ und $\beta \alpha \dot{\varrho} \beta \alpha \varrho 0 \varsigma)$ und TLG erlauben einen raschen Überblick, so dass darauf hier nicht näher eingegangen werden muss.

${ }^{90}$ Besonders bei Tertullian, dem man jedoch keineswegs auf den Leim gehen darf!
} 


\subsection{Gegen die philosophische These von der Ewigkeit der Materie: Creatio ex nihilo}

Von Justin unterscheidet sich Tatian auch in der Hinsicht, dass er die Ungeschaffenheit einer Urmaterie im Sinne von Platons Timaios ausdrücklich ausgeschlossen hat, indem er der Materie das Gottesprädikat der Anfangslosigkeit absprach und sagte: „Denn weder ohne Anfang ist die Materie wie Gott, noch hat sie, weil sie ohne Anfang wäre, gleiche Macht wie Gott; sondern sie ist geworden, und zwar nicht durch das Wirken eines anderen, sondern sie ist allein durch den Schöpfer von Allem hervorgebracht. “91 Justin hatte sich die platonische Kosmogonie weder ausdrücklich zueigen gemacht, noch sie förmlich bestritten, wohl weil er sich an dieser Stelle eines Konfliktes mit dem christlichen Glauben nicht bewusst war. ${ }^{92}$ Für Tatian dagegen war es eine logische Konsequenz weniger des christlichen Glaubens, den er kaum eigens thematisierte, als seines eigenen Gottesbegriffes, dass dieser eine, transzendente Gott seine Anfangslosigkeit oder Selbstverursachung (Aseität) mit keinem anderen teile, schon gar nicht mit der Materie. Er gehört somit zu den Begründern der Lehre von der "Schöpfung aus dem Nichts" (creatio ex nihilo), ebenso wie (sein höchstens wenig jüngerer Zeitgenosse) Theophilos von Antiochia, der sich im zweiten Buch seiner Abhandlung An Autolykos (Ad Autolycum) sehr viel ausführlicher noch als Tatian mit dem Schöpfungsproblem auseinandersetzt und dabei die älteste fortlaufende Auslegung der Anfangskapitel der biblischen Urgeschichte aus dem Bereich der christlichen Theologie liefert. ${ }^{93}$

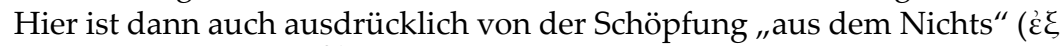

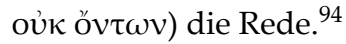

Dieses Theologumenon, noch zu Lebzeiten Tatians - was er in unserer Oratio bezeichnenderweise aber verschweigt! - auch innerchristlich durchaus umstritten, ${ }^{95}$ sollte sich schon bald als gemeinchristliche Lehre durchsetzen. Dabei wird - wie schon bei Tatian und Theophilos - auch eine Rolle gespielt haben, dass bereits im Platonismus, und zwar wohl schon vor Porphyrios, an einem Prinzipiendualismus oder gar -pluralismus, wie ihn etwa der Platoniker und Timaiosausleger Attikos (2. Hälfte des 2. Jahrhunderts) vertrat, ${ }^{96}$ heftigste Kritik geübt wurde. ${ }^{97}$ Christliche und plato-

\footnotetext{
${ }^{91}$ Or. 5,7. Vgl. dazu besonders May 1978, 151-157.

92 So wohl mit Recht PAnnenberg 1967, 316; vgl. auch bereits PFÄtтisch 1910, 93-103.

${ }^{93}$ M. Marcovich, Theophili Antiocheni Ad Autolycum. PTS 44 (Berlin 1995) 37-97.

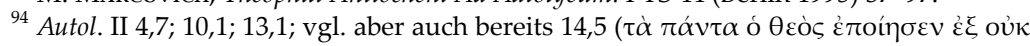

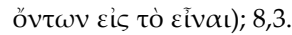

95 S. dazu May 1978, 153f. u.ö.

96 Vgl. dazu KöcKert 2009, 53-83.

${ }^{97}$ Es kann, wie KöскеRт 2009, 198 mit Recht vermutet, sehr wohl sein, dass auch schon die Kritik des Irenäus an den Valentinianern (Adv. haer. II 1,2) diese innerplatonische Auseinandersetzung zum Hintergrund hatte. Das Gleiche könnte für Tatian und Theophilos
} 
nische ,Orthodoxien' oder, wenn man lieber will, christlicher und platonischer mainstream standen also in dieser Auseinandersetzung, ohne sich dessen recht bewusst zu werden, ohne es jedenfalls zuzugeben, in einer Front!

Wem von beiden, Tatian oder Theophilos, mit seinem Deutungsversuch die Priorität zukomme, muss angesichts der fortbestehenden Datierungsprobleme der in Frage stehenden Schriften unentschieden bleiben. Und was das Inhaltliche angeht, so sind die Schriften wahrscheinlich unabhängig von einander konzipiert worden, wiewohl sie starke Ähnlichkeiten aufweisen: Beide argumentieren mit der Priorität des Mose gegenüber Plato (Alter als Wahrheitserweis), beide ziehen die griechische Philosophie ins Lächerliche wegen ihrer Widersprüche, beide geißeln die Immoralität der heidnischen Kultur im Vergleich mit der christlichen. ${ }^{98}$ Doch legt das nicht unbedingt die Annahme wechselseitiger Beeinflussung nahe oder erzwingt diese gar. Erst recht ist der Zugang zum Problem des Prinzipiendualismus, der Ewigkeit der Materie oder ihrer Geschaffenheit in der Zeit, bei Tatian und Theophilos jeweils charakteristisch verschieden.

\subsection{Fazit}

Den Abschluss unserer Überlegungen bilde die Frage, wie sich, mit unserer Begrifflichkeit zu reden, Philosophie und Christentum, von aller Apologetik und Polemik einmal abgesehen, in Tatians Sicht grundsätzlich zueinander verhalten? Der Eindruck, den die Lektüre seiner Oratio ad Graecos hinterlässt, ist in dieser Hinsicht ja einigermaßen verwirrend. Einerseits stellt es der Autor so dar, als habe er, in der griechischen Bildungswelt aufgewachsen, die Brücken zur Vergangenheit völlig abgebrochen und sei entschlossen, nichts mehr anzurühren, was sich bei den Griechen finde,

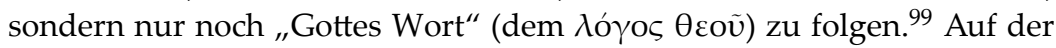
anderen Seite stellt er sich ihnen zum Schluss bereitwillig für die Prüfung seiner Lehren zur Verfügung, so als hoffe er, sie möchten, bei allen Un-

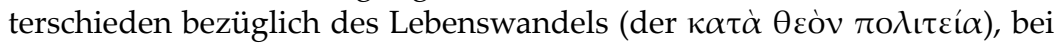
dem es für ihn kein Wanken gebe, doch ausreichend viel ,Geist vom eigenen Geiste' entdecken. ${ }^{100}$

(wie später für Dionysius von Alexandria und Basilius von Caesarea) gelten (s. KöcKERT 2009, 198, Anm. 101-103).

98 So mit Recht Petersen 1994, 32.

${ }^{99}$ Or. 26,7; vgl. 1,$5 ; 35 ; 42,1$.

${ }^{100}$ Or. 42,2. Entsprechend liest P. LAMPE die Formulierung am Schluss von Kap. 1 als verklausulierte Selbstbeschreibung Tatians, wenn es da heißt (Or. 1,5 Anfang): „Aus diesem Grund habe ich eurer ,Weisheit' eine Absage erteilt, auch wenn ich in ihr eine recht respektable Figur machte" ("the statement is formulated in such a way that the reader is supposed to count Tatian among them" [LAmpe 2003, 288]); Fојтік 2009, 23f., stimmt dem zu. Vgl. im übrigen o. den Kommentar zur Stelle, S. 117 Anm. 16. 
Einerseits wird Tatian als Verfasser von Ad Graecos völlig zurecht unter die frühchristlichen Apologeten gerechnet. Auf der anderen Seite hat seine Apologie, wie diejenige des Theophilos, eher den Charakter einer Attacke als einer Verteidigung des Christentums, dazu bestimmt, gebildete "Griechen“ zu der "barbarischen“ Philosophie der Christen zu bekehren.

Gleichwohl kann diese Apologie Tatians einerseits, so besonders von M. Elze, in dem Sinne gelesen werden, dass "ein geschlossenes Bild seiner geistigen Gestalt" entsteht ${ }^{101}$ und die Herkunft aus der (mittel-)platonischen Schulphilosophie überdeutlich wird: Deren Hauptthemen (Theologie, Kosmologie, Anthropologie, Dämonologie, Lehre von der Zeit) stehen auch im Mittelpunkt von Tatians Darlegungen, und auch die Weise ihrer Behandlung sowie die verwendete Terminologie verraten diese Prägung. ${ }^{102}$ Auf der anderen Seite trifft man vielfach auf derart Oberflächliches (wie das Urteil über die angebliche Unwissenheit des Aristoteles ${ }^{103}$ ) oder aber Topisches (тó schung im Gegensatz zu Elze die Meinung vertreten wird, Tatians Bildungshintergrund sei eher literarischer als philosophischer Natur und er selbst sei eher als Rhetor denn als ernstzunehmender Philosoph zu würdigen. ${ }^{104}$

Ich neige einstweilen dazu, aus dem Entweder - Oder ein Sowohl Als auch zu machen. In jedem Fall: hätte man Tatians Polemik und Rhetorik wörtlich aufzufassen, also anzunehmen, für ihn, den Christen, hätte ein unversöhnlicher Gegensatz zwischen Christentum und Philosophie bestanden, so hätte er sich mit dieser Auffassung im antiken Christentum zum Glück - nicht durchgesetzt. ${ }^{105}$

\footnotetext{
${ }^{101}$ Euze 1960, 127.

${ }^{102}$ Vgl. die Einzelnachweise bei Elze 1960, 14. 30f. 38. 61. 64f. 66f. 71. 73-78. 80-85. 90.91 Anm. 2. 94. 103-5. 114. 128f.

${ }^{103}$ Or. 2,2.

${ }^{104}$ S. dazu besonders Lampe 2003, Appendix 3 (426-430) in Verbindung mit Kap. 26; ähnlich auch L. W. BARNARD, "Apologeten“, TRE 3 (1974) 379f.

${ }^{105}$ Vgl. dazu u.a. meinen Beitrag "Christentum und Philosophie als Thema der frühkaiserzeitlichen Kirchenväterliteratur", in: R. Hirsch-Luipold u.a (Hg.), Religiöse Philosophie und philosophische Religion der frühen Kaiserzeit. STAC 51 (Tübingen 2009) 199-233.
} 

D. Anhang 



\section{Literaturverzeichnis}

\section{Abkürzungen}

DK

$D N P$

DPhA

EBR

$F D$

FGrHist

GG

HWPh

$J A C$

JECS

JTS

$L A C L$

LIMC

LSJ

PCG

$P G$

$P M G$

RAC

$R E$

RGG

RhM

$\mathrm{SH}$

SVF

ThZ

TPAPA

TRE

TGF
Die Fragmente der Vorsokratiker, hg. v. H. Diels / W. Kranz, 3 Bde., ${ }^{7} 1954$

Der Neue Pauly. Enzyklopädie der Antike, 16 Bde., 1996-2003

Dictionnaire des Philosophes Antiques, hg. v. R. Goulet, 4 Bde., 1989-2005

Encyclopedia of the Bible and its Reception, 2009-

Fouilles de Delphes, 1902-

Die Fragmente der Griechischen Historiker, hg. v. F. Jacoby, 1923-1999

Grammatici Graeci, 1867-1910

Historisches Wörterbuch der Philosophie, 13 Bde., 1971-2007

Jahrbuch für Antike und Christentum, 1958-

Journal of Early Christian Studies, 1991-

Journal of Theological Studies, 1899-

Lexikon der Antiken Christlichen Literatur, hg. v. S. Döpp /

W. Geerlings, ${ }^{3} 2002$

Lexicon Iconographicum Mythologiae Classicae, 10 Bde., 1981-2009

A Greek-English Lexikon, hg. v. H. J. Liddell / R. Scott / H. S. Jones, ${ }^{9} 1996$

Poetae comici Graeci, hg. v. R. Kassel / C. Austin, 1983-

Patrologia Graeca, hg. v. J. P. Migne, 161 Bde., 1857-1866

Poetae melici Graeci, hg. v. D. L. Page, 1962

Reallexikon für Antike und Christentum, 1950-

Paulys Realencyclopädie der classischen Altertumswissenschaft, 1893-1980

Religion in Geschichte und Gegenwart, 9 Bde., ${ }^{4} 1998-2007$

Rheinisches Museum für Philologie, 1827-

Supplementum Hellenisticum, hg. v. H. Lloyd-Jones / P. J. Parsons, 1983

Stoicorum Veterum Fragmenta, hg. v. H. von Arnim, 4 Bde., 1903-1924

Theologische Zeitschrift, 1945-

Transactions and Proceedings of the American Philological Association, 1869-

Theologische Realenzyklopädie, 36 Bde., 1977-2007

Tragicorum Graecorum Fragmenta, 5 Bde., 1981-2004 


$\begin{array}{ll}\text { VigChr } & \text { Vigiliae Christianae, 1987- } \\ \text { ZAC } & \text { Zeitschrift für Antikes Christentum, 1997- } \\ \text { ZKG } & \text { Zeitschrift für Kirchengeschichte, 1877- } \\ \text { ZPE } & \text { Zeitschrift für Papyrologie und Epigraphik, 1967- }\end{array}$

\section{Ausgaben, Kommentare und Übersetzungen}

Tatian, Oratio ad Graecos

Di CRistina (1991)

FERMi (1924)

Gesner (1700)

Goodspeed (1914)

HARNACK (1884)

Kukula (1913)

Maran (1742)

Marcovich (1995)

von Otто (1851)

Puech (1903)

SCHWARTZ (1888)

TRELenberg (2012)

WHitTAKer (1982)

WoRTH (1700)
S. Di Cristina, Taziano il Siro. Discorso ai Greci (Roma 1991) [ital. Übersetzung mit Anmerkungen]

M. Fermi, Taziano. Discorso ai Greci (Roma 1924) [ital. Übersetzung mit Anmerkungen]

K. GESNER, Lateinische Übersetzung und Anmerkungen zum Text, in: WORTH 1700

E. J. Goodspeed, Die ältesten Apologeten. Texte mit kurzen Einleitungen (Göttingen 1914)

A. Harnack, Tatian's Rede an die Griechen übers. u. erkl. Gießener Ludwigstagsprogramm (Gießen 1884)

R. C. Kuкula, Tatians des Assyrers Rede an die Bekenner des Griechentums. Frühchristliche Apologeten und Märtyrerakten aus dem Griechischen und Lateinischen übersetzt, 1. Bd. BKV 12 (München / Kempten 1913)

P. MARAN, Justini philosophi et martyris opera quae extant omnia, Necnon Tatiani Oratio adversus Graecos ... (Paris 1742)

M. Marcovich, Tatiani Oratio ad Graecos. PTS 43 (Berlin / New York 1995)

J. K. Th. von Отто, Tatiani Oratio ad Graecos. Corpus apologetarum Christianorum saeculi secundi 6 (Jena 1851)

A. Puech, Recherches sur le discours aux Grecs de Tatien suivie d'une traduction française du discours avec notes (Paris 1903)

E. Schwartz, Tatiani oratio ad Graecos. TU 4,1 (Leipzig 1888)

J. Trelenberg, Tatianos. Oratio ad Graecos. Rede an die Griechen. Herausgegeben und neu übersetzt. Beiträge zur historischen Theologie 165 (Tübingen 2012)

M. Whittaker, Tatian. Oratio ad Graecos and Fragments (Oxford 1982)

Tatiani Oratio ad Graecos, Hermiae Irrisio gentilium philosophorum. Ex vetustis exemplaribus recensuit, adnotationibusque integris Conradi Gesneri, Frontonis Ducaei, Christiani Kortholti, Thomae Galei, selectisque Henrici Stephani, Meursii, Bocharti, Cotelerii, utriusque Vossii, aliorum, suas qualescunque adjecit Wilhelmus Worth (Oxford 1700) 


\section{Sekundärliteratur (und Ausgaben anderer Autoren)}

Baltes 2004

BARTON 1994

BAUER 1964

Bidez / Cumont 1938

Bouché-LeClerce 1899

BRown 2002

Christ 2009

Colpe 1992

D'Ambra / Métraux 2006

Di CRISTINA 1977

DiLlon 2004

DöRRIE / BALTES 1990

DöRRIE / BALTES 1993

DÖRRIE / BALTES 1996

DÖRRIE / BALTES 1998

DöRRIE / BALTES 2002
M. Baltes u.a., Apuleius. De deo Socratis. Über den Gott des Sokrates. SAPERE VII (Darmstadt 2004)

T. BArton, Ancient Astrology (London / New York 1994)

W. BAUER, Rechtgläubigkeit und Ketzerei im ältesten Christentum. BHTh 10 (Tübingen 1934; ${ }^{2}$ 1964, mit einem Nachtrag von G. STRECKER)

J. Bidez / F. Cumont, Les mages hellénisés. Zoroastre, Ostanès et Hystaspe d'après la tradition grecque, 2 Bde. (Paris 1938)

A. Bouché-Leclerce, L'astrologie grecque (Paris 1899)

M. K. BRown, The Narratives of Konon. Text. Translation and Commentary of the Diegeseis. Beiträge zur Altertumskunde 163 (München / Leipzig 2002)

K. Christ, Geschichte der römischen Kaiserzeit. Von Augustus bis zu Konstantin (München ${ }^{6}$ 2009)

C. Colpe u.a. (Hg.), Spätantike und Christentum. Beiträge zur Religions- und Geistesgeschichte der griechisch-römischen Kultur und Zivilisation der Kaiserzeit (Berlin 1992)

E. D'Ambra / G. P. R. Métraux (Hg.), The Art of Citizens, Soldiers and Freedmen in the Roman World. British archaeological reports. International series 1526 (Oxford 2006)

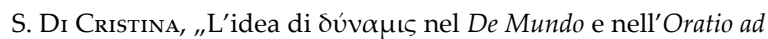
Graecos di Taziano", Augustinianum 17 (1977) 485-504

J. Dillon, „Dämonologie im frühen Platonismus“, in: Baltes 2004, 123-141

H. Dörrie / M. BALtes, Der Platonismus in der Antike II: Der hellenistische Rahmen des kaiserzeitlichen Platonismus. Bausteine 36-72: Text, Übersetzung, Kommentar. Aus dem Nachlass hgg. u. bearb. von M. Baltes unter Mitarbeit von A. Dörrie und F. MANN (Stuttgart / Bad Cannstatt 1990)

H. Dörrie / M. Baltes, Der Platonismus in der Antike III: Der Platonismus im 2. und 3. Jahrhundert nach Christus. Bausteine 73-100: Text, Übersetzung, Kommentar (Stuttgart / Bad Cannstatt 1993)

H. Dörrie / M. Baltes, Der Platonismus in der Antike IV: Die philosophische Lehre des Platonismus. Einige grundlegende Axiome / Platonische Physik (im antiken Verständnis) I. Bausteine 101-124: Text, Übersetzung, Kommentar (Stuttgart / Bad Cannstatt 1996)

H. Dörrie / M. Baltes, Der Platonismus in der Antike V: Die philosophische Lehre des Platonismus. Platonische Physik (im antiken Verständnis) II. Bausteine 125-150: Text, Übersetzung, Kommentar (Stuttgart / Bad Cannstatt 1998)

H. Dörrie / M. Baltes, Der Platonismus in der Antike VI: Die philosophische Lehre des Platonismus. Von der "Seele" als der Ursache aller sinnvollen Abläufe. Bausteine 151-168. 169-181: Text, Übersetzung, Kommentar, 2 Bde. (Stuttgart / Bad Cannstatt 2002) 
Dörrie / Baltes 2008 H. Dörrie / M. Baltes / C. Pietsch unter Mitarbeit von M.-L. Lakmann, Der Platonismus in der Antike VII 1: Theologia Platonica. Bausteine 182-205: Text, Übersetzung, Kommentar (Stuttgart / Bad Cannstatt 2008)

Droge 1989

DüNZL 2000

A. J. Droge, Homer or Moses? HUTh 26 (Tübingen 1989)

F. DünZL, Pneuma. Funktion des theologischen Begriffs in frühchristlicher Literatur. JAC.E 30 (Münster 2000)

Elze 1960

FeLDTKELLER 1993

M. Elze, Tatian und seine Theologie. Forschungen zur Kirchen- und Dogmengeschichte 9 (Göttingen 1960)

A. FeLDTKELLER, Identitätssuche des syrischen Urchristentums. Mission, Inkulturation und Pluralität im ältesten Heidenchristentum. NTOA 25 (Freiburg / Göttingen 1993)

Fiedrowicz 2000 / 2001 M. Fiedrowicz, Apologie im frühen Christentum. Die Kontroverse um den christlichen Wahrheitsanspruch in den ersten Jahrhunderten (Paderborn 2000; ${ }^{2} 2001$ )

Fојтік 2009

J. Е. Fојтік, „Tatian the Barbarian: Language, Education and Identity in the Oratio ad Graecos", in: J. Ulrich / A.-Ch. Jacobsen / M. Kahlos (Hg.), Continuity and Discontinuity in Early Christian Apologetics. ECCA 5 (Frankfurt/M. u.a. 2009) 23-34

FREUND 2006

S. FREUnd, ,, Und wunderbar sind auch eure Dichter, die da lügen...' (Tat. orat. 22,7). Beobachtungen zu Gestalt, Auswahl und Funktion von Dichterzitaten in der griechischen Apologetik am Beispiel Tatians", in: C. Schubert / A. von Stockhausen (Hg.), $A d$ veram religionem reformare. Frühchristliche Apologetik zwischen Anspruch und Wirklichkeit. Erlanger Forschungen Reihe A, 109 (Erlangen 2006) 97-121

FUNK 1883

F. X. FUnK, „Zur Chronologie Tatians“, Theologische Quartalschrift 65 (1883) 219-233

Geffcken 1907 J. Geffcken, Zwei griech. Apologeten. Sammlung wissenschaftlicher Kommentare zu griechischen und römischen Schriftstellern 5 (Leipzig / Berlin 1907)

Gemeinhardt 2007 P. Gemeinhardt, Das lateinische Christentum und die antike pagane Bildung. STAC 41 (Tübingen 2007)

Gemeinhardt /

Georges 2012

P. Gemeinhardt / T. Georges (Hg.), Between Education and Conversion. Ways of Approaching Religion in Late Antiquity $=$ ZAC 16,1 (2012)

GeORges 2011

Georges 2012

Grieser / Merkt 2009

T. Georges, Tertullian. ,Apologeticum'. KfA 11 (Freiburg u.a. 2011)

T. GeORGES, ,JJustin's School at Rome - Reflections on Early Christian ,Schools'“, in: Gemeinhardt / Georges 2012, 75-87

H. Grieser / A. Merкт (Hg.), Volksglaube im antiken Christentum (Darmstadt 2009)

GundeL 1992

H. G. GundeL, Zodiakos. Tierkreisbilder im Altertum. Kosmische Bezüge und Jenseitsvorstellungen im antiken Alltagsleben (Mainz a.R. 1992)

Guyot / KLein 1993 P. Guyot / R. KLeIN, Das frühe Christentum bis zum Ende der Verfolgung. Bd. 1: Die Christen im heidnischen Staat. TuF 60 (Darmstadt 1993) 
HANIg 1999

HARNACK 1882

\section{Hauschild /}

Drecoll 2004

Hinz 2001

Hunt 2003

KaLKMANN 1887

Karadimas 2003

Косн 2013

KöCKeRT 2009

Koltun-Fromm 2008

Krasser 2007

Krause 1958

KuKula 1900

LAMPE 1987 / 1989 /

2003

LANGE 2003

LANGE 2008

LoNA 1993

LONA 2001

LONA 2005
R. HANIG, „Tatian und Justin: ein Vergleich“, VigChr 53 (1999) 31-73

A. Harnack, Die Überlieferung der griechischen Apologeten des zweiten Jahrhunderts in der Alten Kirche und im Mittelalter. TU 1,1.2 (Leipzig 1882)

W.-D. Hauschild / V. H. Drecoll, Pneumatologie in der Alten Kirche (Berlin u.a. 2004)

V. Hinz, Nunc Phalaris doctum protulit ecce caput. Antike Phalarislegende und Nachleben der Phalarisbriefe (München / Leipzig 2001)

E. J. Hunt, Christianity in the Second Century. The Case of Tatian (London 2003)

A. Kalkmann, „Tatians Nachrichten über Kunstwerke“, RhM 42 (1887) 489-524

D. Karadimas, Tatian's Oratio ad Graecos: Rhetoric and Philosophy/Theology. Scripta minora Regiae Societatis Humaniorum Litterarum Lundensis (Stockholm 2003)

D.-A. Косн, Geschichte des Urchristentums. Ein Lehrbuch (Göttingen 2013)

C. КӧскеRт, Christliche Kosmologie und kaiserzeitliche Philosophie. STAC 56 (Tübingen 2009)

N. Koltun-Fromm, „,Re-imagining Tatian. The Damaging Effects of Polemical Rhetoric", JECS 16 (2008) 1-30

H. Krasser, "Shifting Identities. Knowledge and the Construction of Social Roles in the Roman Empire“, Millennium 4 (2007) 43-62

W. KRAUSE, Die Stellung der frühchristlichen Autoren zur heidnischen Literatur (Wien 1958)

R. C. Kukula, ",'Altersbeweis' und ,Künstlerkatalog' in Tatians Rede an die Griechen", in: Jahresbericht des K. K. Staatsgymnasiums im II. Bez. in Wien (Wien 1900)

P. Lampe, Die stadtrömischen Christen in den ersten beiden Jahrhunderten. Untersuchungen zur Sozialgeschichte. WUNT II,18 (Tübingen $\left.1987 ;{ }^{2} 1989\right)$; engl. Übersetzung: From Paul to Valentinus. Christians at Rome in the first two centuries, translated by M. STEINHAUSER (Minneapolis 2003)

A. Lange u.a. (Hg.), Die Dämonen / Demons. Die Dämonologie der israelitisch-jüdischen und früchristlichen Literatur im Kontext ihrer Umwelt (Tübingen 2003)

C. LANGe, Ephraem der Syrer. Kommentar zum Diatessaron. FC 54/1+2 (Turnhout 2008)

H. E. LonA, Über die Auferstehung des Fleisches. Studien zur frühchristlichen Eschatologie. BZNW 66 (Berlin / New York 1993)

H. E. LonA, An Diognet. KfA 8 (Freiburg u.a. 2001)

H. E. Lona, Die ,Wahre Lehre' des Kelsos. KfA.E 1 (Freiburg u.a. 2005) 
LöSSL 2007

LössL 2010

LÜHRMANN 1986

MARKSCHIES 2007

MAY 1978

Monaci Castagno 1995 A. Monaci Castagno, „La demonologia cristiana fra II e III secolo“, in: Pricoco 1995, 111-150

Nesselrath 1985

Nesselrath 2005

Nesselrath 2006

NeymeYr 1989

Niederwimmer 1989

PAnNenberg 1959 / 1967

Petersen 1994

Рғӓтtisch 1910

Pfeiffer 1972

Pilhofer 1990

Pietzner 2013

Plant 2004

Pohlenz 1978

L. Lösst, „Bildung? Welche Bildung? Zur Bedeutung der Begriffe ,Griechen' und Barbaren in Tatians , Rede an die Griechen'“, in: Prostmeier 2007, 127-153

L. LössL, „Zwischen Christologie und Rhetorik: Zum Ausdruck

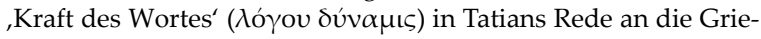
chen“" in: Prostmeier / Lona 2010, 129-147

D. LüHrMANN, „SUPERSTITIO - die Beurteilung des frühen Christentums durch die Römer“, ThZ 42 (1986) 193-213

Ch. Markschies, Kaiserzeitliche christliche Theologie und ihre Institutionen. Prolegomena zu einer Geschichte der antiken christlichen Theologie (Tübingen 2007)

G. MAY, Schöpfung aus dem Nichts. Die Entstehung der Lehre von der creatio ex nihilo. AKG 48 (Berlin / New York 1978)

H.-G. Nesselrath, Lukians Parasitendialog. Untersuchungen und Kommentar. Untersuchungen zur antiken Literatur und Geschichte 22 (Berlin / New York 1985)

H.-G. Nesselrath, „Il testo di Taziano, Oratio ad Graecos, e due edizioni recenti“, Eikasmos 16 (2005) 243-263

H.-G. Nesselrath, Platon. Kritias. Übersetzung und Kommentar (Göttingen 2006)

U. NEYMEYR, Die christlichen Lehrer im zweiten Jahrhundert. Ihre Lehrtätigkeit, ihr Selbstverständnis und ihre Geschichte. SVigChr 4 (Leiden u.a. 1989)

K. Niederwimmer, Die Didache. KAV 1 (Göttingen 1989)

W. PannenberG, „Die Aufnahme des philosophischen Gottesbegriffs als dogmatisches Problem der frühchristlichen Theologie", ZKG 70 (1959) 1-45; wieder abgedr. in: ders., Grundfragen systematischer Theologie (GA) (Göttingen 1967) 296-346

W. L. Petersen, Tatian's Diatessaron. Its creation, dissemination, significance, and history in scholarship. SVigChr 25 (Leiden u.a. 1994)

I. M. РғӓтTIsCh, Der Einfluß Platos auf die Theologie Justins des Märtyrers (Paderborn 1910)

R. Pfeiffer, Geschichte der Klassischen Philologie. Von den Anfängen bis zum Ende des Hellenismus (Reinbek 1970; urspr. engl. Oxford 1968)

P. Pilhofer, Presbyteron Kreitton. Der Altersbeweis der jüdischen und christlichen Apologeten und seine Vorgeschichte. WUNT II 39 (Tübingen 1990)

K. Pietzner, Bildung, Elite und Konkurrenz. Heiden und Christen vor der Zeit Constantins. STAC 77 (Tübingen 2013)

I. M. Plant, Women Writers of Ancient Greece and Rome (Norman / Oklahoma 2004)

M. Pohlenz, Die Stoa. Geschichte einer geistigen Bewegung, Bd. I (Göttingen ${ }^{5} 1978$ ) 
PoHLEnz 1972

Ponschab 1895

Pouderon 2005

Pratscher 2009

Pricoco 1995

Prostmeier 2001

Prostmeier 2007

Prostmeier 2010

Prostmeier 2013
Pouderon / Doré 1998

M. Pohlenz, Die Stoa. Geschichte einer geistigen Bewegung, Bd. II: Erläuterungen (Göttingen ${ }^{4} 1972$ )

P. B. Ponschab, Tatians Rede an die Griechen (Gymnasialprogramm Metten 1895)

B. Pouderon, Les apologistes grecs du Ile siècle (Paris 2005)

B. Pouderon / J. Doré (Hg.), Les apologistes chrétiens et la culture grecque. ThH 105 (Paris 1998)

W. Pratscher (Hg.), Die Apostolischen Väter. Eine Einleitung. UTB 3272 (Göttingen 2009)

S. Pricoco (Hg.), Il Demonio e i suoi complici. Dottrine e credenze demonologiche nella Tarda Antichità (Soveria Mannelli 1995)

F. R. Prostmeier, ,',Die Wolke der Gottlosigkeit.' Gültigkeit und politische Relevanz des traditionellen Wirklichkeitsverständnisses in der Polemik gegen das Christentum bei Kaiser Julian", JAC 44 (2001) 33-57

F. R. Prostmeier (Hg.), Frühchristentum und Kultur. KfA.E 2 (Freiburg u.a. 2007)

F. R. Prostmeier, „Der Logos im Paradies. Theophilos von Antiochia und der Diskurs über eine zutreffende theologische Sprache", in: Prostmeier / Lona 2010, 207-228

F. R. Prostmeier, ,,'Was will wohl dieser Schwätzer sagen?' - Bildung und religiöses Wissen im 2. Jahrhundert n.Chr.", in: P. Gemeinhardt / S. Günther (Hg.), Von Rom nach Bagdad: Bildung und Religion von der römischen Kaiserzeit bis zum klassischen Islam (Tübingen 2013) 127-162

Prostmeier / Lona 2010 F. R. Prostmeier / H. E. Lona (Hg), Logos der Vernunft - Logos des Glaubens. FS E. Früchtel zum 80. Geburtstag. MSt 31 (Berlin / New York 2010)

Ritter / Andresen 2011 A. M. Ritter / C. Andresen u.a., Die christlichen Lehrentwicklungen bis zum Ende des Spätmittelalters (Göttingen 2011)

RoBinson 2009

T. A. Robinson, Ignatius of Antioch and the parting of the ways. Early Jewish-Christian relations (Peabody, Mass. 2009)

SCHUBERT 2014

Strutwolf 1993

Ch. Schubert, Minucius Felix. Octavius. KfA 12 (Freiburg u.a. 2014)

H. Strutwolf, Gnosis als System. Zur Rezeption der valentinianischen Gnosis bei Origenes. Forschungen zur Kirchen- und Dogmengeschichte 56 (Göttingen 1993)

Timotin 2012

A. Timotin, La démonologie platonicienne. Histoire de la notion de daimōn de Platon aux derniers néoplatoniciens (Leiden / Boston 2012)

TLAsCAL 1956

O. Tlascal, Die Dämonenlehre der Apologeten des 2. Jahrhunderts und ihr geistesgeschichtlicher Hintergrund (Wien 1956)

VAN DER NAT 1976

P. G. VAn der NAt, „'Geister (Dämonen) III. Apologeten und lateinische Väter", RAC IX (1976) 715-761

VERBEKE 1945

G. VerbeKe, L'évolution de la doctrine du pneuma du stoicisme à $S$. Augustin (Paris / Louvain 1945)

VoLLKommer 2001
R. Vollкommer (Hg.), Künstlerlexikon der Antike (München / Leipzig 2001) 
WASZINK 1954

WEst 2013

WEY 1957

WHITTAKER 1975

WiLdBerger 2006

ZAHN 1881
J. H. WAszinK, „Bolos“, RAC III (1954) 502-508

M. L. West, The Epic Cycle. A Commentary on the Lost Troy Epics (Oxford 2013)

H. WEY, Die Funktionen der bösen Geister bei den griechischen Apologeten des zweiten Jahrhunderts nach Chr. (Winterthur 1957)

M. Whittaker, "Tatian's Educational Background“, in: E. A. LIvingston (Hg.), Studia Patristica, Bd. XIII. TU 116 (Berlin 1975) 57-59

J. Wildberger, Seneca und die Stoa: Der Platz des Menschen in der Welt. Untersuchungen zur antiken Literatur und Geschichte 84, 2 Bde. (Berlin / New York 2006)

Th. ZAHN, Forschungen zur Geschichte des neutestamentlichen Kanons und der altkirchlichen Literatur. I. Teil: Tatian's Diatessaron (Erlangen 1881) 


\section{Stellenregister (in Auswahl)}

Aëtios

Plac. 308,5-7 Diels: 139

Aelianus VH XII 19: 172

Aischylos Suppl. 230f.: 125

Alkinoos

Didasc.

10: 227

13,1: 122

Ambrosius Ep. 73[18],7: 259

Apollodor

Bibl.

I 6: 160

I 24: 158

II 1-53: 182

II 42: 128

II 46: 128

II 66: 153

III 60-62: 157

III 80-85: 157

III 86-90: 157

III 120: 128

III 188: 128

III 192: 132

Apollonios Rhodios

Arg. I 18f.: 133

Apuleius

De Plat.

I 5: 124

I 5,190: 227

Aristides

Apol.

1,1f.: 220

1,4-6: 219

Ariston von Keos

Fr. 29f. Wehrli: 119

Aristophanes

Ran.

92f.: 117

1291: 151

Aristoteles

Cael.

270a13f.: 159 279b-280a34:

243

De an. II 1,413a4: 159

Gen. an. II 3,

736b27-29: 236

Phys. I 9,192a31: 124

Arrian

Anab. VII 24,4-25,1:

118

Artemidor

Onirocr. V 26: 147

Athanasius

Vita Antonii

1,2: 258

66,2: 258

Athenagoras

Leg.

20,3: 129

24f.: 274

Augustinus

CD XVIII 12: 129

Biblici libri
Vetus Testamentum
Gen

1,26: 126, 138f., 229

2,7: 235

3,23f.: 151

6,1-4: 274

Ex 3,14: 145, 232

Dtn 32,8: 277

1 Sam 16,7: 263

Ps

8,6: 146

12,12: 160

Weish

1,14: 150

2,23: 126, 138

7,26: 146

9,1: 124

13,5: 122

Novum Testamentum

Mt

2,16: 258

5,45: 138
6,1-6: 196

6,16-18: 196

9,14-17: 196

12,9: 196

12,29: 143

13,25: 166

13,32: 166, 199

13,44: 166

23,1-36: 196

Mk

2,18-22: 196

3,1: 196

3,1-6: 196

3,6: 196

Joh

1,1: 123

1,3: 151

1,5: 142,238

3,3-5: 124

4,24: 122

11,25: 238

Apg

11,26: 198

13,4-12: 195

15: 199

17,1-51: 213

17,16-34: 195,

210

17,18: 125

17,21: 217

17,22-31: 210

19,23-40: 195

Röm

6,10: 138

7,8: 166

7,11: 166

7,14: 138

12,4f.: 140

1 Kor

2,4: 141

2,6-8: 141

2,14: 138, 276

2,14f.: 146

3,16: 145

10,20: 218

15,53f.: 153 


\begin{tabular}{|c|c|}
\hline 2 Kor & 56,3: 243 \\
\hline 5,1-4: 153 & 64: 240 \\
\hline 5,2: 153 & 69-70: 280 \\
\hline 5,3: 153 & $76-78: 281$ \\
\hline $6,16: 145$ & Paed. II 1,18,1: 234 \\
\hline Gal 3,26-28: 214 & Protr. \\
\hline Eph & $7,74,7: 234$ \\
\hline 6,14: 146 & 16,1: 130 \\
\hline 6,17: 146 & $16,2: 130$ \\
\hline Kol & $17,1: 130$ \\
\hline 2,20: 138 & 22,3: 130 \\
\hline 3,9: 166 & $22,4: 130$ \\
\hline 1 Thess 5,8: 146 & $27,5: 129$ \\
\hline $1 \operatorname{Tim}$ 6,16: 151 & $66,3: 122$ \\
\hline Hebr & Strom. \\
\hline 1,2: 124 & I 1,11,2: 288 \\
\hline 1,3: 146 & I 74: 20 \\
\hline $12,17: 276$ & I 74,1: 20, 114 \\
\hline 1 Petr & I 74-76: 20 \\
\hline 1,1f.: 213 & I 76,2: 116 \\
\hline 2,17: 122 & I 76,5: 115 \\
\hline 2 Petr 1,16: 218 & I 77,1: 20, 114 \\
\hline \multirow{2}{*}{ Offb 6,16-18: 126} & I 87,2: 186 \\
\hline & I 101,1f.: 11 \\
\hline Cassius Dio & I 101,2: 6, 20, 257 \\
\hline LXIX 11,4: 135 & I 101,3-5: 21 \\
\hline LXXII 31,3: 16 & I 102,1: 21 \\
\hline Chrysipp & I 102,2: 6, 21, 184 \\
\hline SVF II 416: 228 & I 102,3: 21 \\
\hline Cicero & I 102,3f.: 21 \\
\hline Div. & I 102,4: 180 \\
\hline I 91: 114 & I 102,5: 21 \\
\hline I 94: 114 & I 103,2-104,1: 21 \\
\hline Luc. 49: 165 & I 104,1f.: 22 \\
\hline Nat. & I 104,3: 22 \\
\hline I 68: 154 & I 105,1-5: 22 \\
\hline I 85: 163 & I 106,1-6: 22 \\
\hline Rep. VI 21: 152 & I 107,1f.: 22 \\
\hline Tusc. & I 107,3-4: 22 \\
\hline I 38f.: 120 & I 107,5f.: 22 \\
\hline IV 79: 119 & I 107,6: 22 \\
\hline Clem. & I 114,2: 23 \\
\hline 21,8: 260 & I 117: 22 \\
\hline $56,2: 260$ & I 117,1-3: 170 \\
\hline $56,3: 260$ & I 117,6f.: 170 \\
\hline $56,4: 260$ & I 117,8f.: 170 \\
\hline $56,5: 260$ & I 122,1: 180 \\
\hline Clemens von & I 131: 23 \\
\hline Alexandria & I 131,1: 23 \\
\hline Eclog. proph. 55,1: & I 131,2: 23 \\
\hline 279 & I 133,2: 187 \\
\hline Exc. Theod. & III 12,81: 292 \\
\hline 32,1: 240 & III 81,1: 5 \\
\hline
\end{tabular}

III 81,1f.: 8

III 91,1: 20

V 22,1: 186

V 82,1: 145

VI 27,2: 120

VII 2,5: 271

Demokrit

68 B 34 DK: 140

Diodor

I 53,8: 114

III 67,2: 186

III 67,5: 188

Diogenes Laertios

I 3: 187

I 5: 187

I 109-112: 188

III 72: 159

III 78: 145

V 5: 118

VII 157: 229

IX 3: 119

IX 5: 119

IX 6: 119

Diogn.

5,5: 213, 220

Dion von Prusa

Or. 55,2: 119

Epiphanios von Salamis

Panar.

$$
\begin{aligned}
& \text { 46,1,2: } 4 \\
& \text { 46,1,4f.: } 4 \\
& \text { 46,1,6: } 4,15 \\
& \text { 46,1,7: } 4 \\
& \text { 46,1,8: } 4
\end{aligned}
$$

Euripides

Herc. 1345f.: 123

Ion 999-1005: 128

Eusebios von Kaisareia HE

IV 16,7: 4, 8, 19,

251

IV 16,8f.: 19

IV 29,6: 7, 288

IV 29,7: 8, 11,

290

V 13,1: 6, 250

V 13,1-9: 287

V 13,8: 8, 291

PE

IV 19,3: 283

X 9,8-10: 183 
X 10,7: 184

X 10,10: 184

X 10,16: 182

X 11,1-5: 19

X 11,6-35: 19, 178

Flavius Josephus: siehe Josephus

Gellius

VII 10,5: 226

IX 4,3: 157

XII 11,1: 159

Geminos

El. astr.

1,4: 133

3,4: 133

Georgios Monachos Chron. 40,17-20: 11

Gregor von Nazianz Or. 4,121: 129

Gregor von Nyssa De perfectione Christiana 200,10-14 Jaeger: 124

Hellanikos FGrHist $4 \mathrm{~F}$ 88: 115f. FGrHist 4 F 178ab: 116

1 Henoch 8,3: 285

2 Henoch 6: 274 29: 274

Herakleides Pontikos Fr. 157 Wehrli: 186f.

Heraklit

22 B 42 DK: 217

22 B 101 DK: 119

Hermipp

Fr. 13,72 West: 138 Fr. 29 Wehrli: 120

Herodot I 29,1: 178

I 78,2f.: 114

III 38: 165

IV 39,1: 4

VII 63: 4

Hesiod

Theog.

139-141: 116
168-181: 129

280f.: 128

896: 160

897f.: 160

Hippolytos

Haer.

I 19,3: 227

I 19,10: 242

X 13,3: 243

Ref. VIII 16: 292

Homer

Il.

I 225: 164

I 599: 126, 266

II 3-6: 154

II 204: 143

II 248f.: 171

II 372: 151

II 628-669: 188

II 653-670: 188

V 330-367: 127

V 846-870: 127

VIII 78-90: 170

VIII 87: 170

VIII 102f.: 170

IX 533-542: 135

X 77-79: 171

XV 547: 153

XVIII 401: 129

XX 215-218: 179

XX 219: 179

XX 230: 179

XX 231f.: 179

XX 235f.: 179

XXI 599-611: 127

XXII 7-20: 127

XXII 226f.: 153

Od.

IV 561-569: 137

IV 564: 125

IV 565-568: 152

VI 42-46: 152

VII 326: 266

VIII 266-366:

176

IX 568-571: 125

X 106-115: 116

XI 303: 136

XV 133: 137

Hyginus

Astr. II 1: 133

Fab. 70: 129
Ignatios

Mag.

8,1: 197

10,3: 197

Irenaeus von Lyon

Adv. haer.

I 26,1: 4, 6

I 28,1: 248f., 289,

$291 f$.

II 1,2: 301

Josephus

C. Ap.

I 12: 179

I 35: 217

I 215: 179

Justin

1 Apol.

2,2: 248

4,9: 155

5,2: 275

8,4: 213

21,5: 129

23,2: 123

25: 217

27,1: 165

44,8f.: 236

58: 277

61,3f.: 124

2 Apol.

3,1f.: 149

5: 275,280

5,3: 274

7: 278

11,2: 149

12,5: 165

15,3: 141

Dial.

1-8: 217

5,1f.: 243

5,3: 243

5,4: 244

5,4-6,2: 213

6,2: 244

61,1: 123, 271

61,2: 124

61,3: 123

105,1: 123

119,4: 248

128,3: 124, 270

Juvenal

Satiren 1,26-29: 208 
Kallimachos

Hymn. Del. 36-38:

134

Kastor von Rhodos FGrHist 250: 183

FGrHist 250 F 4: 184

Kleitonymos

FGrHist 292 F 3: 133

Lukian

Bis Acc. 27: 5

Dea Syr.

1: 5

28f.: 217

Deor. conc. 5: 133

Dial. Mort.

13,5: 118

24: 126

27: 126

JTrag. 30: 151

Par. 33f.: 118

Peregr.

18: 159

39: 135

Sacr. 5: 135

Sat. 5f.: 134

Symp. 9: 163

Vit. Auct. 26: 118

Marc Aurel

12,3,1: 230

Marius Victorinus

Adv. Arium

I b 62f.: 229

Marsanes

25,1-14: 281

Martial

Epigr. XIII 25: 134

Maximos von Tyros

Dial. 11,9: 122

Minucius Felix

Oct.

21,11: 154

30,4: 165

Neanthes von Kyzikos FGrHist 84 F 25: 120

Nemesios von Emesa

De nat. hom. 2: 226

Origenes

C. Cels.

I 1: 214
I 16: 11

II 71: 268

III 44-55: 218

III 72-78: 218

IV 2: 220

VIII 14: 214

VIII 49: 214

Princ.

I 3,5: 239

III 4,2: 229

Orpheus

Fr. 59 Kern: 129

Fr. 140 Kern: 129

Ovid

Met.

I 490f.: 131

II 340-366: 134

II 405-507: 133

III 218: 188

IV 794-801: 128

X 103-105: 134

XII 307f.: 188

Parmenides

28 B 8,3 DK: 154

28 B 8,21 DK: 154

Pausanias

II 15,5: 183

IX 27,6f.: 153

X 12,1f.: 187

Philon von Alexandria

Fug. 141: 144

Gig.

23-28: 236

24: 271

Leg. alleg. I 32: 236

Mut. nom. 3: 144

Opif.

66: 233

69: 233

137: 233

Quaest. Gen. Fr. 16:

123

Somn. I 29: 145

Pindar

Ol. 2,85-88: 117

Platon

Apol.

26d: 164

41a: 125

Gorg.

485d: 162

523b-524a: 125 523e-524a: 125

Kritias 113d: 173

Leg.

885b8f.: 135

905d-907b.: 135

906a8-b3: 234

Phaid.

66b-68b: 146

67d1f.: 240

99a: 145

110a-111c: 151

Phaidr.

245c5: 236

246a-248d: 151

Rep.

II 379a: 195

IV 442b11: 241

IV 442c5: 241

VIII 546a2: 242

Symp.

202d-e: 282

218b: 130

Tht.

174a: 160

174a4-8: 218

176b: 145

176b1f.: 233

Tim.

27d6: 232

28b2-c2: 243

35a1-b3: 230

41a7-b6: 243

41c6-d3: 242

41d4f.: 242

Plinius der Ältere

Nat.

praef. 25: 163

VII 34: 174f.

VII 197: 115

XXX 99: 163

Plinius der Jüngere

Ep.

X 96,3: 215

X 96,8: 215

X 96,9: 215

Plotin

Enn.

II 9,7-9: 281

Plutarch

III 5,7,30-39: 277

Alex. 75,3-5: 118

De def. or.

13: 282 
39f.: 282

De facie 28: 230

De Is. 25: 140

Lyc. 1,1-3: 189

Pyth. or. 9: 187

Qu. conv. V 10,3: 145

Porphyrios

Abst.

II 38: 283

II 41,3: 283

II 42,1: 286

II 56,9: 165

Sent. 28: 232

Poseidonios

Fr. 57ab Theiler: 181

Proklos

In Remp. I 41,22-25:

283

Ps.-Aristoteles

Mund.

396b28f: 228

398a18-23: 277

Ps.-Clemens Hom. IX 14: 285

Ps.-Eratosthenes

Catast.

9: 132

25: 136

30: 136

40: 133

Ps.-Nonnos

Schol. myth. in Greg.

Naz. or.

5,1: 134

43,2: 134

(Ps.-?)Platon

Kleit. 407ab: 147

\section{Scriptores Historiae}

Augustae

Anton. Pius 11,3: 149

Seneca

Ep.

7,2-7: 202

83,19: 119

88,37: 172

88,40: 163

Sextus Empiricus

Pyrrh. hyp.

II 26: 231

III 30: 189

Solon

Fr. 18 West: 178, 259
Stobaios

I 37,4-15: 228

I 37,23-38,3: 235

II 49,8: 233

Suda

к 2087: 172

$\pi$ 1617: 172

$\varphi$ 214: 120

Suetonius

Vesp. 18: 16

Tatian

Or.

1: 219

1,1: 225, 254, 257

1,1f.: 20

1,5: 5, 252, 260

2,1: 225

2,1-3,10: 204

2f.: 219

3,3: 154, 218, 235

3,5: 226,236

4,1: 272

4,1f.: 219

4,2: 273

4,3: 219, 227,

268f., 273

4,4: 122, 229, 272

4,5: 268

5: 202

5,1: 219, $268 f$.

5,2: $270 f$.

5,3: 270

5,5: 271

5,6: 228, 253, 271

5,7: 268, 271

5-7: 220

6,1: 142, 211, 237

6,2: 211f.

6,3: 211, 241

7,1: 228, 238,

242, 270, $272 \mathrm{f}$.

7,2: 231, 233, 271

7,2-5: 274

7,3: 272

7,4: 275

8,1: 266

8,2: 275,280

8,2f.: 276

8-10: 219

8-11: 202

8f.: 278

9,1: 279
9,2: 126,279

9,3: 280

11,4: 233, 239

12: 278

12,1: 142, 229f.,

239,273

12,2: 268

12,3: 230

12,5: 230, 276

12,7: 142

12,8: 230,272

12,9: 253, 255

12,10: 255, 265

13,1: $236 f$.

13,2: 231, 238f.,

$272 \mathrm{f}$.

13,3: 146, 229,

239,241

13,3-6: 273

13,4: 143, 234

13,5: 239

13,6: 229, 239

14,1: 165, 262,

277

14,2: 277

14,3: 275

14-19: 278

15,1: 213, 229,

239

15,2: 221, $240 f$.

15,3: 229, 268

15,3-5: 231

15,4: 7, 232, 240,

268

15,6: 276

15,6f.: 240

15,8: 145,276

15,9: 231, 280

16,1: 275

16,1f.: 240

16,2: 8

16,3: 241, 272,

277

16,4: 238

$16,7: 229$

16,7-17,1: 204

17,1: 283

17,2: 237

17,3: $283 \mathrm{f}$.

17,4: 284

18,1: 285

18,5: 285 
18,6: 6, 15, 19, 194, 248, $285 f$. 19,1: 15, 263 19,1-4: 204 19,2: 6, 19, 237 19,3: 282 19,5: 281 19,5-9: 204 19,6-8: 281 19,9: 281 20,2: 229, 231 20,2-4: 233

21,5: 256 22,3: 255 22,7: 261 23f.: 202 25,1-27,9: 204 25,3: 226 25,3f.: 236 25,4: 237, 242, 257 25,5: 255, 258

26,2: 218

26,3: 219

26,5: 256

26,6: 261

26,8: 257

27,1: 256

27,2: 219

27,3: 182

27,6: 260

27,9: 255

28f.: 202 29: 217,278 29,1: 5, 7, 16, 252 29,2: 262

29,3: 226, 258 30,1: 199

30,3: 19

31: 219

31,1: 225, 257

31,1-6: 19

31,2: 260

31,4f.: 22

31,5: 22

32,2: $262 \mathrm{f}$.
32,7: 263

33,2: 273

33,2-34,9: 219

34,1: 219,258

35: 206, 217

35,1: 5f., 14, 251

35,2: 16, 252

35,2f.: 259

35,3: 226, 259

35,4: 259

36,1: 180

36,1-42,2: 19

36,2: 180

36-41: 219

37,2f.: 23

38,1f.: 21

39,2: 254

39,4: 6, 21

39,5: 21

40,1: 22, 145

40,2: 261

40,3: 7

41,1: 22

41,2: 22

41,3-5: 23

41,6-10: 22

42: 217

42,1: 4f., 153, 225, 251, 254,

259, 288

42,2: 122

Tertullian

Adv. Prax. 9,1: 271

Apol.

2,6-9: 214

22,3: 274

Cult. fem. I 2,1: 278

De an.

14: 235

46,3: 114

Theodoret von Kyros

Graec. aff. cur. proem. 1: 218

Haer. fab. comp. 2,5: 292 PG 83, 369,5: 5
Theophilos von Antiochia Autol.

I 1,1: 218

I 1,2: 220

I 2,1: 218, 221

I 2f.: 219

I 3: 218

I 4: 219

I 4,5-6,6: 219

I 4f.: 218

I 8: 218

I 13: 212

I 13,1: 221

II: 219

II 2: 218

II 4: $124 \mathrm{f}$.

II 10: 142, 194 , 217

II 15: 142

II 27: $141 \mathrm{f}$

III 7: 218

III 15: 202

III 16: 219

III 16-28: 219

III 16-29: 194, 198

III 27,3: 194

Timon

SH 831: 121

Varro

Ling. lat. V 32: 174

Rust. II 4,18: 176

Vita Adami et Evae $15: 274$

Vitae Homeri [Plutarchi] vita 3: 179 Vita Procli 7: 179

Vita Romana 4: 179

Xenophanes

21 A 37 DK: 159

21 B 2 DK: 156

21 B 11-16 DK: 217

21 B 23-26 DK: 217 


\section{Namens- und Sachregister}

Abas: $182 \mathrm{f}$.

Abdera: 146f.

Abderos: 147

Achill: 127, 153, 164, 171, 177, 179

Achsenthemen: 201, 203, 211f., 218, $220 f$.

Adam: 126, 274, 292

Admetos von Pherai: 153

Adrastos: 157

Aelius Aristides: 18, 148, 286

Aeneas: 175

Afrika: 152

Ägäis: 146

Agamemnon: 22, 151, 154, 183, 185

Agenor: 174, 182f., 254

Agesilaos I.: 189

Agiaden: 189

Agrigent: 175, 258

Agrios: 171

Agrippa: 156

Ägypten: 21, 147, 180, 182, 185, 283

Ägypter: 14, 20, 120, 141, 163, 180

Aiakos: 125

Aigeus: 185

Aioler: 117

Aiolisch: 117

Aithon: 136

Akrisios: 22, 182f., 185

Aktaion: 188

Aktaios: 21f., 184

Aktionsräume: 195, 207, 209, 214

Alexander der Große: 118f., 150, 163, 177,180

Alexander von Aphrodisias: 159

Alexandria: 163, 281

Alkiphron: 174

Alkippe: 174

Alkmaion: 157

Allegorese: 235, 256

Allegorie: 12

Altersbeweis: 10f., 13f., 19f., 23, 178f., 202, 219, 225, 257, 296-299

Ambrosius: 259

Ameipsias: 172

Amosis: 21, 182

Amphiaraos: 157

Amphiktion: siehe Amphiktyon
Amphiktyon: 22, 184f.

Amphion: 22f., 186-188

Amphis: 172

Amphistratos: 173

Amulette: 147, 279, $283 f$.

Amykos: 20

Anacharsis: 141, 156, 255

An Autolykos: 194, 198, 200, 203, 218, 301

Anaxagoras von Klazomenai: 154, 164

Anaxarchos von Abdera: 150, 225

An Diognet: 197, 201

- als Protreptikos: 213

Anthropologie: 8, 10, 203, 212, 220f., 230, 234, 267, 303

Antigenides von Theben: 158

Antimachos: 168

Antinoos: 135

Antiochia: 4, 193, 195-200

Antiochos I.: 180

Antipater von Thessalonike: 173

Antiphanes: 114, 172

Antoninos: 15

Antoninus Pius: 15, 149, 159

Antonius: 258

Anyte von Tegea: 173

Anytos: 120

Aphrodite: 127f., 132, 174, 176

Apion: 21, 163, 182

Apis: $182 \mathrm{f}$.

Apollodor (Mythograph): 153, 182

Apollodoros (athen. Politiker): 177

Apollodor von Athen (Gelehrter): 22, 169f., 189

Apollon: 22, 115, 127f., 130-132, 134,

151, 153, 157f., 185, 187, 217, 282

Apologeten: 125, 129, 135, 142, 154, 194, 201, 203-207, 210-214, 217, 219f., 222f., $237,247,260,264,303$

Apologetik: 220, 256f., 262, 267, 297, 302

Apostel: 299

Apuleius: 151, 227, 282

Araber: 20

Arabien: 4

Archemachos: 22

Archilochos: 170

Areios Didymos: 233 
Areopagrede: 195, 210-213, 217, 221

Ares: 127, 132, 176

Arethas: 24

Argeia: 174

Arges: 116

Argo: 133

Argos (König): 182

Argos Panoptes: 182

Argos (Sohn der Niobe): 183

Argos (Stadt): 169, 182, 185

Ariaspes: 116

Aricia: 165

Aristarch von Samothrake: 22, $169 f$.

Aristeas von Prokonnesos: 157, 188

Aristides: 201, 222

Aristippos: 118, 225

Aristodemos (Bildhauer): 176

Aristodemos von Elis (Autor): 114, 189

Aristodotos: 173

Aristophanes: 114, 117, 151, 260

Aristophanes von Byzanz: 168f.

Aristoteles: 114, 118f., 140, 225f., 231, 236f., 241, 298, 303

Aristoteliker: siehe auch Peripatetiker, 161

Aristotelismus: 124

Aristoxenos: 158

Arkas: 133

Artemis: 128, 133-135

Artemon: 292

Arzneikunde: siehe auch Medizin, 285

Asbolos: 188

Asebie: 162, 174

Asien: 125

Askese: 248, 263

Asklepios: 128, 153, 286

Äsop: 176

Assyrer: 4f., 20, 189, 288

Assyrien: 4f.

Asteria: 134

Astrologie: 141, 219, 278-281, 286

Astronomie: 254

Atalante: 129

Atheist: 162f.

Athen: 15-17, 22, 117, 119, 141, 149, 155f., 159, 162, 170, 185, 210, 222

Athena: 127-129, 133, 153, 155, 160

Athenagoras: 201, 270, 274f., 278

Athenaios: 173

Athener: 16

Atlantis: 152, 173

Atlas: 20, 22, 184

Atossa: 20, 116
Atreus: 183

Attika: 22, 117, 130, 168, 184

Attikos: 225, 243f., 301

Attis: 127, 134

Attisch: 117

Auferstehung: 12, 160, 207, 211-213, 237, $242 f$.

- Auferstehungshoffnung: 212f., 220f., 242

Augustin: 261f.

Autolykos: 201, 203, $221 f$.

Babel: 166

Babylon: 4, 171

Babylonien: 4, 141

Babylonier: 14, 20

Bakis: 188

Barbaren: 11, 19f., 141, 202, 225, 252-254, 257f., 265, 295f., $299 f$.

Basileios von Kaisareia: 138, 302

Basilides: 292

Baukis: 172

Beelzebub: siehe auch Teufel, 143

Bekehrung: siehe auch Konversion, 124, 243, $299 \mathrm{f}$.

Belos: 180, $182 \mathrm{f}$.

Berenike II.: 135

Berossos: $179 \mathrm{f}$.

Besantis: 174

Bibel: 200, 293

Bibliothek von Alexandria: 168f.

Bildung: siehe auch Paideia, 13, 161, 203, 208, 211, 216f., 247, 249, 252-255, 257f., 261-263, 265, $295 f$.

- barbarische Bildung: 248, 264

- biblisch-jüdische Bildung: 198

- Bildungsdemonstration: 203, 212, 219

- Bildungsdiskurs: 202, 219

- Bildungsfeindlichkeit: 218

- Bildungsideal: 217

- Bildungskonzeption Tatians: 264

- Bildungskritik: 253, 260

- Bildungsostentation: 253, 260

- Bildungssystem: 261

- Bildungstradition: 205-207, 211, 217f.

- Bildungsvorstellung Tatians: 247, 254, $264 f$.

- Bildungsweg: 217

- Bildungswelt: 201, 209f., 302

- Bildung Tatians: 251

- christliche Bildung: 247, 259

- formale Bildung: 262f.

- grammatische Bildung: 251, 258 
- griechische Bildung: 4, 247, 259

- hellenische Bildung: 248, 253

- hellenistisch-römische Bildung: 205

- klassische Bildung: 257

- pagane Bildung: 256, 266

- religiöse Bildung: 256

- rhetorische Bildung: 251, 258, 264

- Schul(aus)bildung: 5, 253, 258

- wahre Bildung: 259

Bithynien: 114, 214f.

Boiskos: 172

Bolos von Mendes: 146, 283

Brontes: 116

Bryaxis: 175

Busiris: 18,120

Caecilius: 222

Caesarea: siehe Kaisareia

Calcidius: 140

Cassius Dio: 16

Chaldäer: 14, 180

Chamaileon von Herakleia: 168

Chariten: 176

Cheiron: 133

China: 288

Christen: 7, 11, 13, 150, 152, 160, 162, 196, 198, 201, 203-205, 208f., 213-216, 220, 228, 247, 256-258, 263f., 266, 278, 280, 291, 293, 295, 297f., 303

- als Barbaren: 264

- gebildete Christen: 195, 203, 208

Christentum: 6, 13, 19, 124, 166, 196-201, 203-206, 208-223, 243, 247f., 256, 264f., 294, 296, 298f., 302f.

- als wahre Philosophie: 289, 294, 298

- Frühchristentum: 206, 208, 222, 249, 255, 271, 274f., 278, 286

- hellenistisches Christentum: 199

Christenverfolgung: 204

Christliche Gemeinden: 6, 122, 159, 196f., 262, 287

Christliche Propädeutik: 203

Christologie: 221, 286

Christsein im Alltag: 213

Christus: siehe auch Jesus, 123f., 153, 243, 270, 299

Chrysaor: 128

Cicero: 17, 114, 120, 152, 261, 296

Clemens von Alexandria: 6, 8, 20-23, 114f., 170, 184, 186, 189, 201, 213, 271, 278, 287f., 292-296, 300

Commodus: 201

Como: 216 creatio ex nihilo: $124 \mathrm{f} ., 139,301$

Crescens: 6, 12, 19, 149f., 164

curiositas: 210

Daimones: 282, 284

Daktylen: 20

Damis: 163

Dämonen: 8, 10-12, 126f., 132, 138, 140, 142-146, 149, 151, 154, 230, 234, 240f., 255f., 265, 274-276, 278-280, 283, 285f., 290

- als Betrüger der Menschen: 279

- als gefallene Engel: 274

- als Gesetzgeber: 280

- als Götter: 275

- als Herrscher der Städte: 277

- als Usurpatoren Gottes: 279

Dämonologie: 221, 267, 274, 279, 303

- frühchristliche Dämonologie: 274

- mittelplatonische Dämonologie: 274, 286

- pagane Dämonologie: 140

Danae: 183

Danaiden: 161, 185

Danaos: 22, 161, 182-185

Daphne: 131

Dardania: 22, 179

Dardanos: 22, 179, 185

Dareios: 116,165

Deianira: 153

Deinomenes: 174

Deïphobos: 153

Delos: 120, 134

Delphi: 131, 160, 174, 187

Demeter: 127, 130, 132, 185

Demodokos: 23, 186-189

Demokrit: 12, 146f., 225f., 283

Demonstratio evangelica: 211

Demosthenes: 177

Determinismus: 278, 281

Deukalion: 22, 184

Diagoras von Melos: 162

Dialog mit Tryphon: 197, 222

Diana: 16, 165

Diatessaron: 6f., 193f., 288-293

Dichtung: 118, 172f., 217, 256, 261, 279, 284

Didache: 196, 199

Didymos: 172

Dikaiarch: 159

Diogenes (Kyniker): 118, 158f., 225

Diogenes Laertios: 141

Diognet: 201, 222 
Diomedes: 127, 147, 171

Dionysios von Olynth: 168

Dionysios von Syrakus: 118

Dionysius von Alexandria: 302

Dionysos: 22, 117, 129, 131f., 137, 155, 185

Dionysos Zagreus: 129, 131

Dionys von Halikarnass: 21, 184

Dioskuren: siehe Kastor, Polydeukes

Diphilos: 172

Diskursivität: 202f.

Divination: 12

Dodona: 141

Dorer: 117

Dorisch: 117

Drakon: 189

Drymon: 188

Dualismus: 234, 239, 293

Edessa: 193

Egeus: 184

Eintracht: 206

Ekpyrosis: 120, 160, 164

Elephantis: 178

Eleusis: 22, 132, $184 \mathrm{f}$.

Empedokles: 120, 225, 236

Endgericht: 237, 243

Engel: 12, 126f., 140, 271, 274f., 279, 281

- Engel der Nationen: 277, 279

- Schutzengel: 273

England: 288

Enkratismus: 248f., 266

Epaphos: 182f.

Ephesos: 195, 197

Ephippos: 172

Ephoros von Kyme: 168

Epidauros: 148

Epikur: 154, 163f., 225f.

Epikureer: 15, 159, 161, 163, 211

Epimenides: 163, 165, 187f.

Epimetheus: 22, 184

Epiphanios von Salamis: 4, 6, 15, 294

Eratosthenes: 9, 22, 168-170, 189

Erechtheus: 184f.

Erichthonios: 128, 184f.

Erigone: 132f.

Erinna: 172f.

Erinnyen: 157

Eriphyle: 157

Erkenntnis: 210, 218, 220f., 226, 231, 237, $249,263,265,299$

Erlöser: 206

Eros: 135
Eschatologie: 221, 240

Eschaton: 213

Eteokles: $175 \mathrm{f}$.

Ethik: 8, 10, 221, 233

Etrusker: $114 \mathrm{f}$.

Euanthe: 176

Euboia: 115, 186

Euhemeros: 163

Euklus/-kloos: 188

Eumenes II.: 169

Eumolpos: 22, 185, 187

Euphorbos: 159

Euphorion: 22, 170

Euphrat: $4 \mathrm{f}$.

Euripides: 117, 119, 137, 158, 173, 175, 185

Euristheus: siehe Eurystheus

Europa: 22, 125, 136, 174

Eurystheus: 147, 169, 182f.

Eusebios von Kaisareia: 4, 6, 8, 11, 19, 24f., 148-150, 167f., 170, 180, 182f., 186, 188, 249-251, 283, 287-292, 294, 300

Euthykrates: $173 \mathrm{f}$.

Euthymenes: 22

Eutychis: 175

Eva: 126

Evangelium: 7, 196, 199-201, 206, 209f., 212, 214, 223, 249, 289, 293

- Evangelienharmonie: 7, 200, 288, 290

- Evangelium und Kultur: 213, 219

- Johannesevangelium: 7, 142, 200, 238

- Markusevangelium: 199

- Matthäusevangelium: 196, 199

Exorzismus: 146

Flavius Josephus: siehe Josephus

Freier Wille: 12, 239, 242, 272, 275

Freiheit: 138, 231, $233 f$.

Fremdheit: 213

Friede: 206, 214

Fronto: $17 \mathrm{f}$

Gaia: 116

Galiläa: 209

Ganymedes: 134, 136, 177

Gebet: 196

Gebildete: 195, 200f., 204-207, 210-217, 222f., 256, 258f

- hellenisch Gebildete: 203, 252

- hellenistisch-römisch Gebildete: 208

Geist: siehe auch Pneuma, 12, 122, 142, 145, 153, 221, 226-231, 233f., 236-240, 242-244, 270, 272f., 275, 277, 302 
- als Seele: 229

- Heiliger Geist: 142, 229-231, 233, 238f., $243 f$.

- Weltgeist: 235

Gellius: 157, 159

Geometrie: 254

Geschöpf: 229f., 235

Gibraltar: 152

Glaukippe: 174

Glaukos von Rhegion: 154

Glykera: 174

Gnosis: 201, 206, 281

Gnostiker: 4, 243, 280, $291 \mathrm{f}$.

Gnostische Literatur: 227

Gomphos: 173

Gorgias: 18

Gott: 11f., 120, 122-124, 127, 138, 140, 142, 144f., 151, 154, 159, 161, 164, 202f., 212-214, 218, 220, 222, 226-235, 242-244, 256, 263, 265, 267-269, 271, 273-275, 277-280, 286, 293, 295, 298

- als Geist: 227, 268

- als Retter: 210-212, 221

- als Richter: 211

- als Schöpfer: 10, 210-212, 221, 267f., 295

- als Weltenherrscher: 210

- Anfangslosigkeit Gottes: 219, 301

- Bedürfnislosigkeit Gottes: 194

- Einheit Gottes: 272

- Gottesbegriff: 267, 298, 301

- Gottesebenbildlichkeit: 231-234

- Gotteserkenntnis: 219, 234, 236, 255

- Gottesschau: 219

- Gottesvorstellung: 122, 211-213, 215f., $220 \mathrm{f}$.

- Gottlosigkeit: 155

- Gott Vater: 124, 126, 138, 228, 269-271, 299

- Gott Vater und Sohn: 124, 269

- Kraft Gottes: 270, 285

- Macht Gottes: 285

- Namen Gottes: 123

- Natur Gottes: 11

- Sohn Gottes: 220

- Strafe Gottes: 148

- Transzendenz Gottes: 11, 228, 267f., 273, 286, 298, 301

- Unaussprechbarkeit Gottes: 219

- Unbegreiflichkeit Gottes: 219

- Unberührbarkeit Gottes: 219, 227

- Unkörperlichkeit Gottes: 227f.

- Unsichtbarkeit Gottes: 219, 227
- Unveränderlichkeit Gottes: 219, 273, 286

- Wille Gottes: 243f., 270

- Wort Gottes: 302

Götter: 12, 22, 116, 126f., 129, 132, 135-137, 140, 142, 144, 152-155, 160, $163,176,233 f ., 242,244,251,255 f ., 265$, 275-279, 282f., $285 f$.

Graecarum affectionum curatio: 211

Grammatik: 254

Grammatiker: 161, 257, 261, 263

Granikos: 119

Gregor Thaumaturgos: 253

Gregor von Nyssa: 138, 300

Griechen: 11, 13f., 18f., 23, 127, 131, 141, 143, 151-153, 160-162, 165f., 170f., 176, 252, 254f., 257, 260, 262, 264f., 295-297, 299f., 302

- gebildete Griechen: 303

Griechenland: 14, 147, 163, 193, 285

Gyges: 170

Hades: 125, 127, 130, 133, 185

Hadrian: 135, 197, 201, 205, 208

Halikarnass: 114

Hapax legomenon: 117, 144

Häresie: 4, 8, 124, 156, 249, 292, 299

Häretiker: 251, 294

Harmonia: 176

Hegesias: $157 f$.

Heiden: 195, 205, 223, 264f., 297

Heiliger Geist: siehe Geist

Heilige Schriften: 8

Heilkunde: 278, 285f.

Heilmittel: 283-285

Heimarmene: 12, 126, 138, 278

Hekataios von Abdera: 182

Hekate: 128

Hektor: 153, 170

Helena: 18, 126, 137

Helenus: 176

Helikon: 187

Helios: 132, 134

Hellenen: 218, 253f., 256f., 259, 264f., 298

Hellenismus: 152, 168

Hephaistion: 120, 177

Hephaistos: 116, 126, 128f., 176

Hera: 127, 153f., 169

Herakleides Pontikos: 187

Herakleon: 201

Herakles: 22, 120, 133, 136, 147, 153, 164, $169,171,189$

Heraklit: 119f., 126, 225, 295 
Hermes: 132, 147

Hermias: 204

Hermon: 163

Herodes: 258

Herodes Antipas: 214

Herodes Atticus: 156

Herodoros von Herakleia: 164

Herodot (Geschichtsschreiber): 4, 115, $168,178,188$

Herodotos (Bildhauer): 174

Herophile: 187

Hesiod: 22, 128, 186

Hestia: 127

Hieronymus: 294

Hilaeira: 137

Hipparcheia: 121

Hippobotos: 120

Hippolyt von Rom: 242, 292

Hiram I. von Tyros: 23, $181 f$.

Hirt des Hermas: 200

Homer: 9, 13f., 22, 131, 167-170, 178f., $186,188,256-258,260,296 f$.

Horoskop: 278-280

Horos von Samo: 188

Hyakinthos: 131

Hypereides: 174

Hypostasis: 269, 272

Hypsikrates: 181

Iapetos: 184

Iasos: $182-184$

Idas: 137

Ignatianen: 197

Ignatios: 197

Ikarios: 132

Ilion: siehe auch Troja, 22, 179, 297

Illyrer: 20

Ilos: 179

Inachos: 21, 182-185

Inder: 165

Indien: 152

Inkarnation: 207, 220

Inkubation: 148

Io: $22,136,182-184$

Iolkos: 185

Ion: 22, 154, 185

Ionier: 117

Ionisch: 117

Iphitos: 189

Irenaeus: 301

Irenaeus von Lyon: 4, 6, 150, 201, 248-250, 289, 291f., 294

Isaurer: 20
Isaurien: 114

Isokrates: $17 \mathrm{f}$.

Israel: 198

Istros: $115 \mathrm{f}$.

Iuppiter: 16, 132

Iuppiter Latiaris: 165

Jesus: siehe auch Christus, 7, 124, 143, 196, 211, 213f., 220f., 267

Johannes Chrysostomos: 138, 300

Johannes Philoponos: 160

Josephus: 182, 204, 297

Juba II.: 180

Juden: 20f., 180, 182, 196, 223, 297

Judentum: 195-199, 201

- Diasporajudentum: 195

- griechisches Judentum: 285

- hellenistisches Judentum: 196, 217, 274, 276, 279, 296

Julius Africanus: $183 \mathrm{f}$.

Justin: 4-6, 15f., 19, 117, 121, 123, 148-150, 193f., 200f., 217, 221f., 237, 243f., 248-250, 252f., 264f., 267-272, $274,277 f$., $285,289,291 f ., 296,300 f$.

- Justins Schule: 250, 264

Kadmos: 20, 22, 153, 185, 254

Kaisareia: 24

Kalliades: 177

Kallikles: 162

Kallimachos: 135, 163, 168f.

Kallisthenes: 118

Kallistion: 291

Kallisto: 133

Kallistratos: 168f., 176

Kambyses: 167

Kannibalismus: 160, 256, 258

Kappadokier: 20

Karer: 20, 114

Karien: 114

Karneades: 117

Karthager: 20

Kassianos: 20

Kastor: 136f.

Kastor von Rhodos: 183-185

Kaulonia: 188

Kekrops I.: 22, $183 \mathrm{f}$.

Kekrops II.: 22, $184 \mathrm{f}$.

Kelsos: 201, 212, 214, 220, 268, 289, 297

Kentauren: 188

Kephisodotos: 173

Kilikien: 4

Kleinasien: 114, 199, 216 
Kleito: 173

Kleitos: 119

Kleombrotos: 282

Klytaimnestra: 137

Kodros: 170

Kolchis: 136

Konfliktdisposition: 207, 212-215

Konon (Mythograph): 116, 187

Konon von Samos: 135

Kontinuität: 205f., 215

Konversion: siehe auch Bekehrung, 6, 13, 166, 197, 209, 217, 223, 251f., 262, 265

Kore: 130, 185

Korinna: $172 f$.

Körper: 139f., 145f., 159, 176, 227, 230, 232, 236f., 240-242

Kosmogonie: 301

Kosmologie: 8, 268, 303

Kosmos: 12, 120, 142, 195, 198, 200, 203, 206, 220, 232, 259f., 264, 268f., 273, 281, 284, 286

Kranaos: 184

Krates von Mallos: 22, 169f., 178f.

Krates von Theben: 121, 225

Kratine: 174

Kreta: 22, 136, 163, 185

Kreter: 163

Kreusa: 185

Kriasos: 182f.

Kroisos: 170, 178

Kronos: 127, 129, 132, 134, 160, 256

Krotopos: 22

Krotopos/Krotopas: 182-184

Ktesias: 171

Kultur: 223

Kybele: 127f., 134, 165

Kyklopen: 20, 115f., 153

Kyniker: 147, 159, 226

Kyprier: 20

Kyros: 116, 167

Kyros II.: 198

Lais: 177

Laitos: 181

Lamia: 187

Laodamas: 157

Lapithen: 188

Laster: 140

Latium: 175

Learchis: $172 \mathrm{f}$.

Leda: 134, 136f.

Lemnos: 171

Leochares: 177
Leon von Pella: 163

Leto: 22, 130, 134

Leukippos: 137

Libanios: 18

Libye: 182f.

Linkeus: siehe Lynkeus

Linos: 22, 186-188

Logos: 11f., 117, 123f., 126, 139f., 142, 144, 151, 166, 207, 220, 222, 228f., 234, 238f., 241, 255, 269-273, 284, 286, 293, 295, 298

- als Erstgeborener: 270

- als Schöpfer: 271

- Christus-Logos: 269

- himmlicher Logos: 273

- irdischer Logos: 273

- Kraft des Logos: 269-271, 275

- Logoslehre: 250, 267, 269, 292, 298

- Logosspekulation: 221

- Logos spermatikos: 234

Lucius Tarquinius Superbus: 198

Lukas: 211, 213

Lukian: 5, 16, 18, 118, 120f., 133-135, 149, 155f., 159, 161-163, 217, 226

Lydien: 114

Lykaon: 133

Lykaonien: 114

Lykien: 114, 116

Lykurg: 22, 189

Lynkeus: 22, 137, 182f., 185, 189

Lysipp: 172

Lysistratos: 175

Magie: 147, 254, 283-285

Magnesia: 197

Maieutik: 284

Maira: 133

Majoritätsgesellschaft: 205, 216

Mantik: 151, 278, 281-284, 286

Marc Aurel: 15-18, 149, 194, 198, 201, 230

Marius Victorinus: 229

Markion: 200f., 206f., 249, 287, $293 f$.

Mars: 132

Marsyas: 20, 115, 158

Materialismus: 240

Materie: 12, 122, 124, 139, 148, 154, 227-231, 235, 239, 241-243, 268f., 271, 275f., 285, 301

- Ewigkeit der Materie: 124, 302

Maximos von Tyros: 282

Medea: 20

Medizin: siehe auch Arzneikunde, 12, 140, 147 
Medusa: 128

Megakleides: 168

Melanippe: 175

Meleager: 129, 173

Meletos: 120

Meliton von Sardes: 201

Menander (Komödiendichter): 122, 150, 158,174

Menander von Ephesos: 181

Menander von Pergamon: 181

Menelaos: 126, 137, 159, 181

Menestheus: 184

Merkur: 132

Mesopotamien: 4, 6, 15

Metis: 129, 160

Metrodor von Lampsakos: 154

Mikon: 174

Milet: 170

Miltiades: 292

Minos: 22, 125f., 160, 185, 189

Minotauros: 185

Minucius Felix: 201, 217

Mittelmeer: 141, 152, 156

Mittelplatoniker: 232

Mittelplatonismus: 275f., 278, 280, 282, 286

Mnesarchis: 173

Mochos: 181

Monotheismus: 202, 221, 267, 277

- christlicher Monotheismus: 277

Mons Albanus: 165

Moses: 14, 20-22, 145, 180, 182f., 185f., 236, 257f., 296, 302

Musaios: 22, 185-188

Musanos: 294

Mykene: 116

Myro/Moiro: 173

Myrtis von Anthedon: 172

Myson: 141

Mysterien: 5, 252

- Eleusinische Mysterien: 130, 162

Mystis: 173

Mythenkritik: 204, 217, 219, 256, 261

Mythologie: 12, 114, 127, 276

Nabuchodonosor/Nebukadnezar: 180

Naukydes: 172

Neaira: 177

Nemesios von Emesa: 226

Nemesis: 136

Neptun: 132

Nessos: 153

Nestor: 151, 170f.
Neuplatoniker: 228, 280, 282

Neuplatonismus: 160, 276

Neupythagoreer: 140

Nike: 174

Nikeratos: 173f.

Nikodemos: 124

Nikokreon von Zypern: 150

Nil: 135

Ninos: 137, 171

Niobe: 183

Noët von Smyrna: 197, 201

Noricum: 116

Norm am Anfang: 196

Noroper: 20, 116

Nossis von Lokroi: 173

Nus: 230, 235f., 242, 244

Ochos: 181

Octavius: 201, 222

Oden Salomos: 199

Ödipus: 157, 175

Odysseus: 116, 125, 171, 187

Ogygos/Ogigos: 21, 183f.

Oiagros: 115

Oineus von Kalydon: 135, 171

Oita: 153

Okeanos: 160

Olymp (Göttersitz): 126, 134, 136, 152

Olympias: 163

Olympos (Phryger): 20, 115

Omphalos: 131

Onomakritos: 23, 189

Orakel: 151, 171, 282f.

- Sibyllinische Orakel: 187

Oratio ad Graecos: 3-8, 16f., 19f., 24, 193f., 197, 199, 201-203, 205, 207, 219, 221f., 232, 247-253, 256, 259f., 263-266, 276, 280, 283, 286, 289-293, 299-303

- Adressaten: 18f., 222, 253, 266

- als Apologie: 17, 204, 247, 303

- als Einführung ins Christentum: 204

- als Lehrvorträge: 263

- als Protreptikos: 17, 204, 247

- Datierung: 6, 14-16, 193

- Entstehungsort: 14, 16, 193

- Gattung: 17-19

- Rezeption: 287

- Struktur: 9-14

Orest: 137

Origenes: 253

Orion: 133

Orontes: 193, 195-198

Oropos: 148 
Orpheus: 20, 22, 114, 130, 186-189

Ortygia: 134

Osrhoene: 200

Ostanes: 147, 283

Ozean

- Atlantischer Ozean: 152

- Indischer Ozean: 152

Paideia: siehe auch Bildung, 14, 211, 247, 251, 253-259, 264f., 295f.

- barbarische Paideia: 266

- biblische Paideia: 260

- christliche Paideia: 259, 266

- enkyklios Paideia: 254

- griechische Paideia: 258, 286

- heidnische Paideia: 266

Palamedes: 18

Pandion I.: 184

Pandion II.: 184f.

Panteuchis: 174

Pantheismus: 120

Paradies: 126, 151, 278

Paris: 126, 137

Parmenides: 154

Parthenopaios: 129

Pasiphae: 174

Pathos: 280, 283

Patroklos: 159, 177

Paulus: 125, 153, 195, 210 .

Pausanias: 173

Pegasos: 128

Pelasgos: 183

Peloponnes: 22, 169

Pelops: 22, 160

Penthesileia: 171

Pentheus: 129

Peregrinos: 135, 159

Pergamon: 148, 169

Periander: 141

Periklymenos: 175

Peripatetiker: siehe auch Aristoteliker, 15

Persephone: 22, 129-132, 134, 185

Perser: 20, 116

Perseus: 22, 128, 182f., 185

Persien: 4

Petronius: 208

1. Petrusbrief: 213

Phäaken: 187

Phaëthon: 22, 134

Phalaris von Akragas: 175f., 258

Pharisäer: 143, 196

Phemios: 23, 186-189

Pherekydes: 22, 120, 159, 171, 225f., 236
Philadelphia: 197

Philainis: 178

Philammon: 186-189

Philochoros: 22, 168, 170, 184

Philoktet: 171

Philolaos: 121

Philon (Bildhauer): 177

Philon von Alexandria: 145, 204, 233, 235f., 271, 278

Philosophen: 6, 16, 118, 121, 125, 149, 159, 161, 181, 225, 247, 251, 253, 257, 259,263

- griechische Philosophen: 11, 117, 161, 225

- kynische Philosophen: 159

- pagane Philosophen: 12, 149

- Spott gegen Philosophen: 219

Philosophie: 3, 17f., 120, 202, 211, 216f., 226f., 233, 241, 244f., 249, 253, 258-260, 265, 267, 284, 296, 300, 302f.

- Barbarenphilosophie: 295, $299 f$.

- barbarische Philosophie: 259, 303

- christliche Philosophie: 178, 258, 262, 264

- griechische Philosophie: 11, 154, 225, 256, 300, 302

- hebräische Philosophie: 234

- heidnische Philosophie: 147

- jüdische Philosophie: 20

- pagane Philosophie: 124, 160

- platonische Philosophie: 141, 145, 244

- pythagoreische Philosophie: 141

- wahre Philosophie: 161, 204

Philostephanos: 114

Phoibe: 137

Phönizien: 22, 181

Phönizier: 14, 20, 180, 254

Phorbas: 21f., 182-184

Phoroneus: 21, 182-184

Phrixos: 136

Phryger: 20

Phrygien: 22, 114, 127

Phryne: 174

Pilatus: 214

Pindar: 172f.

Pisidien: 4, 114

Planeten: 132, $279 f$.

Platon: 18, 118, 120f., 135, 139-141, 144, $146,152,154,159,195,217,225-228$, 230, 233f., 236, 240f., 244, 284, 297f., 302

Platoniker: 15, 161, 230, 240-244, 282 
Platonismus: 124, 236, 243, 282, 284, 298, 301

Plinius der Ältere: 115f., 163

Plinius der Jüngere: 201, 204, 214-216

Plotin: 277, 280f.

Pluralismus: 250

Pluralität: 199f., 202

Plutarch von Chaironeia: 144, 151, 225, $230,243,282$

Pluto: 132

Pluton: 125, 133

Pneuma: siehe auch Geist, 12, 120, 122, 138f., 141f., 145f., 152, 221f., 227-230, 235f., 238, 244, 268-270, 272f., 275f., 282, 286

- als Schöpfung Gottes: 273

- als Seele: 142

- als Substanz Gottes: 273

- Pneumatologie: 8, 221, 267, 272

- stoisches Pneuma: 272

Polemik: 19, 220, 222, 225, 234, 278, 302f.

Polyarchie: 277

Polydeukes: $136 f$.

Polykarp von Smyrna: 197

Polyneikes: 157, 175f.

Polyphem: 116

Polystratos: 175

Polytheismus: 143, 165, 277, 286

Pompeji: 208

Pontus: 214f.

Porphyrios: 282, 284, 286, 301

Poseidon: 127f., 133, 160, 173, 187

Poseidonios: 227, 235, 240, 244, 300

Praeparatio evangelica: 211

Praxagoris: 173

Praxilla von Sikyon: 172

Praxiteles: 174, 177f.

Prestige: 208f., 215

Priamos: 137, 179

Prinzipiendualismus: $301 \mathrm{f}$.

Proitos: 22, 182f., 185

Prokles: 189

Proklos: 160, 178, 297

Prometheus: 22, 136, 153, 184

Pronapides: 188

Propheten: 142, 186, 282, 295

Protesilaos: 126

Proteus: 137

Pseudo-Clementinen: 253

Psychologie: 8

Ptolemaios I.: 168

Ptolemaios II.: 168

Ptolemaios III. Euergetes: 135
Ptolemaios von Mendes: 21, 182

Pyrrhon von Elis: 150

Pythagoras: 22, 120f., 141, 159, 174f., 181, 189, 225f., 233, 236

Pythagoreer: 141, 161, 188, 228

Pythia: 151

Rabbula von Edessa: 7

Römer: 14, 16, 215, 252

Religion: 3, 169, 195f., 201-203, 206, 211, 216, 255, 265, 282

- griechische Religion: 280, $282 \mathrm{f}$.

- Religionsdiskurs: 193-195, 201-203, 205f., 210f., 220, 222

Rettung: 202, 218, 220, 238

Rhadamanthys: 125,160

Rhea: 127f., 134, 165

Rhetoren: 10, 16, 149, 261, 263

Rhetorik: 5, 17f., 118, 164, 197, 251, 303

- Rhetorikkritik: 252, 255, 260

Rhodon: 6, 8, 250, 287

Rhodos: 188

Rom: 4, 6f., 14-16, 117, 159, 163, 165, 173, 177, 193f., 197f., 200, 204, 207f., 259, 263f., 287, 292

Salomon: 23, $181 \mathrm{f}$.

Samosata: 5

Sappho: 172

Sarpedon: 188

Satornin: 249, 291

Saturn: 132

Schicksal: 12, 126, 134, 137, 157, 160, 272, 278-281, 284

Schöpfer: 206, 211, 229, 235

Schöpfung: 122, 139, 198, 207, 219, 221, 228, 230, 235, 240, 244, 268, 271, 301

- Schöpfungsgeschichte: 12, 229, 293

- Schöpfungslehre: 221

- Schöpfungstheologie: $211 f$.

- Weltschöpfung: 11f.

Schule: 6, 17f., 169, 249f., 257, 262

- christliche Philosophenschule: 263

- Grammatikerschule: 163

- Philosophenschule: 176, 194, 225f., 257

Scipio Africanus maior: 152

Seele: 8, 12, 122, 141f., 144-146, 151f., 159, 227-244, 258, 272, 275, 281, 290

- als Geschöpf Gottes: 227

- als Luft: 229

- Menschenseele: 123, 146, 229

- Präexistenz der Seele: 241

- Seelenlehre: 8, 10, 225-245, 265 
- Seelenwanderung: 120, 226, 241

- Unsterblichkeit der Seele: 120, 141, 226, 236-244

- Weltseele: 122, 230

Selene: 132

Seleukos: 180

Semele: 153

Semiramis: 116,171

Septuaginta: 122, 145, 180, 260

Sesoosis: 114

Sieben Weise: 22, 120, 141, 178

Silanion: $172 \mathrm{f}$.

Sizilien: 116, 133

Skorpion: 133

Smyrna: 197

Sokrates: 118, 120, 147, 151, 162, 218, 225,284

Solon: 22, 138, 141, 156, 178, 188f., 255, 259

Sophisten: 18, 117, 284

Sophokles: 153, 171

Sophron von Syrakus: 176

Sosibios Lakon: 22

Sostratos: 126

Soteriologie: 8, 200, 221, 249

Sotion: 165

Sparta: 137, 188

Spruchsammlung (Q): 199

Stabilität: 205f., 215

Stephanus: 198

Stephanusrede: 213

Steropes: 116

Stesimbrotos von Thasos: 154, 168

Sthenelaos/Sthenelos: 22, 182-184

Stoa: 118, 120, 124, 126, 141, 147, 225, 227, 234f., 240, 275f., 282

Stoiker: 15, 122, 126, 140, 144f., 154, 159-161, 211, 227, 241

Straton: 114

Sueton: 16, 178, 198

Sünde: 241

Sündenfall: 233, 239

superstitio: 201, $215 \mathrm{f}$.

Symmachus: 259

Synagoge: 196

Synkretismus: 199

Syrer: 20

Syrien: 4f., 14

Syro-Palästina: 199

Tantalos: 160, 256

Tarent: 174

Tartaros: 134
Tatian: 3-11, 13-25, 114-125, 127-151, 153-158, 160-167, 169f., 172-182, 184-189, 193-195, 199-205, 207, 210-213, 217-219, 221f., 225-241, 243-245, 247-265, 267-279, 281-303

- als Barbarenphilosoph: 253, 300

- als Gnostiker: 8

- als Häretiker: 24, 150, $249 f$.

- als Lehrer: 6, 250, 263

- Tatians Schule: 4, 6, 15f., 250

Tauros: 226

Telesilla von Argos: 173

Telmessier: 20, 114

Telmessos: 114

Telmissos: 114

Tertullian: 201, 214, 266f., 271, 274f., 293, 295, 297, $299 f$.

Teufel: siehe auch Beelzebub, 8, 293

Thales von Milet: 160, 189

Thaliarchis: 173

Thamyris: 186-189

Thasos: 168

Theagenes aus Rhegion: 167

Theben: 22, 129, 157, 175, 187, 254

Theodizee: 234

Theodor bar Koni: 289

Theodoret von Kyros: 7, 211, 292

Theodosius: 18

Theodotos: 181, 280f.

Theologie: 199f., 207, 212, 220, 267f., 270-272, 274, 286, 289, 300, 303

- als wahre Philosophie: 212

- apophatische Theologie: 268

- christliche Theologie: 212, 267, 296, 301

- frühchristliche Theologie: 278

- mittelplatonische Theologie: 273, 286

- platonische Theologie: 282

Theophilos von Antiochia: 194f., 198-201, 203, 213, 217-219, 221f., 269f., 301-303

Theophrast von Eresos: 114

Theopomp von Chios: 22, 170

Theron von Akragas: 125

Thersites: 164, 171, 260

Theseus: 22, 183-185, 189

Thespios: 153

Thessalien: 153

Thiestes: siehe Thyestes

Thraker: 20

Thrakien: 116

Thrinakia: 116

Thyestes: 183

Tiber: 175, 200 
Tiberinus: 176

Tiberius: 163, 178

Tigris: 5

Timaios von Lokroi: 297

Timokles: 163, 172

Tiryns: 116

Titanen: 116, 131, 134

Tlepolemos: 22, 188

Toleranz: 265

Trajan: 201, 204, 214-216

Tralles: 197

Trimalchio: 208

Trinität: 142, 221

Triopas: 22, 182-184

Triptolemos: 22, 125, 132, 185

Troja: siehe auch Ilion, 22, 126f., 137, 151, 154, 169-171, 178-183, 187

Trojaner: 18, 127, 137, 159, 179

Tros: 134, 179

Tryphon: 222

Tugend: 140, 234

Tuskanoi: 20, 115

Tuskoi: 20, $114 \mathrm{f}$.

Tyndareos: 134, 137

Tyrrhener: 20, 115

Tyrrhenoi: 115

Unterwelt: 125, 132f., 136, 161

Uranos: 116, 129, 160

Uranus: 132

Valentinianer: 239, 242, 301

Valentinianismus: 239

Valentinos: 4, 201, 249, 292

Venus: 132

Vernunft: 230f., 233, 241

Viktor von Capua: 289

Vorsehung: 118f., 271, 279

Vorsokratiker: 140, 217, 225, 229
Wahre Lehre: 289

Wahrheit: 210, 212, 218-221, 237, 257, 295, 297-300

Weisheit: 5, 20, 142, 161, 239, 258, 298, 302

- barbarische Weisheit: 253, 257f., 296, $299 f$.

Welt: 11f., 134, 140, 147, 152, 159f., 163f., $185,202,209,213,218,220,222,227 f .$, 234, 243f., 263, 265, 267, 269, 273, 279-281, 286, 295

- pagane Welt: 219

Weltchronik: 198

- christliche Weltchronik: 219

Weltenbrand: 226

Wissbegier: 207, 215-217

Wissen: 202f., 217f., 222, 254, 263

- christliches Wissen: 211

- religiöses Wissen: 195, 198, 200-202, 210-212, 216, 218, $222 \mathrm{f}$.

Xanthos: 183

Xenokrates: 140

Xenophanes: 118, 159, 167

Xerxes: 116, 147

Xuthos: 185

Zauberei: 278, $284 f$.

Zenodot von Ephesos: 168f.

Zenon: 120, 225f., $234 \mathrm{f}$.

Zephyros: 131

Zethos: 22

Zeus: 22, 116, 125, 127, 129-137, 153f., 160, 163, 174, 176f., 180, 187, 256, 279

Zweite Sophistik: 17, 141, 156, 207, 209, 217

Zypern: 4, 188 


\section{Die Autoren dieses Bandes}

Prof. Dr. Peter Gemeinhardt ist seit 2007 Lehrstuhlinhaber für Kirchengeschichte und seit 2015 Sprecher des Sonderforschungsbereichs „Bildung und Religion in Kulturen des Mittelmeerraums und seiner Umwelt von der Antike bis zum Mittelalter und zum Klassischen Islam" an der Georg-August-Universität Göttingen. Seine Forschungsschwerpunkte umfassen die christliche Theologiegeschichte (insbesondere Trinitätslehre), die Hagiographie in Spätantike und Mittelalter und das Verhältnis von Bildung und Religion im Christentum und seiner spätantiken Umwelt.

Schriftenauswahl: Die Filioque-Kontroverse zwischen Ost- und Westkirche im Frühmittelalter (Berlin / New York 2002); Das lateinische Christentum und die antike pagane Bildung (Tübingen 2007); Die Heiligen. Von den frühchristlichen Märtyrern bis zur Gegenwart (München 2010); Athanasius Handbuch (Hg., Tübingen 2011); Antonius: Der erste Mönch. LebenLehre - Legende (München 2013; ital. Ausgabe Bologna 2015); Die Kirche und ihre Heiligen. Studien zur Ekklesiologie und Hagiographie in der Spätantike (Tübingen 2014).

Dr. Marie-Luise Lakmann ist Wissenschaftliche Mitarbeiterin am Institut für Neutestamentliche Textforschung der Westfälischen Wilhelms-Universität Münster. Schwerpunkte ihrer Arbeit liegen im Bereich der griechischen Handschriften des Neuen Testaments und des antiken Platonismus.

Schriftenauswahl: Der Platoniker Tauros in der Darstellung des Aulus Gellius (Leiden u.a. 1994); „Papyrus Bodmer XIV-XV (P75). Neue Fragmente“, Museum Helveticum 64 (2007) 22-41; „,Neutestamentliche Texte aus Khirbet Mird. P83 und 0244“, Ephemerides Theologicae

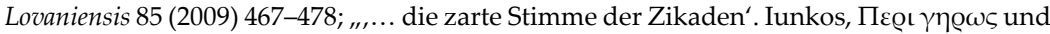
die platonische Philosophie“, in: E. Song / F. Karfík (Hg.), Plato Revived. Essays on Ancient Platonism in Honour of Dominic J. O'Meara. Beiträge zur Altertumskunde 317 (Berlin 2013) $162-181$.

Prof. Dr. Heinz-Günther Nesselrath ist Ordentlicher Professor für Klassische Philologie (Gräzistik) an der Georg-August-Universität Göttingen. Seine Forschungsschwerpunkte liegen im Bereich der attischen Komödie, der griechischen Geschichtsschreibung (vor allem Herodot), der Zweiten Sophistik (vor allem Lukian) und der Spätantike.

Schriftenauswahl: Lukians Parasitendialog. Untersuchungen und Kommentar (Berlin / New York 1985); Die attische Mittlere Komödie. Ihre Stellung in der antiken Literaturkritik und Literaturgeschichte (Berlin / New York 1990); Platon und die Erfindung von Atlantis (Leipzig / München 2002); Platon. Kritias. Übersetzung und Kommentar (Göttingen 2006); Libanios. Zeuge einer schwindenden Welt (Stuttgart 2012); Iulianus Augustus. Opera (Berlin / Boston 2015).

Prof. Dr. Ferdinand R. Prostmeier ist Ordentlicher Professor für Neutestamentliche Exegese und Literatur an der Theologischen Fakultät der Albert-Ludwigs-Universität Freiburg. Seine Forschungsschwerpunkte sind im Bereich der neutestamentlichen Schriften der erste Petrusbrief und die synoptischen Evangelien. Daneben konzentriert sich seine Forschungsarbeit auf die Geschichte, Kultur und Literatur des Frühchristentums. Sein Interesse gilt dabei der Frage, wie sich in den Schriften, Institutionen und Lebensvollzügen der ersten christlichen Gemeinden unter den Vorzeichen von Rezeption und Transformation sowie Kontinuität und Innovation biblisch-jüdische Tradition und hellenistisch-römische Kultur miteinander verbinden.

Schriftenauswahl: Der Barnabasbrief. Übersetzung und Kommentar, in: Kommentar zu den Apostolischen Vätern. Ergänzungsreihe zum Kritisch-exegetischen Kommentar über das 
Neue Testament 8 (Göttingen 1999); Kleine Einführung in die synoptischen Evangelien (Freiburg u.a. 2006); Frühchristentum und Kultur. KfA.E 2 (Freiburg u.a. 2007); Logos der VernunftLogos des Glaubens. MST 31 (Berlin / New York 2010).

Prof. Dr. Dres. h.c. Adolf Martin Ritter ist emeritierter Ordentlicher Professor für Historische Theologie (Patristik) an der Ruprecht-Karls-Universität in Heidelberg. Seine Forschungsschwerpunkte liegen im Bereich der antiken Konzils-, Theologie- und Dogmengeschichte sowie der Geschichte und Theologie der Ostkirchen.

Schriftenauswahl: Das Konzil von Konstantinopel und sein Symbol. Studien zur Geschichte und Theologie des II. Ökumenischen Konzils. FKDG 15 (Göttingen 1965); Charisma im Verständnis des Joannes Chrysostomos und seiner Zeit. Ein Beitrag zur Erforschung der griechischorientalischen Ekklesiologie in der Frühzeit der Reichskirche. FKDG 25 (Göttingen 1972); (zusammen mit G. Heil) Corpus Dionysiacum II. Pseudo-Dionysius Areopagita. De Coelesti Hierarchia. De Ecclesiastica Hierarchia. De Mystica Theologia. Epistulae. PTS 36 / 67 (Berlin 1991; ${ }^{2} 2012$ ); Pseudo-Dionysius Areopagita. Über die Mystische Theologie und Briefe, eingel., übers. u. m. Anm. vers. BGL 40 (Stuttgart 1994); "Dogma und Lehre in der Alten Kirche“, in: C. Andresen u.a., Die christlichen Lehrentwicklungen bis zum Ende des Spätmittelalters. Bearbeitet von A. M. Ritter (Neuausgabe Göttingen 2011) Bd. 1, 99-288; STUDIA CHRYSOSTOMICA. Aufsätze zu Weg, Werk und Wirkung des Johannes Chrysostomus (ca. 349-407). STAC 71 (Tübingen 2012).

Prof. Dr. Holger Strutwolf ist Ordentlicher Professor für Patristik und Neutestamentliche Textforschung und Direktor des Instituts für Neutestamentliche Textforschung und des Seminars für Kirchengeschichte I (Alte Kirche und Mittelalter) an der EvangelischTheologischen Fakultät der Universität Münster. Seine Forschungsschwerpunkte liegen auf dem Gebiet der neutestamentlichen Textforschung, der alten Kirchengeschichte, hier besonders der christlichen Gnosis, der Theologie des Origenes und des Euseb von Cäsarea und der Auseinandersetzung der frühen christlichen Theologie mit der Philosophie der Antike.

Schriftenauswahl: Gnosis als System. Zur Rezeption der valentinianischen Gnosis bei Origenes. FKDG 56 (Göttingen 1993); Die Trinitätstheologie und Christologie des Euseb von Caesarea. Eine dogmengeschichtliche Untersuchung seiner Platonismusrezeption und Wirkungsgeschichte. FKDG 72 (Göttingen 1999); Novum Testamentum Graecum. Editio Critica Maior. Hg. vom Institut für Neutestamentliche Textforschung. Bd. IV, Die Katholischen Briefe, hg. von B. Aland / K. Alandt / G. Mink / H. Strutwolf / K. Wachtel. Teil 1: Text, Teil 2: Begleitende Materialien (Stuttgart ${ }^{2} 2013$ ).

Dr. Andrei Timotin ist wissenschaftlicher Mitarbeiter bei der Rumänischen Akademie (ISEES) und Assoziierter Professor an der Universität Bukarest. Seine Forschungsinteressen liegen im Bereich der religiösen Tradition im Platonismus, der Religionsgeschichte in der byzantinischen Welt und der Geschichte der byzantinischen und post-byzantinischen Texte. Er arbeitet gerade an einer Monographie zum Gebet in der platonischen Tradition, von Plato bis Proclus.

Schriftenauswahl: Visions, prophéties et pouvoir à Byzance. Étude sur l'hagiographie mésobyzantine (IXe-XIe s.) (Paris 2010; Nicolae Iorga Preis der Rumänischen Akademie); La démonologie platonicienne. Histoire de la notion de daimōn de Platon aux derniers néoplatoniciens (Leiden 2012; Reinach Preis von der Association des Études Grecques, Paris); (zusammen mit John Dillon) Platonic Theories of Prayer (Leiden 2016). 